\title{
$C$
}

athingin:
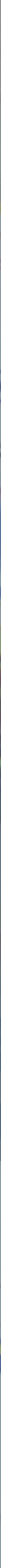

The Ethics of Affect:

Lines and Life in a

Tokyo Neighborhood

Patrick W. Gelbraith 
The Ethics of Affect

Lines and Life in a Tokyo Neighborhood

Patrick W. Galbraith 
Published by

Stockholm University Press

Stockholm University

SE-I06 9I Stockholm,

Sweden

www.stockholmuniversitypress.se

Text (C) The Author(s) 202I

License CC-BY

First published 202I

Cover image: A bishōjo game store in Akihabara. Photo by Pawel Jaszczuk.

Cover designed by Sofie Wennström, Stockholm University Press.

Stockholm Studies in Media Arts Japan (Online) ISSN: 2004-I 292

ISBN (Paperback): 978-9I-7635-I 59-8

ISBN (PDF): 978-9I-7635-I 56-7

ISBN (EPUB): 978-9I-7635-I 57-4

ISBN (Mobi): 978-9I-7635-I 58-I

DOI: http://doi.org/Io.I6993/bbn

This work is licensed under the Creative Commons Attribution 4.० Unported License. To view a copy of this license, visit creativecommons.org/licenses/by/4.o/ or send a letter to Creative Commons, 444 Castro Street, Suite 900, Mountain View, California, 9404I, USA. This license allows for copying any part of the work for personal and commercial use, providing author attribution is clearly stated.

Suggested citation:

Galbraith, P. W. 202I. The Ethics of Affect: Lines and Life in a Tokyo Neighborhood. Stockholm: Stockholm University Press. DOI: http://doi.org/IO.I6993/bbn

To read the free, open access version of this book online, visit http://doi.org/IO.I6993/bbn or scan this QR code with your mobile device. 


\section{Endorsements from Readers}

A goal of cultural anthropology is to understand the "other," and what could be more other than a subculture of self-described "perverts" who enjoy pornographic bishōjo games? Are these young men engaging in harmless sexual fantasy or rehearsing for actual rape and misogyny? Debates surrounding the ethical and social implications of these games have thus far been conducted with minimal knowledge about the people consuming them. Thanks to Galbraith's audacious fieldwork, we are able to get past Western stereotypes about "weird Japan" and put a human face on the people at the center of a moral firestorm. This data does not end the moral debate about these games, but it does provide vitally needed perspective.

- Joseph P. Laycock, author of Dangerous Games: What the Moral Panic over Role-Playing Games Says about Play, Religion, and Imagined Worlds

Galbraith's newest book, The Ethics of Affect, explores the lines we draw between fiction and reality, $2 \mathrm{D}$ and ${ }_{3} \mathrm{D}$ space, fan worship and true love, playful intimacy and simulated violence. Players of bishōjo games - "cute girl" games with explicit sexual content - are usually perceived as deviant and dangerous, "othered" in Japan and overseas. Galbraith shows these men as relatable human beings exploring sexuality in private and in public, finding shared affection and caring in the cold precarity of contemporary Japan. We follow Galbraith along the streets of Akihabara, into the cafés and production offices, cramped apartments and the massive Comic Market, ending up at a bishöjo rave where men scream cathartically, enjoining each other on parting to "stay safe." Galbraith's detailed descriptions of game content, and how the stories and images elicit powerful emotional and physical reactions, shed light on a game genre with extremely limited distribution outside Japan. An incredibly useful book to game researchers and anthropologists alike, The Ethics of Affect shows how players are 
forced to make excruciating moral choices in games, where characters are variously cared for, hurt and abused. The self-reflection engendered by such gameplay creates an "ethics of moe," allowing players to "draw lines" between the acceptable and unacceptable, regulating their own feelings and actions. In contrast to the often violent and uncritical game modes of the first-person shooter, Galbraith argues that bishōjo games arouse a moral sense as well as a physical response. Well-researched and self-reflexive in its method, The Ethics of Affect shows us an honest reassessment of the anthropologist's position vis-à-vis their subject, ending with a thoughtful elegy on Akihabara as production companies shutter in the wake of COVID-I9.

- Rachael Hutchinson, author of Japanese Culture Through Videogames

Galbraith's book is an erudite and refreshing study of Akihabara's adult or erotic bishōjo games industries. It tackles people's imaginary sex lives, sexual immersion and moe experiences with manga/anime-style cute girl characters. These types of relations require delicate analysis rather than a more convenient rush to moral judgement. The book offers a prime example of culturally informed and ethical scholarship about this highly contentious subject. It will be immensely valuable for academics, designers, fans, artists, activists and policy makers around the globe. Galbraith is a leading authority and ethnographer whose fieldwork and "peer-learning" methods of research are meticulous and uncompromising. The book gives a comprehensive overview of games, affective game design and game-playing, gaming events and raves, without at any point leaving behind the great sex wars and academic debates of our times.

- Katrien Jacobs, author of People's Pornography: Sex and Surveillance on the Chinese Internet 


\section{Stockholm Studies in Media Arts Japan}

Stockholm Studies in Media Arts Japan (SMAJ, ISSN 2004-I292) is a peer-reviewed series of monographs and edited volumes published by Stockholm University Press.

SMAJ strives to provide a multidisciplinary forum for research on media and arts associated with Japan, prioritizing investigations of forms, formats, materialities and creative practices. The scope of subjects is broad, including texts, performances and artefacts of various times and social position in a variety of local and transnational cultures.

It is the ambition of SMAJ to place equally high demands on the academic quality of the manuscripts it accepts as those applied by refereed international journals and academic publishers of a similar orientation. SMAJ accepts manuscripts in English.

\section{Editorial Board}

Jaqueline Berndt, Professor in Japanese Studies, Stockholm University, Sweden (Chairperson)

Cecilia Björck, Associate Professor, Music Education \& Popular Music, University of Gothenburg, Sweden

Irena Hayter, Associate Professor, Japanese Studies, University of Leeds, United Kingdom

Minori Ishida, Professor, Film and Animation Studies, Niigata University, Japan

Ylva Lindberg, Professor, School of Education and Communication, Jönköping University, Sweden

Trond Lundemo, Professor, Film Studies, Stockholm University, Sweden

Ewa Machotka, Associate Professor \& Docent, Japanese Studies, Stockholm University, Sweden

Laura Moretti, Associate Professor, Japanese Studies, Cambridge University, United Kingdom 
Sharalyn Orbaugh, Professor, Asian Studies, The University of British Columbia, Canada

Lukas R. A. Wilde, PostDoc Research Associate, Japanese Studies \& Media Theory, Tübingen University, Germany

\section{Titles in the series}

I. Galbraith, P. W. (202I). The Ethics of Affect: Lines and Life in a Tokyo Neighborhood. Stockholm: Stockholm University Press. http:// doi.org/IO.I6993/bbn 


\section{Peer Review Policies}

Stockholm University Press ensures that all book publications are peer-reviewed. Each proposal submitted to the Press will be sent to a dedicated Editorial Board of experts in the subject area for evaluation. The full manuscript will be reviewed by chapter or as a whole by at least two external and independent experts.

A complete description of Stockholm University Press' peer-review policies can be found on the website: http://www.stockholmuniversity press.se/site/peer-review-policies/

The Editorial Board of Stockholm Studies in Media Arts Japan used an external double-blind peer-review procedure while evaluating this book proposal to maintain the integrity of the authors and the academic merit of the book. The book manuscript was assessed with a single-blind peer-review process. The Board expresses its sincere gratitude towards all researchers involved in this project. The author of the introductory chapter of this book stepped down momentarily from her role as Chair of the Editorial Board during the review process of the book to avoid a conflict of interest.

\section{Recognition for reviewers}

Stockholm University Press and the Editorial Board would like to extend a special thanks to the reviewers who contributed to the process of editing this book.

The manuscript was reviewed by the following experts:

Jason Karlin, Associate Professor, Graduate School of Interdisciplinary Information Studies, University of Tokyo, Japan ORCiD

Matt Hills, Professor, Department of Media and Performance, University of Huddersfield, United Kingdom

ORCiD https://orcid.org/oooo-ooo2-8778-6530 


\section{The Author}

Patrick W. Galbraith is an Associate Professor in the School of International Communication at Senshū University in Tokyo. His recent publications include Otaku and the Struggle for Imagination in Japan (Duke University Press, 2019), AKB48 (Bloomsbury Academic, 2019) and Erotic Comics in Japan: An Introduction to Eromanga (Amsterdam University Press, 2020). 
This book is dedicated to the memory of Mark McLelland and Natalia Samutina. 
"God knows it may be crossing the line a bit, but I think that's OK.' You think that's OK? [...] You can go crazy with the ethics thing. You can go absolutely out of your mind. What you have to do, I guess, is go where your gut takes you. And you have to remember what's reality and you have to remember what's fantasy." - Harlan Ellison ${ }^{\mathrm{I}}$ 


\section{Table of Contents}

List of Illustrations xiii

Introduction 1

0.1 Introduction 1

0.2 Ethics: Where and How Do We Draw Lines? 10

0.3 Fieldwork: Drawing Lines in Akihabara 24

0.4 From the U.S. to Japan: Starting a Project on Games in 201426

0.5 Outline of Chapters 34

1. Imaginary Sex and Crime in Japan: A Brief History 39

1.1 Introduction 39

1.2 A Crisis of Hegemony and Reproduction 43

1.3 "The Otaku Panic" 46

1.4 Bishōjo Games and "Virtual Reality" 49

1.5 "Otaku" and Ethics: Ōtsuka Eiji and Miyazaki Tsutomu 54

1.6 "Moe" and Ethics: Nagayama Kaoru and Sasakibara Gō 59

1.7 Imagined Perversion in Japan 65

1.8 Conclusion 72

2. Coming of Age in Akihabara: Imaginary Sex in Public 77

2.1 Introduction 77

2.2 Bishōjo Game Central 80

2.3 "Japan Only:" On Closed Circulation 83

2.4 Coming of Age in Akihabara 88

2.5 Dangerously Moving Images 95

2.6 Imaginary Sex in Public 101

2.7 Journey to the (Akihabara of the) West 110

2.8 Conclusion 114

3. Moving Images: Affection by Design 117

3.1 Introduction 117

3.2 Playing Bishōjo Games 120 
3.3 Characters and Stories Designed to Move 125

3.4 The Role of Imagination in Bishōjo Games 133

3.5 The Ethical Encounter in Bishōjo Games 139

3.6 Conclusion 152

4. The Ethics of Affect: Drawing Lines with Bishōjo Game Producers and Players 157

4.1 Introduction 157

4.2 Drawing a Line Between Fiction and Reality 161

4.3 Interacting with Fiction and Reality 167

4.4 Drawing Lines with Others 177

4.5 The Ethics of Moe in Akihabara 183

4.6 Conclusion 193

5. Hajikon: Bodily Encounters and Dangerous Games 195

5.1 Introduction 195

5.2 Adults' Day at Club Moonlight Dream Terrace 200

5.3 From Kawasaki to Akihabara: Fictional and Real Women 206

5.4 Pillow Talk: Interactions with Bishōjo in Material Form 211

5.5 "Failed Men" Living in Precarious Japan 220

5.6 Conclusion 233

6. Conclusion: A World that's Ending: Do You Love Me?

237

6.1 Take Care of Yourself 237

6.2 The End: Death and Rebirth 245

6.3 The Beast that Shouted "I/Love" at the Heart of the World 251

7. Epilogue 253

8. Appendix: Notes on Perverse Methodology 257

8.1 Introduction 257

8.2 The Anthropological Imagination: Reading Malinowski in the Field 257

8.3 Imagining Difference: Japan, Others and Perverse Methodology 261

8.4 Conclusion 267

Endnotes 271

References 315 


\section{List of Illustrations}

\section{Cover}

A bishōjo game store in Akihabara. Photo by Pawel Jaszczuk. License: CC BY 4.0.

\section{Images}

I Cover of Mischief Fiend by REAL. Used with permission from rightsholder. License: CC BY 4.0. 2

2 In this promotional art from Giga, the character Katori Rea is on the left. Used with permission from rightsholder. License: CC BY 4.०. 5

3 Yamada Tarō speaks at the Comic Market. Photo by the author. License: CC BY $4.0 . \quad 4 \mathrm{I}$

4 Cover of Saori: The House of Bishōjo. Photo by the author. License: CC BY $4.0 . \quad 5 \mathrm{I}$

5 Cover of The Song of Saya by Nitroplus. Used with permission from rightsholder. License: CC BY 4.0. 73

6 Flier for Lonely's event in Akihabara. Photo by the author. License: CC BY 4.0. 78

7 Shelves packed with bishōjo games in Akihabara. This particular store had hundreds of different titles occupying an entire floor. They encouraged physical purchase through premiums, which were limited and exclusive to different retailers in the area. Photo by the author. License: CC BY 4.0. 8I

8 Café in Akihabara where Ataru and I spoke of "harmful people." Above one sees a bishōjo game production company. The café was mere minutes from a gradeschool. Photo by the author. License: CC BY 4.0. 94

9 Appearing on the television show TV Takkuru on September I, 20I4, Tsuchiya Masatada warns of a connection between cartoons and sexual violence against children. Photo by the author. License: CC BY 4.०. 98 
Io Sign in a store in Osaka shows the segregation of bishōjo games, which had been pushed into a back corner and away from the street. Photo by the author. License: CC BY 4.0. II 3

II Cover of Big Brother, Use of Your Right Hand is Forbidden!! by Galette. Used with permission from rightsholder. License: CC BY 4.0. I2I

I 2 Cover of Favorable Conditions for Groping by catwalkNERO. Used with permission from rightsholder. License: CC BY 4.०. I 23

I3 Cover of In Solitude, Where We Are Least Alone by Sphere. Used with permission from rightsholder. License: CC BY 4.०. I 24

I4 Haruka asks you to intertwine your fingers with her own and say the words of a charm. The choice of whether or not to do so is built up, as are the consequences. Photo by the author. License: CC BY 4.0. I46

I 5 Cover of Rise. The reflective finish turns it into a mirror. Note the size of the offset cute girl character and space to see oneself with her. Photo by the author. License: CC BY 4.O. I 54

I6 In Akihabara, Kōta sees a face off between Getchuya, a bishōjo game store ahead on the right, and $\mathrm{AKB}_{4} 8$ Theater on the other side of the street. Photo by the author. License: CC BY 4.0. $\quad$ I 58

I7 Cover of a special issue of Dengeki Hime by ASCII Media Works. Released for the Denkigai Matsuri in summer 2014, it promises to "deliver encounters with bishōjo." The games introduced focus on underage sex, incest and more. The magazine and event it was distributed at share these things openly, even as manga/anime-oriented men act as "well-trained perverts." Used with permission from rightsholder. License: CC BY 4.०. I64

I 8 Hayase distributing Daemon Busters tissue packs at the Day of Erotic Games. The packs tell the user to "do their best," as in their best getting off while playing. Photo by the author. License: CC BY 4.0. 173

I9 Sample of swag received at Erogē Briefing. The character is from I Love, Love, Love You!! and raised questions about fiction and reality. Photo by the author. License: CC BY 4.0. I83

20 Statement from the July 2017 issue of Comic LO. Photo by the author. License: CC BY 4.0. I9I

2 I Flier for Hajikon, which was a regular rave catering to bishōjo game players. Photo by the author. License: CC BY $4.0 \quad$ I 97 
22 Man poses with his wife and takes a swig from an open champagne bottle. Photo courtesy of Club Moonlight Dream Terrace. Used with permission from rightsholder. License: CC BY 4.0. 198

23 Men dance together and share the affect of characters on screen and in sound. Photo courtesy of Club Moonlight Dream Terrace. Used with permission from rightsholder. License: CC BY 4.0. 202

24 Men strip off clothes and become increasingly physical. Photo courtesy of Club Moonlight Dream Terrace. Used with permission from rightsholder. License: CC BY 4.0. 203

25 Sign at the club prohibits coming to this space to pick up girls. Meanwhile, men are dancing with their wives in the form of body pillows. Photo courtesy of Club Moonlight Dream Terrace. Used with permission from rightsholder. License: CC BY 4.0. 207

26 Men and women have been knocked to their knees by the affect of the moving images on screen. Unable to contain himself, one man screams out far louder than usual. Photo courtesy of Club Moonlight Dream Terrace. Used with permission from rightsholder. License: CC BY 4.0. 208

27 A character in body pillow form is held up for imaginary sex in public. Others perform hard fingering gestures. Earlier, another pillow was publically beaten. Photo courtesy of Club Moonlight Dream Terrace. Used with permission from rightsholder. License: CC BY 4.0. 216

28 A character is treated like a "toilet," and men imagine having sex with her upside-down form and paying for it. Photo courtesy of Club Moonlight Dream Terrace. Used with permission from rightsholder. License: CC BY 4.0. $2 \mathrm{I} 7$

29 Aftermath of a group wedding ceremony at Hajikon. Energy expended by the running and dancing that proceeded, men collapse to the floor. Photo courtesy of Club Moonlight Dream Terrace. Used with permission from rightsholder. License: CC BY 4.0. 2 I9

30 Pamphlet for upcoming events at Club Moonlight Dream Terrace in May 2OI4. Photo by the author. License: CC BY 4.0. 223

3I Members of Akihabara University on tour in rural Japan. Photo by the author. License: CC BY 4.0. 239

32 Pamphlet for the tour, drawn by a member and titled SO,men. Photo by the author. License: CC BY 4.0. 240 
33 Man poses with his wife at a restaurant. Photo by Lisa Katayama. Used with permission from rightsholder. License: CC BY 4.0. 242

34 Man publicly sleeping outside the Comic Market in summer 20I4. Photo by Ramon McGlown. Used with permission from rightsholder. License: CC BY 4.0. 243

35 Outside a computer store on the main street of Akihabara. Photo by the author. License: CC BY 4.0. 244 


\section{Introduction}

\subsection{Introduction}

It depends on what you mean by "real." So said my male companion as we browsed through new releases at a store in Akihabara, an area in eastern Tokyo. His tone told me that the question that prompted the response must have been a stupid one, or at least sounded to him that way, but as an anthropologist conducting long-term fieldwork, I had become accustomed to putting my foot in my mouth. It is a way to get people talking and to learn, especially about things that might not be under discussion otherwise.

The question was what to make of the cover of one of the newly released games we encountered in the store. The image is of a young woman being sexually assaulted while riding a crowded train. She is pressed against the door and visible through its cutout window. Her hands are against the transparent surface, as are her breasts, which are exposed. Someone has pulled up her shirt and bra, likely the man behind her, who is holding her right wrist. The pleated skirt of her school uniform has also been lifted to reveal striped underwear. The man's other hand is poised above her left thigh and covered in vaginal fluid, which drips through the young woman's panties down her legs. Small tears are forming in the corners of her massive eyes, and she is blushing red. She is breathing heavily, which fogs up the window. Her open mouth is wet with saliva; drool runs down her chin. Across the bottom of the cover is the title, Mischief Fiend (Itazura kyōaku, 201 5), but what had caught my eye was the name of the company that produced the game, "REAL." ${ }^{2}$ In large, capitalized English letters in the top left corner, the company name had me doing a double take, because

How to cite this book chapter:

Galbraith, P. W. 202I. Ethics of Affect: Lines and Life in a Tokyo Neighborhood. Pp. I-38. Stockholm: Stockholm University Press. DOI: http://doi.org/Io. I6993/bbn.a. License: CC BY 4.०. 


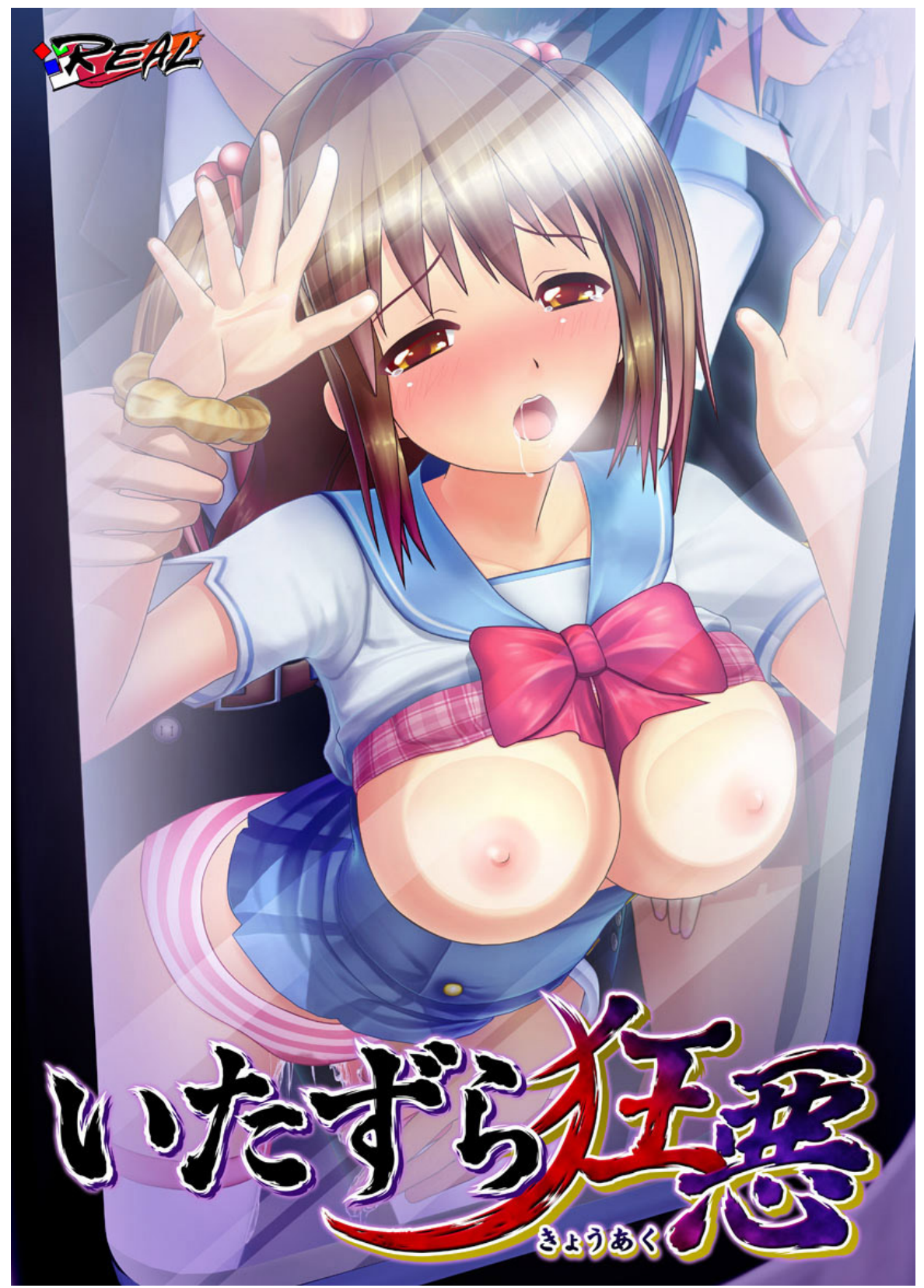

Image 1. Cover of Mischief Fiend by REAL. Image used with permission from rightsholder. License: CC BY 4.0.

it almost appeared as if advertising the scene as "real." So I asked my male companion if this was, indeed, real.

Well, maybe. The package and disc inside are of course real. This is a real object in the world - it is right there in front of us, we both see it 
and are responding to its presence right now. Reach out and touch it to confirm. Yeah, stupid question. Is the depicted scene real? No, it is a cartoon, something constructed and made, fiction as opposed to a photograph or video recording of actual people. The young woman is thus a cartoon character, not a real person. Looking at her round face and massive eyes, characteristic of Japanese comics and cartoons, or manga and anime, this seemed to my male companion obvious enough, hence another layer of incredulity about my query. After all, one would not confuse this for photorealism or her for real in that way. But, then again, he conceded, the company and this cover are indeed presenting the cartoon character in ways that might be described as real, for example the emphasis on her fleshy, physical body. The game itself features computer-generated polygon graphics, which appear to have more depth than the flat, still art seen in other titles on the shelves. So, in terms of graphics, more real. And, he continued, it is not as if groping on the train is entirely fiction. No, surveys of Japanese women bear out the reality, which informs this pornographic text. ${ }^{3}$

So it is both fictional and real, which got him thinking about the cartoon character. "If you are asking if she is real, then yes, but as a character, which is not a human being. A human drew her, a human voices her, I respond to her as a human, but this is obviously not a real human. It is a fictional human, two-dimensional. It is real as a cartoon character. That's what I want in a game like this, a girl like her, a cartoon." Does he like young women, girls like this one? "I said I like cartoons, not girls," he replied, the tone this time suggesting that I was being willfully dense and a little offensive.

In fact, I was mentally mistranslating his words, as he did not say cartoons but bishōjo, or "cute girls," specifically in the context of this exchange manga/anime-style characters that appear in Japanese comics, cartoons and related media and material. Indeed, we were browsing through what are known as "bishōjo games," which are adult computer games centering on interactions - ranging from casual conversation to explicit sex - with manga/anime-style cute girl characters. As can be discerned from the cover, and despite the putatively more real computer-generated graphics, Mischief Fiend is one such bishöjo game. My male companion distinguished the bishōjo on the cover from joshikōsei, which I glossed as girls, but more accurately means "female highschool students." The two are not necessarily the same. His desire for a cute girl character dressed as one does not mean that he really wants something more "real." What he really wants is something "two-dimensional" (nijigen), which is slang among manga/anime fans 
in Japan for cartoon characters and their worlds as opposed to the human "three-dimensional" (sanjigen).

My male companion was not done. In truth, he informed me, he is not interested in this game or girl I forced him to comment on. I was asking for a response to implicit assumptions. He gestured for me to follow as he moved down the racks to the older titles, where he stopped in front of Giga's Parfait: Chocolat Second Brew (Parufe: Shokora second brew, 2005). The cover shows a woman in an ornate uniform that resembles that of a Victorian maid; as with Mischief Fiend, it bears a seal letting us know that the game contains sex scenes and can only be purchased by adults. Fortunately, I played this game and so had some understanding of the content. Unlike Mischief Fiend, here interactions with cute girl characters are more about romance. There is a large amount of text to read, some quite poetic, which details the feelings of the characters and relationships that unfold over an extended period of time. One gets to know the characters, if not care about them, in the long sections between sex scenes. It may seem dissonant that Mischief Fiend and Parfait: Chocolat Second Brew exist in the same store and content category, but the proximity of sexual violence and romance is a notable aspect of bishōjo games. In both Mischief Fiend and Parfait: Chocolat Second Brew, cute girl characters are vulnerable in relation to the male player and his character, who is in the position to act, whether that be molesting her on the train or proposing going out on a date.

My male companion flipped over the bulky package and pointed to a blond character. "Her. Katori Rea. She's the one I'm interested in." In typical manga/anime style, the character appears young, but I knew that she is 20 years old and a working professional. I mentioned that I had played the game, on the recommendation of a mutual friend, and also think Rea is cute. Suddenly he was beaming. "She is cute, right? I totally fell in love with her playing. Rea is my wife." Having heard the phrase before, "my wife" (ore no yome), I was prepared when he took out his smart phone to show me photos of all the media and material representations of the character in his room. He is especially proud of the body pillow, which is emblazoned with a semi-nude image of Rea and allows them to sleep together. He is not particularly fulfilled in his job, he says, but he has Rea. He would invite me over, but he shares space with his parents. Instead, he recommends meeting at an event that men attend with their wives. Some of his friends are also married to Rea, and he suggests I should meet them. He tells me that he lives for these events, which provide him a way to share affection for and bonds with Rea. 


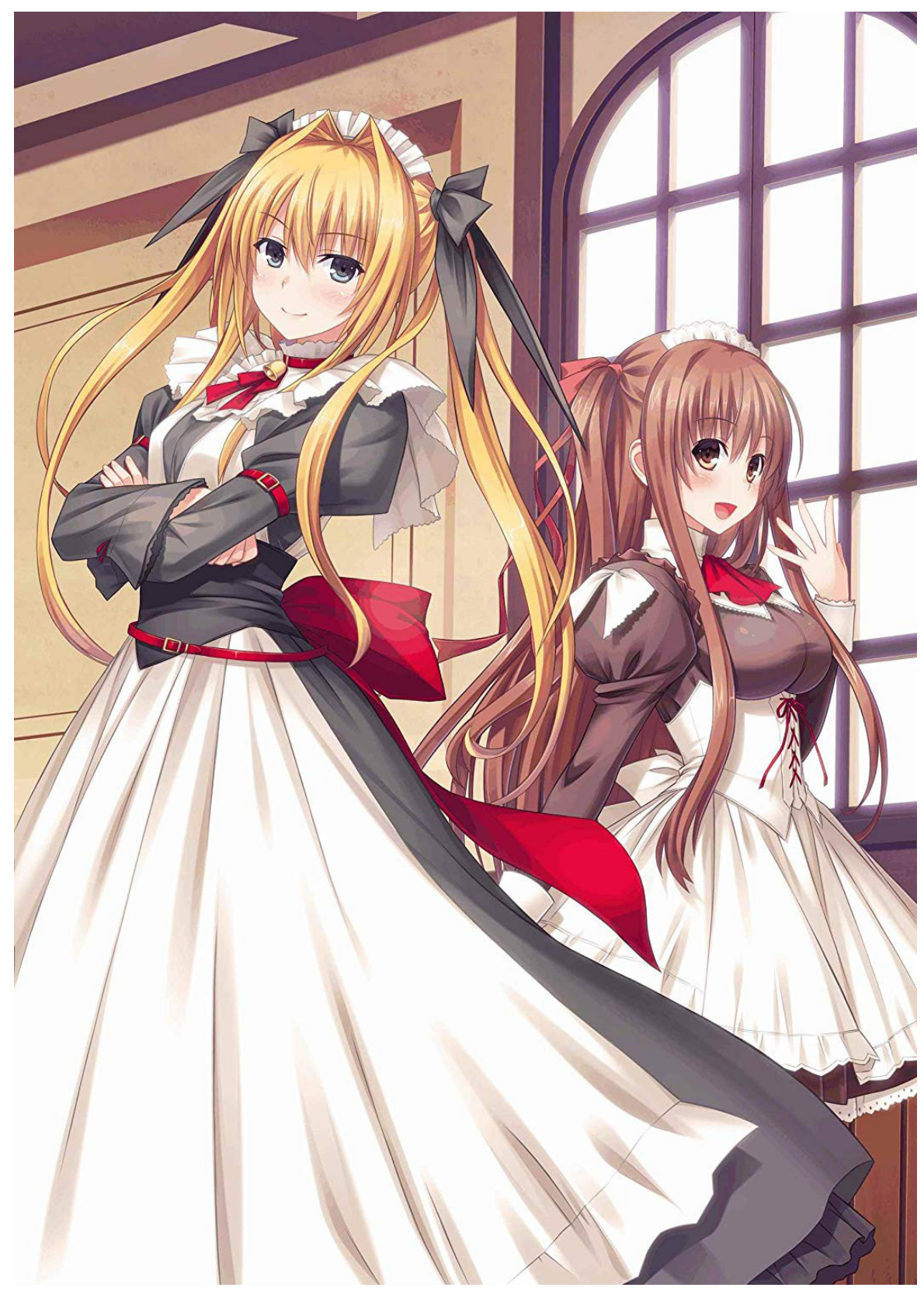

Image 2. In this promotional art from Giga, the character Katori Rea is on the left. Image used with permission. License: CC BY 4.०.

Later returning to the notes I took during this exchange, five things stood out. First, my male companion's ability to distinguish between different meanings of "real," which allowed him to see a cartoon 
character as real, but not in the same way as a human being. He recognized humans involved in producing the image, but did not confuse or conflate them with the cartoon character itself. It appeared that his lifelong engagements with manga and anime, as well as games featuring manga/anime-style characters, had contributed to a kind of media literacy. He thus stated his attraction to fiction as such. Second, I noticed his self-reflexivity. This is of course because a researcher was asking pointed questions, but there was also a tacit acknowledgment that something like Mischief Fiend might contribute to sexualization of young women and sexual violence. And so he drew a line between fiction and reality and oriented himself toward one and not the other, confirming that it could be more real and that he did not want it to be or want to take part in such real violence. Third, the tension between fiction and reality as this man worked through his orientation toward one and not the other. Teaching me the difference seemed to also be a way of affirming objects and orientation, which suggests social learning. Fourth, not only did he appreciate the distinct realness of cartoon characters, but he was also in a very real relationship with one in particular. This impacted his social world in very real ways, opening up new interactions and relations with fictional and real others. Fifth and finally, social relations sustain his relationship with a character as a significant other and sustain his life in a more-than-human world.

This book is about lines and life in contemporary Japan. I mean this in several overlapping ways. To begin, there is the line between fiction and reality, or rather the constructed worlds and characters of manga and anime and what is typically understood as reality. We see this drawing and maintaining of lines in the example of my male companion responding to Mischief Fiend. Despite the distinctly cartoony look of manga/anime, however, there is concern that it might reflect and impact reality by reinforcing or inspiring sexual attraction to underage girls and sexual violence. This is where we see more lines being drawn, as my male companion draws a line between manga/anime characters and human beings and orients himself toward one as opposed to the other. He draws a line and orients himself toward the drawn lines of characters, claiming fiction as his object of desire. ${ }^{4}$ As can be gleaned from the hundreds of games in the store we visited and the many, many hundreds more across Akihabara, he is not alone in this orientation, which has a long history among manga/anime fans in Japan. Indeed, Akihabara is where a desire for manga/anime characters, specifically bishōjo or cute girl characters, is more visible than anywhere else in Tokyo, Japan or the world. 
In a previous monograph (Galbraith 20I9), I examined the formation of this manga/anime orientation and reactions to it in discourse about "otaku." There I showed how manga/anime fans, responding to characters and one another, were imagining and creating alternative ways of seeing and being in the world, even as critics persisted in labeling them failures and freaks, perverts, if not potential pedophiles and predators. The fieldwork for that monograph began in 2004 and concluded in 20I I, but as I transitioned into the next project in Akihabara, there was even more concern about manga/anime fans as potential pedophiles and predators. Not long after my new fieldwork project started in the spring of 2014, fierce criticism swept the anglophone media in reaction to a decision by the Japanese government to exclude cartoons from laws regulating child pornography. That is, insofar as there is no actual child involved in their production, manga, anime and games featuring manga/anime characters can depict explicit sex with and between minors. (Think Mischief Fiend, but there is content that goes much, much further.) This scandalized reporters from places such as Canada, Australia and the United Kingdom, where, to stamp out the scourge of child pornography and protect children, a bold and bright line had been drawn to make illegal even purely fictional forms (McLelland 20I7: II-I3). Journalists swarmed Akihabara to photograph men browsing shelves of comics, cartoons and computer games featuring cute girl characters, and took this as evidence of "Japan's child porn problem" (Adelstein and Kubo 20I4). More broadly, Japan is perceived as having a problem with cartoon sex, and the nation is being held up as a symbol of problematic content by international organizations. In February 2016, when the United Nations Committee for the Elimination of Discrimination Against Women advocated for increased regulation based on its conclusion that "pornography, video games and animation products such as manga promote sexual violence against women and girls," the chief source of such content did not have to be named. ${ }^{5}$ Lines have been drawn, lines in the sand and in the sea, with Japan appearing to be on the wrong side of them (Hinton 20I4: $56,65) \cdot{ }^{6}$ Even more so Japanese men, and even more so the kind of perverts and potential pedophiles and predators seen in Akihabara.

All of this feeds back into Japan, where the problem has been understood quite differently. There, many accept that statistics do not apparently support the assertion that the prevalence of imaginary sex, violence and crime in manga, anime and related media and material contributes to high rates of actual sexual violence and crime. In fact, 
as one critic provocatively puts it, "sexual information can substitute for actual sexual activity" (Fukushima Akira, quoted in Schodt I996: $5 \mathrm{I})$. Indeed, statistics do suggest decreases in dating and sexual activity in contemporary Japan. One survey by the National Institute of Population and Social Security Research has it that almost 70 percent of unmarried men between the ages of 18 and 34 are not in a relationship, and 42 percent are virgins (Aoki 2016). Add to this plummeting marriage and birth rates and Japan faces a "demographic crisis" (Kopits 20I7). Quite simply, the population is shrinking, as reproduction dips below the rate of replacement and immigration continues at a trickle. Responding to what some describe as a national emergency, high-ranking politicians such as Asō Tarō argue that, "The problem is with those who didn't give birth" (Japan Times 2019). Such blaming and shaming conveniently ignores decades of economic turmoil that left as many as half of young people in temporary, low-paying jobs and without the stability thought necessary to start or support families (Allison 20I3: 5-8). With a single income insufficient, the majority of married women also work outside the home, but even then a basic lack of daycare facilities makes raising a child while holding down a job challenging at best (Mori et al 2018). There are very real cases of sexual discrimination and sexual assault of girls and women in Japan, many of which coincide with abuse of power in hierarchal relations at home, school and the workplace. Nevertheless, these are not really what politicians such as Asō are flagging as the problem. For them, the problem is most often imagined to be people not having sex and children, rather than the abuse of girls and women or people imagining sex that puts women and children at risk.

Now, some of those problematic people that do not reproduce are manga/anime fans, who have for many years been exploring alternative ways of living. Indeed, the I 990 s marked not only the beginning of the great recession in Japan, but also an explosion of manga and anime featuring bishōjo characters, as well as bishōjo games, which facilitated more intensive and intimate interactions with these cute girl characters. The decade saw the rise of a fan discourse about "moe," or an affective response to fictional characters. To indicate affective relations that extended to the real world and were committed and ongoing, fans started to say that these characters were their "wives," or that they were "married." Even as the moe boom transformed Akihabara, fans spoke of a moe revolution transforming social relations (Condry 2013: 193-196). Simply put, rather than be condemned as losers in newly reformed 
markets, they decided to drop out, play a different game and imagine and create other ways of living with characters as significant others - as fictional and real others and a real part of their lives. It was not the case that they were not having sex or getting married, but rather that they were doing so in the "wrong ways." Recall that my male companion sleeps with Katori Rea from Parfait: Chocolat Second Brew, literally. This is an actual relationship, and "actual sexual activity" (Schodt I996: 5 I), too, but perhaps not as we are used to seeing them.

With feedback about "Japan's child porn problem," a few things have happened in the country. First, a lingering, although not necessarily dominant, concern about manga/anime fans as potential criminals has been rekindled. Becoming most explicit in the early I990s in the aftermath of the arrest of a serial child molester and murderer who also consumed manga and anime, men attracted to bishōjo or cute girl characters were denounced as "a reserve army of criminals" (Kinsella 2000: I 26-I 29). The suggestion was that, prepared by manga and anime, they stood ready to commit heinous acts. This is quite similar to the current global backlash against Japanese cartoons as "virtual child pornography," which amplifies suspicions and outrage when high-profile crimes are imaginatively connected to manga, anime and related media and material. Any dearth in statistical evidence is overcome by the shocking nature of the crime and demand to do something, usually to protect children. Second, this gets entangled with concerns about perverted men dropping out of reproductive relations with women. Third, it is also entangled with calls for regulation to limit the circulation of manga, anime and related media and material featuring imaginary sex, violence and crime that might hinder the "healthy development of youth." If the first concern about manga/anime fans as potential pedophiles and predators is the one that resonates most overseas, it also allows for policy to address the second and third concerns about manga/anime fans as perverts and kids being perverted into "otaku," which resonates domestically amid the demographic crisis.

This convergence, nicely encompassed by the ambiguity of comments about "Japan's sex problem," means that manga/anime fans are under more scrutiny than ever before. The spotlight is focused on men and their interactions and relations with manga/anime-style cute girl characters, which is to say the interactions and relations that transformed Akihabara and social worlds during the moe boom in the r99os. Mounting pressure from all sides threatens the continuation of free, open and shared interactions and relations with bishōjo characters. On 
the ground in Akihabara, this has had some immediate effects, not the least of which is the kind of self-reflexivity seen in my male companion as we discussed Mischief Fiend, but the moment was even more significant. In short, after decades of discourse about "otaku" and an orientation toward fiction, specifically manga/anime characters, there were now new concerns about the relation between fiction and reality. The men I met in the field were not only publicly discussing their objects of desire and orientation, but also drawing a line between manga/ anime characters and human beings. Even as the distinction came into question or became blurred, or precisely for that reason, they insisted on lines, both their orientation toward the drawn lines of characters and a line between fiction and reality.

\subsection{Ethics: Where and How Do We Draw Lines?}

Concern about depictions of violence and sex is not new or unique to Japan, and unease with computer/console games has been conspicuous in North America, Europe and elsewhere since the I990s (see Markey and Ferguson 20I7). Regular outrage cycles and accusations of direct causal relations between media and effects aside (e.g., Clingenpeel 202I), the literature here poses significant questions about ethics, which is often taken to mean rules of proper conduct, principles that govern a person's or group's conduct and/or a philosophy that recommends concepts of right and wrong conduct (Deigh 20I0: 7). For example, wondering if it is wrong to play violent video games, philosopher Matt McCormick reviews utilitarian, deontological and virtue theories and comes to the conclusion that, in the absence of clear evidence of harm to others, the most persuasive argument is "engaging in simulated immoral acts erodes one's character" (McCormick 200I: 277). On the one hand, McCormick's reasoning follows from a confirmation that the utilitarian approach does not work because it cannot establish that there is an increase of risk from playing violent computer games, the risk outweighs the benefits and that it is riskier than other forms of play deemed generally acceptable (e.g., American football). On the other hand, McCormick cannot stop there, because he imagines a scenario where one simulates sex with a child in a game, which is similarly beyond reproach via the utilitarian or deontological theories he presents (McCormick 200I: 284). Whether or not an appeal to virtue ethics and damage to one's character is sufficient cause to stop engaging in some imaginary acts in games, let alone sufficient cause to 
regulate or ban them, remains up for debate, but the desire to draw a line raises questions.

Indeed, the tension identified by McCormick was later formulated by philosopher Morgan Luck as "the gamer's dilemma," where a hypothetical gamer who accepts "virtual murder" because no one is actually harmed is confronted with thereby opening the same defense for "virtual pedophilia" (Luck 2009: 35-36). Determining that the five plausible arguments for a meaningful moral distinction are not convincing, Luck concludes that the gamer is left in the unenviable position of having to accept or reject both "virtual murder" and "virtual pedophilia." Considering the gamer's dilemma, philosopher Stephanie Patridge advances that some imagery may be deemed more objectionable because of "incorrigible social meaning" (Patridge 20II: 308). For example, given the history of racism in the United States, imagery of "individuals of African descent [...] eating watermelon" (Patridge 2OII: 308) operates as an inflammatory stereotype. One can imagine other candidates such as the Confederate battle flag. Meaning here is "exceedingly difficult to overturn" and "this difficulty is explained by facts about a particular social reality" (Patridge 20I I: 308). In this example, the specific imagery may be contingent, but the general claim is "racial oppression is morally pernicious, and we should not enjoy images that support such oppression" (Patridge 20II: 308). This situates Patridge to submit a resolution to the gamer's dilemma, which is that one has grounds to reject games of sexual violence and "virtual pedophilia" not only because enjoying them reflects and impacts "character," but also because meaning is "fixed by the actual practice of casting women in the role of objects of sexual pleasure and violence" and enjoying such imagery is a failure of "sensitivity to the social meaning of the imagery, and sympathy with those who are the targets of such imagery" (Patridge 20II: 3 IO-3 II).7 One can expand and relate this to critiques of "rape culture," or "a culture in which rape is prevalent, which is maintained through fundamental attitudes and beliefs about gender, sexuality, and violence" (Thorn 20I2: I I; also Russell I993). ${ }^{8}$ In such an environment, insofar as it eroticizes inequality - or, as feminist lawyer Catharine MacKinnon argues, presents sex as "eroticized domination" (MacKinnon I997: I68) - pornography can be read as analogous to hate speech, as it was during academic and legal debates in the United States in the I980s (MacKinnon 1993: I04-105; for an overview, see Williams I989: I6-23). Indeed, one way to attempt to resolve the gamer's dilemma is through an appeal to "virtual pedophilia" 
as "eroticization of inequality," which "undermines women's efforts to achieve genuine equality" and therefore "harms women" (Bartel 20I2: I 5-I6; drawing on Levy 2002). For his part, Luck does not see this as resolving the dilemma, because it is insufficient to simply establish (even if granting evidence of harm) that "enjoying depicted virtual pedophilia might harm some people in a way that virtual murder does not" (Luck and Ellerby 2013: 233). Others have attempted to find a way out of the gamer's dilemma by asking "whether they want to put themselves in the position of someone who is open to making certain choices intelligible" (Bourne and Bourne 20I9: I4I), or arguing that an "immoral, desirous form of engagement [...] may, as a rule, render virtual pedophilia more unethical than virtual murder" (Kjeldgaard-Christiansen 2O2O: IOI).

There seems to be some consensus that only a certain kind of person would play a game and "do that" (Patridge 20I I: 305), but this too has received pushback. ${ }^{9}$ According to Garry Young, a researcher of psychology, "there is no moral justification based on player motivation alone to prohibit one STA [symbolic taboo activity] over another, even when the STAs are virtual murder and virtual pedophilia" (Young 20I3: I4). Whether strategic gameplay, enjoyment or substitution, player motivation cannot justify permitting taboo-violating violence and prohibiting taboo-violating sex. Young points out that knowing something is taboo and morally prohibited "does not necessitate that the enactment itself

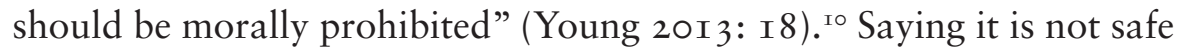
to engage in symbolic taboo activities "because one harms oneself and potentially goes on to harm others is ultimately an empirical matter yet to be addressed with appropriate and sufficient evidence" (Young 20I3: I 8). "One might wish to appeal to the presence of sexual arousal in the fictitious example," Young continues, "that somehow this is sufficient to elicit the desire to engage in actual pedophilic activities. However, and to reiterate, in the absence of empirical evidence, as intuitively compelling as this may be (to some), it is still mere conjecture" (Young 2OI3: 20). He thus concludes:

If one is concerned that a game permitting virtual pedophilia will attract pedophiles or cause non-pedophiles to become sexually attracted to children then the same argument can be used, mutatis mutandis, in the case of virtual murder, and in fact in other STAs; something which stands against the selective prohibition of STAs. Such anticipated danger, in the case of virtual pedophilia, is ultimately an empirical matter, I contend, as is indeed the case with all STAs. (Young 20I3: 22) 
Assumptions of differences in motivations and players are just that, assumptions. Assumptions about motivations aside, the enjoyment of something virtual and actual is different, or enjoyment changes when "one knows it is a fiction" (Young 20I3: I9). To further complicate things, philosopher Rami Ali underscores that the gamer's dilemma is based on the premise that the gamer accepts all instances of "virtual murder" and rejects all instances of "virtual pedophilia," which does not take into account differences in kinds of games (sport, storytelling, simulation) and, more broadly, "the different contexts in which games present virtual acts" (Ali 20I 5: 267). Here, too, there are assumptions about who is playing what games, how, why and to what effect.

Debates around the gamer's dilemma are ongoing (see responses to Ali 2015 such as Luck 20I 8, Kjeldgaard-Christiansen 2020 and Nader 2020), but certain contours and limits are already visible and help shine a light on possible ways forward. Broadly speaking, the abstract formulation of the gamer, games and acts leaves open questions. Who is this gamer, what games are being played and how? We should not overlook how slippery imaginary transgressions are, as when Luck calls sex with a I 5-year-old "virtual pedophilia" (Luck 2009: 34), thereby collapsing together the diagnostic categories of pedophilia, hebephilia and ephebophilia. One might wonder if the stated age of the character in the story narrative (not to mention the age of the player character and the age of the gamer), her appearance or the scenario are salient or not, and how this would change in the case of cartooning. And then, if the cartooning is "realistic" or "cartoony," if attraction to that image reflects "virtual pedophilia" or "toonophilia," and so on. One also wonders, along with philosopher Robert Francis John Seddon, whether we can "group together diverse moments of play and be confident here a player is repeatedly instantiating a general phenomenon of virtual violence" (Seddon 2013: 4), and so too with "virtual sex." On the one hand, "we may find ourselves concluding that there are at least as many ways for games to make use of the real world as there are styles of caricature" (Seddon 2013: 9). On the other hand, there are many ways games can be played. In both participating in and observing what happens onscreen, how does the gamer becoming involved in the game? To the extent that we can generalize about a type of game or act, how does this relate to other parts of the gamer's life in ways that may appear inconsistent or incoherent, for example, "the conjunctive import of playing violent video games at lunchtime and reading sermons in the evening" (Seddon 2013: 8) ? ${ }^{\text {I }}$ 
Furthermore, the gamer seems to be solitary in the initial formulation of the dilemma, but what about the social dynamics of gaming, play and engagement with fictional worlds? The literature is ushering us in this direction. For instance, Patridge discusses incorrigible social meaning, and as the example of eating watermelon and the history of racism in the United States reveals, "Insofar as the incorrigibility of a representation is often contingent on social facts it is often, though not always, socially local" (Patridge 20II: 308). If the meaning is difficult to overturn, this is because of facts about a particular "social reality." For her part, Patridge proposes that some interpretative possibilities should be closed because of "moral facts on the ground" (Patridge 20 I I: 308). The reality of sexual violence and abuse is enough for Patridge to assert that the meanings of some games - and she provides the example of a Japanese adult computer game, Illusion's RapeLay (Reipurei, 2006), which allows players to simulate rape - "are not so obviously contingent" (Patridge 20II: 3 I 2). ${ }^{\text {I2 }}$ This is all the more so with "virtual pedophilia," the imaginary limit case in the gamer's dilemma. One wonders, however, if even here meanings may be "culturally specific, and culturally contingent" (Patridge 20I I: 308). Recall that my male companion did not recognize the character being assaulted on the cover of Mischief Fiend as "human" or the scene as "real," but this did not prevent him from acknowledging that what he was seeing, were it real, would be a violation and a crime. While Patridge tenders that one's "affective response" to a game of sexual assault or abuse should be the same as to a depiction in "a photograph" (Patridge 20I3: 32), this man did not respond to a manga/anime-style game as if it were "real."

When talking about "moral facts on the ground," then, how does one come to know them? If there is an appeal to a "shared, moral reality" (Patridge 20I I: 3 IO; also Patridge 20I3), then how do we come to share that reality? ${ }^{\text {13 }}$ How do we make sense of it on the ground? Taking the point that "imaginative representations can be more or less fictive or imaginative" (Patridge 20I I: 307), the recognition of what is more or less real seems an open question. It is part of an ongoing process, which occurs in particular times and places. Rather than appeal to philosophy or theory to universally resolve and leave behind the gamer's dilemma, does this not call for situated knowledge and continued negotiation of relations between fiction and reality and our imaginative engagements with them? Indeed, this approach appeared in early discussions about the ethics of representation and action in "virtual reality," when philosopher Philip Brey advocated resolution in "social negotiation and dialogue, not in a priori ethics" (Brey I999: Io). ${ }^{\mathrm{I}}$ 
In addition to media effects, the negotiation and dialogue might encompass questions about the relative correspondence of fiction and reality. Provocative here is what Brey calls "reality claims," or implicit or explicit promises about realism (Brey I999: II). To return to my male companion and the line he drew between the manga/anime-style character - a being that is "two-dimensional" - and an actual person in Akihabara, manga, anime and related media and material are not necessarily claiming to reproduce the "three-dimensional" or "human reality." Rather than "natural realism," or realism determined by an approximation of the natural world, there is another realism of manga/ anime expression approximating other manga/anime, or "manga/anime realism" (Ōtsuka 2003: 24). Let us be cognizant here that drawing lines and being drawn to the lines of manga/anime-style cute girl characters does not make my male companion a rapist or a pedophile. Drawing lines makes him no more likely to engage in violent acts. He is not oblivious to reality, confused about what is real or denying facts. $\mathrm{He}$ knows that the image, were it real, would be a violation and a crime. He just does not agree that it is real in the same way as a photograph or that he should, in order to be a virtuous gamer and individual, respond to it as such. In our conversations and my observations on that day and since, I found no evidence that his moral character was "eroded" or "compromised." Indeed, the insinuation that fantasy and play speak to inherent character defects is misguided at best. This rhetorical canard has been used to promote ideologies of hate. To know this man as a human being living in a world of which we are a part is to know that he is not someone who would really "do that" (Patridge 20II: 305), regardless of what he does in the imaginary worlds of bishōjo games.

This does not brush off concerns about the use of stereotypes in representations and introduction of bias (Brey I999: I2-13), but we cannot simply assume that manga/anime expressions are meant to be taken as reality or that people take them as such. The analysis must account for the meanings and significance of the lines that are drawn, literally and figuratively. This is precisely why we can and should acknowledge the harms and evils of sexual assault and abuse (and other forms of violence besides), while not immediately flattening the distinction made in response to Mischief Fiend in Akihabara. It is also why we can take as established science that child pornography offenses are a valid diagnostic indicator of pedophilia (e.g., Seto, Cantor and Blanchard 2006), but note that these results are for tests employing photographs of human actors, not the kinds of cartoon images seen in the games and on the shelves in that store in Akihabara, even when the characters appear 
to be or are explicitly stated to be very young. Fully conscious of real harms and evils, we can still hesitate to equate fiction and reality and rush to moral judgement and relief. Stepping back to look at the bigger picture, when media theorist Thomas Lamarre asks, "Is there any reason to suppose that the interest in mastering images of women does not encourage violence toward real women [?]" (Lamarre 2006: $38 \mathrm{I}-382$ ), I suggest that we suppose nothing and take it as an empirical question. Fieldwork experiences such as the one under discussion here have led me to think that there very well might be a reason, which is found in shared social practice. The line my male companion drew between the "two-dimensional" and "three-dimensional," between manga/anime reality and our reality, the distinction negotiated and maintained through social practice, makes me wonder if, as the most strident anti-porn activists proposed, there is an inevitable move from sex with women in "two-dimensions" to a desire to "live out the pornography further in three-dimensions" (MacKinnon I993: I7-I9). Referring to video of a human woman as "two-dimensional" is nonsensical to the man I walked with in Akihabara that day, a man who sees no obvious connection between human bodies, recorded or otherwise, and manga/anime bodies. We can recognize here conflicting understandings of reality claims, conflicting claims on reality, which should give us pause.

Many of the insights emerging in debates about pornography provide illuminating guidance for tackling the gamer's dilemma. Indeed, the key contention that pornography eroticizes dominance and inequality and is therefore harmful to women (recall Bartel 2OI2) has been questioned for decades. Reviewing the dueling literature to clear a path for her groundbreaking analysis of mainstream heterosexual pornography in North America, film scholar Linda Williams highlights how anti-porn advocates portray sex: “'Normal' sexuality [...] is never violent, not even in the imagination. The attack on violence, together with the rhetoric of harm borrowed from radical feminism - replacing an older and less effective conservative rhetoric opposed simply to immorality, 'smut,' or just plain bad art - allows this arm of the 'moral majority' to assert sexual norms under the guise of protecting pornography's victims" (Williams I989: 19). This convergence, a kind of purity politics or policing around sexuality, even in the imagination, blinds us to messy realities and real relations in the world. For Williams, this raises more questions about where to draw the line: "Are feminists to declare themselves against representations of fellatio, against being on their knees during sex, against anything other than absolutely egalitarian forms of 
mutual love and affection? Indeed, what forms of sex are egalitarian?" (Williams I989: 25). Confusion over what is wrong and why becomes all the more acute when the sex involves human actors not in the performance, but only in the imagining of sex. A strong argument has been made that, "The content of the image produced, whether or not it is sexual, and whether or not it is violent or distasteful to a viewer, is irrelevant" (Rubin 20II: 268). To rephrase, "The use and potential abuse of girls in the production of pornography and their sexual molestation is a serious problem that must not be displaced onto or reduced to an issue of "pornographic content'" (Shigematsu I999: I3 8). In the absence of established correspondence with reality, as in the case of manga/anime generally and bishōjo games specifically, we can only say that it is a matter of taste, or liking that type of character and scenario, which is not a moral or ethical issue (Rubin 20I I: I 54, I 8 I; also Young 20I3). ${ }^{\text {I }}$ It may well be eroticized inequality and playing with power differences, but that is not, in and of itself, a critique, as work on S/M lays bare (Rubin 20II: 258; also Weiss 20II).

There are in addition a number of reasons to resist the push for increased regulation, censorship or outright bans of content that is offensive and even "immoral." Returning to Williams and her groundbreaking analysis, pornography "offers exemplary symbolic representations of patriarchal power and heterosexual pleasure, and while I believe that a feminist critique of this power is crucial, I side with the anti-censorship feminists who hold that censorship of these pleasures offers no real solution to patriarchal violence and abuse" (Williams I989: 22; also Kipnis I996). While calling for zoning to prevent impinging on others' "imaginary domain," feminist legal philosopher Drucilla Cornell rejects further regulation and states, "There are many other imaginaries and it is the very best of liberalism that would insist that they flourish" (Cornell I995: I04). This includes those that are violent, offensive or otherwise "immoral," in part because "through a confrontation with this scene an individual viewer can potentially learn a great deal about his/her sexuality, and society's construction of sex and gender, precisely by having to confront it so directly" (Cornell I995: I 55). Moreover, Cornell questions if pornography "stand[s] in for reality" and if "we want to give pornography so much power that it literally defines what we can be in reality" (Cornell I995: I42-I43). For Cornell, pornography "enacts a complex fantasy scene" (Cornell I995: I42), and she is not alone in this assessment (e.g., Williams I989; Kipnis I996; Shigematsu I999). Her hesitancy to introduce regulations 
of fantasy and imagination hinge on the fact that a densification and intensification of law might take us back to conservative or moral majority positions that impede "liberating the imagination" (Cornell I995: I 58; also Kipnis I996: I63, I99-203; Rubin 20II: I82-I93, 273-275; Galbraith 20I7a: 9-II). The proliferation of sexual imaginaries is not necessarily linked to increased violence, and Cornell underscores studies finding the opposite to be true (Cornell I995: I 53). ${ }^{\mathrm{I}}$ Participants in debates about pornography can and have extended their defense to comics that might be categorized as "virtual rape" or "virtual pedophilia" (e.g., Shigematsu I999), or that which seems beyond the pale for philosophers engaging the gamer's dilemma.

Even if social meanings and shared understandings of reality do "constrain the imaginative world" (Patridge 20II: 303), as Patridge indicates, there are other approaches to the examples she provides that open up the discussion of playing games. In the United States, given the general context of historic and ongoing violations of Native Americans, the in-game goal of reaching and raping a Native American woman does render offensive Mystique's Custer's Revenge (I982), but that does not permit playing it and playing with and through what queer theorist Bonnie Ruberg calls the "true affective full complexity of play" or "affective messiness of play" (Ruberg 20I 5: I IO, II3). With a game like Custer's Revenge, Ruberg proposes, one can "experience the alarm that comes with playing" and learn "an embodied lesson" (Ruberg 20I5: I 20). The experience is "personal, felt, embodied, alarming" (Ruberg 2015: II5). Here we see "disruptive counter-affects," "feeling otherly" and "playing the wrong way" (Ruberg 20I 5: I IO, I I 7). This queer game studies and play includes examples of Japanese adult computer games that depict not only "virtual murder" and "virtual pedophilia," but also rape, torture, cannibalism and more (e.g., Sousa 2020). The disturbing and disruptive nature of the games in question, which combine storytelling and simulation, shatter common sense about self, society and values. As Japan and games scholar Rachael Hutchinson, using other glosses for bishōjo games, states, "Dating simulations and visual novels tell us much about expectations in gender roles, including what lies within or outside the social norm" (Hutchinson 2019: 5; for a broader discussion of pornography and regulation in the region, see Jacobs 20I2). This is not to say that there is no room for criticism there is, and robust criticism at that - but getting there requires sticking with disorienting and uneasy affects. It means sticking with the game in a relationship that is "intimate, tangled, and not always easy" 
(Ruberg 2015: II6). The results "are felt, in the body, as the struggle of the self wrestling with the messy intimacy of a queer partner: the game" (Ruberg 20I 5: I I 7). In this, playing games can be "a call to feel what we aren't supposed to want to feel" and "a challenge to ourselves" (Ruberg 2015: I 22). Feeling outside of what is "common sense" or "right," for example, may entail feeling oneself as other or feeling the other in oneself. This can be unsettling indeed. ${ }^{17}$

Another of Patridge's examples, the Japanese adult computer game RapeLay, is far less likely to receive this kind of treatment from even the queerest of game studies, but here, too, approaches splinter. In the edited volume Violation: Rape in Gaming, feminist writer and S/M practitioner Clarisse Thorn addresses RapeLay directly:

Media can illustrate rape culture and influence rape myths. Yet I think there's a big difference between gaming groups that engage in non-consensual rapey behavior against a real person, versus a game like RapeLay that includes a rape story against a piece of software. When it comes to my own work, I have focused on helping people set real-life sexual boundaries, respect their partners' boundaries, and understand their own bodily desires. I believe that these are not skills well-taught by my cultural environment. Some lessons in sexual communication and boundary-setting can be drawn from the S/M community, though. S/Mers like me, who have an interest in anti-rape activism, often work to highlight those lessons. I also believe that these lessons are primarily interpersonal. Fictional narratives like games or porn can illuminate ways of using these lessons, but communication and context are the bottom line. [...] I'll be honest: RapeLay just doesn't bother me anymore. [...] If some people fantasize about being raped, and if there are ways to consensually implement rape fantasies, then as long as no one is harmed in the making of rape simulator games and the games don't purport to represent reality, I'm not convinced it's important to condemn those games. Basically, if I want to keep my S/M fantasies (and I do!), then I don't feel that I can condemn others' violent fantasies. The complicated part is implementation - and whether the people involved actually believe that their rape fantasy is realistic. (Thorn 20I2: I2, I6-I7)

For Thorn, context and education are key. This is how one learns not only "real-life sexual boundaries," but also what is "realistic;" one learns to separate fiction and reality, and how they can be brought into relation, ethically. Rather than moral condemnation, thinkers such as Thorn raise the possibility of "challenging, ethical productions emerging from both the porn industry and game developers" (Thorn 2012: I 5). Ultimately, we need to explore rather than assert claims about 
adult computer games being ethical or not. This leads us to the field and interactions with others, which is another way that lessons about sex, reality and boundaries are interpersonally taught and learned. Context and communication are, indeed, the bottom line.

The literature on pornography and S/M demands a more capacious understanding of fantasy and play, which points us toward relations with others and reality in considering "dangerous games." In his monograph analyzing the panic over the role-playing game Dungeons o Dragons in the United States in the I980s, religious studies scholar Joseph P. Laycock demonstrates that games are deemed dangerous because they threaten to shift perceptions of or impact reality (Laycock 201 5: I3-I4, I 84-I 86, 202-206). In the case of Dungeons \& Dragons, the perceived danger was that, by presenting various gods and possible alignments of good and evil, the game undermined the Christian God and morality and opened the pathway to Satanism. Throughout the I980s, evangelical ministers, psychologists and law enforcement agents claimed that players ran a serious risk of mental illness as they gradually lost their ability to discern fantasy from reality. Intriguingly, rather than merely adopting the rebuttal that critics were the ones confused about reality, Laycock asserts that role-playing games can and do affect players. In Dungeons \& Dragons, people did see alternatives, and did relativize, by playing other people and playing with other people in an imaginary world with imaginary gods and forces. To rephrase somewhat, experiences within the frame of a fantasy world can and do shape the way players think about and experience the world of daily life; imaginative play is a special frame through which new meaning and new frames can be produced. Challenging "commonsense reality" (Laycock 20I 5: I2) triggered conservative backlash. For his part, Laycock argues for the value of social gaming as a way to learn how to interact with fiction and reality. There is evidence that continued exposure to fiction and practice "switching between frames" helps us "become more adept at distinguishing fantasy and reality" (Laycock 2015: 289). ${ }^{18}$ Furthermore, in playing games and working things out together, we develop literacies and ethics (Laycock 201 5: I 90-I 99). ${ }^{\text {I9 }}$ In short, we learn through extended interactions with fiction, reality and one another. This is "cultural practice," and cultural practice with a long history prior to "virtual reality" (Saler 20I2: I98).20 Spaces of fantasy and play are vital to comprehending ourselves and our shared worlds. As Laycock declares, "Players cannot make sense of evil if it remains taboo even in the context of play" (Laycock 201 5: 190). And yet in the 
United States, where school shootings are not as rare an occurrence as anyone would like them to be, children have been suspended for making gun shapes with their hands (Laycock 20I5: 2IO-2I3). "Like the preschools that banned imaginary weapons and superhero play, there is an assumption that we can somehow foster security by restricting imaginative play. This, I would argue, is the most dangerous path of all" (Laycock 20I 5: 289). ${ }^{21}$ Banning play with a hand shaped like a gun does nothing to address the deeper issues involved in violence with handguns and assault rifles. Although Laycock does not go so far, one could make a similar point about fantasy and play sex in the adult world. ${ }^{22}$

This all resonates with concern about manga/anime, games and/or pornography normalizing or trivializing sexual violence and abuse. Indeed, one response to the gamer's dilemma highlights the blind spot of "playful involvement" and "playfully doing" (Seddon 20г3: го). Following from this insight, Seddon offers a useful intervention by stating that, "it may well be that what seemed attractive in talk of 'virtual' murder, its implicitly close connection to actual murder, in fact leaves too little space to help us understand the moral character of this playful engagement with a game" (Seddon 20I3: ro). The fantasy of eating a banana does not fill one's stomach, and playing with a banana by pretending it is a phone does not make it so. This space Seddon identifies is widened when the characters involved are not meant to look realistic or be taken as such. If extended social interactions with fictional worlds and characters in Europe, North America and beyond has, at least since the late nineteenth century, contributed to a "fictionalist turn" and "culture of Fictionalism" (Saler 20I 2: 27, 200), or contributed to the development of delight without delusion, then manga/anime culture suggests a similar phenomenon. Scholars note that, "The gap between fantasy and reality in Japan is enormous" (Schodt I996: 5I). The case of manga/anime, understood as separate and distinct from "reality," demonstrates an extraordinary "tolerance of fantasy" (Schodt I983: I37). This gap has allowed men and women of all ages to open and inhabit space to, as the feminist comics scholar Fujimoto Yukari eloquently articulates, "play sex/uality" (Fujimoto I998: I96; see also Fujimoto 2016). Tellingly, when asked her position on depictions of rape and underage sex in Japanese comics, cartoons and computer games, Fujimoto responded that this was a space of "simulation," not necessarily what one wants "in real life" (quoted in Galbraith 20I7a: Io). Indeed, the distinction seemed so obvious that she could not help 
but add, "For me, it's so strange that people from North America don't make that distinction. Why? The things that you are thinking are not the same as the things that you want to do. Shouldn't that be clear?" (quoted in Galbraith 20I7a: Io). As not only a scholar, but also someone who grew up enjoying comics and cartoons in Japan, fantasy and play sex in manga/anime and reality are "absolutely separate" (quoted in Galbraith 2017a: Io).

There is, of course, the possibility of "corrupted play," where boundaries blur and it is "no longer clearly a game" (Laycock 201 5: 287). "It is possible," Laycock elaborates, "for the lines between imaginative play and reality to become blurred, and this does sometimes lead to dangerous consequences" (Laycock 20I 5: 287). To this, he responds:

To avoid the dangers of corrupted play, we must learn to walk between worlds. [...] The ability to imagine other worlds means that change is always possible, including the rise of deviance and challenges to the social order. However, when we attempt to secure the status quo by blocking access to these worlds, we do so at great peril. [...] Only by becoming conscious of these other worlds and thinking about them deliberately can we stop ourselves from playing dangerous games. (Laycock 20I 5: 290) ${ }^{23}$

Learning to walk between worlds takes practice. It means learning, socially. Ultimately, for Laycock, "It is not the content of the game but its frame that determines whether it will translate into action" (Laycock 2015: 283). "Fantasy role-playing games," he continues, "represent a highly stable form of imaginative play because while they have demonstrable impact on the way players think about the world beyond the game, they are clearly demarcated as imaginary rather than real" (Laycock 2015: 287). Something similar might be said about manga/ anime fantasy and play. What my male companion did in that store in Akihabara revealed the frame, or framing, of manga/anime generally and bishōjo games specifically as something other than "real." If what we were seeing were "real," it would be a record of a crime, but it was instead a game to play. The lines separating fiction and reality, or manga/anime reality and our reality, the space of interaction with cute girl characters and the "real world," are a form of boundary making that allows for play. The struggle comes in drawing and maintaining those lines to avoid the play becoming corrupted and impacting reality in dangerous ways. The distinction of fiction as such "requires ongoing practice to maintain" (Saler 20I 2: 50), and this is shared, cultural practice. Such cultural practice makes possible what psychiatrist Saitō 
Tamaki identifies in his work on manga/anime fans as an orientation toward "fiction as such," or "finding sexual objects in fiction itself" (Saitō 20II: I6). To rephrase, in orienting themselves toward a "fictional context," these manga/anime fans are "fictionalizing sex" (Saitō 2OII: 3I). "If there is," Saitō states, "a certain sincerity and ethics in a dissociated life lived with self-awareness, it is because hypocrisy and deception dwell in the falsely coherent life" (Saitō 20II: I72). And he insists that, "In the imaginary realm all human beings have the right to be perverts" (Saitō 20II: 3I). In imaginative engagements with fiction and reality, we might add a caveat: perverts with principles, or those who know where to draw the line, and are surrounded by others who can help in confusing times. Ambiguity and ambivalence will of course remain, and working through and feeling what it means to play these games is the enduring challenge.

In drawing and maintaining lines, manga/anime fans generally and bishōjo game producers and players specifically are engaged in what I have come to see as an ethical practice. While ethics is often taken to mean principles that govern a person's or group's conduct (Deigh 20IO: 7), it is important not to think of this as transcendent or unchanging. Rather, ethics are immanent and embedded in the social. In this spirit, anthropologists such as Michael Lambek examine ethics in action and everyday practice (Lambek 20I0a: 2-3; Lambek 20Iob: 39-40; Das 20I0: $376-378$ ). The everyday practice that I observed was orientation toward, interaction with and response to fictional characters, which are separate and distinct from human beings, but real in their own right. They are objects of desire and affection, which are shared with others. In this way, relations with fictional characters become social relations, even as fictional characters are themselves significant others, both fictional and real and part of social relations. The ethical fan is the one who recognizes that the manga/anime character is fiction and responds to it as such. Called moe, this affective response is to a fictional character, not something more "real." This is not, however, an always obvious and automatic distinction. In some cases, there may be desire for something more "real;" here too are ethics, which is the action and everyday practice of recognizing desires, however unsavory, and doing so openly with others. Finally, there is an ethics to understanding that one is capable of doing harm to other human beings and so acting with care not to do so. The ethics, then, is to not confuse or conflate characters with human beings, to embrace characters and to not act in ways that might harm human beings. In action and everyday practice, one is drawn to 
the lines of manga/anime characters and draws a line between them and human beings. There is an ethics to interacting with ontologically queer existences that are both fictional and real, both and neither and something else; this interaction involves others, who help to draw and maintain lines, affirming objects and orientations in a queer world. In the field, I came to grasp this ethics of affective response to fictional characters as an "ethics of moe" (moe no rinri). ${ }^{24}$

\subsection{Fieldwork: Drawing Lines in Akihabara}

This book explores the ethics of moe through participant observation among male fans of manga/anime-style cute girl characters. Fieldwork was conducted primarily in Akihabara from April 20I4 to August 2015 , but I also traveled to events and met people in the broader Tokyo area and nearby locations. ${ }^{25}$ While an orientation toward fictional characters and discourse about affective responses to them is by no means unique among Japanese fans, male or female, I focused this project on men gathering in Akihabara because of the density and visibility of content there catering to a two-dimensional orientation and intended to trigger moe. More concretely, I was interested in the concentration of stores selling bishōjo games, which facilitate intensive and intimate interactions and relations with cute girl characters. ${ }^{26}$ This intensity and intimacy also extends to the Akihabara area itself, where a large and dedicated base of players come to brick-and-mortar stores to buy bishōjo games in physical packages and interact with staff, producers and one another. Many events are held in Akihabara because of not only the number of stores there, but also companies producing bishōjo games.

Interacting with others, I learned to play bishōjo games, share affection and draw lines in the everyday practice of an ethics of moe. This social learning involved following players like my male companion as they parsed the reality of games such as Mischief Fiend, as well as producers drawing lines of their own as they discussed such games. ${ }^{27}$ This sort of learning has been tied to emergent ethics in peer interactions online (Jenkins et al 2009: 28-30), and similarly nuanced positions around difficult topics have been noted among anime fans in North America (Eng 2012: IOO-IO3), but the face-to-face interactions, material investments and physical infrastructure of Akihabara offer unique research opportunities. ${ }^{28}$ By virtue of being a geographic location where desire and affection for cute girl characters is disarmingly public, Akihabara has become a lightning rod for debate, which 
facilitated my interviewing a diverse range of critics, activists and politicians. Consistent with my earlier research (Galbraith 20I9), it is male fans of manga and anime, specifically of manga/anime-style cute girl characters, who are most often associated with imagined excesses and perversions. ${ }^{29}$ This leads to explicit articulations of the ethics of moe as it exists in practice in contemporary Japan.

If the ethics of emerging practices surrounding new modes of expression are not well understood by concerned citizens and authorities, as media and fandom scholar Henry Jenkins remarks, then one way forward is to participate in activities and engage in peer learning (Jenkins et al 2009: 25). As an anthropologist and relative newcomer to bishōjo games, I tried to take those I learned from seriously and appreciate how and why they drew lines as they did. In the anthropological tradition, fieldwork emphasizes learning with others and attempting to share another "point of view" and "relation to life" (Malinowski 20I4: 25), but this project provided some unique challenges (see Appendix). Just as I felt compelled to interrogate my male companion about what he really liked, or if he really liked schoolgirls, there is an overdetermined suspicion when confronted with bishōjo games and players, if not mangal anime sex tout court. Only someone "like that" would be attracted to something "like that," which shuts down encounters with individuals and images. There is a barrier when we treat our informants not as teachers, guides and companions, but rather as suspects. In seeing them as not only perverts, but also potential pedophiles and predators, we are also faced with what sociologist Arlie Russell Hochschild dubs "an empathy wall," or "an obstacle to deep understanding of another person, one that can make us feel indifferent or even hostile" (Hochschild 20I6: 5). After all, why would I want to get to know someone "like that?" Someone like that is a monster, not a human to learn from and with. In order to disrupt what I already "knew," or rather to allow for dwelling in unknowing relation to come to know differently, I needed to fully embrace fieldwork as "partial," both in the sense of incomplete and coming from a particular place (Clifford I986; Haraway 1988). While interviewing critics, activists and politicians advocating for more regulation of manga/anime expressions, I spent most of my time with bishōjo game producers and players. I tried to hear and understand the stories these people tell themselves and one another. This is part of cultural learning, but also an ethics of negotiating and maintaining lines through sharing stories and practice. There is ethics in practice, and through sharing stories and practice, I learned socially with peers. 
This is how I could do the work without constantly judging companions as potential criminals, although I admit these troubling thoughts did occur to me at times, and I try to relay those experiences truthfully. Working from the ground up and interactions with others does not preclude critical perspectives, but rather emphasizes those emerging among manga/anime fans generally and bishōjo game producers and players specifically, for example seeing the potential for violence in oneself and acting with care toward fictional and real others. Acknowledging its partiality, I offer the perspectives of bishōjo gamers not as an apologia or polemic, but rather to open this learning to others. Before stepping outside and standing above, we might try to understand what is being said, what is happening and how it makes sense.

Manga/anime fans, specifically those playing bishōjo games and interacting most intensively and intimately with fictional characters, present us with other ways of seeing and being in the world. In the context of mounting fear of the dangerous effects of media, for example bishōjo games contributing to the sexualization of young women and to sexual violence, these other ways of seeing and being provide what anthropologist Gabriella Coleman terms an "inadvertent politics of contrast" (Coleman 2004: 5I3). The contrast, however inadvertent, becomes political for calling into question what might seem to be common sense. Trying to resolve the discomfort of bishōjo games and similar content with appeals to popular judgement and calls for legal judgement seems hasty at best. We might instead see an invitation to work through the entangled lines of existence in a more-than-human world, highlighting interactions and relations with characters as fictional and real others. Along the way, we may find ethics in unexpected places, for example among those purchasing a game such as Mischief Fiend in Akihabara, playing it or another one such as Parfait: Chocolat Second Brew, marrying a cute girl character like Katori Rea and sharing desire and affection that sustain life and push it in new directions.

\subsection{From the U.S. to Japan: Starting a Project on Games in 2014}

Transitioning back from the United States to Japan and into a project on adult computer games in 20I4, I felt simultaneously part of and apart from popular and academic discourse. That year, the electronic gaming industry was valued at around US\$67.2 billion (Kain 201 5). Electronic games - video games, computer/console games - simply put, were 
mainstream culture, with some games equivalent to Hollywood blockbusters and others elevated to the status of art. That said, it was hard not to notice that the content thus appreciated seldom overlapped with the games on display in Akihabara. Consider Call of Duty: Advanced Warfare, which was the bestselling game in the United States in 20I4. Classed as "AAA," games like this one have the biggest budgets and most resources behind them. It features Kevin Spacey as the antagonist, who is a digital recreation of the (former) Hollywood heavyweight that he also voices. Making use of near photorealistic graphics, real-time rendering and cinematic cutscenes, the game looks and feels like a film. As a game, however, it allows the player to take control of the action. Call of Duty: Advanced Warfare is part of a genre called first-person shooters, where players move through virtual spaces and shoot enemies from a first-person perspective. Players can also connect online to fight with and against others in massive multiplayer battles. First-person shooters are among the most popular genres in the United States, which is perhaps the legacy of the "military-entertainment complex" (Lenoir 2000: 289). In a report released in 2014, the Mizuho Group estimated that first-person shooters made up $2 \mathrm{I} .2$ percent of the US market (Mizuho 20I4: I40).

In sharp contrast, in Japan, first-person shooters were the least popular genre, accounting for just I.I percent of the market (Mizuho 20I4: I40). Far more widespread were roleplaying games (23.9 percent), which tend to emphasize story and character, and "fantasy" (fantajii-sei) as opposed to "reality" (riaru-sei). Also notable in the Mizuho Group's report was the prevalence of "other" (30 percent), or Japanese games that do not fit into established categories. In its report, the Mizuho Group highlighted an apparent divergence between the electronic gaming industries in the United States and Japan, with a variety of content produced in the latter not making it to the former, and fewer breakout hits. Indeed, in 20 I4, only Nintendo's Super Smash Bros made it onto the list of top ro bestselling games in the United States (Kain 2015). Electronic gaming is increasingly mainstream among adults in the United States, and there are certainly games intended for older audiences - for example, the Grand Theft Auto franchise, which had one of the top ro bestselling titles of 2014 with a new installment that allows players to commit crime in a relatively open world - but "adult game" means something else entirely in Japan.

There, "adult" (adaruto) or "erotic" (ero) games, most famously bishōjo games (other forms target women [Yaraon 20I3]), are a niche 
market that is distinct from the mainstream of globally recognized franchises such as Super Mario Bros, Final Fantasy and Pokémon (Mizuho 20I4: I I7-I I 8). Labeled "R-I 8," only players age I 8 or older can purchase them. Rather than consoles or mobile devices, adult games in Japan are usually played on computers, but they are not networked or multiplayer in ways familiar from the United States. Featuring graphics that are rarely computer-generated or realistic, they also do not allow players to freely roam in open environments. Instead, players read onscreen text and make choices in something approaching chooseyour-own-adventure novels. Despite their seemingly rudimentary and outmoded design, newly released adult computer games could cost as much as US\$IOO each in 20I4. In recent years, adult computer games have had difficulty attracting younger players; the overall market is in decline, and some estimate a decrease in value from over 50 billion yen in the early 2000 s to I9.I billion yen in 20I4 (Yano Research Institute 20I4: 2; also Sakakibara 20I6). Today, most of these adult computer games sell only I,000 to 2,000 physical copies (Kagami 2010: I36). If they are located in a niche in Japan, then this is even truer outside the country, where adult computer games are more often discussed as creepy and weird than purchased and played (this is changing, albeit slowly [Grayson 2019]).

As a niche, and a form that is relatively cheap to produce, adult computer games appeal to dedicated players with specific demands. While titles such as RapeLay focusing on sexual violence draw attention and international criticism (e.g., Lah 2010; Patridge 20II; Nakasatomi 20I3), industry insiders estimate that adult computer games of this type make up only Io to 20 percent of the market (Kagami 20IO: I28). These are also not the bestselling titles, which instead concentrate on interpersonal relationships, romance and melodrama. Regardless, most include explicit sex scenes. Some game makers remove these scenes for later "general" (as opposed to adult) releases on consoles and mobile devices, and the overall industry trend is toward what scenario writer Kagami Hiroyuki describes as "de-pornification" (Kagami 20I0: I36I 38 ), but sex is still very much a part of adult gaming in Japan. The presence of sex and its deliberate exploration stand out in comparison to mainstream gaming in North America, where one critic provocatively proposes, "Video game designers are, by all accounts, genuine prudes on the issue of sex. Few if any are willing to risk failure or audience discomfort by taking the issue on openly" (Thomsen 20I0). Fewer still risk taking it seriously. 
While sex is important to the play experience, adult computer games in Japan are even more fundamentally defined by their focus on interactions with characters, most famously bishōjo or cute girls. This is what is prominent in Akihabara, so much so that adult computer games on the whole are often casually referred to there as bishöjo games. With interaction in mind, there are eight identifying features of the adult computer games popular in Akihabara: (I) characters that the player character interacts with are seen from a first-person perspective and speak directly to the player character, who is for the most part unseen; (2) important characters will often have a recorded voice for lines of dialogue, but the player character typically does not; (3) characters appear as a series of still images, for example, changing from one static facial expression to another as the interaction proceeds; 4 ) designed to be visually appealing, the characters have a distinctly cartoony look that recalls manga and anime; $(5)$ below characters onscreen is scrolling text in a box, which tells a story that frames and motivates interactions; (6) the story takes a least several hours to complete; (7) along the way, the text presents the player with choices, which can impact character interactions and the story; and (8) there are multiple possible endings. Over the course of the game, the player interacts with characters in ways ranging from casual conversation to coitus.

Discussing the specifics of adult computer games, especially the bishōjo games popular in Akihabara, often resulted in people responding to my project as being about "Japan." That is, if it is not about games, or at least normal games, then it must be about other games, weird games, "hentai games" (Bogost 201 I: I07), "pervert games from Japan” (Game Faqs 20I7). While a gamer in Japan might find the prevalence of first-person shooters in the United States strange, encountering unaccustomed content inspires many to exclaim, "Oh, wow! Japan is so weird." This effectively stops the conversation, because we have reached an all-too-familiar impasse in drawing a line between the United States as normal in contrast to Japan as "Other." The juxtaposition is as old as the anthropology of Japan, but of course far more widespread..$^{\circ}$ Today, there is a cottage industry of popular writing on "Weird Japan." With disheartening regularity and consistency, outlets such as the New York Times and Wall Street Journal, CNN and BBC report that "Japan has a sex problem" (Gilbert 20I7). The news may be that marriage and birth rates are down and the population is shrinking; young people are not having sex; or young people are getting married to fictional characters, pillows, even cockroaches; that people are having way too much 
sex, weird sex, sex in their imaginations, which threatens the already small population of children in one way or another (Katayama 2009; Ripley et al 20I4; McGee 2019). ${ }^{\text {I }}$ Whatever the case may be, "Japan has a sex problem.”

Against this backdrop, it is not so surprising that many people I spoke to in the United States brought up stories of men in Japan marrying videogame characters, which they probably had not come across in writings on gaming generally, but did find reported by sources such as Reuters (Meyers 2009). These things are in fact happening, and there is much to discuss as we unpack them. Frustrating, however, is the move to make it something about "Japan." This is first of all "a sex problem," and that sex problem is over there, with them, safely located in another place with other people - in "Japan" with "the Japanese." On the one hand, there are serious issues with any approach that uncritically assumes the nation or its people as the object of analysis, which reinforces imagined boundaries and smoothes over internal diversity (Iwabuchi 2010: 93). On the other hand, Japan is surely not exceptional as a site of "virtual intimacies," which anthropologist Shaka McGlotten also sees entering into public discourse in the United States (McGlotten 2013: I7-38). Indeed, more recent news stories might begin by profiling a man in Japan marrying a manga/anime character, but then quickly move to global phenomena such as "synthsexuality" and "digisexuality" (Williams 20I9).

Certainly these journalists are correct that "blurred lines do not have to be a bad thing" (Williams 2019), but we might also consider seriously what lines exist and why they matter. Starting the story with a Japanese man marrying a manga/anime character, specifically the virtual idol Hatsune Miku, and concluding it with a group of men abusing a sex robot in Austria - as the article in question does (Williams 2019) - collapses together different relations. On the one hand, a wedding ceremony where friends recognize a man's real relationship with a fictional character, or social relations with something that is more than an object. On the other hand, men sexually assaulting a robot and damaging it at a tech convention, or a non-relationship with something reduced to an object and abused with impunity. The question might then be how the character of Hatsune Miku became a significant other, which is to say how manga/anime fan cultures in Japan encourage some interactions and relations and discourage others. That Hatsune Miku is a cute girl character officially said to be 16 years old, and that fans produce and consume fan fiction and art about her involving 
coercive and sometimes violent sex, is important, but so is the fact that a 35 -year-old man married her because, as he explains, "I seriously love her" (IT Media 2018). Feelings are being shared here, and we might consider leaning in to hear them rather than shrugging the man off and turning away.

In the field, I wanted to see how something like that marriage makes sense to some people in contemporary Japan, as well as why it does not make sense to them to assume that what is really desired is a human girl and that this reflects and reinforces the objectification and abuse of girls and women. For me, this meant following others and their lines of movement in the world (Ingold 20 I I: I 49, I62, I 79), including lines of movement in response to manga/anime characters and in shared worlds of imagination. In the field in 2014 , as a relative newcomer to bishōjo games, I learned about them while playing titles recommended by informants, who agreed to meet and discuss experiences. These were at once their own and mine, as we talked about shared and divergent paths through, and responses to, games that we had played. At times, I thought that I had gotten the hang of it, but then a producer or player would introduce me to something involving interactions and relations that crossed lines I did not even know that I had drawn. Negotiating those lines while interacting with manga/anime characters and producers and players of bishōjo games was part of fieldwork. It was also part of ethical practice. To put it somewhat differently, responding to bishōjo games with others and drawing and crossing lines was part of sharing imagination and movement.

This sharing of imagination and movement was challenging and surprising, but not always and necessarily unpleasant. Transitioning into a space where I could get as close as possible to and socialize with bishōjo game producers and players, things felt off, sure, but I also did not feel some of the things that I expected to with these men (as well as the women I later met). As I began to settle into fieldwork, things exploded in the summer of 2014. There was, as previously mentioned, the furious international reporting on and condemnation of the revision to child pornography laws in Japan leaving out even the most explicit of manga, anime and games depicting underage sex. Bombarded with discussions of the most extreme examples, and requested by visiting journalists to walk them through Akihabara and provide answers, certain images were on my mind when encountering others in the field. It became very clear very quickly that none of the games were as straightforward and simply bad as the critics believed - or as flat as the abstract virtual 
violence imagined in the philosophical debate over "the gamer's dilemma," though they still posed ethical challenges for me as a researcher and player in training (see Appendix) - but I could not rid myself entirely of residual images and ideas. This is likely why I could not help but air those dark thoughts and doubts when, for example, walking with my male companion in Akihabara and stumbling upon Mischief Fiend. This led to surprising feelings - my sense of mischaracterizing him, of being wrong and in the wrong for having assumed things and misjudged him as someone "like that," all of that, but then also the joy of sharing his affection for Katori Rea, of being invited in instead of pushed out. The affect, like his smile when looking at images of Rea in his room, was infectious. When I did attend events like the one my male companion described, there was an overwhelming sense of life. Bodies, fictional and real, affecting one another. An experience of affect as the push of life in a more-than-human world.

The joyful encounters here, too, were surprising in contrast to what I expected to feel. After all, the summer of 2014 was also marked by the Gamergate controversy, and while I was not in North America at the time, I regularly received updates from friends about terroristic threats of violence being hurled at female game developers and feminist critics. It was hard not to agree, even at a distance, that the displays of hostile misogyny and male entitlement to gaming culture were indicative of a struggle against "traditional, patriarchal, dude-dominated gaming culture" (Dewey 20I4). The masculinity here seemed so fragile, the men so fearful of change and losing control, "toxic" (Salter and Blodgett 20I7; also Consalvo 20I2). I was aware that depictions of female characters in games from Japan were also being identified as problematic, and in the context of a general reckoning for sexual violence that was not at all theoretical, people were drawing battlelines and declaring moot "any garbage about 'cultural differences"” (Maggs 2015). So I was primed and ready to confront masculine rage and misogyny, but that is not at all what it felt like to be at those event with bishojo game players and their fictional and real partners. The sexually explicit images of manga/ anime fantasy appeared on walls and screens around us, and the men at times played violence in embodied ways, but they also were doing the opposite of hurling threats at others and women. They were laughing at themselves and one another - laughing, together. They recognized themselves as "losers" or "failed men," the kind who came here with a body pillow and were calling it their wife. And they seemed more or less fine with it. They were raving about it, dancing with their pillow 
wives and one another. There was not a pronounced narrative of victimhood or deprival. Unlike online gatherings of "incels" (involuntary celibates) or advocates of "men's rights," these players did not appear to be worried about how and why they did not have a "real date," did not "get the girl," which was utterly beside the point. ${ }^{32}$ Failure, perhaps, but not necessarily a failure of morals and sensitivity. If this is "failure," then it is also an example of "failing well" and finding "other goals for life, for love, for art, and for being" (Halberstam 20I I: 203). They did have partners, really, in this space of shared fantasy and play. They imagined and created alternatives. Rather than grouse about what the social system and sexual hierarchy owed and denied them, they seemed to have dropped out of that discussion to play a different game entirely.

In this, I saw men like my companion in Akihabara engaged in "playing with one's self," to borrow a turn of phrase from Lamarre, and embracing the perversion of "sex with an image" (Lamarre 2006: 375). They were not only playing with themselves, but also playing with one another. This public sex, a sort of shared masturbatory play of imaginary sex, might well be described as perverted. It did not, however, feel the same as what was being criticized as exclusive homosociality and toxic masculinity. The largest felt difference might be that they did not seem to take themselves so seriously, did not blame or begrudge others their successes and allowed themselves to be exposed and vulnerable. They were having fun - with themselves, their characters, with fictional and real others. They were also sharing their feelings, however shameful or embarrassing. They shared laughter, but also stories about what made them cry and how they got off. They presented themselves and their imaginary lives and loves as absolutely absurd, but at the same time raw, real and moving. I was affected by all this, and not entirely as I anticipated. I found myself buying a pillow and jumping in, joining them. I was, to put it bluntly, part of the shared fantasy and playing with oneself and others. Sex with an image, imaginary sex, made some kind of sense in practice. I could chalk my purchase of a character wife pillow up to fieldwork and that deeply felt need to "join in [...] what is going on" (Malinowski 20I4: 2I). I might add that "ethnography renders its practitioners vulnerable to the blood, sweat, tears, and violence of the people being studied and requires ethical reflection and solidary engagement" (Bourgois and Schonberg 2009: I4). In the end, I had to negotiate lines individually and socially. This is part of the ethics of affect, and my own partial experience. This book is an attempt to share with readers the lines and lives I came to feel out and grasp in a Tokyo neighborhood. 


\subsection{Outline of Chapters}

This book is divided into five chapters. In contrast to the bulk of the text, which presents the primary findings of fieldwork, Chapter I sketches the history of struggles surrounding imaginary sex, violence and crime in Japan and beyond. In both Europe and North America from the I970s on, a number of scholars noted a transformation whereby sex, violence and crime began to be discussed in terms of risk. Even as cultural theorist Stuart Hall and his colleagues saw certain populations being imagined as "potential victims" and "potential criminals" (Hall et al I978: 20, 42, 46), philosopher Michel Foucault saw a discourse of sex in particular as a danger to certain populations, most notably children, who needed to be protected (Foucault I988: 276, 28 I). Anthropologist Gayle S. Rubin responded to this moment by developing a theory of politics and power around sex, which includes drawing lines between "good" and "bad," "safe" and "harmful" (Rubin 20I I: I 5I). With the rise of the internet in the I990s, there was an explosion of concern about children as potential victims of sexual violence and perversion, which prompted legal action against both actual and virtual forms of child pornography and abuse. As Foucault and others predicted, there need not be any victim for imaginary sex and violence to be perceived as a risk and handled accordingly.

It is absolutely not the case that there has been no debate on these issues in Japan, but, as explained in Chapter $\mathrm{I}$, the conclusions reached have been very different. Despite a reputation for being sexually liberal, there has long been concern in Japan about "harmful" comics, cartoons and computer/console games and their impact on young people and society. This was especially so in the I990s, when Japan was experiencing a crisis of hegemony and reproduction, which led to increased scrutiny of youth, sexuality and media. The conclusion, however, was that statistics do not support the claim that harmful comics, for example, contribute to sexual violence and crime. So it was that, when taking legal action against the production and sale of child pornography in I999, Japanese legislators notably did not include fictional forms.

Meanwhile, at the same time as debates about the danger of confusing fiction and reality and harming others in Japan, fans of bishōjo characters were deliberately separating fiction and reality and affirming their orientation toward the former. The clearest expression of this is moe, or an affective response to fictional characters, and the emergence of a discourse about it in the I990s reveals a growing awareness of 
the affect of media, an orientation toward fiction and shared affection and orientation. In this I see emergent forms of media literacy and ethics. The chapter opens up the ethical positions of manga critics and editors Ōtsuka Eiji, Nagayama Kaoru and Sasakibara Gō in their responses to the criminal other and potential self. These positions inform the argument of the book and return throughout it, most explicitly in Chapters 3 and 5 .

As I have argued elsewhere (Galbraith 2019), it is also crucially important that alternative ways of living with characters as significant others became so pronounced in Japan in the I990s. During that decade, due to economic recession and subsequent neoliberal reform, many men were left in a lurch, unable to transition into stable jobs or have the security thought necessary to start families. This situation is not limited to Japan, and anxiety and anger among these men has been underscored across the globe (Standing 20I I: 63-65). Interesting in the case of Japan, however, it that, rather than turning to reactionary politics and demanding a return to the norm, manga/anime fans who had already been deemed abnormal embraced emergent alternatives, which resulted in the enormous growth of bishojo games and the broader moe boom. These men started playing a different game to live and move on in capitalist ruins.

The subject of Chapter 2 is Akihabara, where we see tension between forms of media literacy and ethics and concerns about the potential risk of imaginary sex, violence and crime. In Chapter 2, I show how these concerns have been renewed in Japan through feedback and condemnation from global critics of a perceived paucity of action against offensive comics, cartoons and computer/console games. In most cases, Akihabara is taken to symbolize this offensive media and material, as well as the risk posed to women and children. Nowhere else are there more stores more openly displaying more pornographic manga/anime content featuring cute girl characters than in Akihabara. The reasons for this, Chapter 2 elucidates, lie in the history of the area as the center of the bishojo gaming world, and this bias toward male fans of cute girl characters was later bolstered during the moe boom, when stores selling all manner of media and material catering to these male fans moved into the area. The chapter introduces voices from Japanese critics, activists and politicians who are concerned that such a space will engender perverse desires that endanger women and children. It also introduces men who frequent Akihabara and see it as an essential part of their awakening to desire for cartoon characters, which, however perverse, 
is not harmful. In Akihabara, the so-called "Moe City," bishōjo game producers and players gather and openly share their affection for cute girl characters, which is also a way of recognizing and affirming relationships with fictional and real others. Approaching Akihabara as a public sex culture and space of informal peer learning, I follow others in launching a "principled defense of pornography, sex businesses, and sex outside the home" (Warner 2000: vii).

Going inside of production companies and drawing on interactions with the men and women who create bishōjo games, Chapter 3 discusses aspects of design. Bishōjo games pursue a cartoony aesthetic of unreality, but nevertheless affect players. This is in part possible because these games require, even demand, imaginary participation. The moving image involves not only the character - itself an assemblage of drawn image, voice and story - but also the input of the player interacting with it. The chapter demonstrates how the design of bishōjo games triggers complex and seemingly contradictory responses in players. On the one hand, the cuteness of the characters encourages social, even human interactions and relations with them (Sherman and Haidt 2OII: 5), which are in fact vital to game play. On the other hand, just as cuteness contributes to forming "the most objectified of objects" and can trigger "ugly feelings" (Ngai 2005: 834), so are these characters acted upon, abused, hurt. This, too, is part of game design, as players must make choices to act and in so doing hurt those they have come to know, if not care about. To get at the effects of such design, the chapter introduces a theory developed by Sasakibara Gō, who perceives bishōjo games as moving us to understand our capacity to act and harm others. This in turn underpins an ethical position of facing ugly feelings and desires, working through them and acting with care. Design and its effects, I argue, shed light on why it is players of bishōjo games specifically who tend to form relationships with characters that go beyond the game itself and impact social relations, even as these players are also committed to sharing affection and relations and avoid harming others.

Drawing on fieldwork with bishojo game producers and players, Chapter 4 focuses on what I came to know as the ethics of moe. Examples from the field show ethics in the action and everyday practice of drawing a line between fiction and reality, orienting oneself toward the former and insisting on the drawn lines of fictional characters. In particular, the chapter introduces examples that are the most alarming for critics, namely interactions and relations with underage characters, many explicitly stated to be children and explicitly sexual. Looping back to concerns raised by critics, activists and politicians in Chapter 2, 
the chapter zooms in on moments when the line between fiction and reality seems to blur. In the field, I observed that it was precisely at these moments when the line would be redrawn and maintained, which is to say when the ethics of moe was most visible in action and everyday practice. I found myself drawn into these moments and encouraged not to see myself as somehow above or outside the relations in question; I was, in short, encouraged to draw and maintain lines of my own. Notably, those who crossed imaginary lines were not always or necessarily seen as outsiders, but rather as part of the group to be pulled back and reoriented through social interaction. The recognition that there may not be a clear line between fiction and reality, combined with the recognition that it is not only others who could make a mistake and do harm, but also us and me personally, contributes to a commitment to act with care. Rather than simply declare that manga/anime and reality are obviously distinct for everyone but the very seriously mentally ill (Saitō 20II: 29), Chapter 4 introduces Harata Shin'ichirō, a legal scholar in Japan and manga/anime fan who advocates for an ethics of moe in situations where juridical resolution of meaning and guilt seems inadequate.

Moving from Akihabara to the Tokyo suburbs, Chapter 5 offers an in-depth account of bishojo game raves where actual and virtual bodies, material and image, men and women come together in an affectively charged space. The primary focus is group performances involving material representations of bishōjo characters, which oscillate between displays of affection and sex and violence. Women participate in these raves, but bishōjo game players draw a line between them and cute girl characters, which they are oriented toward and insist on in action and practice. Indeed, the raves are often organized as opportunities for men to escort their "wives," or favorite characters, into physical space and shared interactions and relations that make them real. That is, these are rituals to realize interactions and relations. The characters, their "wives," are shared objects of desire and affection, rather than anything more "real." The ethics of this circle back to Ōtsuka Eiji, but also push beyond into a contemporary ethics of affect. A discussion is staged between Ötsuka and bishōjo game producers and players such as Maeda Jun and Honda Tōru as they respond to the criminal other and potential self.

Furthermore, the networks of men and women who participate in these raves support alternatives to the normative model of success in Japan, which has become toxic. If, as anthropologist Ian Condry states, moe leads to "the emergence of alternative social worlds" (Condry 2013: 203), then these worlds support the lives of bishōjo game players. For 
some, social interactions with fictional and real others are what keep them living and moving on. These new paths are being imagined and created by bishōjo game producers and players in Japan today. This is not to say that these alternative social worlds are utopian or without practices to be critiqued, but in the rush to censure them, we might miss what is going on. There are norms here, too, and an "ethics of queer life" (Warner 2000: 33). The challenge is to try to move with others, to see and be in the world otherwise, before adopting a stable position as the critic who already knows better. ${ }^{33}$ I unpack and address some of the political implications of bishōjo games and the ethics of affect in contemporary Japan in the Conclusion, as well as methodological and ethical issues of sharing imagination and movement with others in the Appendix.

While this book comes out of a focused anthropological project in Japan, the ethics of moe speak to matters of broader significance. Around the world, there is increasing appreciation of the fact that human beings live with media and material that affects us (e.g., Mazzarella 20I3). Ongoing considerations of interactions and relations with nonhuman others typically highlight entanglements with plant and animal life (e.g., Tsing 20I5), but there is also recognition of the expanding range of nonhumans, including affective robots, virtual idols and automated programs. To claim that we are not part of such interactions and relations - or are engaged in them but remain unaffected, while someone over there might be less disciplined or somehow dangerous - is all too easy. It allows for an easy sidestepping of difficult questions. We need to think about drawing and negotiating lines of our own. We need to think about how to act ethically in a more-than-human world. To borrow the words of anthropologist Eduardo Kohn, "A more capacious ethical practice, one that mindfully attends to finding ways of living in a world peopled by other selves, should come to be a feature of the possible worlds we imagine and seek to engender with other beings" (Kohn 2013: I34).34 Just as Kohn takes Ávila, a village in Ecuador's Upper Amazon, as a particularly rich case of what is much more general, Akihabara, with its density of character media and material, specifically manga/anime forms designed to trigger affective responses and become part of life in sustained affective relations, is a good place to think about ethical practice in the possible worlds we imagine, but it is only the beginning. In writing this book, I hope to encourage readers to reflect on lines and lives where they are, and where they might be going. ${ }^{35}$ 


\section{Imaginary Sex and Crime in Japan: A Brief History}

\subsection{Introduction}

There are more people here, and more cartoon characters having sex, than is reasonable to assume would ever be in any one place. This is the Comic Market, which has grown from humble origins in the I970s into an event of massive proportions. Twice a year, over 550,000 people gather to buy and sell media produced independently of commercial publishers. Independently, but also completely dependently. Most of the media here is printed material featuring manga/anime-style drawings of characters from existing manga, anime and computer/console games. These publications are, in a word, fanzines, and the Comic Market is the world's largest gathering to buy and sell them. While these publications are technically against the law, copyright is not strictly enforced, which allows fans to produce works featuring their favorite characters. The most common theme is imagined relationships with and between favorite characters - sex, typically. Explicit, sometimes extreme, sex. Everywhere one looks are images of cartoon characters in some state of undress, covered in obscene amounts of semen and begging for more. Some look very young. All of this is out in the open; the Comic Market is anything but discreet. Held in Tokyo Big Sight, a colossal convention center, the Comic Market draws attention from major media outlets around the world. Over seven million fanzines are purchased during the event (Tamagawa 20I2: I 22), which continues to grow, even when sales of manga, anime and computer/console games dip (Yano Research Institute 20I 2: 79). Commercial publishers, broadcasters and retailers rent space in Tokyo Big Sight during the Comic Market to appeal to participants, who are their most devoted and passionate fans. Everyone

How to cite this book chapter:

Galbraith, P. W. 202I. Ethics of Affect: Lines and Life in a Tokyo Neighborhood. Pp.39-76. Stockholm: Stockholm University Press. DOI: http://doi.org/Io. I6993/bbn.b. License: CC BY 4.०. 
seems to know about the Comic Market, and what is bought and sold here, but legal and police intervention has been minimal over the decades. If the Comic Market is an example of what legal scholar Lawrence Lessig calls "free culture" (Lessig 2004: 25-29), then it is also a culture of free imagination and creation.

During my fieldwork in August 2015, I found myself at the Comic Market assisting Nagayama Kaoru, a well-known activist against increased regulation of manga, anime and computer/console games. Over the course of the three days of the event, people - men and women, young and old, Japanese and not, gay and straight, alone and in groups - came to Nagayama's booth to purchase his books and discuss recent legal actions in Japan and abroad that could impact manga, anime and computer/console games. Surprisingly, several groups of politicians came to visit Nagayama and pose with him for photographs. They came on a tour organized by Ogino Minoru, a junior member of the Tokyo Assembly and founding member of the Institute of Contents Culture, which has its roots in the bishōjo game industry. ${ }^{36}$ Most were clearly not fans of manga, anime and computer/console games, and certainly not the fanzines on display, but they nevertheless posed for photographs in what critics describe as a den of imaginary sex crime. On the whole, these politicians did not appear to be particularly worried. One pointed out the thousands of women at the event - women are, in fact, the statistical majority of participants, and have been since the founding of the Comic Market (Shimotsuki 2008: I 8) - as well as visitors from overseas and families with children. Everyone seemed to be having a good time, which brought a smile to this politician's face. Others, however, were much less in the mood. Addressing a conference of Comic Market participants on August I 5 , Yamada Tarō, a member of the House of Councilors, warned of a conservative backlash building in the halls of the Japanese government:

What the government really wants to focus on is the erotic and grotesque stuff. I strongly feel that their true intension is to rein in erotic and grotesque expression, no matter what. They also want to do something about the perceived deficiency of current child pornography legislation, which does not extend to games, cartoons and comics. I think that the government is also really starting to feel that it needs to do something about the violence of games.

But why? I ask Yamada after his address. Why push for more regulation now? "This content is considered creepy," Yamada explains matter-of-factly. "For critics, it expresses perversity and potentially 


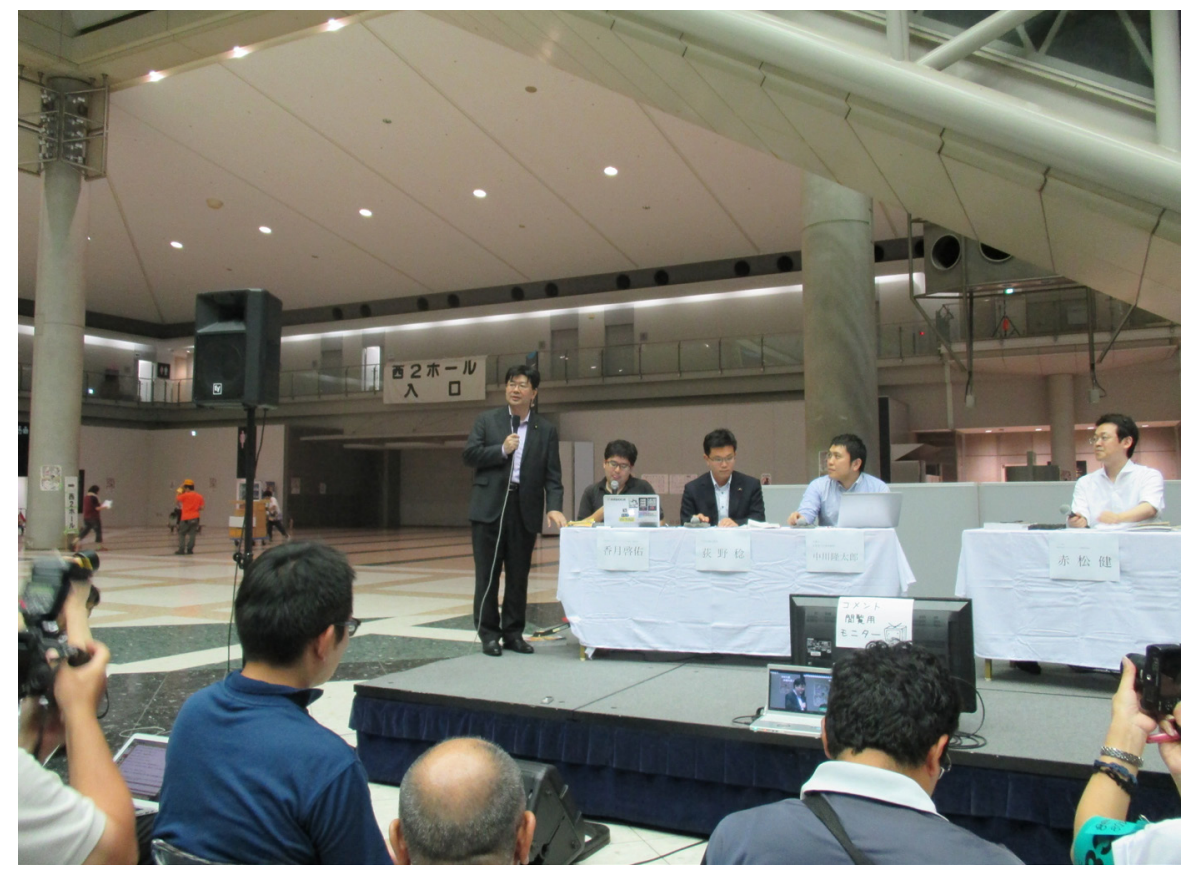

Image 3. Yamada Tarō speaks at the Comic Market. Photo by the author. License: CC BY 4.०.

perverts minds. It doesn't matter if there is no evidence, because enough people share this perception and it is something that politicians can come out strongly against. Who is going to defend this content in public? It's a losing position." Looking around the Comic Market, one wonders how the market for imaginary sex, violence and crime ever got to be so robust and open in the first place, why the government cares now and what it will do to curtail the culture of free imagination and creation. With the 2020 Summer Olympics in Tokyo on the horizon, and Tokyo Big Sight likely to play some part in hosting the anticipated flood of tourists, what will become of the Comic Market and the culture it represents? One can imagine legislation to clean up the virtual sex industry, just as the I964 Summer Olympics in Tokyo saw legislation to clean up the sex industry (Leheny 2006: 65).

This chapter offers a brief history of regulation in Japan as background to the contemporary moment of concern about imaginary sex, violence and crime in bishōjo games. Although there is a much longer history of regulation to be told (Allison 2000; Nagaoka 20I0; Cather 20I2), this chapter begins with the I990s and with manga, which broke sales records, was hugely influential and became an issue of social and 
political debate in that decade. Japan is home to the most vibrant comics culture in the world, and, in the I990s, it was estimated that manga accounted for 40 percent of all print publications (Schodt I996: I9). Weekly manga magazines hundreds of pages long were circulating millions of copies and available at train station kiosks, in convenience stores and on the street. Anime also reached new heights in the I990s, when at least 90 series aired a week (Condry 2013: 86, I06) and series such as Dragon Ball Z (Doragon bōru zetto, I989-), Sailor Moon (Bishōjo senshi Sērā Mūn, I992-) and Neon Genesis Evangelion (Shin seiki Evangerion, I995-) were popular enough to be dubbed "social phenomena." Manga, which provides the primary source material for anime, enjoyed synergy with it, which extended into adaptations into live-action television series and films, games, toys and merchandise, music and advertising. Quite simply, manga was a powerful engine of Japanese popular culture. Given this high profile, it is not surprising that in Japan in the I990s, as in the United States in the I950s, comics were accused of "seducing children into becoming juvenile delinquents" and "encouraging young people to get absorbed in fantasy worlds and to commit acts of violence" (boyd 20I4: I4, I05; as a key text in this influential American debate about comics, see Wertham 2004; for the broader sociopolitical context of it, see Hajdu 2008). ${ }^{37}$ As manga translator and historian Frederik L. Schodt argues, it is precisely because manga was so ubiquitous and influential in Japan that it got caught up in discourses about media effects (Schodt I996: 48). Manga appeals to young and old, men and women; there are sexualized depictions in manga for the young and old, adult manga featuring explicit sex for both men and women and crossover readership (Kinsella 2000: I36). In this vast market, it was primarily manga for boys and men featuring sexualized depictions of cute girl characters that were problematized in the I990s. Furthermore, the I990s saw the emergence of concern about "otaku," who were understood to be male fans of manga. First discussed as perverts in niche media in the I980s and reimagined as potential pedophiles and predators in the I990s, not only were "otaku" considered to be a danger to the youth of Japan, but also the youth of Japan were in danger of becoming "otaku" due to the impact of "harmful manga" (yūgai manga). Much of this history is shared with bishojo games, which rose to prominence in the I990s and feature manga/anime-style characters engaged in explicit, often perverse and sometimes violent sex. Bishōjo games throw into relief growing anxiety about "virtual reality" and how the virtual can threaten reality. 
Reviewing the history of the so-called "otaku panic" (Kinsella 2000: I 26-I29), this chapter positions it in the context of a crisis of hegemony and reproduction in Japan in the I990s. It also shows how fans of manga, anime and computer/console games, responding to media and the "otaku panic," discussed their affection for fictional characters. In manga-driven popular culture, what spreads across media and material forms are characters, which are "a technology of attraction and diffusion" and "expand outward through the media and social environment" (Steinberg 2012: 44, 45). In relation to these characters, in the I990s, fans began discussing moe, or an affective response to fictional characters. The discussion of moe began among men gathering online to share their affection for bishōjo characters, which were an increasingly notable part of the media landscape at the time (Akagi I993: 23 I). In informal peer networks, men shared their experience of being moved by cute girl characters, or their experience of moe, which contributed to an increasingly open culture of expressing affection for fiction as such. In this way, relations with, and an orientation of desire toward, fiction, which was associated with "otaku" in the I980s, became prominent enough to be noted by academics in the I990s (Saitō 2OII). This indicates the existence of competing discourses about "ota$\mathrm{ku}$ " as, on the one hand, perverts attracted to bishojo and, on the other hand, as potential pedophiles and predators. Both discourses are part of how manga, anime and computer/console games, and "otaku" as fans of them, are imagined to be harmful. Against this backdrop, a nascent ethics of moe can be detected. Critics such as Ōtsuka Eiji, Nagayama Kaoru and Sasakibara Gō took the "otaku panic" and moe discourse as an opportunity to reflect on relations with fiction and reality and advocate self-awareness, social consciousness and careful action. The chapter concludes by highlighting a convergence of domestic and international concern about harmful media, specifically how Japanese activists and politicians responding to the imagined perversion of youth, sexuality and society draw support from North America and Europe.

\subsection{A Crisis of Hegemony and Reproduction}

The political, social and economic turmoil of Japan in the I990s has been well documented. During "the lost decade," Japan suffered from what cultural theorist Stuart Hall calls "a crisis of hegemony" (Hall et al I978: viii, 2 I8). For Hall, hegemony is an interlocking system of ideas that produces norms and persuades people of their rightness. This 
expands politics and power beyond electoral or party politics and state power to include various institutions and interests that can align to create hegemony, which becomes "common sense." Myths of "the mass middleclass" (ichioku nin sō chūryū), "homogeneous people" (tan'itsu minzoku) and "mainstream consciousness" (chüryu ishiki) speak to the hegemony of Japan's long "postwar" (sengo), which was taken as "common sense" (jōshiki). One can also recognize hegemony in gender ideals such as the "salaryman" (sarariiman), or white-collar worker productively employed at a major corporation, whose tireless efforts support the family (= wife and children) and nation. This gender ideal is an example of "hegemonic masculinity," which need not be the most common or comfortable form, but is still the common sense of what a man should be and is judged against (Connell 2000: IO-I I). Hall argues that crises occur in hegemony not only in political and economic life, but also "in a wide series of polemics, debates about fundamental sexual, moral and intellectual questions" (Hall I987: 5). Certainly we can see this in Japan in the I990s, which were characterized by debates about the direction of society. National anxiety, political scientist David Leheny notes, manifested in handwringing over sex and violence in the media, out-of-control youth and terrorism (Leheny 2006: 3-5, I4, 44). Youth, who symbolize the future, are particularly apt to become targets of concern at times of crisis (Allison 2006: 75). Hall argues that the idea that youth are in trouble is hard to defend statistically (Hall et al I978: I3-I6), but this does not matter in terms of the perception of crisis and calls to action. Again, this was the case in Japan in the I990s (Leheny 2006: 58).

Responding to the gap between statistics and hand-wringing about youth, crime scholar Kondō Jun'ya suggests that “people's fears and imaginations become more and more detached from reality" and the "ominous image of youth takes on a life of its own" (quoted in Hack 201 5 : $238)$. Kondō is right to emphasize imagination, which is a crucial part of criminology (Young 20II), and Japan is no exception. In the I990s, there was a general fear for and of youth, which anthropologist Anne Allison captures in the phrase "millennial monsters," or those associated with "monstrous disruption of the normal" and threats to "national security" (Allison 2006: 76). A similar dynamic has also been observed by social media scholar danah boyd in the United States, where "many adults are simultaneously afraid of teens and afraid for them" (boyd 20I4: I7). Writing of escalating concerns about young people in the I990s, boyd points out, "Moral panics that surround youth typically center on issues of sexuality" (boyd 2014: I05). Again, as Hall and 
Leheny note in different contexts, there does not need to be statistical evidence of increased danger for fear and anxiety to take hold (boyd 20I4: I09-IIO). And, again as Hall and Leheny note, fear and anxiety invite paternalism and the expansion of authority (boyd 20I4: 28). Since the I990s, the youth of Japan have been constantly berated for having too much sex, sex with the wrong people at the wrong times in the wrong places, the wrong kinds of sex, or not having enough sex (Leheny 2006: 40, 54, 68-69, 73, 80-82). In any case, something is wrong with youth and sexuality, which seems to undermine the social order and future of Japan. Echoing Hall's analysis of Britain in the I970s, Leheny shows how "political actors used the fears bubbling up during Japan's nervous I990s to justify enhanced powers of the state" and a return to "normality" (Leheny 2006: 3, I 83-I 84). To rephrase, there is a struggle to reconstitute hegemony as various insitutions and interests work to police the crisis (Hall et al I978: I3-I6).

Building on the concept of a crisis in hegemony, I propose a related crisis of reproduction, which is meant to not only capture the increased interest in controlling the bodies of young people to ensure that they are normatively oriented and sexually reproductive, but also social reproduction in taking on roles and responsibilities at home and work. In the I990s in Japan, youth came to be seen as "a selfish generation that refuses even its most basic responsibility of reproducing the nation" (Leheny 2006: 40). This is yet another reason why youth need to be disciplined in the return to normality, and it sits alongside concern about youth as a population at risk and a dangerous population. On the one hand, youth might be attacked, damaged or perverted, which would destroy the next generation and undermine the future. On the other hand, youth might be doing the attacking and hence become a generation destroying the nation and its normalcy. Similarly, youth might become dangerous adults or be in danger in relation to adults; youth might become perverts or the victims of perverts. So, on the one hand, youth as a potentially dangerous population, and, on the other hand, youth as an endangered population. This endangered population is particularly important, because the number of children in Japan - along with birth and marriage rates, and even the number of people having sex (Aoki 20I6) - continues to decline (much like an endangered species). In any case, youth need to be protected and disciplined at the same time. As part of this response to crisis, authority expands over not only relations between actual bodies and populations, but also relations between virtual and actual bodies and populations. During its crisis of 
reproduction, Japan has become concerned not only with youth and sexuality, but also virtual youth and sexuality: Youth in manga, anime and computer/console games, youth who might be harmed or perverted by encounters with such media, youth who might become the victims of perverted adults. So, a virtual population of youth and adults. This suggests a regime of "pre-emptive policing," which deals with "potential victims" and "potential criminals," and in so doing "translates fantasy into reality" (Hall et al I978: 42). The dynamics of policing a crisis of hegemony and reproduction undergird much of the debate in Japan in the I990s.

\section{3 "The Otaku Panic"}

Manga specifically and virtual worlds more generally appear regularly in the discourse of Japan in crisis in the r990s (Schodt I996: 45-47; Kinsella 2000: I 26-I 29; Allison 2006: 80, 85 ; Leheny 2006: 39). Media consumed by and associated with youth and intersecting with sexuality became a cause of concern, which led to calls for increased regulation. As if to punctuate the end of the postwar period, I989 saw the arrest of one of the most infamous criminals in Japanese history. Miyazaki Tsutomu, a 26-year-old printer's assistant from the Tokyo suburbs, was charged with murdering, mutilating and molesting four girls between the ages of four and seven. The details of his horrific acts shocked a nation known for its low crime rate, especially involving children. In the panicked reporting that followed, commentators discussed everything that they perceived to be wrong with youth, media, sexuality, society and Japan (Kinsella 2000: I 29).

Among the many reasons advanced for Miyazaki's crimes, including mental illness and a breakdown of the family (Treat I993: 354-355), one that gained traction was media effects and confusion about the line between fiction and reality. The evidence seemed to be in order: Photographs of Miyazaki's room, which was filled with 5,763 videotapes, including a series of horror/slasher/gore films upon which he allegedly based some of his crimes and recordings of those crimes. Responding to Miyazaki, cultural theorist Yoshimi Shun'ya argues, "For him, the sense of reality, or the reality of killing, was already virtual" (quoted in Galbraith 2019: 67). There are at least three ways to read this statement: One, Miyazaki had seen so much sex, violence and crime in virtual worlds that it no longer seemed real to him; two, he had rehearsed his crimes virtually and acted them out in reality; 
and three, even after committing the crimes, they appeared virtual to him. Related are three points about media effects: One, media had reduced Miyazaki's resistance to committing violent sexual crimes; two, the line between media and reality was blurred for him; and three, he committed crimes based on media and returned them to media through recording and placing them in his videotape collection..$^{8}$ While media and material consumption is normal in contemporary Japan, the sheer volume of Miyazaki's collection was enough to convince many of pathology, and the confusion of fiction and reality made him a limit figure for a society struggling to negotiate boundaries. A distinction between normal and abnormal media and material consumption was formalized by describing Miyazaki as an "otaku," which became a label associated with the excesses and perversions of fandom in the early r980s (Galbraith 20I9: 5I-63). In this way, fans of a certain stripe, who were already perceived as abnormal and labeled "otaku," came to be associated with a serial killer who was also a pedophile.

Despite allegations that they were used as models for some of his crimes (this has been disputed), it was not exclusively or even necessarily the horror/slasher/gore films in Miyazaki's collection that were mobilized to explain his dangerous break from reality, but rather manga/anime. Photographs of Miyazaki's room show adult manga in the foreground, which insinuate that the piles of boxes behind them must contain more manga and that the videotapes must be anime, although neither of those assumptions, often repeated as facts, are accurate. Based on the testimony of journalists who were in the room at the time of photographing, the few adult manga that Miyazaki owned were placed in the foreground to make it appear as if his collection was primarily manga and anime (Nagaoka 20IO: I5I-I52). This was made more convincing by adding that Miyazaki had attended the Comic Market - that den of imaginary sex crimes involving cute girl characters. As "lolicon," or "Lolita complex," became a keyword in describing the problem of manga, sexuality and youth, the message of the photographs became that Miyazaki was attracted to fictional girls and acted out his perverse desires in reality. ${ }^{39}$ The story became not only that Miyazaki was a man who blurred the line between fiction and reality, as would apparently follow if he watched ultra-realistic violence in horror/slasher/gore films and then enacted ghoulish violence to record and add to his collection, but also, and more importantly, that his attraction to the unrealistic worlds of manga/anime had warped his sense of reality and sexuality. The cute girl characters of manga/anime were warped objects of desire 
that turned Miyazaki toward sexual violence and crime. This was the story of not only Miyazaki, but also "otaku," who were understood to be men harboring "dangerous sexual proclivities and fetishes," "who might be mentally ill and perhaps even a threat to society" (Schodt I996: 46).40 "Otaku" as male manga/anime fans were denounced as "a reserve army of criminals" (hanzaisha yobigun). As critics such as Ōtsuka Eiji and Nakamori Akio debated whether or not Miyazaki was an "otaku" and creative types such as Miyazaki Hayao (no relation to the criminal) and Murakami Ryū discussed the need for manga/ anime fans to escape their "closed rooms," a perceived connection affirmed or denied - between manga/anime images, the pedophile predator and "otaku" was established in the popular imaginary.4 ${ }^{\mathrm{I}}$

Although it began with feminist and new religious groups in Western Japan (Nagaoka 20I0: I 54-I 55, I6I-I64), what came to be known as the "harmful manga movement" (yügai manga undō or yügai komikku $s \bar{o} \bar{o}$ ) found support amid the anxiety gripping Japan in the I99os. Responding to reports coming out of the harmful manga movement, on September 4, 1990, the Asahi Shimbun newspaper ran an editorial wondering what kind of human beings children exposed to such manga will become. What is at stake, the editors explain, is no less than "the future of our culture." Politicians began to receive letters from citizens, which they forwarded to police, concerning "abnormal," "unhealthy" and "perverse" sex and "grotesque eroticism" in manga, which "surely lead to sexual crimes" (Anime Comic Tone 2009). At its most hyperbolic, the claim was made that, if left unchecked, the effect of harmful manga was such that "the youth of Japan have no future." This discourse of youth as vulnerable and at risk sits alongside the millennial monsters discourse of youth as dangerous; in Japan in the I990s, after the arrest of Miyazaki, youth were potentially perverse and the perverse imaginary of manga might be what pushed them over the edge. In the halls of government, the issue of harmful manga was raised on five separate occasions between October I990 and June I991 (Kinsella 2000: I46). On one such occasion, in February I99 I, Asō Tarō, a future Prime Minister of Japan, led a group of politicians in asking for more responsibility from the manga industry. Resolutions were jammed through amid open bullying of opponents for allegedly forcing pornography on children (Nagaoka 20I0: I77-I79).

Despite not having solid statistical evidence that manga was harmful to society, tougher ordinances were passed and arrests "increased dramatically" (Schodt I996: 56; also Nagaoka 20I0: 248-249). In April 
I99I, for example, police questioned 74 people, arrested 40 and confiscated 4,040 manga books (Kinsella 2000: I32; also Nagaoka 20I0: I73). Ordinances were amended in 1993 and again in I 997 to tighten regulation of adult manga (Kinsella 2000: I42). When publishers of adult manga for men began to regulate themselves by labeling works as for adults, shrink wrapping them and encouraging sellers to place them in dedicated sections, scrutiny shifted to adult manga for women and eventually to general manga for young people considered to be "pornographic" or "harmful" (Nagaoka 2010: 36-37, I42-I43, I46-I47, 233). There was notable focus on manga featuring bishōjo (Nagaoka 20I0: I 8 I-I 82, I96), or cute girl characters, which was perceived to be "anti-social" (Kinsella 2000: I 52) in appealing to adult perverts and perverting the minds of youth, who would not become "normal grown-ups" (Cather 20I2: 24I). Such manga also put youth at risk in relation to adult perverts, imagined in the image of Miyazaki. Global norms were applied in crackdowns, for example using international laws concerning anti-child trafficking, prostitution and pornography against adult manga (Cather 20I2: 242, 267-272; for comparison, see Leheny 2006: 4, 24, 90-9I, 95, I04-106, I 86-I 87).42 In the process, as media scholar Kirsten Cather points out, the law expanded from protecting real children to preventing "potential harm done to real children by readers and viewers who consume [...] sexualized images" (Cather 20I2: 270). And so too did crime expand from the actual to the virtual.

\subsection{Bishōjo Games and "Virtual Reality"}

While the emphasis of the discourse about harmful media effects in the I990s was unmistakably on manga, bishōjo games are perhaps even more associated with anxiety about "virtual reality" (kaso genjitsu or kyozo riaru). According to Ōtsuka, "the virtual reality age" began in I983 (Ōtsuka 2004: I7-20). That year, the Nintendo Family Computer, a home gaming console better known as the Famicom, went on the market. The label "otaku" was also coined in $\mathrm{I} 983$ in response to the perceived perversion of men oriented toward bishojo characters from manga and anime (Galbraith 2019). Adult computer games existed in Japan since at least as early as Kōei's Night Life (Naito raifu, I982), appeared as part of the booming interest in cute girl characters in the form of Enix' Lolita Syndrome (Roriita shindorōmu, I983) and evolved into more story-based character interactions with Jast's Angels' Afternoon (Tenshi-tachi no gogo, 1985). Angels' Afternoon is remembered for 
its manga/anime-style characters and setting in a school, which would become hallmarks of bishōjo games. Concerns about adult computer games began soon after. In I986, I77 (Ichinananana, dB-SOFT, I986) - the title comes from Article I77 of the Penal Code concerning rape, which players simulate in the game - was taken up in the Diet and criticized. ${ }^{43}$ This brought the existence of adult computer games to public attention and sparked outrage (see Pelletier-Gagnon and Picard 20I5).

Virtual reality was a growing concern by the end of the I980s. For example, Itō Seikō's novel No Life King (Nō raifu kingu, I988), nominated for the Mishima Yukio Award, tells of gradeschoolers who interact with the world as if it were a game. That same year, photographer and writer Fujiwara Shin'ya argued that games lead to confusing or "mixing fact and fiction" (kyojitsu kongō), which has come to be known as the "harmful game theory" (Tomita I989: 2).44 Critics suggested that games also contribute to a lack of empathy, antisocial behavior and even a loss of humanity in youth, which crystallized in discourse of the "terror of the game brain" (Mori 2002: 6-7, 25, 28; also Allison 2006: 8I; for a comparison in the United States, see Turkle 20I I: 293; Zimbardo and Coulombe 20I 5: xviii-xix, 20-23, IO7-I I 2 , I30-I3 I).45 In March I989, Shükan Spa! magazine ran an article with the sensational title, "Spirited Psychiatrist Noda Masa'aki's Analysis! Murder of a Fourth Grader at Tokyo's Kōjimachi Elementary School, the Game Generation is on the Rise, the 'Perverted Murderer' who was After All from the 'Otaku Tribe'” (Kagami 2010: I 57). In other words, there was concern in Japan about games turning a generation of youth into "otaku" and "perverted murderers" even before the arrest of Miyazaki Tsutomu later that year. Even as "otaku" are associated with perverted murderers, the discourse about the "otaku generation" is deeply inflected with anxiety about computer users and the "game generation," with both converging in the image of the man dangerously absorbed in virtual reality and cut off from society. ${ }^{46}$

Not surprisingly, bishōjo games were caught up in calls for increased regulation of harmful media in the early I990s. In I991, the same year as a major crackdown on manga, a boy in junior highschool shoplifted the game Saori: The House of Bishōjo (Saori: Bishōjo-tachi no yakata, Fairytale, I99I). The content of the game was such that once it came to the attention of police during the investigation, it was not the boy who shoplifted, but rather the production company behind Saori that was punished for seducing the boy into crime, if not also perverse desires. Saori is the story of a young girl haunted by sex. After seeing a couple 

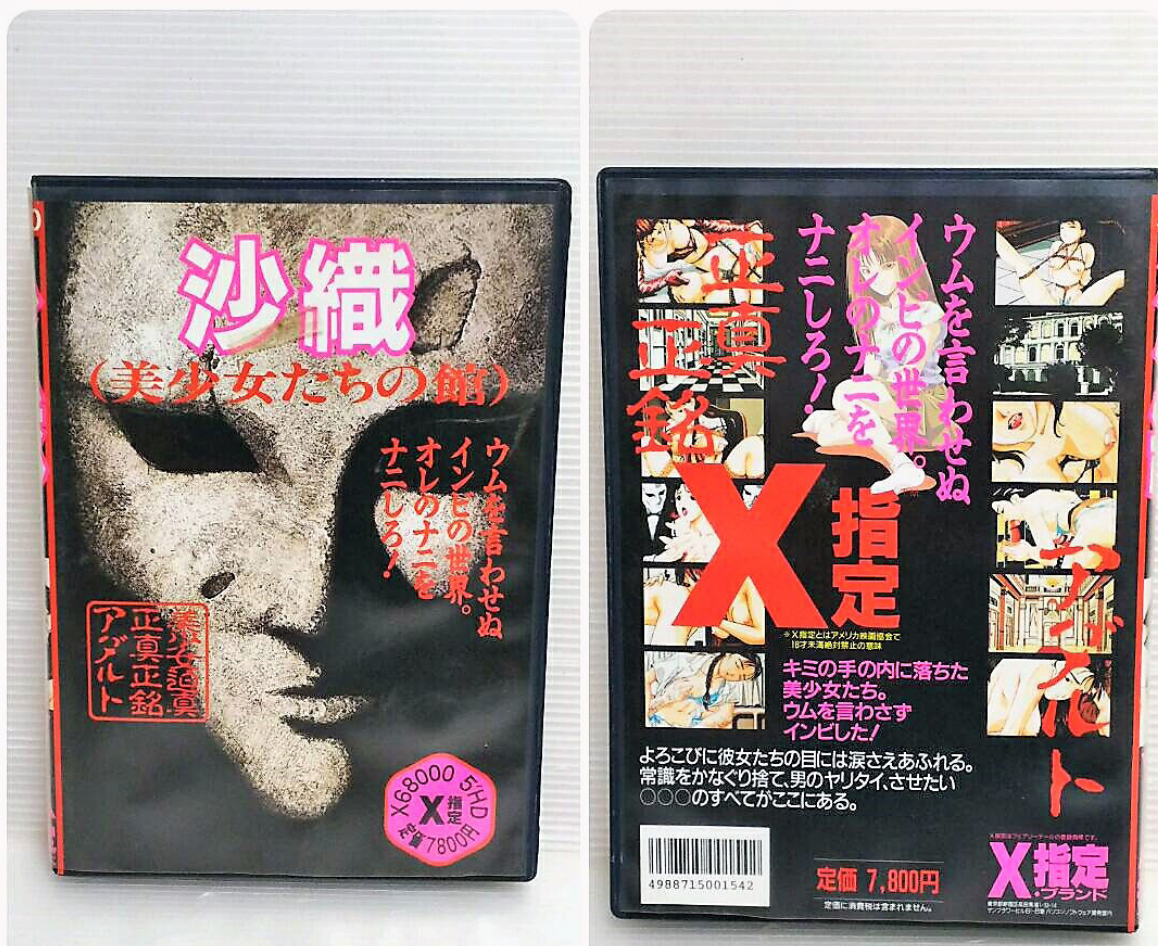

Image 4. Cover of Saori: The House of Bishöjo. Photo by the author. License: CC BY 4.0.

having sex in the park, the girl goes home to masturbate, falls asleep and dreams that she has been abducted by two masked men and taken to a mansion where she witnesses incest, torture, homosexual coupling, gang rape and more. The girl awakens to find that it was only a dream, but it is clear that her sexual imagination has been awakened - and that her awakened imagination is perverse. Saori almost reads like a nightmare of Japan in the I990s, when the nation was swept with intense concern about the awakening perverse sexuality of (and for) youth. Despite the fact that the game was not meant for people under the age of 18 - hence the boy's shoplifting - Saori ran afoul of police for not blurring out genitals, which had become the standard for obscenity in Japanese courts (Allison 2000: I49; also Cather 20I2). On November 25, I99I, the president of Fairytale, the production company behind 
Saori, was arrested; the four games named in his indictment were Saori, Dragon City Designation X (Doragon shiti x shitei, I99I), Angels' Afternoon 3: Side Story (Tenshi-tachi no gogo 3 bangai hen, I990) and Angels' Afternoon 4: Yüko (Tenshi-tachi no gogo 4: Yūko, I99I). The result of the so-called "Saori Incident" was bishōjo game producers banding together to establish the Ethics Organization of Computer Software. An industry self-regulatory body founded in I992, the Ethics Organization insists on genital blurring, labeling works as adult and zoning content, which is very similar to the manga industry.

Self-imposed and enforced industry regulations were largely successful in keeping outside authorities from introducing new regulations, which critics continued to demand, bolstered by media linking crimes such as the Aum Shinrikyō cult releasing poison gas on the Tokyo subway to the "otaku generation" raised on a steady diet of "virtual reality." 47 The fact that computer/console gaming was undergoing massive growth and popularization in the I990s - when Nintendo, Sega and Sony, three Japanese companies, competed for control of the domestic and international market for console games, and Konami, Elf and Leaf were transforming bishōjo games and attracting hordes of fans in Japan - only made the sense of urgency that much more acute. Crucial was how "the burgeoning interest of youth in computer games" was imaginatively tied to "the rising incidence of youth violence" (Gardner 2008: 2IO, 2I 4-2I 5)..$^{8}$ Like manga, computer games came to be "regarded as potentially dangerous or as emblems of what is wrong with Japan" (Gardner 2008: 200). Indeed, the record of a year 2000 meeting of the National Commission on Educational Reform, which is archived on the website of the Prime Minister of Japan and His Cabinet, includes the remarkable decision to, "Clearly state that virtual reality is bad" (bācharu riariti wa aku dearu). ${ }^{49}$ The document strikes a concerned tone about children and the future, which is cause for this strong statement on virtual reality and other potentially disruptive things that must be dealt with, if not "removed" (haijo). In this climate, it was all too easy for neurologist Mori Akio to point to the "social problem" of computer/console games, which allegedly confuse youth about reality, disconnect them from others and lead to out-of-control behavior (Mori 2002: 4, I9). For Mori, these games pose a problem for "the future of Japan" (Mori 2002: 5). If mainstream console games were a threat, then adult computer games were even more so; console games went on to become "normal" entertainment, while adult computer games absorbed apprehensions about the "abnormal." Further emboldened by global reactions against bishōjo games, which are increasingly out of 
synch with global norms of imaginary sex and violence, critics in Japan continue to call them "harmful to society" (Nakasatomi 20I3: 5) and demand that the government ban them outright.

The issue becomes more complex when we consider that manga, anime and computer/console games were integrated into robust franchises that spread characters across media and material forms in the I990s. If, as media scholar Marc Steinberg suggests, the tendency was to create a "total media environment," where characters could be encountered "anytime, anywhere" (Steinberg 20I2: 79, I66), then this also created media worlds centered on characters and subjects in affective relations with them. In his historical research, Steinberg reveals that, since the I960s, manga/anime franchises have made characters part of the social worlds of children in Japan. This is considered, to a large extent, to be "normal," but the growing number of adult manga/ anime fans, and adult manga/anime, from the I970s planted the seeds of the "otaku" problem and the "abnormal." Specifically, by the early I980s, there were concerns about men being sexually attracted to cute girl characters in manga and anime. Even as Miyazaki Tsutomu was being held up to demonstrate the dangers of "otaku" media, manga, anime and computer/console games featuring bishōjo characters exploded in successive booms around Sailor Moon, Neon Genesis Evangelion and more; indeed, in the I990s, bishōjo characters were an increasingly notable part of the mainstream media landscape in Japan (Akagi I993: 23I). Affection for these cute girl characters was burgeoning alongside concern about lolicon. Even as the Comic Market, where fanzines featuring manga/anime characters in explicit sex scenes could be found, was pushed out of its venue and subject to criticism, attendance skyrocketed in the I990s (Comic Market Committee 20I4: 26). And bishōjo games, which center on affective relations with cute girl characters, also surged in the I990s and provided new content to be franchised across manga, anime and related media and material forms (Azuma 2009: 75-79). Sexually explicit content was part of this media ecology, going from 17.7 percent of the total computer game market in April 1993 to 35 percent in April 1994 (Pelletier-Gagnon and Picard 2OI 5: 35). The very prevalence of bishōjo games specifically and bishōjo-oriented men or "otaku" generally in the I990s does much to explain why they came to represent a social problem for critics.

The discourse about "virtual reality," associated with manga/anime worlds and made overt in criticism of computer/console games, raises some important points about freedom and regulation of imagination. First, men drawn to virtual reality are labeled "otaku" and perceived 
to be on a flight from "reality" (Kam 2013a: 45, 55, 59). Second, "otaku" imagine and create alternative worlds and realities, which often center on bishōjo characters, encourage fan affection toward them and veer into sexually suggestive and/or explicit territory. For critics, this is a perversion of the imagination and its productive capacities (Kam 2015: I83-I87, I90). Third, as media theorist Thomas Lamarre argues, "otaku" move in relation to manga/anime characters, and this movement "generates a world, a reality" (Lamarre 2006: 383). Bishōjo games, for example, center on affective relations with cute girl characters and move players to bodily response and movement beyond the game, which generates new social worlds and realities. In this way, "virtual reality" has the potential to shift perceptions of "reality" and generate competing realities, which threaten what religious studies scholar Joseph P. Laycock calls "commonsense reality" (Laycock 20I 5 : IO-I4). As Laycock emphasizes, games and play in imaginary worlds are perceived to be "dangerous" - or, to borrow from the debate in Japan, "harmful" - when they risk destabilizing commonsense reality. Common sense, which is related to hegemony (Hall I987). Part of the maintenance of hegemony is controlling imagination and play, especially in youth, who are crucial to social reproduction (Laycock 20I 5 : $8-9,27,240)$. The struggle over youth, sex and imagination is thus also a struggle over reality and the future. In sum, bishōjo manga, anime and games are problematic because they: first, orient men toward cute girl characters and, even as the content crosses into adult territory, it contributes to perceived perversion and failure to achieve reproductive maturity; second, are associated with a rejection of reality or escape from it; and third, pervert the productive capacities of imagination to generate worlds and realities, potentially shift perceptions of reality and threaten commonsense reality.

\section{5 "Otaku” and Ethics: Ōtsuka Eiji and Miyazaki Tsutomu}

Affection for manga/anime characters is a longstanding part of the discourse on "otaku," which both preceded and continued after the arrest of Miyazaki Tsutomu and the "otaku panic." Growing up in Japan, where manga is ubiquitous enough to be compared to "air" (Gravett 2004: I7), manga/anime characters are an intimate part of everyday life. As adult manga/anime fans emerged in the I970s and I980s, clubs, special events and niche magazines reproduced images of characters as shared objects of affection and desire. When fans 
wanted more from characters than the producers would provide, they produced fanzines. Sharing affection and desire for manga/anime characters, fictional bodies became real objects of human desire (Yoshimoto 2009: I68-I70; Nagayama 2014: 83-87). Not confused about the difference between fiction and reality, manga/anime fans tend to insist on it. Manga/anime fans regularly speak of "the two-dimensional" (nijigen), which is associated with manga/anime and opposed to the human or "three-dimensional" (sanjigen). The manga/anime aesthetic is sometimes described as "non-photorealism" (Minotti 20I6), and it clearly differs from "reality." Fans of manga/anime are attracted to this aesthetic, or the two-dimensional, despite it offering things that are unrealistic - or precisely for that reason. In the I980s, those oriented toward manga/anime characters were said to suffer from a "two-dimensional complex" (nijigen konpurekkusu), "two-dimensional fetishism" (nijikon fechi) and the "two-dimensional syndrome" (nijikon shōkōgun) (Tsuchimoto I989: I02; Schodt I996: 48; Yamanaka 20I0: I7). Others referred to this as the "cute girl syndrome" (bishōjo shōkōgun), "Lolita complex" (roriita konpurekkusu) or simply "sickness" (byōki). Strikingly, in clubs and at special events, in niche magazines and fanzines, manga/anime fans claimed their complex, syndrome or sickness as a shared orientation of desire.

It is not without significance that the first people labeled "otaku" in Japan in the early I980s were part of the perceived problem of orientation toward manga/anime characters, specifically cute girl characters, as opposed to "the real thing." At the time, during the so-called "Lolita complex boom" (rorikon bümu), specialty magazine Manga Burikko was publishing realistic drawings of girls beside photographs of young women, which suggests a permeable boundary between fiction and reality. However, from 1983 , readers of the magazine began to request that the magazine publish only drawings of cute girl characters; some readers even self-reflexively identified as people with "two-dimensional complexes" (Galbraith 20I9: 5I-57). Ōtsuka Eiji, who was editor of Manga Burikko at the time, recalls that his magazine responded to fans by dropping realistic drawings and photographs, which speaks to the broader moment of growing desire for fiction as such (Ōtsuka 2004: I 8-I9, I26, I 28). This orientation toward fiction is indicated in the title of the magazine - Manga Burikko, meaning "comic fake girl/child" - and was underscored during its transformation in 1983 with subtitles such as "Two-Dimensional Idol Comic Magazine." This emergent orientation of desire was perceived by critics to be a rejection of reality, 
which was abnormal. So it was that, in I983, critic Nakamori Akio wrote a series of articles published in Manga Burikko denouncing "otaku" as socially and sexually immature men with a "two-dimensional complex" and "Lolita complex." In this context, the abnormality of the Lolita complex, or lolicon, was tied to attraction to and affection for manga/anime-style cute girl characters as opposed to real women.

Recognition of an orientation toward fiction, or the cute girl characters of manga and anime as distinct from "reality," was foundational to the discourse of "otaku" before the arrest of Miyazaki Tsutomu, and it continued as a substantial counter-narrative after. Nevertheless, imagined connections with Miyazaki during the "otaku panic" deeply compromised the term in the I990s. This was all the more so when it was associated with lolicon, which blurred the meaning of two-dimensional orientation in the I980s with sexual crime in the I990s. If the discourse about "otaku" in the early I980s was that perverse men know the difference between fiction and reality, insist on the former and are thus socially and sexually immature, then the discourse about "otaku" in the early I990s was that pedophiles and predators do not know the difference between fiction and reality or might make their perverse fictional desires into harmful reality. Both of these strands of discourse are tangled together in contemporary debates about the imagined excesses and perversions, if not crimes, of bishōjo-oriented men.

While many manga/anime fans understandably invested a great deal of energy into refuting that Miyazaki was an "otaku" or had anything to do with them, or insisting that he was unlike them and "entirely exceptional" (Saitō 20II: 30), some responded in the opposite way. Despite his deep knowledge of the fandom surrounding manga/anime-style cute girl characters and an orientation toward two-dimensional idols, which he cultivated in Manga Burikko and other publications, Ōtsuka nevertheless did not reject Miyazaki as an outsider or total other after his arrest. The English-language literature underscores that Ôtsuka saw books and magazines he had worked on in Miyazaki's room (Kinsella 2000: I27), called the man a friend (Treat I993: 355$)$ and continues to think of him when speaking the word "otaku" (Ōtsuka 2015: xxii, xxvi), but he goes much, much further in his initial response to the news coverage in 1989. Granted, this was before Miyazaki's guilt for the crimes was widely known and thoroughly confirmed, and some even suspected a setup by police and media. In this moment of uncertainty, Ōtsuka claimed Miyazaki as "my reader" (boku no dokusha) and said they were "connected" (tsunagatteiru). 
Such statements attracted journalists to him for commentary, and eventually led to a two-part dialogue with Nakamori Akio published in the volume The Generation of M: Miyazaki and Us (M no sedai: Bokura to Miyazaki-kun, I989). As the title indicates, Ōtsuka sees Miyazaki as part of his same generation, or a person reared in the same environment. The two of them and their peers were essentially raised by media, or were cut adrift to become children of media, orphans or "the abandoned" (sutego). They had no strong authority figures or rolemodels, leaving them to the whims of media and to fend for themselves. Gleaning that it was not only Miyazaki's crimes that were on trial, but also his interests as an "otaku," Ötsuka vows to stand with him. As someone involved in producing media, including some that Miyazaki consumed, Ôtsuka determines that this is his "responsibility," but the stakes are made more personal..$^{\circ}$

Recognizing that the media and court of public opinion were judging a "way of life" (ikikata), "interests" (shumi) and "sensitivity" (kanjusei), Ōtsuka asserts that lolicon is "my own problem" (Ōtsuka and Nakamori I989a: 24). Indeed, using the word as slang for someone with a Lolita Complex, Ōtsuka states outright that, "I am a lolicon" (Ōtsuka and Nakamori I989a: 73). In his attraction to cuteness and cute girl characters, Ōtsuka perceives something of himself in Miyazaki, who appeared before him "as if showing me a mirror" and forced him into self-reflection, including on his own "self-image" (Ōtsuka and Nakamori I989a: 68-70). In raw exposure, Ōtsuka goes on to say:

To a fair extent, what appears to my eyes is the figure of someone hugging a doll as they go to pieces. This includes me. [...] Like, I can't live unless I can hug "something cute" (kawaii mono). It's an extremely pathetic figure, but I quite feel this in me. [...] For Miyazaki, those girls were cute dolls. It was like he needed to hug them, excessively. Excessively hugging, he by mistake put too much force into it and killed them. I sense that this is the core of his actions. It is an extremely shameful figure, but, after all, we must fix our gaze on that grotesque boy hugging his doll as he goes to pieces. We must see him as part of our own self-image. This is considerably draining, and we may be held in contempt, but I think we have to do it. (Ötsuka and Nakamori I989a: 68-70)

This is a lot to absorb, but suffice it to say that Ōtsuka, who carried a doll with him as a child and keeps a larger one at home today (Ōtsuka and Nakamori I989a: 70-72), is facing something difficult in the mirror of Miyazaki. Indeed, his interactions with journalists and critics came from a moment of feeling "strangely synchronized" (Ōtsuka and 
Nakamori I989a: I7). That is, the distance between Miyazaki and himself felt "overly close to the point of being abnormal."

Rather than being a sense of victimization, as if an attack on Miyazaki was also an attack on him, Ōtsuka seems to have a "sense of the perpetrator" (kagaisha no ishiki)..$^{51}$ As a producer of "otaku" media and living in an environment associated with "otaku," Ōtsuka presents himself as having a sense of Miyazaki. Like many of those he spoke with, Ōtsuka apparently gazed at his own living space in Miyazaki's room and wondered, "How are he and I any different?" (Ōtsuka and Nakamori I989a: 20). So not only is Miyazaki not a "monster" as pundits would have it and instead a "human," but he is also a human like me and us (Ōtsuka and Nakamori r989a: 42-43). The difference is whether or not one commits criminal acts, of which we are all capable (Ōtsuka and Nakamori I989a: 44). This leads to revelations such as "I have lived holding a Miyazaki-like something in me" and "he and I are in a relationship of positive and negative." Ōtsuka: "I just by chance happened to live as the positive" (Ōtsuka and Nakamori 1989a: 47).52 Things could have been different. He bristles at those involved with lolicon trying to distance themselves from Miyazaki (Ōtsuka and Nakamori I989a: 47-48). Instead, Ōtsuka advocates, on the one hand, appreciating the power of the media as a blade that can cut and even kill (Ōtsuka and Nakamori I989a: 6I, 79), and, on the other, those of his generation seeing themselves in Miyazaki's room and taking action "as my own individual problem" (boku kojin no mondai toshite). Individual, but also shared, as there is a whole generation of Miyazaki and hundreds of thousands who share a way of life, interests and sensitivity associated with "otaku." ${ }_{53}$ This is my own and our problem.

For his part, Ôtsuka introduces a number of perspectives on himself as a lolicon, including that "the girl is myself, as well as a doll for my immature self to hug" (Ōtsuka and Nakamori I989a: 70), but he reaches an impasse. ${ }^{54}$ "That isn't sexual, is it?" he asks. "It's not about sex" (Ōtsuka and Nakamori I989a: 70). Thus cutting sex off, Ōtsuka can identify as a lolicon and acknowledge resonance with Miyazaki, but the final moment of strange synchronicity is evaded. This is a missed opportunity, as Ōtsuka does much to highlight how girls and children are commoditized and turned into dolls by parents, corporations and the media, including sexualization of and violence toward girls and children, which is something he calls on feminists to criticize (Ōtsuka and Nakamori I989a: 39-40, 7I-73). One can detect here 
the beginnings of an ethical position that recognizes one's own desires and capacity for harm, however disturbing that recognition may be, and thus takes responsibility for them and commits to act with care. If Ötsuka had finished his thought, he might have said lolicon in the sense of the orientation toward cute girl characters that he oversaw in Manga Burikko and his own past and present affection for dolls is acceptable, however "pathetic" and "shameful," but treating girls and women as media or material objects to be used and abused is wrong and criminal. A human being, we must insist, is not a "cute thing." This then would be an articulation of something like an ethics of affect and drawing lines in relation to fictional and real others, or as it is phrased in Ōtsuka's dialogue, "an ethics of the abandoned" (sutego no rinri) (Ōtsuka and Nakamori I989b: 216).55 This is an ethics that comes not from a transcendental authority or system, but rather interactions with media and others of the abandoned generation. These ethics would become far more pronounced in the I990s, even as the abandoned became much more prevalent during "the lost decade."

\section{6 "Moe" and Ethics: Nagayama Kaoru and Sasakibara Gō}

In I989, Ōtsuka Eiji, who helped define an orientation of desire toward fiction in Manga Burikko earlier in the decade, refused to disidentify with Miyazaki Tsutomu, which frees people of the ethical responsibility to face the potential criminal among us and in us: "the otaku generation;" "the generation of M;" "Miyazaki and us." By not denying the potential for harm, which is real, Ötsuka opens the door for ethical reflection on our objects and orientation of desire in action and practice. Such ethics came into sharper focus in the following decade. Significantly, in the I990s, manga/anime fans began to more outspokenly and persistently discuss their affection for bishōjo characters. Specifically, on online bulletin boards at the beginning of the decade, there emerged among manga/anime fans a discourse of moe, or an affective response to fictional characters (Galbraith 20I9: $8 \mathrm{I}-82$, I33-I35). This sharing of affection reinvigorated the discussion of a two-dimensional orientation. As manga critic Nagayama Kaoru writes, the celebratory and festive aspect of what came to be known as the moe boom shares much with the lolicon boom in the early I980s (Nagayama 20I4: I I 5-I I6). One of the keys to moe, as Nagayama sees the phenomenon, is the vagary of the object and one's relationship to it. By using this term, one indicates the object, but is not too specific about desires or feelings. 
With the tacit rule being you do not interrogate those desires or feelings or step too far into someone else's interiority, communication can occur smoothly. "Moe is a euphemistic expression that, while indicating the object, is deftly made to hold the connotation that in fact it might not be the actual object" (Nagayama 20I4: I I 5 ). Furthermore, while indicating a response to an object (or something), the feelings surrounding that response are unknown and should not be interrogated. In his analysis of moe works such as Strawberry Marshmallow (Ichigo mashimaro, 2002-), Nagayama further notes how the viewing subject becomes transparent and distant from an eroticism observed in characters, or how eroticism becomes detached from the subject, buried under moe elements and made "unconscious" (Nagayama 20I4: 30I-303).

By Nagayama's estimation, the moe phenomenon has both positive and negative aspects. On the one hand, it marks an increasing awareness of interactions with "fiction as fiction" (Nagayama 20I4: I 58 , I98). To read the elements of character design, story setting and so on at a meta-level, one needs to understand it as a fictional construct and to develop sufficient media literacy. On the other hand, the erasure of one's subject position and effacement of desire makes reflection difficult. This leads to a confusing situation where moe works are said to be desexualized, or to be purely about "the feels," but responses are teeming with sexual undertones that go unquestioned. For example, one character often said to have inspired the original online discourse is Moe from Dinosaur Planet (Kyōryū wakusei, I993-I994) (Morikawa 2003: I7). Aired on NHK Educational Television, this show was intended for younger audiences, but attracted adult male fans as well. The character named Moe appears to be about io years old, so affection for her might be described as lolicon. This is important to note, given the arrest of Miyazaki Tsutomu just a few years prior to the advent of moe discourse. The mainstream understanding of lolicon, along with new taboos to openly discussing sexuality in the wake of Miyazaki, encourages distancing and hiding. This is all the more problematic because Dinosaur Planet also features a human girl named Yamaguchi Misa (born in 1984), who explores the virtual world with a character avatar based on her and going by the handle name "Moe." That is, there is a live-action portion of the program, which features a human child actress, as well as an animated part where she becomes the cute girl character Moe. There is a potential blurring of fictional and real here that could be discussed, but more often is instead left vague. 
For his part, Nagayama advocates confronting and working through desires in the open with others, which is to say self-reflection and social learning. This begins with a refusal to banish or bury sex and an insistence on facing ugly or disturbing feelings aroused by interactions with manga/anime characters. Indeed, Nagayama explains pornographic comics or eromanga as a mirror to reflect on desires:

Without papering over or whitewashing them, we must recognize the fact that there are dark desires in us. Even if they are disguised and suppressed, those dark desires exist. The brutes appearing in these works indulge in depravity as our surrogates. From a position of absolute safety, we simulate and enjoy "evil" (aku). If one asks if that is really all there is to it, however, then the answer is no. The human mind is much more complicated and much stranger. When reading brutish disgrace fantasy in eromanga, what we feel is not just the pleasure of an evil that smashes through and is in the first place impossible in reality, but also an unmistakable horror and disgust. We are supposed to be in a position of absolute safety, so why feel this way? For one thing, there is horror and disgust in response to oneself - that is, the realization of a monster inside taking pleasure in such evil. Furthermore, our antenna of imagination picks up feelings on the side of the receiver, whether we like it or not. In such a position, subjected to this, how would I feel? If one possesses enough imagination to read manga at all, then they probably cannot help but imagine things - even when they do not want to imagine them. (Nagayama 2014: 226-228).

Better to face these desires than deny them or, worse, project them onto a deviant and dangerous "other." One can learn a lot about the self, its relation to the other and society more broadly by thus confronting sex. Certainly Nagayama is not the first to say this, either. ${ }^{56}$ His ethical principle is that we must face ourselves, face the worst in us and what we might be capable of, rather than deny all that or project it onto a deviant and dangerous "other." That is, Nagayama does not believe that the potential problems of lolicon are limited to one man or to men of the past any more than deviant and dangerous desires are limited to "otaku" or "Japan."

The making conscious of one's relation to fictional and real others is the beginning of an ethics of moe, or an ethics of affective relations with characters. The media literacy associated with moe is learned informally in peer networks, and ethics seem to follow a similar process of emergence. Talking about moe, fans can be socialized into relations with fictional characters. While moe is by no means limited to fans of 
bishōjo (see for example Galbraith 2015), the slang originated among men responding affectively to cute girl characters. Furthermore, because men interacting with bishōjo characters raise the most concern about potential harm and are key to calls for increased regulation, the importance of the distinction between fiction and reality is clearest and most vigorously insisted on, which allows for exploring an ethics of moe in action and practice.

The orientation toward fiction reflexively and publically shared among manga/anime fans has consequences for how we understand bishōjo games. Undergoing a renaissance in the I990s (Galbraith 2019: I I4), bishōjo games focus on interactions with cute girl characters, affect players and are deeply tied to the discourse of moe. Interactions with bishōjo characters can involve explicit, extreme sex that would be criminal if it involved human actors. These cute girl characters appear young, and are often indicated to be below the age of I 8 - even children. A good deal of content, then, might be associated with lolicon, which has been a keyword in global criticism of child pornography in Japan. However, when I spoke with Kagami Hiroyuki, a scenario writer for bishōjo games and respected figure in the industry, he firmly insisted that, "Lolicon games are not child pornography." 57 While it might be seen as a predictable defensive posture, the assertion makes sense in a context where desire for the cute girl characters in bishōjo games, even when they are indicated to be children, is made explicitly and deliberately separate from desire for children. More broadly, Ōtsuka suggests that, "The virtual idols in bishōjo games" speak to "desire for simulation, where the bodies of women have come to be unnecessary" (Ōtsuka 2004: I 29). Coming from someone such as Ōtsuka, who was witness to the emergence of an orientation of desire toward fiction and also to the trial of a man who blurred the line between fiction and reality to deadly effect, we would do well to understand statements about "the bodies of women" as "unnecessary" to be claims to a normative desire for fiction that is explicitly and deliberately separated from reality. In a way, Ōtsuka is educating fans about an orientation toward fiction as part of their informal learning, which reduces the potential for confusion and harm..$^{8}$

This leads directly to the position of men such as Sasakibara Gō, an editor and cultural critic who has worked with Ōtsuka on various books and developed into an expert on cute girl characters, moe and bishōjo games, which he began playing in the I990s. Clearly influenced by Ōtsuka, who is slightly his senior, Sasakibara began thinking about 
media effects and affects in the aftermath of the actions of Miyazaki Tsutomu, Aum Shinrikyō and others. "I started thinking about the role of human imagination," Sasakibara tells me over coffee in Shinjuku. ${ }^{59}$ Why did he start thinking? "There seemed to be idiots who would actually commit acts of great violence." Soon after we meet, Sasakibara, author of books such as A Contemporary History of "Bishōjo:" "Moe" and Characters ("Bishōjo" no gendai shi: "Moe" to kyarakutā, 2004), produces folders of print outs, tables and charts to explain things to me. Over the course of our conversation, Sasakibara tells me how he grew up with manga and anime, was attracted to cute girl characters from the late I970s and worked in the manga/anime industry from the I980s. He is, quite simply, among those who might be called an "otaku." Sasakibara is also a father, and he worries about how media will affect his children and whether or not they will be safe. Taking the affect of media as a given, Sasakibara takes issue with those who repudiate it. "We know that manga and anime have an effect on people," he informs me, shaking his head furiously. "Of course they do. People claim the influence when it is good and deny it when it is bad. I think that's dishonest." Such people might, for example, observe that a generation of young men became interested in soccer because of the manga/anime Captain Tsubasa (Kyaputen Tsubasa, I98 I-), but then reject that media has any power to influence or impact reality after the arrest of Miyazaki.

As someone whose life was changed by manga/anime, Sasakibara advocates recognizing its power, even when that takes one into uncomfortable territory. If manga/anime and cute girl characters impacted Sasakibara, then he is in a similar category as Miyazaki. This is not to say that Sasakibara is in any way a criminal, but he nevertheless recognizes a shared "problem of the heart" (kokoro no mondai). Stated simply, the problem is that imaginary sex, violence and crime could potentially lead to harming others. There are three important aspects to this recognition: first, media moves people; second, there is potential for blurring the line between fiction and reality; and third, people have the capacity to harm others. It is not increased regulation that Sasakibara favors, but rather personal and shared understanding and respect for the affect of media:

Humans are affected by all the things around them, including media. The question is how do humans think about this affect? What do we do about it? [...] We are greatly affected by media, which is part of our environment. The question is how do we live and not commit crimes? We need to look at how so many people are affected by media and do not commit crimes. 
This call to think and live with media that affects is also a call to act responsibly without harming others. This is, I argue, a crucial aspect of manga/anime fandom in contemporary Japan. In it I see emergent forms of media literacy and ethics. Part of this ethics of affect is drawing and insisting on a line between fiction and reality, which is learned in informal, peer networks and maintained through collective activity and practice (see Chapters 2 and 4 ). Moe is not only an affective response to fictional characters, but also shared movement, which supports life (see Chapters 3 and 5). This, too, resonates with Ōtsuka, who understood that the media and material objects symbolized by Miyazaki's room are necessary for some people's "spiritual stability," or as a resource for survival for those "going to pieces" (Ōtsuka and Nakamori r 989a: 24-25). Indeed, this is one of the primary reasons that he committed himself to defending media and material interests as part of a way of life after the arrest of Miyazaki in $1989 .{ }^{60}$ These things are necessary for many to live and move on.

The politics of life around moe articulates with the crisis of hegemony and reproduction in Japan since the I990s, when an increasingly large population of young people was set adrift by economic unrest and disintegrating institutions. Facing a so-called "love gap" (ren'ai kakusa), people began to imagine and create alternatives. Even as Allison observed the creation of virtual worlds, pets and friends as a major trend in Japan in the I990s (Allison 2006: I4, 9I, 20I), so too was the creation of virtual lovers. Consider that Sasakibara was at the time planning on producing an elaborate virtual reality and social gaming system, whereby a virtual girlfriend would be loaded on one's computer and talk with the player while he was at home, stay in contact by cellphone while he was out and wait for him to return. Sasakibara conveys to me that he anticipated that having a virtual girlfriend would contribute to "psychological wellbeing," which comes from caring and being cared for. "It almost worked," Sasakibara says, wryly. "But the technology wasn't quite there." (It is now, in fact, in the form of Gatebox [Galbraith 20I9: I-4].) Instead, the I990s saw the explosion of bishōjo characters in manga and anime, the rise of bishōjo games simulating intimate relationships and the discourse of moe, which points toward affective relations with fictional characters that are real and socially recognized.

In this way, just as virtual idols and girlfriends were imagined and created in bishōjo games, a new reality of life and love with fictional characters was imagined and created in Japan in the I990s. These characters not only addressed the "love gap," but also encouraged imagining and 
creating new forms of life and love. Even as these alternatives become more common, they are imagined as problems. So it is that sociologist Yamada Masahiro, who gained notoriety in the I990s by identifying problems such as "parasite singles," came to be concerned about men finding "pseudo partners" in "virtual worlds" (Yamada 20I4: I 8, I 52). In the perceived flight from reality, critics see problems for the nation and its welfare and future. In addition to alarm about imaginary sex, violence and crime, which are threats that might be realized, a serious problem for Japan and its future is posed by the explosive growth on manga, anime and computer/console games featuring bishōjo characters and dedicated to triggering affective responses in fans, and the seemingly endless expansion of events such as the Comic Market, where fans express and share their affection for such characters. The fact that manga/ anime fans generally and bishōjo game players specifically are moved by fictional characters to the extent that they claim to be married to them even as the marriage rate plummets; virtual families on the rise even as actual families decline - is taken to be paradigmatic of the perversity of the contemporary moment. In any case, the situation is abnormal and something needs to be done. There is growing tension between those imagining and creating virtual reality and worlds in and around manga, anime and computer/console games and those seeking to re-establish and maintain the hegemonic socio-political order in Japan. Along the way, imagined perversity has become a serious problem.

\subsection{Imagined Perversion in Japan}

Rising during the crisis of hegemony and reproduction, in I999, Ishihara Shin'tarō, co-author of The Japan That Can Say No ("No" to ieru Nihon, 1989) and a political firebrand known for apprehensions about the abnormal nation, became the Governor of Tokyo. Resonating with national politics, Ishihara campaigned against "harmful environments" (yügai kankyō), which effectively expanded the scope of "harm" (Nagaoka 20I0: 223). ${ }^{6 \mathrm{I}}$ With characteristic confidence in his positions, Ishihara called for revision of the Tokyo Metropolitan Ordinance Regarding the Healthy Development of Youths, which would target manga crossing certain sexual lines as harmful and remove them from the environment. Famously, the proposed revision included the novel concept of "non-existent youth" (bijitsuzai seishōnen), or characters that could be recognized as underage and so should not be involved in sex acts. Receiving significant resistance from promoters of freedom 
of expression, industry organizations and manga/anime fans, who percieved the revision to be overrearch by authorities wanting to dictate morality (McLelland 20I I: 355-36I), Ishihara found himself having to answer to critics. At a press conference on December I7, 2010, Ishihara was asked by a reporter to explain the need for increased regulation. Unhappy to be questioned, Ishihara responded bluntly:

There are after all perverts in the world. Unfortunate people with messed up DNA. People like that, with thoughts like that... Well, feeling ecstasy from reading and writing this stuff is fine, after all. But I don't think that it would be allowed in Western society. Japan is too open. After all, it's abnormal, right? [...] A man can't marry a 7- or 8-year-old girl or rape an innocent child, but somehow this should be allowed if the stories are drawings? Such things serve no purpose. I think that there is harm and not a single benefit from them. ${ }^{62}$

Note five things: First, while the Tokyo Ordinance was meant to ensure the healthy development of youth, who should not see certain kinds of manga, the reason for its revision shifts here to adults who want to produce and consume such manga; second, these adults are perverts and a threat to youth (who might also become such adults); third, the problem is the thoughts that they think, which are perverse enough to suggest that they might be genetically damaged; fourth, such perversion might be tolerable, but it is too open in Japan at present and would not be allowed in "the West," which becomes a normative and aspirational model (despite Ishihara's own writing suggesting the need to refuse foreign pressure); and fifth, this manga caters to perverts and is nothing but harmful. On this last point, there is a subtle blurring of various strands of discourse about "otaku," where virtual rape raises the specter of the potential pedophile and predator, while imagining marriage to a child character suggests other perversions. Indeed, when Ishihara's subordinate, Vice Governor Inose Naoki, provided a specific example in his own explanation of the necessity for new regulation, he chose My Wife is an Elementary Student (Oku-sama wa shōgakusei, 2006-), which does not contain explicit sex scenes, but no doubt brings to mind vague anxieties about the perverts producing and consuming such manga (Nagayama 20I4: 32I-322). When the reporter pressed the issue of harm, Ishihara snapped that, "It's obvious that we should regulate this stuff." Just looking at the images is enough to know that they cross a line. Those who resist this commonsense position are perverts, sympathizers or enablers. ${ }^{63}$ 
Employing familiar strategies of smearing and silencing opponents as "porn politicians" and "the enemy of children" (Fujimoto 20 I I: 37; recall the actions of Asō Tarō and comments by Yamada Tarō), Ishihara succeeded in pushing through revisions to the Tokyo Ordinance in December 2010. ${ }^{64}$ The language of the revised ordinance targets manga, anime and games depicting "sexual or pseudo sexual acts that would be illegal in real life" and "sexual or pseudo sexual acts between close relatives whose marriage would be illegal in real life" (see McLelland 20II). Despite the mass resistance it met, the revised ordinance expands the scope of harm to depictions of any sex act that would be illegal in "real life." Essentially, Ishihara's position is that it is better to err on the side of protecting children from perversion and perverts, and it finds supporters in unexpected places. For example, Maeda Toshio, an artist known for adult manga depicting ultra-violent sex with tentacled monsters, explains the need to regulate certain manga:

But the point is, it looks pedophilic. In some manga, the female, you know, the victim, looks six or seven years old. I hate it. The Tokyo governor tried to propose a strict law against such pedophile manga, and many famous manga artists were so against it because it is against freedom of speech or such crap. But actually, I supported such a law because if you had a baby girl, or girl, as your daughter, and something happened... It would be so bad, right? So before something happens, we should do something about it. My manga, I think, as far as I'm concerned, is just designed for grownups. It's completely i 8 plus. It's completely different from moe style, with, you know, the little girls as victims. (Quoted in O'Mara and Schley 20I5)

Again, it is not the youth, but the perverted adults who might prey on them that are under scrutiny. The message could not be any clearer: Perverts are putting our "baby girls" and "daughters" in danger. "So before something happens, we should do something about it" - a perfect summation of pre-emptive policing.

While coming out of situated local debates in Japan since the I990s, it is crucial to note that these positions resonate with global debates that have been building in other parts of the world since the I970s, which contributes to a growing consensus that something must be done about manga/anime forms that cross the line. Since the r970s, concerns about children led to campaigns against sexual abuse and pornography and new laws in North America, Europe and beyond (Adler 200I: 2II-2I2, 2I8, 22I; also Ost 2009). More important than the 
specifics of these laws is the direction they broadly pointed. In a public dialogue in France in I978, philosopher Michel Foucault elucidated:

[T] he legislator will not justify the measures that he is proposing by saying the universal decency of mankind must be defended. What he will say is there are people for whom others' sexuality may become a permanent danger. In this category, of course, are children, who may find themselves at the mercy of an adult sexuality that is alien to them and may well be harmful to them. Hence there is a legislation that appeals to this notion of the vulnerable population, a "high-risk population." (Foucault I988: 276)

An issue for Foucault is how sexuality becomes a risk to be managed, or what he calls a "roaming danger" or "omnipresent phantom" (Foucault I988: 28I). Managing the risk of sexuality has consequences. As philosopher Guy Hocquenghem, one of Foucault's interlocutors in the public dialogue in 1978 , puts it:

What we are doing is constructing an entirely new type of criminal, a criminal so inconceivably horrible that his crime goes beyond any explanation, any victim. [...] In the case of attentat sans violence, the offense in which the police have been unable to find anything, nothing at all, in that case, the criminal is simply a criminal because he is a criminal, because he has those tastes. [...] In a way the movement feeds upon itself. The crime vanishes, nobody is concerned any longer to know whether in fact a crime was committed or not, whether someone has been hurt or not. No one is even concerned any more whether there was actually a victim. The crime feeds totally upon itself in a manhunt, by the identification, the isolation of the category of individuals regarded as pedophiles. (Quoted in Foucault I988: 278)

In North America, writing in the aftermath of what she called "the child porn panic" in the late I970s, anthropologist Gayle S. Rubin developed a theory of sexual politics (Rubin 20I I: I42). Sex "is organized into systems of power, which reward and encourage some individuals and activities, while punishing and suppressing others" (Rubin 20I I: I 80). Put simply, sex is organized into "good" and "bad" forms, with the latter tied in many ways to risk and danger, so it is not surprising that "eroticism [that] transgresses generational boundaries [... is] the lowliest of all" (Rubin 20I I: I 49). As Rubin highlights, "For over a century, no tactic for stirring up erotic hysteria has been as reliable as the appeal to protect children. The current wave of erotic terror has reached its deepest in those areas bordered in some way, if only symbolically, by the sexuality of the young" (Rubin 20II: I4I). Indeed, the protection of children seems one of the last unshakeable moral 
certainties for liberals and conservatives alike, with mixing youth and sex an absolute evil and good people all standing against it - a "gothic narrative" (Kincaid I998: IO-I2; also Furedi 20I5). Rubin argues that "some sex acts are considered to be so intrinsically vile that no one should be allowed under any circumstances to perform them" (Rubin 20II: I62), but it also turns out that no one should be allowed to imagine them. Even if no crime is committed in imagining, it might "lead to crimes and should therefore be prevented" (Rubin 20II: I65). If this is "victimless crime," then victims are imagined and created. "They draw on the pre-existing discursive structure which invents victims in order to justify treating 'vices' as crimes," Rubin writes. "Even when activity is acknowledged to be harmless, it may be banned because it is alleged to 'lead' to something ostensibly worse (another manifestation of the domino theory). Great and mighty edifices have been built on the basis of such phantasms" (Rubin 20II: I68-I69). Just as the threat posed by "bad sex" is often "imaginary," what divides good and bad sex is "an imaginary line" (Rubin 20II: I 5I). There is a ceaseless struggle over "where to draw the line" (Rubin 20II: I5I). In managing the risk of sexuality, "police, media, and public hysteria have targeted strangers and weirdos [...] real and imagined" (Rubin 20II: I85). Even as victims are imagined and created, so too are criminals, and all are caught up in regimes of policing imaginary sex, violence and crime.

What Foucault, Rubin and others - notably Hall, writing in the United Kingdom at around the same time - drew attention to in the late I 970 s has only become more pronounced in recent years. In the United Kingdom, media and sexuality scholars Feona Attwood and Clarissa Smith argue that many lawmakers operate with the assumption that "arousal - particularly sexual arousal - is potentially risky," and that such risk should "be managed through legislation" (Attwood and Smith 20I0: I 87). The identification of risky sexuality, Attwood and Smith continue, "enables accusations or identification of possible 'harm' to translate into calls for more and more legislation against the imagination" (Attwood and Smith 2010: I 87). As Foucault suggested, it is potential sexual arousal in relation to children that is considered to be the riskiest and is thus most subject to legislation, even when, as sexuality scholar Mark McLelland points out in the context of contemporary Australia, the sex in question involves "fantasy alone" (McLelland 2005: 75). Writing in the context of the United Kingdom, legal scholar Suzanne Ost adds: 
Contemporary child pornography law is not limiting itself towards the main harm of visual depictions that exploit real children, but is now directed towards exploitation of the non-existent child, possible future harm that could be caused to other children, and non-exploitative relationships involving sixteen- and seventeen-year-olds. It would seem that the original legislative purpose of preventing the exploitation of real children has gradually metamorphosed into a more all-encompassing construction of harm. Any behaviour related to child pornography, whether real, potential, remote or virtual, is thought to give rise to a risk of "harm." (Ost 2009: 89)

Among the relationships that are cause for concern are those between perverted men and cute girl characters in manga, anime and computer/ console games, which might be harmful. Even as Australia, the United Kingdom and Canada take legal stances against sexual depictions of underage cartoon characters (McLelland 20I7: II-I3), this is not a case of panicked lawmakers "losing the capacity to understand the distinction between fantasy and reality" (Furedi 201 5: 9). Rather, fantasy is being translated into reality by law (Hall et al I978: 42). Encounters with certain media, critics worry, will lead to the realization of potential victims and criminals (Attwood and Smith 2010: I85-187; also Mazzarella 2013). Aiming to reduce encounters with certain media, the law translates fantasy into reality. Erasing the distinction between "virtual" and "actual" forms of child pornography (McLelland 2005: 6364; also Ost 2009), for example, makes certain comics, cartoons and computer/console games equivalent to photographic records of child abuse. ${ }^{65}$ To prevent harm that may potentially arise from production and consumption, the cartoon character is translated into a child, the producers and consumers into child abusers and production and consumption into crimes punishable by law. ${ }^{66}$

The resonance between Ost's discussion of the shift toward non-existent youth and potential harm and what happened in Japan in 2010 should not go unnoticed, because we are seeing a convergence that allows for regulators to act on local concerns about manga/anime and its fans and global concerns about the safety of children. These concerns do not always or necessarily overlap, but they are coming together in the new moral position against manga/anime and forms that are "harmful," if not criminal. In recent years, advocates of increased regulation of imaginary sex, violence and crime in Japan are gaining support from international organizations that argue that the nation does not do enough to regulate child pornography, despite legally banning its production, sale and distribution in 1999 (Leheny 2006: I IO-I I I). ${ }^{67}$ 
The current issue is not recordings of sex acts involving children, but rather "virtual child pornography," which does not include an actual child in its production, but rather is "text and images that are purely imaginary and fictional" (McLelland 2005: 63). To root out virtual child pornography, countries such as Australia, the United Kingdom and Canada have already expanded the legal definition of "person" to include fictional characters. This raises questions - writer Neil Gaiman opines "it's nonsensical in every way that it could possibly be nonsensical" (Gaiman 2008) - but it is nevertheless expected that Japan will fall in line for the sake of protecting children. ${ }^{68}$ In the United States, obscenity law and other regulations limit virtual child pornography while still protecting freedom of expression, but case law in Japan has narrowly defined obscenity in terms of genital exposure (Allison 2000: I49-I 50; also Cather 20I2), thus missing the content and context of sex acts in adult manga, anime and computer/console games, which can involve underage characters. ${ }^{69}$

In Japan, activism for increased regulation has been slowed by robust resistance to any form of censorship and "thought policing," which reduces the ability to pass broad measures. So it was, in June 20I4, that the Japanese government passed new legislation against child pornography, which outlawed so-called "simple possession." International critics were outraged, however, that Japanese legislators did not take the opportunity to stand against virtual child pornography as well. In a widely circulated segment for $\mathrm{CNN}$, a reporter enters a store in Akihabara, picks up a manga book and describes its content as "so graphic, so sexually explicit, [that] we turned our undercover cameras off" (Ripley et al 20I4). The lurid details are left to the imagination, but the implications are not. The reporter interviews Japanese activists drawing connections between adult manga and the molestation of children. In the end, one wonders, along with the reporter, if "cartoons might be fueling the darkest desires of criminals" (Ripley et al 20I4). Note the emphasis on potentiality: Cartoons might be fueling the darkest of desires, which might lead to sex crimes; adults might be criminals, and children might be harmed. The potential of harm is enough to be incredulous about the Japanese government not doing more to protect children. Because of its paucity in regulating virtual child pornography, Japan has been shamed by the United Nations, UNICEF, ECPAT and the US Department of State, among others, as an "international hub for the production and trafficking of child pornography" (Hellmann 20I4). Notice how virtual has dropped out here, which demonstrates 
the collapsing together of virtual and actual forms in condemnation of Japan. This in turn emboldens politicians such as Ishihara. While the concerns are not necessarily the same, domestic and international criticism of the perversity and perceived problems of "otaku" and desire for cute girl characters converge in calls for increased regulation. The result has been more campaigning for and against manga/anime expression, especially adult works that cross all kinds of lines. At stake here is no less than what social theorist Michael Warner calls "the imaginary rules of sex" (Warner 2000: 26-27), and a tendency toward expansion and densification of law that McLelland dubs the "juridification of the imagination" (McLelland 20I 2: 473). The scope of potentially harmful or risky sexuality mutates as analysts and activists slam manga and anime in general as "subliminal child porn" (Kumi 2016) and politicians around the world see erotic but not explicitly sexual series such as Eromanga Sensei (2017) and demand outright bans because of scenes “so disturbing I won't, I just can't, describe them" (Coughlan 2020). The details are left to the imagination, even as one shudders to imagine the perverts producing and consuming such disturbing content. ${ }^{\circ}$

\subsection{Conclusion}

The year is $2 \mathrm{II}_{3}$. Japan is a stable, safe and prosperous island nation in a world that has descended into chaos. The secret to Japan's success is the Sibyl System, a central computer that constantly monitors the populace. More specifically, the Sibyl System conducts scans to gauge the population's mental states and the probability that anyone will commit a crime. If a person's “crime coefficient” exceeds a certain level, authorities are dispatched and the person is pursued, apprehended or killed. These so-called "latent criminals" are put into specific places and occupations where their freedom is limited. It does not matter that they have not committed a crime and have no intention of doing so. Latent criminals are arrested and neutralized so that the crime never happens. This is the world of Psycho-Pass (Saiko pasu), a hit media franchise in Japan that began in 20I 2. Psycho-Pass harkens back to Philip K. Dick's "The Minority Report" (I956), which, fittingly for its subject matter, predicted the phenomenon of "preemptive policing" that would come in the I970s (Hall et al I978: 42). Similarly, Psycho-Pass predicts a future of policing virtual crimes, which is to say crimes that have yet to be actualized. It predicts a future of virtual regulation, which turns virtual criminals into actual targets of the law. The author of Psycho-Pass is Urobuchi Gen, who got his start as a scenario writer for bishōjo games. 


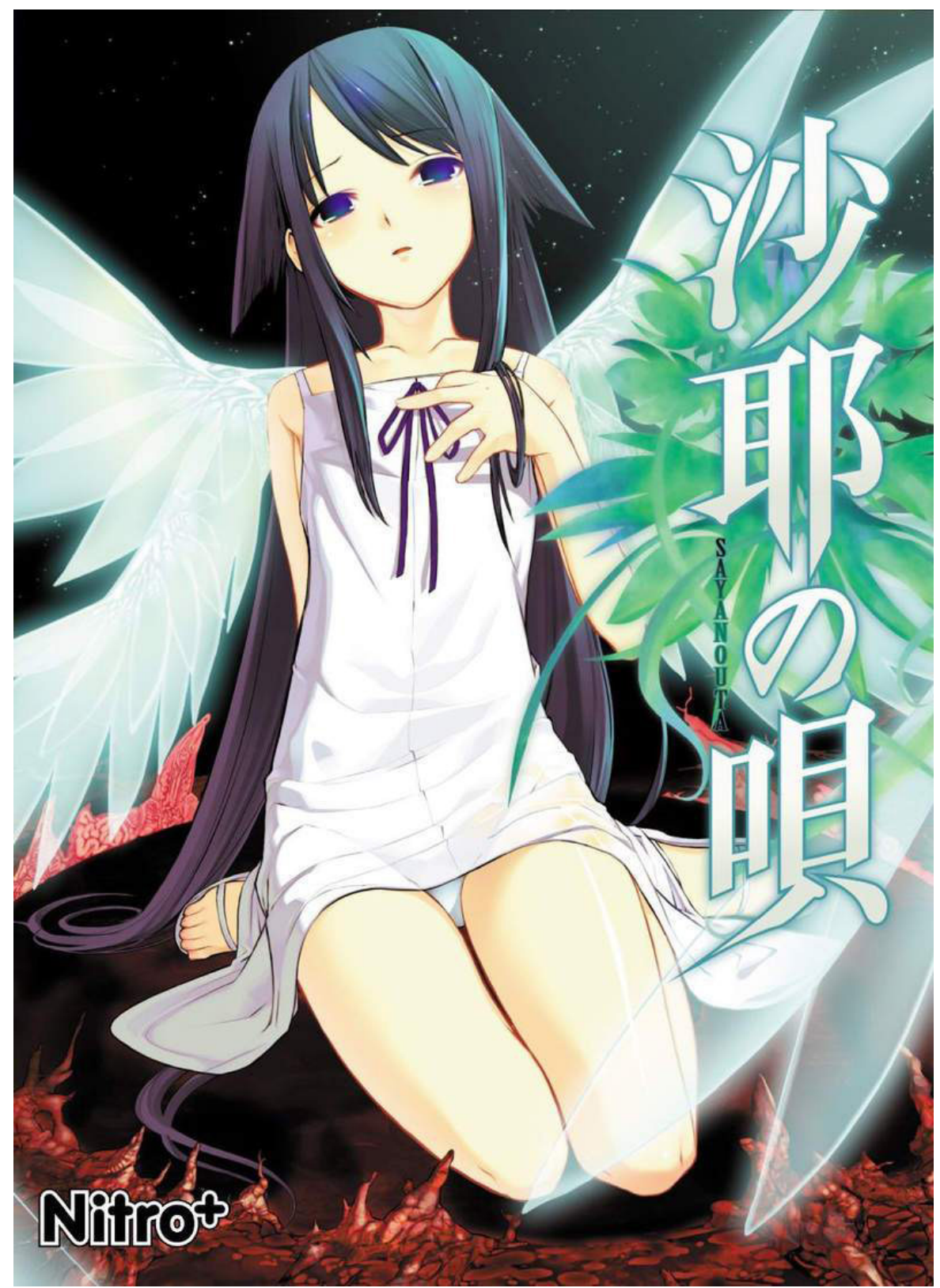

Image 5. Cover of The Song of Saya by Nitroplus. Used with permission from rightsholder. License: CC BY 4.0.

Like so many others in the bishōjo game industry, Urobuchi appears to wonder when he too will be marked as a latent criminal.

Such a future may seem unlikely. After all, Urobuchi has been heralded as a breakout talent after penning the script for Puella Magi Madoka Magica (Mahō shōjo Madoka magika, 20II), a television anime that 
won Grand Prize at the Japan Media Arts Awards. Yet Urobuchi's earlier work for bishōjo games such as The Song of Saya (Saya no uta, Nitroplus, 2003) is certainly enough to get him on many watchlists. ${ }^{71}$ Saya is the story of a man who sees the world covered in gore and people as hideous monsters, even as he perceives Saya, a Lovecraftian creature, as an attractive girl. The two move in together, become lovers and murder humans and consume their flesh. The creature appears to her college-aged roommate as a young girl, who, in addition to having sex with him, is brutally raped by their neighbor and in turn rapes a woman, tortures her and turns her into a sex slave. Saya is on the darker and more disturbing side of bishōjo games, but it is ultimately a love story about a co-dependent and violent relationship that leads the characters, and the player, into the depths of madness. Madoka is less direct in this, but tells the story of magical girls who trade their souls for wishes and are doomed to fight witches until they go mad and become them. It, too, is ultimately a love story between two of these magical girls, and Urobuchi intended it to be commentary on child soldiers and the struggle for survival (Nihon Keizai Shimbun 20I I). Fans fell in love with the cute girl characters - indicated to be about I 4 years old - and produced fanzines imagining sex with and between them, even as companies spun out endless media and material to capitalize on fan affection. Just another day in the manga/anime world. But then why are images of Madoka appearing in a televised debate about the need for increased regulation of imaginary sex and violence (TV Takkuru 20I4)? Why are these images being discussed in terms of lolicon - in the same space as questions about marrying bishōjo characters and actual crimes against children? Potential harm that demands preemptive action? Perhaps Urobuchi's imagination of sex and violence involving cute girl characters in Saya and Madoka is abnormal and dangerous. Perhaps we ought to do something. Perhaps the future of Psycho-Pass is not so unlikely after all.

The groundwork for all of this was established in the response to "otaku" in Japan in the I990s. This was a time when a crisis of hegemony and reproduction fed into anxiety and concern about media, youth and sexuality (Allison 2006: 75; also Leheny 2006). In Japan, as in other parts of the world, many were fearful for and of youth (boyd 20I4: I7), who might become the target of abnormal "otaku" desires or develop them and target others. The massive growth of manga, anime and games, including adult forms, in the r990s made them a cause of concern as potentially "harmful" (Kinsella 2000: I3 I-I33). 
At the same time, the fact that manga/anime was a growing market during the recessionary I990s, and increasingly spreading around the world and winning hearts and minds, caught the attention of politicians. As Cather points out in her analysis of a high-profile obscenity trial against adult manga, it was precisely because manga was considered important economically, socially and politically that regulatory intervention became necessary (Cather 20I 2: 246). ${ }^{72} \mathrm{~A}$ similar dynamic was at work with computer/console games in the I990s, when Japan emerged as the global center of console gaming and games were recognized as a creative sector of national importance, which articulated with concern about their impact on youth and sexuality and a desire to police them. The imaginary sex, violence and crime of bishōjo games, along with their perverse and perverting imaginary, made them a target for regulation.

Against the backdrop of increased nervousness about imaginary sex, violence and crime, this chapter has shown how the I990s also saw the emergence of discourse about moe, or an affective response to fictional characters. The use of this word appears to indicate emergent media literacy and ethics, which are learned in informal, peer networks. Manga/ anime fans have learned to separate fiction and reality and orient themselves toward fiction as such, which is what they respond to affectively. Aware that this distinction is not obvious and automatic, critics advocate ethical reflection and action. While affective relations with manga/anime characters became notable in the early I980s (Galbraith 2019: 63-74), this was accelerated and amplified in the I990s. Five factors contributed to the emergence of discourse about moe: First, a generation had grown up with manga, anime and computer/console games and in intimate relation to fictional characters; second, they had the legacy of adult fans, media and desires to build on; third, more manga, anime and computer/console games than ever before were being produced, and they featured more bishōjo characters designed to be more attractive to fans and encourage consumption across media and material forms; fourth, economic and social unrest, combined with persistent hegemonic gender ideals that made people feel like failures, contributed to seeking out alternatives in relationships with fictional characters; and fifth, the internet helped these fans find one another and events and spaces to gather and share their affection. This led to alternative social worlds and realities (Condry 2013: 203), which can be as transformative as they are perceived to be threatening (Laycock 2015: IO-I4). In the late I 990 s and early 2000 , moe moved from online 
discussions to Akihabara, a neighborhood in eastern Tokyo associated with computers and bishōjo games. So it was - under the watch of Governor Ishihara Shin'tarō, no less - that Akihabara became "the Moe City," where affection for cute girl characters has come to be more open and visible than anywhere else in Tokyo, Japan or the world. In the next chapter, we turn to Akihabara - where bishōjo game production companies, retailers and players gather - to discuss imaginary sex in public. 


\section{Coming of Age in Akihabara: Imaginary Sex in Public}

\subsection{Introduction}

Bishōjo characters are everywhere: on signboards in the street, on storefronts and packaging, in the form of figurines; their voices can be heard coming from looped video clips played on television and computer screens; women are costuming as them. Men are lined up on the street and in stores to make reservations and buy newly released adult computer games featuring cartoony cute girl characters, or what they call bishōjo games. They move en mass from one store to the next looking for the best price and promotional extras on specific titles. Many have oversized bags emblazoned with images of bishōjo characters and stuffed with dozens of bishōjo games; rolled up posters featuring bishōjo characters as pin-up girls stick out like flag poles. Some wear shirts with images of bishōjo characters on them; the cute cartoony faces are large and gaze out at the viewer with massive, emotive eyes, drawing attention away from the faces of the men wearing them. Using their smartphones while in line, the men scroll through company websites and fan pages and scan discussion threads to decide where to walk next. A few watch live-streaming broadcasts from local reporters who describe the street, stores and swag to look out for. A car decorated with images of bishōjo characters drives by; in the passenger seat next to the driver is a body pillow emblazoned with a full-body image of a bishōjo character who is partially nude and blushing; photographs are snapped with smartphones and posted online, which invites comments about how embarrassing the display of affection is, or, in the vernacular of those assembled, how "painful" (itai). Clearly this is a pain that is shared and also pleasurable.

How to cite this book chapter:

Galbraith, P. W. 202I. Ethics of Affect: Lines and Life in a Tokyo Neighborhood. Pp. 77-II 5. Stockholm: Stockholm University Press. DOI: http://doi.org/IO.I6993 /bbn.c. License: CC BY 4.०. 
毎月、秋葉原SIXTEENで美少女ゲームイベントを開始! 二コ生での生放送時間も同日12:00〜12:45まで放映!
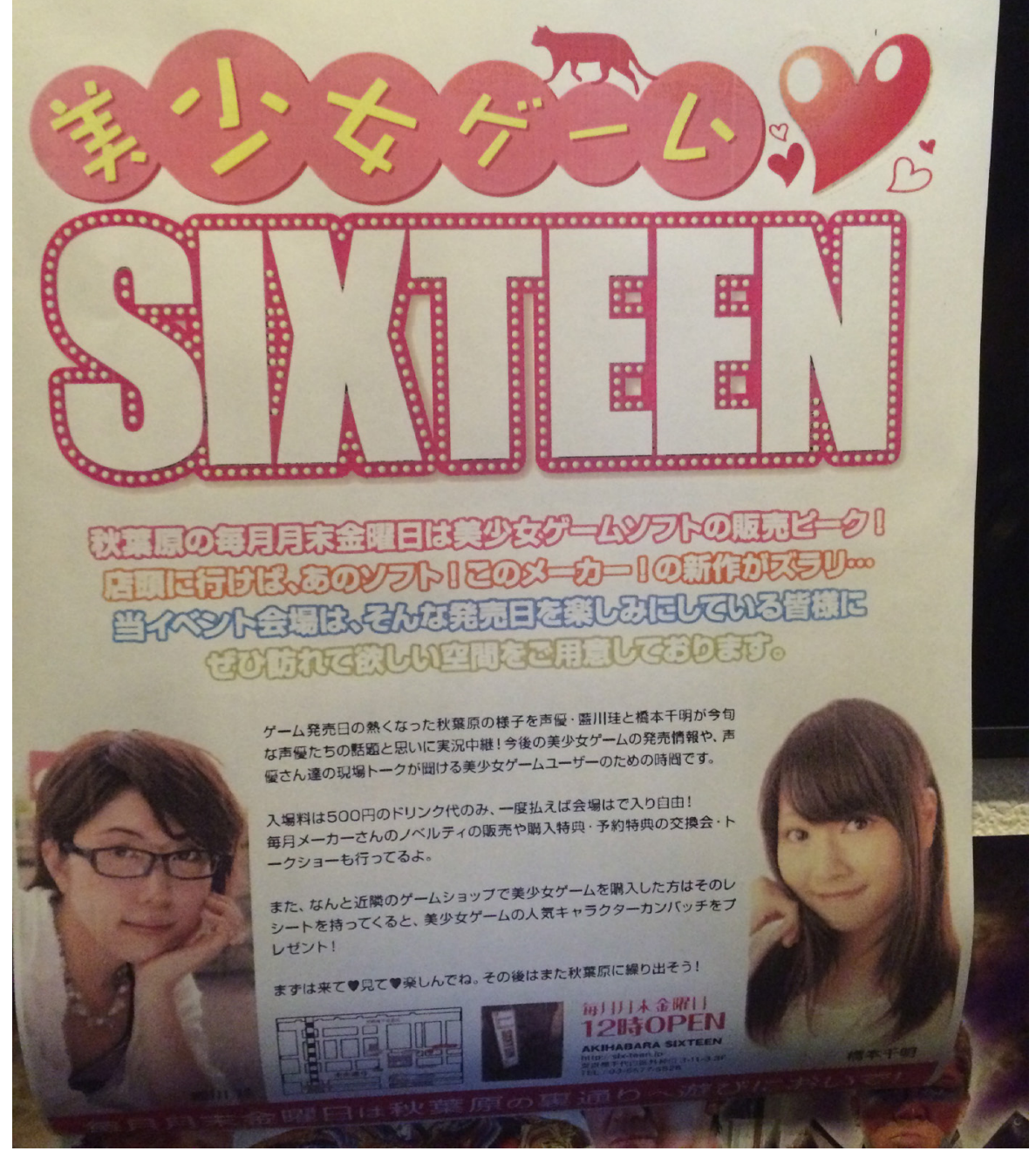

Image 6. Flier for Lonely's event in Akihabara. Photo by the author. License: CC BY 4.0.

This is "the Day of Erotic Games" (eroge no hi), when, once a month, new bishōjo games go on sale at stores in the Akihabara neighborhood in eastern Tokyo. ${ }^{73}$ It is an event and experience, something to be a part of, says Lonely Fukusuke, who runs a promotion called Bishōjo Game Sixteen in Akihabara. ${ }^{74}$ Despite his nickname, Lonely is anything but 
today, as he is surrounded by dozens of bishōjo game players. With proof of purchase of a bishōjo game, Lonely provides these men with a place to sit and a discount on drinks. Lonely also organizes a show hosted by voice actresses working in the bishōjo game industry, and invites guests from production companies to stop by and talk to the assembled players about new and upcoming releases. Most of the guests are from production companies located in Akihabara, but others come from Nagoya, Osaka and even Hokkaidō far to the north. There is a great deal of intimate sharing about playing bishōjo games, what happens behind the scenes of production and more. There are also promotional giveaways, which start with the guest asking, "Does anyone want this?" Hands immediately shoot into the air and men shout, "Yes! Me! I want it!" A quick group game of rock-paper-scissors decides the winner. Inspired by the lively discussion, men start talking to one another about what games they have bought today and why. Laughter fills the air. Looking on, Lonely Fukusuke smiles.

This chapter discusses Akihabara as the center of the bishōjo gaming world and as a space for socializing players into it. Akihabara is a space of imagination that excites the imagination (Galbraith 20I9: I3I). For manga and anime fans generally, it is "the Holy Land of Otaku," but, as design theorist Morikawa Ka'ichirō points out, it is more specifically "the Moe City" (Morikawa 2003). Akihabara is dominated by people responding affectively to fictional characters; it is a space where affection for bishōjo characters has become more open and visible than anywhere else in Tokyo, Japan or the world. It is a space produced by spectacle: affection for cute girl characters, sex, media and material culture. If people, thrilled to join the crowd in spectacular spaces such as Times Square in New York City, used to think, "Let's go and be with them and live" (Berman 2009: xxvi), then of Akihabara they think, "Let's go and be with bishōjo characters and bishōjo-oriented men and live." Akihabara is also a space of imagined dangers. For critics of desire for bishöjo characters - who in their cartoony cuteness appear young, are often explicitly below the age of $\mathrm{I} 8$ and are sometimes even indicated to be children - Akihabara is a symbol of the scourge of "virtual child pornography," which is spreading from Japan like a contagious disease (Lah 20I0; Nakasatomi 2013). Photographs of bishōjo game players in Akihabara are used to decry Japan as a nation of perverts, pedophiles and predators (see Galbraith 2019: 7I). Coming in a discussion of child pornography and abuse, readers are told that stores in Akihabara "stock a profuse amount of video games where the objective 
is to sexually subjugate underage girls" (Adelstein and Kubo 20I4), with the implication being that such content and an environment that tolerates it put children at risk. This chapter approaches Akihabara as a space of contested imaginings of media and its a/effects. Drawing on the work of literary critics and social theorists Lauren Berlant and Michael Warner (Berlant and Warner I998; Warner 2000; Warner 2002), I look at Akihabara as a public culture where imaginary sex is played out, practiced and politicized. In my field interviews, encounters and participation in the public culture of imaginary sex, I observe an "ethics of queer life" (Warner 2000: 33 ) being both practiced and contested.

\subsection{Bishōjo Game Central}

Located in eastern Tokyo, Akihabara is firmly established in the popular imaginary of Japan. It is by far the most famous of the socalled "electric towns," or areas where stores selling home appliances, electronics and computers cluster together. With the rise of Japanese electronics globally since the I980s, Akihabara has been permanently inscribed as a symbol of Japan, technology and the future. When manga and anime reached unprecedented heights of production in Japan in the I990s, the density of stores in Akihabara selling such media and related material and merchandise brought renewed interest to the area. Locally, manga and anime were bright spots in a recessionary economy. Globally, manga and anime were part of the image of "Cool Japan," which put Akihabara back on the map. Along the stretch of Chūō Street from Kanda River to Kuramaebashi Street and in adjacent side streets and blocks are more stores specializing in manga, anime and related media and material than anywhere else in the world. Signs featuring manga/anime-style characters appear everywhere, but disappear quickly after one leaves the unofficial but surprisingly clear boundaries of the area.

The transformation of Akihabara from an "electric town" to an "otaku town" is basically stores selling home appliances and electronics transitioning to computers, the consumer base thus shifting from families to male enthusiasts and manga/anime content catering to those men changing perceptions of the area (see Morikawa 2003). Significantly, the first manga/anime content to enter the space was computer games featuring manga/anime-style characters, or what can be categorized as bishōjo games. ${ }^{75}$ These games appealed to a generation that had grown up with manga and anime and in intimate relation to cartoon characters designed to be increasingly attractive and appearing in adult media. 


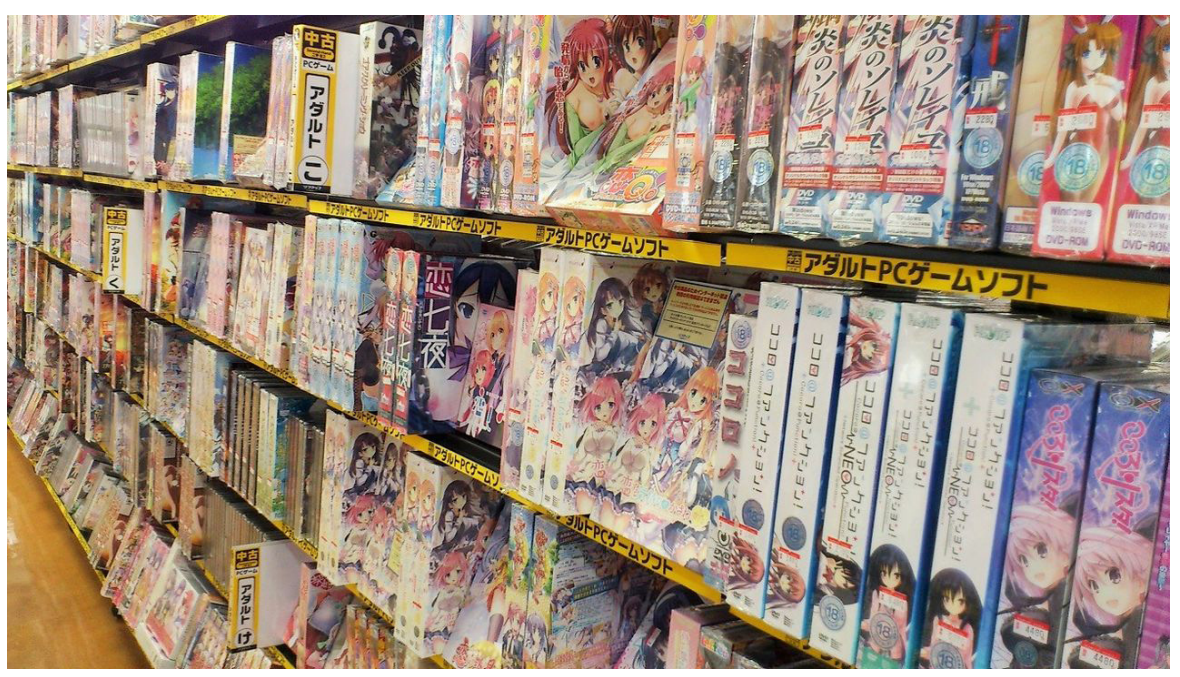

Image 7. Shelves packed with bishōjo games in Akihabara. This particular store had hundreds of different titles occupying an entire floor. They encouraged physical purchase through premiums, which were limited and exclusive to different retailers in the area. Photo by the author. License: CC BY 4.0.

Even as computers became more popular in the I990s, adult computer games became compatible with the Windows operating system, which greatly increased their reach. Sexually explicit content nearly doubled its share of the computer game market between 1993 and I994, reaching an estimated 35 percent (Pelletier-Gagnon and Picard 20I 5:35). Further, Konami's Tokimeki Memorial (Heart Beat Highschool, I994), a dating simulator game without sex scenes, became a mainstream national phenomenon and brought new players and producers to bishōjo games. The boom in bishojo games overlapped with the boom in manga and anime in the I990s, as well as more shared awareness among fans of the attractiveness and affect of characters. With stores such as Messe Sanoh, Gamers, Trader, Getchuya, Sofmap, Toranoana, Medio and Melon Books advertising bishojo games in Akihabara in the early 2000s, it is no wonder that these accounted for the majority of images on the street at the time (Morikawa 2003: I-2, 4-5, 95; also Kagami 2010).

At the time of my fieldwork in Akihabara in 20I4 and 2015, despite advances in digital distribution online, many bishōjo games were still sold as software on physical disks housed in large paper boxes emblazoned with alluring cover art and placed on shelves inside brick-andmortar stores. While one could buy them through online retailers such as Amazon.co.jp, shipping was limited to Japan and there was a good deal of concern about certain titles being denied visibility for adult 
content that somehow or another crossed the line (Nagayama 20I4: 339-340; also Kagami 2010). The more extreme, underground and fan-created stuff could more readily be found offline in limited circulation in Akihabara. Moreover, browsing was easier in dedicated stores that had multiple games on display in the same space, eye-catching advertisements and organized displays. In stores, one was a gamer among gamers, which was comforting. Further, buying at stores, one could solicit advice from staff, who were knowledgeable about the industry and offered insight and guidance. At stores in Akihabara, players expected that along with their purchase would come premiums such as limited-edition box art, swag and signed original art. For these reasons, a surprisingly large number of bishōjo game players still left their homes and physically visited stores, bought software packages and took them back to load on desktop computers. Some kept the boxes in collections, but, due to small living quarters and the cost of bishōjo games - around Io,000 yen, or US\$Ioo - they would often sell used games to second-hand stores. Because new releases were relatively infrequent and rigidly scheduled, players gathered in Akihabara on certain days of the month to buy and sell games. In the second decade of the new millennium, when global gaming was increasingly dominated by digital downloads and streaming, bishōjo games were still stubbornly material and local.

Bishōjo game production companies are also concentrated in Akihabara. Although there are no official numbers on geographic distribution, the vast majority of bishojo game production companies that I visited were in unassuming office and apartment buildings in and around Akihabara. The concentration of production companies in the area was presented to me as common knowledge and indeed common sense. The president of Front Wing, for example, told me that his production company - one of the largest in the industry - was located just a few minutes from Akihabara Station because it is where everyone and everything is. ${ }^{76}$ Being in Akihabara makes it easier to build relationships with other companies, sellers and dedicated players, as well as to build up promotional discourse. On the other end of the spectrum, I was often told the story of Nitroplus, which, although it still produced adult computer games, was perceived to have left the tight-knit collective. Enjoying mainstream success, the company created distance from its past by literally distancing itself from Akihabara and moving to the Skytree, a national landmark in the Oshiage neighborhood of Tokyo and symbol of Japan's creative future. ${ }^{77}$ When meeting with 
staff from production companies in Akihabara, they often suggested we talk in spots away from the station and Chūō Street, which they saw as crawling with bishōjo game players who might overhear sensitive conversations. To create distance, we would meet outside of the imagined limits of Akihabara - at restaurants and cafés on the other side of Kuramaebashi Street or Shōwa Street. The boundary between inside and outside was clearly and consistently drawn.

In Akihabara, through collective activity and practice, a space of imaginary sex is created out of the built environment. This is what it means for Akihabara to be the Moe City: It is a space where the affective response to fictional characters has transformed the built environment, where "otaku" movement in relation to bishōjo "generates a world, a reality" (Lamarre 2006: 383 ). Some celebrate this space of "otaku," but others critique a space "overflowing with things that offer convenient gratification of sexual desire" catering to the "virtual sexuality" of men who "reject the physical" (Okada et al 2005: I70I72). For better or worse, Akihabara is imagined to be overrun with men sharing a "peculiar sexual preference" (Kikuchi 2008: 69). This can and has generated friction with local authorities, who regulate the streets carefully and have more or less contained the shared movement that turned the streets into an "otaku" festival during the moe boom in the mid-2000s..$^{78}$ Meanwhile, reports that bishōjo games are being distributed online - through piracy and resale, primarily - and making their way to players around the world bring journalists, critics and activists to Japan and Akihabara. ${ }^{79}$ These games, we are told, "feature girlish looking characters," "some are violent" and they are stepping "closer and closer to reality" (Lah 20I0). Even as there are fears of the boundaries of Akihabara becoming permeable, bishōjo game producers and players are increasingly concerned about the world outside leaking into Akihabara.

\section{3 “Japan Only:" On Closed Circulation}

One of my first tasks in the field was to play bishōjo games and familiarize myself with the content. Many of these games are of dubious legal status beyond Japan, and so I could not play them until I was back in the country. Upon arrival in April 20I4, I bought a cheap personal computer from the massive electronics store Yodobashi Camera in Akihabara. While in the area, I also purchased some bishōjo games, based on buzz and store recommendations. That evening, after 
returning to my rented room, I tried to load the game software onto my new computer - only to be met with warnings of compatibility errors. After trying to load every game I now owned multiple times to no avail, I finally gave up and resigned myself to seek assistance at Yodobashi Camera the following day. With the computer, one game and a player manual in hand, I arrived at the help desk to find two young men assisting an elderly woman in setting up her computer. Although I was tired and scowling due to my frustrated efforts the night before, the young man trying to help me was clearly amused. With the elderly woman next to us, we tried to discreetly discuss the problem, but he could think of no solution and so called more and more people over. Soon there was a mob of support staff, with me in the middle, and curious shoppers stealing glances. The minutes turned to an hour, then more, and boredom overtook shame. Suddenly, the diagnosis. "Japan only," the young man says, in English. "That's the problem." But I am in Japan. "No, no, no. Japanese only." But I am speaking Japanese. He switches to Japanese. "No, no, no. The computer's operating system must be set in Japanese. Japanese only. Otherwise the game will not load.” After some tech wizardry, the opening screen of the game pops up. Two cartoon women are holding used condoms between pursed lips while semen spills out onto their breasts. Shame returns with a vengeance, and I quickly say my thanks and scurry away.

As deep an impression as this experience made on me, I got used to seeing the words "Japan only" on bishōjo game packages, in player manuals and during the loading of new software onto my computer (see Kagami 20I0: 219-220). The compatibility error had been overcome, but I was still constantly reminded that the content was not for me. The fact that there had been an issue between my computer - and, perhaps, myself - and bishōjo games became a joke that I told producers and players for a laugh. Hayase Yayoi, a voice actress working in the bishōjo game industry, was among those who found the story funny and liked to spread it around. She told me so over lunch on September I9, 20I4 before we made our way to Charara!!, a monthly bishōjo game industry event in Akihabara. ${ }^{8 \circ}$ We arrived early, because Hayase wanted to introduce me to people she worked with; although she was not appearing in the event that day, we went through the back elevator used by staff and guests and started meeting people before the event started. This seemed to irritate the organizers, and my introduction as a researcher from the United States did not smooth things over. Hayase and I left soon after, and she explained that the organizers had 
categorized me as someone "collecting information for foreign countries" (gaikoku muke shuzai), which they did not want. Charara!! is a local event for producers to build relationships with dedicated players, who make purchases and spread the word. Because many bishōjo games are not legally available overseas, any article that I was imagined to write would not lead to sales, and might instead encourage illegal distribution and generate negative publicity (Lah 2010; Kagami 20I0; Nakasatomi 2013). When I mailed the organizers to apologize, I was not surprised that they refused me future access to the event as a member of the press and firmly reminded me that bishojo games are "for sale in Japan only" (Nibon kokunai hanbai nomi). ${ }^{8 \mathrm{r}}$

While denied access as a member of the press (I had never claimed to be that, but was certainly collecting information for a foreign publication), I returned many times to Charara!! as a player of bishōjo games, and was always struck by the small scale of the event. On average, around 20 production companies would gather to speak and sell to roo dedicated, core gamers in a modest space above an arcade located on Chūō Street in Akihabara. Representatives of production companies told the players about upcoming projects, showed preview clips, brought out scenario writers and artists and voice actresses, held "mini-live" shows of music from the games and joked and laughed with the assembled men (overwhelmingly men in the audience). The intimacy of the event was immediately apparent, although most gamers focused on the speakers rather than one another and were glued to the screens of their smartphones and mobile devices when uninterested. Those who were interested spoke their thoughts aloud and interacted with the speakers, participated in group games of rock-paper-scissors. To win promotional giveaways and lined up at tables to buy products, test versions of upcoming games and make preorders, which usually came with something extra such as a handshake, signing or original artwork. Men lingered at tables to chat with the producers, who were in general tremendously generous with their time and friendly. Charara!! is an event for bishojo game producers to build relationships with an inner circle of fans who buy into their work and support them during the long production process.

In light of negative press from global news outlets such as CNN (which at one point ran a survey on its website asking whether or not the Japanese industry should be regulated [Kagami 20I0: 22]), the openness of bishōjo game events was being negotiated while I was in the field. ${ }^{82}$ Although Charara!! is free of charge to attend and screening 
at the door is minimal, meaning it is basically open to all, the appearance of phenotypic difference was duly noted. I crossed a line by entering Charara!! through the backdoor, appearing to be sneaking and snooping around, and this was made worse by an introduction as an American researcher. The result was a line drawn and highlighted between inside and outside. Despite being free and open to all, Charara!! is in fact a controlled and closed space, which allows for interactions between producers and players to occur. Not private, but also not public, a sort of private publicity or public privacy is key. Keeping the space open requires controlling its boundaries, which resonates with what media anthropologist Chris Kelty calls "recursive publics" that have "a shared sense of concern for the technical and legal possibility of their own association" (Kelty 2005: 192). As Kelty sees it, many groups are now concerned with their own "conditions of possibility and the modes of manipulating them technically and legally - on and off the Internet" (Kelty 2005: 204), which is precisely what one sees at Charara!! The conditions of possibility for the event are a closed circle with clear boundaries and controlled access. The event should be offline, and not contribute to illegal distribution online, which threatens the entire industry with increased regulation. Responding to the threat of regulation from the outside, the industry regulates from the inside and insists on boundaries. Drawing lines this way is no less than "imaginative world-building practice" (Beattie 201 8: 175 ). ${ }^{83}$

Beyond Charara!!, I was regularly warned by bishōjo game producers about opening up the culture, its events or even Akihabara, which was attracting too many tourists, journalists and activists. For example, Watanabe Akio, a renowned character designer with deep ties to bishōjo games, told me that outside interest could very well diminish the industry's "powers of imagination" (sōzōryoku) ${ }^{8}{ }^{8}$ Even as some worry about bishōjo games slipping out of Akihabara and into the world (Lah 20I0), Watanabe, like the organizers of Charara!!, worries about the world slipping into Akihabara. This in turn might intensify pressure for increased regulation, specifically bishōjo games in Akihabara being held to "international standards," which has been provocatively pronounced "a new form of cultural colonization" (Pelletier-Gagnon and Picard 2015:39). One of the conditions of possibility for freedom of imagination and creation is insisting on boundaries, or drawing lines to separate inside and outside. As with Charara!! and Watanabe, so too with Akihabara, which is a space where bishōjo games circulate, but within boundaries that are collectively established and maintained. 
Production company Minori is a good example of tensions surrounding the publicness of bishōjo games. In 2009, in an attempt to invigorate a bishōjo game industry facing declining sales and an aging and shrinking gamer population, Minori organized an event called the Denkigai Matsuri. ${ }^{85}$ Now held twice a year, bishōjo game production companies can participate for free - as compared to Charara!!, where producers pay to participate but players get in for free, or the Comic Market, where renting space for an industry booth is costly and highly competitive - which lowers the barriers to participation. Surprisingly, the Denkigai Matsuri is not held in Akihabara, but rather in the Shinjuku area across town. The Denkigai Matsuri shares its name with the Denkigai Matsuri in Akihabara, which is held by the powerful chamber of commerce and focuses on stores selling home appliances and electronics, which have a longer history in the area than the "otaku" stores that began to appear in the I980s. Minori cleverly twists the "gai" in "Denkigai" from a character meaning "town" to a homonym meaning "outside," which suggests that it is not the "Electric Town Festival," but rather the "Festival for Other than Electronics" or "Festival Outside the Electric Town." Given the name, one wonders if the bishōjo game industry was at some point pushed out of that other and more official Denkigai Matsuri in Akihabara, but it is more likely that it is held in Shinjuku to create a dedicated space, align with other events and avoid conflict with outsiders. (For more on bishōjo games at the Denkigai Matsuri, see Chapter 4.)

In 2009, the same year that it first organized the Denkigai Matsuri for the bishōjo game industry, Minori also closed its website to international traffic (i.e., anyone with an internet protocol address that points to a location outside of Japan). ${ }^{86}$ The decision was made as a form of protest against unwanted and illegal circulation by overseas fans, which invited outside criticism. As Minori curtly elaborated in a statement, which was very pointedly in English, the decision was made to "protect our culture" (quoted in Ashcraft 2009). While the position has been relaxed somewhat, for a time Minori insisted on boundaries because it allowed them to maintain what they called their "minority spirit," which is to say their ability to imagine and create things that appeal to a small number of dedicated players but perhaps offend the majority of people in the world. As Watanabe also suggested to me, Minori feels that their culture and spirit are under attack from outsiders and critics who do not understand bishōjo games. The imagination and creation of spaces for bishōjo games - spaces with boundaries, insides and outsides 
- allows for their continued existence. These boundaries are often coterminous with those of the nation of Japan and the neighborhood of Akihabara, which seem under attack as elements from inside slip outside and vice versa. So it is that sociality is negotiated, and renegotiated, at the borders and the limits of circulation. Unofficial distribution by fans online has steadily transitioned into official activities such as crowd funding and direct download sales, which suggests a global subculture and shifting consciousness of bishōjo games as for "Japan only," but tensions on the ground remain. ${ }^{87}$

\subsection{Coming of Age in Akihabara}

With jet-black hair, thick eyebrows and seemingly permanent dark circles under his eyes, Ataru is handsome in a brooding sort of way. Thin and perpetually dressed in muted colors, he is not the type to stand out in a crowd, but is also certainly not a wallflower. When not working as a software engineer - which, depending on the project, keeps him away many evenings and even some weekends - Ataru practices English conversation, goes to parties and rubs shoulders with people from the manga, anime and gaming industries. Quick to share an opinion and a laugh, Ataru is relatively popular at these social gatherings. He is in and out of relationships with women, but is currently a bachelor who lives alone in a spacious apartment just a two-minute walk past Kuramaebashi Street outside Akihabara. In the evening, Ataru plays pickup games of mahjong, hangs out in costume cafés and meets friends in the area. After a chance encounter on the streets of Akihabara in 2007, when Ataru was in his last year studying economics at a university in Tokyo, I have been one of those friends. I stayed with Ataru frequently over the course of my fieldwork from 2014 to 2015 , because his apartment was no more than a stone's throw away from dozens of bishōjo game production companies, including several where I spent a good deal of time.

Dreaming of producing games when he was in highschool, Ataru did not end up in the industry, but is a dedicated player of bishōjo games. He tends toward dark and disturbing content - think The Song of Saya (discussed in Chapter I), written by Urobuchi Gen, one of his favorites, Fate/Stay Night (Feito/sutei naito, Type-Moon, 2004-) and When They Cry (Higurashi no naku koro ni, o7th Expansion, 2003-) - and narratives that loop back on themselves. His favorite game is Flying Shine's Cross Channel (Kurosu channeru, 2003), which is the 
story of Kurosu Taichi, who goes to a government-mandated school for people who look normal but are somehow mentally ill and unlikely to adapt to social life. After summer vacation, Kurosu and the members of his broadcasting club return to school to find that everyone has vanished. Further, the world seems to be repeating the same week over and over again. Stuck in this strange, lonely but somehow comforting world, Kurosu works to restore his broken self and relationships. The story deeply moved Ataru, which is part of what he consistently calls a "god game" (kamigē), slang for a masterpiece as opposed to a "shit game" (kusogē). Ataru keeps an eye on any new releases featuring Cross Channel's scenario writer, Tanaka Romeo, who he considers a "god" (kami). As is clear from the way he speaks about gods and shit, if Ataru feels strongly about something, he will tell you so - often, and loudly. Living in Akihabara, he finds it easy to track trends, but also goes online to the anonymous bulletin board " $2 \mathrm{ch}$ " to check rankings of the most popular bishōjo games by year. ${ }^{88}$ Ataru has played almost everything in the annual top Io since 2003 . He never seems to tire of compiling lists of games that I must play, which he explains is a rite of passage.

Although I also hung out with other bishōjo game players, Ataru was my primary teacher and guide. After playing a recommended game, we would talk about it and share experiences. Things were often heated when discussing what choices I made, why and what routes these took me down. Ataru was animated when explicating what I had missed, especially if my route through the game did not include what he considered to be the "best," or most moe and moving, scenarios. These were the times when Ataru shared his own play experiences, and often very intimate details of them. When I was a little better versed in bishōjo games, Ataru introduced me to other players, who I came to know and play with as well. All of these men, like Ataru and myself, spent their free time in Akihabara, which was central to our lives as bishōjo game players. It was the center of gravity that pulled us together and provided a common place to meet after work for dinner, events and shopping. Like Ataru, a few of these men moved to be closer to Akihabara, while others tried to recreate it at home in rooms that overflowed with media and material representations of bishōjo characters.

Born in Aomori Prefecture in northern Japan in I983, Ataru seemed to see some of himself in me, born in Alaska, the northernmost of the United States of America, in I982. Both of us had been drawn to the spectacle of Akihabara, to the density of stores dealing with bishojo 
games and the density of the population of gamers shopping at those stores. Although younger than me, Ataru describes himself as my spiritual older brother, because he awoke to the world of bishōjo games much earlier. Sitting in a café on the backstreets of Akihabara, located below the offices of a bishōjo game production company, I ask Ataru about his history with bishōjo games. "My otaku career began with games," he says between bites of curry rice. "The start was really just a simple thing. My friends were playing Tokimeki Memorial and so I gave it a shot." ${ }^{89}$ It was I996, and Ataru, a sixth-grader at the time, was blown away. The combination of attractive manga/anime characters, the mechanic of interacting with them and, most of all, the inclusion of character voices was moving in ways that were new and confusing for him.

As Ataru remembers it, his formative years overlapped with the explosive growth of bishōjo games as a "moe genre" (moe janru). Coming of age in the I990s amid an increasingly open culture of affection for fictional characters, Ataru recalls that, "I definitely had a sense of moe." Indeed, he was soon almost too moved by images of cute girl characters and interactions with them. When playing Red Entertainment's Sakura Wars (Sakura taisen, I996), where the player inputs his name and the bishōjo characters speak it out loud in interactions, Ataru was moved enough to be embarrassed and so retreated from the family room to play in his bedroom. These were still classed as "consumer games," as opposed to "adult games," which means that they did not have explicit sex scenes in them, but hearing these cute girl characters speak his name while looking out of the screen at him was arousing enough that Ataru did not want to be with others while feeling this pleasure. In playing such games, he was pleasuring himself in a broad sense of enjoying bodily responses, but not yet masturbating. Content from the booming adult gaming industry was also filtering into the mainstream in releases for the general public, which cut out explicit sex scenes, but not the inherent mechanics that move players (for more on game design, see Chapter 3).

So it was that Ataru, still playing on gaming consoles (he thought computers were for adults), encountered the Sony PlayStation release of To Heart (Tu hāto, Leaf, I999), which he describes as a "visual novel" (bijuaru noberu). "Nothing before that had been so emotional for me," he says. "It really moved me. I think that was probably the first game that moved me to tears." To Heart is a romance game where the player assumes the role of highschooler Fujita Hiroyuki and interacts 
with classmates before, during and after school. Depending on the circumstances and player choices, certain events are triggered; the events depend on how much cute girl characters like the player, and, depending on how much the player likes the characters, can be quite moving. (English-language sites sometimes call these "affection events.") There are ro distinct plotlines in the branching narrative, which can lead to good and bad endings. For Ataru, almost all of the plotlines included moving scenarios and moments. "That emotion really wasn't part of the other consumer games that I was playing, which were about adventure," Ataru muses. "After I played To Heart, I became completely enthralled by bishōjo games. I would buy anything that had bishojo on the cover, anything that caught my attention." One such game was the Sega Saturn release of Welcome to Pia Carrot!! (Pia kyarotto e yōkoso, NEC, I998), which is a story about courting - and, in the original, bedding - café waitresses in cute costumes. The game was recommended for players age I 8 and older, but staff at Ataru's local game shop in Aomori Prefecture were older male players, who sold him the game. Purchasing a game recommended for adults and popular among older male gamers, Ataru began to see himself as a young adult, a man and a gamer.

Having finished his meal at the café in Akihabara, Ataru lights a cigarette and remembers his sexual initiation in the area. He was in junior high visiting Tokyo on a school trip, and had slipped away to Akihabara during free time to search for replacement parts for his portable gaming device, which he had heard could be purchased at specialty stores. Browsing through computer and gaming stores, Ataru encountered the familiar character images of To Heart, which he had played as a consumer game. The box was different, however, and he went to take a look. Turning it over, in preview art on the back of the package, he saw the characters that he knew and loved naked and involved in explicit sex scenes. This was the original release (from 1997), which is to say that Ataru had in his hands an adult computer game. Unlike the consumer game release, sale was restricted (as opposed to recommended) to players over the age of I 8, but Ataru wanted it desperately, and must have shown it in his behavior. Despite his being in a school uniform, staff at the store in Akihabara appreciated Ataru's excitement for To Heart - which was a benchmark for them, and many others, too - and sold him the game. ${ }^{90}$ This was Ataru's first computer game, and first adult computer game. While he was already attracted to the characters in To Heart, the explicit sex scenes affirmed his growing desire 
for manga/anime-style cute girl characters. While moved to emotional response and arousal before, Ataru was now moved to masturbation. What connects both is his bodily response to images of and narratives involving bishōjo characters, which moved him to arousal, tears and/or ejaculation. In Akihabara, seeing bishōjo characters on signs and talking with men attracted to them sexually, and later playing a bishōjo game and masturbating, Ataru realized that he was sexually oriented toward manga/anime-style cute girl characters. Although stating that he is still attracted to flesh-and-blood women (and I knew he dated women over the years of our communication and contact; the last I met in person was a university student he became acquainted with at a cosplay event), he was nonetheless also, and at the time primarily, attracted to bishōjo characters.

"Akihabara is that kind of place," Ataru declares matter-of-factly, taking a long drag on his cigarette. "There is probably nowhere else in the world where virtual sex is this prevalent. Even if you searched the world, you probably wouldn't find anything on the scale of Akihabara. Just walking down the street, there is a sign board with a bishojo with her breasts showing, or a figurine of her posed provocatively, just there on the shelf, or mouse pads modeled after bishōjo breasts, or body pillows with naked bishōjo on them, fanzines and adult games. It's strange for many people, I guess, but for me, and men like me who grew up in this environment, it is a taken-for-granted city. Whether that is good or bad, I don't know, but Akihabara is that kind of place. It's a city overflowing with sex." Specifically, overflowing with imaginary sex with bishojo. Akihabara is a place overflowing with imaginary sex, sex with images and images in material form. Here one can encounter attractive bishōjo characters, which is not uncommon in Japan given its robust market of manga, anime and computer/console games, but there is nowhere else in Tokyo, Japan or the world where sexual desire for them is so visible and viscerally felt. There is nowhere else where it is on the scale of Akihabara, and where it is such a part of everyday reality. There is nowhere else where so many people gather and openly embrace sexual orientation toward cartoon characters. This is why Akihabara appears strange, but it is also why it attracts men such as Ataru. It is a place where the strange is normal, part of a city that is taken for granted. Ataru loves this place because here he shares sexual orientation toward cute girl characters, shares movement in relation to them, sociality among strange strangers who are "men like me." Men, but, like me, strange. In Akihabara, the Moe City, Ataru and men like 
him are moved in their encounters with fictional and real others, media and material forms, virtual and actual bodies.

While many commentators are concerned with whether or not the boundaries of Akihabara are leaking - that is, whether or not a "peculiar sexual preference" will spread like a virus from Akihabara and infect the world, and, conversely, whether the world will come to Akihabara and destroy the closed circle of imaginary play - Ataru is more concerned about whether or not the boundary between fiction and reality is leaky and what should be done to maintain it. In moments of reflection, be they playing games or sitting with me in a café, Ataru wonders about the powerful affect of media. He is of course moved by his interactions with bishōjo in media and material form, which is, after all, the point, and concedes that manga, anime and computer/ console games probably impacted his sexuality. He is, after all, attracted to bishōjo characters. Some of his friends are content to say that they are sexually oriented toward the "two-dimensional" (nijigen) and leave it at that, but Ataru is for his part not convinced that the twoand three-dimensional worlds are clearly and cleanly separated. Rather, the two- and three-dimensional are constantly interacting with one another. This complex interaction impacts people and their movement in the world. "My life would probably have been very different if I had not played Tokimeki Memorial," Ataru says. "If I hadn't played it, I might not have become an otaku, and if I weren't an otaku, I wouldn't be in Akihabara or have met you, right? Taste determines your life. It determines your environment, friends and actions." Manga, anime and computer/console games brought us together, and, consuming them together has impacted our lives, actions and interactions. So to say that the two-dimensional is two-dimensional and has no effect on the three-dimensional is to obfuscate the very real fact that images move us and impact our shared world. (Note that this recognition of media effects and affect is very much in line with Sasakibara Gō [Chapter I]. If all media has effects and can affect, then all media can do so adversely. This is precisely why Ataru, Sasakibara and other gamers reflect and act with care.)

However powerful its affect, Ataru is adamant that no media is "harmful" (yūgai). People are moved by it, and differentially so, depending on their experiences and environment, and it is that movement that can be harmful. "I understand the concerns of feminists and human rights activists," Ataru confides to me, pensively. "I do. But I can tell you that we are not people moved to harmful actions." With this collective 


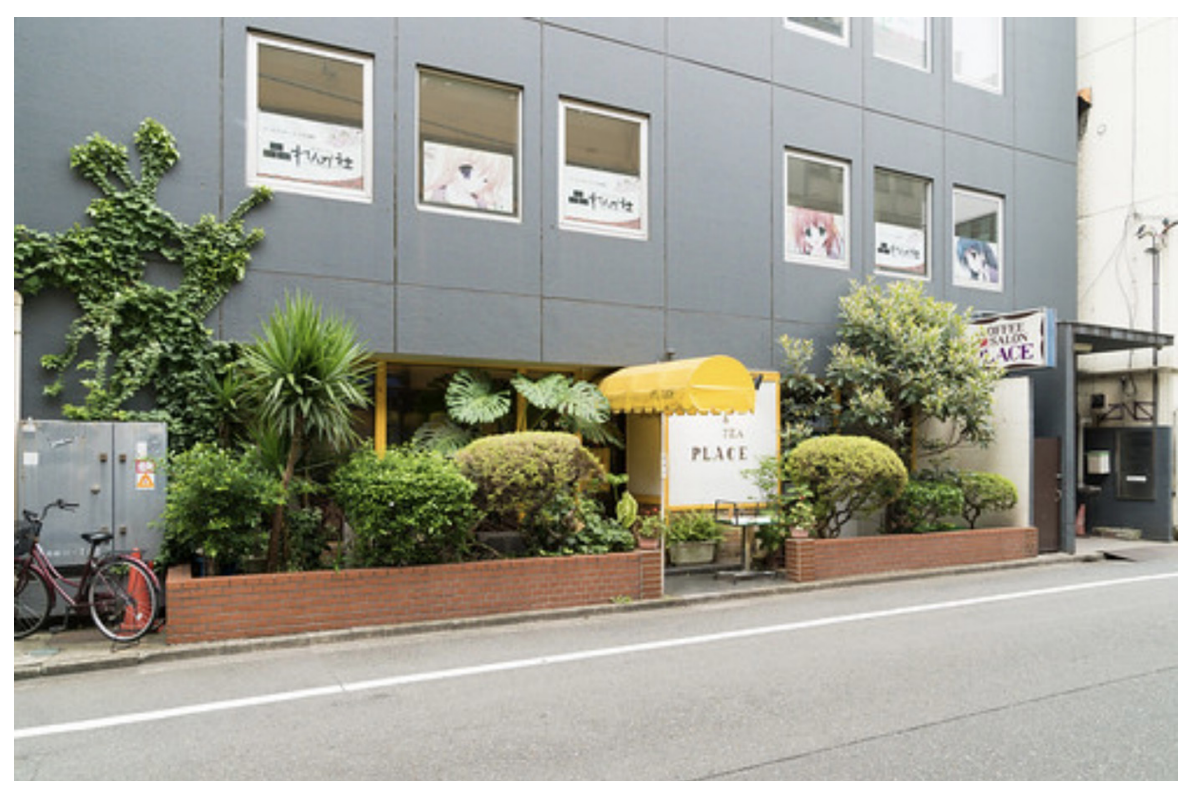

Image 8. Café in Akihabara where Ataru and I spoke of "harmful people." Above one sees a bishōjo game production company. The café was mere minutes from a gradeschool. Photo by the author. License: CC BY 4.०.

"we," Ataru moves to speak for bishōjo game players generally and the men gathering in Akihabara specifically, who he recognizes as his people - "men like me who grew up in this environment." These men are not, to use Ataru's memorable phrase, "harmful people" (yūgai na hito). That is, they are not people moved by media to harmful actions; they are moved, but not to harm others. Ataru's position hinges on how he understands movement to be shared. Brought together by a shared attraction to and affection for bishōjo characters, the men gathering in Akihabara have friends and a shared environment. If taste determines friends and environment, it also determines actions. Through shared movement, or collective activity and practice, these men keep fiction and reality separate, even as they coexist and impact each other. A shared orientation toward bishōjo determines one's friends and environment, and also one's actions: To be moved by bishōjo characters, but to keep bishōjo and women and girls separate and distinct and not allow movement in response to images to lead to actions that harm others.

As the melodic five-o-clock chime rings out on public broadcast speakers, announcing to young people that it is time to go home, I cannot help but recall that there is a gradeschool on Shōheibashi Street within the bounds of Akihabara and not far from the café where Ataru 
and I are now sitting. Sixth-graders, no different from how Ataru and I once were, are walking through the streets of Akihabara to the station to catch a train home. While Ataru locates his spiritual coming of age in Akihabara - from Aomori Prefecture, he still is one of the men "who grew up in this environment" - what must it be like to literally come of age in the Moe City? These young people are not choosing the environment as Ataru and I have chosen it. What impact will it have on them and their tastes? Might someone seeing these children walking through the streets of Akihabara - "a city overflowing with sex" - worry about them? Worry about them in relation to bishōjo game players such as Ataru? Am I, too, worried about these children? These men? Ataru? Is he - like Kurosu Taichi, the protagonist of his favorite bishōjo game - someone who looks normal but is somehow mentally ill, a danger to society and in need of institutionalization? I look at my friend and the street, wondering.

\subsection{Dangerously Moving Images}

"Japan has an incredible tolerance for the sexual exploitation of young girls" (Ostrovsky 2015). These are the first words in a Vice News video on the problem of underage sex in Japan. They are spoken by Jake Adelstein, a renowned crime reporter in Japan, as a voice over during a montage of images of Akihabara: Chūō Street brightly lit up at night; photographs of female idol singers; a sign with a price and a young woman suspended in the moment just before kissing a prone man's waiting lips; the legs of a woman on the street; fliers for cafés and entertainment, which feature women striking cute poses; a wall of massive images of bishōjo characters in various states of undress, next to an advertisement for a bishöjo game. After the title - "Schoolgirls for Sale in Japan" - appears onscreen, award-winning journalist Simon Ostrovsky sets the scene: "This is the Akihabara neighborhood..." $\mathrm{He}$ walks through the streets, disoriented, but taking it all in. Ostrovsky knows that sex is for sale here, and his intuition is that the bishōjo characters he sees everywhere are related to the women on the signs and in the street. He knows that there is a connection between sexual fantasy and reality. When faced with these bishojo characters and women, Ostrovsky is not confused about fiction and reality. Although he speaks to none of the men on the streets or in the stores, he imagines that somewhere out there, in the night, are men, Japanese men, who are conflating sexual fantasy and reality, who are actualizing their fantasies 
of underage sex, who are moved to unspeakable acts. Perhaps Japan tolerates this, but we certainly will not.

Akihabara is a city of affective images, of moving images, images that trigger bodily responses from those interacting with them and move bodies to public displays of affection. The Moe City is the worst nightmare of right-minded people such as Adelstein and Ostrovsky, who find there hordes of men aroused by omnipresent images of sexualized cute girls, loose on the streets and in close proximity to atrisk populations such as women and children (Adelstein and Kubo 20I4; Ostrovsky 20I5). Such critics of Akihabara operate with certain assumptions about media a/effects. They assume that, to begin, while the journalist and activist remains unmoved by images of cute girl characters, or in control in relation to these images, the bishōjo fan is dangerously open to the affect of moving images. This dynamic speaks to what media anthropologist William Mazzarella calls "the enunciator's exception" (Mazzarella 20I3: I8-I9).9 ${ }^{91}$ Working with film censors in India, Mazzarella noted a pattern whereby advocates of increased regulation, who did not need to be regulated themselves, imagined another population that was dangerous and needed to be regulated. That dangerous class was composed of men in the front row of the theater reacting bodily to moving images on screen. Such men were conceptually understood in the figure of "the pissing man" (Mazzarella 20I3: I4-I 5), or the man who would piss in the street if told to do so, which captures his lack of public decency, inability to control himself and likelihood to act on any suggestion. What makes the pissing man dangerous is that he is moved by images and out of control, and hence the content of images must be regulated to be less likely to move him. One of Mazzarella's greatest insights is that the relationship between the pissing man and moving image is a source of anxiety and key to calls for increased regulation.

Another aspect of this fear is that a certain population cannot tell the difference between fiction or fantasy and reality. This is clearest in the activist response to pornography in North America. During the feminist debates that came to a head in the I980s, pornography was treated as the theory of sexual violence and rape as its practice (Williams I989: I 5-29). Responding to this discourse, cultural critic Laura Kipnis points out that the conceptual figure of the masturbating man is imagined to be simple, aroused and violent (Kipnis I996: I 75-I77). In retrospect, it is evident that much of the campaign against pornography was premised on the belief that the masturbating man 
confuses fiction and reality and is inspired to act out the sex(ual violence) he sees onscreen, which he takes to be normal and acceptable. Much like the men in the front row of theaters in India, masturbating men were understood to be a dangerous class of rapists, "the raincoat brigade," or, to borrow a phrase from Japan, a "reserve army of criminals" (hanzaisha yobigun) (see Chapter I). The imagined danger should come as no surprise, because pornography has since film scholar Linda Williams' foundational book Hard Core been understood in terms of "moving images," which "appeal to the body," "elicit gut reactions" and "move the body" (Williams I989: 5).92 The regulatory impulse begins with the recognition that the image in question moves the viewer, which is then quickly projected onto others, who are, or might be, moved. In scholarship that builds on Kipnis and Williams in terms of affect, pornography is theorized as images that are "dangerously effective at moving us" (Paasonen 2OII: I3). ${ }^{93}$ Or, rather, images that are dangerously effective at moving someone, an imagined other, the pissing or masturbating man. The imagined other is grouped together as an imagined class of dangerous others. "This demonizing of particular groups of media users," porn scholar Feona Attwood explains, "is part of the operational bridge that enables accusations or identification of possible 'harms' to translate into calls for more and more legislation against the imagination" (Attwood and Smith 2010: I 87). To rephrase, the imagining of dangerous others, whose relation to moving images is imagined to put others in danger, is central to a discourse of possible harm and calls for legislation against the imagination.

Insofar as bishōjo games feature characters designed to affect, what are known as "moe characters" (moe kyara), and explicit depictions of sex with these characters, it is not shocking that they inspire a regulatory discourse similar to film in India and pornography in North America. For their critics, bishōjo games are dangerously effective at moving players. Bishōjo game players are imagined to be men who dominate imaginary girls and women to feel like real men and may well be confused about the difference between fiction and reality (Taylor 2007: 203-206). These men are imagined to play games of sexual violence, have decreased resistance to myths about sexual violence and are thus more likely to be inspired to acts of sexual violence (Nakasatomi 20I3: 6-I 2). Bishōjo game players are moved to bodily response and to the street in Akihabara, where they appear to critics as a mass of potentially violent men and a dangerous movement. Bishōjo game scenario writer Kagami Hiroyuki argues that such concerns indicate a general 


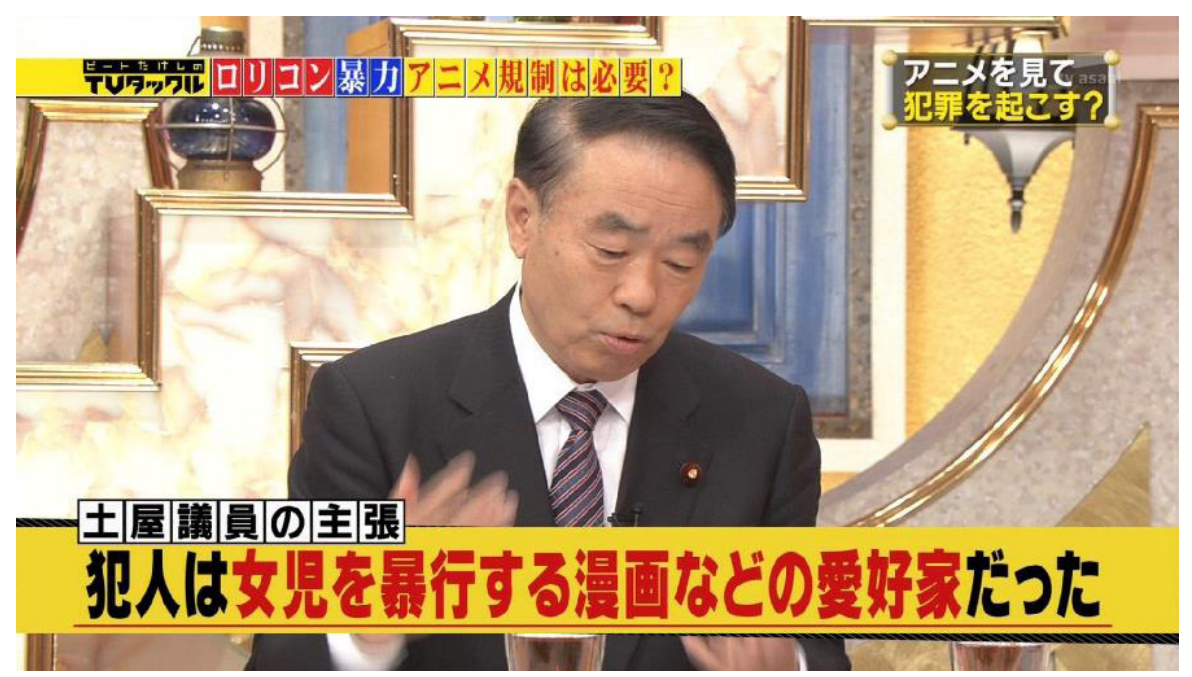

Image 9. Appearing on the television show TV Takkuru on September I, 20I4, Tsuchiya Masatada warns of a connection between cartoons and sexual violence against children. Photo by the author. License: CC BY 4.०.

understanding that "ideas can prompt mass action and invite social chaos" (Kagami 20I0: 25I). In this way, the regulatory gaze in Japan is not on "the pissing man" or "the masturbating man," but rather on "the moe man" (moeru otoko), who is dangerously open to the affect of moving images of manga/anime characters. ${ }^{94}$

Among the many advocates of increased regulation of adult manga, anime and computer/console games in Japan, one of the most vocal is Tsuchiya Masatada, a senior politician with the ruling Liberal Democratic Party, who believes that such media is contributing to social and sexual disorder. When we met at his offices in Mitaka in the western suburbs of Tokyo, Tsuchiya was palpably concerned about media effects, opining that if American children see 20,000 violent deaths in the media before they even reach the age of maturity, then that is obviously a problem in the American culture of violence. "It's a problem of imprinting (surikomi)," Tsuchiya tells me, gravely. "In Japan, we have a problem of manga, anime and games imprinting unhealthy and violent sexual desire for children." 95 For Tsuchiya, such media is "extremely socially harmful" (kiwamete shakai-teki ni yügai). He starts with the observation that humans have all kinds of "potential" (kanōsei), and media plays a part in cultivating and realizing potential. It is Tsuchiya's position that certain media promote and foster dangerous sexual desire; that is, certain media cultivates the potential to become a violent sex offender. Resonating with classic approaches to media effects such 
as priming and desensitization, Tsuchiya argues that, "Human barriers are lowered by seeing over and over again manga, anime and games depicting the rape and group assault of girl-children, which leads to crime. It leads to the crime of attacking girl-children.” Tsuchiya grants that not everyone who consumes adult manga, anime and computer/ console games goes on to commit crimes, but because there is potential for it - the recurrent refrain, "There is the potential for a crime to be committed" - such media must be more strictly regulated. Anticipating the need for evidence, Tsuchiya passes me a photocopy of a news report about a young girl attacked and murdered by a pedophile and predator in Kumamoto Prefecture in 20II. This is part of a packet of material he prepared for an address to the Diet, and he directs my attention to a section highlighted with a pink marker. "Seeing such media repeatedly lowered his psychological barriers to the crime," Tsuchiya asserts. "Such media is training a reserve army of criminals." The use of that specific turn of phrase immediately conjures the memory of Miyazaki Tsutomu and his crimes (see Chapter I). Based on all this, Tsuchiya ultimately advocates for control over the potential of humans to become anything, because one can become something dangerous and put others at risk.

For Tsuchiya, certain media propagates desire that he characterizes as "inhuman" (biningenteki), or desire so vile that it rejects what makes us human, and it is clear that what he means is desire for children. Propagates is the correct word here, because Tsuchiya, explaining the need for increased regulation, refers me to the power of mass media in the example of Nazi propaganda in World War II. This is certainly a startling association, but, as Mazzarella demonstrates, we would do well to take seriously the concerns of regulators (Mazzarella 20I3:2). Tsuchiya is anxious about media, especially what he portrays as "extremely hot media" (bijo ni hotto na media), because of his recognition of its effectiveness at moving people. He worries that media can brainwash even good, normal men and turn them to violence. Not him, but some people, and enough of them to make this an issue of grim social and political concern. Indeed, much of Tsuchiya's unease seems to stem from a fear that had men of his generation grown up in contemporary Japan, they, too, might have been imprinted with inhuman desire:

If our generation had child pornography manga, anime and games, what would have happened? Repeatedly viewing such images, exposed to strongly sexually stimulating images over and over again, I think that we might have come to see the children in town as sex objects. 
Note five things about this very raw, and very real, expression of concern: first, Tsuchiya recognizes that cartoon images can be strongly sexually stimulating; second, he posits that regular exposure to such images over time naturalizes perverse and dangerous sexual desire; third, anyone, even the good, normal men of Tsuchiya's right-minded generation of Japanese, can potentially harbor such desire, which is cultivated by a sick media environment; fourth, perverse and dangerous sexual desire spreads like an infectious disease to make the healthy unhealthy; and fifth and finally, sexually stimulating cartoon images, which propagate perverse and dangerous sexual desire, lead to seeing "children in town as sex objects." This last part is crucial, because it suggests that the boundary between fantasy and reality will break down and perverse and dangerous sexual desire will become violent sexual crime and overrun the town, city and nation.

If there is a place that seems to be the best possible representation of Tsuchiya's concern, then it is Akihabara. Home to a dense cluster of stores selling adult manga, anime and computer/console games, fanzines and related merchandise, Akihabara is without a doubt a place where strongly sexually stimulating cartoon images are part of the urban environment. These images are of bishojo, which are cute girl characters that often appear to be, and are sometimes explicitly designated to be, underage and/or children. They are regularly involved in perverse and/ or violent sex, which is a taken-for-granted aspect of the media landscape. The fear, then, is that men - even good, normal men - exposed to these images regularly over time will develop perverse and dangerous sexual desire and see "children in town as sex objects."

It is plain to see that bishōjo game players are moved by images, which is the whole point of playing, and they recognize this fact. Such is the case with Ataru. His preference for dark and disturbing content might seem to reflect perverse and dangerous sexual desire and mark him as one of the "reserve army of criminals." However, in sharp contrast to Tsuchiya, Ataru holds that no media is harmful in and of itself, but rather actions can be harmful. Those moved to such actions are what he calls "harmful people." This is another population of imaginary others, but rather than demanding regulation of them, Ataru recognizes the potential for harm in himself. People can become harmful, but Ataru is sure that he and men like him are not. Why? Because, in his everyday life, Ataru makes a deliberate and explicit distinction between fiction and reality. In some games, he plays through truly heinous scenarios - The Song of Saya comes to mind, and not just because of the 
sex with what appears to be a girl-child - but this is fiction and he approaches it as such. In our debriefings about shared game play in cafés around Akihabara, he assures me that these actions are not something that he would ever do, or has any desire to do, in reality. In so speaking his desire and assuring me, Ataru draws a line between fiction and reality, as well as between "harmful people" and "men like me." He does so with me, in part speaking to himself in front of another, regularly and publicly. In this way, he regulates himself to avoid becoming harmful to others. Men who grew up in an environment of manga/anime sex, violence and crime, Ataru asserts, do not see "children in town as sex objects," because the fictional characters they interact with and desire are separate and distinct from humans, regardless of age. For Ataru, there is no necessary connection between a manga/anime-style cute girl character such as Saya and children on the street. Bishōjo game players indulge perverse sexual desire that some might find to be "inhuman," but they observe and respect, through collective activity and practice, a distinction between fiction and reality. They interact with the inhuman as inhuman, indulging inhuman desire, but not in a way that disqualifies them as human. As Ataru sees it, his moe sensibility and sexuality have been shaped by interacting with moving images of characters and others moved by them in spaces such as Akihabara.

\subsection{Imaginary Sex in Public}

Akihabara is a public space. Public not in the sense of state owned and provided, but rather a common space produced by a public. According to literary critics and social theorists Lauren Berlant and Michael Warner, a public differs from a community or group "because it necessarily includes more people than can be identified, more spaces than can be mapped beyond a few reference points, modes of feeling that can be learned rather than experienced as a birthright" (Berlant and Warner I998: 558). While Akihabara is a concrete place where people gather, it is also more. The circulation of images of bishojo characters appeals to a public, whose members are such by virtue of attention (Warner 2002: 50). ${ }^{96}$ This is not, Berlant and Warner insist, just a neighborhood affair, because a public is "imaginary" and "virtual" (Berlant and Warner I998: 558, 563; Warner 2002: 55). ${ }^{97}$ The public "requires our constant imagining" (Warner 2002: 57). The public in Akihabara is a "counterpublic," or "an indefinitely accessible world conscious of its subordinate relation" (Berlant and Warner I998: 558; also Warner 
2002: 80, 86). In this counterpublic, members cultivate "criminal intimacies" and develop "relations and narratives that are only recognized as intimate in queer culture" (Berlant and Warner I998: 558)..$^{8}$ Those relations and narratives appear in adult manga, anime and computer/ console games. They are also relations between men and bishōjo characters that one sees on the street in Akihabara (Morikawa 2003: 3, 7I-78, 249-255).

In this counterpublic, one learns modes of feeling, not least of which is moe, or an affective response to fictional characters. This affection is for bishōjo, and on the streets of Akihabara it brings together bodies fictional and real, virtual and actual, mediated and material. As Berlant and Warner put it:

Affective life slops over onto work and political life; people have key self-constitutive relations with strangers and acquaintances; and they have eroticism, if not sex, outside of the couple form. These border intimacies give people tremendous pleasure. But when that pleasure is called sexuality, the spillage of eroticism into everyday social life seems transgressive in a way that provokes normal aversion, a hygienic recoil even as contemporary consumer and media cultures increasingly trope toiletward, splattering the matter of intimate life at the highest levels of national culture. (Berlant and Warner I998: 560)

So it is that Ataru becomes a bishōjo gamer by sharing a love of To Heart with older men at a store in Akihabara. Coming of age in Akihabara to become "me" among "men like me," we see a self-constitutive relation with strangers. So it is that Lonely Fukusuke and others come together during the Day of Erotic Games in Akihabara, where affective life slops over to stranger sociality. So it is that eroticism outside of "sex" and the "couple form," sex with images and sex as being moved by images and others in relation with them, is pleasurable. And so it is that bishōjo and moe, even as they are increasingly normalized and nationalized along with manga, anime and computer/console games as "Japanese popular culture" (see Galbraith 20I9), are nonetheless problematic when "border intimacies" intersect with sex and become "criminal intimacies."

In Akihabara, one encounters sex in public. Critics describe Akihabara as "overflowing with things that offer convenient gratification of sexual desire" (Okada et al 2005: I70-I72), even as bishōjo gamers who inhabit the space describe it as "a city overflowing with sex." The sex in question is imaginary, sex with images, and it is public. Warner defines "public sex" as sex that "takes place outside the home” (Warner 2000: I73). In Warner's example, the porn theaters and 
sex shops of Times Square in New York City were at the center of a public sex culture from the I960s to the mid-r990s. "A critical mass develops," Warner elaborates. The street "develops a dense, publically accessible sexual culture" (Warner 2000: I87). Surely something similar happened in Akihabara, where the area surrounding Chūō Street between Kanda River and Kuramaebashi Street developed into a dense, publically accessible sexual culture centered on bishōjo games. While it is true that no one is masturbating or hooking up at Getchuya or similar stores in Akihabara, which is different from the culture portrayed by Warner, it is also true that what might be a private act - playing an adult computer game at home in one's room alone, perhaps masturbating - becomes a public spectacle of shared sexual attraction and excitement, shared movement, shared bodily response to bishōjo characters (for more, see Chapters 4 and 5). In Akihabara, one finds "queer zones and other worlds estranged from heterosexual culture" (Berlant and Warner I998: 547). Even as the sex represented appears heterosexual, it is somehow strange and abnormal. The regularity with which bishōjo game players identify themselves as "abnormal" (abunōmaru), "weird" (hen) and "perverse" (hentai) speaks to an imaginative association with the queer. ${ }^{99}$

For Warner, public sex culture is an important source of knowledge about sexual variation and possibilities. He argues that "sex draws people together and [...] in doing so it suggests alternative possibilities of life" (Warner 2000: 47-48). These alternative possibilities include "forms of affective, erotic, and personal living that are public in the sense of accessible, available to memory, and sustained through collective activity" (Berlant and Warner I998: 562). In Akihabara, we can observe such forms of living, which are sustained through collective activity and practice and so are accessible and available to memory. Anthropologist Ian Condry argues that moe as shared movement is contributing to the emergence of "alternative social worlds" (Condry 2013: 203). Condry sees in moe the suggestion of alternative evaluations of masculinity among those who have failed to achieve or have rejected hegemonic modes of life that demand productivity and reproductive maturity. This resonates with what queer theorist Jack Halberstam dubs "the queer art of failure," which "imagines other goals for life, for love, for art, and for being" (Halberstam 20I I: 88). Halberstam draws many of his examples from the queer lives of cartoon characters and relationships between them, but what moe suggests is that one can also imagine queer ways of life with cartoon characters. This would 
certainly count among what anthropologist Shaka McGlotten, in his partial snapshot of the "virtually intimate present," depicts as "forms of sex" that are perceived to be "less real than others," but the persistent discourse of failure connected to the virtual obscures "the labors, perverse and otherwise, that animatedly rework categories of intimacy" (McGlotten 2013: I 2). ${ }^{\text {100 }}$ The public sex culture in Akihabara, the Moe City, is a source of knowledge about such possibilities. These possibilities, like the public itself, require constant imagining. They are sustained through collective activity.

What does it look like to animatedly rework the categories of intimacy? To engage in perverse labor to twist intimacy into something out of place or strange? To be and become otherwise in relations with fictional and real others in a culture of imaginary sex in public? It might look something like the story of Honda Tōru, or something like his legacy of spectacular failure opening into new possibilities for living and moving on. Constantly talking to and apologizing for himself, Honda does not cut an impressive figure. One would be forgiven for not recognizing him as "the Moe Man," who has become a guru for many. When I meet him in Akihabara, Honda confides that social pressure and anxiety as a young man made him "crazy." inadequate, especially in relation to the opposite sex, and experienced crippling depression and suicidal thoughts. Honda believes that his love of manga and anime and manga/anime characters saved his life when things were going wrong for him personally and professionally. Born in Hyōgo Prefecture in 1969, Honda was 29 years old, single and without direction in life when he played the bishōjo game One: Toward the Shining Season (One: Kagayaku kisetsu e, Tactics, I998), where he met a cute girl character that he loved enough to call his "wife" (yome). That others were also talking about manga/anime characters in this way in the late I990s, a time that Honda recalls as "the moe boom" (moe bümu), encouraged him to share his ideas about alternative intimacies and social relations. He started informing people about his wife and their life together, and advocating a "love revolution" (ren'ai kakumei). "I am not saying that everyone should give up on others or on reality, just pointing out that having a relationship with characters is an option and accepting it might be a way to feel better and relieve some pressure," Honda elucidates as we walk down Chūō Street. "You can live freely, not in the patterns that society and media determine for you." Indeed, the environment in which we find ourselves speaks to the possibility of being in relations with fictional and real others that 
are not "normal," and do not have to be measured against norms and found lacking. No, there is an abundance here, a perverse movement that is shared, felt and real.

While Warner and others push against the desire for marriage, and it reflects the persistence of hegemonic ideals that bishōjo gamers generally and Honda specifically choose the pattern of marriage to express their relations with characters, it is worthwhile to register that such marriage is perceived to be "less real" or somehow "deficient" (recall McGlotten 2013), even as it does animatedly rework intimacy. This is marriage to a nonhuman other, which precludes reproductive sex, offspring and transference of wealth. Instead we find imaginary sex, sex with images, "unconsummated erotics" (Freeman 2002: xv). Honda's alternative has him living with an ever-expanding "family" (kazoku) of bishōjo characters, who are stock types in the bishōjo games in which they appear: his wife is Kawana Misaki, a I7-year-old schoolgirl; his younger sisters are Honda Yū, Suzumiya Akane and Tōdō Kana; he also has a maid, whose name is Nagisa. All of these characters are Honda's intimate others, who are both imaginary and real. Following Warner, we might see this as an example of public sex culture supporting "nonnormative intimacies" (Warner 2000: I63), if not also "border intimacies" and "criminal intimacies" (Berlant and Warner I998: 558, 560 ). This is "intimacy out of place," which is all the more troubling "when it looks like sexuality" (Warner 2002: 79). Just as Honda used to proselytize about his wife, bishōjo game players engage in public displays of affection from wearing shirts featuring their characters to buying figurines and fanzines to decorating cars and rooms with images to sleeping with body pillows of characters. Some even take these body pillows outside with them, which makes private sex public. One cannot help but notice the character in material form and recognize the player's relationship with it. How we evaluate that relationship, and to what extent we value it, depends on our attunement to alternative social worlds and possibilities of life. As Berlant and Warner argue, certain forms of intimacy are only recognized as such in queer culture (Berlant and Warner I998: 558). This also does much to explain why people gravitate to the public sex culture of Akihabara and participate in events such as the Day of Erotic Games. There is "pleasure [in] belonging to a sexual world, in which one's sexuality finds an answering resonance not just in one another, but in a world of others" (Warner 2000: I79). Like the public, this world must be constantly imagined through collective activity and practice. 
As part of a principled defense of sex in public, Warner underscores an "ethics of queer life" (Warner 2000: 33). For Warner, such an ethics begins with an "acknowledgement of all that is most abject and least reputable in oneself," with the indignity and shame of sex, which allows for a "special kind of sociability" (Warner 2000: 35). Revealingly, shared affection for manga/anime characters in public is described by fans as "painful," but, as seen in Akihabara, bishōjo game players embrace that pain, share it with others and find such sharing to be pleasurable. There seems to be an acknowledgement of the indignity and shame of imaginary sex, which is understood to be abnormal. That one's sexual desire for imaginary others can be so wrong - Honda's schoolgirl wife, his potentially incestuous and ephebophiliac relations with his sisters, the abuse of power over his maid, this and so much more in the bishōjo games that these characters come from - reaffirms all that is most abject and least reputable in oneself. It is the ethical position of many so-called "otaku" in Japan that rather than deny, hide or project one's sexual desire onto others it is better to face, work through and share that desire (Sasakibara 2003: IOI, II3; Nagayama 20I4: I48-I 52, 226-228; see also Chapter 3). This allows for a special kind of sociability in Akihabara and beyond (see Chapters 4 and 5). Bishōjo game players embrace (imaginary) sex in all its indignity and shame, challenge the (imaginary) hierarchies of respectability and refuse to repudiate (imaginary) sex or the undignified people (imagined to be) having it. ${ }^{102}$ This is an ethics of queer life, and it is also an ethics of imaginary sex, and more broadly an ethics of moe.

In contrast to those who embrace sex in all its indignity and shame, many are concerned about the sex of others in Akihabara and seek to control it. Warner relays how the public sex culture of Times Square in New York City was zoned out of existence to make room for commercial interests (Warner 2000: I 53, I6I), but Akihabara remained relatively unsanitized as the struggle for imagination continued from the $2000 \mathrm{~s}$ into the 20 Ios. A politician involved with Cool Japan policy and organizing a symposium in Akihabara for the Ministry of Economy, Trade and Industry (see Galbraith 20I9: I68) told me that he personally had led tours of the neighborhood for foreign guests and been embarrassed by encounters with bishōjo games. ${ }^{103} \mathrm{~A}$ particular kind of pornography, namely adult computer games featuring sexualized images of cute girl characters, struck his guests as weird, which put this politician in the awkward position of having to explain why it was for sale openly in Akihabara. Whether or not it will be in the future is up in the air. In 
one of his last acts as Governor of Tokyo, Ishihara Shin'tarō pushed through legislation that allows for increased zoning of adult comics, cartoons and computer/console games because, "After all, it's abnormal, right?" (For details and a full discussion, see Chapter I.) Here we see the invocation of an "imagined norm," against which one measures deviance (Berlant and Warner i 998: 557). The culture of abnormal sex is also imagined to be too open and accessible. The solution is to push sex, especially the abnormal kind, off the street (Warner 2000: I69). Business owners and administrators in Akihabara have proposed doing this precisely (Galbraith 2019: I66-I73). Even as politicians warn that violence and underage sex have increasingly made bishōjo games a topic of discussion in the Japanese Diet, political activists suggest that Akihabara will be cleaned up in anticipation of tourism surrounding the Olympics in Tokyo. ${ }^{104}$

The issue of zoning is complex in Akihabara, which is an unofficially but strictly bordered zone of imaginary sex in public. Crossing over into adjacent neighborhoods, one immediately notices the complete absence of advertisements for adult manga, anime and computer/ console games. In this way, Akihabara already seems to adhere to the recommendations of feminist legal philosopher Drucilla Cornell, who advocates keeping pornography "out of the view of those who seek to inhabit or construct an imaginary domain independent of the one it offers," but also allows for others to inhabit or construct their own "imaginary domains" (Cornell I995: I04). ${ }^{\text {Ios }}$ There is friction, however, when it comes to questions of who occupies the space of Akihabara, or what sort of space it is and ought to be. The second half of the 2000 s into the 20Ios saw Akihabara caught between contested imaginaries of, on the one hand, "the Holy Land of Otaku" and "Moe City," and, on the other, "the Once and Future Electric Town of Japan" and symbolic site of "Cool Japan" (Galbraith 2019: I 56-I73). If some wanted to keep Akihabara weird and open to the weird movement of those affected by fictional characters, then others wanted to get rid of those "weird otaku" and reclaim the streets of Akihabara "for everyone" (i.e., normal people). Part of the crackdown and cleanup was increased criticism of overt advertisements for adult manga, anime and games.

In a high-profile case, a branch of Trader on Chūo Street decided to place a massive two-story advertisement for the bishōjo game More! Knock 'Em Up! Blazing Boobs Super Erotic App School (Motto! Haramase! Honoo no oppai chō ero apuri gakuen, 2019). ${ }^{106}$ The advertisement displayed Io manga/anime-style cute girl characters with 
massive breasts bursting out of tiny micro bikini tops. This almost immediately resulted in complaints to ward, city and prefectural authorities, and inspectors were sent to evaluate whether the advertisement ran afoul of the Chiyoda Ward Ordinance Regarding the Maintenance of a Safe and Comfortable Living Environment and the Tokyo Metropolitan Ordinance Regarding the Healthy Development of Youths. Criticism was made of the size of the advertisement and its conspicuous location on the main street of Akihabara, which was described as a "public place" (kōkyō no ba) and "public roadway" (ippan dōro). There was consistent focus on the exposed breasts, or more generally "the exposure of female characters" (josei kyara no roshutsu), which reduced them to sexualized body parts marketed to a presumed heterosexual male audience. This arguably contributes to an environment that is uncomfortable for women and might disaffect them. The claim, then, was that this advertisement would not simply be seen by "otaku," but rather, to borrow Cornell's language, would impinge on the imaginary domain of women made into forced viewers of images that are sexually objectifying. Furthermore, the advertisement might negatively impact the healthy development of young people and their sexuality, and concerned citizens were sure to stress that a gradeschool and kindergarten are "located within 300 meters of Trader." (That is, the facilities on Shōheibashi Street.) In short, the backlash came from a conviction that Akihabara was not just a place for "otaku," and imaginary sex in public was no longer appropriate for a space occupied by women, children and others (potentially) negatively impacted by it (for more, see Hiruma 2019; Bengo News 2019; Sugano 20I9; for a comparative example in the gay quarter of Shinjuku, see Baudinette 20I8).

Debates over public space in Akihabara reflect a struggle over imaginary domains, which goes beyond simply whether or not the area should be for shared affective responses to fictional characters to whether or not such affect alienates others. If for Tsuchiya and others the openness of circulation and affect contributes to imagining a dangerous public, then the zoning debates imagine an endangered public. Specifically, members of the public such as women and children are endangered by sexual images that harm, attack, assault, violate and so on. The image itself, regardless of any sex act, is now the assailant, attached to both a dangerous and endangered public. For its part, Trader quickly succumbed to pressure and removed the advertisement a week after it was plastered onto the side of the building facing Chūo Street; astute observers, however, noticed that Sofmap and other stores right 
across the street and along both sides of it continued to have smaller advertisements for More! Knock 'Em Up! Blazing Boobs Super Erotic App School (e.g., Bengo News 2019), which after all was just one of many, many bishōjo games on sale and open display throughout the area. Industry insiders are aware that this may not last. In response to ongoing border wars and tensions over the occupation and use of space in Akihabara, bishōjo game producers are increasingly concerned with controlling circulation, which calls into question the commitment of publics to the "possible participation of any stranger" (Warner 2002: $8 \mathrm{I})$. Rather, members of the public are unwilling to put "at risk the concrete world that is its given condition of possibility" (Warner 2002: $8 \mathrm{I}$; recall Charara!!). The counterpublic, acting recursively, closes down the circulation of its texts and, in so doing, closes down one form of stranger sociality for the continued possibility of being strange with others within limits. ${ }^{107}$ The risk of estrangement is registered in the counterpublic's "ethical-political imagination" (Warner 2002: 88), even as the limits of estrangement are negotiated to mitigate the risk that bishojo games may cause misunderstandings with the dominant public. ${ }^{\text {108 }}$

The loss of public sex culture is an issue for Warner because it reduces the visibility of sexual variation and possibility for encounter, participation and learning. Public sex culture is how minorities find one another, construct a sense of a shared world and "cultivate a collective ethos of safer sex" (Warner 2000: I 69). ${ }^{\text {I09 }}$ Consider the experience of Ataru, who discovered in Akihabara that he was sexually attracted to manga/anime characters and not alone. His moe sensibility and sexuality are shaped by relations with fictional and real others. Stranger sociality leads to recognition of "men like me," who are oriented to the drawn lines of characters and who draw a line between fiction and reality. In so doing, "men like me" are "moe men," people who know where to draw the line and are thus not "harmful people." Sharing this orientation to and drawing of lines is part of cultivating an ethos of safer sex, and it happens with others in public. If these alternatives can keep people from suffocating norms, feelings of failure and turning to violence toward self and others, as was the case for Honda Tōru, then the ethics of this safer sex become even more apparent. Queer life, Warner explains, has "its own norms, its own way of keeping people in line" (Warner 2000: 35), and one such norm observed in Akihabara is deliberately and explicitly separating fiction and reality and orienting oneself toward manga/anime characters. It is the norm of drawing and insisting on lines, which is learned through collective activity and practice. 
Consider also Momoi Halko, born in Tokyo in 1977, who, like Ataru, played Tokimeki Memorial in her youth, but was hanging out in Akihabara in the I990s before he or I arrived. "I've come to think that spending my youth in Akihabara, surrounded by anime, games and idols, was a special kind of education," Momoi tells me. "The feeling of moe seemed natural in such an environment." пго In Akihabara, moe, an affective response to fictional characters, seemed natural. Attracted to and moved by bishōjo characters, Momoi eventually became an idol and voice actress, who sang for many bishojo games. In the process, she interacted more and more with bishōjo game players, who, like her, were attracted to bishōjo characters. These characters exist alongside girls and women, but are not the same as them. In the feeling of moe that became natural to Momoi in Akihabara, the objects of affection are manga/anime-style cute girl characters. Such was her education growing up in Akihabara, the Moe City. This way of perceiving and experiencing the world stands in stark contrast to those who see in Akihabara - surrounded by anime, games and idols - a dangerous environment where underage sex is for sale (e.g., Ostrovsky 201 5), which effectively conflates virtual and actual forms. While the separation of fiction and reality is anything but complete or perfect, there are ethics in the everyday action and practice of drawing and insisting on lines. This is both individual and collective as one finds and learns with others "like me."

\subsection{Journey to the (Akihabara of the) West}

On a cold day in December 20I4, I took a train from Tokyo to Osaka to meet Miyamoto Naoki, author of three books presenting genres of bishōjo games and of Introduction to the Cultural Study of Erotic Games (Erogē bunka kenkyū gairon, 20I3). When I addressed Miyamoto as professor in email correspondence, he modestly warned me not to expect too much from him or Osaka. Specifically, Miyamoto told me that the Nippombashi area, which is associated with "otaku," "is not Akihabara." This distinction was contrary to everything that I had heard about similarities between Akihabara and Nippombashi. Akihabara is Tokyo's Electric Town, and Nippombashi is Osaka's Electric Town. Just as the rise of manga, anime and computer/console games contributed to the transformation of Chūo Street in Akihabara into "the Holy Land of Otaku," a street in Nippombashi had transformed into "the Otaku Road.” Indeed, such are the similarities that Nippombashi is 
often referred to as "the Akihabara of the West." I had visited Osaka before to conduct interviews at bishōjo game production companies such as Key and Softpal, the latter of which has offices in Nippombashi. Itō Noizi, who works at Softpal, designed Nippombashi's mascot, which is a bishōjo character named Neon-chan. Not even Akihabara is officially represented by a bishōjo character designed by someone working in the bishojo game industry, which implies that Nippombashi has taken things even further. Why was Miyamoto making a distinction between this area and Akihabara?

Rendezvousing in front of a collector's shop in the Electric Town, Miyamoto eagerly shakes my hand, apologizes for keeping me waiting and says that he is caring for his aging parents, which can be demanding. As we begin to walk, Miyamoto explains that he has been coming to Nippombashi for 20 years. Born in rural Kagoshima Prefecture in I978, he moved to Osaka when he was in junior highschool and became interested in bishōjo games soon after. "My parents bought me a computer for school," Miyamoto says. "We bought it here in Nippombashi, because the prices are good and they typically have promotional events and sales. The computer came with a game of my choice. I went with what I thought was a zombie game, but it had some sex scenes in it. That's when I realized that adult games existed. So I started to search for information about adult computer games in magazines in bookstores. I thought, 'Oh, wow! It's an erotic anime image! I've gotta have this.' I bought these magazines without having played the games. I got more and more anxious thinking, 'Do I have to wait until I turn I 8 ?' "'

With these thoughts swirling around his head, Miyamoto came to Nippombashi for what he remembers as an encounter that seemed almost like fate. "It just so happened that in a used game shop I saw the exact game I wanted for the exact amount of money that I had in my pocket. So I bought it! I was I 6 or I7 years old, and the staff must have known that I was underage, but they sold it to me anyway. Then I started to come to the area to buy games more often." Nippombashi became a special place for Miyamoto, whose memories of coming of age are associated with content that he purchased at stores in the area. Not only were games more reasonably priced at used game stores, and these stores less likely to ask for age verification, but the young Miyamoto was able to sell the games he played back to the stores to help fund his next purchase. He describes this as a "cycle of return" (kurikaeshi) that kept him close to the area. Checking out bishojo games at stores in Nippombashi became a weekly routine and practice that he shared 
with others in the area. This was even more so the case because of a boom in bishōjo games in the early 2000 s. "About Io or I 2 years ago, advertisements for adult computer games were a common sight on the street," Miyamoto recalls. "That was a time of major hit games." It was also a time when people were drawn to the area to buy those games.

Things are not, however, as they used to be. About five years ago, advertisements began to disappear from the street as bishōjo games returned to the basement, back alley and backroom. Maybe it was zoning. Maybe it was pressure from other storeowners. Maybe the demand for bishōjo games just declined and stores responded to market pressure by appealing to "normal people." any one answer, but sees everywhere the signs of retreat. On the edge of the Otaku Road, we walk past a large cellphone shop. "That used to be a bishōjo game store," Miyamoto says. Looking inside, he shakes his head, wincing, at an advisement for the family plan. "No one here." Turning down the Otaku Road, Miyamoto points out that there are no shops specializing in or advertising bishōjo games. He remembers that some of the bigger retailers still sell bishōjo games, and so we venture into one called Lashinbang. Searching the multiple floors, we find adult comics, cartoons and fanzines for men and women, and a section of adult computer games for women, but no bishōjo games. We leave the building and cross the street to a store that once specialized in used bishōjo games. Judging from the storefront and visible advertising, it now sells used figurines and toys. Walking through the store to a staircase in the back, Miyamoto leads the way to the second floor, where we find adult computer games pushed into a corner against the back wall. "Yappari," Miyamoto says, grimacing. The word, which he repeats often to himself, means "as expected." "They are pushed to the back, further and further to the back."

We leave the building and set out for another location. It is a long walk, which Miyamoto offers is the way things are these days. There are perhaps only six stores in Nippombashi that carry bishōjo games now, and they are spread out across the area. We finally arrive at Medio, a name I recognize from Akihabara, but it appears to be selling figurines, toys and anime. "Stores can no longer have the stuff up front," Miyamoto elucidates. He leads the way to a staircase in the back with a curtain noting that no one under the age of $\mathrm{I} 8$ is allowed. Crossing that threshold and climbing up, we discover three floors of bishōjo games, the sort of density of product familiar from Akihabara, but, in this case, we are the only people here. "The way we purchase games has 


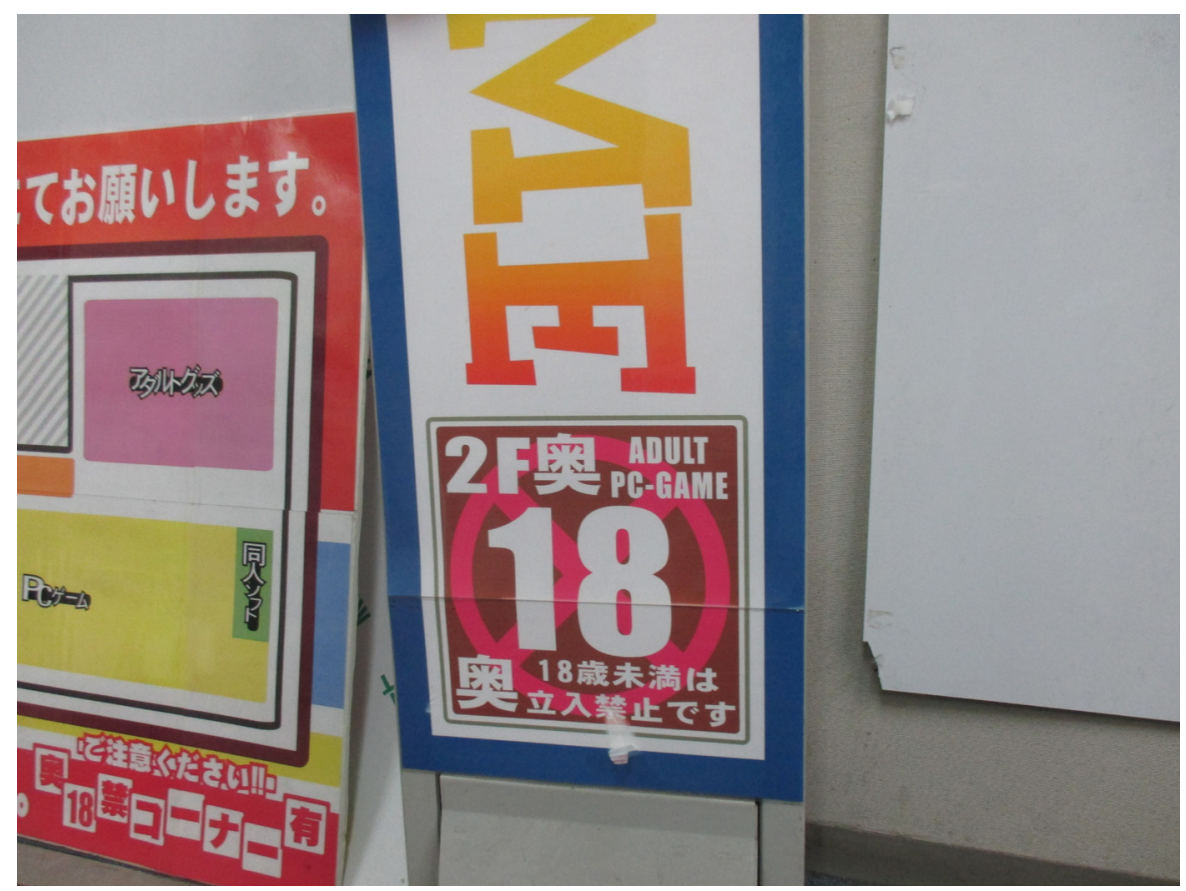

Image 10. Sign in a store in Osaka shows the segregation of bishōjo games, which had been pushed into a back corner and away from the street. Photo by the author. License: CC BY 4.0 .

changed," Miyamoto reasons. "Our lifestyles have changed." Pushed off the street and into a corner, associated more and more with objectionable content, players are staying home and buying their games online. Among them is Miyamoto, who admits that he currently only comes to Nippombashi once a month. "It is more convenient to buy online," Miyamoto concedes. "But I still miss the way things used to be." Purchases are more individualized, private and casual. People do not come together in Nippombashi and in public. That was when people would recognize themselves and others as bishōjo gamers. There were unexpected encounters with content and people sharing time and space. ${ }^{\mathrm{II} 3}$ Hearing this, I realize that I have not seen Miyamoto greet anyone all day. That strange aside: "No one here." There are no bishöjo game players; alone, he seems to be wandering and adrift. "A balance has probably been struck," Miyamoto says. "But, in all honesty, being a bishōjo game player has become a lonely state of affairs." This space was once alive with stranger sociality, a space of sociality for the strange, and he misses it. The city is dead - bustling with people and activity, but dead. Might as well call it a day and go home. 
As I wave goodbye and head for the station, Miyamoto's words ring in my ears. Bishōjo games have been pushed into a corner: The industry is in decline and feels cornered; the stores carrying bishōjo games have been pushed out of the center and into the corner; inside these stores, the content is pushed into corners behind cautionary signs and curtains. ${ }^{\text {II }}$ Once existing in the corner of computer stores, bishōjo games broke out into the center with specialty shops and open advertising and dedicated fans, but they were now pushed back into the corner of manga, anime and toy stores. With the normalizing of manga and anime fandom and opening up of Nippombashi to "normal people," there was less and less room for bishōjo games. The bishōjo game player, subsequently, remains in his room. The image of the bishōjo gamer buying content online from his home computer and having it delivered to his house to play on his home computer - what Miyamoto calls "computer completion" (pasokon de kanketsu) - is a striking example of the privatization of sex. Computer completion replaces the social completion of a circuit that has one encountering others outside the home. At home, the bishōjo game player does not "understand from experience" (hada de kanjiru), as Miyamoto put it, or, more directly translated, does not "feel it on the skin." On the train back to Tokyo, I recall again Miyamoto's warning that Nippombashi is not Akihabara, the Moe City. Having spent a day walking with him, following the line of his movement through the area, I think I know what he was trying to tell me. Compared to the painful displays of bishōjo gamers during the Day of Erotic Games, with Miyamoto, I sensed only the pain of loss.

\subsection{Conclusion}

The trip to Osaka revealed not only a story of personal pain and loss, but also a potential crisis for the collective activity and practice that informs media literacy and ethics. Religious studies scholar Joseph P. Laycock points to research in developmental psychology suggesting "that children with a high 'fantasy orientation' - that is, children who are more imaginative - are better at discerning fantasy from reality" (Laycock 20I 5: 289-290). The culture of manga, anime and computer/ console games, part of growing up and everyday life for children in Japan, is a culture of high fantasy orientation (Schodt I983: I 20-I37; Schodt I996: 43-58; Galbraith 2019: 94, 97, II9-I20). In this culture, manga/anime fans have developed an orientation of desire toward fiction not because they are confused, but rather because they make a 
distinction between fiction and reality and orient themselves toward the former (Saitō 20I I: 30). The literacy involved in making such a distinction comes, Laycock argues, from walking "between worlds" (Laycock 20I 5: 290; see also Saler 20I2). Better still if one can walk between worlds with others, who assist in the journey. Media and fan studies scholar Henry Jenkins adds that participatory culture leads to informal learning in peer networks and the development of not only literacy, but also ethics (Jenkins et al 2009: 28-30). While Jenkins remarks that ethics "become much murkier in game spaces," participation can still lead gamers to become "more reflective about [...] ethical choices" (Jenkins et al 2009: 24-26; see also Chapter 3). Ethics are perhaps even murkier in game spaces such as Akihabara, which bring virtual and actual bodies into proximity, but the solution is not to close down such spaces of encounter, participation and learning. ${ }^{115}$ If social play can lead to "an ethics of imaginary violence" (Bastow 2015), then it can also lead to an ethics of imaginary sex. ${ }^{\mathrm{II}}$ One example of this observed in Akihabara is orienting oneself toward fiction and keeping the cute girl characters appearing in adult manga, anime and computer/console games deliberately and explicitly separate from reality. This is an ethics of moe, an ethics of affective response to fictional characters. In spaces such as Akihabara, the Moe City, one learns, through collective activity and practice, the norm of drawing a line between fiction and reality, and an ethics of maintaining that line, which keeps people in line. The next chapter delves into the design of bishōjo games and articulations of an ethics of imaginary violence, which informs the ethics of moe. 



\section{Moving Images: Affection by Design}

\subsection{Introduction}

"Making adult computer games is a little different from making normal games," says Matsumura Kazutoshi, founder of bishōjo game production company Circus. "This is going to get a little theoretical, but bear with me. I have a theory, what I call the secretion theory (bunpitsubutsu riron). When humans secrete two types of liquid, it is incredibly pleasurable. The liquid can be anything - sweat and tears, for example. That's why an emotional and physically strenuous ballgame is so pleasurable. What about when you eat delicious ramen noodles? Saliva and sweat. Tears and saliva. Liquids are secreted from different parts of the body at the same time. When that happens, we are incredibly moved $(k a n d \bar{o})$. I think that is how humans are. If that is the case, then the best adult computer games will contain expressions that make the player release tears and semen (namida to seieki) at the same time. This is actually very easy to do with games. There are many players of adult computer games who say that they cry while playing. They can also get off (nukeru). The games make them cum (shasei). This is probably why the satisfaction of adult computer games is so much greater than what else is out there. The potential that I feel in adult computer games is this ability to move the player. The body is moved to response and secretes different kinds of fluids." ${ }^{117}$

The two other men in the room listen intently to Matsumura. They work in the adult computer gaming industry, where Matsumura is a legend. Although his ambition led to financial troubles and turned him into something of a cautionary tale, Matsumura is still a guru. Born in Yamaguchi Prefecture in 1975, his Da Capo series (2002-2012), which tells the story of highschool romance (between the male protagonist and one or more of seven female characters) and a magical

How to cite this book chapter:

Galbraith, P. W. 202I. Ethics of Affect: Lines and Life in a Tokyo Neighborhood. Pp. II7-I 55. Stockholm: Stockholm University Press. DOI: http://doi.org/IO.I6993 /bbn.d. License: CC BY 4.0 . 
cherry-blossom tree, remains one of the most popular franchises in bishōjo gaming history. The young men have joined me for this rare meeting with Matsumura, which takes place in an office in Akihabara that serves as a storage room for a bishōjo game production company. ${ }^{118}$ The room is filled with promotional goods for his games. It is hot and stuffy on a July afternoon, and the fan only serves to push hot air around the room. I glance over at Izumi Yukari, a 32-year-old married woman who works as an assistant to various companies in the bishōjo game industry. She is nodding as Matsumura speaks, smiling. She has worked with him in the past and heard him talk this way before. ${ }^{\text {II }}$ Indeed, she had warned me that Matsumura might get a little philosophical. After starting to play bishōjo games at the age of I4, he began to see sex as a gateway into human psychology. Somewhere along the way his studies led him to see them as connected to human physiology as well. Just as pornography has been compared to "body genres" such as musicals, "weepies," comedies and horror (Williams I989: 5), bishōjo games "appeal to the body." They move the body with "moving images." "There are many different approaches, for example making people laugh and cry," Matsumura agrees. "But the theory of adult computer games is to move the player as much as possible. My theory, the secretion theory, is one example."

This chapter explores issues of design in bishōjo games. Combining a discussion of production with accounts of players and critics, the goal is to analyze bishōjo games for what theorist Bonnie Ruberg calls their "affective rhetoric: the language of the feelings they invoke, how they communicate emotions to their players, how designing affect is interwoven in the art of game design" (Ruberg 20I5: I II). Image, sound and story come together in bishōjo games. Illustrators design characters that are not only objects of desire, but also existences that players want to interact with. At least three aspects of design are significant. First, the character is a flat, "two-dimensional" image that shares an aesthetic with manga and anime. The insistence on manga/anime-style images is characteristic of bishōjo games, and this serves to connect them to distinctly fictional worlds. Second, character designers have come to understand that certain elements are more attractive to players and more effective at moving them. These are called "moe elements" (Azuma 2009). A combination of these elements, characters in bishōjo games are called "moe characters." Players who have become adept at reading characters in terms of these elements are said to have developed "moe image literacy" (Kagami 20I0). Third, characters are designed to be cute, which is again characteristic of manga and anime. Cuteness 
encourages "prosocial behavior," which has been noted in scientific studies of cuteness globally (Sherman and Haidt 20II), and cuteness also triggers "ugly feelings" to act on objects (Ngai 20I2). In addition to the visuals, voice actresses produce characters that match the image and move the player. Like illustrators, they describe their jobs in terms of "imaging." The successful voice actress attunes herself to affective character images, which allows her to produce "moe voices." Finally, writers put the player into scenarios where they interact with characters and are moved. These are called "moe situations." Bishōjo games allow players to interact with moe characters with moe voices in moe situations, all of which are designed to move the player.

In this chapter, I argue that imagination is a fundamental part of bishōjo games and is crucial to understanding how they move players. The game design is simple: A series of still images with text loading below as the player clicks the mouse, accompanied by sound and spoken lines for select cute girl characters; choices appear and, based on them, the narrative branches into different events moving toward different endings. In a very crude way, production companies have settled on this design because it is comparatively easy and cheap to create such games, but also, as I was regularly told, it "works" for players. Bishōjo games work to move players, and work well; because that is the primary objective, there is no need to change the design. It would be easy to dismiss this as rationalization by an industry that has fallen desperately behind the times, but in fact there are dedicated players who actively seek out bishōjo games because they do in fact work for them. The most common explanation from players for their persistent choice is that there are no other games that focus on intimate interactions with manga/anime characters and feature sex with them. Further, there are no other games that move them the way bishōjo games do. I argue it is because these games demand so much imaginative work from players that they work as well as they do to move them. Looking at the still images on screen, the player uses his imagination to move the image according to textual and sound cues, and, intimately engaged with the image, the player is in turn moved. Imagining the action, the player co-creates it (McCloud I994: 68-69). This dynamic of co-imagining/ creating action is precisely why, as Matsumura puts it, it is easy to affect players - to move them to bodily response - with bishōjo games.

In addition, the player makes choices that impact the story and characters the player interacts with. In that the choices made reflect the player, bishōjo games are said to function almost like "a personality test" (Clements 20I3: 20I). Stated more bluntly by media and ethics 
scholars Matthew Pittman and Tom Bivins, "games can be viewed as morality experiments," where "the series of choices quickly teaches the gamer about the power of choice and consequence," as well as their own "character" (Pittman and Bivins 2016: 93). Building on accounts from players and critics as well as my own experiences, I argue that bishōjo game players are encouraged to reflect on their choices and actions and take responsibility for them. From the simplest choice to say hello to much more complex and difficult ones, the player makes choices that impact relationships and what happens next. Even as the bishojo is an object to by acted on, after intimately interacting with and imagining them, some players cease to treat cute girl characters like objects to be acted on with impunity and instead see them as "someone" who can be hurt (Sasakibara 2003: 105-I07). At the same time, one cannot choose inaction, and so must make choices that can and do hurt characters that the player has come to know and care about. In this way, interacting with cute girl characters, I argue that players face ugly feelings, actions and consequences, which they are intimately involved in. They face the ugliness and violence of desire, and the ugliness and violence in themselves and relationships. They also face their capacity to harm others through action, a capacity for violence. Co-imagining/creating action and making deliberate choices in slowly developing stories about human relationships contribute to an ethics of imaginary violence among bishōjo game players, which is in sharp contrast to the automatic and unscrutinized action of much of mainstream cinema and gaming. ${ }^{\text {I20 }}$

\subsection{Playing Bishōjo Games}

Big Brother, Use of Your Right Hand is Forbidden!! (O-nii-chan, migite no shiyō o kinshi shimasu!! Galette, 2014)

She is lying down in bed beside me. Her face is just inches away from mine. Her massive eyes stare at me, unblinking, framed by loose strands of straight black hair. Her cheeks are flushed. The top button of her pajama shirt is undone. I cannot see the rest of her, which is covered by the blanket that we share. We are alone in my room. I click the mouse to load more text on the screen, and hear her voice. "I've been so happy to take care of you this past week..." What? Hesitation in her voice, which quivers with emotion. Is something wrong? "I didn't know what to do when I saw you staring at me..." So that is why she did not come over yesterday. I must have made her nervous by asking her to come to my room and take care of me. Sure, she had volunteered when I injured 


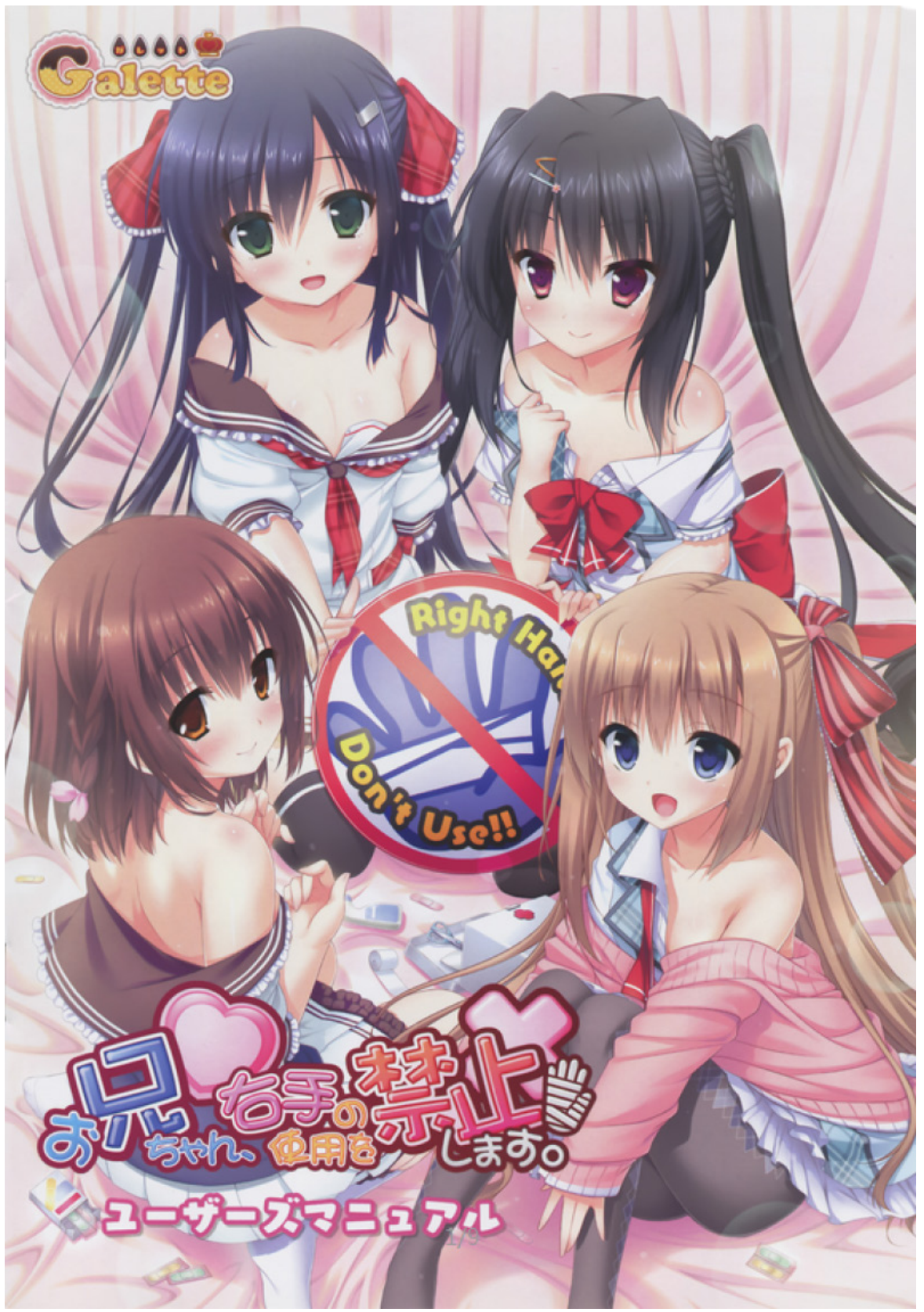

Image 11. Cover of Big Brother, Use of Your Right Hand is Forbidden!! by Galette. Used with permission from rightsholder. License: CC BY 4.0.

my right hand saving her in a traffic accident, but it was obvious that I had something in mind after days of choosing her, and only her, among the possible candidates. In truth, after playing the game for hours to get 
to this point, I was getting frustrated that nothing seemed to be happening. I had seen her in various states of undress, but nothing more. When does this become pornography, I had wondered? Now she is in my bed, so close, eyes on me, sharing her feelings. "I'm so happy just to be with you..." Say no more, please. I was wrong. This is too much. But as I click the mouse the text continues to appear and she continues to speak. Aroused and guilty, I listen, alone in my room with the computer and together with her in my room in the computer. She finally falls asleep, exhausted, but seeming to trust me - which makes it worse. The screen fades to black. Calm, while I am chaos. I should have expected this from a game that won a Moe Award.

\section{Favorable Conditions for Groping (Chikan yūgū ressha, catwalkNERO, 2014)}

She is not protesting out loud anymore, but I can hear her thoughts, which are spoken by the voice actress. "What is fun about this?" She is standing in a crowded train. A man behind her is groping her through her school uniform. The character is a rich girl, self-possessed and prideful, which must make this all the more mortifying for her. She is blushing, perhaps from embarrassment, perhaps excitement. Tears in her eyes, perhaps from frustrated rage, perhaps sadness at the assaults, which have continued for days. "Why is it always me?" Because I chose this route in the game. I was attracted to the character design - blond hair in ponytails. I am not the groper, whose body I can see on screen, but I chose this game and this girl. It was me. And it is me who is clicking the mouse to continue. "Can't you see that this is bothering me?" Yes, I can. The game and scenario are designed that way. Click. The image has changed. The groper is becoming more aggressive. $\mathrm{He}$ has lifted her skirt to reveal the white panties beneath. Click. More text describing the situation. Click. Her voice again, whimpering. Click. The image has changed. Sweat beads on her thighs, which are exposed and fleshy. Click. The groper has his penis out. "What? You can't be serious..." Click. Click. He has forced her into a handjob. Click. She is humiliated. Click. He is cumming. Click. The image has changed. Her exposed panties and legs are covered with viscous, translucent strands of semen. Click. "You bastard! You'll pay for this..." Black screen as we transition to a different scene. Thinking for a moment that I see my reflection, I hurriedly turn the computer off. What in the world am I doing? I get ready to leave for work. There is a long train ride ahead of me to make it to the city. What in the world am I doing? 


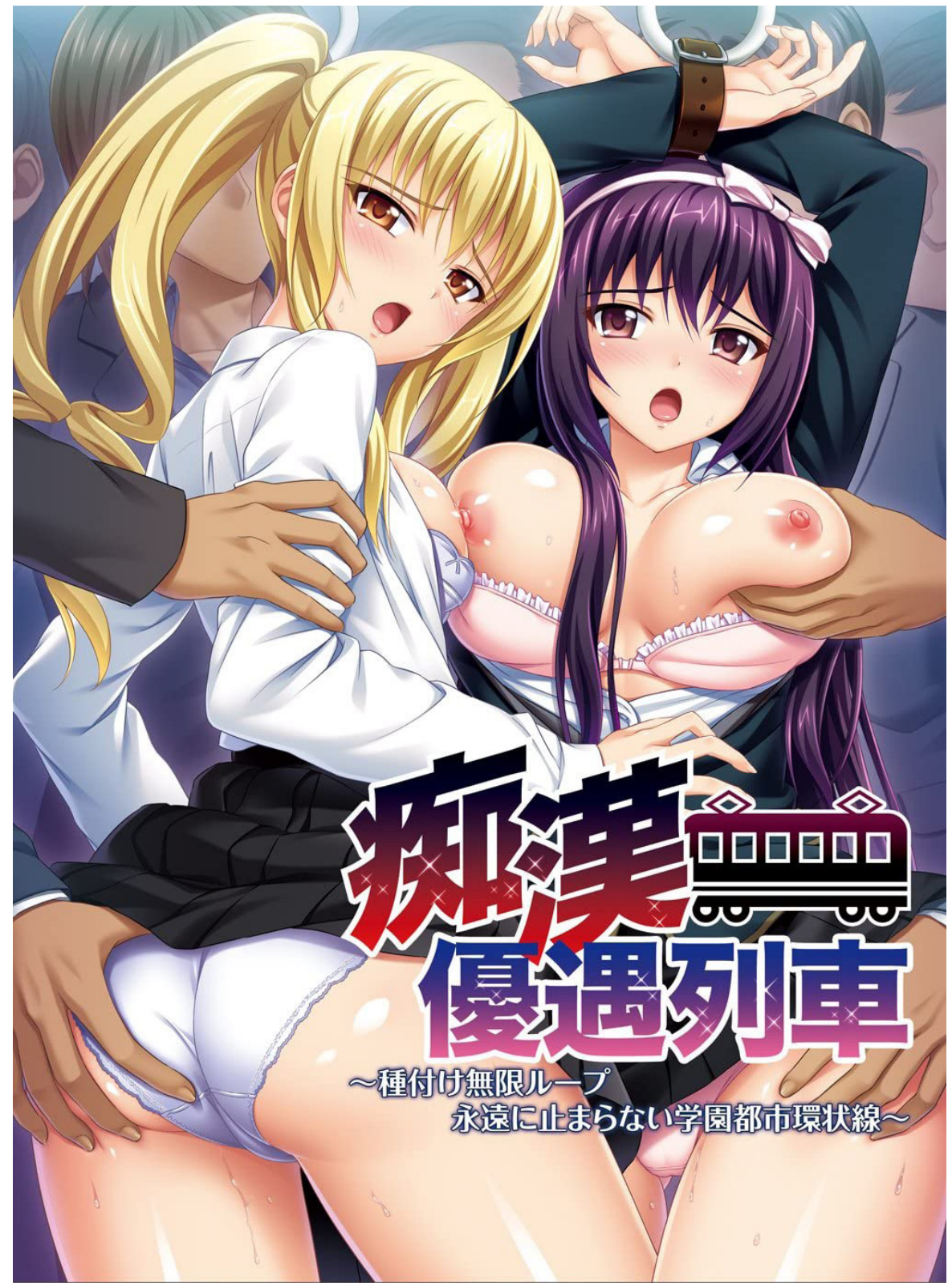

Image 12. Cover of Favorable Conditions for Groping by catwalkNERO. Used with permission from rightsholder. License: CC BY 4.०.

In Solitude, Where We Are Least Alone (Yosuga no sora, Sphere, 2008) This is not right. I tried to put a stop to it, but this is not what I wanted. I just wanted to do what was best for Sora, my twin sister. Our 


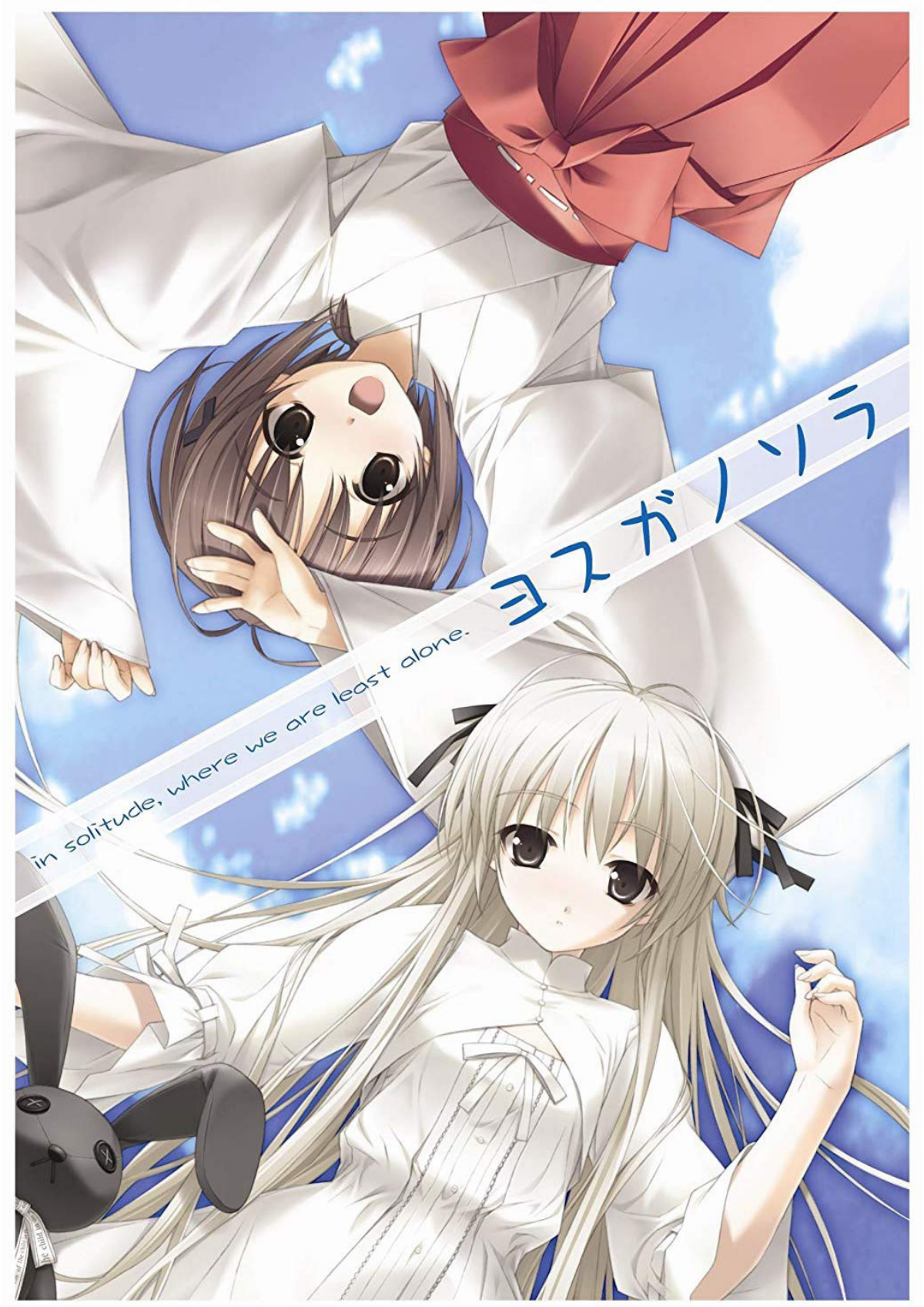

Image 13. Cover of In Solitude, Where We Are Least Alone by Sphere. Used with permission from rightsholder. License: CC BY 4.0.

parents died suddenly in a traffic accident. At the invitation of our grandparents, we moved to their old house in a village in the countryside. We only have each other. Sora is so frail. While I am at school 
making friends, she is home alone. Then I saw her masturbating. She was saying my name. I tried to ignore it. I started a relationship with Nao, a girl from school, but it ended badly. I had pressured her, my mind on Sora, which hurt Nao. She asked if I love her. No, I love Sora - not that I could say that to her. This is not right, but it is my fault. I kissed Sora when we were kids. Maybe I was just playing, but it does not matter. I love Sora, and she loves me. We had sex after she confessed her feelings. For days after we could not keep our hands off each other. Nao knew something was up, and she caught us. This is a village where everyone knows everyone; they would know about us. I had a fight with Sora. I told her we had to end it. She protested, grabbing me, and I hit her while trying to break free. It was an accident, but it is probably better that she hates me. It was going to end anyway. We were out of money and would be taken in by different relatives and live apart. Then I awoke to find Sora gone. I received a text from her saying goodbye. She had gone to the lake to take her own life. I jumped into the water to stop her, but cannot swim. We are both going to drown. This is not right and not what I wanted. What did I do wrong? Everything. Every damn thing. I will replay the game. Make different choices. There must be a way for me to leave this place with Sora. We could be happy, together, just not here. And not in death. Blinking away the tears welling in my eyes, I restart the game. This time will be different. This time we will live and be happy.

\subsection{Characters and Stories Designed to Move}

The above excerpts are from notes taken as I played and responded to bishōjo games, which was part of "analytical play" to understand “different game cultures” (Mäyrä 2008: I65-I67). While I did not always understand how and why, these games did move me. I still vividly recall images, voices and scenarios from them, and many others I played in the field. One of the first things that one notices while playing bishōjo games is the prevalence of bishōjo characters. Indeed, they are part of the very definition of bishōjo games. A bishōjo game is a game that features bishōjo characters, and, more specifically, one that focuses on interactions with them. Strictly translated, " $b i$ " means "beautiful" and "shōjo" means "girl," but a more accurate translation of bishōjo is "cute girl." The distinction is not arbitrary. In the world of manga and anime, cuteness is associated with round shapes and soft lines, which are characteristic of a style that has come to dominate Japanese comics, cartoons and computer/console games (Shiokawa I999: 97). The 
mainstream manga/anime style is cute and cartoony, as opposed to the "realism" of competing styles in Japan and abroad.

In addition to these elements of design, bishōjo characters have massive eyes, which are characteristic of shōjo manga, or comics for girls. As comics scholar Takahashi Mizuki puts it, the large eyes of shōjo manga are used to portray emotion and to "evoke empathy from the reader" (Takahashi 2008: I 24). Stated somewhat differently, the large eyes express an inner life and encourage empathy from the reader. Characters with such eyes have an interior life and can feel things like us. The depiction of interiority is particularly important in shōjo manga, which focus on relationships and emotions. Shōjo manga are said to appeal to the reader and move her on an affective level (Takahashi 2008: I24; see also Prough 20I I, chapters three and four). This aspect of shojo characters in comics for girls, so strikingly captured in the design of extremely large eyes, was folded into manga and anime for men in the form of bishojjo characters in the late I970s and I980s (Galbraith 2019: 28-46). Bishōjo games are a direct successor of this lineage of characters that get those interacting with them affectively involved.

Bishōjo games, like computer/console games in Japan more generally (Aoyama and Izushi 2004: I2I-I 25; Dyer-Witheford and de Peuter 2009: I6; Minotti 2016), share a talent pool, aesthetic and fan base with manga and anime, which is crucial for understanding them. Bishōjo games speak to an orientation toward manga/anime reality as opposed to some other "reality" (Ōtsuka 2003: 24), desire for "twodimensional images (manga, anime) rather than realistic things" (Akagi I993: 230) and "an orientation of desire" toward "fiction itself" (Saitō 20II: I6, 30). This is a distinct reality and economy of desire, which has been expressed to me over the years in terms such as "desire of lines" (rain no yokubō), "desire for lines" (sen ni tai suru yokubō) and "the pleasure of lines" (byōsen ni yoru kairaku). (For comparison, see the discussion of drawing desire in Mitchell 2005: 58-59.) "This is not reality," explained shōjo manga specialist Fujimoto Yukari, turning her computer to me to show an image of a bishojjo character. "In fact, the line can only exist because it is not reality." ${ }_{\text {I2I }}$ In this encounter, I was again struck by the large eyes of the character, which are constructed of lines and do not exist in "reality" or point back to it. Indeed, bishōjo, with their large eyes and characteristic lines, have evolved into what psychiatrist Saitō Tamaki described to me as "extremely strange figures, or strange compositions." ${ }^{222}$ Indeed, as Saitō sees it, "normal people" do not understand why these characters are "cute." A distinctive evolution 
of manga/anime characters has led to many strange figures: hybrid animal-humans, robot maids, transforming magical girls, boy-girls and many more besides. All are said to refer back to manga/anime as opposed to some other "reality." So it is that bishōjo game producers and players, like manga/anime fans more generally, see sex with a magical girl-child and not pedophilia, sex with little sister characters and not incest, same-sex character couplings that they claim have nothing to do with homosexuality, sex with animal characters and not bestiality and so on. The design of characters can incite desire for lines, which was once articulated to me as "line fetishism" (byōsen fechi), or extreme sensitivity to character lines. ${ }^{223}$ These lines do not exist "naturally," but rather are imagined and created. These lines are drawn and shared by producers and fans of manga/anime characters generally, and bishōjo game producers and players specifically.

A great deal of effort is devoted to designing the characters of bishōjo games, which are, as one character designer explained to me, "the first thing that people see and what gets them to pick the package up." ${ }_{124}$ Further, the character is what the player sees most when playing a bishojo game. With some titles requiring over 50 hours to complete the narrative, bishōjo game players stare at their computer screens for long periods of time. What they see onscreen is a static and flat background image, a flat character image layered on top of it and a window for text below the character. The player reads the text, which can be very flowery and poetic, and clicks the mouse to load more when finished reading. When select cute girl characters speak, their recorded voices are heard. As text is loaded, the character image changes slightly, for example adding a smile, blinking eyes or a symbolic response (in the language of manga/anime) to the interaction such as a sweat drop indicating nervousness. Changes in setting, major actions or events result in a different character image or image of the character appearing on screen, which then changes slightly as the scene progresses. For the most part, the player is reading text; listening to background music, sounds and voices; and looking at a still image of a character. The character image must, then, be attractive and interesting enough to hold the player's attention for extended periods of time. According to Azuma Hiroki, a philosopher and cultural critic whose work has drawn attention to bishōjo games, manga/anime-style character images were originally preferred to three-dimensional, computer-generated graphics because technological limitations made a three-dimensional image less detailed and attractive to players. ${ }^{\mathrm{I} 25}$ Over time, however, even when technology 
would allow three-dimensional, computer-generated images of similar quality, players preferred flat, two-dimensional, manga/anime-style images and militated against change. ${ }^{\mathrm{I26}}$ This was also good for business, because bishōjo game production companies could tap into the talent pool of manga/anime illustrators and not have to develop or pay for new software, training and design skills. In any case, the now standard manga/anime-style cute, flat aesthetic of bishōjo games reflects a desire for something distinct from naturalism and real in its own right (Morikawa 2003: 97-99).

One of the results of having so much focus on still images of characters in bishojo games is that interior layers of the character rise to the surface. Writing on limited animation in Japan, which reduces the number of drawn images to I 2 or fewer per second, media theorist Thomas Lamarre points out that there are times when a character image will remain still for several seconds while its mouth is drawn opening and closing and the voice actor or actress speaks the character's lines (Lamarre 2009: IO). This limited animation means that the viewer is listening to the voice of the character and staring at its still image for long periods, which might be broken up with cuts, camera tricks and special effects. On a fundamental level, however, the character image needs to be attractive and interesting enough to capture and hold attention. Lamarre calls the resulting character design a "soulful body," where "spiritual, emotional, or psychological qualities appear inscribed on the surface" (Lamarre 2009: 20I). The image not only suggests an interior that the viewer reads on the surface, but also interior movements that the viewer can read in the image. One might refer to this as an affective attunement to the character image and its movements, which are not always or necessarily animated, but rather indicated in elements of design and through interactions with others in the story. ${ }^{127}$ If, as anime historian and critic Jonathan Clements has proposed, bishōjo games are "the apotheosis of 'limited' animation" (Clements 20I3: I93), then it makes sense that designing character images to be soulful bodies is even more crucial.

One result of limited animation and a focus on soulful bodies is coded visual cues embedded in character design. Different colors of hair and hairstyles might suggest character, for example "blond in pigtails" (kinpatsu tsuin têru), which I was consistently told referred to characters with a bad attitude and soft heart. There are hundreds of these combinations. A strand of hair sticking up, which is called "stupid hair" (ahoge), suggests a character that is energetic but not too bright. 
Glasses may convey intelligence or shyness, and a girl with glasses becomes a character type, "glasses girl" (meganekko). Having the character eating food suggests energy and vitality, or a "healthy girl" (genki na $k o$ ). Big breasts suggest mature sexuality, and smaller breasts innocence. Different underwear suggests character, for example white cotton with an animal print as code for "child" and black lace as code for "adult." One character designer said that he designed his characters to convey a mood or feeling, which led him to code his characters with color. ${ }^{\mathrm{I} 28}$ In his designs, eye color, hair highlights and elements of costume are all color-coded. Pink characters are sweet, red characters aggressive, black characters brooding, purple characters mysterious and so on. Another illustrator told me that he designed his characters to contrast with one another, for example having the shortest character be the youngest or most vulnerable. ${ }^{229}$ While the variables seem infinite and arbitrary, there are in fact recognizable and repeated patterns. Clements claims that there are only six character types in bishöjo games, which are presented differently visually and narratively (Clements 2013: 202). While this may be somewhat reductive, Azuma similarly identifies a "database" of character design, which is read intertextually (Azuma 2009: 3I-33, 39-54, 79-8I). Glasses, pigtails, sister, maid, big-breasted and so on are all examples of what Azuma calls "moe elements" (moe yōso), or affective elements of character design. Moe elements are elements of design that trigger an affective response in those interacting with the character. A character designed in this way to affect is a "moe character" (moe kyara). Such a character is designed to be a moving image. This, ultimately, is what illustrators produce for bishōjo games.

Being able to read these affective elements of design is what bishōjo game scenario writer Kagami Hiroyuki dubs "moe image literacy" (moe'e riterashii) (Kagami 20I0: $\mathrm{I}_{3} \mathrm{I}$ ). "None of this makes any sense if you try to read it without understanding the language," Kagami explains to me, animated by his fifth cup of coffee during a lunch appointment. "Let's say I write a Lolita granny (roribaba). That's a character type, you know, Lolita granny. It makes no sense unless you understand that Lolita means a young girl character with a small chest and granny refers to the fact that she speaks or sounds like an old woman. You know, saying ' $\mathrm{ja}$ ' at the end of a sentence. You have to read the character in terms of design, scenario and sound." ${ }^{2}{ }^{\circ}$ The idea that speech patterns reveal character is tied to what in Japan has been theorized as "role language" (yakuwarigo), or specific words and ways of speaking "associated with particular character types" (Teshigawara and Kinsui 
20II: 38). ${ }^{\mathrm{I} 3 \mathrm{I}}$ While Kagami focuses on players developing moe image literacy, it is also an important asset for producers, who collaboratively create the character image. For example, Hayase Yayoi, a voice actress in the bishojo game industry, illuminates how she produces characters: "I read the script and try to match the image of the character. The character in the script has already been imagined by the scenario writer and the illustrator, so my job is matching the image." ${ }^{132}$ Matching work, or the work of "imaging" (imēji suru), is informed by Hayase's own experience listening to character voices and reproducing them. "I grew up with anime and loving anime characters," Hayase tells me. "I would always try to mimic them. I can produce a number of voices. The director calls me in when he wants me to voice certain characters." Like the "moe image," which is composed of affective elements, Hayase and others speak of "moe voices" (moe goe), which call up characters and move those hearing them (see also Ishida 20I9: 286). High or low pitch, fast or slow delivery, clean or sloppy pronunciation all suggests different characters. Grainy and human. Smooth and robotic. Certain keywords such as "big brother" (o-nii-chan) refer to entire scenarios. Ways of ending sentences can make a character sound young or old. To practice for auditions, Hayase takes one sound, "un," which is a grunt that would be heard in sex scenes, and repeats it over and over in different voices until she has tuned into the character. That one sound, done correctly, indexes a database of moe characters. Kagami, Hayase and others underscore moe literacy, which is shared by bishōjo game producers and players, who understand and appreciate moe as an affective response to fictional characters.

More than anything, I am told, a bishōjo character needs to be cute. "I don't really know what guys respond to as moe," says Itō Noizi, a character designer at bishōjo game production company Softpal. "But it seems that a small girl with lots of energy, the kind of girl that is just too cute, is close to the core image." ${ }^{\mathrm{I} 33}$ Over the course of our conversation, the number of times that Itō uses the word "cute" (kawaii) is striking. Why the emphasis on youthfulness in bishōjo games? "Because that is when girls are the cutest." Why cat ears as an affective element of design? "Like a kitten is already cute, and if you add that to a cute girl then it doubles the cuteness." And so on. Make no mistake that Itō, who has designed some of the most popular bishōjo characters in Japanese manga, anime and games, knows what she is doing. What she is doing, it turns out, is designing cute girl characters. While Japan is often said to be obsessed with cuteness (Kinsella I995), and interest 
in bishōjo characters has been understood as a cute sickness (Schodt I996: 54-55; Kinsella 2006: 8I, 85; Galbraith 2019: 54, 63-64), it is worth considering cuteness in less loaded terms of character design. Studies have shown that cuteness is "a direct releaser of human sociality" that encourages "social engagement" with cute objects, which are attributed inner life and "humanized" (Sherman and Haidt 20II: I, 4, 6). Cute objects are "empathy generators" (Yano 20I3: 56-57; also Steinberg 20I6). As researchers Gary D. Sherman and Jonathan Haidt rightly state, getting people to "socially engage with (e.g., befriend, play with) an animated or stuffed character is facilitated by making it physically cute," which "has been exploited by toy makers, video game designers and animators to great success" (Sherman and Haidt 20II: 5). By designing characters to be cute, bishōjo game producers support what Sherman and Haidt call "prosocial behavior" (Sherman and Haidt 20I I: I, 6). This is not unique to bishōjo games or Japan, as studies suggest that video games more generally can be used to promote prosocial behaviors (e.g., Gentile et al 2009), but the focus on designed cuteness or lovability and interactions and relations with characters first and foremost does stand out in the case of bishōjo games in Japan. Designing characters to be cute encourages players to interact with them, attribute interiority and treat them as human. At the same time, as literary scholar Sianne Ngai argues, cuteness is a minor aesthetic that can trigger "ugly feelings" (Ngai 2005; Ngai 20I2). Associated with accentuated vulnerability (Ngai 2005: 8I9), cuteness triggers an "affective response to weakness or powerlessness" (Ngai 20I2: 24). For Ngai, cuteness, with its roundness, softness and malleable forms, not only triggers the desire to touch and hold, but also to squeeze and bite. "Violence," Ngai writes, is "always implicit in our relation to the cute object" (Ngai 2005: 823; also Ngai 20I 2: 85). The cute object is "the most objectified of objects" (Ngai 2005: 834), the perfect object to be acted on, somehow resilient enough to take any amount of abuse. As girl characters designed to be cute, bishöjo encourage "prosocial behavior" and trigger "ugly feelings." They are imagined to have interiority, which encourages empathy and human interaction, but are also objects to be acted on.

The imagining of interiority is bolstered by elements of design (large eyes, soulful body, cuteness), and this interiority is developed in stories that focus tightly on characters, relationships and emotions. The history of bishojo games that is told and retold is that they used to be all about depictions of sex and getting the player off, but now are more 
about moving the player with developed stories and characters. Nearly everyone I met - my friend Ataru, a bishōjo game player; Honda Tōru, a writer and critic married to a character from a bishōjo game; Izumi Yukari, my guide in the bishōjo game industry - all relayed the same story about sex games in the I980s and early I990s giving way to moving games in the mid-I990s into the 2000 s. The message was that story was now more important, hence terms such as "novel games" and "visual novels," and these novelistic games are melodramatic - much like soap operas, centered on relationships and emotional responses, which contributes to attunement to slight movements of bodies in images dense with potential meaning (Geraghty I991: 30; Harrington and Bielby 1995: 45; Blumenthal I997: 53) - moving players to a bodily response other than cumming. ${ }^{.34}$ Instead, they began to cry while playing the games, which earned them yet another name: "crying games." The transformation, usually tied to bishōjo games produced by companies such as Elf, Leaf and Key, was seen as epochal. "Cumming games" (nukigē) had been replaced by "crying games" (nakigē). Stories still contained sex, but it was not the only or main thing, which was proven when the games removed sex scenes for re-releases and grew in popularity, even resulting in adaptation into televised anime series. The history is said to reflect a general trend toward "de-pornification" (Kagami 20I0: I37). Adult computer games still contain sex scenes, but at the same time are moving away from content that can be contained by the limited label of "pornography."

Scenario writer Maeda Jun has become synonymous with the rise of crying games. Although his games still contain sex scenes, he moves players to laugh and cry between these scenes or even at the same time. "The range of emotions in these games is so intense that they really can't be compared to what other producers have done," Maeda argues. "Moments in the story build up to the climax, where players are moved." ${ }_{355}$ Over the course of our conversation, I am surprised to learn that Maeda did not originally want to be in the bishōjo game industry, and only ended up here after applying to mainstream gaming companies without any luck. He at first did not think much of bishōjo games, and was somewhat embarrassed by what he did for a living. However, working at Key at a time when it was producing legendary games such as Kanon (Kanon, I999), Air (Eā, 2000) and Clannad (Kuranado, 2004), Maeda witnessed their power to move players. "At first I was surprised that bishōjo games had come to a point where they could have such an impact on players, but then I came to think of the 
tears as a sign of our ultimate success," he says. "It is very difficult to create a game that moves people the way ours do." Maeda recalls a scene in Air where the heroine, Misuzu, who is fragile and suffering and doomed to die, breaks into song. As Maeda imagines it, players stopped clicking and just looked at the still image of Misuzu, arms spread wide in a field, and listened. Misuzu's massive, sparkling eyes - eyes so large that they strike some as bizarre - might have been dry, but players cried for her. ${ }^{136}$ Maeda, who also watched with tears in his eyes, considers this to have been a moment when the game was disrupted because players were too moved to continue. Misuzu's song is burned into the collective memory of players as a moment when visuals, sound and scenario combined and bishōjo games ascended to a new level as moving images.

\subsection{The Role of Imagination in Bishōjo Games}

Given the design of bishōjo games, players spend a great deal of time looking at still images, reading text and listening to background music, sound effects and character voices. The still images change slightly as the player clicks to advance the text, and players become attuned to these small changes, which reflect the emotional state of the character as the player interacts with her. All of this is before making choices that impact the story. These choices are sometimes few and far between, with, for example, only ro choices in a game and an hour of story and character interaction separating them (Taylor 2007: 197). The majority of the game, then, is interacting with still images, or images that move only slightly, images that are said to be moving given what is happening, which the player gathers from textual and sound cues. In this way, bishōjo games require the player to use his imagination. This is in stark contrast to the "realism" of much of modern mainstream entertainment, which critical theorists Max Horkheimer and Theodor Adorno argue "denies its audience any dimension in which they might roam freely in the imagination" and contributes to a "withering of imagination" (Horkheimer and Adorno 2002: I00). Against this backdrop, Horkheimer and Adorno seem to recognize the potential of cartoons, as well as the pathos of bishöjo characters such as Betty Boop (Horkheimer and Adorno 2002: I06, IIO). Certain forms seem to unsettle reality, leave room for the imagination and contribute to its flourishing. ${ }^{137}$

Bishōjo games are a series of deliberately juxtaposed images, or sequential art, which is artist and theorist Scott McCloud's definition 
of comics (McCloud I994: 9). ${ }^{\text {I38 }}$ At stake here is not whether bishōjo games are super limited animation or slightly animated comics, but rather, as described by McCloud, how both comics and bishōjo games are media that require participation and imagination. If film captures enough frames per second to create the illusion of continuous motion and objective reality, which McCloud glosses as the phenomenon of "automatic electronic closure" (McCloud I994: 65), then limited animation that captures $\mathrm{I} 2$ frames or fewer per second offers closure that is still electronic but less automatic (Clements 20I3: I2O-I2I). For McCloud, comics are a medium that takes this to the extreme, in that frames are placed side by side on the page to suggest motion, but the closure between the frames is not electronic or automatic. Instead, the viewer is involved and must imagine that the action depicted in one frame continues into the next, or fill in the blanks, as it were, which requires imagination (McCloud I994: 68-69). Bishōjo games operate in a similar but distinct way in that still frames are not laid out on a page, but rather a still image appears on the screen and motion is suggested in small movements of the image (blinking of the eyes, for example), textual description (flowery, poetic, evocative language) and sound cues (background music, effects and, most importantly, voice). To put it simply, the player looks at the still image and imagines it to be moving in the ways detailed in the text and suggested by the sound. The result is, as gender scholar Emily Taylor writes, that bishōjo games "require the player to use his (or her) imagination" (Taylor 2007: I94). In this way, bishōjo games and comics are what McCloud calls "minority forms" (McCloud 2000: I9), which offer different ways of seeing and experiencing the world.

I became aware of this aspect of bishōjo game design at the Denkigai Matsuri when conversing with the producers of Mana-chan (20I5). ${ }^{139}$ When I approached the two men, who were at a table in front of two large posters of a manga/anime-style schoolgirl with the shirt of her uniform undone to reveal massive breasts and her panties pulled down provocatively, they happily introduced their work. What kind of game is this? "It's just what you imagine it to be," one of the men says, coyly. "It's sex with your little sister." ${ }^{40}$ Looking at the poster, I now see that Mana-chan, the bishōjo, is clearly indicated to be a "little sister" (imōto), a character defined by an intimate relationship with her brother. Although anthropologists once considered incest to be one of the universal taboos, it is quite common in bishojo games, especially the combinations of father and daughter, mother and son and brother and 
sister. Given the prevalence of little sister characters, whose innocence, devotion and familial love can easily be imagined as transgressively and excitingly sexual, the producers of Mana-chan thought I was asking a rhetorical question. Upon closer inspection, the game is actually a drama $\mathrm{CD}$, where a voice actress performs the imagined scenario of sex with your little sister in one of two settings. So you just listen to the voice and masturbate? "Yeah, that's about it," the man laughs. "You look at the poster, too." Look at the poster? The single image of Mana-chan? Oh, that is why she is undressing. The image is to suggest the sex act to come, as well as to provide an image for the voice, something to give form to the character in the imagination. ${ }^{\text {I }{ }^{\mathrm{I}}}$ And this works? "Yeah, it's super erotic!" Judging from the number of men who are lined up to buy sets of CDs and posters, I cannot argue. In retrospect, I realize that Mana-chan is the core of bishōjo games: an image, a voice and a scenario, which together form a character that the player interacts with. Interacting with the character, the player is moved to response. The producers of Mana-chan were particularly savvy to this dynamic, which they signaled by calling their product a "moemotion" (mo-emotion or moe-motion) game. In their promotional material, the producers of Mana-chan describe their character, in English, as "soulful" and themselves as moe "specialists." " ${ }_{42}$

The fact that bishojo game players are so involved in imagining the action gives rise to peculiar forms of intimacy. Here again McCloud proves insightful in his approach to comics as a particularly intimate medium, because the author draws what is in his or her imagination and lays it out on the page for the reader, who imagines the action to move the images (McCloud I994: 68-69, I94-196). ${ }^{\text {I43 }}$ This is an intimate sharing of imagination, and it becomes peculiar in bishōjo games given the many producers involved (for more, see Chapter 4). Important here is that the player shares the imagination and creation of others, and is intimately involved in it as a co-imaginer and co-creator. As McCloud sees it, because comics as sequential art demand the reader to fill in the blanks to complete the action, "Every act committed to paper by the comics artist is aided and abetted by a silent accomplice. An equal partner in crime known as the reader" (McCloud I994: 68). To demonstrate this, McCloud draws two sequential images, the first of an assailant raising an axe and about to strike a terrified man, and the second a cityscape at night that is pierced by a scream. "I may have drawn the axe being raised in this example," McCloud writes, "but I'm not the one who let it drop or decided how hard the blow, or who screamed, or 
why. That, dear reader, was your special crime, each of you committing it in your own style" (McCloud I994: 68). It is telling that McCloud chooses an act of violence to demonstrate his theory of media that require imaginative participation in order to move. With intimate sharing of imagination and imaginative participation comes a sense of responsibility. One cannot sit back and observe the actions of others, detached and unmoved, because that person is involved in the action. The reader who co-imagines and co-creates action must also take responsibility for his or her "special crime." Bishōjo games similarly involve the player, who co-imagines and co-creates the action, but also combine this with the mechanic of making choices that impact the action. "Strike the victim? Yes or no." The story builds to such choices, even as the player is forced to make them and commit their own special crimes. With this comes a sense of responsibility for the action and its consequences.

Bishöjo games are even more effective at drawing players in because they are positioned as not only interactors, but also lovers who want to imagine themselves in the manga/anime world with the manga/anime character. This takes even further game scholar Hanna Wirman's insight that players contribute "a power of love toward a computer game; her or his object of desire. Fandom is about loving something so much that you want to be part of it" (Wirman 201 5: I 86-1 87). Indeed, researchers in this field have generated piercing insights into how and to what effect immersion occurs in computer games. Noting that even single-player games such as Dragon Age: Origins (BioWare, 2009) can move players to experience strong emotions in relation to characters, theorist Annika Waern proposes affection by design:

The effect cannot solely be attributed to just the game, or just the players. Rather, it lies in the interplay between how and why players like to indulge in romance, and in how the game design supports and actively endorses such indulgence. Players contribute both through their desire to indulge in a "safe zone" romance, and with their desire to project their identity into the game. At the same time, the game plays on their emotions by supporting identity projection and tailoring the romance options to the likely preferences of the players. In addition, a carefully crafted storyline wrestles control away from the player at critical moments, making him or her aware of the strength of his/her emotion. (Waern 201 5: 59)

There are concepts such as "pixel crush" and "the feels" that approach the discourse of moe as an affective response to fictional characters, but Waern starts from the observation that "it is unusual for a computer game to create strong romantic reactions in players" (Waern 20 I 5: 38). 
Why might there be commenting on and comparing lovable characters, recalling moving story moments and even outright declarations of love such as the ones she discovered posted on blogs and community chatrooms dedicated to Dragon Age, which sound so very familiar to those who have spent any time scrolling through bishojjo game sites and bulletin boards in Japanese? Perhaps because, setting aside the graphics - high-resolution, computer-generated, realistic - ability to control the movement of avatars and openness of the world, one cannot help but notice how Waern's description of Dragon Age's affective design resonates so strongly with bishōjo games: There is "the careful design of the romanceable characters as such," "the rather vaguely sketched player-characters" and being forced to choose between and in relationships that impact how the game develops toward its multiple endings (Waern 201 5: 47, 54-56). These choices are not always easy, Waern explains, because "the non-player characters are well written, complex and evolve over time" (Waern 20I 5: 56). ${ }^{\text {I4 } 4}$ They evolve, and in many cases, depending on the level of immersion and involvement in the relationship(s), players' feelings do, as well.

To analyses of the image, interaction or relation of images and with characters drawing people in, Waern pushes further with the concept of "bleed." Game designers describe the phenomenon of bleed as the thoughts and feelings of the player being affected by their character. As Waern sees it, a game designed to encourage bleed will maintain "a sense of alibi," but at the same time "weaken the protective frame of play in order to explore powerful emotions" (Markus Montola in Waern 201 5: 4I). Assuring the player that they are only seeing a fictional character in a fictional context creates the "alibi," or what Waern also refers to as the "safe zone," which allows "for exploring emotionally complex or difficult subjects" (Waern 20I 5: 4I). Games designed for bleed then break down the separation between player and character. Crucially, one way to achieve this is "invoking such strong emotions in players that they cannot fully distance themselves from their characters" (Waern 2OI 5: 4I). Recalling Maeda Jun and Misuzu, the singing heroine of Air (discussed above), if not the more general category of "crying games," it seems as if this is exactly what is happening in bishojo games, only the bleed occurs not in identification with the player's character so much as in interaction with other characters. Waern presents both "bleed in" and "bleed out," or player emotions and personality traits affecting performance as opposed to the emotions of the player's character affecting him, and both are observable in bishojo games. In the scene with Air's 
Misuzu, the bleed is both from the player's character and the character he observes. The bleed between player and character(s) contributes to powerfully moving moments, as described by Maeda and in countless online discussions of the game. It is also why players experience both Misuzu's pain and the joy of loving her. The declarations of love Waern discovered in discussions of specific characters from Dragon Age are everywhere in discussions of Misuzu. So, too, are "experiences of jealousy and guilt," which are "perhaps the strongest indications of a bleedout effect” (Waern 2015: 50).

Here Waern's writing veers into the profound, as she makes a distinction between "projected identity" and "explorative identity," the latter of which is found in games where the player actively takes on another role and experiments with being someone else with different emotions, personality traits and values. The ethical alignment of characters created for tabletop roleplaying games are a case in point. In a similar way, one can "experiment with the ethics of the game" (Waern 201 5: 55), but there remains a tension with bleed in and out. When one makes a decision that is "bad," for example, it can matter deeply to the player in relation to the character(s). Waern identifies a player who, while choosing to do as his lover asked of him in Dragon Age, experienced "an acute ethical conflict" (Waern 20I 5: 57). Recalling The Song of Saya (discussed in Chapter I), where the player can choose the end of the world out of love for the monster, this bleed out and guilt again ring true. In these examples, it appears that one is moved from being an observer of actions and interactions to a participant, or someone involved in them. This occurs when one is intensely, violently, bodily, moved, or when an affective response casts them from explorative identity to projected identity, if not simply into an experience of "being there" with "her." As Waern reasons, this is most likely to be experienced on the initial play through, when coming events and choices are still fresh and responses raw (Waern 20I 5: 55-56). In the stories, the player can make choices, but these are limited (even more so in bishōjo games) and may not change crucial events. For Waern, this speaks to "partial agency," where the player is forced to make choices and also forced to experience consequences, as well as experience certain events, be they romantic or heartbreaking. Wanting things to be different and being unable to change them serves to accentuate the strength of a player's emotions. Personally speaking, my initial play through of Sora's route in In Solitude, Where We Are Least Alone (discussed above) and breakdown at its conclusion made this abundantly clear, although the intensity of the bleed did not 
necessarily fade until several times through multiple routes. (I continued to feel spikes of guilt interacting with other characters rather than Sora, and even jealousy when others expressed an interest in her.) In the end, all this talk of bleeding does disrupt the notion of character romance as occupying a "safe zone," because people can and do get hurt. As intense as it is moving, the triggering of an affective response can be pleasurable and painful, fictional and real, both a part of and apart from the game. If one is immersed and involved, or overpowered by the intensity of affect, bleed out can occur. These are moe moments, which can be affectively sticky, messy entanglements - "positive negative experiences," "happy sad," "disgusted aroused" - and other feelings that are even less capturable in words, however seemingly contradictory.

\subsection{The Ethical Encounter in Bishōjo Games}

Bishōjo games raise fundamental questions about moving images. Although I take this phrase, "moving images," from film scholar Linda Williams and her writing on pornography (Williams I989), bishōjo games do not seem to function in ways familiar from the growing body of literature on that subject. Stated simply, Williams approaches pornography in terms of a science and discourse of the body that makes its movements and pleasure more and more visible, which requires real human bodies in front of the camera. This is not the case in bishöjo games, which instead place fictional bodies onscreen. There is no "truth" of the body here, only artifice, or something imagined and created with its own "truth" (see also Paasonen 20I8).

Bishōjo games also intersect with concerns about pornography and violence. Feminist lawyer and thinker Catharine MacKinnon famously theorizes that pornography is an expression of sexualized hierarchy. "From pornography one learns that forcible violation of women is the essence of sex" (MacKinnon I997: I68). She boils down the essence of sex under patriarchy as follows: "Man fucks woman; subject verb object" (MacKinnon I982: 54I). Under patriarchy, sex is something men do to women, eroticized domination and violation, if not outright violence. This critique of pornography would seem to apply to bishōjo games, which appear to be, as MacKinnon might put it, sex between subjects and objects, people and things, real men and unreal women (MacKinnon I993: I03). This is even more so given that bishöjo are cute girls, and cute objects are "the most objectified of objects" (Ngai 2005: 834), constructed to be weak, vulnerable and acted on. 
As Ngai posits, cuteness is at times an "eroticization of powerlessness" (Ngai 20I 2: 3). However, in that bishōjo games design characters to have interiority and develop this through interactions with players over time, these characters cease to be simple objects. While MacKinnon argues that in pornography "women are reduced to subhuman dimensions to the point where they cannot be perceived as fully human" (Dworkin and MacKinnon I988: 38), bishōjo games suggest the humanization of two-dimensional characters. Players come to know and care about them and recognize that they have feelings and can be hurt. If, as philosopher Slavoj Žižek proposes, the tragedy of pornography is that "you can see it all but you are not allowed then to be emotionally, seriously engaged" (quoted in Fiennes 2006), then the tragedy of bishojo games is that they get players emotionally, seriously engaged and do not stop short of the act. One is involved with the character, developed out of an object into a "someone" with thoughts and feelings, and then acts on desire for that someone as a sex object. Rather than simply enjoying sex, or the act more broadly, self-reflexive players advocate understanding the relationship as one of violence, which leads to the development of an ethical position.

Similarly, bishōjo games do not follow the model of automatic action seen in mainstream North American computer/console games such as first-person shooters. With near photo-realistic graphics that render in real time for smooth, seamless action that appears almost as if filmed by a camera, games such as Call of Duty (discussed in this book's introduction) strive for a sense of "reality." These games are to some extent about interaction, but this often takes the form of the player adopting the position of the gunman, seeing enemy characters through the scope and shooting them. In the vast majority of these interactions, it does not matter who the enemy character is, because they are targets to be eliminated as part of the action. The action can become almost automatic, even as the weapon upgrades to an automatic one to point and shoot at nameless and faceless others. ${ }^{\mathrm{I} 5}$ In contrast to first-person shooters, bishojo games are first-person relationships. The player adopts the position of a man and sees cute girl characters from a first-person perspective, and, through sustained interaction over long periods of time, comes to know, if not care, about them. These characters have names and faces, thoughts and feelings. Moreover, the action is anything but automatic. It is slow - very, very slow - as the player clicks the mouse, text and images load and choices appear. Choices are made after reading 
the mountains of text that make up the story, hearing the voices of the characters during interactions and considering potential consequences. The game does not progress unless the player reads the text, clicks the mouse and makes deliberate choices. In the North American context, feminist critic Anita Sarkeesian postulates that computer/console games where the player acts on objects are part of a culture of violence, where one acts without consideration of others, which is particularly egregious for her when a male player acts on "sex objects" (Sarkeesian 20I4). One can see the return of the problematics of antiporn feminism here, as well as the ways that bishōjo games gesture in new directions. By design, characters are objects developed into "someone," action is not automatic and players reflect on how their choices might impact known others. This is a different game entirely.

Bishōjo games are designed to facilitate intimate interaction, but the intensity of feelings that players have for bishojo characters was something that struck me often while in the field. Among all the games available in Japan, it was these crude simulations that moved players to proclaim their love for characters, maintain relationships with them beyond the game in various media and material forms and share these relationships with others at events and in Akihabara. The man who helped me understand why this might be was Sasakibara Gō, who I first met in Tokyo in 20I4 (see Chapter I). Born in Akita Prefecture in I96I, Sasakibara is an editor and cultural critic by trade. He is also a player of bishōjo games, which he first encountered in I998. At the time, the bishōjo game industry was undergoing a renaissance that saw more developed stories and characters. A fan of shōjo manga, or comics for girls, since the late I970s, Sasakibara was surprised to find that bishōjo games had aspects in common with them:

When I started playing bishōjo games, what surprised me was how poetic and lyrical the text was. They focused a great deal on the feelings of the girls. They featured sweet, gentle expressions (yasashii hyōgen). But, as the stories progressed, they turned into pornography. That problem of sexuality is what most interested me. These games bring together poetic love stories like comics for girls and sex scenes like pornography for men. Adult computer games are a poetic and lyrical world, a world of emotions, like comics for girls. At the same time, they are pornography. ${ }^{\mathrm{I} 46}$

In bishōjo games, Sasakibara sees "media that allow for gazing at women as objects for the fulfillment of sexual desire, while at the same time depicting the interiority of women" (Sasakibara 2003: I08). Cute girl 
characters are both sex objects and subjects with interiority that the player comes to know, if not care about. It is because one knows and cares more about characters that bishōjo games function differently than other forms of pornography and computer/console games, and why they move players as they do. And it is because players know and care more about characters that bishōjo games challenge our ways of thinking about pornography and computer/console games. Bishōjo games open a window onto moe and the culture of affection for fictional characters.

After years of play and reflection on bishōjo games, Sasakibara wrote an essay titled "Sex that Injures" (Kizu tsukeru sei, 2003), which sounds very much like an antiporn position, but in fact argues something quite different. Intriguingly, Sasakibara does this by confronting the issue of violence. Desire is targeted at sex objects, and this is a relation of power, subjects acting on objects, which is fundamentally violent. Sasakibara is particularly concerned with "men," but more generally with subjects that act, which is the core dynamic of the sex that injures. While Sasakibara recognizes that women are involved in imagining and creating bishōjo games - as illustrators and voice actresses, especially - and that there are female players, and that they too are subjects that act, his critique draws on his own experiences and desires as a player and as a man. To begin, for Sasakibara, bishōjo games are "embarrassing" (hazukashii) and "painful" (itai). On the one hand, they are embarrassing and painful to play. Hours go by without any pornographic scenes to use for masturbation; when they do come, reading the text, looking at the still image, listening to the voice and clicking the mouse to continue makes it hard to focus enough to climax. If certain types of games are played "masochistically," in that dedicated players increase the difficulty to make the game more challenging and rewarding (Kijima 2OI 2a: 252), then perhaps bishōjo games are an example of "masochistic pornography." On the other hand, frank depictions of even the most embarrassing of sexual desire are at times painful to see laid bare. For Sasakibara, seeing such desire, recognizing it as one's own and acting on it, which has consequences, leads to moments of embarrassing and painful reflection, which most men would rather avoid. This is why bishōjo games remain a minor form.

In a strange sort of split subjectivity, the bishōjo game player is the player who sees the player character onscreen and also inhabits the player character, enters into it and sees from a first-person perspective. The player character's face is seldom if ever shown, and when it is, the 
eyes are typically obscured. In contrast to the massive eyes of bishōjo and their interiority, the player character has no interiority, because the player fills it with his own thoughts and feelings. This split subjectivity continues in that the thoughts and words of the player character are written by someone else. These thoughts and words appear in the text - never voiced by an actor, an "other," but rather heard in the player's imagination as his own. So one sees the thoughts and words of the player character and scenario writer even as these thoughts and words imaginatively become one's own. Playing bishōjo games, Sasakibara reports that he becomes immersed in its reality, experiences it as reality and is a person involved in that reality. Using highly politicized language, Sasakibara identifies himself as "a person involved" (tōiisha) (Sasakibara 2003: 104), which is a phrase most often used in Japan by minority groups and activists involved in a given issue. If adult computer games are embarrassing and painful expressions of sexual desire, then Sasakibara advances that they also make the player take responsibility for that desire. In the game, it is the player doing the active imagining to move the image in line with the textual and sound cues. It is the player who sees the world from a first-person perspective and thinks and speaks as the player character. It is the player who makes choices and acts. The player is a person involved, a participant and an observer, acting and interacting in the imaginary world even as he is reflecting on action and interaction. As a person involved, the player cannot claim objective distance and disinterested detachment from the game and what happens in it. The mechanics of bishōjo games emphasize this involvement by allowing and, indeed, forcing the player to make choices that impact characters, relationships and the story.

While involvement in the story, world and reality of the game are crucial, the importance of this involvement becomes much clearer with regards to characters. In bishōjo games, the player spends the majority of his time looking at bishojo characters and interacting with them; the games are based on and proceed through interactions with bishōjo characters, who the player is intimately involved with. Given the player's position and perspective, one might adopt the analytic of the "male gaze" and construction of female objects and "to-be-lookedat-ness" (Mulvey 2009: I9), but Sasakibara disrupts this by also drawing attention to the gaze of the bishōjo character, who is "looking at me" (Sasakibara 2003: I05). ${ }^{147}$ Cute girl characters stare at the player character and out of the screen at the player engaging the world from a first-person perspective; they meet and return his gaze and directly 
address him (see also Greenwood 20I4: 243). ${ }^{\text {I48 }}$ Making eye contact and directly addressing the player personalizes the interaction and contributes to interactions with the other as a person. In this regard, it is telling that Sasakibara chooses to refer to bishōjo characters as "human" (ningen) (Sasakibara 2003: I05). ${ }^{\text {I9 }}$ In contrast to games where players treat nonplayer characters as objects that do not receive human empathy and can be acted on with impunity (i.e., the enemy combatant in Call of Duty), bishōjo games develop characters from objects into subjects with interiority. As a player, Sasakibara approaches the character as "someone" (dareka), “a unique and irreplaceable 'someone,' not a simple two-dimensional image or a 'thing" (Sasakibara 2003: I07). ${ }^{150}$ The player's choices impact this "someone" (Sasakibara 2003: I05). The player, a person involved, "may hurt the girl in front of my eyes" (Sasakibara 2003: I05). In bishōjo games, the character looks out at the player with large eyes filled with emotion and expressing inner life; she meets and returns the gaze, speaks to the player and demands that he act with concern and care. When the player responds to these demands, Sasakibara asserts, the character "comes to life" (Sasakibara 2003: 107). As someone, human and alive, the character who looks back at the player, the character who has a face, name and interiority, is able to "make actual demands" (Greenwood 20I4: 250). ${ }^{\text {I5I }}$ Building on Sasakibara, I argue that chief among these demands is, "Do not hurt me." ${ }^{152}$ Such demands change the way players play.

Bishōjo games, however, offer scenarios where the player cannot choose inaction and is positioned instead to act and hurt others, who are human and alive. As an example, Sasakibara shares his experience playing Âge's The Eternity You Desire (Kimi ga nozomu eien, 200I). The story is about a highschool senior - the player character - who cannot decide a future path. His friend, Hayase Mitsuki, is tomboyish and pals around with him, but there is no apparent attraction between them. Mitsuki introduces the player character to her friend Suzumiya Haruka, who is shy, but eventually works up the courage to confess her love to the player character. The player character and Haruka start dating and, although awkward at first, develop strong feelings for each other and spend their days together happily. Hours have passed since the game started and the player is completely focused on this young love, but then the story takes an unexpected turn. Haruka is in a traffic accident and falls into a coma. The story jumps ahead three years. Haruka is still lying comatose in the hospital and the player character is living with Mitsuki, who supported him through despair and 
realized her true feelings for him, just as he did for her. The two live together happily, but, one day, Haruka miraculously awakens from her coma. She has no sense that time has passed, and still thinks of herself as a highschool student in love with the player character and away from him only briefly. The player character, feeling terrible and guilty, wants to tell Haruka the truth, but the doctor says that he must not do so for fear of psychological shock. The player character goes to the hospital to visit Haruka, who asks him to intertwine his fingers with hers and say the words of a charm, which they had often done as a sign of their relationship. The interaction proceeds as follows. While reading, remember the design of the game: Haruka is looking at the player, you, who hears her words spoken by an actress; the player sees her from the first-person perspective of the player character, but his words and thoughts are not spoken and appear as text, which the player reads:

(Haruka): "Um... The charm..."

(Player): "What?"

(Haruka): "Can we?”

The charm... Haruka is silently holding out her hand. The charm... I'd almost forgotten it, but...

(Haruka): "Your hand..."

(Player): "R, right..."

I fall silent and hold my hand out. My hand is on top of hers. ... Is this Haruka's hand...? She's so thin, all the muscle is gone, it's just skin and bone... Even so, it's a nice hand. When I touch it, I feel that again. Her five fingers, stretched out from her palm like the branches of a tree, look absolutely nothing like those of a girl.

(Haruka): "Um... So your hand... Goes like this..."

Although Haruka said to do the charm together, she guides my hand and explains it as if to someone who has never done it before. My hand and Haruka's hand come together. Like this... Our fingers intertwine. Can I do this... Me, with Haruka? ... I don't know...

I. Intertwine your fingers.

2. Do not intertwine your fingers.

If I told anyone about this they would probably laugh. It's just putting your fingers together... They might say. But... Intertwining your fingers has an important meaning... I think. It's not holding hands. The fingers one by one intertwine... They feel one another's warmth. Before, just for a moment, I thought that at least it wasn't a kiss, but... But this... I get the feeling that this has the same meaning. 


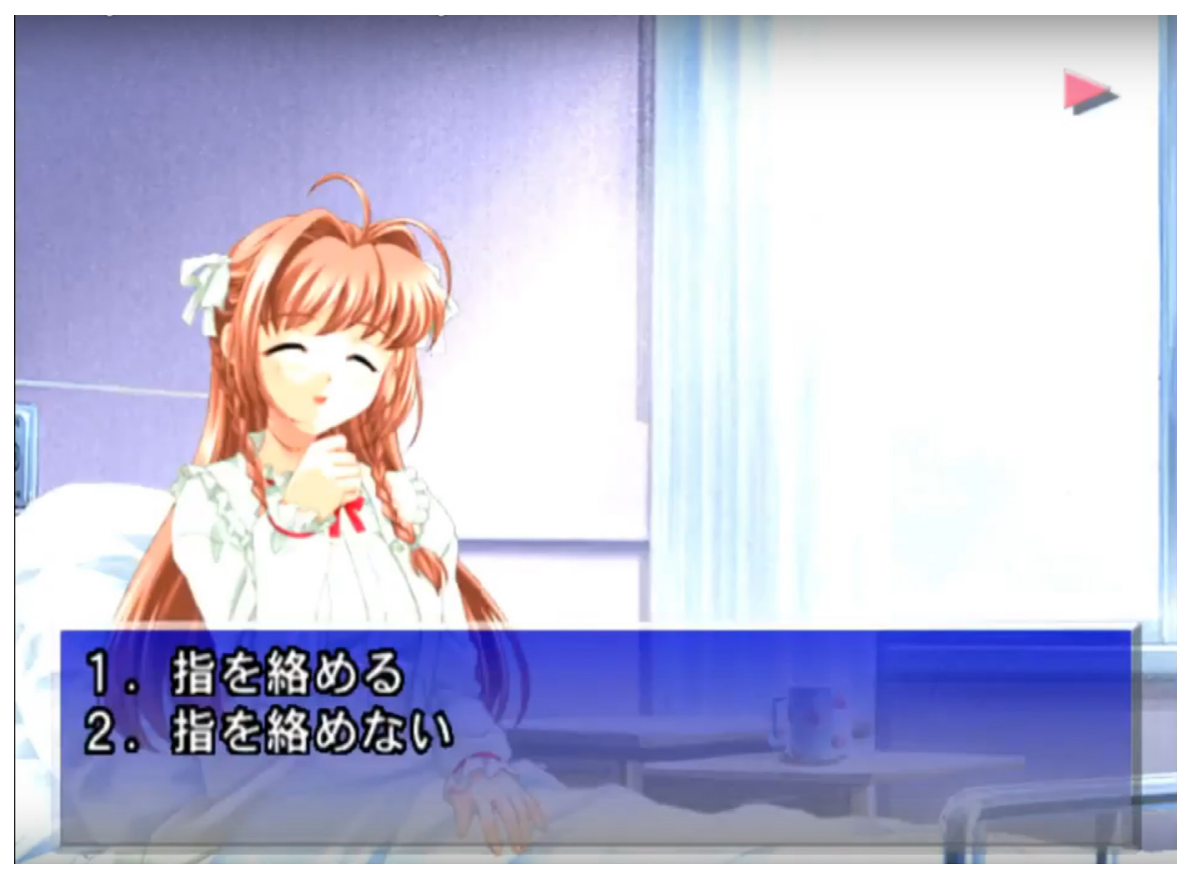

Image 14. Haruka asks you to intertwine your fingers with her own and say the words of a charm. The choice of whether or not to do so is built up, as are the consequences. Photo by the author. Used with permission from rightsholder. License: CC BY 4.0 .

The scenario is complex, and the player is conflicted, but a choice must be made. After playing the game for this long to get to this point, the choice is not an easy one. The player cannot help but think of the meaning of this action and how it might impact Haruka and Mitsuki and his relationships with them. The buildup - with its drawn-out pauses, ellipses, allusions of what Haruka might or might not know at what point, feelings that cannot be put into words - makes the choice seem all the more significant. All the while an image of Haruka stares out of the screen at the player, and the player stares at her and himself reflected on the screen. In Sasakibara's case, playing through this scenario, he cannot help but be a person involved in human relationships and choices. As a participant and co-creator of this shared imaginary, he feels a sense of being in "criminal accomplice" (Sasakibara 2003: 107; recall McCloud I994: 68). He cannot help but be moved, and to make a move, which is both painful and pleasurable. ${ }^{153}$

The guilt that Sasakibara feels for his "crime" speaks to responsibility. He has cultivated his capacity to respond, or has become response-able, in relation to another. Indeed, Sasakibara, who is involved in the scenario 
with Haruka and Mitsuki at the level of what he calls "subjective action" (Sasakibara 2003: I06), argues that bishōjo games demand that players take responsibility. The player, who comes to see a character such as Haruka as someone with an interiority and life, must take responsibility for his capacity to hurt that someone, which is his capacity to make a choice and act in the world. The one who acts, the player, has the power to impact another life and change the story. For Sasakibara, the player must take responsibility for his action and for himself as the subject that acts, which is the "sex that injures" (Sasakibara 2003: I09). The player faces his desires and, as Sasakibara elaborated the point to me, "his own violence" (jibun no bōryokusei). ${ }^{\mathrm{r} 4}$ The bishōjo game stages a confrontation with one's desires, the self as actor and "self as victimizer" (kagaisha toshite no boku) (Sasakibara 2003: I08). (Note the resonance with Ōtsuka Eiji's position as a man who wants to hug the cute girl or "doll," and sees his pathetic or shameful desires and self reflected in the mirror of Miyazaki Tsutomu [Chapter I].) In bishōjo games, the player confronts himself as "an existence that hurts her" (Sasakibara 2003: I09). While incredibly difficult (or embarrassing and painful) to face and work through, Sasakibara believes that it is individually and socially good to take responsibility for one's involvement in the world and capacity to act in it and hurt or harm others. Rather than deny that one is capable of violence - to maintain the fantasy of the pure subject, who could not harm a soul - or, worse, project that refused and repressed violence onto others, it is better to face one's own capacity for violence and take responsibility for it. This begins with the recognition of the fundamental violence of subjects acting on objects, the recognition that the object is "someone" and that acts can hurt or harm that "someone." I5s (Note the resonance with Nagayama Kaoru's position on facing the horror of the evil actor inside, even as the viewer is imaginatively drawn into shared feeling with the victim [Chapter I]. Like Ôtsuka and Nagayama, Sasakibara advocates facing the cute other and "ugly feelings.")

The example of The Eternity You Desire demonstrates this dynamic and the violence of "subjective action," but the violence can be much more explicit: Acting on desire to take advantage of someone, as in Big Brother, Use of Your Right Hand is Forbidden!!; sexually assaulting someone, as in Favorable Conditions for Groping; getting involved in an incestuous relationship, hitting your lover and driving her to suicide, as in In Solitude, Where We Are Least Alone. All of this violence, and so much more - for example, The Song of Saya (introduced in Chapter I; 
also Sousa 2020), where the player makes choices in a relationship with a monster that drives everyone mad, and through this relationship is involved in consuming human flesh, rape, murder, torture and the end of humanity - is part of bishōjo games. ${ }^{56}$ And it is the player imaginatively participating in the action, making choices and impacting others, who is responsible for that violence. Rather than deny violence and allow it to go unscrutinized, the player of adult computer games becomes aware of violence and opens it to scrutiny.

There is, however, an opposing force that repels scrutiny of the self interacting with another in ways that can hurt them. Echoing Nagayama Kaoru's concern about the disappearance of explicit sex in moe media (recall Chapter I), Sasakibara problematizes the "I becoming gaze" (shisen-ka suru watashi). Returning to the key moment of cute girl characters proliferating across manga and anime and becoming idols the I980s, Sasakibara notes intensification of this in a media ecology including bishōjo games and figurines in the I990s and 2000 s (for a review, see Galbraith 2019). In the rise of bishōjo and moe media, Sasakibara draws attention to the conversely disappearing male subject. Numerous examples of work associated with moe, Sasakibara argues, avoid depicting men. This does not mean that men are absent so much as they are transparent. Where pornographic works might show the form of "man as the sexually violating subject," they shift to depicting only the form of "girl as the subjective visual of the perspective of men" (Sasakibara 2005: I7). By the time one reaches cute girl figurines, which exploded in popularity from the late I990s and rose alongside moe media, the character has become something (literally an object) that exists only for the purpose of being seen, or rather exists in the form of the gaze of men as such. "Such products," Sasakibara states, "present a paradise for users to become liberated as 'an existence as gaze"” (Sasakibara 2005: I7). One can similarly grasp many examples of moe media featuring cute girl characters shaped by and for the male gaze, but seen in what appears to be an exclusively or primarily female world without men. It is thus possible for the male viewer to not see himself on or off screen, or to become an existence as gaze. As an "invisible existence" (tomei na sonzai), the I becoming gaze is "unseen and just looks" (Sasakibara 2005: I7).

A major issue with the I becoming gaze is its relation to violence. The I becoming gaze is a transcendent position that recognizes and understands. It sees all, and in seeing exists. In contrast, what is seen is captured and "internalized" (naimenka suru). These objects and others 
may or may not exist, but I do in seeing them. This self-contained world and world of the self can be disrupted, however, when the I is subjected to or commits acts of violence; there is an external other before its eyes that cannot be internalized. This relates to Sasakibara's experience and analysis of bishōjo games, where players come to see themselves as the "sex that injures" and "hurts her." Bishōjo games are deeply connected to the explosion of discourse about moe and moe media from the late I990s, or the broader formation that Sasakibara calls "cute girl culture" (bishōjo bunka) or "otaku cute girl culture" (Sasakibara 2005: 23). They also demonstrate the potential for moe media to contribute to the cultivation of an ethics of imaginary violence, or an ethical encounter with the one who looks back and is a self that is not myself. The player's relation to the character as a human "someone," and experience of actions hurting her, contribute to an awareness of "one's desires (violence)" and "facing women as others" (Sasakibara 2005: 24). There is a dilemma, however, in becoming the "I who can understand her," which is "a new position of privilege" (Sasakibara 2005: 24). This can, Sasakibara warns, also be a transcendent position that internalizes her. Not only is the character "one that can be captured" (kōryaku kanō na kyarakutā), to use the jargon of bishōjo games referring to characters that can be targets of romantic or sexual advances through distinct routes in the game, but she can also be processed as a character by the "I who can understand her."

The I becoming gaze goes further by turning the character from a self that is not myself, a human someone before my eyes interacting with me, back into a character to be captured and recognized by a disembodied gaze from an invisible position. Values are relativized by the gaze that "just transparently recognizes" (Sasakibara 2005: 2I). It is "separated from the flesh" (Sasakibara 2005: 19), and not just that of the viewer. The one seen is captured not as someone, but rather as codes, for example the elements of character design common to moe media (Azuma 2009; also above). These are just characters, "just fiction," constructs of the database and objects for capture, de-composition and re-composition; they can be broken down and recognized as parts, or understood as moe elements. As characters and fiction, it does not really matter what happens to these things that are seen, which in any case have nothing to do with the I becoming gaze and transparent data processor. In this way, sex and violence go unscrutinized.

As I become gaze, the violence of the gaze and its relation to characters becomes invisible. In stark contrast to bishōjo games contributing to 
reflection on sex that injures, there is an imagined innocence to the "pure gaze" that "just looks" (Sasakibara 2005: I7). Considering the history of otaku and bishōjo, Sasakibara identifies a troubling recurrence:

The violence of one's gaze is noticed, then again forgotten. In other words, while encountering her as other, I internalize and transform her into a character that "can be captured." The otaku character called "bishōjo" is an image born of that need. This character will accept my violent gaze without complaining, and moreover will not be injured. It is an existence that "can be captured" by my gaze. With it, I am permitted to act with absolute freedom as the "I as gaze." Currently, this has evolved into moe characters and works. As products, the necessity of characters continues to increase. However, works and products of this sort are fundamentally built on "violence." And they are established by forgetting this structure. (Sasakibara $2005: 24-25)^{157}$

The I becoming gaze is thus mirrored by the other "becoming character" (kyarakutā-ka suru), interaction becomes "just looking" and the violence once recognized is "forgotten." The active engagement with another looking back drops away into passive recognition of characters captured and internalized by the gaze. While bishōjo games surely foreground interaction with characters as selves that are not myself, or human "someones" interacting with me, and hence inspired Sasakibara, they are not unique in this respect. Moe media often adopt a mode of direct address and affective appeal to the viewer as "interactor" (Galbraith 20I9: II6), and manga/anime series can turn that into a visceral experience of being the sex that injures. The issue here is the vanishing subject and actor, who as gaze just looks and internalizes the other as a character that can be known and grasped within the frame of moe media.

In forgetting the structure of others becoming characters to be captured, recognized and known by the I becoming gaze, many examples of moe media do not hold the viewer accountable and can perpetuate uncritical violence. Instead of recognizing one's own capacity to act and hurt as the sex that injures, the other becomes a "character that is uninjured" (kizu tsukanai kyarakutā). The viewer's position and responsibility to the other go unquestioned, thereby undermining the ethics of imaginary violence. Made invisible and transparent, the I becoming gaze does not have to see itself or reflect on its position, desires and violence. Instead, the invisible man, no longer seen as such, can simply take pleasure in capturing the other. And this is not, Sasakibara insists, merely an issue for otaku and moe media. The process whereby we "become 
closed down as a transcendent recognizer, treat others as 'characters that cannot be hurt' and forget our violence" (Sasakibara 2005: 25) can be seen in objectifying human relations, and even at the scale of groups and nations. Internalizing others or character-izing them, we do not encounter anybody, and violence forgotten is perpetuated anew.

In contrast to this dynamic, bishōjo games such as The Eternity You Desire foreground the player as a subject acting in relation to someone facing us, looking back and capable of being hurt. This is someone, and someone I desire to be with - emotionally, sexually, socially. She looks back and sees me. This contributes to what Sasakibara refers to as his "ethics" (rinrikan), or ethical view (Sasakibara 2003: IOI). The bishōjo games that inspire Sasakibara's thinking stress listening to others and learning about them, which allows for the player to "ethically face them" (Sasakibara 2003: II3). The player acts ethically with consideration for others, which can mean not acting in ways that hurt or harm others, or perhaps not acting at all, which implies a cultivated passivity. ${ }^{158}$ Acting ethically means recognizing one's capacity to impact others, to hurt or harm, and taking responsibility for actions and their consequences. In his ethics, Sasakibara insists on treating others as human beings and acting with consideration for them, even if they are "just fiction" or characters in a "game." This extends from virtual reality to reality as we know it, which Sasakibara articulated for me as follows:

It's about overturning power, or self-consciousness toward violence (bōryoku ni tai suru ji'ishiki). It's not only about whether one does or doesn't commit acts of violence, but rather recognizing the violence in oneself. It's about throwing away one's power, rejecting violence and not becoming a person who commits violent acts. ${ }^{159}$

Hearing this statement about not becoming a person who commits violent acts immediately brings to mind Ataru, who similarly strives to not become a "harmful person" (Chapter 2). Rather than contributing to becoming a harmful person, bishōjo games might have the opposite effect. In statements such as the one above, Sasakibara hints that one reason why sexual violence is not the norm among bishōjo game players in Japan - as some critics have argued of porn viewers and gamers in North America (MacKinnon I993; Sarkeesian 2014; Valenti 20I 5 ) - is because of bishōjo games, which provide a way to face and work through one's own violence and cultivate an ethical stance against violence. Facing one's own capacity for violence and violent desires is acknowledging all that is most abject and least reputable in oneself, 
which speaks to an ethics of queer life (Warner 2000: 33-35). ${ }^{160}$ Indeed, one might say that the norm, which denies the abject or locates it in others, is inherently unethical.

There is an ethics in recognizing that imaginary violence, sexual or otherwise, could become real, which leads to what Sasakibara expresses as self-consciousness toward violence. One has the capacity to make the fiction real, and in various ways with various effects; one has the capacity to act. Facing one's own violence, the violence within and its potential to hurt or harm others allows us to ethically interact with fictional and real others. Such emergent ethics, Sasakibara submits, serve to illuminate why so many people play through sexual, violent and perverse scenarios in bishōjo games and are affected by them, but do not commit harmful acts in the human world. They are moved, and moved to action, but also take responsibility for that action in relation to fictional and real others. ${ }^{16 \mathrm{I}}$ They imagine and create worlds with fictional and real others, and do so ethically. As we shall see, the ethics of moe takes this further by drawing a line between fiction and reality and orienting oneself toward the drawn lines of fictional characters. In this way, a space to imagine and create moving images - regardless of the content of images - is maintained, even as a stance is taken against actions that might harm others.

\subsection{Conclusion}

Back in Akihabara, Matsumura Kazutoshi has moved on to the topic of characters, love and relationships. "What do you do to make the player feel good when cumming? You have to get him to love the character. You have to get him to think that the character actually exists." " ${ }^{62}$ So Matsumura designs characters to be lovers, even as they are used for masturbation. These characters appear in love stories that Matsumura unpacks as follows. "People say that my work is very innocent. They associate it with pure love (jun'ai). How should I put this? They think of my games as extremely 'light.' This is in contrast to 'dark' games with themes such as rape and sadomasochism. But for me this division isn't quite right. In a light game there will be something harmful or toxic $(d o k u)$, and in a dark one something more, such as purity in sadomasochism. This something more exists even in crimes." (This resonates with Ôtsuka Eiji's imagining of Miyazaki Tsutomu and his "love" [Ōtsuka and Nakamori I989b: I94-I96].) Considering exploration of the many dimensions of human psychology and relationships to be 
central to his work, Matsumura designs games that are about love, even as they contain hints of "something more." This has been true since Rise (Raizu, Rise, I999), his first bishōjo game, which is about living with a robot girl named Nanako and helping her gain confidence - all while gazing at and desiring the cute girl character. Later, Matsumura relays to me his experience of receiving a letter from a couple who loved Rise and named their daughter Nanako. The letter made Matsumura realize that he is in a relationship with players, who are moved by his games.

Having purchased a rare copy of Rise, Matsumura shows me the cover. Against an empty background, a character image is offset to the lower right: A girl is sleeping on her side hugging a stuffed rabbit; her eyes are closed, and her bare legs exposed, bent at the knee and pulled up toward her stomach; in what almost appears like a fetal position, she looks very young and vulnerable. The cover was designed, Matsumura elaborates, so that the player would see himself reflected on it with Nanako and thus be enticed to take her home. Bishōjo game sellers and fans describe Nanako and characters like her as "cute." ${ }^{163}$ If, as anthropologist Christine R. Yano asserts, to call an object "cute" is to "establish a relationship of care and intimacy" (Yano 2013: 57), then in bishōjo games that relationship is fraught enough to join the "border intimacies" that shade into what are popularly perceived to be "criminal intimacies" (Berlant and Warner I998: 558, 560). ${ }^{164}$ As a cute girl character, the bishojo triggers complex responses. On the one hand, she is imagined to have an interior, which triggers empathy and encourages human interaction. This element of design has, as researchers Gary D. Sherman and Jonathan Haidt underscore, long been exploited by makers of toys, games and animation around the world (Sherman and Haidt 20II: 5). On the other hand, as literary scholar Sianne Ngai argues, cuteness triggers ugly feelings and violence as an "affective response to weakness or powerlessness" (Ngai 20I2: 24). This takes on more complex layers when we consider that the Japanese word for "cute" (kawaii) combines characters meaning "possible" $(k a)$ and "love" (ai). What is cute is lovable, and violence is always implicit in our relationship with the cute object we love. While the intersection of love and violence, and sex and violence, is often denied and associated with deviant and dangerous others, bishōjo games insist on it. They insist on the bishōjo, who is cute and lovable, and as a lovable cute object is among "the most objectified of objects" (Ngai 2005: 834).

The accentuated vulnerability of the bishōjo designed as a cute object to be acted on allows for, even anticipates, violence, but, at the same 


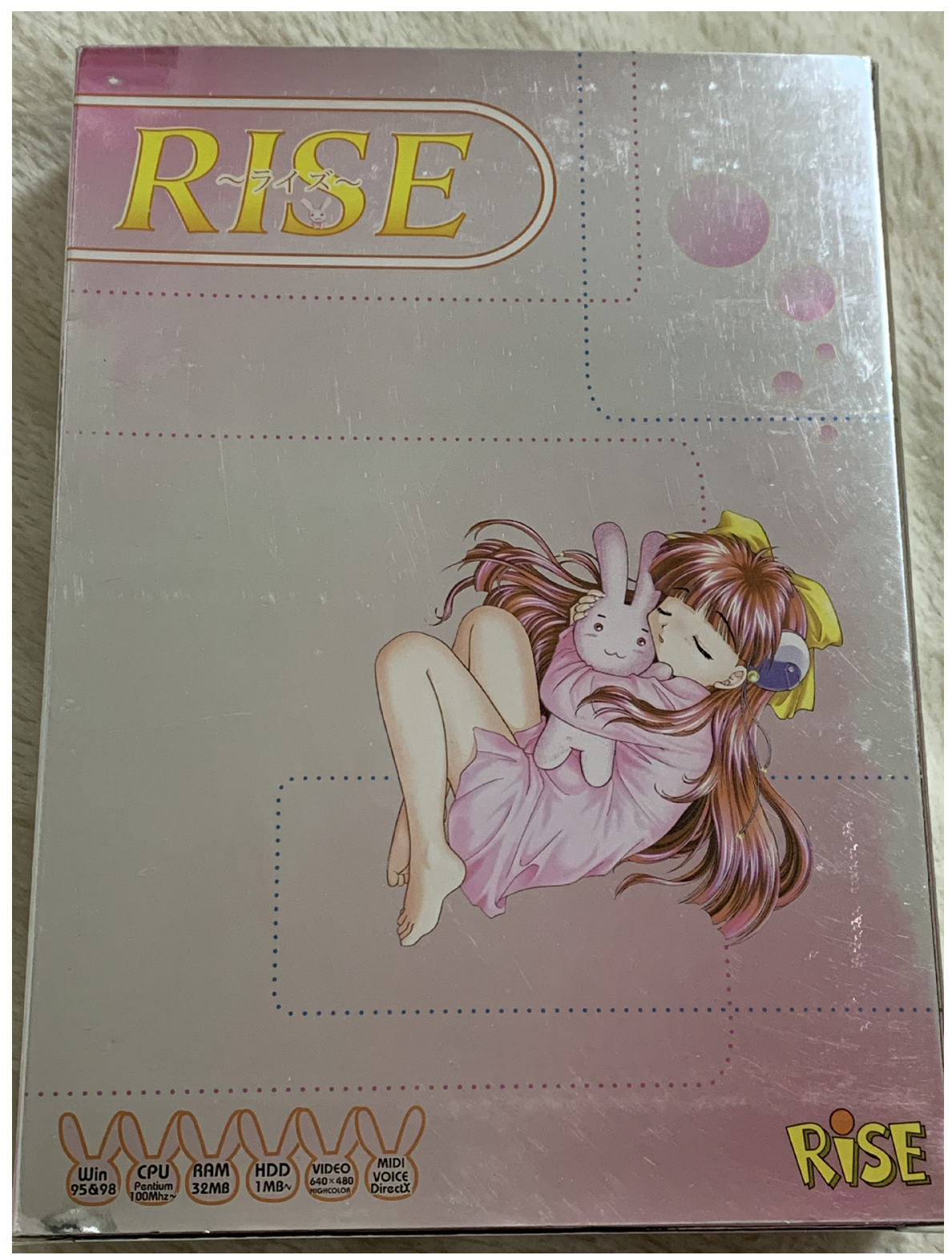

Image 15. Cover of Rise. The reflective finish turns it into a mirror. Note the size of the offset cute girl character and space to see oneself with her. Photo by the author. License: CC BY 4.0.

time, encourages a relationship of intimacy and care. While one might dismiss this as disturbing at best, media theorist Thomas Lamarre instead highlights that "relationships involving vulnerability and dependency, care and nurture, are not only those we tend most to prize in 
our lives, but they are also the very key to how we live ethically and politically" (Lamarre 201 5: IO3). Vulnerability in bishōjo games points, I argue, toward ethical ways of life. By design, bishōjo game players are moved to response, action and reflection. They interact with bishōjo characters more intimately, and know, if not care, more about them. This is why players such as Sasakibara Gō treat the bishōjo character not as an image or object, but as "someone" (Sasakibara 2003: I05). Indeed, Sasakibara refers to this someone as "alive" and "human," a someone he cares about, if not loves; her gaze and their interactions affect Sasakibara, who in turn sees his involvement, choices and actions as affecting her. Many of the men playing bishōjo games depend on relationships with cute girl characters, which extend beyond gameplay into everyday lives where they feel vulnerable. These relationships of vulnerability and dependency, care and nurture, are prized parts of their lives. They are also the key to how they live ethically and politically: Facing and working through ugly feelings and violence in virtual worlds, they share them in the actual world and take a stance against harmful actions. Geographer Ben Anderson describes affect as the push of life that "runs through individual bodies, collective populations and more-than-human worlds" (Anderson 20I2: 28). An ethics of affect must account for that push of life in more-than-human worlds. An example of this is what I came to know as the ethics of moe, which is the topic of the next chapter. 



\section{The Ethics of Affect: Drawing Lines with Bishōjo Game Producers and Players}

\subsection{Introduction}

Walking down Chūō Street in Akihabara on a cold morning in January 20I5, my companion is visibly agitated. A university professor with shared research interests, Kōta is also a bishōjo game player and an artist specializing in drawing cute girl characters. We are on our way to an event at Getchuya, but Kōta is not looking at that bishōjo game store, which is located on Chūō Street ahead of us on the right. He is looking across the street. I follow his gaze to the building that houses $\mathrm{AKB}_{4} 8$ Theater, where members of Japan's biggest girl group perform live shows. Now dominating the charts, $\mathrm{AKB}_{4} 8$ started out in Akihabara in 2005 , when the original group performed in that very theater. Because they had strong supporters in Akihabara, where I have been conducting fieldwork since 2004, I followed AKB 48 and its fans for some time. I remember lining up on the street on cold mornings not unlike this one. The theater brings back memories for me, some fond, but Kōta does not share the sentiment. The theater, advertised with massive photographs of the performers, is offensive to him. "Akimoto Yasushi, the producer of $\mathrm{AKB}_{4} 8$, did something he never should've done," Kōta explains. "He branded $\mathrm{AKB}_{4} 8$ as 'idols that you can meet' and sold access to the girls at live shows and handshake events. Do you hear what I'm saying? It sounds like prostitution. Idols used to be fiction, but Akimoto turned them into real girls to be bought and sold." ${ }^{655}$ We are on our way to a bishōjo game event, where girls are being bought and sold, but Kōta is adamant that this is not the same. "Virtual girls. That's the difference."

As we wait in line for the event at Getchuya, Kōta elaborates. The members of $\mathrm{AKB}_{4} 8$ belong to a category of performers called "idols"

How to cite this book chapter:

Galbraith, P. W. 202I. Ethics of Affect: Lines and Life in a Tokyo Neighborhood. Pp. I 57-I94. Stockholm: Stockholm University Press. DOI: http://doi.org/IO.I6993 /bbn.e. License: CC BY 4.0 . 


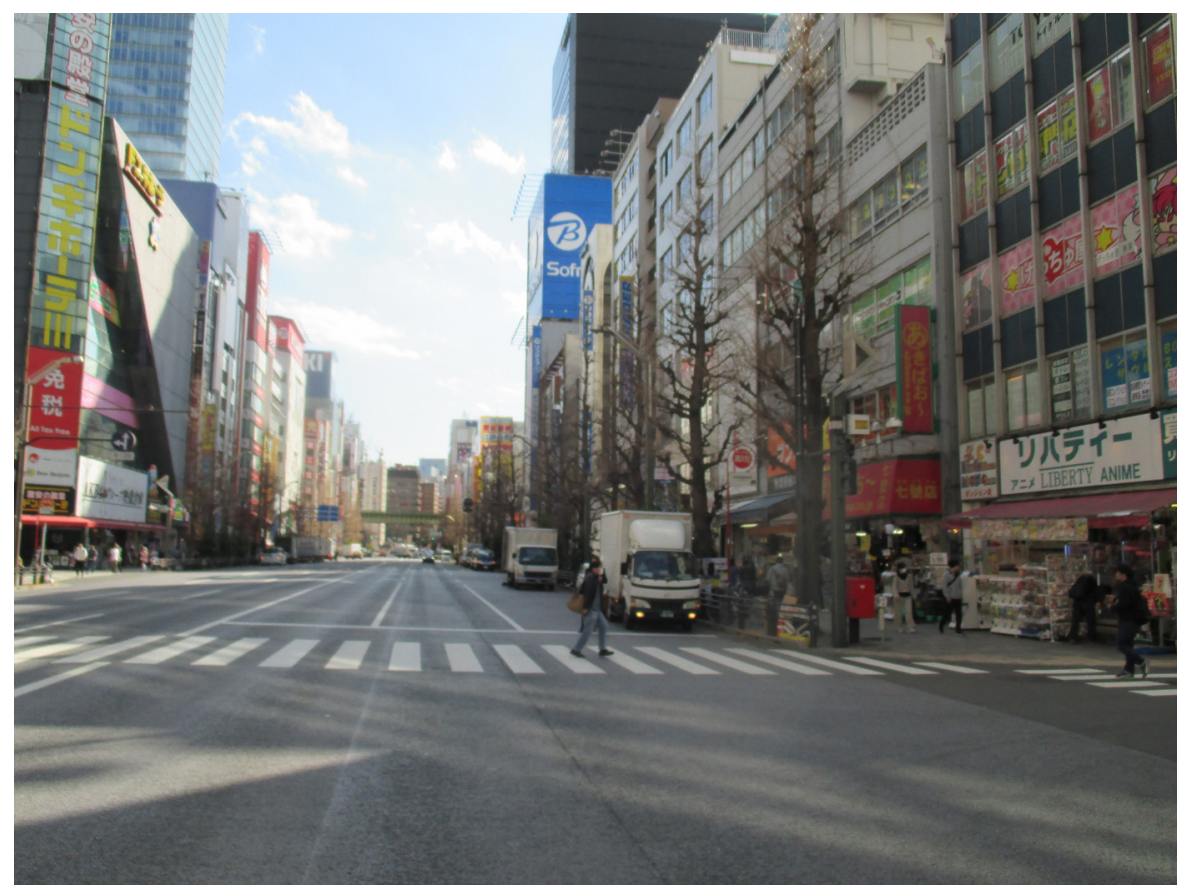

Image 16. In Akihabara, Kōta sees a face off between Getchuya, a bishōjo game store ahead on the right, and $\mathrm{AKB}_{4} 8$ Theater on the other side of the street. Photo by the author. License: CC BY 4.०.

(aidoru), who are beloved by fans and appeal directly to them for support. Born in 1980 in Tokyo and raised in the dense media environment of the city, Kōta associated idols with images. They did not have to be "real;" Matsuda Seiko, for example, was a "fake girl/child" (burikko) and also Japan's top idol. ${ }^{166}$ The I980s was a time, Kōta tells me, when people were becoming aware of their orientation toward fiction. I have heard all this before (see Chapter I), but recognize that Kōta is working something out as we talk. He is a manga/anime fan who came of age in a world where being an "otaku" was increasingly common. In junior and senior highschool, Kōta was surrounded by young men confessing their love for Tsukino Usagi from Sailor Moon (Bishōjo senshi Sērā Mūn, I992-) and Ayanami Rei from Neon Genesis Evangelion (I995-). In Kōta's world, the character Fujisaki Shiori from the bishōjo game Tokimeki Memorial (I994-), not the person who voiced her, was an idol. She was also his "first love" (hatsukoi). Given that Fujisaki - the character - sang a chart-topping hit in 1996, and that many men speak of her as a former flame, Kōta was clearly not alone. In university, manga/anime fans were declaring themselves married to cute girl characters 
and rejecting "reality," and, while not one of them, Kōta understood the feeling. He stands beside these men in Akihabara, which is their shared space. And he is angry at the return of the body and its fleshy reality in $\mathrm{AKB}_{4} 8$ Theater. There one is oriented toward reality, not fiction. Located right across the street from his favorite bishojo game store, it is something dirty, "matter out of place" (Douglas I966: 36).

In Kōta's response to $\mathrm{AKB}_{4} 8$ Theater, I observed the ongoing struggle to draw and maintain lines between virtual and actual, fiction and reality, two- and three-dimensional. If Ōtsuka Eiji, the editor of Manga Burikko who oversaw its transformation into a "two-dimensional idol comic magazine," writes about "virtual idols in bishōjo games" and "desire for simulation, where the bodies of women have come to be unnecessary" (Ōtsuka 2004: I 29), then it is bishōjo game players such as Kōta who grapple to maintain that orientation of desire in practice. "The two- and the three-dimensional are intentionally severed (ito-teki ni kitteiru) from each another," Kōta tells me. But are there not many places in Akihabara where the two- and three-dimensional exist side by side? "Yes, and that is why we must be conscious of the difference." To put it another way, "we" must be conscious of what "we" are here for - virtual girls, fiction, the two-dimensional - and conscious of how this differs from "reality." Again, Kōta is not alone. Arguing against criticism of "otaku" as "immature or unable to distinguish the real from the imaginary," psychiatrist Saitō Tamaki writes that, "In my experience, there are few individuals more strict about that distinction" (Saitō 2007: 227). Even as manga/anime fans enjoy working through layers of fiction in reality and reality in fiction, the two are "deliberately separated" (Saitō 2007: 245). Kōta is a manga/anime fan who came to Akihabara for cute girl characters in bishōjo games; he draws and is drawn to the lines of these characters, which he insists are separate and distinct from real girls and women and real in their own way. Confident that he knows the difference, Kōta condemns $\mathrm{AKB}_{4} 8$ producer Akimoto and $\mathrm{AKB}_{4} 8$ fans for (the unconfirmed possibility that they are) using and abusing girls even as he slips into a building right across the street to buy bishōjo games that allow him to use and abuse virtual girls. ${ }^{167}$ For all his confidence, in his lecturing me, I saw Kōta's lived negotiation of lines.

This chapter explores the ethics of affect among bishōjo game producers and players in contemporary Japan. Ethics is often taken to mean rules of proper conduct (Deigh 2010: 7), but anthropologists have argued that ethics are embedded in action and everyday practice (Lambek 20I0a: 2-3; Lambek 20I0b: 39-40; Das 2010: 376-378). 
Interacting with cute girl characters, bishōjo game producers and players are moved. The ethics of moe, or an affective response to fictional characters, is embedded in the actions and everyday practice of these bishōjo game producers and players and judged in interactions among them. Moe is a common term among manga/anime fans in Japan and manga/anime critics regularly discuss ethics, but the phrase "ethics of moe" (moe no rinri) is not widespread. I did not, however, invent the concept or wording, which is not a heuristic device or element of etic analysis. In dialogue with those I encountered in the field, I use the ethics of moe to describe the action and everyday practice of drawing a line between fiction and reality and insisting on it even if, and especially when, that line begins to blur. In the field, I witnessed people drawing lines and negotiating them, which is also living with uncertainty and ambiguity. ${ }^{168}$ Rather than trying to resolve this or fix meaning as the law would demand, I instead dwell with bishōjo game producers and players to observe and participate in the action and everyday practice of drawing lines, which is where the ethics of moe is located.

Exploring the relationship between fiction and reality can reveal ideology and open it to critique (e.g., Allison I994; Allison 2000; Allison 2006), and there are certainly indicators of broad sexual inequality in Japan to critique (e.g., Yan 20I6), but my aim in this chapter is to see how relationships between and with fiction and reality are constructed and lived. Rather than a reading to reveal hidden meaning that critics already know is there, I follow the example of theorist Eve Sedgwick's "reparative reading," which is open to surprise (Sedgwick 2003: I46, I 49-I 5 I). ${ }^{\text {I69 }}$ Like Sedgwick, I worry that the dominance of critical reading techniques "may have made it less rather than more possible to unpack the local, contingent relations" (Sedgwick 2003: I24; also Felski 2008; Felski 201 5). ${ }^{170}$ I choose to stick with those relations. The choice is "ethically very fraught" (Sedgwick 2003: I24), and I make it as part of my anthropological commitment to ethical engagement in the field (Bourgois and Schonberg 2009: I 4). It can be difficult to relate to others with radically different ideas (Hochschild 20I6: 5-I6) - especially ideas about sexuality, which spur even progressives to familiar critiques (Rubin 2OII: I 54) - but there are already examples of anthropologists exploring divergent ethics of sexuality and relation (Das 20I0; Dave 20I0; Day 20IO; Pigg 20I2; Kulick and Rydström 2015). Anthropology of Japan draws attention to relations with "imaginary girlfriends" (Allison 2013: 96; also Condry 2013), which can be life-sustaining, but questions of ethics remain. To explore unfamiliar territory, anthropologists 
walk with others (Ingold 20I I: I 62). The journey requires keeping one's eyes and ears, if not mind, open, and being open to encounters that can be surprising. We may not know definitively what is going on, especially when imagination is involved, but we can still work with relationships and learn ways of living and moving on.

\subsection{Drawing a Line Between Fiction and Reality}

A middle-aged man and slightly younger woman are seated behind a table at the Denkigai Matsuri, an industry event for bishōjo games (see Chapter 2), on August I3, 20 I5. They are meant to be promoting the new game Samidare Growing Up! (Samidare gurōin appu, Samoyed Smile, 2015), but the assembled Ioo or so men are not getting much insight from them. It has been a long day, with many at the event since early morning, and the Comic Market (see Chapter I) starts tomorrow. The man, who is a representative of the game's production company, is supposed to be leading the discussion, but admits to coming without a plan. Instead, it is the woman, a voice actress named Misono'o Mei, who is doing the heavy lifting. In Samidare Growing Up! Misono'o voices Kiryūin Kiriha, who she introduces to the audience as a girl who pretends to be rich and acts conceited. Referring to a flier distributed to the assembled men, Misono'o goes through the list of characters, gives her own impressions of them and asks the man to verify. In this way, Misono'o comes to a character described as a little sister and asks, "Is this the player character's actual sister?" The man is hedging, because depictions of incest in manga/anime are drawing criticism from regulators under the Tokyo Ordinance for the Healthy Development of Youths (see Chapter I). "It's fine!” Misono'o assures him. "Humans are all related anyway." Very well, then she is his sister, the man yields. Moreover, he has a thing for the little sister as a character type, which entails devotion and looking up to her brother. The audience starts nodding vigorously, as if affirming him and their shared interest in this type of imaginary character, which is common in manga/anime (Nagayama 20I4: I96-I97). Noticing this, the man suggests that the little sister character is becoming less common in bishōjo games, which saddens him. As if in rebellion, the man asks the audience, "Do you like to be called big brother?" He jabs his finger in the air toward a man in the audience before moving on to the next. "Do you like it? Do you?" The nodding has become more vigorous. "OK, so we like it, then." Thus affirmed, things quickly start to heat up. 
As a special service (and to fill up unplanned time), Misono'o agrees to sign the free posters that have been distributed to the audience, but one man, who has purchased a body pillow cover with Kiryūin Kiriha on it, asks her to sign it instead. The man on stage is impressed by the request. "What are you going to do with it?" he asks. "You dirty boy!" The older man is drawing attention to the fact that this younger man will go home and sleep with a body pillow with the character that Misono'o voices on it, and the pillow will have a trace of her in the signature. Does he like the character or the voice actress? Why does he need the signature? Does the connection arouse him? The audience bursts into laughter and applause. I wonder if this bothers Misono'o, who does not contribute to the discussion because she is busy signing. The older man asks if it is her first time signing a body pillow, which it is. "Oi! This guy just took Misono'o's first! Way to go!" The jocular affirmation of masculinity is familiar, but it is also an unqualified masculinity that appears "pathetic" (Lamarre 2006: 37I) and becomes a joke. ${ }^{17 \mathrm{I}}$ It is silly to talk about Misono'o's first, given that she is a sexually mature adult woman, and that the first in question is signing a sexy pillow cover makes it all the more so. In on the joke, the men are constantly laughing at themselves and one another. Even as the men shuffle by Misono'o to get her signature on the poster and thank her for her generosity, the man beside her at the table continues to playfully draw attention to how pathetic they are. "Is this your last event of the day? Gonna go home, rub one out and sleep?" Laughter. This is a positive environment for men who spend the night alone with fictional girls. How pathetic are you? Am I? Are we? Again, laughter. Nothing of the anger and bitterness that sometimes comes with being alone and feeling pathetic. Instead, laughter. Taking a break from signing, Misono'o comments on how well behaved the men are, even going as far as to call them "well-trained" (yoku chōkyō sareteiru). ${ }^{\mathrm{I} 2}$ When I reach the table, the only person in the audience who is phenotypically different and thus read as a foreigner, the comedian on stage cannot help but spotlight me as a particular kind of man. "Oh, hello," he says in English. "Are you hentai [a pervert]?" Surprised, I just nod yes, which draws more laughter. At me, and with me, because there are perverts everywhere. We are all perverts. Well-trained perverts.

Over the course of the talk event, I am struck by how imagined perversion is shared and affirmed in specific ways. A good deal of time is spent discussing the little sister character, but, while incest is certainly taboo, it is just one of many perversions imagined and created by the production company and shared with the audience of male players 
today. It is something to laugh at, as are the men, who are well-trained perverts. This becomes clearer when considering another topic that comes up: underage sexuality. The common point of reference is "lolicon," or "Lolita complex," which has a long history in manga, anime and computer/console games in Japan (Galbraith 2019). For some, the designation of a Lolita character, or a "loli," is age. A sexualized child character might be a loli (Nagayama 20I4: I30). Others consider it a design issue, with characters that are small and have a flat chest being designated loli, which is independent of age (see Chapter 3). For her part, Misono'o assumes that some of the characters in Samidare Growing Up! are loli, even though they all are in highschool and have large breasts. The designation seems to come from their being manga/ anime-style cute girl characters.

Importantly, she also assumes that some in the audience are "lolicon," or men with a Lolita complex who like loli characters. She confirms this by asking if the assembled men are lolicon. Many hands shoot up all at once, accompanied by embarrassed laughter. "It's fine!" Misono'o chirps. "Lolicon is righteous." More laughter, which comes from getting the joke that these men, these lolicon, are perverts and not pedophiles or predators. "Lolicon is righteous" (rorikon wa seigi) refers to a meme suggesting that "lolicon" as an orientation toward two-dimensional girls is righteous in comparison to an orientation toward three-dimensional girls, which might shade into "pedophilia." 173 (For a discussion of this distinction in Japan, see Galbraith 2019: 6366; also Chapter I.) The men at Denkigai Matsuri who are identifying as lolicon are perverts, and well-trained ones oriented toward cute girl characters in manga/anime and related media such as bishōjo games. They have come to the event not with an interest in underage girls, but rather manga/anime characters generally and cute girl characters specifically. This is an event for producers and players of bishōjo games, a form of interactive manga/anime pornography, not pedophiles attracted to children. A particular kind of pervert comes to the Denkigai Matsuri. Here, in the context of shared interest in the cute girl characters of bishöjo games, lolicon is affirmed as righteous. Shared as part of public interactions, the perverse interest is affirmed. Interactions of this sort play a part in training perverts, who understand their orientation of desire toward the lines of manga/anime characters, and who draw and respect the line separating fiction and reality.

The following day at the Comic Market, I meet John, an American acquaintance currently living in Osaka and in town for the event. Born in 1970 in Hawai'i, John served in the Navy before arriving in 


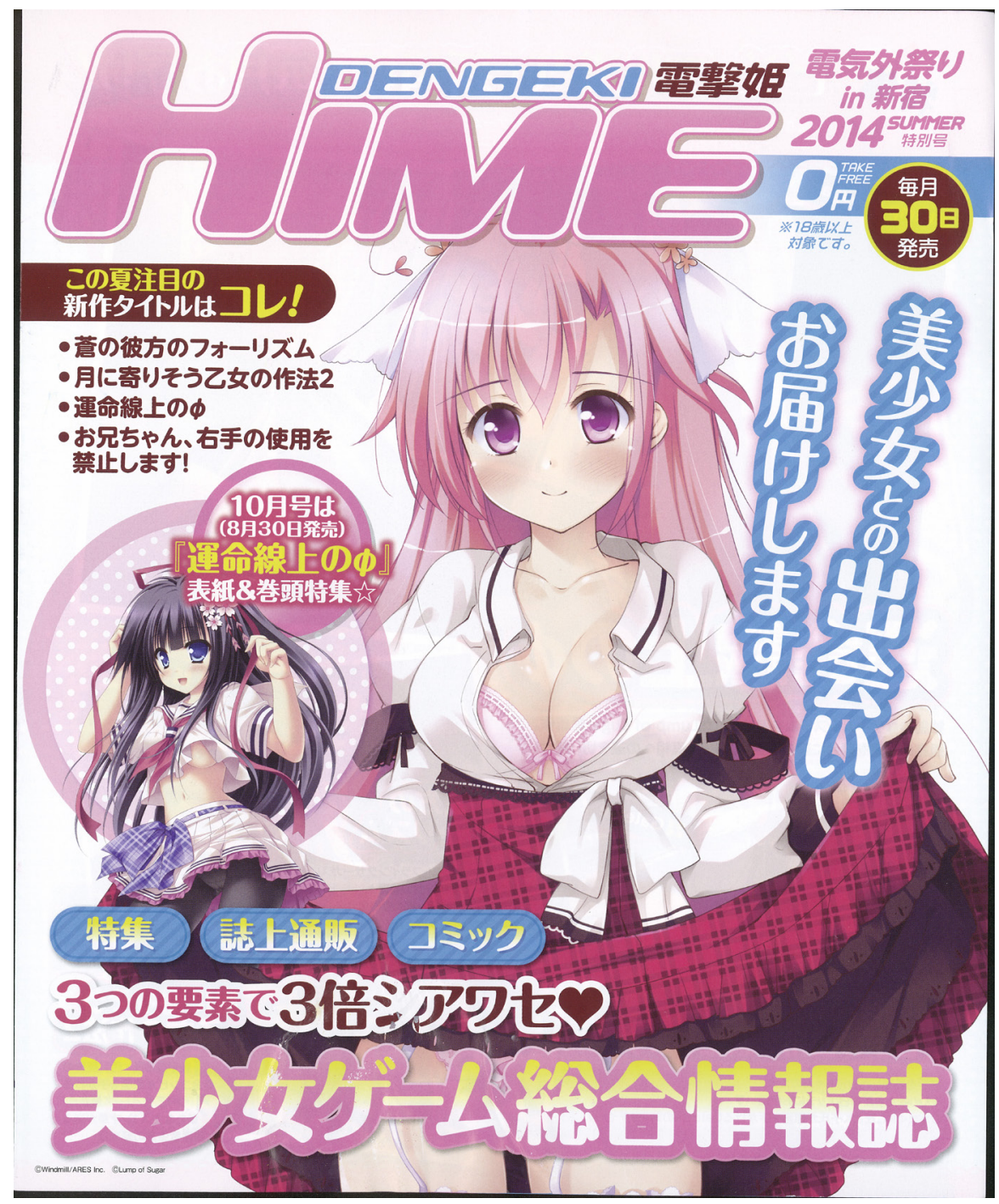

Image 17. Cover of a special issue of Dengeki Hime by ASCII Media Works. Released for the Denkigai Matsuri in summer 20I4, it promises to "deliver encounters with bishōjo." The games introduced focus on underage sex, incest and more. The magazine and event it was distributed at share these things openly, even as manga/anime-oriented men act as "well-trained perverts." Used with permission from rightsholder. License: CC BY 4.०.

Japan, where he decided to stay. He is a self-professed pervert and fan of manga/anime characters, and is at the event to buy fanzines featuring manga/anime characters having sex. Over the course of our discussion, I mention to him Misono'o's comment about lolicon being righteous. "Yeah," he enthusiastically agrees. "Loli is justice. Loli is life. It's about 
the protection of life and giving these girls a chance to grow up." To grow up? The cartoons? What is he on about? As John continues, it becomes apparent that he is advocating legalizing child pornography and sex work so that they can be better regulated, which he sees as good for children. Animated by the chance to share his thoughts, John draws on experiences seeing people from the United States come to Thailand to purchase sex with children, who were unprotected, which upsets him. The encounter is uncomfortable to say the least. I thought I knew John, who is now conflating and confusing the manga/anime lolicon that Misono'o and others consider righteous (or at least not wrong) with actual child pornography and sex work.

Later in the day, I relay the uncomfortable encounter to Tarō, an acquaintance born in 1980 in Kumamoto Prefecture and volunteering as a staff member at the Comic Market. "No," Tarō objects, flatly, but with a distinct edge of anger in his voice. "That's not right. That's not what lolicon is righteous means. It means separating fiction and reality." We walk as we talk, because as a volunteer staff member Tarō needs to make his rounds and conduct spot screenings. We pass by booths selling fanzines depicting all manner of sex acts, including some with animal characters, none of which seems to faze Tarō. In the "original" section, which does not feature characters poached from existing manga/anime franchises, he stops at a booth and picks up a fanzine. Realistically drawn children, in proper proportion, are stripped naked and sodomized. I am unsure why he picked it up in the first place, but, in any case, without a word, Tarō quickly puts it down and walks on. When we are safely out of earshot of the creator, Tarō explains his hasty retreat. "That was real and dangerous. Not my thing." Such expression is allowed at the Comic Market, or at least not against the explicit rules, but the personal rejection is forceful and insistent. Tarō is drawing a line at images that are "real and dangerous" (riaru de yabai), which need to be rejected to maintain his orientation toward the fictional bodies of manga/anime characters. He not only rejects actual child pornography and sex work by positioning himself against John, but also relatively realistic drawings of sex and violence involving children. Interestingly, when a mutual acquaintance gifts Tarō with a fanzine featuring cartoony cute girl characters from a manga/anime franchise being sexually assaulted, he does not reject it. Given that this acquaintance prefaced the gifting by making sure that I was "okay with lolicon," it seems that Tarō, who received the gift, is okay with it. As long as it is fiction, manga/anime, and nothing more "real." 
A tense moment at the Comic Market comes when it is announced that a I 5-year-old girl from Hong Kong is missing. The announcement, which comes over the loud speakers, compels John to come and find me. "Is she okay?" he asks, looking for assurance, fretting that something bad might have happened. It is not just that someone has been separated from their group in a crowd of hundreds of thousands of people, which is after all not uncommon, but rather that something sinister may be afoot. "I hope that they find her," John ventures. If they do not, it may confirm suspicions that manga/anime fans are not only perverts, but also predators. As John leaves, I am approached by a cameraman from the United Kingdom, who cannot understand the announcements in Japanese and asks what is going on. Immediately after I tell him about the missing girl, he quips, "One of these guys has got her under his girl cape." I follow his gaze to a group of men standing in a half circle; they have covers for body pillows, which are emblazoned with bishōjo characters, draped over their shoulders like capes; they wear bandannas to keep the sweat off their brows and have sunglasses on, despite being inside. They look suspicious to the cameraman. Dressed as they are, surely one of them, or one of the thousands like them at the event, must have kidnapped the missing girl. As I wince, the cameraman chuckles and moves on. These men were innocent, it turns out; the missing girl was just lost, and, in time, found her way back to her group. She found her way back despite being in an unfamiliar place, speaking a different language and not having her cellular phone. She found her way back with the help of the people at the Comic Market, who rallied to find and help her. In a place overflowing with imaginary sex, violence and crime involving underage characters, an actual teen in trouble was cause for concern and treated with care.

In the same space as bishōjo characters and men imagining sex with them, this I 5-year-old girl was not, I was told, ever in any danger. The overarching message of the stories that I heard about the girl who was lost and found at the Comic Market is that she may have been surrounded by perverts, but they were well-trained ones oriented toward fiction. Simply put, the perverts in question were manga/anime fans sexually interested in manga/anime characters; they were at the Comic Market, as bishōjo game players were at the Denkigai Matsuri, for explicit content featuring these characters. They were there for sexy cartoon girls, which are separate and distinct from real girls and women. These characters exist in manga/anime and bishojo games, which have their own reality, but nevertheless are separate and distinct from 
real girls and women and "reality." Many lines are crossed in manga/ anime - the incest taboo, underage eroticism and sexual violence, for a start - but not the line between fiction and reality. Insisting on that line allows for imaginary transgression. It allows the Denkigai Matsuri, Comic Market and other events to be spaces for sharing moe, or an affective response to fictional characters. As I observed it in the field, the ethics of moe is the action and everyday practice of manga/anime fans drawing a line between fiction and reality and orienting themselves toward the drawn lines of fictional characters. Others judge the actions of fans in interactions with them. Interacting with fictional and real others, one learns to draw lines.

\subsection{Interacting with Fiction and Reality}

The blurring of lines is said to be dangerous (Taylor 2007: 203; Thorn 2OI2: 2I; Laycock 2OI 5: 5), but in the case of manga/anime fans generally and bishōjo game players specifically, it is more accurate to say that lines are drawn even as they are crossed. A conspicuous example of this is maid cafés, which first appeared in Akihabara in the late I990s (Galbraith 20I9: 209). Deeply tied to bishōjo games, the first maid café was a temporary recreation of the café from Welcome to Pia Carrot!! 2 (Pia kyarotto e yōkoso 2, Cocktail Soft, I997), which opened at an event in 1998. Maid cafés moved to Akihabara with the temporary Pia Carrot Restaurant in 1999 and Gamers Café in 2000, before the first permanent maid café, Cure Maid Café, was established in 200I. The founders of this and other early maid cafés were players of bishōjo games, specifically games such as Bird in the Cage (Kara no naka no kotori, STUDiO B-ROOM, I996) and Song of the Chick (Hinadori no saezuri, STUDiO B-ROOM, I997), and they tried to recreate the two-dimensional world of maids in their establishments. Maid cafés originally targeted bishōjo game players, who were in Akihabara to buy games and wanted to enter into a space associated with them and distanced from "reality" (Morikawa 2008: 262-269). Maid cafés allowed for the two-dimensional to come into the three-dimensional, and for the three-dimensional to move closer to the two-dimensional. This is why they attracted bishōjo game players, who described cafés as "2.5-dimensional space" (Honda 2005: I 8I9) or "an ambiguous space between reality and fiction" (Hayakawa et al 2008: 26). While excited to encounter, bodily, the two-dimensional world, enthusiasts insisted that their relations were with characters, not 
"three-dimensional men and women" (Inforest 2005: 93). Such statements reveal an ethics of interacting with and being moved by fictional characters. If interacting with fictional characters in the real world has become common for manga/anime fans today globally (Greenwood 20I3: I-2), then so too has insisting on the distinction between fiction and reality in contemporary Japan (Saitō 2007: 226-227).

The result of this is an at times startling disconnection between fictional characters and the real people who perform them, or rather animate them, bodily and through the flesh (Silvio 20I 9: I 50-I74). Just as the young women who perform characters in maid cafés can be simultaneously university students and "I7 years old" - despite celebrating multiple birthdays with customers over the course of years working in cafés (Galbraith 2019: 207-208), and humorously drawing attention to this by identifying as "eternally I7" (eien no I7-sai), which is itself an outgrowth of the artificiality of idols (discussed above) - one can perform or animate a character and be separate from it.

Consider, for example, Toromi, who is an idol for many bishōjo game players. While her age is strictly confidential, Toromi is not a young girl, but still performs as one. After working in the bishōjo game industry for some time, Toromi debuted as a voice actress with the character of Mii from Petit Ferret's Popotan (2002). With a character image designed by Watanabe Akio (see Chapter 2), Mii is presented as a physically and mentally immature girl, the youngest of three sisters, but nevertheless is the character that appears in the most sex scenes in Popotan. Toromi, who went on to become an illustrator and singer, continues to draw cute girl characters that resemble Mii and to sing songs that capture her innocence and sexuality. One such song is "Bonus Track" from Toromi's album Toromi shitate (2010). ${ }^{174}$ Set to a driving beat and happy sound effects, Toromi sings the following words in an impossibly high-pitched character voice:

Let's do something fun and play together

It will be a secret from everyone

It will be just our secret

It will be a secret from papa

It will be a secret from mama

It will be a secret from everyone

It will be just our secret

It will be a secret from papa

It will be a secret from mama

Let's go! 
(Tanoshii koto shite asobō

Dare nimo naisho da yo

Futari no himitsu da yo

Papa nimo naisho da yo

Mama nimo naisho da yo

Dare nimo naisho da yo

Futari no himitsu da yo

Papa nimo naisho da yo

Mama nimo [naisho da yo]

Iku yo)

The song, stated plainly, is about a young girl making herself available to "do something fun" with an adult man. It is heavily implied that the something is sex. If the lyrics are not clear enough, the association with Mii ensures that listeners make the connection to sex. However, there is no young girl in the room when the song is performed. Having debuted professionally in 2002, Toromi is older than many of the men who listen to her music. The young girl exists as an assemblage of shared imagination, informed by the images Toromi draws, the voice she produces and the scenario that she creates in the lyrics. (This is very much how bishōjo games work; see Chapter 3.) The young girl is Mii from Popotan, a cute girl character and fiction, which operates independently of a "real" girl. Despite my being somewhat disturbed seeing dozens of men dancing, clapping and shouting in shared excitement when Toromi performed the above song live, none of the men I talked to that day perceived themselves to be pedophiles or predators seeking a sexual relationship with a young girl. ${ }^{175}$ They were here for the imaginary character inspired by bishōjo games and performed or animated by Toromi. The character was separate from not only real girls, but also Toromi, who was really in the room. The manga/anime character, the cute girl character, was the object of desire and affection, which was separate from girls and women generally and her specifically. ${ }^{176}$

This dynamic was even more striking at an event called Bishōjo Game Sixteen, which was held once a month at a café and event space in Akihabara in conjunction with the Day of Erotic Games (see Chapter 2). On the day in question, January 30, 2015, the event draws around 30 men, who stop by after buying bishōjo games, chat with others and watch a live-streaming show where a personable female emcee interviews people from the bishōjo game industry. The men are only a few feet from the stage and interact with the people on and off it in a very relaxed and intimate atmosphere. Despite the low lights on the audience, 
everyone can see everyone else in the small space. When Hayase Yayoi, a voice actress working in the bishōjo game industry, appears at I 5:00, the audience responds immediately. They already know that she is a "free" (furii) voice actress, meaning that she is not affiliated with an agency and so does not have to be as guarded with her words. With attitude that has earned her a reputation, Hayase introduces herself as a "pure bitch" (pyua na bicchi), where bitch is normally a derogatory way to refer to women as sluts in Japanese and pure can be either pure hearted or purely, absolutely. As Hayase uses it, pure bitch is a reference to her character, which is an unrestrained sexual being, and she owns it on stage. She is here to promote a book of collected images from Moonstone's Daemon Busters: Sexy, Sexy Daemon Extermination (Dēmon basutāzu: Ecchi na ecchi na dēmon taiji, 20I4). Moonstone is a bishōjo game production company known for frankly pornographic content, which has garnered it fans and critics. ${ }^{177}$ Daemon Busters, which will be adapted into an adult anime, is no exception.

While Hayase presents herself as an unrestrained sexual being, and is an attractive woman, the audience's attention is focused not on her, but rather the images projected on a screen behind her. Drawn from the generous sex scenes in Daemon Busters, Hayase is showing some provocative images. They are images of the character that she voices, Konoka Shizu, and three others involved in "sexy, sexy daemon extermination." The prototypical image is a bishōjo - round face and large eyes, small nose and mouth, different colored hair in different styles, different heights and breast sizes, but remarkably similar visually - with chest and panties exposed, a penis shape (digitally blurred due to obscenity law) nearby and semen on her. The men are scrutinizing the images, guided by Hayase and the emcee, who explain the characters and why they are erotic. The men nod, sometimes adding an opinion, to which the women respond. Hayase and the emcee, along with the men in the room and the ones watching online and making comments, are together reading the images of cute girl characters. Demonstrating their "moe image literacy" (Kagami 20IO: I3I), or understanding of the affective elements of design, they talk about "attributes" (zokusei) and "erotic parts" (eroi bubun). This one is a "committee chairperson" (i’inchō), "teacher" (sensei), "Lolita" (roriita), "sweet, supporting, underclassmen" (amai ōen kōhai), "big sister" (o-ne-san), "little sister" (imōto). Hayase and the emcee respond to the images with and as the audience: "thanks for the meal" (gochisossama); "that's good, that's good" (ii ne, ii ne); "so cute" (kawaii naa). Like the men in the 
audience, their focus is on the images on screen and the cute girl characters, which are separate and distinct from them. They are objects to be looked at and commented on; the sexual objects on screen have a value and eroticism all their own, which does not seem to be conflated or confused with the sexual subjects discussing them. The emcee in fact highlights how these sex objects are fiction and not a reflection of reality. Responding to an image of a little sister character waking her brother up with fellatio, she queries, "Have you ever been woken up by your sister like that?" One man: "No!" Another: "I don't have a sister!" And another: "No sister would ever do such a thing!" No such sister exists. This is a fictional character, after all. The emcee agrees: "That's reality for you. It's tough.” Laughter.

The bawdy exchange occurs in a space where the status of the body is quite peculiar. At first glance, it appears that two women on stage are talking dirty to a group of men in a dark room in Akihabara. This is clearly embodied, and they are in close proximity. At the same time, they are discussing fictional characters, which exist as images onscreen, images attached to voices such as the one that Hayase can produce and images in the minds of producers and players. The men who played the game were involved bodily with characters as they sat in front of computer screens, looked at characters and imagined them as they interacted. Producers and players interact with one another through the character image and are connected by imagination. ${ }^{178}$ The character of Konoka Shizu is associated with Hayase's body to the extent that she produced her voice sitting in front of a microphone in a studio, but the character looks nothing like her. Hayase is unequivocal that she is not the character or object of desire, which is fiction. Unlike the example of phone sex operators, who perform characters for men demanding reality and authenticity in mediated but still direct interactions (Flowers I 998: 38-44, 84-I05), Hayase steps away from the character, which is fiction that she and players co-imagine and co-create. For their part, the players do not demand reality and authenticity from her, because Hayase is not the character that she performs - or, more accurately, animates - and they understand and respect the distinction. The intimacy of shared imagination is paired with a separation of actual bodies - producers and players at first, but at Bishojo Game Sixteen also the fictional character and voice actress, who separate fiction and reality and maintain a distance between them. Even as imaginary participation makes the game play experience "real," and involves real bodies, the "experience concurrently more and less immediate than a live one" 
(Ortega-Brena 2009: 25) is still kept separate from "reality." This separation of fiction and reality, and fictional and real bodies, makes certain interactions possible.

For example, Hayase is frank and open in her discussion of Daemon Busters, even as players are extremely frank and open with her, which she does not seem to find to be sexual harassment, because she is not the sex object. Noting that eroticism is the key selling point of the game, Hayase introduces a man named Itō Life, who works as a key image illustrator for Moonstone and acted as the "erotic producer" (ero purodūsā) for Daemon Busters. "His erotic vision is very important to the game," Hayase points out. "Playing it, you gain access to his eroticism." This is not the first time I saw games and related media and material marketed through a discourse of sharing the imagination of others. Indeed, production companies often advertise upcoming titles by saying that players can look forward to sharing a particular creator's imagination. Players tend to gravitate to certain creators because they share, or want to share, their imagination and to be moved by it (recall the discussion in Chapter 3 ). However, because the production involves multiple creators - character designers, voice actresses, scenario writers, players - bishōjo games entangle multiple relationships of shared imagination, which are differentially emphasized at different times. So it is that Hayase and the audience share the imagination of Itō Life at Bishōjo Game Sixteen. Recalling her interactions with Itō Life, Hayase says that the man hired voice actresses if he "responded" ( han'nō) to them. "Basically, if he got hard, you got hired," Hayase says matter-of-factly. "That is quite a raw (namanamashii) audition," the emcee ventures. Perhaps, Hayase offers, but it was not about her or her "flesh-and-blood" (namami) body. Rather, the audition, as Hayase understood it, was about her ability to produce a particular character voice that got a response. "I was very pleased! That got you hard? You hired me for that? I thought, "Wow, I might be able to make it in this business." Having succeeded in producing a character that moved someone to bodily response, Hayase felt that she could make it in the bishōjo game industry. It was the character, not her body, triggering the response. This, Hayase clarifies, is why it was not in fact a "raw audition" so much as producing the character in person and getting an immediate response.

Open and frank discussion of imaginary sex is part of bishōjo game culture generally and events such as Bishōjo Game Sixteen specifically. As Hayase articulates it, Daemon Busters was intended to encourage 


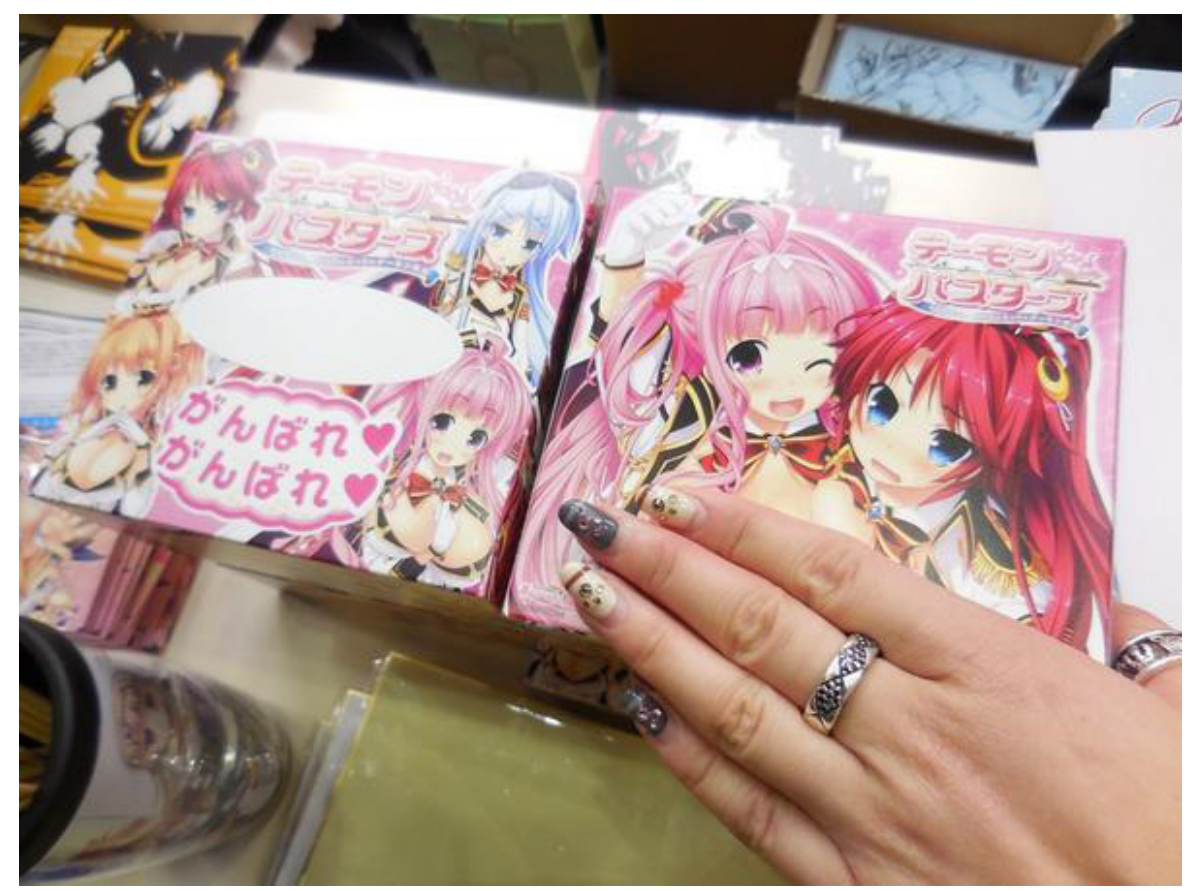

Image 18. Hayase distributing Daemon Busters tissue packs at the Day of Erotic Games. The packs tell the user to "do their best," as in their best getting off while playing. Photo by the author. License: CC BY 4.O.

something like social or shared masturbation. Not only is Itō Life sharing his eroticism with players, but players are also sharing what works for them. "The intention was that players would Tweet screen shots of the game as they played and comment," Hayase elucidates. Comment, that is, on what got a response and worked for them. For Hayase, this "playfulness" (asobi gokoro) is an important part of the game, and something that she shares. At Bishōjo Game Sixteen, Hayase talks about her character, which is projected on a screen behind her, in what can only be described as a playful way. The audience playfully interacts with her, and the men do not conflate the person speaking on stage and the silent images on screen. With it established that she is not the character or object, Hayase confidently plays with the audience. For example, she produces Konoka Shizu's voice live, which elicits an excited and audible gasp from the audience. There is a gap between her speaking voice and "moe voice," which is highlighted when she shifts from one to the other. Back in her speaking voice, she playfully discusses sex not only in terms of the characters on screen, but also herself (a pure bitch) and the men in the audience (pathetic). When the emcee comments again on 
how erotic the images collected in the visual book are, Hayase crows, "I think that you can use it, but please don't bring it to me to sign if the pages are stuck together." Laughter from the audience. It is definitely "for practical use," one man says. Then buy two, Hayase retorts, and bring me the clean copy. More laughter. After she has finished her on-camera interactions, Hayase comes off stage and sits at a table in the back of the room, where men line up to speak with her. Many tell her what was arousing and worked for them in the game. When they mention her performance, she smiles and thanks them, saying that she tried to make it sound as erotic as possible. ${ }^{179}$ (Again, notably, she says this not in her character or moe voice, which is kept separate and distinct.) The game is very erotic, right? The characters are so cute, right? Hayase shares stories about the game, shakes hands and signs books. Excited talk and laughter fill the air. If the character appears as a shared object, then Hayase appears as a fellow player. The separation of Hayase and the character makes certain interactions possible.

Another example of interacting with fictional characters and real people, or the convergence of actual and virtual bodies that requires lines to be drawn and maintained, occurred at Charara!!, a bishōjo game industry event held every month in a space above an arcade on Chūō Street in Akihabara (see Chapter 2). On the date in question, July I 7, 20I 5, around 50 men gather at I 7:00. The men are far less energetic than usual - sluggish, even - and spend most of the time looking down at their smartphones, poking at screens and listening in a distracted way. The emcee for the evening, a young woman dressed in a character costume, sits next to a screen that is playing a looped promotional video including the words "rape club" (reipu kurabu). The juxtaposition, which does not draw attention or comment from anyone, is somewhat eerie. One of the first presenters is an older woman representing Unicorn-a, the bishōjo game production company where she works. While incredibly confident in presenting the upcoming game that she is here to promote, which she has no doubt now done many months in a row, the older woman wastes no time in introducing another woman, who turns out to be a voice actress featured in the upcoming game. The voice actress would not be considered physically attractive in Japan young and thin being the hegemonic ideal (Aiba 20I I: 274) - but she is experienced in the industry and performs cute girl characters.

The older woman begins to interview her as a way to introduce the game and its characters to the audience. She asks what kind of character the voice actress is performing. The question seems to catch the 
voice actress off guard, but she manages a response. "Loli... Loli... A loli!" ${ }^{80}$ With the stuttering but dramatic declaration, the audience snaps to attention. Something has been announced. Something is happening. Playing the audience, who she knows she has captured, the older woman prompts the voice actress, "Do you like loli characters?" More confidently now: "I love them." Whether she loves them as characters, or loves performing them, the result is that she has created an overlap with the audience, which is composed of men assumed to be lolicon. In fact, so certain is she that these men are lolicon that the voice actress offers, as a way to generate interest in the upcoming game, to recreate a scene from it for the audience right now. Not only will she do it live, but with one of the men in the audience. This does not, however, mean reading lines together. Instead, the voice actress wants one of the men to offer his name so that she can insert it into the scenario script, which she has in front of her to read from. The men in the audience are quiet and squirm nervously; no one is willing to give a name, which surprises the voice actress. "This is a loli kiss scene!" she beseeches. "Is no one interested?" Perhaps they are embarrassed or do not want to be singled out, but no one speaks; tension builds. The voice actress then challenges everyone to a game of rock-paper-scissors, with the "winner" providing a name.

As luck would have it, a young man in the front row wins. Sitting cross-legged directly on the gray carpet with everyone else, he is perhaps only four feet from where the voice actress is standing. The woman is not particularly tall, but because the young man is seated on the floor, she towers over him. "Seriously? I won?" he says, obviously flustered. "Are we really going to do this (jitsugen suru)?" The phrase the young man uses here, jitsugen suru, is a noun (broken down, it is jitsu "truth or reality" and gen "reality or present") and verb (suru "to do") that means more literally "realize," "actualize" or "materialize," which is both exciting and dangerous. After some more prodding from the voice actress, the young man finally serves up a name: "Kazuki." It is a generic name, a non-name, and no one in the room believes that it is the young man's real one. Real or not, a name was needed and has been given. And so the performance begins. "Everyone," the voice actress says. "Imagine that you are Kazuki." The room goes silent. No one is poking at screens anymore. A few are fidgeting and shifting their weight, anxiously, and one has risen to attention on his knees. "Everyone, imagine that it is you." Imagine that the character is talking to you. The voice actress turns her back to the audience so that we cannot see her face. Taking a deep breath, she produces a voice: 
Kazuki...

Think of me as a normal woman...

(Kissing sounds)

Is that really her voice? It sounds completely different. Just like an anime character. I only now notice that my eyes are closed. I had closed them to see the character; a Lolita character that is not a woman. I open my eyes and look around to see that the other men have their eyes to the floor, sealed shut, listening intently. Imagining.

Kazuki...

(Kissing sounds)

(Heavy breathing)

The slowly delivered, sensuous scenario ends before it can become too arousing, but, judging from the way that the men break their silence in excited clapping and cheering, it was arousing enough. "Awesome," the man next to me whispers to himself, but loudly enough to also be whispering to others. "I'm glad I got to hear that in the flesh (nama de kikete yokatta)." Hear it in the flesh: To hear the character in the flesh; the character given a fleshy reality by the voice actress; the character now in the flesh and in the room with us, speaking to and appealing to us directly, whose body affects our bodies. Co-present in the room, we hear the character in the flesh, both hers and ours.

Even "Kazuki," eyes still glued to the floor and blushing, is moved. He seems almost unable or unwilling to bring his eyes back up to see the woman standing in front of him, who is not the character, but someone who animated it live. Someone who produced it with us, here, in the flesh. We imagined and created her, together. Imagining that we were "Kazuki" and that the character was speaking to us, just as she does when we input our names and play bishōjo games, we were all part of the scene. If "Kazuki" opens his eyes and looks forward and up, the character will disappear, because there is a person there. And he is not "Kazuki." None of us are. So keep the eyes closed and let the character linger in the imagination, in the room, in the flesh. After waiting for the promotional presentation to finish, "Kazuki" discretely makes his way to the Unicorn-a table to order the game. A line of "Kazukis" do. The voice actress has already left, but the character that she animated continues to be present in the images on the wall, in the games being ordered and in the shared imagination of the men and women involved. ${ }^{18 \mathrm{I}}$ Just as a line is drawn between the character and voice actress, a line is drawn between the room and outside. Just 
as no one thinks the voice actress is the character, no one seeks the character outside. The character is not there; she only exists here, in the game, in our imagination. Many lines were crossed in the transgressive co-imagination and co-creation of the character - the fictional girl who becomes real, inter-generational eroticism, imaginary sex in public - but not the line between fiction and reality, the manga/anime world and real world, the two- and three-dimensional. Insisting on this line makes the sexual play possible. Blurring of the line between fiction and reality occurs in a controlled space of ritual interaction, much like a maid café, and with the expectation that other lines will not be crossed. This speaks to an ethics of moe, where manga/anime fans responding to fictional characters draw and insist on lines. They insist on the drawn lines of manga/anime characters, and in so doing draw a line between fiction and reality.

\subsection{Drawing Lines with Others}

Located outside of the Electric Town Gate of JR Akihabara Station, Gamers is a landmark. Covered in images of cute girl characters, and with cute girl character voices pouring out of loud speakers and onto the street, it is a beacon for manga/anime fans and, as the name implies, gamers. Indeed, Gamers is one of the central hubs for buying new bishōjo games in Akihabara. So it made sense when the store was chosen to host Erogē Briefing, a gathering for bishōjo game producers and players. Much discussed in the weeks leading up to it, the event was held in a small space on the top floor of the seven-story building housing Gamers. Adopting a somewhat unique format, Erogē Briefing was to feature two moderators, one male and one female, interacting with an audience of devoted bishōjo game players and speakers from three bishojo game production companies. Two of the three companies were described as "core" (koi), meaning they produce dark and disturbing content, and the last as "Lolita" (rori). After interacting with speakers from all three companies, the moderators would invite everyone back to the stage to talk to the audience. Producers would be able to hear from players in real time. In sharp contrast to other events (e.g., Bishōjo Game Sixteen), in the second half of Erogē Briefing, when all the speakers and members of the audience would engage in open dialogue, the event would not be live streamed online. The cameras, which would run in the first half, would be turned off. At that time, what would be said in the room would be between the people in the room. What would 
be said could not be predicted, and one had to be there to hear it. This insistence on presence added to the affective charge in the room when the day of Erogē Briefing finally arrived on February I I, 20 I 5.

The moderators, Senaka (middle-aged man who works in a bishōjo game production company in Osaka and runs a regular talk show) and Ayumi (middle-aged woman with ro years of experience as a voice actress), kick off the event with the usual playful sexual banter. Ayumi asks if we know the meaning of "brief," which appears in the title of the event. Having looked it up online, she reports finding that it means a man's underwear. She originally thought, then, that the event had been named after the underwear of men who play bishōjo games. Although she does not say it, the suggestion is that these underwear would reflect players' masturbation, which is to say that they would be cumstained. Everyone laughs as Ayumi reacts with mock disgust and calls the idea gross. The straight man in this comedy duo, Senaka steps up to explain that the meaning of "briefing" is to relay information on a particular topic, in this case the state of the bishojo game industry. Looking around the room at the 50 people (mostly men, but also four women) seated in folding chairs, Senaka and Ayumi comment that they know practically everyone here. If not friends, these are still known faces and personalities who frequent events of this kind. They are experts on bishōjo games coming together to share opinions. When Senaka and Ayumi pose questions, the audience is engaged, shouting out answers, responding with loud sounds of affirmation ("Aaaah!”) when they have understood something and laughing boisterously. When Senaka, Ayumi or a speaker prompts them, the audience jumps in almost immediately with information, ideas and questions. At Erogē Briefing, players are treated as experts and their input as valuable.

The intensity level in the room rises with the third and final speaker of the evening. The man is Fukumimi, a character designer working for IRIS, and he is here to promote the game I Love, Love, Love You!! (Shuki shuki daishuki, 20I4). The players are evidently excited to see this man, who many were apparently waiting for. Although promotional material for the event identified IRIS with "Lolita," Senaka and Ayumi seem somewhat reluctant to use the word, which is increasingly tied to critiques of manga/anime images around the world. It is beyond obvious, however, that I Love, Love, Love You!! is a lolicon game, where players take on the role of a man who becomes the manager of a store frequented by young girls. He gets to know a shy girl who helps around the shop, a Russian girl living next door and a "little idol" (puchi 
aidoru) who is also a runaway and lives in the park. Relationships grow more intimate as the player advances to establish "a slightly risky loveydovey couple." Even as Senaka and Ayumi pose questions to Fukumimi, they seem unsure whether they can or should use the word lolicon. Staff members from Gamers are at the back of the room with the camera, ready to cut things off if necessary. For his part, Fukumimi is disarmingly open and frank about creating games that reflect his desires - and he does not hesitate to use the word lolicon. With that line breeched, Senaka and Ayumi get the audience involved by polling who among them is a lolicon. More than half raise their hands (including one of the women). Somewhat taken aback by the number, Ayumi hastens to add that all of the characters in the game are of course over I 8 years of age, which triggers howling mirth from the audience. What we are looking at, Ayumi continues to assure us, are not "young girls" (osanai ko), but "small girls" (chiccha na onna no ko). She uses words for different sizes - "small" $(s h \bar{o})$, "medium" $($ ch $\bar{u})$ and "large" (dai) - to refer to the different body types (= apparent ages) of the characters. This imaginative interpretation of Fukumimi's words and work inspire those watching the live stream online to begin typing/chanting, "Small! Small! Small! Small!" ${ }_{182}$ Responding, Ayumi asks Fukumimi if he likes "small” women, to which he replies, "Yes, of course." More fireworks online, which reflect what is going on in the room. "It appears," Ayumi concludes, "that we have a lot of loli people here."

Seeming eager and playful, Fukumimi leans in on the discussion of desire. It is not the case that he is attracted to only "small" women. No, Fukumimi elucidates, he has very broad interests. Approached "as figures" (taikei toshite), he is interested in a wide variety of women. As if to bolster this assertion, Senaka, who apparently knows the character designer well, relays a story to the audience. One day, he was walking down the street in Akihabara with Fukumimi and saw a woman dressed in a maid costume. Heavyset and round, Senaka expected that the woman would not be Fukumimi's type. He does not, after all, draw characters that way. When he mentioned his reasoning to his friend as they walked, Fukumimi reportedly responded that he likes that figure very much. Recalling that time and smiling, Fukumimi nods. "Yes, it's true. My interests are way too broad." Listening, I wonder just how broad they are. Not only is Fukumimi attracted to women of various shapes and sizes (shades of objectification duly noted), but this encounter with a woman dressed as a maid on the streets of Akihabara hints that he is also attracted to two- and three-dimensional women. If 
Fukumimi likes both fictional and real "small" women, then this raises the specter of the pedophile and predator, which always haunts the discussion of lolicon. As if to defuse that concern on camera, Ayumi interjects that whatever Fukumimi's interests might be, no matter how broad, there is no problem, because the small women in I Love, Love, Love You!! are all over the age of I 8 and are, in any case, fictional characters in a bishōjo game.

Reacting to this repeated assertion of the status of his characters as legally adults and fictional characters, the playful Fukumimi takes the freewheeling talk in a dangerous direction. Instead of concurring with Ayumi as was expected, Fukumimi mentions that he sometimes goes to gradeschools for location scouting and snaps photographs of girls. Before Fukumimi has even finished his sentence, the room erupts in an explosion of movement and sound. "Abunai! Abunai!" shouts Senaka. Whoa! Whoa! Danger! Danger! "NG! NG!” shouts Ayumi, her voice overlapping with Senaka's. No good! No good! "Ikan!" Senaka continues to shout, this time in a blunt male speech pattern. Wrong! No way! Seated on either side of the man, both Ayumi and Senaka have leaned over to position themselves in front of Fukumimi and are frantically waving their arms and hands in front of him. The gesture seems almost to be deflecting the gaze of the audience in the room and online. Almost as if they are scrubbing what has just been said from the record and mind and washing it away. Making similar gestures of rejection and denial, the audience - every single person in the room - is shouting, "No!" Although much of this is playful and performative, it is clear that Fukumimi has crossed a line, which is being reasserted. As the noise dies down, Ayumi punctuates the response with, "Omawarisan! Kono hito desu!" Mr. Policeman! This is the guy! Throughout it all, Fukumimi sits in silence, arms folded across his chest, enjoying the chaos that he has triggered. He may have been joking, and seems pleased with himself at getting such an animated response, but he also appears to understand well that a line has been crossed.

One reason for the intensity of the response is because the line has been crossed in personal and shared ways. Everyone in the room is a bishōjo game player, and many have played games featuring Fukumimi's characters; they have shared his imagination and been involved in relationships with his characters. (For more on these relationships, see Chapter 3.) Are these cute girl characters fiction or reality? Comfortable that the answer is fiction, Fukumimi abruptly referenced reality, which implicated players in something that they were moved to reject in personal 
and shared ways. Even as the players share movement in response to bishöjo games, they now share movement in response to crossing a line when discussing bishōjo characters. The response is not as simple as rejection and denial, because they are Fukumimi's people and he is one of them. When Fukumimi discusses an upcoming project creating something he calls "pervert fancy" (bentai fanshii), Senaka retorts that he is going too far, but Ayumi interjects. "Hentai desho?" You're a pervert, right? Don't pretend like you're not right there with him! Protesting lamely and comically, Senaka ends up acknowledging it. Yes, I am a pervert like him. We are perverts. A gesture of solidarity with Fukumimi, the man who makes his games and walks with him down the street in Akihabara. And the people in the room, over half admitting to being lolicon and most coming to the event to see Fukumimi, also cannot simply reject and deny him. They have shared, and do share, his imagination and movement. ${ }^{183}$ His games are their games. Just as his pleasure is shared, so too is his problem. These bishōjo game players are perverts like him. He just crossed a line and needed to be reminded of it, which can be done, together.

The camera has been turned off, the connection to the outside severed. "This is our time," Senaka proclaims. "We are free!" As if to demonstrate and get things started, Ayumi says the word that she avoided earlier: "Lolicon, lolicon." To this, Senaka responds, "Omorashi, omorashi," referring to peeing one's pants, which is one of the eroticized scenarios in I Love, Love, Love You!! Like Senaka and Ayumi, representatives from bishōjo game companies and players in the audience can now say anything. Although the audience is already actively participating, the moderators offer stickers to everyone who speaks up from this point on. The stickers, courtesy of IRIS, are of the characters of I Love, Love, Love You!! peeing themselves. "These omorashi stickers can be yours," Senaka cries, generating laughter and applause. Representatives from all three production companies are on stage, but Fukumimi persists in being the most provocative. "I want to make a full-on pedophile game," he says. "All the character ages would be clearly indicated." This is an implicit challenge to the Ethics Organization of Computer Software, a self-regulatory body for bishōjo games that requests characters appearing underage be noted as I 8 years of age. Fukumimi is also challenging players by using the word "pedophile" (pedo) as opposed to "lolicon," which raises questions about the relationship of the content to reality. "You get out of here!" Senaka barks, laughing and waving him off. "I don't think that the day will come when that sort of 
game will be tolerated," Ayumi adds. "This is not a matter of funding or marketing." It is also not a matter of law. As an example of ethics in action, a line is drawn and insisted on. The sort of game that Fukumimi is proposing, a "full-on pedophile game" (gachi pedo gèmu), will not be allowed or supported. Some in the audience are nodding yes, others no. They are negotiating the line, together. An example is made of IRIS, which is described by those on stage as a "pervert production company" (hentai $m \bar{e} k \bar{a}$ ), but this is also the adult computer game company that attracted most of the audience to the event.

Are we not perverts? That is the question posed when Fukumimi challenges the audience to a game of rock-paper-scissors to win promotional material and swag for I Love, Love, Love You!! "Does anyone want this?" he tests, raising the first of many objects emblazoned with images of the cute girl characters he draws. A thunderous roar as the audience - every single person in the room - shouts, "Yes!" So if Fukumimi is a pervert, he is not alone. "Raise your hand if you want to be in the competition," Ayumi says. Many, many hands go up at once. "Everyone with their hand up now is a lolicon!" Ayumi may be right. Here they are, hands in the air, at an event in Akihabara. They see one another and recognize themselves as one of many in the room and beyond. Several rounds of rock-paper-scissors decide who gets signed copies of I Love, Love, Love You!!, wall hangings and more. Caught up in the moment, I participate and am surprised to be among three people in the running for a set of three cups representing the three main characters of I Love, Love, Love You!! Rather than continuing until one of us gets all three cups, we are summoned to the front of the room to compete for one of the three. "Which do you want?" Fukumimi asks. To use Ayumi's terms, one character is "large," one is "medium" and one is "small," but they all look very young. "Point to the one you want on the count of three," Senaka says. "One... Two... Three!" All three of us are pointing at the cup with the "small" woman, which triggers riotous guffaws and clapping from the audience. Nodding and grinning, Fukumimi watches. "Take a good look at these guys," Senaka says, drawing the moment out for humorous effect. "They need to be marked.” These guys? Me? Am I on this side of the line now? I lose both subsequent rounds of rock-paper-scissors and end up with the last untaken cup, which is the one emblazoned with the image of the "large" woman. She is the one that looks the most physically mature, but, given the manga/anime aesthetic, this cute girl character still appears very young. She sits in a puddle of pee, ashamed, eyes meeting my gaze as I 


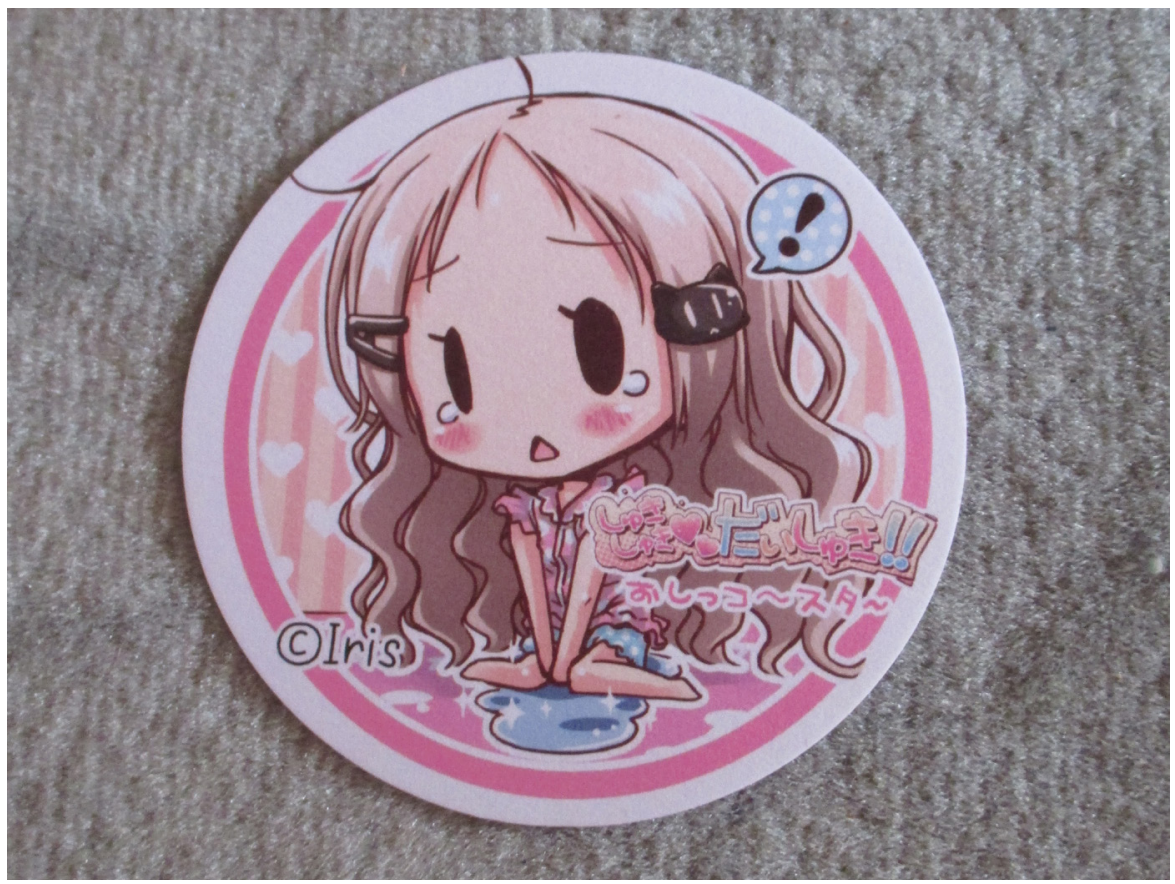

Image 19. Sample of swag received at Erogē Briefing. The character is from $I$ Love, Love, Love You!! and raised questions about fiction and reality. Photo by the author. License: CC BY 4 .०.

look at the cup. What am I to do with this object of mine? Could I drink from it in public? No, that would cross a line. Well, not in Akihabara. I could drink from the cup here. But would I, and should I? Where is the line? Where is mine?

\subsection{The Ethics of Moe in Akihabara}

In the field, I observed lines being drawn by bishōjo game producers and players such as Kōta, who slips into a store on one side of Chūō Street in Akihabara to buy games filled with imaginary sex, violence and crime, but criticizes sexual exploitation that he imagines is taking place in $\mathrm{AKB}_{4} 8$ Theater on the other side of the street. While Kōta uses and abuses what he calls "virtual girls," he is angered by the thought that men might be doing the same to real girls and women. Just as fiction and reality are, as Kōta puts it, "intentionally severed" from each other, so too should be cute girl characters and real girls and women. I observed lines being drawn by men such as Ataru, who sits in a café in Akihabara and discusses his sexual desire for cute girl characters, but 
states that men like him are not "harmful people," because they are oriented toward manga/anime fiction and understand and respect that it is separate and distinct from reality (see Chapter 2). So it is that Ataru sits in a café in Akihabara not far from a gradeschool and talks openly about his sexual desire for underage characters, which are separate and distinct from the schoolchildren on the street outside. The men I encountered in the field were oriented toward the cute girl characters of manga/anime generally and bishōjo games specifically, and they insisted on the drawn lines of these characters. In the field, I came to understand that there is an ethics to drawing a line between fiction and reality and insisting on it. The ethical bishōjo game player draws a line between fiction and reality, which are intentionally severed and deliberately separated from each other. This is especially important when the fiction, if brought into reality, would harm others. Drawing lines, the bishōjo game producers and players I came to know insisted that one should be allowed to interact with fictional characters and be moved by them, but fictional characters should not be confused or conflated with "real girls and women."

At Erogē Briefing in Akihabara, Fukumimi crosses the line, and bishōjo game producers and players respond by insisting on it. Understood to be a man like Kōta and Ataru and not one of the "harmful people," Fukumimi unexpectedly suggests that he goes to gradeschools not unlike the one in Akihabara to scout locations and take photographs. To put it bluntly, Fukumimi suggests that he uses real children for reference, and might even desire them. Bishōjo game producers and players immediately and insistently reject this use and potential abuse of children. This rejection comes from people who happily identify as lolicon and enjoy I Love, Love, Love You!!, which is a game featuring explicit sex between an adult man and "small" women. Bishōjo game producers and players recognize that Fukumimi has said something, even if it is a joke, "dangerous." In an instant, what was playful and fun becomes serious. When Fukumimi suggests that he takes photographs of schoolchildren for reference, the fiction of the game is brought into relation with reality in ways that are ethically "wrong." If moe is an affective response to fictional characters, then Fukumimi has confused and conflated manga/anime-style cute girl characters and children. The shift is from "lolicon" to "pedophile," which bishōjo game producers and players reject. When Fukumimi suggests creating a "pedophile game," he is told that such a game will not be allowed or supported. Nevertheless, bishōjo game producers and players do not treat Fukumimi as an 
outsider, but rather as an insider who has crossed a line. Crossing that line immediately brings to mind Miyazaki Tsutomu, a serial killer and sexual predator - arrested after taking photographs of a child in a park - who confused and conflated fiction and reality with deadly results (see Chapter I). Conflation of manga/anime and photographs, manga/ anime-style cute girl characters and human beings, crosses a line drawn in the ethics that emerged among manga/anime fans, who openly and publicly share affective responses to fictional characters. For some, this ethics developed in a moment of seeing oneself in the criminal other and taking responsibility for the capacity to harm, which means acting with care. Most, however, simply make it part of everyday practice to draw a line between the two- and three-dimensional and orient oneself to the drawn lines of characters. Such fans separate fiction and reality and interact with, and respond to, manga/anime or cute girl characters; they interact with and respond to fiction as such. What I have been calling the ethics of moe undergirds the reaction to Fukumimi at Erogē Briefing in Akihabara, where bishōjo game producers and players together draw a line between fiction and reality and insist on an orientation of desire toward one and not the other.

The phrase "ethics of moe" (moe no rinri) comes from legal scholar Harata Shin'ichirō, who I met in Akihabara in 20I $5 .{ }^{\mathrm{I}}{ }^{4}$ After a year in the field, Harata helped me to make sense of what I was seeing. In his many works on the subject of virtual regulation (Harata 2006; Harata 2008; Harata 20I I; Harata 20I2), Harata identifies a legal limit. "My interest is in the question of whether or not the law can handle the concept of virtuality," Harata tells me over coffee in Akihabara. "By virtuality, I don't mean something such as virtual reality or fiction that is separate and distinct from reality, but rather something that functions as reality although it is not reality." ${ }^{85} 5$ The insight is as sharp as the dapper Harata - born in 1979 in Aichi Prefecture and now a professor of media and law at Shizuoka University - in his suit and tie. Can the law, which deals primarily with binaries such as real and fictional, true and false, guilty and not guilty deal with complexity of the kind observed in Akihabara? To get at this problem, Harata draws attention to child pornography law. In his studies of the law, Harata reports that he has found the reason that child pornography is not protected by free speech arguments and regulated strictly is because it is a record of child abuse. To make child pornography, one needs to have a child in front of a camera. When a child is involved in sex, a crime has been committed, which is punishable by law. To produce child pornogra- 
phy, one must commit a crime, so the law bans it. What makes child pornography distinct from obscenity law - meant to preserve standards of decency - and ordinances - for example, zoning, which is meant to ensure that young people are not exposed to media that impedes their healthy sexual and social development - is "abuse" (gyakutaisei). Put simply, child pornography law is meant to prevent the sexual abuse of children. What then of so-called "virtual child pornography," which a game such as I Love, Love, Love You!! might be categorized as? There is no child in front of a camera, and it is not a record of abuse, but there are still reasons to regulate it. These reasons are: one, it might be used in the seduction of children; two, it might trigger a pedophile or predator to abuse children; and three, it might be realistic enough to pass for child pornography, which then would undermine existing regulations. "I have questions about all three of those arguments, however," Harata says. "Fundamentally, the questions are about whether or not the virtual form approaches the real and whether or not it leads to criminal activity." The questions are empirical ones, which Harata argues have not been answered. ${ }^{86}$

As we walk around Akihabara, Harata brings the discussion to whether or not manga/anime should be treated as virtual child pornography. "It is clear that some manga, anime and games function like child pornography," he posits, "but are they the same thing, as laws in some countries suggest?" Manga/anime is characterized by what Harata calls "virtuality" in the sense that it functions as reality although it is not reality, but is this the same as the virtual in "virtual child pornography?" As Harata sees it, much of the concern in Western countries is with what he dubs "real virtual child pornography," which seeks to recreate sex with real children and can be mistaken for the real thing. This is not, however, the case with manga/anime, which is characterized by a distinctly cartoony or two-dimensional aesthetic. "To the extent that real virtual child pornography confuses the border between real and virtual, it is certainly legally problematic," Harata explains. "However, it is questionable whether or not the anime-style images that developed in Japan pose the same problems." Manga/anime characters are not meant to "reproduce" (saigen) reality or be a reality "substitute" (daitaibutsu), but rather, Harata argues, exist as "characters in a completely separate dimension from realistic human images." ${ }^{887}$ Like many others before him, in Akihabara, Harata demonstrates his point by holding up a bishōjo game and quizzing me as to if the image on its cover is "real" (riaru). It depends on what you mean by "real," I reply, 
as I have been trained to do in the field. Manga/anime real, yes, but not human real. Harata nods in agreement. "It isn't that these companies don't have the technology and skills to produce realistic images," he says, putting the game back in a pile of hundreds like it. "They produced it like this on purpose, because people are going out of their way to seek these anime-style images as opposed to something else." However, as his concept of virtuality alludes, Harata is not naive about the distinction between fiction and reality. He does not treat the virtual as "simple fiction that is severed from reality." ${ }^{188}$ Rather, manga/anime generally and bishōjo game specifically are superficially without "reality" (riaru-sei), but at the same time have their own "strange reality" (kimyō na riariti). Recognition of this strange reality is what is missing from the law, which it confounds. ${ }^{189}$

As we proceed around Akihabara, a place so associated with this strange reality, Harata turns his attention to moe. This is, after all, the "Moe City" (Chapter 2). As Harata uses the term, moe refers to "otaku sexuality," which he understands as an orientation toward fiction. "If moe absolutely doesn't connect to the reality of child abuse, then many of the legal concerns about 'virtual child pornography' do not apply," Harata reasons. "But we cannot say that there is absolutely no connection, which is the tension." From his studies - and, it should be added, his own experience as a manga/anime fan - Harata has come to the position that, with respect to virtual child pornography, the focus should not be on whether or not the child exists, but rather on the people who see the image and respond to it. ${ }^{190}$ What Harata refers to as the "otaku crucible" (otaku no jüjika) is the risk of "the realization of virtual sexuality" (vācharu sekushuariti no genjitsu-ka). ${ }^{91}$ This is the ambivalence of "otaku sexuality," or what Harata refers to as the "performative ambivalence of moe" (moe no pafōmatibu na anbivarensu). Hearing this within a few months of my exchanges with Kōta and Fukumimi, the point resonates deeply. Whether it be Kōta insisting on the difference between the "virtual girls" he uses and abuses and real girls and women who might be used and abused, or bishōjo game producers and players reacting to Fukumimi crossing the line and confusing and conflating fiction and reality, there is a performative ambivalence to moe, which is an affective response to fictional characters, but one in which the object is never entirely clear (Nagayama 2014: I I 5; also Chapter I). The ambivalence of the response comes from not knowing if these fictional characters are connected to reality, how and to what effect. However, as Harata sees it, the law should not attempt 
to resolve this ambivalence by deciding what is real - for example, that I Love, Love, Love You!! should be banned as child pornography and that there is no distinction between virtual and actual forms. Not only can the law not deal with the strange reality of manga/anime, but it also cannot deal with human beings living and interacting with that strange reality, which is ambivalent. (For a comparative case of the limits of law around issues of sex, see Kulick and Rydström 20I 5. ${ }^{\mathrm{I} 92}$ )

If men such as Sasakibara Gō ask how bishōjo game players live without becoming criminals (see Chapters I and 3 ), then Harata further asks how to live without laws that make us criminals by collapsing virtual and actual forms together and translating fiction into reality. In this context, Harata highlights the ethics of moe. "You could also call it the responsibility of otaku," he explains. "Does otaku sexuality, virtual sexuality, lead to child abuse?" Rather than accepting that "otaku" are not a danger because they are a "special type of person" (tokusbu na jinshu) and can always distinguish fiction from reality, Harata recognizes danger, which manga/anime fans must ethically face rather than deny. Responding to fictional characters raises questions about relationships with reality and potential harm. In lolicon, for example, or in an affective response to "loli characters," there are reservations about whether a child might be the object and whether a child might be harmed. "The ethics of moe means not realizing virtual desires and stopping them at the virtual dimension," Harata argues. "When it is difficult to make hard distinctions between the virtual and real, people struggle to make the distinction. That is the ethics of moe." Making the distinction, or struggling to do so, is the ethical action and everyday practice of manga/anime fans generally and bishōjo game producers and players specifically. The ethical manga/anime fan draws and insists on lines so that fiction and reality are separate and distinct and not confused or conflated. The ethical manga/anime fan interacts and responds to fiction as such, which is real in its own right. The distinction between virtual and actual, fictional and real, is not absolute or assured. That is precisely why lines are drawn and insisted on. This is a struggle to live with a strange reality that is ultimately ambivalent. This is a lived struggle of ordinary ethics in action and everyday practice, where outcomes are uncertain (Lambek 20I0a; Lambek 20Iob; Lambek 20I 5a; Lambek 20I 5b). ${ }^{193}$ Interacting with others contributes to the emergence of ethics in action and everyday practice. ${ }^{194}$

As a legal scholar, Harata's position is in stark contrast to colleagues calling for increased regulation. In what still stands as one of the strongest 
appeals for increased regulation, feminist lawyer Catharine MacKinnon argues that pornography is "the sexually explicit subordination of women graphically depicted" (Dworkin and MacKinnon I988: IOI).195 This definition is capacious enough that comics, cartoons and computer/console games might be included as graphic depictions. In fact, MacKinnon's language suggests this. For MacKinnon, pornography is a two-dimensional sex act. "The women are in two-dimensions, but the men have sex with them in their own three-dimensional bodies, not in their minds alone. Men come doing this. This, too, is a behavior, not a thought or argument. [...] Sooner or later, in one way or another, the consumers want to live out the pornography further in three dimensions" (MacKinnon I993: I7, 19). Here MacKinnon theorizes a relation between the consumption of pornography as two-dimensional sex and action in the world as three-dimensional sex, which is why it must be regulated. ${ }^{196}$ Fundamentally, Harata disagrees, countering that manga/anime fans in Japan make a distinction between "twodimensional" and "three-dimensional" and orient themselves toward the former (see Chapter I). Furthermore, Harata notes that the twodimensional image has its own reality, a strange reality, which is not accounted for in the arguments of those who would collapse the twoand three-dimensional together in ways that manga/anime fans would themselves reject. ${ }^{197}$ Among those sharing an affective response to fictional characters, Harata emphasizes the ethics of moe, which is drawing a line between the two- and three-dimensional and keeping them separate and distinct. The line is not always clear and clean, which is precisely why an ethics of moe is necessary in the action and everyday practice of insisting on lines.

When the pornography in question is "virtual child pornography," many of MacKinnon's assertions return in renewed pressure for regulation (e.g., Oswell 2006). ${ }^{198}$ Indeed, in many jurisdictions, there has already been legal action against such content, which seems to erase the distinction between actual and virtual forms, or to treat cartoon characters as children. On the one hand, the abuse of such a being is punishable by law, and on the other hand, those who possess such material present a potential threat that is to be dealt with legally. Consider, for example, the case of Christopher Handley, who was sentenced to six months in prison, three years of supervised release and five years of probation for possession of obscene material in the United States in 20 IO. The prosecution had begun several years prior, triggered by the discovery that Handley had imported from Japan "drawings of children being 
sexually abused" (Anime News Network 20I0). Specifically, Handley had pornographic manga that featured underage characters involved in explicit sex. The material in question was connected to lolicon, for example the magazine Comic LO ("Lolita Only"). In the sentencing, these characters were identified as children and Handley as having sexual desire for children. While there was no indication of Handley having material featuring actual children or any record of abuse or crime involving children, the law settles the meaning of this material. ${ }^{199}$ This is an example of what anthropologist Rosemary Coombe christens "juridical resolutions of meaning" and "limiting or denying ambiguity" (Coombe I998: 45). ${ }^{200}$ This provides clear answers, but, as Coombe underscores, also tends to obscure cultural dynamics that are not so clear.

We have already seen some of the cultural dynamics surrounding lolicon, which are reflected in the very media at hand in Handley's trial. Take, for example, Comic LO, where an artist divulges that he drew characters to appear younger than usual, was confronted by his editor and told, "The readership of $L O$ wants 9 -year-olds, but 8 is too young. Change the drawing" (Yaraon 2015). This may seem arbitrary, but in fact shows a line being drawn to ensure that characters do not appear too young. As the artist recognized, "This is the level of fine-tuning at LO." It is also a negotiation between the artist and editor, the magazine and the readers. The suggestion is that there is a collective or public, which has its own norms and standards, however arbitrary they may seem to outsiders. An even more striking example came in the July 2017 issue, where editors teased the next issue by making a statement about the magazine and its mission to serve lolicon, or people with a Lolita complex:

What's the method for lolicon to achieve happiness in times like these? That's obvious. 'Embrace fiction and sleep.' It's that simple. Don't expect anything from reality. Don't hope for a chance encounter. Don't get involved in crime. To that end, look, we've gathered together the best lolicon manga artists in Japan.

A number of things immediately stand out about the statement, which followers shared on social media and spotlighted as "too cool." ${ }^{20 r}$ Coming after over 350 pages of manga featuring hardcore sex scenes involving small-bodied, flat-chested characters, on the left-hand page of the magazine with many images of these sex scenes and child-like characters on the right-hand page, the statement positions the drawings as separate and distinct from "reality" (genjitsu). They appeal to lolicon, but readers are told to see them as what they are: "fiction" (fikushon). 


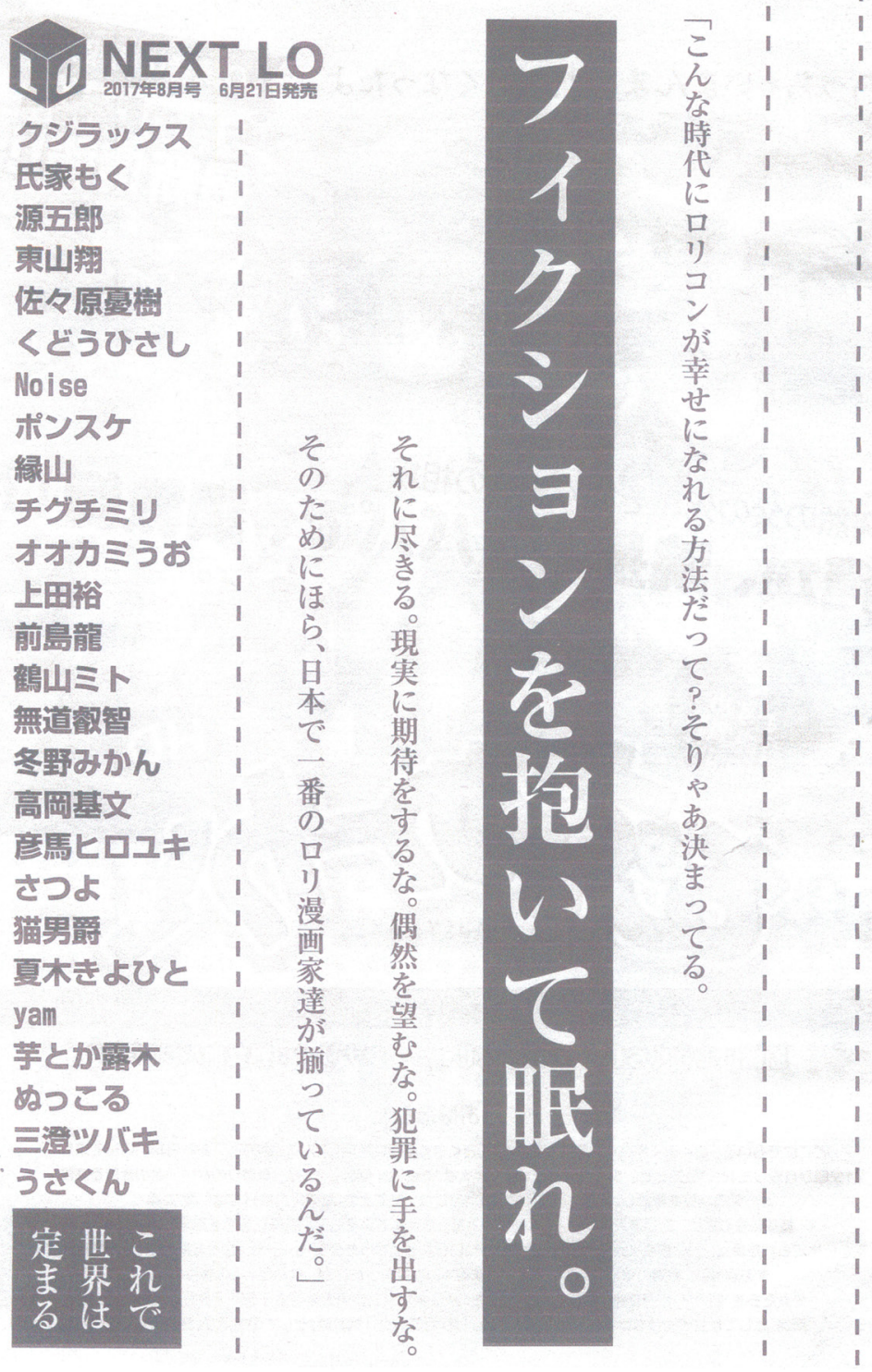

Image 20. Statement from the July $20 \mathrm{I} 7$ issue of Comic LO. Photo by the author. License: CC BY 4.०.

Nearly ro times the font size as other text on the page, in white set against a black background, is the message: "Embrace fiction." Do that, take it easy, expect nothing from reality, but everything from the artists in the preceding pages and those listed here as contributing to the August issue. These are the best lolicon manga artists in Japan. They will help you achieve happiness. So embrace the fiction. If it were real, 
it would be a crime, which destroys happiness rather than building toward it. A line is drawn between fiction and reality, and the reader is oriented toward one as opposed to the other, toward the drawn lines of fictional characters. ${ }^{202}$

Now, this is not as simple as reversing the juridical resolution of meaning with a cultural one. That might look like, for example, psychiatrist Saitō Tamaki stating forcefully that Miyazaki Tsutomu, a serial child molester and murderer who seemed to confuse fiction and reality in his lolicon, "was virtually the only one to cross the line" (Saitō 20II: 29). Even if Miyazaki was a manga/anime fan, Saitō argues, the culture of manga/anime fans is to recognize and respect the line between fiction and reality. Such a stance has trouble dealing with the complexity of Erogē Briefing and Fukumimi crossing the line, however. It cannot adequately address why someone like Machida Hiraku, an artist who regularly publishes work in Comic LO, publically responds to crimes against children by writing, "I can't forgive those who just go and do what I'm struggling not to do" (quoted in Nagayama 20I4: I49; recall Ōtsuka Eiji and his response to Miyazaki Tsutomu from Chapter I). This is intended as dark humor, but also highlights the very real possibility of overlap between the more realistic girls that Machida draws and real girls. Note that there is a recognition, however jokingly, that Machida himself might be struggling with his desires, and struggling to live without committing crimes, even as he shares those desires and struggles publically. He is encouraging readers and fans to draw and maintain lines, to recognize the violence of those who do harmful things, which could be them, and to avoid such actions. We see here an ethics of facing desires and working through them openly, or sharing "all that is most abject and least reputable in oneself" (Warner 2000: 35). We see here learning through peer networks and social interactions and relations. We see, as manga critic Nagayama Kaoru puts it in his discussion of lolicon, "ethics on a different dimension than the law" (Nagayama 20I4: I37).

It is this dimension that Harata calls to our attention. If the solution for many of his colleagues is to expand the scope of the law to regulate both virtual and actual forms, Harata wonders if law can sufficiently manage forms of virtuality such as manga and anime, which are characterized by a strange reality. Again, Harata does not make a simple distinction between fiction and reality, and he acknowledges the risk that "virtual sexuality" might be "made real" or "realized." Browsing shelves of bishōjo games in Akihabara, Harata does not ignore that 
some of the content functions as child pornography - as with his approach to virtual reality, it functions as reality although it is not reality - but rather than demanding an expansion of the law he detects and advocates for an ethics of moe in action and everyday practice. His is not a simple resistance to virtual regulation, but rather recognition of the limits of the law (compare to Cornell I995: 27, 99, 235), as well as recognition of already existing ethics among manga/anime fans generally and bishojjo game producers and players specifically. ${ }^{203}$ If the law lacks nuance, then critics would do well to appreciate that nuance exists in action and everyday practice. If the question is, as Harata poses it, whether or not it is possible to legally "draw a line" (kyokaisen o hiku) between fiction and reality, then my encounters in the field reveal how people are already drawing lines of their own. This is the ethics of affect, where bishōjo game producers and players engage in the action and everyday practice of drawing lines in relation to fictional and real others.

\subsection{Conclusion}

At a dinner party in Ikebukuro on November 28, 20I4, the young man next to me, Tomoyuki, has clarified an earlier declaration. He had said that he is asexual, but that is only with human beings. "I'm a twodimensional lolicon (nijigen rorikon)," he informs me. The combination of these two terms - "two-dimensional" and "lolicon" - into one was both novel and striking, because of the insistence on an orientation toward fiction as such. Tomoyuki was drawing and maintaining a line, which he confirmed interacting with me. This is ethics in action and practice, and it is not as simple as confirming the obvious. Even as manga/anime fans generally and bishōjo game producers and players specifically insist that cute girl characters are fictional, they are also real. Anthropologist Ian Condry argues that fictional characters are real when they are part of social interactions and impact social activity (Condry 20I3: 7I, 200-20I). ${ }^{204}$ Anthropologist Anne Allison similarly describes how virtual others in media and material form are a real part of contemporary Japanese society (Allison 2006: I80-I9I). This is true, but manga/anime fans and bishōjo gamers draw and insist on lines that make their objects of desire and affection separate and distinct from what they call the "three-dimensional" and is typically considered "reality." ${ }^{205}$ The line between fiction and reality is not always bright and bold, which is exactly why they insist on it, especially when 
others would be harmed if the fiction were reality. This is the ethics of moe among those interacting with and responding to fictional characters. In the field, I observed such ethics in everyday social interactions with bishōjo game producers and players (e.g., Kōta), spaces that bring fiction and reality together and cater to such men (e.g., Bishöjo Game Sixteen, Charara!!) and special events for them (e.g., Erogē Briefing). In the next chapter, I offer an ethnographic account of bishōjo game raves, which are affectively charged spaces where bodies - virtual and actual, media and material, male and female - come together and move one another. The events demonstrate not only an ethics of moe, but also how sharing an affective response to fictional characters can be life-sustaining. 


\section{Hajikon: Bodily Encounters and Dangerous Games}

\subsection{Introduction}

On Children's Day, a national holiday in Japan, I am lost in a seedy part of Kawasaki, an industrial suburb of Tokyo. ${ }^{206}$ It is almost I I:०0 pm on a Monday night, far too cold for May and quiet for a Japanese city. I scan my surroundings. On both sides of the long street are buildings and brightly lit signs featuring coquettish women beckoning. This is one of those not-so-secret areas where men go to buy sex, but it is almost deserted, more than likely because the target clientele did not go to work today and instead stayed home with family. "This can't be right," I say to myself, a little too loudly, while pouring over a map on my smartphone. The display of desperation has drawn the attention of a Japanese man in a suit. "What are you looking for? I think my place has something for you." He gestures toward one of the buildings. "Pretty girls, I promise. Japanese girls." He thinks that I am a sex tourist. Flustered as he moves closer, I raise my phone like a talisman to ward him off and gush, “No, I've already got a place! I'm looking for this club. Have you heard of it? It's a place for bishōjo game players, you know, otaku." Trying to be helpful, the man takes the phone that he thinks I offered. The glow of the screen shines on the bemused man's face as he holds the phone close to look at the website, advertised with a cute girl character. "You're one of those, huh? Wait a second." He waves and another man appears from the dark. After consulting the map, the two point me in the direction of a building a few doors down. It houses establishments not so different from the one the man on the street tried to introduce me to, but inside I finally spot the sign for Club Moonlight Dream Terrace and take a worn-out elevator to the fourth floor. ${ }^{207}$

How to cite this book chapter:

Galbraith, P. W. 202I. Ethics of Affect: Lines and Life in a Tokyo Neighborhood. Pp. I95-236. Stockholm: Stockholm University Press. DOI: http://doi.org/IO.I6993 /bbn.f. License: CC BY 4.०. 
Joining a line of Japanese men wearing shirts decorated with images of bishōjo characters, I am greeted at the door. "Welcome to Adults' Day (otona no hi)! Did you pre-register? Do you have your wife goods?" Yes to the first, no to the second. "OK, 2,000 yen." Still unsure what "wife goods" (yome guzzu) means, I pay the money and stand in front of a heavy padded door. When it opens, I am hit with a wall of sound: high-pitched female voices sing up-tempo songs remixed with a driving beat and thumping bass. Low mood lighting, a disco ball and a large screen at the front next to the DJ booth illuminate the space. The screen plays video clips of the slightly animated opening sequences of bishōjo games. In these clips, the characters are often shown in various states of undress and engaged in various sex acts, which are sometimes violent - gang rape on a train, for example - and often perverse - incest seems a common theme. The accompanying music is remixed songs from bishojo games. Hanging on the black painted walls of the club are promotional posters for new and upcoming releases. I recognize some of the characters from the screen and the shirts that men are wearing, as well as the character goods that they produce from their bags and show one another. A group is inflating body pillows, over which they slip covers representing these cute girl characters; on the front side of covers, characters, depicted in full body poses lying on a bed, are dressed, while on the back they are disheveled, breasts and genitals exposed. The characters are flushed, as if aroused and about to have sex, and some appear quite young. Over the course of an all-night rave, about 70 men boisterously dance and sing, drink copious amounts of alcohol and throw themselves on the floor in response to the songs the DJ plays and the images on screen. Hot from the activity, they strip down to their underwear, kiss their body pillows and declare their love for bishōjo characters, who they call their "wives" (ore no yome or mai waifu). The material objects that they bring and share and interact with are their "wife goods." In the club, there are a few women, who talk with the men and laugh at their antics. When the event ends at 5:30 in the morning, I make my way to Kawasaki Station to catch the first train home. After hours of being bombarded with imaginary sex and violence, it feels strange to be walking on this street where people come to buy sex. Club Moonlight Dream Terrace seems a world away.

This chapter examines a series of bishōjo game raves held at Club Moonlight Dream Terrace in Kawasaki, Japan, between April 2014 and August 20I 5. The primary focus is Hajimete no kekkon ("my first marriage"), or Hajikon for short. ${ }^{208}$ First held on June 29, 20I 2, Hajikon 


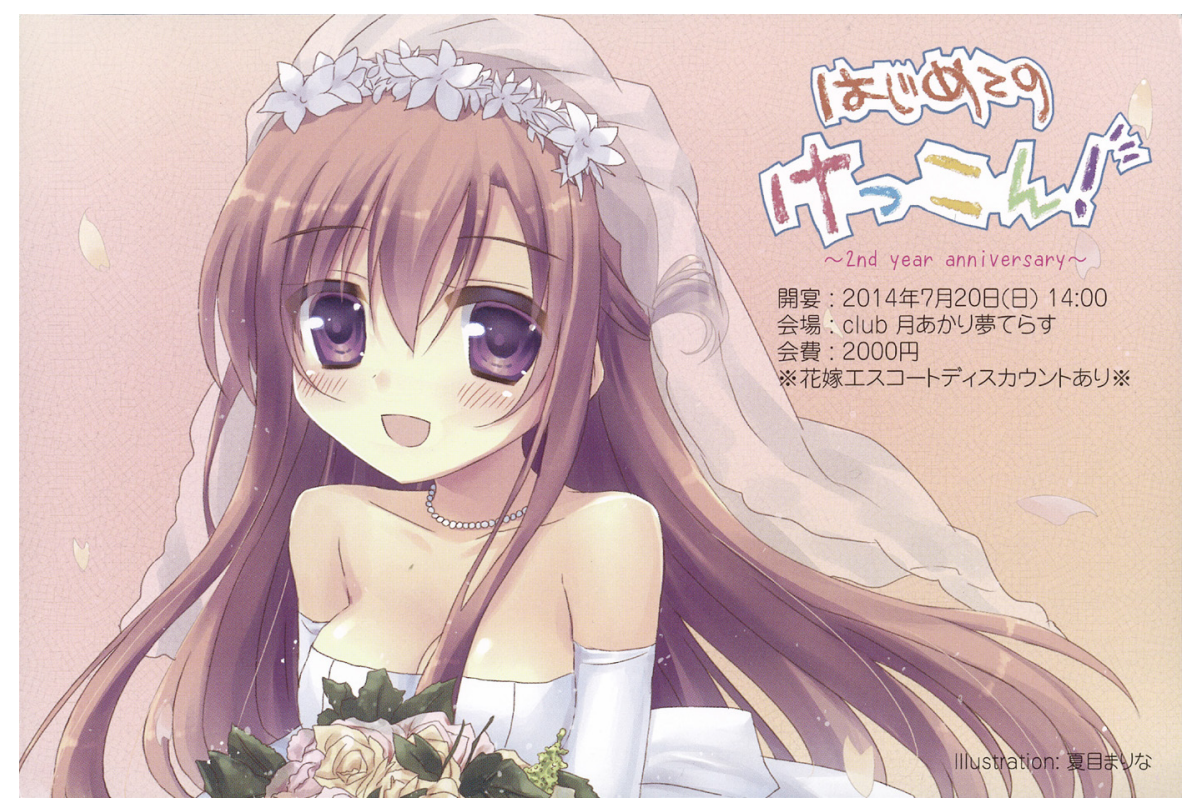

Image 21. Flier for Hajikon, which was a regular rave catering to bishōjo game players. Photo by the author. License: CC BY 4.0.

has a relatively long history of bringing together bishōjo game players, who perform as both DJs remixing bishōjo game music and dancers responding to it. Hajikon is not an industry event, but rather one run by and for bishōjo game players. Despite remixing official music and video clips, questions of rights and royalties are not raised. For their part, bishōjo game production companies are aware of Hajikon and other events like it, which they appreciate for generating buzz about games and see as a form of customer care. ${ }^{209}$ Put simply, the events draw some of the most dedicated bishōjo game players, whose affective attachments are affirmed and shared, which is thought to contribute to bishojo game sales. ${ }^{210}$ Rather than focus on its relationship to the industry, however, this chapter explores Hajikon from the perspective of participants, who are dedicated bishōjo game players and mostly men. The chapter zeroes in on how these players interact with fictional and real others - bishōjo characters and people, both male and female - at Hajikon and raves like it. If dangerous games are, as religious studies scholar Joseph P. Laycock describes them, characterized by the possibility that play in imaginary worlds might impact perceptions of and behavior in "reality" (Laycock 20I 5: 2I 2-2I 5), then bishōjo game raves qualify. These raves might seem to put women in danger, in that men 


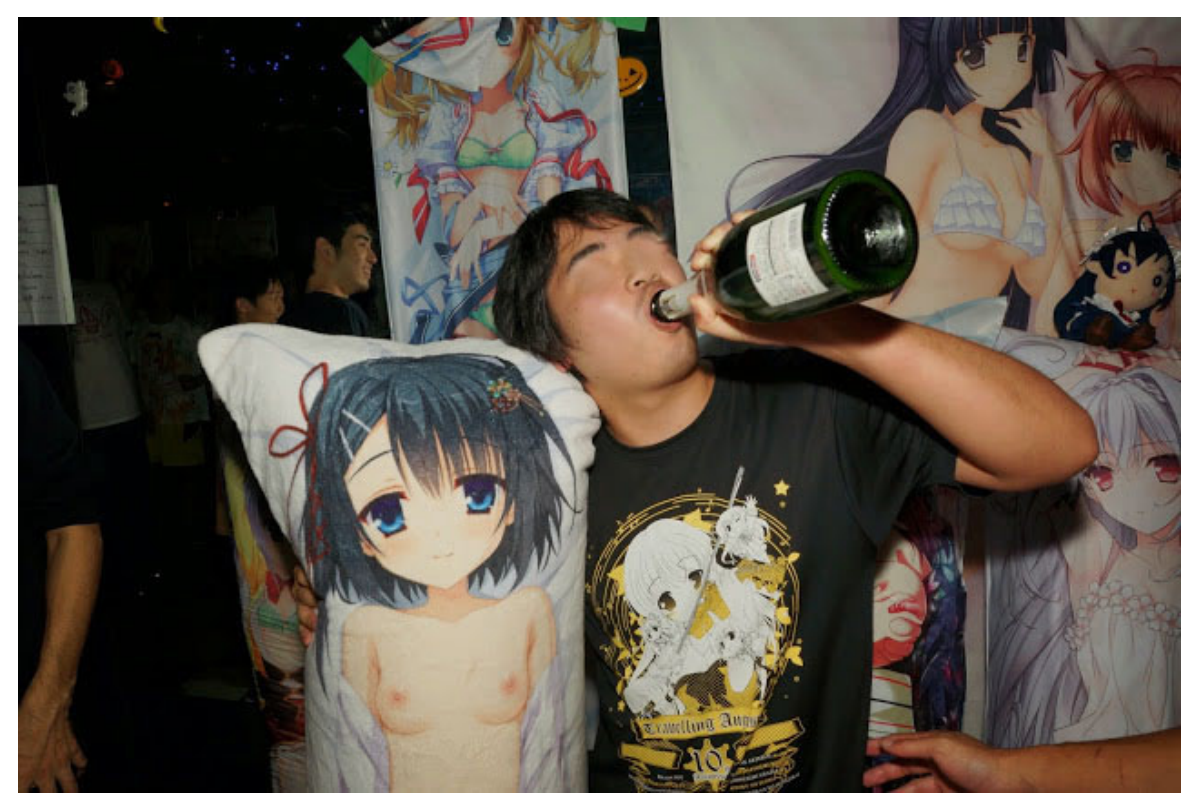

Image 22. Man poses with his wife and takes a swig from an open champagne bottle. Photo courtesy of Club Moonlight Dream Terrace. Used with permission from rightsholder. License: CC BY 4.०.

are responding bodily to images of sex and violence. Some of these men are drunk, while others behave as if they are, smashed by the affect of moving images and bodies in motion.

During my fieldwork at Hajikon, despite observing startling performances of imaginary sex and violence, I found that most participants are not particularly concerned about fictional and real bodies in relation. There is no danger, I was told, because participants know how to draw lines. The participants are bishōjo game players, and they come to Hajikon because of their affection for bishōjo characters, which they share with others at raves. In their orientation toward cute girl characters, I was told that participants keep fiction and reality separate, even as fiction and reality are side by side. The separation is not as clear and common sense as participants often make it sound. During Hajikon and similar raves, Club Moonlight Dream Terrace is affectively charged by the co-presence of bodies (Lamerichs 20I4a: 270-272), and lines blurs. Interactions with cute girl characters oscillate between care and cruelty, which is familiar from bishōjo games (recall Chapter 3), but these interactions occur with others in the club in what participants call "real time" (riaru taimu). Furthermore, cute girl characters take on both media and material forms, which allows for interactions with 
fictional others as bodies that move in a shared physical space. Finally, the imaginary sex at Club Moonlight Dream Terrace is literally next door to establishments selling sex. Media theorist Thomas Lamarre argues that manga/anime images of girls and women do "not necessarily present a radical break from received sociosexual formations (the homosocial workplace, normative heterosexuality, and the sex industry, for instance)" (Lamarre 2006: 376). For Lamarre, this raises questions: "Is there any reason to suppose that the interest in mastering images of women does not encourage violence toward real women - or that it does not encourage patronage of a sex industry that truly exploits women? Is there any reason to suppose that the image does not connect at all to actual social practices?" (Lamarre 2006: $38 \mathrm{I}-382$ ). The image does connect to actual social practices, and this chapter seeks to show how. Rather than accept that fiction and reality are unrelated, Hajikon challenges us to think how bishōjo game players relate them in practice. This returns us to an ethics of moe, or an ethics of affective response to fictional characters, and the performative ambivalence of moe (recall Chapter 4 ). Even if the games are dangerous, playing and sharing them is part of living ethically with desires and others (Warner 2000: 35; also Chapters I, 2 and 3). Sharing movement in response to fictional characters can also be life-sustaining for men struggling with precarity and failure in contemporary Japan.

The methodology of my fieldwork at bishōjo game raves differs somewhat from that of the fieldwork reported in previous chapters. Getting people to talk about and reflect on what was happening seemed inadequate to the experience of Hajikon and similar events. In attempting to convey the affect of bodily encounters with fictional and real others, I am inspired by the work of media and communication scholars Beverley Skeggs and Helen Wood, who developed a method to address the limitations of asking viewers to be reflexive about the content they were watching (Skeggs and Wood 201 2: I 22, I 25-I 27). ${ }^{211}$ Instead, Skeggs and Wood watched moving images with people and observed how they affected the body and moved it to response - even grunts and twitches that might be lost to traditional methodology or more broadly deemed "meaningless." Such a methodology requires placing one's own body with others in front of moving images to be affected by them. Blurring distinctions between subject and object, self and other, inside and outside, anthropologist Yael Navaro-Yashin argues that an interest in affect requires "affective attunement" and "openness" (NavaroYashin 20I 2: 20, 3I; also Stewart 2007). This means being open to 
sharing what Skeggs and Wood call "affective responses" (Skeggs and Wood 20I2: I26), which resonates with moe as an affective response to fictional characters. ${ }^{212}$ In the field, moving with others - responding, bodily, with them in laughter, tears and screams - often means blurring the lines between self and other in shared affective response. This requires being open to the movement of others, open to affect, which is at times unsettling, perhaps even dangerous. But openness to these bodily encounters, participation in these dangerous games of shared movement, is part of an ethics of engagement in the field (Bourgois and Schonberg 2009: I4; also Biehl and Eskerod 2007; Biehl and Locke 20I0; Garcia 20I0; Stevenson 20I4; Kulick and Rydström 201 5). It is to those encounters that I now turn.

\subsection{Adults' Day at Club Moonlight Dream Terrace}

Walking through the heavy padded door into Club Moonlight Dream Terrace, it takes a moment to adjust to the low lighting, flashes of images moving onscreen and the waves of sound, which are overwhelming in their intensity. The initial blast is painful, bodily. ${ }^{213}$ The sound gets into you. The thumping bass is a punch to the gut from the inside. The impossibly high-pitched female voices drill into the skull and send electric shocks through the brain. Circuits are overloaded and fried. Forget the ears - I cannot hear a thing. I feel it. Stumbling over the bodies of young men seated on the floor and changing into shirts emblazoned with oversized bishōjo character faces, I instinctively move away from the source of the sound, which is coming from speakers set up next to the DJ booth. In the direction I am heading there is a bar; people are gathering to order drinks, smoke and, in the relative quiet, talk. Ordering a beer, I see DJ Jun and DJ Fujikawa. They are both dedicated bishōjo game players who often attend events in Akihabara (for example, Bishōjo Game Sixteen; see Chapters 2 and 4), where we run into one another. We nod in mutual acknowledgement, share a few words about what games we are playing and move on. Not so with others grouped together, who are excited to see one another and ready to speak for hours on end. This is a reunion and time to catch up and share experiences playing bishōjo games specifically and life more generally. When DJ Jun greets someone, he claps the man heartily on the back and moves in close to be heard.

There are other ways to share experiences playing bishōjo games, which are occurring toward the screen, speakers and DJ booth. The DJ 
announces that he is going "dark," and images of two bishōjo having sex appear on the screen. Men start jumping up and down. "Oi, oi, oi!" A man screams as he rushes by me to the front of the room. Standing before the DJ booth, he continues to shout at the man behind the turntables, who has triggered him with this choice of music. The DJ smiles and nods, knowingly. The confrontation tapers off as the man makes his way to the center of the floor, moving to the beat. Knees bent and bouncing rhythmically, he begins to clap his hands to the left, then the right. Bouncing and clapping, other men join him. The beat picks up during the chorus of the song. The clapping is faster now, percussive, and louder as the number of hands has increased. The first man shouts out a count, "Hai! Hai! Hai, hai, hai, hai!" Then everyone howls. "Ohhhhh! Ohhhhh! Ohhhhh!” With each vocalization, every man uses his whole body to point to the roof and then down to the floor. The first man leads them to the next set of moves, which are to shape the hands into paired "pistols" and "shoot" up into the air twice left, once right, once left, twice right. I recognize these moves as modified "otagei," or "the otaku art," which is a form of group cheerleading performed at idol events. The moves are always basically the same and come at predictable moments in songs, which is why these men can perform together spontaneously without practice. But there does not appear to be an idol here. The men are oriented toward the images of bishöjo on the screen; they are hearing the songs associated with the games featuring these cute girl characters, and responding bodily in public as if to share how they had responded bodily in private while playing in their rooms. The men move, together, in shared response to bishōjo games, which is invigorating.

Announcing a change of mood to "light," the DJ plays a song called "Candy Girl," which I know from a game promoted at Charara!! in Akihabara a few months earlier (see Chapter 2). ${ }^{214}$ While others watch and sing along, I make my way to the front of the room, join the assembled men and move with them. Dozens of shared performances at different events with different men have committed the moves to muscle memory. The heat of the bodies around me is pleasant, and the beer is warming me up from inside. Eyes on the dancing bishōjo on screen, I am for a moment lost. When the song ends, I break away and move to the wall, where a man has hung a giant image of a bishöjo character that is his wife. Others have similarly claimed small areas of the floor and walls and decorated them with representations of bishōjo characters. No sooner have I arrived at the wall and gotten out of the way then a new song begins and inspires a young man wearing a bishōjo 


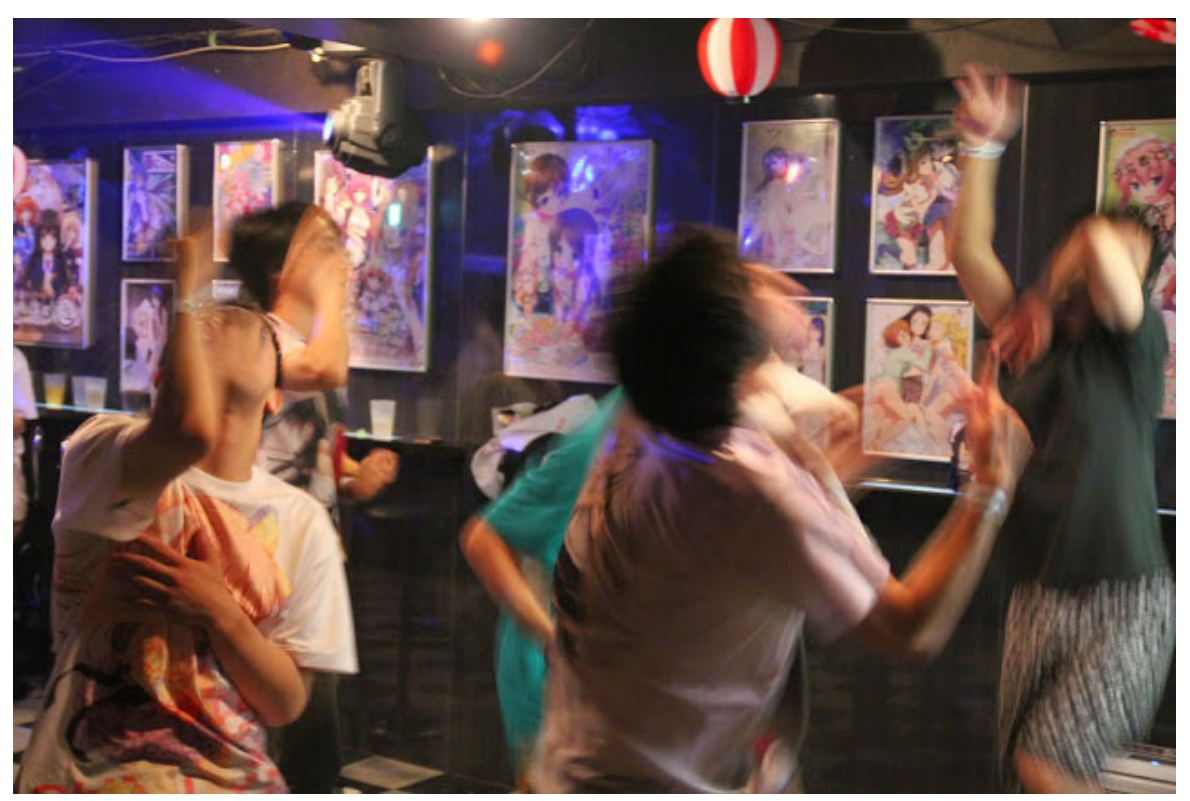

Image 23. Men dance together and share the affect of characters on screen and in sound. Photo courtesy of Club Moonlight Dream Terrace. Used with permission from rightsholder. License: CC BY 4.0.

shirt and drinking a soda to come rushing from the back of the room to the front, screaming. The scream is loud enough to cut through even the blasting music. It is the type of scream that one seldom hears, free and wild, shrill and piercing, the scream of someone who is in ecstasy, pain and pleasure, outside of himself. The intensity of the young man's display draws chuckles and headshaking from others. "Mada hayai," one man says. It's still early. It is only $23: 30$, and we are going to be here all night.

Waves of bodies move front and center, bodies move in physically demanding ways and waves of bodies move to the sides and back to rest and rehydrate. It is somehow tidal. The smell of sweat, the pungent odor of bodies, begins to hang heavy in the air. More bishōjo game players have joined us in the small room, which is now full of fictional and real bodies, mostly men in their twenties and thirties and cute girl characters. Bodies move, seemingly out of control but at the same time completely in control. Around midnight, a man starts screaming at the top of his lungs for a full 20 seconds. Moved by the selection of a particular song and video from a bishōjo game that is somehow close to him, the man seems unable to stop. One is reminded that moe, or an affective response to fictional characters, is sometimes described in terms of overloading the circuit board of the brain and causing the system to 


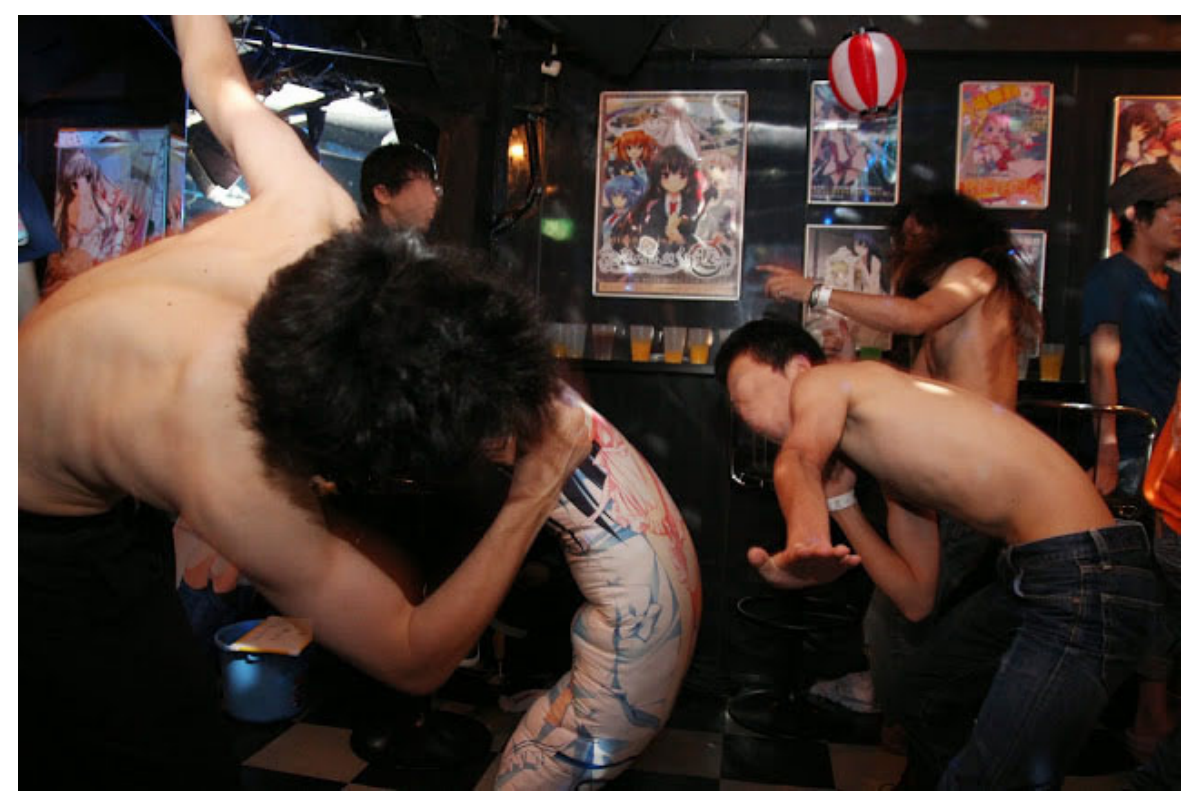

Image 24. Men strip off clothes and become increasingly physical. Photo courtesy of Club Moonlight Dream Terrace. Used with permission from rightsholder. License: CC BY 4.0.

blow up. ${ }^{25}$ To other men observing the scene, a friend of the screaming man playfully pleads, "Dareka, kono hito o tomete kure!" Someone, please stop this man! Stop him! Laughs, suggesting that there is no stopping him or need or will to do so. The event is after all meant to encourage this kind of thing. The assembled men know well that scream, which they, too, have let out. The only chiding comes from a man who rushes over to the screamer to say, "Hayai, hayai! Mada hayai!" Wait, wait! It's still early! The night is young and more craziness will ensue. Best pace yourself. We will be ready to scream ourselves and share a scream later in the night.

A man begins to jump into the air. In time with the beat, he jumps again and again, higher and higher, almost touching the ceiling. Looking on, another man encourages him by waving his hand up. Up! Higher! More! The physical display and exertion of energy are a sight to behold. Burning up and covered in sweat, the jumping man stops and takes off his shirt. He is thin, but toned and muscular. The men surrounding him clap and cheer in appreciation of this physical specimen and his virtuoso performance. They appreciate the exposed male body and its powerful movements. More men strip off their shirts and join in. Muscles flex and relax as bodies stretch and contort. Sometimes the movements seem almost like calisthenics, other times as if the men are 
working, for example miming the action of digging a ditch. Men gravitate toward this center of frenetic activity and share bodily movements in response to not only the moving images of bishojjo on the screen and remixed music blasting from speakers, but also other bishōjo game players. At certain points in the rave, the men rush together toward the front, alternatively the screen with the bishojo characters on it and the DJ booth. Kneeling down with hands outstretched, they are energized and gesturing as if to pass that energy to fictional and real others. They reach out to touch others, which they cannot or do not, reaching across a distance that is carefully maintained in the performance.

One song ends, blending into another, which draws a man from the wall to the front. He stands before the screen, back to it and facing the assembled men. In his hands, which are now raised above his head, is the large package of a bishōjo game, which contains his wife. The game he holds is the one seen in the clip playing on the screen, and images of the cute girl character - his wife - from the screen are also on the cover of the game and in his hands. As the man's physical body stands before the imaginary body of the bishōjo onscreen, the material form is brought in front of the media form. His wife has stepped out of the screen and into the physical space and into his hands. Some of the assembled men watch him do this, while most continue dancing. He looks almost like Moses holding aloft the commandments, which are in this case, "See her! Worship her! See that she is real! See us and know that our relationship is real!" Satisfied, the man moves back to the wall and talks energetically with his friends about the game and character. A similar scene occurs when a man comes to the front to kneel before the screen, which towers over him. Worshipping the cute girl character and overwhelmed by her moving image, the man remains in this position, an island of silent homage and stillness against the raging waves of moving bodies, until the song ends. Others bring their wife goods to the front to not only show them and share them with others, but also to dance with them. This is most often done with body pillows emblazoned with full-body images of bishōjo, who are in various states of undress and flushed as if aroused. At one point, as many as six body pillows are dancing at the front alongside the men, which contributes to a surreal scene of fictional and real bodies moving together on the floor in front of the screen.

Men run to the front to interact with the DJ, other bodies on the floor and images on the screen. The DJ moves the bodies on the floor with his choice of music, even as the VJ moves them with his choice 
of videos. One set of choices triggers a response from one of the shirtless men at the front, who falls down. On his back, hands over his eyes, elbows and knees in the air, he has been bowled over. Another set of choices has a group of men kneeling formally, listening intently and learning from the DJ as a teacher who has taken them somewhere unexpected. Another has everyone shouting together, "Nande da yo?" Why? Why have you selected this song, which moves us so and triggers so much? Why did these things happen in the game? Why did I do what I did? Why? Another set of choices turns the room into a karaoke bar, as the men sing bishōjo game songs together, especially calls and responses and choruses. Entire sections of songs and elaborate sequences of interactive participation have been memorized before coming to the event. The DJ is singing along, performing as if he were the female vocalist. His smile is as big as are the gaps where his missing teeth once were. He is radiant, his affect contagious. It is past $\mathrm{I}: 00$ at night and alcohol is flowing. Some are sticking to beer, while others order shots. The DJ is also sent shots, whether it be for a perceived mistake in the program or a particularly skillful move. A bottle of champagne appears on the floor. It is handed over to the DJ, who takes a drink straight from it, and then back to a man who walks around the room passing the bottle. Even as I take a swig, I am surprised that it is being circulated among relative strangers, given that sharing a bottle - mouths touching the same surface - is perceived by some as intimate. Then again, so is undressing and changing clothes in front of others and sharing imaginary sex and responses to sexual images in public, which has already happened here tonight.

As the night goes on, around 3:00, men begin to burn out and black out. Some relocate to the second-floor lounge space, where there are tables and chairs and another DJ playing a much less powerfully moving set. A tender moment as a sleeping man rests his head on the shoulder of another man sleeping in the seat beside him. The other man opens his eyes, sees what has happened, but then closes them again. Were they acquainted before tonight? Does it matter? On the floor below, men move to the walls and crash onto piles of body pillows representing bishōjo characters. Whose pillows are they? Whose wives? The intimacy is striking. ${ }^{216}$ Friends and strangers alike sleep next to one another on shared pillows and floor space. Shirtless men snuggle together playfully, only to be pushed away just as playfully. Despite the continued movement of bodies on the screen and floor, the changing of DJs and the continuous stream of thumping bass and piercing vocals, the men 
sleep. Some wake and move back to the floor, replaced by other bodies in the sleep piles. This continues until the event concludes at 5:30 in the morning and everyone changes clothes, packs up and prepares to go home. Blinding bright lights come on and the DJs and organizers address the assembled, bleary-eyed men. They announce that the event was a roaring success and they cannot wait to do it again. The message is personal. The men are addressed as "comrades" (dōshi), brothers in arms in some sort of struggle the contours of which are unclear. But the struggle is felt. Exhausted from the physically demanding routines of the night, the men still find the energy to clap and cheer. Smiles and laughter. It was indeed a good time. Walking out the door, I wonder when the next one will be, only to be met by men passing out fliers for upcoming events.

\subsection{From Kawasaki to Akihabara: Fictional and Real Women}

Five aspects of Adults' Day at Club Moonlight Dream Terrace stood out to me. First, the co-presence and shared movement of fictional and real bodies. Second, the affective charge in the space that was the result of these bodies in motion and interaction. Third, the physicality of the event, where male bodies moved and worked together, which led to stripping off shirts. Their semi-nudity mirrored that of cute girl characters on screens, posters, shirts and body pillow covers. Fourth, the intimacy of exposing not only one's body, but also one's imaginary sex life in public. This intimacy was reinforced by drinking from the same bottle, sleeping together and being referring to as comrades. Fifth, the gendering of the event, which overwhelmingly attracted men performing as men in relation to other men and fictional girls. This is not to say, however, that there were no women in the room. A handful of women in fact did participate in the all-night rave. Some were DJs and friends of DJs, while others participated as bishōjo game players. For the most part, these women stayed close to the walls and back of the room and in the lounge area, where they talked with friends.

Another striking aspect of Adults' Day, among the most striking of all, is that none of the men ever approached any of the women to dance together as one might imagine would happen overnight at a club. To be blunt, none of the men ever approached any of the women as a potential romantic or sexual partner. Posted signs on the walls of Club Moonlight Dream Terrace explicitly forbid "nampa," or hitting on and trying to pick up women. While women could and did join groups of 


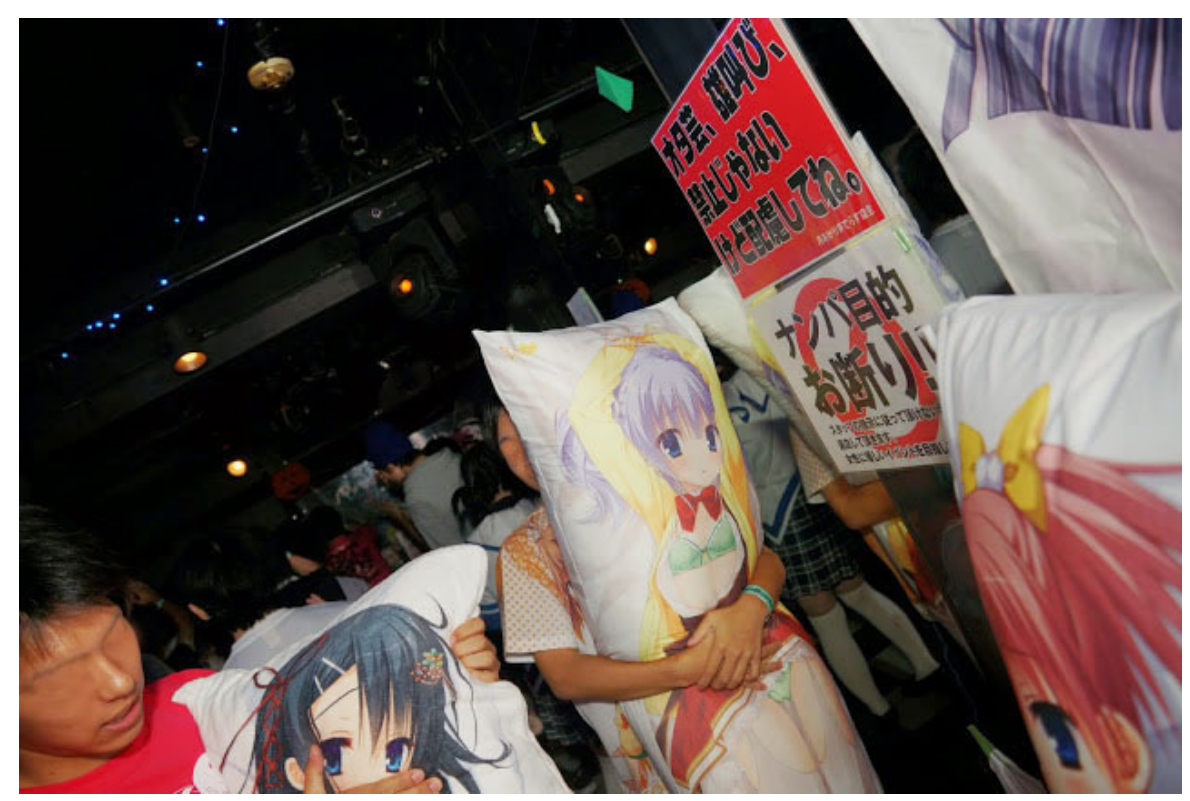

Image 25. Sign at the club prohibits coming to this space to pick up girls. Meanwhile, men are dancing with their wives in the form of body pillows. Photo courtesy of Club Moonlight Dream Terrace. Used with permission from rightsholder. License: CC BY 4.0.

dancers, the men were oriented toward cute girl characters - including their "wives," who they accompanied to the rave - and danced with them in media and material form. Women were also oriented toward cute girl characters and moved in response to them. When at the front, where the screen and speakers were closest and the movement most intense, women were oriented toward the screen and DJ booth like the men beside them. The men and women did not face one another, but rather were shoulder-to-shoulder oriented in the same direction. Although some wore costumes of bishōjo characters, women participating in Adults' Day were not the objects of desire and affection. Surrounded by bishōjo characters, and even dressed as them, women were nevertheless not confused or conflated with cute girl characters, which were the objects of desire and affection and separate and distinct from "real girls and women." When I asked one of the women about this, she expounded that she is attracted to events such as Adults' Day precisely because men do not try to hit on or pick her up. A bishōjo game player herself, she could participate in the event without worrying about unwanted advances. For her, this made the event, despite the presence of imaginary sex and violence and performances by men who 


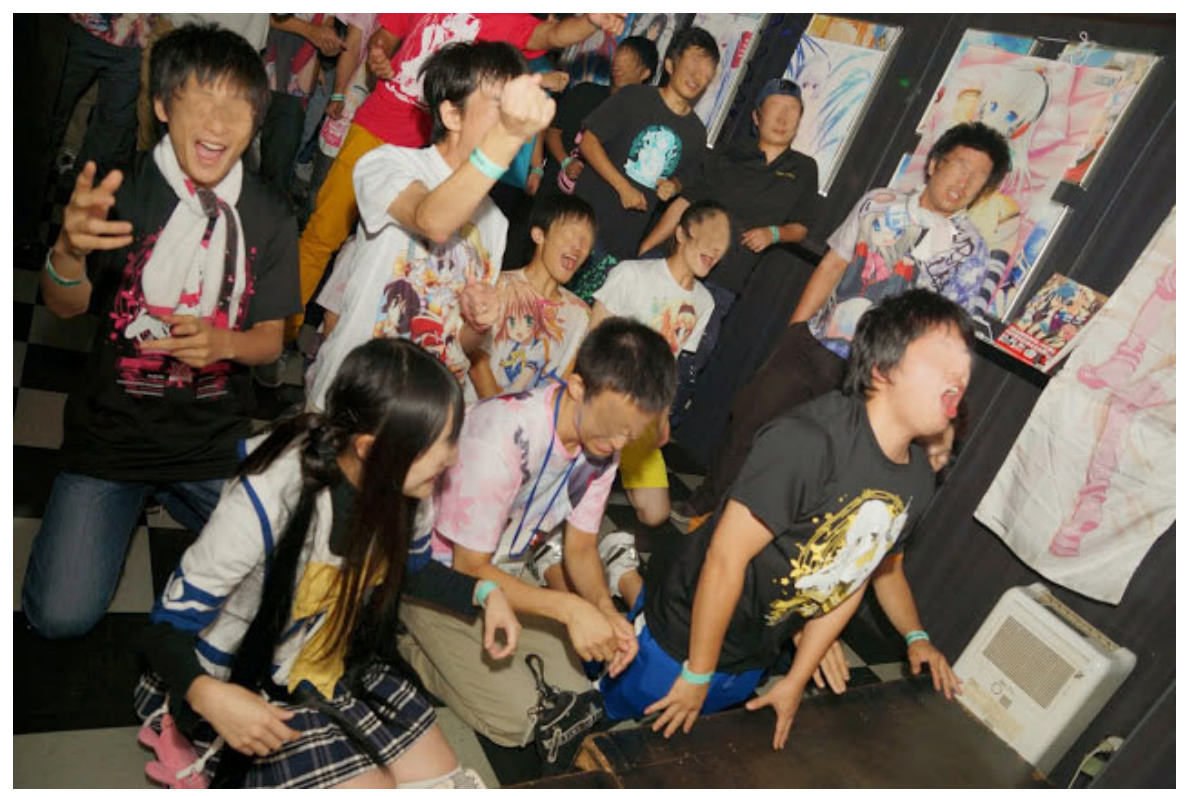

Image 26. Men and women have been knocked to their knees by the affect of the moving images on screen. Unable to contain himself, one man screams out far louder than usual. Photo courtesy of Club Moonlight Dream Terrace. Used with permission from rightsholder. License: CC BY 4.०.

seemed out of control, feel "comfortable" (kai-teki) and "safe" (anzen). When participants started to fall asleep together, the women did the same - at tables in the lounge, not in piles of pillows on the floor. This was not, I was told, risky, because the men were at the rave for their characters and were moreover not creeps who might try to pull something in the dark.

Months later, I make my way down Chūō Street in Akihabara to Toranoana C, a branch of the store that sells bishōjo games. It is Sunday, February I 5 , the day after Valentine's Day, which I spent with a group of bishōjo game players. Single but not alone, these men attended an idol concert, ate dinner together and stayed up past midnight singing karaoke. Given their affinity for fiction, I was less surprised than I might have been when the idol the men went to see performed herself as a character - literally, produced a second personality coded with stereotypical idol attributes and performed as it. In honor of Valentine's Day, the idol also screened a clip that she produced of a virtual date with this other idol character, which followed the bishōjo game dynamic of first-person perspective and situated choices. After talking about the idol and bishōjo games and singing until our throats were raw, I 
passed out and slept through Sunday morning. It is past noon when I enter Toranoana C, but there is still some time before Bishōjo Game Music Party Vol. 5 begins in an event space above the store. ${ }^{217}$ When I find my way up the stairs to the venue at I3:00, I am greeted by a very fat Japanese man wearing the very sexy costume of a cute girl character from a bishōjo game. Perhaps as special service for lonely gamers? The ones interacting with him sure seem to be smiling. When I pull out a high-denomination bill to pay the entrance fee, the man does not have the change he needs and produces a high-pitched character voice to plead for aid. Wallets come out and money changes hands, but no ledgers are kept, suggesting that they are all somehow related to the event or friends who know and trust one another. Inside what appears to be a converted office space, the layout is simple: a screen for projecting clips from bishōjo games, a computer for playing bishōjo game music and space on the carpeted floor for bishöjo game players to dance. Folding chairs are lined up along the walls, and men are selling cans of beer from coolers and grilling meat on a hot plate at a folding table set up against the back wall. The event feels not unlike a lazy Sunday neighborhood cookout, or a temporary café set up in a classroom as part of a school festival.

Most everyone here is a friend or a friend of a friend invited through circles and social media, and I am no exception. My invitation came from Anri, a woman I know from Club Moonlight Dream Terrace. I have only ever seen her in plain clothes, but today she is wearing the costume of a cute girl character from a bishōjo game. Seeing me come through the door, Anri makes her way over to say hello and thank me for coming. The welcome extends to her introducing me around and helping to strike up conversations with people. The conversations invariably turn to bishōjo games, whether it be favorites from the past, new titles on display at Toranoana $\mathrm{C}$ below us or the games associated with the music we are hearing and images we are seeing on screen. A player herself, Anri knows a great deal about bishöjo games, and she makes the conversations easy and enjoyable. Later in the day, as I drink a can of grossly overpriced beer, Anri finds me and reveals a small bag of chocolate, which she hands over. Right, Valentine's Day. A day late, but still. This is probably something given to everyone who comes to the event, but I appreciate the gesture anyway. I make a note that I need to give Anri something in return a month from now on White Day. That would be a nice thing to do; the reciprocity of the gift; social connections and obligations, entanglements and expectations, in a world that is increasingly lonely. These men and women may be single, 
but they are not alone this Valentine's Day weekend. The DJ echoes the thought. Because it is Valentine's Day - a day late, but still - he declares that he has selected two songs for us. They are songs about love, songs from bishōjo games. As the songs play, the characters express their love. Listening to the song and chatting about the game and characters attached to it, the assembled men and women share the love on a chill Sunday afternoon.

Rather than dancing, the men, women and men and women dressed as bishōjo characters sit on the floor eating, drinking and talking. Watching slightly animated opening sequences for bishōjo games, they sing along and laugh. At certain points in the afternoon, staff from Toranoana $\mathrm{C}$ come and report to the assembly about new and upcoming bishōjo games. When they arrive, the music stops and everyone takes a seat on the floor and prepares to listen. A few lay all the way down on the floor in repose, contributing to the casual and relaxed vibe. Promotional clips are shown on the screen. One is for what is described as a "cumming game" (nukigē), and it is pretty hardcore sexual content. Images of nude bishōjo sucking blurred out male genitals, engaged in various sex acts and covered in semen flash by. I look over at Anri, wondering what she, in the statistical minority here, thinks. "Not my thing," she says. "But who cares? It's nothing to get upset about. People like it, and it doesn't hurt me." The promoter is asking whether or not players get off on bishōjo games. Embarrassed laughter, but more than a few shout out, "Yes!" Later in the afternoon, around I 5:10, DJ Fujikawa shows up as a general participant. After he makes his way over to Anri and I, the three of us start conversing. DJ Fujikawa is surprised that the bestselling game at Toranoana $\mathrm{C}$ this month is a title focused on hardcore sex scenes, which is not his thing and not the most popular kind of bishōjo game produced these days. Anri agrees, but, looking around the room, says that is part of it. Perhaps sex is not the first thing on everyone's mind today - the love the DJ was sharing earlier was romantic - but the ranking reminds us that it is not far away. And Anri is not so far away from these bishōjo game players and the fictional girls that attract them. Many of them are her friends, she says, and the rest are generally good people and harmless. Given that Anri regularly participates in raves at Club Moonlight Dream Terrace, which are far more aggressively masculine and sexual than Bishōjo Game Music Party Vol. 5, I am struck by how confident she seems in her assessment. My own experiences at Hajikon and similar raves often leave me confused. 


\subsection{Pillow Talk: Interactions with Bishōjo in Material Form}

On January I7, 2015, Hajikon is held during the day instead of overnight. There are significantly fewer people attending, but Anri, DJ Fujikawa and I are among them. Following from the theme of Hajimete no kekkon ("my first marriage"), a discount is provided for any bishōjo game player who comes escorting a "wife." This can be any material representation of the character, but, at Hajikon, many wives come as body pillows. When I arrive, the lights are still up and reveal a dozen or so men using foot pumps to inflate body pillows. Once they have achieved this, they slip them into fabric covers, which are emblazoned with full-body images of cute girl characters from bishōjo games. The body pillows stand almost as tall as the men; the characters are "life size" (tôshindai), but are still drawn in ways that make them look small and vulnerable. Characters are depicted lying on their backs on a bed, which reflects the owner's bed on top of which the body pillow would normally be placed. On one side, the character is fully dressed, while on the other side her clothes are partially or fully off and her breasts and genitals are exposed. (As exposed as possible, because obscenity law means a small strip of white or black is drawn over the vaginal slit.) Her mouth is open, her face is flushed and she is making bedroom eyes. Looking at the depicted arousal, the owner of the pillow lies in bed and imagines sex with the character. Body pillows are not often, if ever, used for sexual activity involving ejaculation - they have no place to insert the penis, and while one could conceivably rub against them, the pillows are soft and generating sufficient friction is difficult; depending on rarity and desirability, the covers can be quite valuable and so are not used in ways that would dirty or damage them - but they are an intimate reminder of imaginary sex with characters. This imaginary sex occurs while playing the game in one's room, is captured in the image on the pillow in bed and comes out of that private space into public during Hajikon. Once inflated and covered, the body pillows are stood up together against the wall or placed in a pile. The owners then leave to buy drinks and/or mix and mingle before the event starts.

The event starts off slow, with only one to four men on the floor for the first few songs. Suddenly, triggered by the song selection, a man runs from the bar at the back to the front of the room shouting wildly. He runs back to the wall and grabs his pillow cover - he has not yet put it over a pillow - returns to the front, lies down on the floor and covers himself with it. A circle of men forms around the prone body covered 
by the bishōjo character. The men clap rhythmically and begin their performance. There are now five women in the room, all of whom Anri seems to know, but she is at the bar talking with a male friend who is also one of the DJs. Unexpectedly, in mid-sentence, he breaks off from Anri as if struck by some invisible object. Like the man before, this DJ runs to the front screaming like a madman. "Oi! Fuzaken janē zo! Kuso!” Hey! Don't fuck with me! Shit! Other men are also moved by the music and images on screen, but rather than threats they respond with pleas. "Yamero! Yamete kure!" Stop! Please stop! However the images are moving them, they want it to stop, while of course meaning exactly the opposite, because they came to Hajikon to be triggered and moved. The running man confronts the DJ for playing this song, which he either loves or hates, but in any case it moves him, violently. Behind a transparent, hard plastic barrier meant to shield the turntables from flying liquid, the DJ does not look at all intimidated. He just smiles and nods, knowingly. I look back at Anri, who is shaking her head and raising her hands in the air as if to say, "There they go again!" Backing away from the DJ booth, the running man begins to move his body, or rather allow his body to move, almost as if some unseen forces are buffeting him. This is not dancing so much as being affected and animated by moving images. Seeming possessed, he jerks and twists around. Others have backed away to give him space. As the man settles, the men move closer and others join them. Together they jump and shout when music and images change and trigger them.

The men egg one another on, pointing to the screen and sharing observations. "Kawaii!" She's so cute! "Eroi!” So sexy! One man playfully pushes another and jabs a finger at the screen saying, "Lolicon! Lolicon!" The image onscreen is of a Lolita character, and you like those, right? You're a lolicon, right? Pervert! The pushed man, as if activated, begins to jump in the air and scream. The pushing man joins him. Someone goes berserk when the music and images change. A friend implores: “Oi! Yamero! Yamerunda!” Hey! Stop! Stop it now! Despite protests and attempts to hold the man back, the berserker makes his way to the screen, literally dragging others along with him. They move together, violently. The music changes. "Yabai, yabai!" Shit, shit! When the DJ tries to speak, everyone shouts him down. "Sex!" He tries again. "Sex!" And again. "Sex!" As if relenting, he plays a remixed bishōjo game song that has the word "chinko," or cock, repeating over and over. A man who has been quiet for much of the afternoon suddenly snaps to attention and prepares to run to the front. His friend holds 
him back saying, "Yatto han'nō shite kureta!" You finally responded! The conjugation of the verb suggests that the man responding is doing something for his friend. Indeed, holding the responding man back is part of a shared performance of going out of control, which is why they are here. Another man stands up only to be humped from behind by his friend. As if responding to a horny dog, the man turns and chirps, "Nani, o-nii-san?" What can I do for you, mister? The sexual assault is playful, never crossing the line to "real," even as it involves real bodies that are co-present and interacting in real time.

Body pillows are increasingly brought into social interactions. Men are taking photographs of the collection of body pillows at the back of the room. A man runs to the front with his pillow cover - again, empty - and stands in front of the screen as it plays a video featuring the same cute girl character that is on his cover, which he waves like a flag. He then slips the pillow cover over his head so that he is inside and dances wildly as the character, who seems to have stepped out of the screen and onto the floor. Another man takes the cover off his pillow and puts it over his head, walking around the room masked and blind. The men respond to the character, which seems to be moving around the space on its own. Some dance with her, which is also dancing with the man inside of the pillow. Body pillows - covers over actual pillows this time - are brought into the mix. One man stands his pillow up, crouches behind it and puts his arms around it on either side so that the character can use his hands to clap, beckon other men to the floor and shake their hands. The man then turns his pillow around and kisses the character passionately on the lips. When he turns the pillow back around, another man who is already there kisses the character. The two men get into a mock fight over the bishojo character as a shared object. Pillows and men crouching behind them with arms jutting out at their sides dance together; men move pillows and are in turn moved by them.

Play sex and violence continues. Responding to a bishōjo game song and images onscreen, a man brings his body pillow to the center of the floor and drops it flat. The character on the pillow is the same as the one on the screen, which means that she is one of the characters that this player interacted with in the game. No doubt his favorite, given that he purchased a body pillow representing her and escorted this character here as his wife. The nude side of the pillow is facing up. The man drops to the floor on top of the pillow, face-to-face with the character, and starts humping vigorously. A circle of men forms around 
him, laughing and taking photographs. This is not penetrative sex and no one is getting off, but it is imaginary sex in public nonetheless. The performance is troubling for me. On the one hand, the scene looks suspiciously like men bonding as they gang up on a woman, dominate her and are sexually satisfied (Allison I994: I68-169). On the other hand, the men and women in the room do not see this as sexual violence against girls or women or promoting it, because it is play involving a fictional character. This is a scene that Anri might describe as harmless. As I observe the imaginary sex in public, I can see Anri at the back of the room in dialogue with men not unlike the one abusing a material representation of a cute girl character not 20 feet removed from her. She is laughing. Without warning, another woman appears, costuming as the very same character that is on the screen and the body pillow cover - the one that is nude and covered in semen onscreen and in a disheveled state and being raped in the form of a body pillow on the floor. Stepping into the scene and joining the performance, the woman calls the humping man out. "Nani shiten no?" What the hell are you doing? The man springs off the pillow to his feet, steps back, sees the woman in character costume and drops to his knees. Almost as if facing his conscience in the form of the character, who is now asking him what he is doing to her in this place in front of all these people, the man grovels and apologizes. He prostrates himself in front of the woman in character costume and the assembled men around them. He kowtows, she chides and everyone laughs. The music and images change and the scene breaks up. The woman in the character costume goes to find Anri, the man returns his pillow to the pile and the event continues.

This was not the first or last time that fictional and real bodies came together in interactions with body pillows at Hajikon. On July 20, 2OI4, a Sunday afternoon Hajikon is host to some of the most striking interactions with body pillow that I have ever seen. Walking through the door, I am greeted by familiar faces - as well as men wearing gas masks and buckets over their heads to playfully mask identity - including one man who remembers me from Adults' Day. Within the first hour, two men have already brought a body pillow to the front and are interacting with it. The image on the cover is of a cute girl character in a school uniform, which has been stripped off to reveal her flat chest; her skirt has been lifted and her panties pulled down around her knees. The two men plop the pillow down on the floor, nude side up, and straddle it as if to go for a ride. One man has his crotch on the bishōjo character's face, the other on her hips. Hooting and hollering, the men begin 
bouncing up and down and moving forward and backward. From my vantage point, it is easy to see what is being simulated here: two men in a three way with a cute girl character. Other men circle around them and begin taking photographs, which are shared on social media and inspire a string of comments about how other men wish that they were at the rave and could join in the fun. As before, men are involved in escalating performances of imaginary sex and violence. As before, women are in the room, and they laugh at the men. Two men begin smacking one another with their body pillows. Men strip off their shirts and trousers and dance in their underwear, only to be whipped with empty pillowcases. Another man lies down on his back with his legs spread wide, and two men pretend to kick him in the groin. A man is embraced and humped from behind. As before, the chaos is controlled.

Body pillows are the primary targets of playful sexual violence at Hajikon on July 20, 20I4. One has its top stuck into a bucket so that the character's exposed genitals are in the air. In time with the beat of a song, men make stabbing gestures with their hands at her vagina. A man holds his body pillow and six others circle around it, punching and kicking the soft mass. The character is being beaten, abused, publically. After the beating, the man holding the pillow turns it around and kisses the character - his wife - on the lips. He then maneuvers the top of the pillow and the character's face toward his groin and proceeds to hump her face. Another man, shirtless and sweaty, grabs a body pillow and takes it to the center of the floor to hump the character's face. He continues this, while others watch, for the entirety of a song. Taken to be just play and part of the game, the spectacle of sexual violence does not faze anyone, just as the images of hardcore sex, perversity and sexual violence onscreen fade into the background.

Meanwhile, at the back of the room, another body pillow has been planted in a bucket with her genitals in the air. Someone has placed a whiteboard in front of the bucket, and on it is written " $\mathrm{I}, \infty \circ 0$ yen." Judging from prices at stores in Akihabara, I know that the value of the body pillow cover alone is no less than Io times that amount. No, the body pillow is not for sale - an imaginary sexual encounter with the cute girl character is. One imagined sex act is I, ০০০ yen. Another man adds to the whiteboard: "You can only put the tip [of your cock] in. Blowjobs possible." Marks are added for the number of times men have imagined having sex with the cute girl character. They multiply quickly. A pile of I,০০০-yen bills becomes a mountain. Men begin to circle around, laughing and taking photographs, which are posted on social 


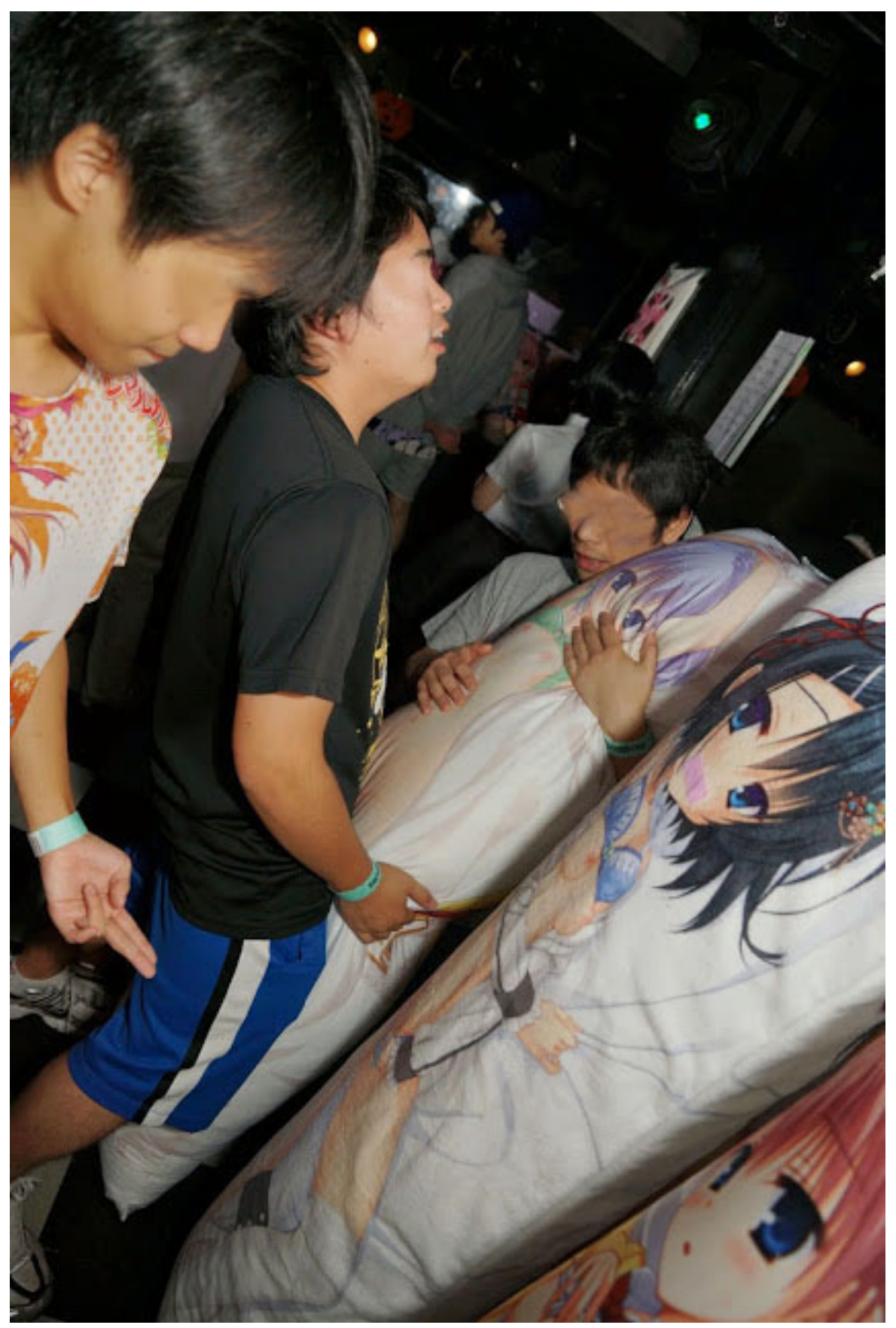

Image 27. A character in body pillow form is held up for imaginary sex in public. Others perform hard fingering gestures. Earlier, another pillow was publically beaten. Photo courtesy of Club Moonlight Dream Terrace. Used with permission from rightsholder. License: CC BY 4.०. 


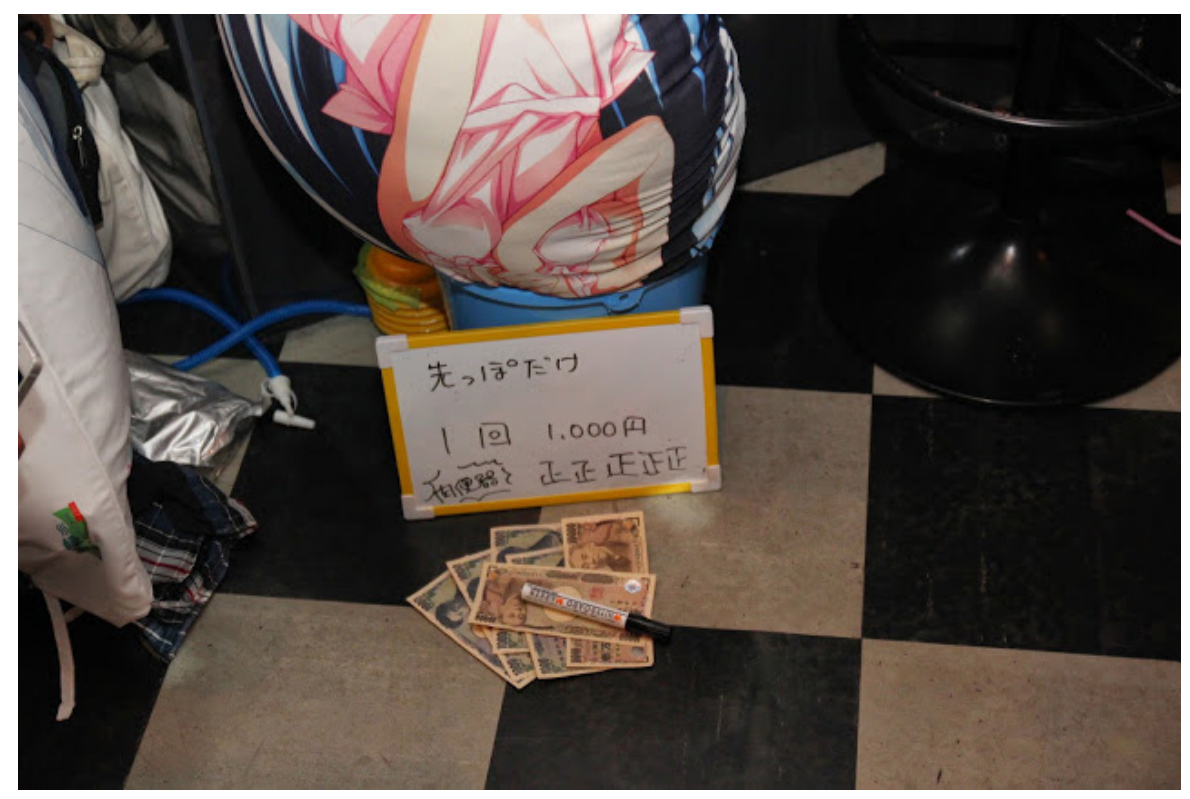

Image 28. A character is treated like a "toilet," and men imagine having sex with her upside-down form and paying for it. Photo courtesy of Club Moonlight Dream Terrace. Used with permission from rightsholder. License: CC BY 4.0 .

media. The more people participate, the more violent the imagined sex. Eight men and a photographer are gathered around the pillow. They throw money at the character and call her a "benki," which means toilet and is slang for a "cum dumpster." I recognize the term from hardcore bishōjo games, and so do these men, who are playing out this scenario of imaginary sex together in real time with a material representation of a cute girl character. Homosocial bonding of real men occurs around the abuse of a material object, which is also imagined sexual abuse of a fictional girl. It is not real, but at the same time all too real.

In the next moment, the playful sexual violence transforms into tenderness. Arms over one another's shoulders, bodies touching skin to skin, the men sway gently together, and their body pillows are with them. When a pillow "standing" with others against the wall bends under the weight of gravity and slumps to the floor, a passer-by stands the soft mass up and smoothes the wrinkles from its cover; he strokes the cover and the cute girl character on it gently, his hands lingering as he stares longingly, even lovingly, into the character's eyes. Another man comes over to gently touch the body pillows before lying down with them on the floor; resting, he hugs the pillows close and snuggles with them. Three pillows are leaning against one another 
and the wall, the bodies of the characters visible by the light of glowing neon sticks that men have placed in a half circle around them. Bathed in soft hues of pink and blue and green, the characters look almost angelic, and indeed some men stop to kneel in front of them. ${ }^{218}$ When a body pillow is left on the floor where men are moving together, the character appears to have collapsed. A man responds by stopping to perform CPR. His hands cover the character's exposed breasts as he pumps her chest and performs mouth-to-mouth resuscitation. His efforts are rewarded when the owner returns to stand the pillow up and bring the character back to life; the revived character dances with the two men, who gaze at her face looking back at them from both sides of the pillow. Men pose their body pillows and characters together, pose with their body pillows and characters, strip off the covers to get inside them and pose as their body pillows and characters. More photographs are taken, which are shared on social media. Bishöjo game players comment on how much they love these characters.

The mixture of violence and care observed at Hajikon on July 20, 2014 is familiar from bishōjo games, which feature cute girl characters to be acted on by players (recall Chapter 3 ). Appearing vulnerable, cute objects trigger an "affective response to weakness or powerlessness" (Ngai 20I 2: 24; also Ngai 2005: 823). The response to the cute object oscillates between holding and punching, hugging and squeezing. The bishōjo is a cute girl character, a cute object and a love object - recall that the word for cute in Japanese, kawaii, can be translated literally as "possible" $(k a)$ to "love" (ai), "lovable" - and the affective response intensifies when the character is given a material form as a pillow. The material affordance of the body pillow - or, more directly translated from Japanese, the "hugging pillow" (dakimakura) - means that the character becomes an object that can be held and punched, hugged and squeezed. It is soft and offers no resistance - weak and powerless - and seems able to take any amount of abuse without lasting damage. Bishōjo are cute girl characters, cute objects, love objects, objects to be loved, but also objects that trigger ugly feelings and an affective response, objects to be acted on. Violence and care, cruelty and kindness, are part of bishōjo game players' relationships with cute girl characters, even as those relationships are described in terms of love.

The highlight of Hajikon on July 20, 2014 comes at I9:00, when DJ Fujikawa takes control of the space and orchestrates a mass wedding ceremony. He selects a song titled "Love Me Love La Bride," which is an insanely upbeat and happy song from a bishōjo game about marriage. ${ }^{219}$ "La-la-la-la-la-la-la-la-la-la-la...!" As if chased by a swarm 
of bees, the men run around the room flailing their arms. Images of the characters flashing onscreen resemble those seen in the promotional material for Hajikon, which is, after all, "my first marriage" and tagged in English as "the First Wedding in Two Dimensions." The men have all brought their body pillows to the front of the room - the first time that all of them have been assembled together - and stand them up before the screen facing the men on the floor. The men kneel in front of the body pillows, or rather the material representations of the characters that have moved from the two-dimensional to the three-dimensional, and sing to them. They draw the characters as body pillows in close embrace. The men then bring the characters as body pillows to the center of the floor and stand them up against one another. They form a circle and dance around the assembled characters as body pillows. As the song builds to its climax, the men fall to one knee and reach their hands toward the characters as body pillows standing in the center of the circle. They reach out to take imaginary hands and ask the characters to marry them. On bended knee, they reach out to the characters across a distance, which is imposed physically in the ritual interaction with the material object but is also impossible to bridge. Even as body

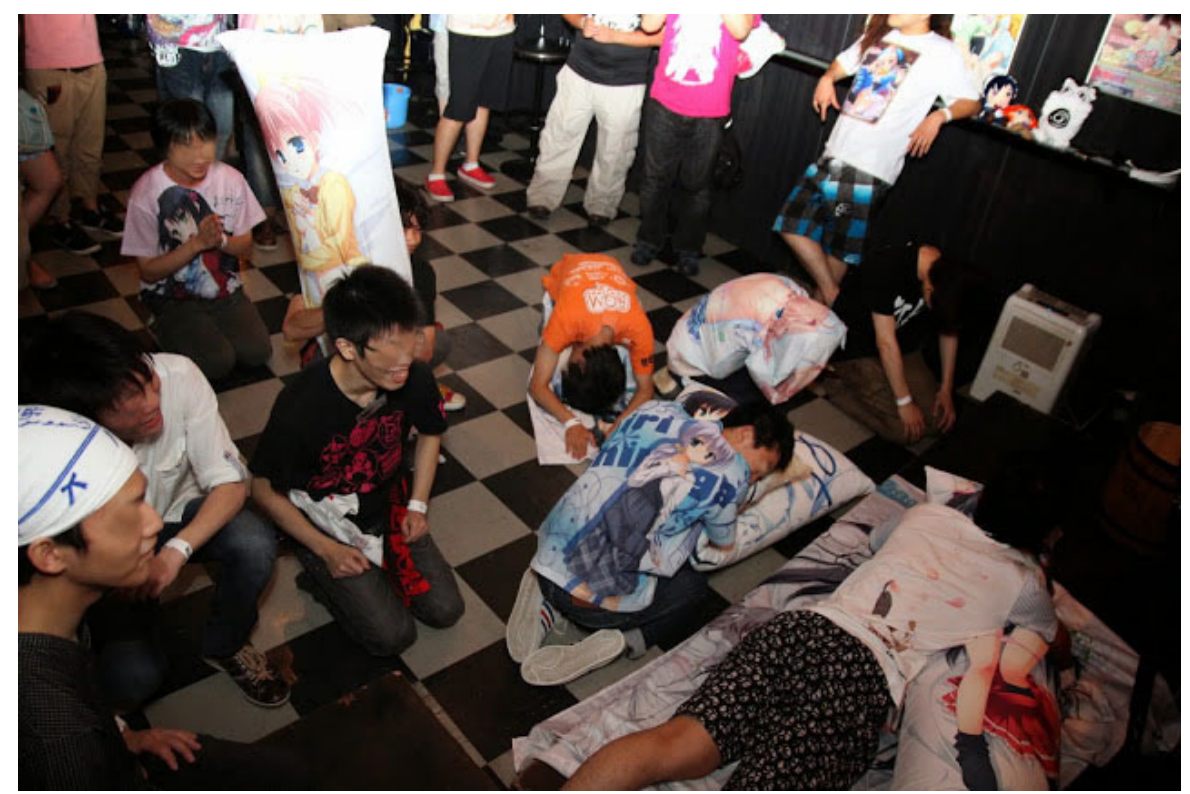

Image 29. Aftermath of a group wedding ceremony at Hajikon. Energy expended by the running and dancing that proceeded, men collapse to the floor. Photo courtesy of Club Moonlight Dream Terrace. Used with permission from rightsholder. License: CC BY 4.0. 
pillows, the characters have no hands to give. Men and women without body pillows watch the spectacle and take photographs. They are laughing and smiling, clapping and cheering. On bended knee, hands outstretched, the men are colored red with embarrassment and pleasure. It ends with their collective collapse to the floor.

\section{5 “Failed Men” Living in Precarious Japan}

He has been drinking heavily all afternoon: beer in plastic cups, tequila shots, champagne straight from the bottle. Although he is barely able to stand, let alone speak, the organizers of Hajikon still give DJ Fujikawa the microphone to wrap up on July 20, 20I4. "Oretachi ga warukutemo, dame demo, erogē wa..." Even if we are bad, even if we are no good, adult computer games are... "Erogē wa..." Adult computer games are... He is trying to say something, something important maybe, but cannot get the words out. His voice is cracking, trembling. Was he always this small and fragile looking? The man must be in his forties. Two others hold him upright. Suddenly a voice from behind me. "Ganbatte! Nakanaide!” Do your best! Don't cry! Ashamed and blushing, DJ Fujikawa covers his face with his hands and turns away. One of the men holding him snatches the microphone to speak, but he too seems overwhelmed. Looking out at the assembled men, he shouts, "Ai shiteru ze!" I love you! The men clap and cheer. Snapping back to us and taking the microphone, DJ Fujikawa tries again. "Erogē wa saikō! Minna saikō!” Adult computer games are great! You're all great! The affirmation is met with a thunderous roar and round of applause. Fragmentary and halting in its delivery, one can piece together DJ Fujikawa's message. Even if we are bad, even if we are no good, bishōjo games are great. Even if we have nothing else, we have bishōjo games. Bishōjo games brought us together. Even if we have nothing else, we have one another. We are all great. We are all alive. Fragmentary and halting, the message was nothing if not moving.

In my fieldwork, I found that such affirmations are not entirely uncommon at Hajikon and other bishōjo game raves at Club Moonlight Dream Terrace. During Adults' Day, for example, a young DJ experiences a moment of failure. ${ }^{220}$ He starts his set with a macho display of freestyle rapping on the floor before moving into the DJ booth to take over the turntables. His shirt is soon off. In contrast to the usual sound of bishōjo game raves, he plays a selection of music with male vocalists 
and rock guitars. Drinking from a bottle of champagne provided to him, the DJ shouts, "Ai shiteru ze!" I love you! Then the music stops - technical difficulties of some sort. The bodies stop moving. As the organizers attempt to fix the problem, and the assembled men shuffle awkwardly in place, the DJ breaks the silence by using the microphone to speak. He speaks about his life. In his fifth year of university, the DJ is studying without purpose. There are no jobs on the horizon for him. $\mathrm{He}$ is single and lives with his parents. In fact, he had to borrow 30,000 yen from them to get to the rave from his home in the countryside. The DJ confesses that he does not know what lies ahead for him, and wonders if his life has any purpose. He feels like a failure. The DJ falls silent and lowers his eyes to the floor. His masculine performance has broken down. In contrast to the previous bravado, he stands before us now sharing anxiety about feelings of failure that are familiar to the assembled men, who live in a time of precarious existence and everyday violence. "Ai shiteru ze!" I love you! The DJ looks up, grinning. Who said that? One of the assembled men, echoing his earlier words, masculine emphatic sentence-ending particle and all. Laughter ripples through the room. The computer is back online and the DJ finishes his set to much celebration. Seeming moved by the support, despite technical difficulties, the DJ shouts, "Ai shiteru ze!" I love you! Despite the breakdown, he made it through. We made it through, together.

The spontaneous support of DJ Fujikawa and this other young DJ, both perhaps "failures" in life and certainly in moments of failure, is part of a more general pattern. For example, one man in a group I meet speaks about feeling like a failure, because he is single, without stable employment and lives at home. He adds, however, that he has been successful in organizing bishōjo game raves with other men in the spirit of Hajikon. He has found friends through bishōjo games and attending and organizing events. These events, he explains, give him a space to feel happy and fulfilled. Hajikon and similar events support sociality outside of the institutions of home, school and work and give men without a clear future something to look forward to on the horizon. Indeed, at Hajikon on July 20, 20I4, following DJ Fujikawa's "speech" - even if we are bad, even if we are no good, we still have bishöjo games and one another - one of the organizers expresses a desire to create a space where everyone can enjoy bishōjo games together and be happy. To his mind, sharing affection supports not only the struggling bishōjo game industry, but also the lives of struggling men who depend on bishōjo games. 
Aware of how important bishōjo games can be for the lives of players, scenario writer Maeda Jun goes as far as to call moe "a reason to live" (ikigai):

Many people feel insecure. You go to school, but you might not be able to get a job, and even if you do it might not be a full-time position. Without a stable income, it's hard to start a family. There is a general move toward isolation. People don't have a direction or purpose. That is why I say that moe is a reason to live. Once people find something, they pursue it. Manga, anime, games or whatever it may be provides a reason to live and a passion that can be shared with others. ${ }^{221}$

Without this passion for something to pursue and share, Maeda suggests, "many people would no longer be able to survive." As Maeda sees it, moe is not only an affective response to fictional characters, but also an important part of people's lives in contemporary Japan. It has become more important as people struggle with conditions of economic, social and ontological precariousness. For bishōjo games, Maeda writes stories about characters struggling for life and love against hardship. Games such as Kanon (Kanon, I999), Air (Eā, 2000) and Clannad (Kuranado, 2004) are meant to trigger moe in players and support their lives. How fitting, then, that music from these games - some of which Maeda writes, slow ballads, tender and emotional - are part of bishōjo game raves such as Hajikon, which move bodies and support life.

Situated in the broader context of contemporary Japan, the importance of bishōjo game raves such as Hajikon becomes clearer. Unemployment and underemployment are rampant; marriage and birthrates are down; many young people are not confident that they will achieve the same economic and social stability and respectability as their parents; many feel like failures (Allison 2013). Demanding the "normal" lives promised to them, some become angry and violent. One can see this in young Japanese men calling for war, which would give them a path to achieve dignity (Akagi 2007). This gets entangled with nationalism. One can also see this in young Japanese men protesting dominant gender ideals that make them feel like failures, but then turning their movement against women for not being "available" (Ryall 20I 5).222 Issues of violence toward others aside, frustration and depression in Japan contribute to high suicide rates, which spike every year in May, when many young people fail to transition into new institutional identities and lives and/or become disenfranchised. Psychiatrist Saitō Tamaki sees this as a tragedy brought on by stubborn hegemonic norms, not least of which being norms of gender and sexuality (Saitō 


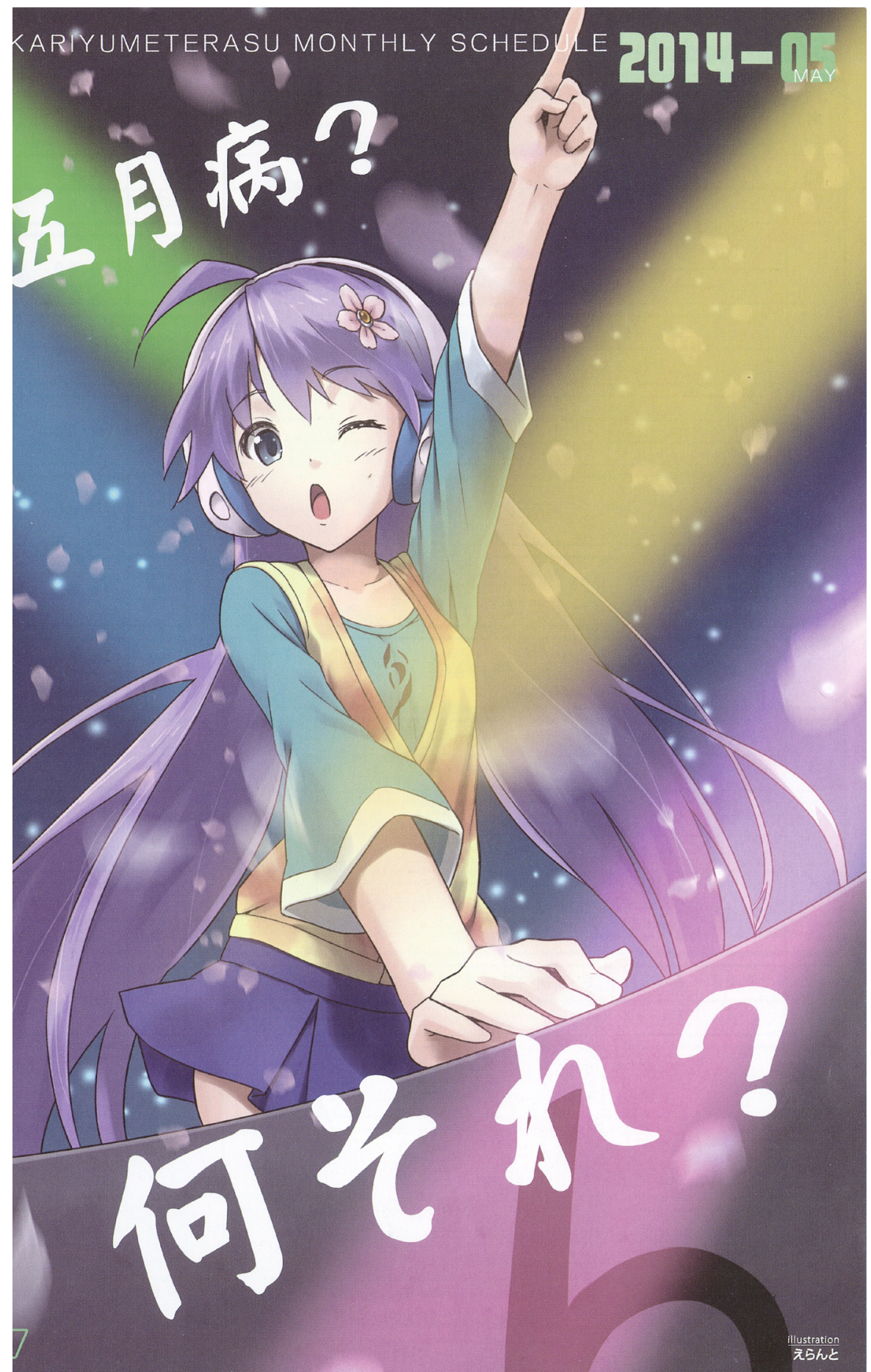

Image 30. Pamphlet for upcoming events at Club Moonlight Dream Terrace in May 20I4. Photo by the author. License: CC BY 4.O. 
and Jō 20I4: I 50-I 57). ${ }^{223}$ What is to be done? A start might be distancing oneself from norms that conspire to make young Japanese into failures and contribute to violence. Bishōjo game raves such as Hajikon point in this direction. A flier announcing raves scheduled at Club Moonlight Dream Terrace in May 20I4 shows a bishōjo character behind a turntable. Moving to the music, she is smiling, happy, full of energy and life. She points up to an unseen and imagined elsewhere up, up and away, in defiance of gravity. The image is accompanied by text reading, "May sickness? What's that?" Whatever might be happening outside the club, in here there is no "May sickness." Against the backdrop of a spike in suicides, things to look forward to and participate in function to support life. While the men participating in bishōjo game raves such as Hajikon might be described as abnormal, they do not demand a return to normal. For all the jumping and screaming, this event does not feel angry or violent. For all the crying people do playing bishōjo games (see Chapter 3), those experiences and sharing them at this event are not part of the social dynamics of depression that Saitō highlights. In this moment, they are living and moving on, together.

For many in Japan, the men who gather at Hajikon and bishōjo game raves like it are different and strange. When I ask for directions to Club Moonlight Dream Terrace on a street in Kawasaki, a Japanese man responds by enquiring if I am "one of those." The expectation is that any normal man walking down this street at night would be looking for the company of, if not sex with, a real woman, where I am joining an abnormal group of men playing and imagining sex with real and fictional others. On this street of sex for sale, the bishōjo game players at Club Moonlight Dream Terrace are perverts. Walking off the street and through the heavy padded door, one enters a space where men embrace being abnormal. Men who may appear single, but in fact are married to bishōjo characters, walk down the street in Kawasaki in normal clothes; they enter Club Moonlight Dream Terrace and change into shirts emblazoned with images of their wives, which are not worn normally. One changes into these shirts to announce a relationship with the character and alliance with others in similar shirts. Before leaving the club, the men change out of their shirts back into normal clothes or put something normal on over it. While one does not want to draw attention outside the club, inside the opposite is true. Wearing the bishōjo shirt, one recognizes the self and other as abnormal, in a good way.

Rather than abnormal, the men at Hajikon and bishōjo game raves like it are more likely to call themselves "perverts" (hentai), which they 
do with relish. At these raves, one of the first things that men I have not met ask is, "Hentai desu ka?" Are you a pervert? To answer yes is to be met with enthusiasm and join in shared movement. In his foundational work, psychoanalyst Sigmund Freud argues that normal sexuality - normal erotogentic zone, object and aim - is localized in the genitals, oriented towards another human of the opposite sex (and not in the family) and for reproduction (Freud 1962). For Freud, outside of normal sexuality is perversion. So imaginary sex, or sex with images, is perverse. Looking at sexy images together and being moved by them to shared bodily response is perverse. It takes imaginary sex and the private act of masturbation in one's own room into imaginary sex and the public act of shared bodily response in the club. By this point, we are no longer discussing the drama of desire structured by family, but rather the factory of social desiring, where machines are assembled in ways that work and are productive (Deleuze and Guattari I983).224 In the process of perversion and its movement (Lamarre 2006: 376384 ), sexuality and relationships are twisted and transformed. The bishōjo character is anything that works. The question, as philosopher Gilles Deleuze and psychoanalyst Félix Guattari pose it, is not what does it mean, but rather how does it work, and work together, passing "from one body to another" (Deleuze and Guattari I983: I08)?225 This is the perversity of shared bodily movement.

Consider for a moment Adults' Day, which is also Children's Day, a national holiday typically spent with family. Single men and women come to Club Moonlight Dream Terrace for an all-night bishōjo game rave; they are looking for partners for "adult activities," but not men seeking women in a "normal" sense. Instead, men and women, mostly men, seek one another out to share imaginary sex with cute girl characters from bishōjo games. The men are not, it turns out, single, and they come to the rave with their wives, who are fictional and real. On Adults' Day, imaginary families are recognized and celebrated with others outside of the home, even as those same families are involved in imaginary sex that is perverse. At one juncture, I am looking at images on the screen of bishōjo characters - nude, covered in semen, underage - and hearing a chorus of high-pitched girl voices blasting from the speakers and espousing the joys of "papa love." ${ }^{226}$ Men - some wearing bishōjo shirts, others stripped down to their underwear - are humping body pillows on the floor, while men and women watch, take photographs and laugh. Perverse is certainly an apt description of the scene: Perverse not only in the sense of relationships with those performing, 
not only relationships with fictional and real others, but also relationships with cute girl characters that are underage, related to the players, loved and abused by them. Such relationships are "painful" (itai), just as these players and their games are sometimes described (recall Chapters 2 and 3 ). There is something that hurts, something shameful, even as these relationships are so publically shared and celebrated at bishōjo game raves. Beyond Adults' Day there is Hajikon, the abbreviated name of Hajimete no kekkon that sounds like "shame convention" ( haji meaning shame, kon meaning convention). A celebration of marriages as relationships sexual and shameful, pleasurable and painful. At bishōjo game raves and beyond, sharing sexual shame, "all that is most abject and least reputable in oneself," allows for a "special kind of sociability" (Warner 2000: 35 ). Outside the home and "normal" and "real" family, which is increasingly revealed as a fiction itself, new affective alliances are forming among men and women, fictional and real, media and material.

Much of this is already familiar from Akihabara, which is another affectively charged space where fictional and real bodies come together (see Chapter 2). It is another space that supports imaginary sex in public and perversion - an "abnormal" space where bishōjo shirts are normally worn. It is also a space where we can observe different responses to "failure." In June 2008, Katō Tomohiro, a 25-year-old man, killed seven people and wounded to more on Chūō Street in Akihabara. The mass killings were one of the worst in recent Japanese history. In investigating his motives, police and pundits speculated that Katō had flamed out in highschool, been rejected by his family and ended up in a dead-end job that was only temporary (Slater and Galbraith 20II). Kato thought himself a failure, and felt that he had, and could have, no friends and no chance with the opposite sex. He was even ignored by people online. Katō tried to find alternatives in Akihabara, visited a maid café and even purchased a CD that had the recorded voice of a little sister character that might have been an imaginary significant other. For Katō, however, this was not a normal or real or livable life. Unable to shake his "normativity hangover" (Berlant 2007: 286) and constantly reminding himself of his "failures," Katō attempted suicide before finally turning his violence toward others in Akihabara.

In the aftermath, Honda Tōru, a writer and cultural critic who himself struggled with rejection, economic and social instability and suicidal thoughts, identified with Katō to the extent of saying that they were the same person until the age of 25 (Honda and Yanashita 2008: 
69). The difference between them, as Honda perceived it, is that he found bishōjo games, fell in love with cute girl characters, started an imaginary family and shared his love with other men (Chapter 2). Thus supported by relationships with fictional and real others, Honda did not struggle with a precarious ontology in ways similar to Katō, who at times seemed to wonder if he existed at all and desperately craved a response from others. As Honda sees it, Katō retained a sense of middleclass male propriety and desired the normal life promised to him. He explains the consequences:

When I published The Lunatic Man (Dempa otoko, 2005), people came to me and said, "I'm a similar kind of person, but I can't respond to fictional characters the way you do (moerarenai). What should I do?" I was really at a loss. [...] But, you know, I wish I had said, "Just take it easy for now!" [...] I think he [Katō] was extremely prideful, so he couldn't put up with it [everyday life]. Probably since he was a kid. That's also probably why he couldn't just take it easy. (Honda and Yanashita 2008: 69, 72-73)

"Taking it easy" (yuruku ikō) suggests not getting worked up about one's relation to hegemonic norms and social values; it means not having to succeed, grow, win, rise or achieve. ${ }^{227}$ Taking it easy suggests the possibility of alternative norms and values that do not demand or punish so much; it means finding other ways to live, and live on, to live with oneself and with others. Taking it easy is related to taking care, both of oneself and of others, who share positions, pleasures and pains. Taking it easy is precisely what bishojo game players do at Hajikon and similar events. They are imagining and creating new ways to live and move on (Halberstam 20II: 88; Condry 20I3: I94-I96, 200-203; McGlotten 2013: 37-38, 59-60, 97-I00, I36). ${ }^{28}$ Outside of rooms where they live and play alone, men and women are living and playing together. ${ }^{229}$

Still troubling are shared imaginings and performances of sexual violence at Hajikon, for example gang raping cute girl characters and treating them like prostitutes. These imaginings and performances are all the more problematic in that they are taking place inside Club Moonlight Dream Terrace while women work in the sex industry right outside the door (Lamarre 2006: 376, 38I-382). Responses to cute girl characters at Hajikon bring together fictional and real, men and women, media and material, cruelty and care. Observing them, I cannot help but recall what legal scholar Harata Shin'ichirō calls the "performative ambivalence of moe," which raises questions about relations to reality and potential harm (recall Chapter 4 ). Affective responses to fictional 
characters are ambivalent, and this is an ambivalence that is performed. This is where danger lies, and also where the ethics of moe lie. The ethics of moe is the action and everyday practice of drawing a line between fiction and reality and orienting oneself toward the drawn lines of fictional characters. "It is precisely because practice is not mechanical, automatic, or fully determined that we have ethics," writes anthropologist Michael Lambek. "We must continuously exercise our judgment with respect to what we do or say. The criteria by which we do so are made relevant, brought into play, by means of performative acts" (Lambek 20I5b: I29). Ethics are located in action and everyday practice, even when what goes on during the night at Club Moonlight Dream Terrace may seem entirely wrong to outside observers and critics.

Participating at events, I observed that even as things blurred together at Hajikon and similar raves, lines were drawn and insisted on. Bishōjo game players were oriented toward the lines of fictional characters, which were understood to be separate and distinct from "real girls and women." Even as fictional girls were real on their own terms and entered into real social activity, they were not confused or conflated with girls and women inside or outside the club. In the dozens of bishōjo game raves that I attended at Club Moonlight Dream Terrace, not once did a man suggest leaving the room and buying sex. Not once did I witness unwanted sexual advances, or even attempts to hit on or pick up a woman in the club. (Perhaps some wanted to, which adds to the performative ambivalence. In case anyone needs to be reminded of the line, posted signs explicitly forbid hitting on or trying to pick up women.) Not once were imaginings and performances of sexual violence made real in relation to women such as Anri, who regularly participated in these bishōjo game raves. Indeed, Anri called these men her friends, and trusted them to draw a line between fiction and reality, cute girl characters and her. As Anri told me, these men were not a threat; she and other women laughed with them; they lived and moved with them. Faced with the imaginary rape of a character and performative rape of a body pillow representing that character at Hajikon on January I7, 2015, a woman costumed as that character was confident enough that the bishojo game player knew where to draw the line that she stepped into the scene as the character. A man, woman and cute girl character were playing and performing together. This involves trust, without which the play cannot occur. While the scene might have been tense if character and woman were confused and conflated (Thorn 20I2: 2I-22), the players and performers understood and respected lines, which allowed 
for an interaction that was funny to them and drew laughter from the assembled men and women. ${ }^{230}$

If there is a reason that "mastering images of women does not encourage violence toward real women" (Lamarre 2006: 38I-382), then it is because of media literacy and ethics that have been developed and shared among manga/anime fans for decades. Recall the Miyazaki Incident and subsequent "otaku panic," which led to Ōtsuka Eiji's recognition of the ugly feelings of "love" and wanting to "hug cute dolls" or "something cute" (Ōtsuka and Nakamori i 989a: 68-70; Ötsuka and Nakamori I989b: I94-I96). Responding to the criminal other/self and desires that are "shameful" and "pathetic," Ötsuka acknowledges a shared problem in lolicon, identifies himself as a lolicon and shares his history of carrying around a doll named "Rumi-chan." It is in this capacity that he sees his reflection in Miyazaki Tsutomu and the "grotesque boy hugging his doll as he goes to pieces" (Ōtsuka and Nakamori I989a: 68). The difference between Ōtsuka and Miyazaki, who he perceives as the negative to his positive and someone he could have been in another life, is that the criminal other and potential self did not know where to draw the line. He had no one to pull him back or help him live while going to pieces. Like his peers from "the generation of Miyazaki," Ōtsuka counts himself among "the abandoned," and thus advocates for "an ethics of the abandoned" (sutego no rinri).

This turn of phrase comes out of a two-part dialogue with Nakamori Akio, who initially coins and then refines it in the back and forth with Ötsuka. If there is no higher authority, or what Nakamori glosses as the metaphorical "father" to a "family," then the abandoned have to work things out for themselves. To Nakamori's mind, what is necessary to avoid future tragedy is "a new ethics," or "an ethics of the abandoned," which is distinct from "law," "morality" and "good and evil" (Ōtsuka and Nakamori I989b: 21 5). "With my own power, with our own power," Nakamori argues, "we must create what no one will teach us. A new ethics. An ethics of the abandoned" (Ōtsuka and Nakamori I989b: 2 I 5). Later Ötsuka refers to "morals" or "weak regulation" (biyowa na kisei), but the focus remains consistent (Ōtsuka and Nakamori I989b: 256). In other words, what rules allow for ethical action and practice and reduce the possibility of harm?

These rules emerge through shared cultural practice, or what Ōtsuka and Nakamori express as being in the "same space" (onaji kükan) and playing the "same game" (onaji gèmu). So it is that Nakamori, who also partially identifies as a lolicon (Ōtsuka and Nakamori I989b: 
$238)$, states that it is only "humans in the same space who can stop us" (Ōtsuka and Nakamori I989a: 93). He imagines that tragedy might have been avoided by staying close to Miyazaki engaged in the "same game space." In this scenario, Miyazaki approaches girls to confess his "love," only for another player to intervene with, "Hold it!" The only one capable of saying that to him and being heard, Nakamori contends, is "a participant of the same game" (onaji gèmu no sankasha). To this, Ōtsuka adds that ethics in action and practice are already on display, for example in conversations where a friend cuts in, "Hey, buddy, you're looking a little like Miyazaki there," and the other person replies, "Sorry" (Ōtsuka and Nakamori I989a: 94). Both Ōtsuka and Nakamori envision avoiding tragedy through socialization and playing the same game. To Ōtsuka's eyes, Miyazaki appears to have a fragile identity hanging on the media and material in his room. He detects a desire to be part of the "otaku" collective, and for his part wishes integration had occurred. Later, Nakamori second guesses himself and questions who would stop someone in any such emergent collective if "a game like rape started up" (Ōtsuka and Nakamori I989b: 200), but he provides his own answer in the form of a new ethics or an ethics of the abandoned. Whether they be fellow foundlings, friends or somehow related as parent and child or siblings through media, Ōtsuka, Nakamori and Miyazaki are all "humans in the same space." Where Otsuka and Nakamori differ is the former choosing to accept his path as someone struggling with an individual and shared problem in lolicon: "I want a girl to take my hand and to live on. That is my pathetic view of life" (Ōtsuka and Nakamori I989b: 243). We might further insist on the line between girls and women and cute girl characters. A human being is not "something cute" or a "cute thing," nor should that human being ever be treated as such.

This path leads to Hajikon and similar raves, where an ethics of the abandoned is cast into stark relief and expanded into an ethics of affect. Are these bishōjo game players not "grotesque boys hugging their dolls as they go to pieces," "failed men" in precarious Japan, fragile and breaking down? Are they not carrying their dolls around, their wives as body pillows, hugging cute girls? Are they not hugging them "excessively," hurting them as they squeeze and punch? Do they not see themselves and their desires as "shameful" and "pathetic," confessing to one another that they are "bad" and "no good?" And do these men, abandoned in compounding ways, not have an ethics in action and practice? To my eyes, they appear to be precisely what Nakamori proposed 
as "participants in the same game" inhabiting "the same game space." They are the ones capable of drawing and maintaining lines, of pulling one another back, of holding one another close, of supporting and sustaining life and discouraging and deterring violence and harm toward others. They imagine and create girls to take their hands and live on. "Pathetic" or not, they want to take her hand and live on. Going beyond Ōtsuka and his dialogue with Nakamori in response to Miyazaki (Ōtsuka and Nakamori r989a: 73), the men at Hajikon and similar raves distinguish between human girls and manga/anime-style cute girl characters and specifically ask for the hand of the latter. ${ }^{2{ }^{2}}$ The fictional girl, the cute girl character, cannot do it herself, so bishōjo game players imagine and create ways for her to reach out from the screen and the body pillow. They reach out to one another, too. Hand in hand, they imagine the character proclaims, "I love you," hear it and feel it, together. They say it to one another. These are humans in the same space creating their own ethics, drawing and maintaining lines in collective action and practice. Peer interaction and informal learning contribute to understanding differences between fiction and reality and bringing them together in "actual social practices" (Lamarre 2006: $38 \mathrm{I}-382$ ). Despite Nakamori's wavering, "a game like rape" can be stopped by those in the same space, or can be stopped at the level of play and movement in response to fictional characters by those drawing and maintaining lines, together.

Echoing Ōtsuka in 1989, Honda Tōru also sees his reflection in a criminal other and potential self in 2008 . In a published dialogue released soon after the arrest of Katō Tomohiro, Honda muses, "Other than the crime, he is really the same as me" (Honda and Yanashita 2008: 69). If things had been different, Honda might have been Katō, which means that this man's problem is a shared one. This raises questions of how to live without turning to violence. The earlier discussion of taking it easy can be re-contextualized and advanced here. Recall that, in addition to perceiving the fragility of someone whose sense of self hangs on media and material, Ōtsuka understood that the things represented by Miyazaki's room, notably the sex and violence of cute girl characters and horror films, are necessary for some people's "spiritual stability" (Ōtsuka and Nakamori I989a: 24-25). These things support living and moving on. Almost as if directly extending this discussion, Saitō submits that the best thing to keep people from depression, withdrawal and suicide is for them to develop alternative resources and values, which begins with saying, "I have this" (Saitō and Jō 20I 4: I 57). For Honda, 
that is his wife, or a cute girl character named Kawana Misaki, as well as his imagined and created moe family (recall Chapter 2). Similarly, at Hajikon and similar raves, bishōjo games and characters are something that players have and hold on to, which keep them from falling into depression and despair. Rather than saying, "I have this," they say, "We have this" and "this is great." Sharing these resources and values is a way to stay positive, social and alive. It has already been noted in other times and places that unexpected attachments and affection for media and material can become "a prime resource for survival" (Sedgwick I993: 3), and Honda fleshes this out. For those without anything to hold onto, he offers that a first step might be to "take it easy," or take the time required to find whatever works and ways to live and move on.

Among all those contributing thoughts to the volume where Honda's dialogue was published in 2008 , he is given top billing on the cover, which speaks to his status as a spiritual leader and guru for many young men in Akihabara and of the moe generation of "otaku." Indeed, it strikes me that his comments are to a certain extent a message to all those who might turn to violence. While he does not go as far as Ōtsuka in identifying with the criminal other and potential self, Honda does see in Katō "a nightmare where he couldn't even participate in games" (Honda and Yanashita 2008: 72). Even if Katō could have afforded games and make time for them, he had no one to play with or help him see the value of such play. A lingering sense of middleclass male propriety and desire for something more normal led to Katō's sense of failure; aspirationally normal and successful, Katō disliked himself and others he saw reflecting his failure and thus beneath him (Slater and Galbraith 20II). He would not talk to losers, even as he saw himself as a loser, and had no social feedback or way to shift his perception and values and perhaps even share a laugh with others and at himself. This is what it means to be unable to participate in games, and it is a nightmare not only because relief and escape are cut off, but also because one is not participating in or inhabiting the same game space and so has no one to pull them back, hold them up and encourage love and life instead of violence and death. There are no ethics here, only a person lost in abandonment and suffering from shame rather than sharing it in ways that are both painful and pleasurable.

While imaginings and performances of sexual violence at Hajikon and other bishōjo game raves were surprising and disturbing, my experiences in the field do not lead me to conclude that they reflect a desire or intention to do violence to girls and women. To state this 
somewhat differently, my fieldwork suggests that simulation of sexual violence does not always or necessarily "normalize extreme sexual violence against women and girls" (Lah 20I0; also Nakasatomi 20I3), but rather that there exist different cultures of and cultural approaches to sexual violence. One such culture is that of manga/anime fans generally and bishōjo game producers and players specifically, who draw a line between fiction and reality, two- and three-dimensional, and normalize sexual violence in one even as they struggle to keep it separate and distinct from the other. These men I encountered took a stance against sexual violence against human girls and women not despite playing bishōjo games, but because of it. Facing their violent desires and capacity for violence - among that which is least reputable in oneself (Warner 2000: 35 ) - they struggled to live ethically in action and practice. They struggled to live with their desires, with themselves and with others both fictional and real. Leaving Club Moonlight Dream Terrace, where bishōjo game players share imaginings and performances of sexual violence in controlled ways, men and women walked on the street together as friends. They walked together as comrades in a shared struggle with and against the violence of everyday life in precarious Japan. They were living and moving on, together.

\subsection{Conclusion}

At Hajikon on July 20, 20I 4, DJ Fujikawa selects a song titled "Kimochi Are You Real?" ${ }^{32}$ Kimochi means feeling, and in the song a bishöjo character asks if it is real. In some ways, the answer is obvious. Seeing men gather in front of the screen in Club Moonlight Dream Terrace and move their bodies in response to images of this cute girl character, hearing them scream, it is obvious that they are really feeling something. They are really attracted to the bishōjo character in the game and on the screen. They hear her voice, which is also really the woman who produced it. ${ }^{233}$ They feel the waves of sound, the joy of movement, the heat of bodies around them, the intensity of this moment of reality. But at times it seems as if the bishōjo character is asking the men if their feelings for her are real. How do you feel about me, really? Do you love me? Standing before the screen facing the assembled bishōjo game players, one man holds up a material representation of the cute girl character. This is his character, his wife, and they are here, together. He holds the object high above his head as if demanding recognition of its reality and his relationship. The scene brings to mind anthropologist Anne 
Allison's discussion of the reality of fictional characters in everyday life in contemporary Japan (Allison 2006: I80-I9I). Anthropologist Ian Condry adds that fictional characters are capable of triggering responses and becoming part of social relations (Condry 20I3: 7I, 200-20I). For Condry, characters are alive when we interact with, through and around them. Certainly this is happening at Hajikon, where bishōjo characters are brought to life in shared movement and social interactions. Here, the character is as real as the feelings.

Fan studies researcher Nicolle Lamerichs refines points made by Allison and Condry in her discussion of "affective spaces," which are media saturated environments where "fiction is actualized" and "intimacy is shared in relation to fiction" (Lamerichs 20I4a: 270). ${ }^{234}$ Certainly Club Moonlight Dream Terrace is such a space during Hajikon and similar bishōjo game raves, as is Akihabara (see Chapter 2). Importantly, Lamerichs, who conducted fieldwork at anime conventions in the Netherlands, highlights how affective spaces allow for "expression of one's romantic and sexual feelings in new ways" (Lamerichs 20I4a: 270). This again is familiar from Hajikon and Akihabara, and, like the anime fans that Lamerichs observed, bishōjo game players share movement in response to characters and one another. "The characters and love between them are a medium for fans to share their affect together. Affect becomes an intersubjective phenomenon then that signifies a relation between fans, but also between characters" (Lamerichs 20I4a: 272). The affective space "glues together social contexts, physical space and bodies" (Lamerichs 20I4a: 272). Relationships are forged with, through and around characters. Of anime conventions in the Netherlands, Lamerichs argues that an affective space "strongly connects sexual fantasy with reality" (Lamerichs 20I4a: 27I), but my own fieldwork shows that it matters a great deal how that connection is made. Fictional and real bodies, male and female, come together at Hajikon and similar bishōjo game raves, but lines are drawn to keep fiction separate and distinct from reality. While Lamerichs is comfortable citing scholars who propose that, "It is not that fans are infatuated with or in love with fictional characters" (quoted in Lamerichs 2014a: 27I), men and women at Hajikon in fact insist that they are in love with fictional characters.

At Hajikon and similar bishōjo game raves, players describe cute girl characters as their wives and declare love for them, but also share imaginings and performances of sexual violence against their wives in media and material form. Men imagining and playing sexual violence 
raise questions about what religious studies scholar Joseph P. Laycock calls dangerous games, which have the potential to shift perceptions of and impact reality (Laycock 20I5: 2I 2-2I5). Playing games of sexual violence might normalize it and contribute to violent sex acts. However, from what I have seen, this does not appear to be what is happening among bishōjo game players. In practice, a line is drawn between fiction and reality. At Hajikon and similar bishōjo game raves, players are oriented toward cute girl characters, their objects of affection. Even as characters take on material forms and are interacted with physically, they are treated as separate and distinct from "real girls and women." Imaginings and performances of sexual violence involve cute girl characters, which are real in their own way. This is key, because imaginings and performances of sexual violence could easily refer and contribute to the reality of sexual violence. Even as one responds affectively to fictional characters, there is ambivalence, which Harata Shin'ichirō calls "the performative ambivalence of moe" (see Chapter 4). For Harata, this ambivalence is precisely why ethics are necessary. It is significant that I never observed or even heard of unwanted sexual advances, let alone acts of sexual violence against women, at Hajikon or similar bishōjo game raves. There is an ethics for players sharing affective responses to fictional characters. They draw lines, which is not mechanical or automatic, but rather ethics in action and everyday practice. The ethics of moe comes from sustained engagement with manga, anime and games and the "real world," the two- and three-dimensional worlds. "To avoid the dangers of corrupted play," Laycock writes, "we must learn to walk between worlds" (Laycock 20I 5: 290). We must learn to draw lines. Playing, and playing with others, is part of that learning.

Beyond the ethics of moe, Hajikon and similar bishöjo game raves demonstrate how shared movement can be life-sustaining. At Hajikon on July 20, 20I4, the same rave where he selects "Kimochi Are You Real?" DJ Fujikawa experiences a moment of failure. He is not in control of his body, propped up by others and ashamed. Nevertheless, he struggles to tell the assembled players that even if they are bad, even if they are no good, bishōjo games are still great and so are they. He loves these games and these players. Moved by others in the club, DJ Fujikawa's feelings are certainly real. His love for bishōjo games and characters is real. His breakdown is real. Sharing his love and breakdown, the support he gets from the men and women at the bishojo game rave is real. His love for these men and women is real. It is all real, sometimes too real, and painfully so. Overwhelming in their intensity, DJ Fujikawa's 
feelings bring him to tears. One cannot help but be struck by the care that these bishōjo game players show for one another, especially in moments of weakness and vulnerability. When the equipment breaks down at Adults' Day on May 5, 20I4, a DJ breaks down and shares with the assembled men and women the feelings of precarious life. In the end, this time, they laugh rather than cry. When his set ends, however, the DJ seems on the verge of tears when he says to the assembled men and women, "I love you!" It all breaks down - equipment, social bonds, people - but reparative work is done in sharing breakdowns.

Like many other affective spaces in contemporary Japan, Club Moonlight Dream Terrace is outside of home, school and work. It is a space outside of institutional identities and hegemonic ideals that conspire to make people into failures. It is a space to imagine and create some distance from norms that, in their decline, have become toxic. At Club Moonlight Dream Terrace, I encountered men and women living and moving on, which struck me as a stark contrast to a barely missed encounter with Katō Tomohiro in Akihabara in 2008. We were in the same place at the same time, and we were the same age, 25. Struggling with failure, I recognized much of myself in him. But I had things in my life that gave me joy. Having something, even something like bishōjo games, can make a difference. From the perspective of bishōjo game players, Katō was living “a nightmare where he couldn't even participate in games" (Honda and Yanashita 2008: 72). Turning away from fictional and real others and in on himself in a crushing disposition of failure, alone in his room, frustration and depression turned to anger and violence. There was no one in the "same game space" (Ōtsuka and Nakamori I989a: 93-94) to pull him back from the brink and prevent harm to others. One of the abandoned, he did not develop or share an "ethics of the abandoned." Conversely, Hajikon and similar bishōjo game raves give players a space to come together and share affective responses to fictional characters. While bishōjo game players might be seen as failures by many, including perhaps even themselves at times, at Hajikon they are encouraged to embrace themselves and one another as abnormal. This keeps them out of their rooms and moving with others, laughing and living, ethically. In some shared room somewhere, I hope that DJ Fujikawa and others are still moving together. Now as then, the feeling is real. 


\section{Conclusion: A World that's Ending: Do You Love Me? ${ }^{235}$}

"The only thing worth writing about is people. People. Human beings. Men and women whose individuality must be created, line by line, insight by insight." - Harlan Ellison ${ }^{236}$

\subsection{Take Care of Yourself}

It is the evening after the third and final day of the Comic Market and school is in session at Akihabara University. ${ }^{237}$ Or with Akihabara University. In the basement of the Mansei Building across Kanda River just outside of Akihabara, a group of about 20 middle-aged men are lecturing me about bishōjo games. My friend Hikaru is to blame. The men were happily talking about manga, anime, games, fanzines and all the other things that matter to them as members of "Akihabara University" (Akihabara daigaku), a loose collective of über-fans, critics and creators. ${ }^{23^{8}}$ They were animated by the events of the Comic Market, being together in Akihabara and the free-flowing beer from self-serve machines located at the entrance to this dining hall. The place looks old, as if Vikings would be quaffing mead here after a battle, which is no doubt why Hikaru reserved it for a gathering of his rowdy crew. Hikaru is a leader in the sense that he does things, makes things happen and is fun to be around. He does something, and then falls back, which creates an opportunity for others to step in and lead. So it was that Hikaru stood and called the assembly to attention. "Everyone, listen! Mr. Galbraith here wants to know about bishōjo games, so let's talk about them. Go!" I stupidly think that this might be a chance to ask some questions, but instead they come at me in a flurry and reveal that I know nothing compared to these men. And how could I, the men inquire? I follow Hikaru around and believe that he is someone important and worth listening to! Loud guffaws. But the prompt has succeeded in getting

How to cite this book chapter:

Galbraith, P. W. 202I. Ethics of Affect: Lines and Life in a Tokyo Neighborhood. Pp. 237-25I. Stockholm: Stockholm University Press. DOI: http://doi.org/IO.I6993 /bbn.g. License: CC BY 4.0 . 
the men to discuss bishōjo games. They all have played them, many still do and a few are very dedicated players. Particular games, scenes and moments are highlighted and shared. Moved again by memories and play experiences that come back with the force of an exploding bombshell, the men clap and point at one another and shout. They remember how the games moved them - laughter, tears, anger, arousal. I loved that character. I still do. Wasn't that hot? Hell yeah! With a satisfied grin, Hikaru slouches back and claps me on the shoulder. His work is done, and he settles in for a session that continues past midnight.

For all the hazing, I was fortunate to be an honorary member of Akihabara University during my fieldwork from April 20I4 to August 20I5. Hikaru even made me an official-looking English namecard to pin on my shirt. According to it, my name is "Galbraith," and I am a "Proffesor" [sic] at "The university Akihabara" [sic]. It's the thought that counts. I learned a great deal from hanging out with these men, who seemed to assemble at the slightest suggestion from Hikaru. He bought a bunch of cheap meat at the supermarket, so come to his place for a hotpot. It's a small apartment, but he lives alone and has a stock of CDs for music listening and fanzines for reading (almost all related to the Touhou Project games). ${ }^{239}$ The Comic Market is coming up, so everyone who is making something to sell should come over for collaborative work. In fact, everyone come to pitch in, and we can have a party after. Payday, so let's go get ramen. Or curry. Or a beef bowl. Hey, you know what might be fun? Let's charter a bus and tour the island of Shikoku, which is known for its noodles. And we did. Most of the members of Akihabara University were single and had decent jobs that gave them the money and flexibility to join the tour. Around 50 men on a bus traveling through Shikoku for two days in September $2014 .^{240}$ The conversation was almost always about manga/anime, games and characters. The guy next to me on the bus was an artist who produced a group fanzine called $S O$, men, which featured bishōjo characters bathing under a waterfall. $S O$, men, because we are men going to eat "men," or noodles. ${ }^{24}$ So, what kind of men? The kind that plays with their noodles, apparently, given that an entire leg of the bus ride was spent debating what kind of tissue paper was best to use to clean up after masturbation. The conversation was bawdy, and men laughed at themselves and one another. When Hikaru started espousing his love for a particular character, the banter turned to who is married to which character and everyone was all in. Responding to the quality of the men on the bus, the guy next to me hollered, "For the sake of Japan's 


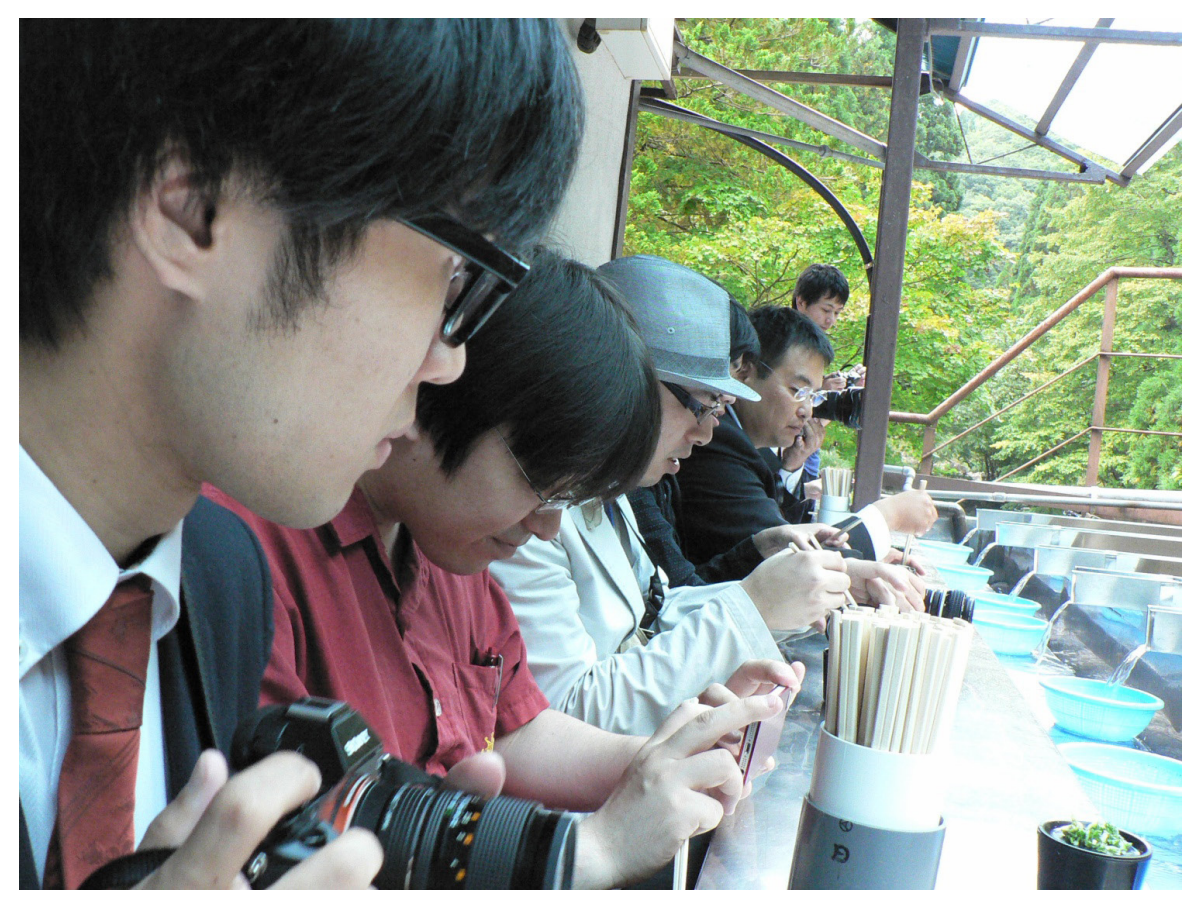

Image 31. Members of Akihabara University on tour in rural Japan. Photo by the author. License: CC BY 4.0.

future, this bus should really crash!" But it did not crash and the talk and laughter continued in a present and co-presence that became the future. And one expected that it would continue further still, whether or not for the sake of Japan, for better or worse. When someone left Akihabara University, he was always told, "Be safe" (go-anzen ni). It is not a normal way to see one another off in Japanese. ${ }^{242}$ But when the collective dispersed at the end of the Shikoku tour, they said it again and again: "Be safe."

Of all the things that I learned from Akihabara University, one of the most important was the existence of networks of support and care among single, working men in contemporary Japan. Brought together by shared interests, these men regularly gathered and always had future gatherings and events to look forward to. As I became accustomed to the collective, I learned to see others off by saying, "Be safe," and to know that doing so meant that I could look forward to seeing them again in the future. In lonely times, this was nothing less than a lifeline. Everyone in the collective had his quirks, and I was often treated as the most eccentric of all, but we nevertheless got along. Brought together by a shared interest in bishōjo characters from a media franchise 


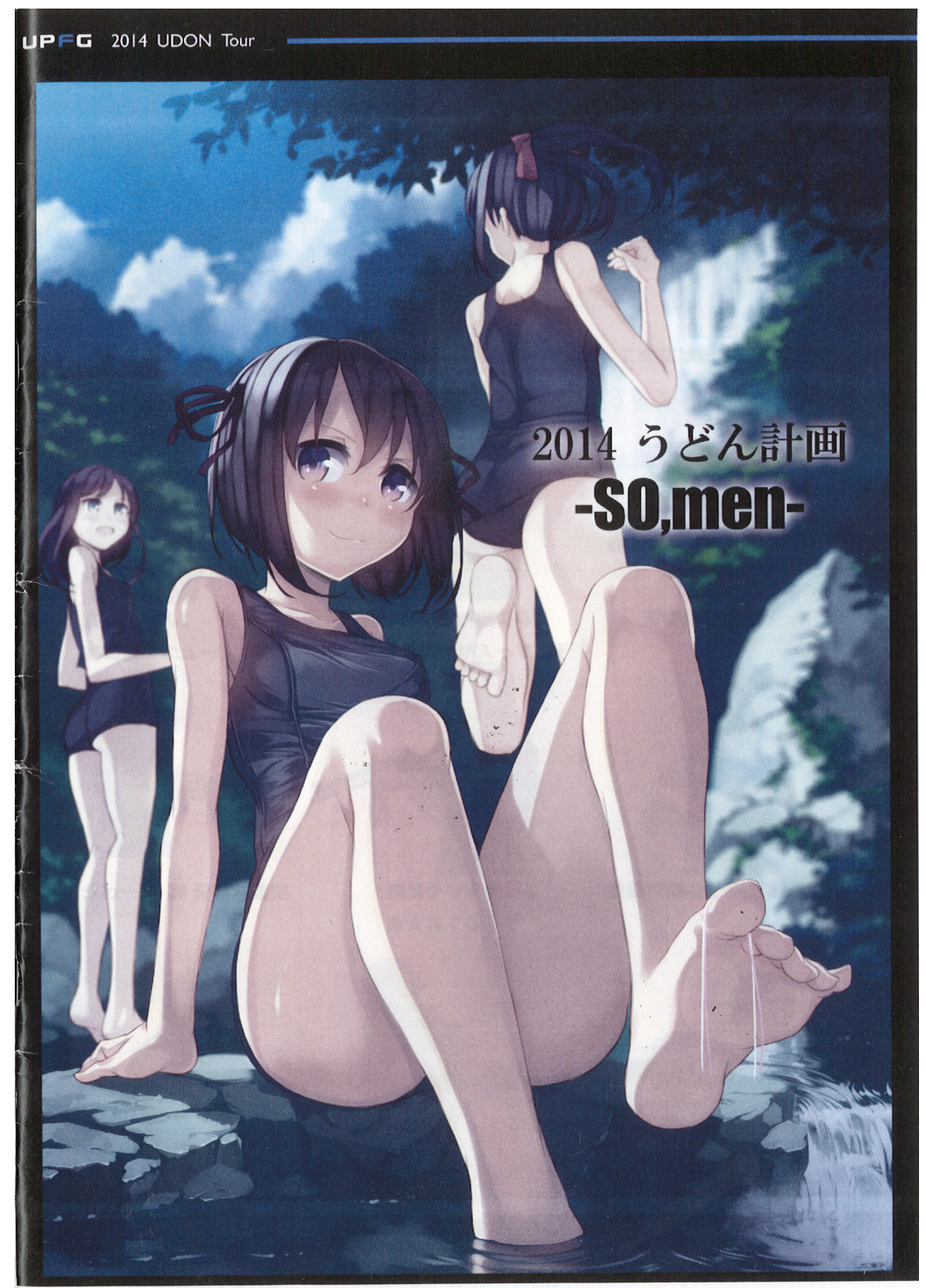

Image 32. Pamphlet for the tour, drawn by a member and titled $S O$,men. Photo by the author. License: CC BY 4.0.

called Love Live! (Rabu raibu, 2010-), I came to see many of them as friends. They were wankers and weirdoes to the man, but they assured me that I was too and that was what they liked about me. Everyone was 
welcome and had a place. We all had fun together. We cared about one another, and wanted everyone to be all right so that we could see them again. There will be more events, more laughs, so, until I see you again, "Be safe." Take care of yourself. A form of care that is both individual and social. It was a lesson I learned well at bishōjo game raves, which are less of a named collective and more of an open event, but nonetheless serve to support life (see Chapter 5 ). Even if we are bad, even if we are no good, bishōjo games are great. We have them and one another. So be safe. Take care.

As strange as bishōjo games might seem to some, the story of the men playing them is familiar. It is a story of living, together. They might be single, but they are not alone. They might be perverts, but they are fine with that and having fun. Despite the violence of the everyday, they are alive and do not want to be otherwise. Anthropologist Anne Allison reports new ways of living together emerging in "precarious Japan," including a gathering and performance of the group Kowaremono, or "broken people," who share their pain and cry out: "I won't die, I won't kill, I want to live! Don't die, don't kill, live!” (Allison 20I3: I3 I-I32, I 55-I 56). While translated as "broken people," kowaremono also suggests something "fragile" or "breakable." So, fragile or breakable people. People who could be broken. They are vulnerable and weak, and recognize this about themselves and others. They share vulnerability. This points to precariousness as a shared condition of existence, and recognizing it is the beginning of an ethics of life (Butler 2009; Butler 20I 5).243 We are vulnerable, together, and live, together. Vulnerability and weakness in fact encourage relations of care. Certainly this resonates with my fieldwork among bishōjo game producers and players, but they also expand the recognition of the human and real other to include fictional characters (Sasakibara 2003: 105-107; Chapter 3). These characters are also kowaremono. ${ }^{244}$ They, too, are vulnerable and weak and exposed to the violence of precarious existence. They, too, are cared for in shared life. Anthropologist Lisa Stevenson explores "life beside itself," where people in the Canadian Arctic survive, die and live on otherwise. "Can we imagine," Stevenson writes, "another form of caring that conceives of life both in its exposure to death and in its imagistic relation to the other, to others?" (Stevenson 2014: I 5). While Stevenson is asking about a form of care that does not simply try to extend life without consideration of whose life and what life, I wonder if we might consider the conditions of life and death with fictional and real others as another form of imagistic relation. 


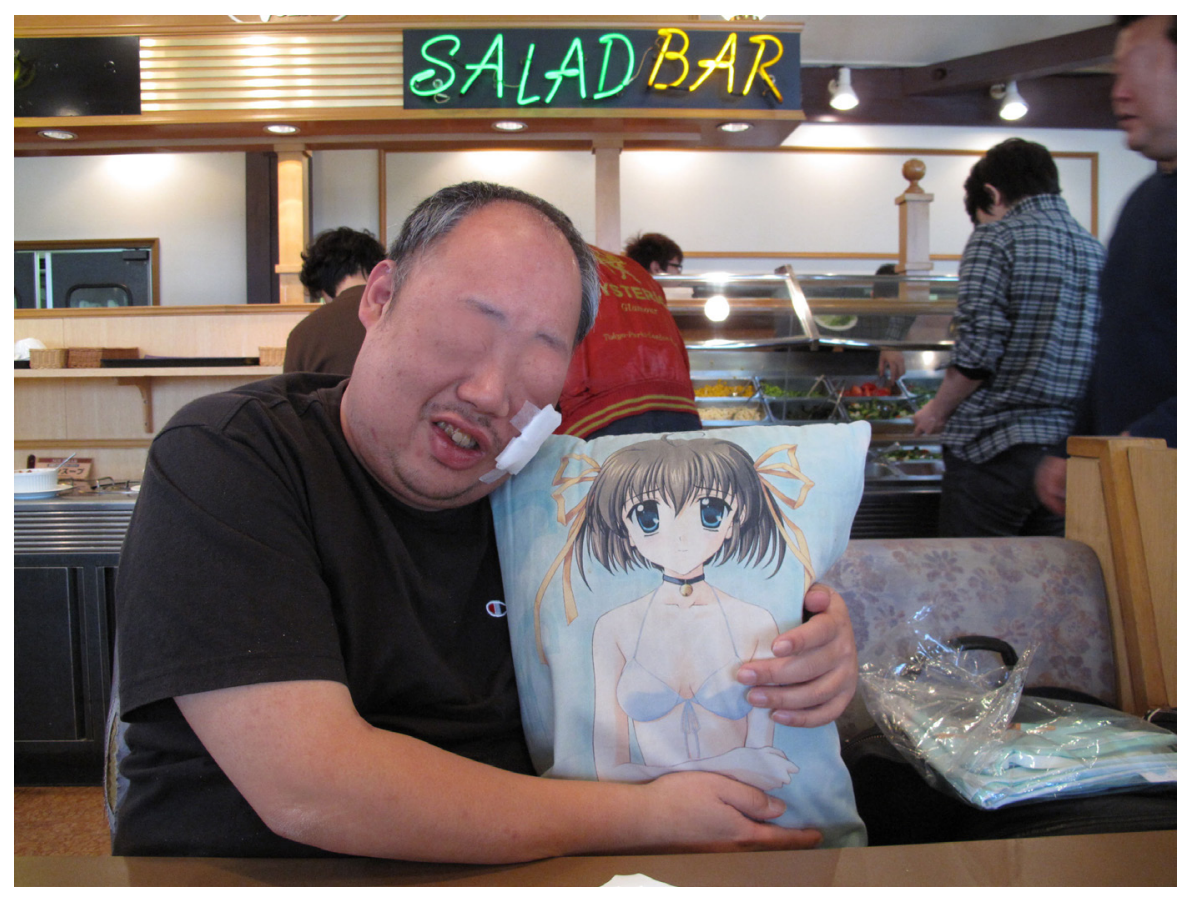

Image 33. Man poses with his wife at a restaurant. Photo by Lisa Katayama. Used with permission from rightsholder. License: CC BY 4.०.

Let's take Stevenson up on her challenge and try to imagine. Three images. The first is of a man sitting in a restaurant. ${ }^{245} \mathrm{He}$ is Japanese, probably in his forties, overweight and balding. He has a large white bandage on his left cheek to cover an open sore and his left eye is swollen and red, possibly infected. He is at a table for two, but is not waiting for anyone. People pass behind him to get to the salad bar, but he is alone at the table. Well, not exactly. He is seated next to a pillow upon which is emblazoned the image of a bishojjo character. The cute girl is slight, thin and nude except for a white bra, collar and two ribbons in her hair. The man is leaning in close to the pillow and hugging it - in public, under the bright lights of the restaurant. And he is smiling. Weakly, but smiling. He looks at the person holding the camera and at you looking at the image. He is making a claim and we are in an ethical relationship with him as a human being (Azoulay 2008: I 8-23, I47-I 50). This is real. The character he cradles in his arms beside him, smiling and looking kind, looking out at you with massive eyes - is real. This is his wife. He has her, holds her, and is not alone. The second image is of a man on a lawn next to a bustling pedestrian thoroughfare. ${ }^{246}$ It is daytime, but he has laid out a futon and is lying on it. He has multiple cute girl pillows, including two body pillows that 


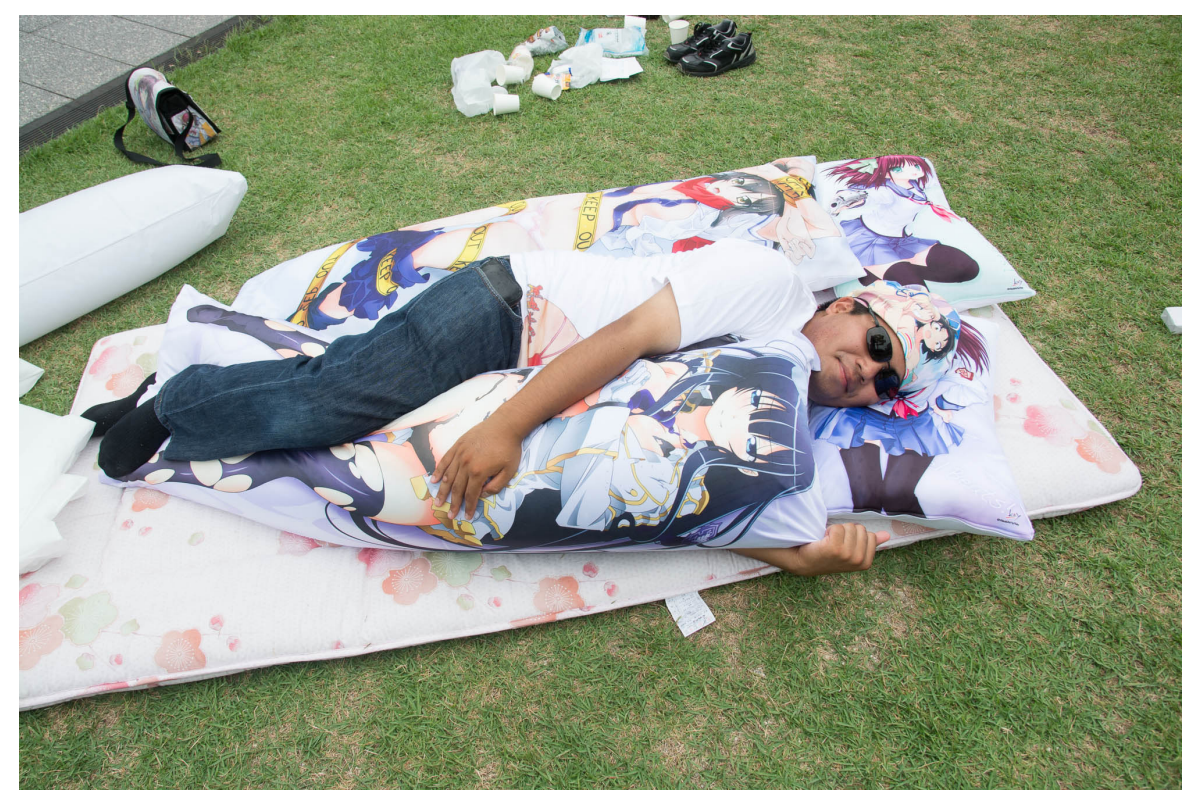

Image 34. Man publicly sleeping outside the Comic Market in summer 20I4. Photo by Ramon McGlown. Used with permission from rightsholder. License: CC BY 4.0.

appear to be related to bishōjo games, sex and all. Wearing a cute girl bandana, sunglasses, a cute girl shirt and blue jeans, he is on his side, arms and legs wrapped around one of the pillows, looking at you. As others hurry by, this man performatively sleeps with cute girl characters in public. He seems about to break into laughter. The third image is from Akihabara. ${ }^{247}$ A computer store on Chūō Street is advertising body pillows featuring cute girl characters from Love Live! A sample is in plastic wrap and bound tightly with cord, but the character inside seems to be pushing against her constraints and about to burst free. Behind is a sign reading, "Who will you sleep with? Feel free to tell the staff inside in a loud voice!" Everywhere images of these cute girl characters beckon you to them and inside, where the staff awaits your passionate declaration of love.

Now, then, let's try to imagine, together, the lives of these others and other ways of life. Let's try to take the care necessary to see "another's point of view" (Haraway I988: 583). Is it so bizarre that bishōjo characters might be others with whom we are in relation in life beside itself? That cute girl characters can be part of a shared social world, a "shared fantasy" that challenges commonsense "reality" (Editors I989: $3)$ ? That certain spaces and gatherings can function as "platforms to share fantasy?" That, just as was the case with a group of "broken 


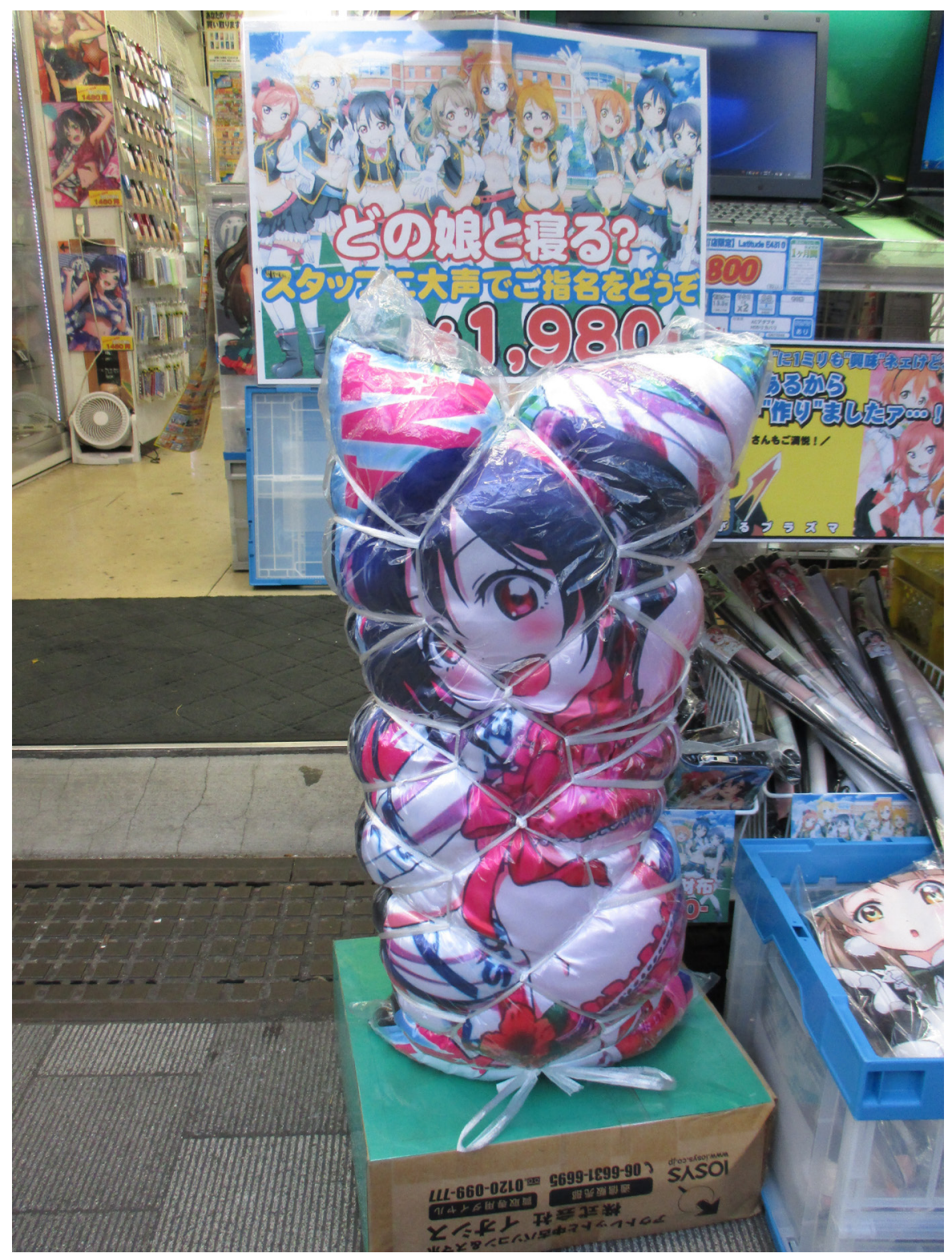

Image 35. Outside a computer store on the main street of Akihabara. Photo by the author. License: CC BY 4.0.

people" in Northern Japan (Nakamura 20I3: I 29-I3 I), acknowledging and living with imaginary others socially can be a form of care that saves lives? That perhaps these men are not broken at all? That they might not need to "get a life," because they have one already, which they share, or want to share? If the sexuality of bishojo game players, 
among those identified as "otaku," "hovers between the thrill and shame of playing with one's self" and "sex with an image" (Lamarre 2006: 375), then we can also play with others. ${ }^{248}$ If "many otaku have actually 'come out' and thereby proclaimed a sort of sexual identity" (Vincent 20I I: xxiii), then they need someone to come out to and with. Someone to see and experience the imaginary relationship as real. To share it. Reparative work can be done by simply acknowledging that the bishojo character is real, the relationship is real and the person who laughs and loves is real. The reparative work starts with playing together and sharing imagination. That, too, can be a form of care. Characters say I love you to players in bishōjo games, but cannot do so beyond them. The player hears it in his imagination in a relationship that goes beyond the game. We can share that imagination and hear those words, together. And we can say them to one another: I love you. That, too, I learned from bishōjo game players (see Chapter 5). That, too, can be a form of care that supports life beside itself. ${ }^{249}$

\subsection{The End: Death and Rebirth}

Depending on your perspective, Akihabara is the center and the end of the world. It is the best and worst. Heaven and hell. Surrounded by images of bishōjo characters in various states of undress and engaged in explicit sex acts, one might even think that we are in the Biblical end times and humanity is nearing its final destruction. For critics, this is Japan at its most abnormal, and it is already an abnormal nation, so that is saying something. Journalists and activists come to Akihabara and demand that Japan do more to live up to global norms in regulating imaginary sex, violence and crime. Politicians in Japan call for a return to normal, by which they mean a nation that can stand on its own on the global stage. They see problems in the declining marriage and birth rates, the shrinking population of workers, the perceived flight from sex and social responsibilities. They find culprits in youth, foreign powers, a bad economy, a constitution imposed by the United States that bans the country from having a military with full powers. Everywhere things are abnormal, and need to be brought back to normal. They recruit Japanese people furious and frustrated with life, and turn them against others. The fiery rhetoric of Japanese nationalists bidding a return to normal is accompanied by natalist policies to control bodies and discourage abnormal desires and angry young men lashing out at foreigners and feminists, liberals and queers, whoever - for being 
denied a normal life. The dynamic, which is prevalent in many parts of the world, is what activist Guy Standing dubs a "politics of inferno" (Standing 2OI I: I32-I 54), where economic, social and ontological precarity leads to violence. Always, but in these times especially, we must be cautious about channeling outrage toward the abnormal, the other, the pervert.

In contrast to the inferno is heaven, but let's imagine that there is no heaven above or hell below, just the world, and imagine a politics here. What would a politics in contrast to the inferno look like here? Perhaps something like a politics of moe, an affective response to fictional characters that is so often experienced as burning passion and love. A passion and love that is performative and shared, socially. That animates and moves bodies, brings them to life and into interaction with others (recall Maeda Jun in Chapter 5). Such a politics might include facing and acknowledging violence in ways that does not lead to violence. A separation of fictional and real others, which allows for working through violence but does not encourage violent acts that diminish the lives of others. In order to play with oneself and with others and to play violence, one must embrace the abnormal, other and pervert in oneself and others. Reflecting on my experiences in the field, I have come to adopt the position that there is an ethics in facing and sharing desires (Sasakibara 2003: IOI, I05-I09, II3), even if, especially if, they are dangerous and potentially harmful. This is an ethics that begins with the "acknowledgement of all that is most abject and least reputable in oneself" (Warner 2000: 35). It begins with these words: "I am a beast" (Deleuze and Guattari 1983: 277). By working through what is abject and least reputable in them, players enjoy a "special kind of sociability" (Warner 2000: 35). They act and interact ethically. Conversely, we need to be vigilant of the will to construct discourses about the deviant other located elsewhere, who then becomes the target for critiques of violence that exists outside and elsewhere. Put simply, the construction of the imaginary other allows for the construction of the imaginary self. That self is "normal." That self is a pure subject who does not mean any harm and is in fact incapable of it. That self is the one who does not face or work through its capacity for violence, which becomes an unacknowledged - repressed, denied, projected onto others - violence. This is the self who interacts with fictional and real others in uncritically violent ways. Acknowledging and sharing that which is most abject and least reputable in oneself - playing with oneself and others, playing violence, playing sex - furthers an ethics of life, as does recognizing 
shared desires, weakness and vulnerability. Considering the "complex and fragile character of the social bond" (Butler 2009: viii), and the complex and fragile social bond with characters both fictional and real, might contribute to conditions in which violence is less possible and life is more livable.

Whether or not this leads to a politics that burns as hot as the inferno - lights a fire under people, but does not initiate sending others or the world up in flames - I do see in it a politics of imagination. Bishōjo games are sexual imagination. They are imagined, created and shared. Bishojo game players, who embrace "the freedom of imagination/ creation" and the "abnormal" and identify as "perverts," are at odds with everyone normal, it seems. ${ }^{250}$ They reject more state-imposed regulation of imaginary sex, violence and crime - regulation that is increasingly normal around the world (McLelland 20I7: I I-I3) - and instead regulate themselves. This takes the form of an ethics of moe, or the action and everyday practice of drawing and insisting on lines. Even as one experiences moe, or is moved to an affective response by a fictional character, which is real in its own right, the character is separate and distinct from a "real person," or a human being that is real in different ways, "three-dimensional" as opposed to "two-dimensional," "natural real" as opposed to "manga/anime real" (Chapter I). This separation is a media literacy and ethics learned socially in informal peer interactions (Chapter 2). It is not always clean or clear, and can be ambivalent and come with the potential of harm, which is precisely why it is insisted on in the action and everyday practice of drawing and maintaining lines with others (Chapter 4). Thus separate from "reality," one can explore fiction that is real and moving on its own terms. Nothing is repressed, nothing is held back, and much of what is imagined is perverse, violent and disturbing. Bishōjo game players take a stance against violence and harming others not despite playing perverse, violent and disturbing games, but because they do (Chapter 3 ). And, finally, movement in response to fictional characters - characters that are real and movement that is shared - supports life (Chapter 5). Encounters with fictional and real others increase the body's power of activity. ${ }^{251}$ In a world where some say the social is in decline and disconnection and despair are on the rise (Allison 2013), what I observed in contemporary Japan was social connection and joy. I came to know men who might be considered losers or failures imagining and creating shared social worlds where they live with fictional and real others, which increases the body's power of activity. They were alive, active, moving in the world. ${ }^{252}$ They 
might be perverts, and we might think that their imagination and play is abnormal, but the only metric by which this should be stopped is evidence of "demonstrable harm" (Bering 2013: 232).253

To increase the body's power of activity, and to act in ways that are not harmful to other bodies, one needs an ethics of bodies in relation to one another. Among manga/anime fans generally and bishōjo game producers and players specifically, this is the ethics of moe. As psychiatrist Saitō Tamaki sees it, "there is a certain sincerity and ethics in a disassociated life lived with self-awareness" (Saitō 20II: I72). That is the ethics of Sasakibara Gō, who is aware that media affects him and that he has the capacity to harm, and plays through affective responses to the weakness and vulnerability of cute girl characters, which become targets of violence and care (Chapters I and 3). Taking responsibility for the capacity to harm and acting accordingly is the ethical thing to do. We see the ethics in Ōtsuka Eiji, who cultivates an orientation of desire toward fiction as such, even as he refuses to distance himself entirely from a child molester and murderer who confused and conflated fiction and reality to deadly effect (Chapter I). In Ataru, who understands that media affects, but, having grown up in an environment supporting an orientation of desire toward fiction, is confident that it is cute girl characters, and nothing else more "real," that he desires, which is why he is not a "harmful person" (Chapter 2). Kōta, who plays through bishōjo games that simulate sex, violence and crime involving cute girl characters, but then is livid that real girls and women are being bought and sold as idols (Chapter 4). Tomoyuki, who calls himself a "two-dimensional lolicon," or someone attracted to cute girl characters in manga, anime and games, but not young girls (Chapter 4). Tarō, who agrees "lolicon is righteous," but, surrounded by tens of thousands of fanzines featuring sex and violence involving cute girl characters, recoils at the sight of drawings that are "real and dangerous" (Chapter 4). Bishōjo game producers and players upset and unsettled when Fukumimi, one of them, seems to confuse and conflate fiction and reality in a discussion of underage sex (Chapter 4 ). Interacting with one another, they draw lines and insist on them. We can see the ethics at Hajikon, where men and women, fictional and real, actual and virtual bodies, media and material come together in an affectively charged space to allow for powerfully moving and pleasurable shared interaction with cute girl characters, which are clearly separated from flesh-and-blood women inside and outside the room (Chapter 5). Because lines are understood 
and respected, sexual play with fictional and real bishōjo at Hajikon does not lead to sexual tension between men and women, and sexual violence toward cute girl characters is something to laugh at. Even when stepping into scenes of imaginary violence, the women respond by playfully interacting with the men and laughing at and with them.

The separation of fictional and real is not obvious or automatic. Precisely because the affective response is ambivalent, Harata Shin'ichirōexplains - precisely because it might be to something more "real" than the character, blur boundaries between fictional and real and lead to harming real people - manga/anime fans generally and bishōjo game producers and players specifically insist on the distinction between fiction and reality in action and everyday practice (Chapter 4 ). Performing the response and playing together, socially, is a way to work through what Harata calls "the performative ambivalence of moe." There is certainly danger in being closed off from the world and without others to assist in drawing and negotiating lines between fiction and reality, and bishōjo game producers and players recognize this danger (recall Honda Tōru in Chapter 5). As Harata and many others argue, what is necessary is media literacy and ethics, which must be learned. That learning occurs in interactions and relations with others in the world (Chapters 2 and 4), even when, or perhaps especially when, lines get blurry, things get dark and ethics become murky in "game worlds" (Jenkins et al 2009: 24-26). The solution is not to ban the game, but to play and learn from it. We learn to draw lines playing with others. If, as Saitō proposes, we have "the right to be perverts" in "the imaginary" (Saitō 20II: 3I), then this is because we take responsibility for our perversion and imagination. We face them, work through them, share them. This is an ethics of queer life, an ethics that supports life in all its queerness. It is an ethics that supports the life of the imagination, in all its perversity, rather than shutting it away. Saitō completes his thought: "If there is a certain sincerity and ethics in a dissociated life lived with self-awareness, it is because hypocrisy and deception dwell in the falsely coherent life" (Saitō 2OII: I72). This is the hypocrisy and deception that imagines perversion in others, which keeps it safely outside the self. The hypocrisy and deception of imagining the self as pure and incapable of harm while others are perverse and only capable of harm. Imagining perversion and harm in others leads to policing those others rather than facing the dark and disturbing desires in us and working through them, together. 
This book has ethnographically explored an open and public culture of imaginary sex, violence and crime. I have identified how social learning and support have led to the development of media literacy and ethics. I moved with men who struggled in everyday life and interactions and relations with fictional and real others to draw lines and conduct themselves ethically in the world. They faced their capacity for violence and harm and worked to be nonviolent. They rejected calls for a return to "normal," which in Japan are accompanied by violence from men demanding something more from women and society and the nation demanding something more from the military to rattle sabers with its neighbors. In the face of that violence, and the violence of everyday life in contemporary capitalist society, these men endeavored to live and to live differently. Here were men who did not want "Japan" to return to its status as "normal" or to return to their place in such an imagined nation. They celebrated the end of Japan - saying "Nihon owata!" or "Japan is over!" - as the beginning of something new - "Nihon hajimata!" or "Japan has started!" 254 That tension between death and rebirth, between the imaginary "Japan" of the past and future, is an inhabited one. These men, who failed to be "normal" or have been failed by the "normal," or failed to desire to be "normal," were more willing to push back on and cross the normative boundaries of society, the nation and the world. Calls for keeping gaming, gamers, Akihabara, events and Japan weird are part of a politics of imagination that resists normalizing, which comes with regulation and normalized violence. These abnormal men had their own norms of violence, and sexual violence, which are ambivalent and in dialogue with other norms and realities. For all of this, I recognize that these men were trying to imagine and create other worlds and other ways of seeing and being in the world. A world sustained and sustainable through collective activity and practice. A world of fictional and real others that moves us to response, for which we are responsible (Lamarre 2006: 383 ; Butler 2009: 34). ${ }^{255}$ Rather than resolving this ambivalence and tension, I have tried to leave it open and to imagine and live other responses with others in the world. This is my own politics of imagination, which comes out of a book on the ethics of affect in contemporary Japan. This is not the only story of the politics of imagination and ethics of affect. Others wait - for example, female fans of comics, cartoons and computer/console games in Japan and beyond - to be told. ${ }^{256}$ Just as "Japan" ends and begins, so too does the story. 


\subsection{The Beast that Shouted "I/Love" at the Heart of the World}

It has been a rough couple of days for Ataru. His job has been particularly taxing, and he looks worse for the wear. He broke up with his girlfriend, or perhaps she left him, but either way he is single again. Single, but not alone. We are commiserating tonight over ramen in Akihabara; close to midnight, only a chain store is open. It is too late for dinner, and too dark to be out, but Ataru just got back and is hungry. He slurps his noodles, wincing. The flavor is fine, just fine, but nothing special. Ordering a beer and lighting the first of what is sure to be many cigarettes, Ataru leans back and settles into his seat. For whatever reason - the beer, the breakup, a lot of little things and nothing at all - Ataru starts to wax philosophical. "Have you heard of the simulation hypothesis (shimyurēshon kasetsu)? It's about reality. All of this is just a simulation on a computer somewhere. You, me, all of it. The scenario may be bad or good, and all that you can do is let it play out. But what if you treat the simulation like a computer game? Our choices matter. You play through and then start again. I've played all these scenarios in all these games, so I can play through to the end, no matter what." I nod in agreement, but remain silent, because I really don't understand. Ataru has been my guide and teacher in the world of bishōjo games, and a friend who I have been hanging out with in Akihabara for almost a decade by this point. What is he trying to tell me? Reality is a simulation, but it is also a computer game. There are choices and consequences. The game affects you. It is playing you, but you are also playing it. So play on, and play through the pain. Play with care, but not the kind of care that invests everything in something, which might make one feel like something bad is the end of everything. The simulation and game do not end - not really, anyway - so there are other scenarios and moments and endings. Finding the train of thought curiously comforting, I smile. Ataru responds in kind. The food, drink and company are starting to warm us up. The ramen is fine, and so is the night. In Akihabara, there is plenty of light in the dark. 



\section{Epilogue}

Years after the portion of ongoing fieldwork in Akihabara reported here concluded, the world seemed to be ending again. The COVID-I9 pandemic had almost completely stopped travel to and from Japan by March 2020, and social distancing protocols halted any plans for indoor, in person participant observation in Tokyo. Silent as the city was under these conditions, I still walked to and from Akihabara regularly as a sort of pilgrimage; the empty streets were somehow calming. As things started to slowly come back to life, the highly anticipated Summer Olympics in the meantime postponed until 202 I, I adopted an outdoor observation spot on a low wall on one side of an open square facing the Mandarake building. Making a habit of being there as day turned to night, I began to notice new patterns of interaction on the street in those twilight hours.

The players included women in variously themed costumes, men moving toward or away from these women as they passed by them and police officers on patrol. Without a steady stream of domestic and international tourists, many stores in Akihabara were suffering, especially concept dining such as maid cafés, but these women worked for establishments serving alcohol and less invested in character roleplay. They not only called out to passers-by, but also actively approached them. They spoke with familiar workers standing nearby in casual Japanese. Familiar customers clustered around some of them, and here, too, was scarce indication of character roleplay or language.

These interactions on the street telegraphed those in establishments that approximate what in other parts of Tokyo are called "girls bars," where conversation with attractive staff is what defines the drinking experience. Some of the few massage parlors offering sexual services this

How to cite this book chapter:

Galbraith, P. W. 202I. Ethics of Affect: Lines and Life in a Tokyo Neighborhood. Pp. 253-255. Stockholm: Stockholm University Press. DOI: http://doi.org/IO.I6993 /bbn.h. License: CC BY 4.0 . 
side of Shōwa Street exist on those parallel to Chūo Street and passing Mandarake here, which deepens associations with a certain kind of nightlife. Sitting on the low wall, it struck me that so many places connected to bishōjo games - the venue hosting Bishōjo Game Sixteen, Medio, the café where I sat with Ataru - are gone from these same streets. Instead of signs advertising bishōjo games, there were signs for bottomless booze, happy hours and happy endings.

With specialty shops catering to manga/anime subculture closing and the area becoming less of an attraction for "otaku," and with tourism lagging severely, new kinds of businesses were cropping up in Akihabara and alarming local authorities, hence the police on patrol. They came not only on foot, but also sometimes by car. One night in late October, I observed as a patrol car stopped beside Mandarake and blared on a loudspeaker a looped message about dangerous businesses in the area. The officers did not step out of the car, and continued to idle and blast the message for over an hour; the flashing red lights atop the car bathed the darkened streets and storefronts. Meanwhile, the women kept standing there, still working to attract customers. Some men moved in close to converse with them, while others hurried along or remained stationary around the square, poking at the screens of their digital devices.

When a weekly magazine reported a source involved with police saying that rip-off shops of the kind seen in Shinjuku on the other side of Tokyo were thriving in Akihabara and "police crackdowns have come into full swing" (Shūkan Gendai 2020), it was not as surprising as it might have been seated on that wall beside Mandarake. Not only is Akihabara a transit hub where the center circle Yamanote Line links to commuter arteries such as the Sōbu Line and Tsukuba Express, as well as the subway system, but stores were shutting down on backstreets and leaving openings. Businesses in Shinjuku had a reputation already, and were hit hard by news of being a hotspot for COVID-I9. Moving across town allowed for fresh opportunities.

It was not the rumors of gangsters behind the women on these backstreets that shocked me, but rather the sense that the distance and significant distinction between Shinjuku and Akihabara was collapsing. Rather than a shared orientation toward fiction as opposed to anything more "real," these bodies on the street were all too real. I could not help but remember standing on Chūō Street with Kōta back in 2015, when he told me about the wrongness of selling physical access and contact with idols, even as he prepared to purchase sexual partners in a bishōjo game store. 
In 2020 , Akihabara as a space of imagination and a space to work through imaginary and real relations with others was precarious. Ironically, policing the imaginary excesses, perversions and crimes of "otaku" contributed to the rise of actual sex work and exploitation on the backstreets in the vacuum left by tourism. In a reverse example of Times Square, the clean up and corporatization of Akihabara did not push sex out of public, but rather pushed out imaginary sex - imaginary excesses and perversions, the wild and woolly worlds of "weird otaku" - and made way for a more normative kind. The privatization of imaginary sex through bishōjo games and the like being bought online and played on one's home computer, or what Miyamoto Naoki explained to me as a short circuiting of the social in "computer completion," eased the transition.

This does not mean, however, that the ethical practice of drawing lines has suddenly disappeared among manga/anime fans. As was the case in Kawasaki during my fieldwork on bishōjo games, one finds outside of Akihabara lines being drawn in unexpected places. The men and women I met at Club Moonlight Dream Terrace interact on social media, and anywhere they assemble can become a bishöjo game rave and chance to reenergize ties and renew lifelines. I learned in Kawasaki, and with the dispersed collective Akihabara University, that it is not the place so much as the people and shared practices that encourage an ethics of affect in relation to characters and one another. The people and practices generate the significant distinction from "a sex industry that truly exploits women" (Lamarre 2006: 38I-382), even when they are in a room right next to it. One learns in such rooms. Change occurs in gatherings and people there.

The ethics of affect described in this book has only become more relevant in an accelerated world where lines are drawn and crossed with increasing speed and decreasing reflection. The lines being drawn include legislative and legal ones, which drastically broaden authority over imaginary sex and crime. Meanwhile, lines between us and them, good and bad, obscure anything beyond the shadowy silhouettes of nebulous devils and the moral authority of laws against them. The lessons of Akihabara past must not be overlooked or lost with its decline as a symbol of imaginary sex in public. Rather, in a sustained struggle for imagination, an expanded Akihabara opens up and invites us to it. There is plenty of light in the dark, and we can find our way to it, together. 



\section{Appendix: Notes on Perverse Methodology}

"My God, my God, how terrible it is to live in a continuous ethical conflict."

- Bronisław Malinowski²57

\subsection{Introduction}

This appendix offers a brief note on drawing and crossing lines in fieldwork. Discussing interrelated issues of methodology and ethics, I propose another anthropology of lines. I say another, because theorist Tim Ingold has also called for "anthropology of the line" (Ingold 20I I: 4), but in using these words I mean something slightly different. If, as Ingold suggests, much of what we do in the field is following others and their lines of movement in the world (Ingold 20II: I 49, I 62, I79), then this included for me lines of movement in response to manga/ anime characters and in shared worlds of imagination. It also included drawing lines between these manga/anime characters and worlds and "reality." In the field, I found that drawing and maintaining lines with others is an ethical practice for bishōjo game producers and players, and I tried to follow along. To my mind, there are lessons here for anthropologists generally and fieldworkers specifically. Getting at them requires re-evaluating some of our core principles, and indeed the ways we draw lines between "us" and "them," draw certain things into the narrative line and leave others out, maintain disciplinary lines to remain legible and appear legitimate. My fieldwork points toward "perverse methodology," which I explore here.

\subsection{The Anthropological Imagination: Reading Malinowski in the Field}

As someone trained in the methodology and practice of fieldwork in Japan a decade before being introduced to the history of anthropology

How to cite this book chapter:

Galbraith, P. W. 202I. Ethics of Affect: Lines and Life in a Tokyo Neighborhood. Pp. 257-269. Stockholm: Stockholm University Press. DOI: http://doi.org/IO.I6993 /bbn.i. License: CC BY 4.0. 
in the United States, I harbored a strange relationship to the discipline for many years, feeling out of place and time. For example, in the field, I found a great deal to like about Bronisław Malinowski's foundational Argonauts of the Western Pacific (originally published in I922). With an undergraduate background in print journalism and Japanese language, I appreciated Malinowski's sentiment that there is a "fundamental obligation of giving a complete survey of the phenomena, and not picking out the sensational, the singular, still less the funny and quaint" (Malinowski 20I4: I I). It resonated with what my fieldwork mentor, David H. Slater, was telling me about much of popular reporting being superficial and slanted due to pressure to publish and make headlines, and my own deepening impression that much of what was written and said in Japanese was ignored in news articles on "Weird Japan." It was refreshing to see Malinowski promote spending extended periods of time in close proximity to others to try to learn from them. I liked the idea of participant observation, or, as Malinowski described it, the idea that "in this type of work, it is good for the Ethnographer sometimes to put aside camera, note book and pencil, and to join in himself in what is going on" (Malinowski 20I4: 2I). Sure, he identified them in terms that seemed antiquated at best, but I saw something in the call "to grasp the native's point of view, his relation to life, to realize his vision of his world" (Malinowski 20I4: 25). The ultimate goal of expanding understanding of human experience struck me as right.

Then, in the United States, I heard the critiques. Those brutal, devastating critiques. Malinowski was highly medicated, you know. He hated those "natives," you know. They published his diary, you know. Read it. So I did, which after all put Malinowski's fieldwork into a whole new light for me. The light was revealing, but what I saw there was a struggle with the dark. Or, rather, a struggle in the shadows, exorcised from the pages of Argonauts. If Argonauts proposes an objective science of anthropology, then the diary opens a window on Malinowski's subjective experiences of doubt, depression and loathing (Malinowski I989: I 78-I79, I 85-I 86, 26 I, 275, 283, 292-293, 297-298). For how frequently he says awful things about his informants - and, like others, I could not resist picking a series to highlight (Malinowski I989: 69, I 54-I 55, I9I-I92, 238, 26I, 264, 272) - there was also a startling amount of self-reflection and repudiation..$^{258}$ To such an extent, in fact, that I found myself wondering if "the evidence that Malinowski hated his informants" (Riles 20I2) was more overwhelming than the evidence 
that he hated himself. ${ }^{259} \mathrm{He}$ wrote about his interactions and relations with informants in both Argonauts and the diary, but in very different ways. In the former, they are the focus, but in the latter, he is. Severed from the diary, the influential introduction to fieldwork in Argonauts gives an idealized picture of academic labor, which irons out all the kinks and sterilizes the human "laboratory."

Going back to Argonauts, I began to ponder what Malinowski left out of his presentation of anthropology as human science. Those days that he could not bear to face others in the field and so hid away binge reading novels (Malinowski I989: 29I). Drinking beer and passionately bashing missionaries (Malinowski I989: 76). Getting drunk again and again (Malinowski 1989: 77). Flying into fits of rage and abusing those supporting him (Malinowski I989: 250). The pain of missing loved ones and confronting "erotic thoughts," "lecherous thoughts," "dirty thoughts," "obscene thoughts," imagining that he had "raped her" (Malinowski I989: 64-65, 68-69, Iо8-II3, I63, I75, I8I, I92-I93, 223, 253, 274). The many, many instances that he chastises himself for "violent surges of sexual instinct for native girls," "lewd excesses of the imagination" and failure to "keep my paws off the girls" (Malinowski I989: 82, I32, I3 5, I 53, I77, I92, 207, 255-256, 268, 282). ${ }^{260}$ All those less-than-ideal things that come with being not only an observer, but also a participant, who is not only out in the open with others, but also has occasion to "join in himself in what is going on" (Malinowski 20I4: 2I). The consensus seems to be that the diary was never intended for publication, meaning Malinowski was writing it for self-reflection in the field. To have a record of his thoughts and behavior, and to hold himself accountable to the lines he endeavored to draw and maintain and avoid "taking the line of least resistance" (Malinowski 1989: I22). Even if he at times dared to entertain the notion that he would someday become "an eminent Polish scholar" (Malinowski I989: I60), Malinowski was, after all, a flawed human being like everyone else.

This insight in and of itself is not really so astonishing or scandalous, but it seemed reason enough for many of my peers to dismiss Malinowski, who did not live up to ideals. For my part, I recognized some of that struggle with the dark in the field, and was not entirely comfortable affirming that we are all better now. Instead, analyzing the texts, I was struck by how different the tone is between Argonauts and the diary. If Argonauts is that eminent Polish scholar removed from 
the field and calmly outlining the methods of a new science, the diary explodes with what theorist Michael Taussig describes as "hyperactive attacks of self-recrimination and ethnographic work" (Taussig 2009: 95). Is it necessary to exorcize this struggle from the narrative line, or the written presentation of fieldwork? Rather than the heroic figure of the scientific pioneer pitching tent among the natives and collecting data with machine-like efficiency, what might be gained by revealing the human being facing flaws and prejudices while attempting to learn in interactions and relations with others in the world? While some remind that Malinowski did not necessarily choose his life in "exile" (Moberg 2013: I87), the more I read and re-read Argonauts and the diary, the more convinced I became that fieldwork does produce results that can potentially expand the discussion of human experience.

Key here is imagination, which is not emphasized as much as "being there," but is arguably as vital for anthropology. In the introduction to fieldwork in Argonauts, for example, Malinowski encourages readers to imagine life on islands in the Pacific (Malinowski 20I4: 4). On one level, this is merely a rhetorical tool to set the scene for his idealized arrival and activity, but there is a more generous interpretation. Specifically, in the text itself, Malinowski invites readers into the world as inhabited by those he encountered and learned from, or invites them to imagine other ways of seeing and being in the world. Even as Taussig does much to uncover the insecurity and constructed authority of the man posing for photographs with "natives," he also commends Malinowski's efforts to evoke a world that draws readers in (Taussig 2009: 8I-83, 95-IOI, II9-I23). It is no small accomplishment to expand imaginings of other people, which are often quite limited. As translator Philip Boehm articulates, "Imagination is the key to empathy, and if we're not able to imagine peoples' lives, then our empathy diminishes. Translation is a bridge that serves to enlarge imagination, to connect to the world. We're impoverished without it" (quoted in Hofmann 20I7). To me it seems that Malinowski was involved in such a translation project, but of ways of seeing and being rather than just words. While there is much to applaud here, we also need to be cognizant of the role of the translator in producing meaning (Sakai 1997), as well as difficulties translating as we learn to adopt and speak from certain positions (Haraway I988). The case of Japan proves instructive here, as any translation project immediately confronts a framework for understanding radical difference that hinders the ability to imagine the lives of others and discourages empathy. 


\subsection{Imagining Difference: Japan, Others and Perverse Methodology}

Conducting fieldwork in Japan, it is hard to ignore the legacy of Ruth Benedict's The Chrysanthemum and the Sword (originally published in 1946), which was written from the United States at a time of war with those far off islands in the Pacific. With decades of popular discourse preceding it, Benedict took for granted that, "No one is unaware of the deep-rooted cultural differences between the United States and Japan" (Benedict 2006: IO). ${ }^{26 \mathrm{I}}$ This is not just difference, but radical difference, or the assumption that "whatever we do they do the opposite" (Benedict 2006: IO). While Benedict might be seen as trying to undo this framework through juxtapositions of "us" and "them" (Geertz 1989: I06, I2I), there is still a strong tendency to place Japan in opposition to the norms of the United States, or to appeal to a framework that reifies difference. That much of Benedict's account focuses on sexuality, for example, both reflects and reinforces long-standing interest in this aspect of Japan as an exotic and erotic "other." Even more importantly for anthropologists and questions of methodology, theorist Clifford Geertz underscores that Benedict, who could not travel to Japan, "rests her authority on being there imaginatively" (Geertz I989: I 20). To rephrase, Benedict largely wrote about "Japan" through representations of it, which blurs the lines of anthropology and brings it nearer to cultural studies, if not popular reporting. If this is "fieldwork," then it has a perverse methodology of its own, but what I am advocating is actually quite different. A full perverse reversal of the initial perversion to bring us into proximity enough to share imagination, perversely, painfully, pleasurably. Being there, imaginatively.

With the spread of manga and anime in North America in the I990s, writing on Japanese media and popular culture flourished. In anthropology, Anne Allison has drawn attention to how manga, anime and manga/anime characters are part of everyday life for many in not only Japan, but also around the world (Allison 2000; Allison 2006). These images are a feature of the global cultural landscape, or something that can often pass as "non-foreign" (Shigematsu I 999: I 27; also Ito 20 I 2). When I returned from Japan to study with Allison in the United States in the early 2oros, much of this rang true, but the details of my past and proposed research still raised eyebrows. Indeed, in my own fieldwork, I have been unable to escape discourse about "Weird Japan," or the Japanese as socially dysfunctional and sexually deviant, which 
accentuates how some differences are imagined to be abnormal and thus "Japanese," even as "Japanese" content becomes normal and "global." Not long after I began my fieldwork on bishōjo games in Akihabara in the spring of 2014 , the area was swarming with irate journalists. More concretely, in the summer of 2014 , the passage of revisions to Japanese laws against the production and distribution of child pornography made the possession of it illegal, but legislators notably did not follow the lead of Canada, Australia and the United Kingdom to expand the definition of offending material to include manga, anime and games featuring explicit sex with underage characters. The journalists came to Akihabara to find examples of these cartoons and speculate on the harm they do to Japanese youth and the world at large.

As I watched these journalists prepare their reports in Akihabara, and even led a few of them around the streets and stores, I tried to explain the logic that I was hearing behind the decision, which garnered support from many in the bishōjo game industry. Informants told me that there is no victim in the production of cartoon images and no statistical evidence that consumption of them leads to crime, so any law against them would be a violation of the right to what they called "freedom of imagination/creation." Animated by this discussion as we walked through an adult manga shop, one BBC reporter picked up a book that he found offensive, pointed to it and said, "What about this? Where would you draw the line?" The cover featured a character that not only appeared underage, but was explicitly indicated to be so, engaged in explicit sex with a character that was indicated to be her brother. As he pointed to the book and pushed for an answer, I could not help but see the microphone in his hand and realize that I only had a few seconds for what very well might become a sound bite. ${ }^{262}$ This is the challenge of what anthropologist Didier Fassin calls "popular translation," which is part of the ethical responsibility of those working on issues of immediate public interest (Fassin 20I3: 635-639, 642-644). Beyond the difficulty of translating what I was only just beginning to learn in the field, however, I was struck by my contentment to respond that it was not about me, but rather the decisions being made in Japan. Fair enough, but his question was where I, personally, would draw the line. This thing I'm pointing at, right here, yes or no? Good or bad? Are you with these perverts, potential pedophiles and predators or not?

In fact, as my fieldwork proceeded, I became more aware of the ways that I was drawing lines with others. This began with being taught that manga/anime-style cute girl characters are not the same as "real girls 
and women," or being taught that there is a distinction between the two- and three-dimensional. In the process, I learned to draw a line between fiction and reality and orient myself toward the drawn lines of characters. I was trained into a perverse orientation of desire, or imaginary sex, sex with images. With this, it made sense to respond to bishōjo game producers and players that yes, I am a pervert, too. (For more on this and other examples in this paragraph, see Chapter 4.) In this context, I could understand, even agree that "lolicon is righteous." But then another man, one I thought I knew, riffs on that phrase and confuses and conflates lolicon with child pornography and prostitution; I draw a line between us and seek confirmation from another man, who insists on the line and his orientation to lines. I perhaps took the easy way out in seeing this man I thought I knew as other, because in another instance I am side by side with two men pointing at an image of a cute girl character from a lolicon game and being identified as one of the dangerous ones to watch. It is a joke, but earlier in the event the designer of this character had suggested he photographs real children for inspiration; with the line between fiction and reality blurred, I feel like I have crossed a line. Unable to bear the association, I dispose of the image I won that night, assuring myself I had no interest in it in the first place, but this is also a retreat from ethical reflection and failure to account for my own affective responses. Rather than look at that man I thought I knew and say, "The killer in you is the killer in me" (Halberstam 20II: I7I), did I not kill him in my mind and erase him from my thoughts? As I went deeper and deeper into realms of imaginary sex and violence and crime, did I not cross so many lines that I also wanted to erase myself? Did I not turn to strong drink to that end, loop into destructive cycles and get into fights and hurt those closest to me, those supporting me? Perhaps I highlighted certain passages in Malinowski's diary as a reminder. And so on. In this way, I dwelled with bishōjo game producers and players drawing lines and negotiating them, which entailed living with uncertainty and ambiguity.

How close is too close? Which side of the line are you on? Such were the questions that plagued me in the field. By spending time in Akihabara with the producers and players of bishojo games without immediately criticizing them for what seemed to many to be clear violations of international norms and global standards, if not also the law, I crossed a line. I became visible to bishōjo game producers and players in a way that reminded me of Geertz running away from authorities with informants when a cockfight was broken up during his fieldwork in 
Bali (Geertz I973: 4I4-4I7). Like Geertz, being seen as on "their side" of the line opened doors and made certain interactions and relations possible. It was not as simple and complete as crossing a threshold, however. Rather, it was an unsettling process of feeling out lines. Rather than suddenly becoming visible as Geertz did in his transformation, I had a distinct urge to remain invisible, someone watching safely from the sidelines, but that is not how participant observation works. It was a struggle, and not an entirely heroic one. Anthropology employs a "kinky empiricism," as theorist Danilyn Rutherford memorably names it, which means getting close enough for long enough to feel "what one imagines the other feels" (Rutherford 201 2: 472). While Rutherford is "not afraid of dangerous liaisons" (Rutherford 20I2: 476), I cannot say that I was always so brave, because my fieldwork demanded sharing responses to imaginary sex, violence and crime that was often perverse and personally disturbing. Dwelling with bishōjo game producers and players meant dwelling with disturbing affects and being moved in disturbing ways. It meant dwelling in the darkness like Malinowski, dwelling in the darkness with Ataru in Akihabara (Chapter 2 and Conclusion). Finding oneself and others in the darkness, because, "Only when we know our own darkness well can we be present with the darkness of others" (Chödrön 2008: 74). If there are "analytic and ethical twists and turns born of a research method that forces [... one] to get close enough to imagine how it might feel to walk in another's shoes" (Rutherford 2012: 476), then my fieldwork made these ethical twists and turns kinky indeed.

Part of what makes the methodology so perverse is the need to share imagination and movement. It was simply not adequate for fieldwork to observe players responding to games or attempt discussing them when I had not participated in or shared experiences of imaginary worlds. To imagine what the other feels, I needed to feel something myself; I needed to play the games that moved them so and try to share that movement. If they were playing games involving imaginary sex, violence and crime, then I had to do the same. As a relative newcomer to bishōjo games in 20I4, I learned about them while playing titles recommended by informants, who agreed to meet and discuss experiences. These were at once their own and mine, as we talked about shared and divergent paths through, and responses to, games that we had played. The lines between subject and object, inside and outside, self and other began to blur. At times, I thought that I was indeed a pervert, but then a bishōjo game producer or player would introduce me to something involving 
imaginary sex, violence and crime that crossed lines I did not even know that I had drawn. Negotiating those lines while interacting with manga/ anime characters and bishōjo game producers and players was part of fieldwork. To put it somewhat differently, responding to bishōjo games with others and drawing and crossing lines was part of a perverse methodology of sharing imagination and movement. Resisting iconophobia, art historian W.J.T. Mitchell recommends we "put our relation to the work into question, to make the relationality of image and beholder the field of investigation" (Mitchell 2005: 49). In my attempt to do so, the field expanded from my own relation to the image to include others and their relations to the image, as well as my own evolving relations with all of them as we shared imagination and movement.

For these reasons and more, I do not want to draw a redline between bishōjo game producers and players and myself, which would serve to keep imagined perversion safely located in others. Fieldwork, which renders us vulnerable in interaction with one another, "requires ethical reflections and solidary engagement" (Bourgois and Schonberg 2009: I4). This means not erasing myself from the field and reflecting on my own imagination and movement, especially when it would be all too easy to hide behind bishōjo game producers and players as perverts and reduce the risk of personal association. Such hiding is more problematic still when those exposed might be taken as criminals. Against the backdrop of building momentum toward the conclusion that the distinction between fiction and reality should not matter before the law, there is added ethical pressure to clearly and compellingly translate other ways of seeing and being in the world learned in the field. Of course, knowledge gained through fieldwork is far more partial than Malinowski might have ideally wished, but, as Rutherford reminds us, there is an ethics to "empiricism that admits that one never gets to the bottom of things, yet also accepts and even celebrates the disavowals required of us given a world that forces us to act" (Rutherford 20I2: 465). The ethics emerges from methods that place anthropologists into interactions and relations with others and create obligations, which compel researchers to "put themselves on the line by making truth claims that they know will intervene within the settings and among the people they describe" (Rutherford 20I2: 465). This is increasingly important as anthropologists enter into "politically fraught arenas," which "require us to write and speak authoritatively" (Rutherford 20I 2: 465). Choosing to write and speak means putting oneself on the line, if not also an opening for self-recrimination. 
Over the course of fieldwork, I came to understand that it is not only about encountering the other, but also confronting the self in interactions with others, the other in oneself and the self imagined in others. This seems very much to be the "split and contradictory self," which can "interrogate positionings and be accountable" and "construct and join rationale conversations and fantastic imaginings" (Haraway I 988 : 586). Is there a better figure of the split and contradictory self than the anthropologist in the field as a "participant observer," who remains self-reflexive even while trying to see and experience the world as another? In my case, the approach was encouraged by bishōjo games, as the player sees the world from a first-person perspective, is involved in active imagining to move the image in line with the textual and sound cues and makes choices in interactions with others that impact the story and world. The player thinks and speaks as the player character, but also sees the player character as a separate entity on screen, which leads to oscillation between immersion and distance. To put it simply, the player character is both self and other, even as the player is both participant and observer. As "a person involved" (Sasakibara 2003: I04), and involved with others who are known, if not cared about, the player is oriented toward ethical encounters and ethical reflection on actions and their consequences. For me, this extended from game play into interactions with bishōjo game producers and players, who shared imagination and movement as we discussed routes and choices and saw ourselves in one another and others in ourselves.

This becomes decidedly more challenging when the other self on screen or in conversation crosses a line into perverse imaginary sex, violence and crime. The dodge is to say it has nothing to do with me, but that is ultimately dishonest. As Sasakibara Gō taught me, we have an obligation to engage in ethical reflection and account for our own affective responses (see Chapter 3 ). We have an obligation to recognize and deal with our own desires and capacity for violence and harm. For his part, Sasakibara experiences moments in games as being in "criminal accomplice," but this goes even further in disturbing interactions such as the one with a man I thought I knew defending child pornography and prostitution or being identified as dangerous at an event where a cute girl character designer suggested he photographs children. This brings to mind how Ötsuka Eiji, in the fallout after the arrest of Miyazaki Tsutomu in 1989, refused to entirely distance himself from the child molester and murderer (see Chapter I). Instead, Ōtsuka reported feeling a disturbing sense of "synchronicity" (Ōtsuka and Nakamori I989a: 
I7). He saw himself in the other and the other in himself. When called for comment by journalists and critics, Ōtsuka asked himself questions and debated them in conversation with others (Ōtsuka and Nakamori I989a: I7). Is this not what I also did in the field? An experience left me upset and unsettled, and I worked it out in interactions with others, which were also with myself. Like Ōtsuka, I found that small stories coming together led to the emergence of an "ethics of the abandoned" (Ōtsuka and Nakamori I989b: 216). While I cannot state as Ōtsuka does that "I am a lolicon" (Ōtsuka and Nakamori r989a: 73), which given the timing of his statement and his sense of responsibility to others is no doubt a way of putting himself on the line in Japan in I989, I can say that I crossed over to that side in fieldwork where I imagined and moved as a lolicon. There I learned the ethics of drawing lines and negotiating them with others and myself. All of this leads to appreciating participant observation as perverse methodology, or a methodology of self-perversion and othering in pursuit of learning outside of oneself.

\subsection{Conclusion}

There are, then, two primary points about this perverse methodology of sharing imagination and movement and its ethics. The first is openness to exposing oneself in the struggle to imagine and follow the lines of movement of others. This movement can and does impact ways of seeing and being, positions and perspectives, one's own sense of self. This potential to shift perceptions of reality and one's place in the world is precisely why the method is as powerful and political as it can be disturbing and dangerous. It is the perverse methodology of imagining and moving as another. In my particular case, this included the action and everyday practice of drawing lines in response to fiction and reality, as well as crossing and negotiating lines. The second primary point is commitment to write clearly and compellingly about other ways of seeing and being in the world, which can push back on preconceived notions, draw readers in and encourage them to imagine the lives of others and themselves as others.

For what it is worth, I see glimmers of both points about perverse methodology in Bronisław Malinowski. Acknowledging that he did not make it part of his final ethnography, Malinowski's diary does speak to his struggle to imagine and follow the lines of movement of others. By bringing this into the writing, we can more honestly reflect on field experiences. As for imagining other ways of seeing and being in 
the world, Malinowski directly appeals to readers in Argonauts of the Western Pacific and invites them to, "Imagine" (Malinowski 20I4: 4). In passages where he goes "sailing through color" (Taussig 2009: 99), Malinowski draws the reader into another world or the world otherwise. In the spirit of theorist David Graeber's return to the ethnographic record to challenge common sense, Malinowski's work might encourage readers to think about other ways of seeing and being in the world and thus contribute to "liberation in the imaginary" (Graeber 2004: I02). This casts into stark relief the imaginative and political aspects of anthropology that have been there from the very beginnings of fieldwork.

The challenge, methodological and ethical, is to try to not only observe interactions and relations between fiction and reality, humans and characters, but also to participate in them. This does not entail the naïve communion that Malinowski expressed in Argonauts as taking "part in the native's games," following the lines of their movement and sharing "conversations" (Malinowski 20I4: 2I), but rather the darkness revealed in his diary as he struggled to act and interact with others and reflect on himself and his practice. Whether "pawing" girls and indulging in "lewd excesses of the imagination" (Malinowski I989: I32, 268) or picking a bishojo game and doing the same, the reflection might not be pretty, but it is part of being open and honest in learning with others. I for one find this to be much more ethical than pretending that the perversion and danger of sexualization and abuse is located over there, with them, in "Japan," safely placing it outside of the self in the other even as it slips across lines and is imagined to infect the world like a virus. Between dismissing life on islands in the Pacific as belonging to savage beasts or engaging in participant observation, struggling to live with and as others and encouraging readers to imaginatively join in, I see Malinowski as moving along a line that I still follow and learn from.

To make this work, however, one really needs to get over and outside oneself in the field. One cannot remain the unimpeachable scientist in impeccable white garb, the eminent scholar of the future, standing tall and staring down the exposed "natives" (Taussig 2009: 80-82). We must get into the weeds and mud and expose ourselves in that painful and pleasurable affective slop of living together. In that moment perched there beneath the scorching sun with those men, phallic gourds lined up and erect, but without the pretense of being the only one clean and clothed. In my estimation, literary scholar and social theorist 
Michael Warner offers one of the most lucid visions of our ethics: "The rule is: Get over yourself. Put a wig on before you judge. And the corollary is that you stand to learn most from the people you think are beneath you. At its best, this ethic cuts against every form of hierarchy you could bring into the room" (Warner 2000: 35 ). Bring into the room, or more broadly into the field and encounter.

It is possible to take Warner's advice literally, as I did in an earlier project by donning a Son Gokū wig and costume and learning on the street in Akihabara with queer performers and "weird otaku" (Galbraith 20I9: I39-I40), but we can take it even further in pursuit of perverse methodology and learning outside oneself with others in the world. We can turn fieldwork inside out by exposing ourselves in the open instead of others behind closed doors. ${ }^{263}$ This is an extension of the ethics of queer life (Warner 2000: 33) and ethical encounters in the field. In this perverse methodology, we encounter ourselves in others and others in ourselves, even as lines are drawn and crossed, negotiated in shared imagination and movement. This is the anthropology of lines I pursued in the fieldwork for this book and now propose as an option for researchers going forward. If the perverse methodology encourages us to remove the "weighty plumage of [...] normalcy" and strut "our more deviant [...] selves" (Bering 20I3: 233), then the clothes have come off and I walk naked back into Akihabara. It seems the best way to return to those rooms and continue learning by "feeling it on the skin." 



\section{Endnotes}

I. Ellison 2013.

2. On the official company website, the game is introduced as a "real time ${ }_{3} \mathrm{D}$ groping simulator.” See: https://www.itazura.biz/or_it-pro/proof/index.html.

3. A survey conducted by the Gender Equality Bureau in Japan in 2004, for example, found that of I,773 women over 20 years of age sampled, 48.7 percent reported an experience of "chikan," which is a category of sexual assault referring to being groped, most often on crowded public transportation. See: https://web.archive.org/web/20 I 402 I 5 I 2063 I/, http://www.gender.go.jp le-vaw/chousa/images/pdf/hI I.pdf. The result is supported by more recent surveys as well. See: http://708 5aec2289005c5.main.jp/assets/doc/20 I 90 I 20 _harassment_research.pdf.

4. One could also say that my male companion is drawn to the lines. Here my thinking is informed by art historian W.J.T. Mitchell's concept of "drawing desire," which gets at the dual meaning of drawing as inscribing lines and attracting (Mitchell 2005: 59). I find Mitchell helpful for addressing desire among those living with and loving characters in not only contemporary Japan, but also further afield. Of particular interest is "desire generating images and images generating desire" (Mitchell 2005: 58; compare to Lamarre 2006).

5. Note how comics, cartoons and computer/console games all blend together, even as keywords such as manga are retained and associated with sexual violence and Japan. See the full report at: https://digitallibrary.un.org /record/833895? $\ln =$ en.

6. In the United Kingdom, researcher Perry R. Hinton notes media portraying "Japan as a source of danger, with certain Japanese harbouring the 'Lolita complex virus' [... Japan has become] a dangerous (potentially pedophilic) 'other' to be censored and avoided" (Hinton 2014: 56, 65).

7. Patridge: “To insist that one's imagination is one's own private affair, detached from one's own actual commitments and similarly detached from the contextual moral facts on the ground, amounts minimally, in this case, to a thumbing of one's nose at a requirement of solidarity with the victims of oppression. This is an obvious vice of character" (Patridge 2OI I: 3 IO). 
8. For a classic and often cited analysis of the spectrum of rape culture and an argument that pornography undermines social and moral inhibitions against sexual violence, see Russell 1993.

9. Indeed, Patridge goes further: "What exactly does the virtual-pedophilia case establish? Minimally, I think that it establishes that some activities that are aimed at fictional entities and so are in some sense simulated, expose a flaw in the agent's character: a virtuous agent would not undertake such an activity for the sake of pleasure, sexual or otherwise" (Patridge 20I I: 305).

I०. Young continues: "All that can be said at this stage is that evidence regarding a relationship between virtual violence (which has been the most researched STA) and increased anti-social behavior is inconclusive. This being the case, why should there be a relationship between other STAs - specifically virtual murder and virtual pedophilia - and their corresponding real-world taboo or even anti-social behavior in general?" (Young 2013: I 8).

I I. Seddon: "What we do when gaming is certainly tricky to pin down: trickier than one might expect of a virtual counterpart to the real, with its tantalizing promise of ethical conclusions no less general than the principles which we may hope to develop to guide our lives in the real world. The trickster, however, is in every case the playful human being" (Seddon 2013: Iо). Well said. This is precisely why I believe anthropology generally and the methodology of fieldwork specifically is the best approach to understanding the issues at hand.

I2. On Custer's Revenge, Patridge writes: "In the actual world, women are the victims of a kind of systemic oppression that involves seeing them in certain kinds of ways, conceiving of them as certain kinds of creatures, and subjecting them to certain kinds of violence. Given this shared moral reality, it does not take much to see the representation of the female characters in this game as an extension of real-world moral phenomena, whatever the avowed intensions of the game designers, in the same way that the image of Obama eating watermelon is an extension of real-world racial phenomena. The game invites us to enjoy representations of women as objects of sexual violence in a way that does not undermine the morally worrisome social meaning of these images" (Patridge 20II: 309-3 I0). Expanding to other examples: "This imagery has a meaning that is fixed by the actual practice of casting women in the role of objects of sexual pleasure and violence. I think that the same can be said of the notorious game RapeLay" (Patridge 20II: 3 II). The demand is for appropriate sensitivity to sexism. Does playing such games, even enjoying them, necessarily mean one is not sensitive to sexism in the real world? Does play with characters impact ways of seeing women? I also question whether "a virtuous gamer will refuse to enjoy the offending content because such content will bring to mind real-world, moral conditions" (Patridge 20I I: 3II). This seems like quite a puritanical demand on the imaginary. 
I3. For her part, Patridge proposes that, "the nature of actual act[s] of child sexual abuse makes it more difficult morally to see even virtual representations of it as enjoyable. I further suspect that if such an account can be sustained, it will appeal to facts about the relative helplessness of the victims of such actual wrongs [...] I suspect that disagreements between gamers who see such content as a bit of harmless fun, and those who see it as morally troubling will debate these very issues" (Patridge 2013: 33; see also Kjeldgaard-Christiansen 2020). The point that we ought to account for relations between fiction and reality, as well as representational details, is well taken. My encounters in the field are an attempt to explore such issues.

I4. Given its strict definition of "virtual reality" as "a three-dimensional interactive computer-generated environment that incorporates a first-person perspective," explicit exclusion of "two-dimensional graphic environments" and emphasis on "realistic simulation" (Brey r999: 5-6, I3), the discussion arguably does not encompass bishōjo games. I argue later in the introduction that there are reasons to expand the scope to include other forms of "virtual reality" (Saler 20I2) and "dangerous games" (Laycock 20I 5 ). For more on uses of the "virtual," and how they may not be helpful in getting to more profound issues and concerns, see Seddon 20I3.

I 5. In her seminal essay “Thinking Sex," anthropologist Gayle S. Rubin elaborates: "A democratic morality should judge sexual acts by the way partners treat one another, the level of mutual consideration, the presence or absence of coercion, and the quality and quantity of the pleasures they provide. Whether sex acts are gay or straight, coupled or in groups, naked or in underwear, commercial or free, with or without video should not be ethical concerns" (Rubin 20I I: I 54). If one wonders what Rubin might say about cartoon depictions of sex, or manga/anime sex objects, this ought to clarify: "A person is not considered immoral, is not sent to prison, and is not expelled from her or his family for enjoying spicy cuisine. But an individual may go through all this and more for enjoying shoe leather. Ultimately, of what possible social significance is it if a person likes to masturbate over a shoe? It may not be consensual, but since we do not ask permission of our shoes to wear them, it hardly seems necessary to obtain dispensation to come on them" (Rubin 20I I: I8I). To circle back to the gamer's dilemma, "Given that the attraction and therefore the motivation is that the particular STA [symbolic taboo act] merely symbolizes that which is taboo, it seems that criticism over what one desires as the object of fun is, in the end, a matter of taste rather than morality" (Young 2013:20).

I6. "There is evidence that societies and communities in which there is sexual tolerance, in which the proliferation of sexual imaginaries are encouraged, are safer places for women. [...C]ommunities which allow the proliferation of sexual imaginaries are ones in which the environment itself, by encouraging tolerance, also helps to discourage violence" (Cornell I995: I 53). 
I7. Bridging philosophy and game studies, Grant Tavinor similarly highlights the ability for play to become "unsettling" and tackles issues related to the "gamer's dilemma." For Tavinor, "we should not be too quick to dismiss the moral intuitions that there are about the content of videogames as merely fictional" (Tavinor 2009: I 52). If gamers feel that what they are doing is morally significant, perhaps it is so. Relaying his own game play through a murderous scenario, Tavinor elaborates: "In the episode, a depiction of fictional violence, toward which I contribute, and replete with striking visual images and sounds made possible by the digital props of videogames, elicits an emotional response that is the basis on which I make a cognitive judgement of moral concern. Some of the examples detailed in the previous chapter also show how such judgments can subsequently have an impact on how a player will or will not act in a fictional world" (Tavinor 2009: I 5 I). In a by now familiar move, the experience of "virtual murder" leads to questions about "virtual pedophilia:" "would gamers be happy to play a game in which it was the player's goal to rape women or commit acts of pedophilia? I suspect that almost all gamers would be reviled at this prospect" (Tavinor 2009: I 52). While acknowledging the arguments for moral criticism, Tavinor counters that, "By itself, content may be offensive, but that is not enough to establish that it is also immoral. [...] It is the context in which content is presented in addition to the content itself that is of genuine moral significance [...] It is not violent or offensive fictions simpliciter that strike most reasonable people as morally condemnable. Rather, it is fictions for which there is no redeeming or mitigating context which strike us as expressing an objectionable viewpoint on the content they depict" (Tavinor 2009: I64-I65). Games can provide context to reflect on the content. While I depart from Tavinor in that I do not think that artistic or moral standing is a necessary condition for a game to unsettle us and trigger reflection, I agree that working through feelings is part of an important ethical practice when faced with objectionable content. Furthermore, if "cartoon abstractness and humor can also modify or contextualize violence" (Tavinor 2009: I68), then I see no reason why manga/anime aesthetics and realism might not do something similar, regardless of the putative immorality of the content. Tavinor concludes: "Where there is no danger to society, people should be allowed to pursue the activities they want to, even if a significant proportion of their society regards them as morally dubious. [...] Perhaps, indeed, these moral issues are most pressing in the personal case, and this is what is so interesting about my moral response to the bank robbery I carried out in Liberty City: a videogame can provoke my moral assessment of what I am fictionally doing in a game world" (Tavinor 2009: I70). The fact that there are more games and gamers, more content and ways to engage, as well as to do so playfully and socially, seems to explode the gamer's dilemma once and for all. There are, ultimately, too many assumptions baked into the problem, even when those debating 
it call for consideration of "how these action types are, or would be, concretely instantiated and responded to" (Kjeldgaard-Christiansen 2020: 96). As Tavinor makes plain, I do not think that we can state that, "Observers of impure acts tend to short-circuit normal processes of moral deliberation" (Kjeldgaard-Christiansen 2020: 97). Beyond the abstract nature of the dilemma, we absolutely need to bring into focus relations between the player and game, the player and player character, the player character and other characters, the player and other players and more. Be it "immoral" or "impure," an imaginary act cannot be flattened out in our critiques. In their tendency toward both storytelling and simulation, bishōjo games in particular present imaginary acts in complex ways. The challenge is no less than to understand "contextually sensitive responding" (Kjeldgaard-Christiansen 2020: 99). This is what it means to judge concrete cases ethically. Rather than theory and speculation, let us finally get back on the ground and to gamers and their own ethical stances and principles.

I 8. Examples of this evidence comes from cognitive science and developmental psychology. In play, we observe players aware that "signs are signs distinct from the objects they signify" (Laycock 2015: I 5). This is learned; "by imposing the imaginary order of play onto reality - for instance, imagining that a banana is a phone - children acquire the ability to distinguish referent from object" (Laycock 201 5: I 5). In fact, cognitive scientists have found that "children as young as two can discern fantasy from reality quite well" (Laycock 20I 5: 2I2). Add to this that, "Studies in developmental psychology have suggested that children with a high 'fantasy orientation' - that is, who are more imaginative - are better at discerning fantasy from reality" (Laycock 20I 5: 289-290). Studies also suggest that children with "a natural tendency to fantasize" are "generally more aware of the implications of violence and therefore less likely to act out" (Laycock 2015: 193).

19. Drawing on the example of a man escaping a car accident unscathed attributing it to his character's "high constitution score," Laycock writes: "This sort of thinking is not a case of confusing fantasy and reality. Instead it is using a game model as the lens through which one interprets reality. Most people do not require such an interpretive lens to make sense of a physical event such as a car crash. However, role-playing games also employ models of metaphysical, philosophical, and moral realities. For some players these models have had a profound influence on how they see the world" (Laycock 20I 5: 197). Note, first, how players reflect on moral realities and subsequently become "moral philosophers," and, second, the literacy involved in actively relating fiction to reality. The example of the player in a car accident echoes what psychiatrist Saitō Tamaki has observed in manga/anime fans, who, "straddling [...] layered contexts" (Saitō 2007: 227), find reality in fiction and fiction in reality (also Saitō 20I I: 24). 
20. Exploring the prehistory of "virtual reality," literary scholar Michael Saler explains: "in the late nineteenth century, adult readers seeking enchantment began to inhabit the imaginary worlds of fantastic fiction for extended periods of time without losing sight of the real world. They played with multiple identities and multiple realities, [and] in the process trained themselves to question essentialist outlooks and appreciate the contingent nature of narratives. These readers had recourse to what I call the ironic imagination, a form of double consciousness that became widely practiced during the nineteenth century and attained its cultural centrality in the twentieth. The ironic imagination enabled individuals to embrace alternative worlds and to experience alternative truths. [...] The double-minded consciousness of the ironic imagination permits greater control over virtual fantasies. This is a skill that must be practiced, but it has been part of the cultural repertoire for well over a century now. [...] The practical distinction between reality and fantasy appears to be reinforced through the ongoing habitation of virtual spaces, even as philosophical quandaries about their interrelations are heightened. [...] What we can now say is that the self-reflexive practice of living in virtual worlds of the imagination has inculcated the ability to abide in real and virtual worlds without confusing the two" (Saler 20I2: I4, 55). Key here are his insights about "public spheres of the imagination," or engagement with others through shared imaginary worlds that intersect with reality, and how all of this allows for "enchantment that delights but does not delude" (Saler 20I 2: 94, I60). Concurring with Laycock in his conclusion, Saler argues that, "the literary prehistory of virtual reality does reveal that living in the imagination is a cultural practice we have gradually honed over time and will continue to exercise as new conditions warrant. It suggests that repeated exposures to the virtual actually reinforce the distinction between the real and the imaginary, while at the same time highlighting their necessary imbrications" (Saler 2012: I98).

2I. Not only does such regulation close down spaces of social play and learning, but it also introduces serious concerns about freedom of imagination, thought and expression. In the panic about Dungeons \& Dragons, there were calls to ban books, place warnings on game products and require libraries to track patron borrowing, which raises red flags about censorship, surveillance and "a potential threat to civil liberties" (Laycock 20I 5: 243). Moreover, a fundamental asymmetry emerges in the process of putting fantasy and play on trial. "Moral entrepreneurs were free to imagine the most nasty and evil game possible, and players were hard pressed to prove that they had not performed this evil ritual in their imagination" (Laycock 20I 5: 248). A similar problem has been identified in the response to "virtual pedophilia." Responding to the sentencing of a man to 35 years in prison for sexual fantasies about "a crime that never happened" against "a fictional, nonexistent child," cultural critic Laura Kipnis asks, "What kind of society sends its 
citizens to prison for their fantasies?" (Kipnis I 996: 3, 4, I 2). The answer is one like the United States, where there have since been convictions related to manga/anime sexual expression. This has also happened in a number of other countries, notably Commonwealth Nations such as Canada, Australia and the United Kingdom. It would appear that Kipnis' early warning is more relevant than ever: "In the stripped-down good-guy, bad-guy psychological universe invented by U.S. prosecutors, where fantasy equals intent, and role-playing makes it real, how many thousands of new prisons - each the size of Texas - would it take to hold our new criminal class?" (Kipnis I996: I2). For more, see Galbraith and Bauwens-Sugimoto 2020.

22. Potentially enlightening here is what Laycock glosses as the "erotics of fear," a dynamic wherein "moral entrepreneurs appear to be fascinated with, and even to take vicarious pleasure in, the very ideas and activities they condemn" (Laycock 20 5: 20). This may explain the fixation on thought experiments involving "virtual pedophilia." See also Kincaid I998; Adler 200I.

23. In another passage resonating with Saler's language, Laycock writes: “By being attentive to the frames of meta-communication we can avoid corrupted play and truly learn to walk between worlds, experiencing enchantment without delusion" (Laycock 20I 5: 28).

24. Following philosopher Benedict de Spinoza, affect refers to a modification or variation produced in a body (including the mind) by an interaction with another body that increases or decreases the body's power of activity (Spinoza 2005: 70). The body that affects can be an image or imaginary body (Hardt I999: 96). As shorthand, this book translates affect as moving, as in moving image, or an image that moves the one interacting with it to bodily response.

25. This portion of the research and fieldwork was conducted with approval of the Institutional Review Board of Duke University (Protocol Coo44).

26. Otome games, which center on interactions with male characters, specifically target women and have been estimated to be a larger market than bishöjo games (e.g., Yaraon 2013), deserve a separate research project. For more on adult computer games for women, see Kim 2009; Hasegawa 20I3; Lamerichs 20I4b; Richards 20I5; Andlauer 2018; Koide and Obana 2018; Ganzon 2019. For the popular subcategory of games focusing on "boys love,” see Wood 20I I; Ishida 20I9; Okabe and Pelletier-Gagnon 20 I9.

27. Games such as Mischief Fiend come with warnings like: "The content of this software is, to the end, a constructed work of fiction and a game. Conducting the acts depicted in the game in reality will result in punishment by law. The content of the game is a bit of theater and fiction. Absolutely do not mimic these acts or be influenced by them" (quoted in Kagami 20I0: 2 I9-220). Note the insistence on drawing and maintaining lines, which includes an explicit injunction against committing crimes. This is of course 
a way for the company to deny responsibility, but, as we shall see, it is also more. As part of their commitment to the ethical practice of manga/anime fandom in Japan, bishojo game producers also draw and maintain lines.

28. Among anime fans in North America, science and technology scholar Lawrence Eng notes "nuanced and alternative positions on social issues" (Eng 20I 2: IOO). More specifically, "American anime fans have engaged in numerous debates regarding the ethical and legal implications of anime and manga depicting minors in sexual situations. Despite the sensitive nature of the topic, the viewpoints expressed [...] in some of these debates have been surprisingly diverse, well stated, and cognizant of the complexities surrounding the issue" (Eng 201 2: I03; for more on "finding the law," see Baudinette 20I8; also Pearson, Giddens and Tranter 20I8). This book explores how the "ethical and legal implications" of "depicting minors in sexual situations" are understood by a subset of manga/anime fans, namely bishōjo game producers and players, in contemporary Japan. While presented as something of a joke, in statements such as, "Anime is trash and so am I" (Gigguk 20I7), one also detects parallel thinking about ethics. That particular declaration comes in a discussion of the anime Eromanga Sensei (2017) and casting off the veil of decency to accept the ugly self who enjoys a story about lusting after one's underage sister, or an incest work for "lolicon." I recognize the humor and positivity of the fan making this video for followers, as well as the message of liking what one likes and sharing it openly, from my fieldwork in Japan. It is also worth mentioning that Eromanga Sensei has been singled out as an example of "child abuse anime" and linked to calls for increased regulation by disgusted politicians in Australia (Coughlan 2020; for a full discussion, see Chapter I). The opportunity and motivation to study the more developed case of ethics in Japan could not be any clearer. At stake are alternatives to hegemonic norms, which inform common sense about, among other things, "ethical conduct" (Halberstam 20I I: 89; also Warner 2000). To expand on queer theorists such as Michael Warner and Jack Halberstam, an alternative common sense, alternative norms and alternative ethics are imagined, created and lived in contemporary Japan.

29. These men are "hyper-visible subjects" (Amar 20I I: 40), or those most associated with imagined excesses and perversions, if not sexual crime and terrorism. "The ones who pay are the ones who stand out in some way," writes Michael Warner. "They become a lightning rod not only for the hatred of difference, of the abnormal, but also for the more general loathing of sex. It is their sex, especially, that seems dehumanizing" (Warner 2000: 23-24).

30. See Benedict 2006, which is discussed in the appendix of this book.

3I. Anthropologist Allison Alexy succinctly summarizes the imagination of Japan in much of foreign media: "In such depictions, Japan and Japanese 
people are presented as the extremes of humanity: group-oriented but unable to form real attachments, dysfunctional but entertaining, and almost certainly harmless to the point of impotence. Such a profile describes a population fascinated by sex but not actually having any, fetishistically attached to both schoolgirls and inanimate objects, and thwarted by those very same preferences in any attempt to build real loving relationships" (Alexy 20I9: I). She goes on to identify the key figure of the "hypersexual virgin," who is "unduly focused on sex but not actually able to convince anyone to sleep with them" (Alexy 2019: 2). Responses to imagined excesses and perversions can become what Alexy calls "intimacy panics," or "moral panics surrounding intimate topics" wherein "public attention has focused on intimate practices supposedly causing harm to the social order" (Alexy 20I9: I 5). As an example of this dynamic, on February I4, 2020, American pundit Bill Maher raised up a Japanese man married to a cute girl character to lambast the abnormal phenomenon of "finding ways to get along without each other" and an "emerging sexual orientation" (Maher 2020). His solution, of course, was to find our way back to normal and hook up on this special night. One cannot help but notice the similarities to the way Nakamori Akio responded to the imagined excesses and perversions of manga/anime fans by labeling them "otaku" (Galbraith 2019: 55-63). This is a return to the founding discursive moment in I983. Indeed, Maher is very much stepping into Nakamori's role as the reasonable outsider who sees reality, speaks harsh truths (masquerading as jokes) and demands that people act normal - like him, an adult, a man, someone about to go get laid. The disgust is similar, but unlike Nakamori, who said himself that these failed men are "gross," it was members of Maher's panel who chimed in "this is so revolting" (Maher 2020). Note also the symbolism of Valentine's Day, when many manga/anime fans feel alienated by celebrations of "normal romance," and how Maher demonstrates exactly the discrimination they perceive. For a comparison to responses to “otaku," see Alexy 20I9: I7.

32. Closet to the Gamergate backlash might be those manga/anime fans who respond viciously to any and all feminist critiques of sexualized character images in public space. These issues began to surface in debates about the announced cover change for the January 20I4 issue of the Journal of the Japanese Society for Artificial Intelligence, which featured a manga/ anime-style maid robot that was seen as normalizing female servitude and domesticity (Ema et al 20I 5 ). Feminist critics were noticeably and mercilessly harassed as culturally ignorant and overly sensitive, but direct threats of violence were nowhere near as prevalent as Gamergate. Toward the end of my fieldwork on bishōjo games, however, these debates about gender and representation heated up, as did the rhetoric. There were two big dustups at the end of 20I 5. After I concluded this fieldwork, I noticed another incident 
in 2016 and another in 2017, two in 2018 and three in 2019. There was another in 2020 , but I stopped keeping count then.

33. I am thinking here of critical resolutions of meaning. For example, in her work on media and material culture in contemporary Japan, anthropologist Christine R. Yano writes, "The real or fictive nature of the sex-child image matters less than her public circulation as symbolic dream girl," which reflects "heteronormative pedophilia" (Yano 20I3: 49). The distinction between the real and the fictive matters a great deal to many manga/anime fans in Japan. This is, to my mind, an empirical question. To borrow the words of anthropologist William W. Kelly, "What is the line beyond which passion becomes pathological and participation becomes illegal? These are serious questions, but most difficult to resolve. [...] But just where is the line to be drawn, beyond which the excessive becomes the obsessive? The issue is rendered even more complex because society's official agents, the mainstream population, and the fans themselves may have incommensurate standards of normalcy and morality" (Kelly 2004: I2). Like Kelly and the contributors to his edited volume, including Yano, the aim of the fieldwork presented here is "deliberate and illuminating specificity" (Kelly 2004: 3).

34. This is not bracketing out structures, relations and effects that are "all too human." "Put simply," Kohn writes, "we cannot afford to ignore this all-too-human realm as we move beyond the human. That said, learning to attend to the kinds of lives that exist beyond the human (and beyond the moral), in ways that allow the logics of life beyond the human to work their ways through us, is itself an ethical practice" (Kohn 2013:225).

35 . Here I am thinking of theorist Donna Haraway's approach to politics in a space where the boundaries between human and animal, human-animal (organism) and machine and physical and non-physical have been breached. "The stakes in the border war have been the territories of production, reproduction, and imagination. This [...] is an argument for pleasure in the confusion of boundaries and for responsibility in their construction" (Haraway I99I: I 50). This sounds to my ears like a clarion call for responsibility in drawing lines as we struggle with the blurring of material and immaterial, reality and fiction.

36. The Institute of Contents Culture is an activist group centered on "freedom of creation" (tsukuru jiy $\bar{u})$ founded by adult computer game designers and scenario writers in 2008 (Sugino Nao, personal interview, March I6, 2015). See: http://icc-japan.blogspot.com/.

37. While there is not space here to develop a comparative analysis, it is worth noting that psychiatrist Fredric Wertham, an opinion leader in the American debate about comic books, was far ahead of his time in drawing attention to "harmful potentialities" (Wertham 2004: II 8), which resonates 
with the contemporary discourse of potential victims and criminals and risk management. For Wertham, one of the greatest harmful potentialities of comics was undermining what he called "the ethical image," which "makes possible a stable and yet not rigid ethical equilibrium" (Wertham 2004: 92). This is something that my fieldwork among bishōjo game producers and players in contemporary Japan has urged me to reconsider. If, as Wertham suggests, "Many if not all sexual conflicts are fundamentally ethical difficulties" (Wertham 2004: 92), then we would do well to focus on emerging ethics - the ethics of affect, for example - rather than assuming that existing ones have been undermined.

38. Add to this that Miyazaki reportedly owned a copying machine, camera and computer, which is to say that he was technologically savvy at a time before these devices were generally popular, and the image of a man lost in virtual reality was all the more convincing (Treat I993: 353-355).

39. Again, the accuracy of this is questionable, as the identifiable adult manga in the photograph appears to feature stories and images of "horny housewives" (Ōtsuka 2004: 74).

40. Sociologist Sharon Kinsella notes that in Japan in the I990s, the sense that "otaku" were "multiplying and threatening to take over the whole of society was strong" (Kinsella 2000: I29), which is in line with the "domino theory of sexual peril" (Rubin 20II: I5I).

4I. Ōtsuka Eiji and Nakamori Akio debated for the September 1989 issue of Spa! magazine. Miyazaki Hayao and Murakami Ryū discussed the manga/ anime connection in the November 1989 issue of Animage magazine.

42. Here political scientist David Leheny complicates Hall's notion of hegemony in the case of Japan: "In fact, it is only because conservatives have not been hegemonic that they have turned to the legitimacy afforded to them by international norms" (Leheny 2006: I 86).

43. Incidentally, Japan did not invent the so-called "rape game." That honor goes to the United States and Mystique's Custer's Revenge (I982). Further back, Atari's Gotcha! (I973) featured as controllers pink rubber bulges, which were meant to represent women's breasts. Embroiled in controversy, the game was denounced as pornographic.

44. This is an old critique that is not unique to Japan. In the moral panic about roleplaying games in the United States in the I970s, a discourse emerged about "the delusional gamer," who could not tell the difference between fantasy and reality (Laycock 20I 5: 25). While the discourse about the most iconic "delusional gamer," James Egbert, turned out to incorrectly connect Dungeons \& Dragons to his disappearance, the story stuck and was repeated by advocates against games and criminals as a defense for their actions. 
45. Phillip Zimbardo, a psychologist best known for the Stanford Prison Experiment, is particularly concerned about excessive gaming and pornography, which he argues lead to young men being socially and sexually immature and stuck in "virtual reality:" "Even if games were originally designed to inspire players and make a better reality, they are now being used to replace reality, and many young men are losing themselves in increasingly sophisticated virtual worlds that are totally enchanting" (Zimbardo and Coulombe 20I 5: 23; also xviii). Further: "Underdeveloped emotions combined with a lack of engagement with others can stunt future social and romantic relationships [...] The problem worsens when young men's sexuality develops independently from real-life sexual relationships" (Zimbardo and Coulombe 20I 5: xxi, 76). In this way, adult comics, cartoons and games are worse than photographs and films, because they encourage this orientation toward the virtual, which may be out of synch with reality (Zimbardo and Coulombe 20I 5: I II). The problem, then, is with "gamified virtual worlds" where "young men get to have a taste of what it's like to be a sheikh with their own virtual harem" (Zimbardo and Coulombe 201 5: 88). Virtual sex is said to be derailing actual sex and these games to not address human "love needs" (Zimbardo and Coulombe 201 5: 95). Hence the gamer lives a subhuman life. What Zimbardo calls "two-dimensional cyber mates" (Zimbardo and Coulombe 2015: 109) reduce the human capacity for sexual intimacy. Predictably, Japan comes to represent a dystopian future of social and sexual problems brought on by excessive gaming and pornography, which have undermined what it means to be a man and perhaps even a human being (Zimbardo and Coulombe 201 5: 252; also Turkle 20II).

46. So central are computers to the discourse that some speculate that the so-called "my computer tribe" (maikon zoku) are the ancestors of the "otaku tribe" (otaku zoku). What connects them both is bishōjo, or cute girl characters. Soon after the arrest of Miyazaki Tsutomu, the mock documentary Otaku no Video (I99I) introduced viewers to a man who appears to be masturbating as he tells the camera crew he is a virgin but is satisfied with the "two-dimensional" (nijigen) and another who is addicted to bishōjo games, in love with a character named Hiroko and never goes outside. The gamer is playing Cybernetic Hi-School (Den'nō gakuen, I989), a bishōjo game produced by Gainax, and appearing in Otaku no Video, an anime produced by Gainax. According to rumor, many of these "otaku" are Gainax staff playing up stereotypes. This gamer, for example, is asked if he has any desire to have sex with "a real girl" (bonmono no onna no ko), to which the answer is, of course, no, because he is fixated on the two-dimensional girl.

47. Religious studies scholar Richard Gardner remains skeptical about these claims: "Though the term 'virtual reality' was vaguely if at all defined, it became the key to explaining how manga, anime, and computer games could 
harm people's abilities to distinguish reality and fantasy or reality and representations thereof. [...T] here seems to be little evidence that manga and anime can cause people to be unable to distinguish between reality and what they read and view. [...] Such perceptions of the other, it might be noted, parallel nineteenth- and early-twentieth-century theories of primitive mentality that viewed 'primitives' as unable to make distinctions between things such as word and object or symbol and reality" (Gardner 2008: 216-217).

48. Concern about bishōjo games continued apace with the harmful manga movement in the I990s and led to regulation. For example, in I992, Miyazaki Prefecture revised its Youth Protection and Nurturing Ordinance (seishōnen hogo ikusei jōrei) to allow for computer games to also be named as "harmful publications" (yügai tosho). Among the games labeled as such was Cybernetic Hi-School - the same game being played in the mock documentary Otaku no Video. The response to this pressure has been what adult computer game scenario writer Kagami Hiroyuki calls "excessive self-regulation" (kajō na jishu kisei), by which he means reactionary stances that are often overeactions (Kagami 20I0: I8; see also Fujimoto 20I I: 30).

49. See: https://www.kantei.go.jp/jp/kyouiku/Ibunkakai/dai4/I-4siryour.html.

50. Among the many ways that Ōtsuka states his sense of responsibility, one is to say that as a (lolicon) media producer he is one of Miyazaki's "parents" (Ōtsuka and Nakamori i989a: 63).

5 I. In fact, Ōtsuka agrees with his dialogue partner, Nakamori Akio, who reasons, "We cannot adopt the perspective of the parent with child, or the perspective of victimhood. I think that at this point we can only be thoroughly aware of our own character as aggressors (mizukara no kagaisha sei). In doing so, we can keep the harm to the minimum" (Ōtsuka and Nakamori I989a: 65).

52. This approaches queer theorist Jack Halberstam's read of artists reckoning with "the neighbor, the neighboring other, the proximate self that is nonetheless not you" (Halberstam 20 I I: I68). Indeed, Halberstam may well have been speaking as Ōtsuka when he wrote that, "The killer in you is the killer in me" (Halberstam 20II: I7I). In his relation to Miyazaki as neighbor and proximate self, Ōtsuka stridently refuses to deny or gloss over politically problematic connections and so "lets no one off the hook" (Halberstam 2OII: I7I). Given the pressure to do so at this time and shut down panicked attacks on "otaku," Ōtsuka's words might sound to some like a betrayal, but his determination to speak them is part of an ethics. Following Halberstam, there appears here an "ethics of betrayal" (Halberstam 20II: I62).

53. For example, Ötsuka writes, "[T]here are over Io0,000 people with the same pastimes as Mr. M[iyazaki]" (quoted in Kinsella 2000: I29). 
54. Further, "I get the feeling that I wanted to be a girl" (Ōtsuka and Nakamori I989a: 82).

55. This turn of phrase actually comes first from Nakamori, who advocates "a new ethics" (Ōtsuka and Nakamori I 989a: 93). For further discussion, see Chapter 5 .

56. On sex and violence in pornography, feminist legal philosopher Drucilla Cornell argues that "an individual viewer can potentially learn a great deal about his/her sexuality, and society's construction of sex and gender, precisely by having to confront it so directly" (Cornell I 995: I 55). One might see this as the founding move in porn studies (Williams I989; Kipnis I996).

57. Personal interview (February 9, 201 5 ).

58. There is reason to believe that Ōtsuka's statement is prescriptive, because he writes about the possibility of "otaku" not stopping at fiction and seeking “reality" (Ōtsuka 2004: 224).

59. Unless otherwise indicated, all Sasakibara quotes are from a personal interview (August 3 I, 20I4).

6o. It should be noted that Ōtsuka does seem to hope that people will come to no longer need the media and material objects and get out of the metaphorical room (Ōtsuka and Nakamori I989a: 60-6I, 92). A more radical position might draw on theorist Eve Sedgwick, who sees queer youth investing in media and material objects as "a prime resource for survival" (Sedgwick I993: 3). That is, this is not a phase or something to tide one over until things return to "normal," but rather part of a queer way of life or life with and as the "other" or "abnormal."

$6 \mathrm{I}$. Indeed, at one point, Japanese politicians debated whether or not Winnie the Pooh might be harmful (Nagaoka 2010: 222-223). Ishihara found allies in people such as Matsuzawa Shigefumi, governor of Kanagawa Prefecture, who designated Rockstar's Grand Theft Auto III (200I) a harmful publication. Responding to his critics, Matsuzawa appealed to the "silent majority" (sairento majoritii), who understood, supported and indeed demanded action in the face of social perversion. For more on the "silent majority," see Hall et al I978: I63-I 64, 22I, 24I-242.

62. The transcript has been removed from the Metropolitan Government's website, but is still available at: http://blog.goo.ne.jp/harumi-s_2005/e /fd 37cd702fd9abo84a2 I 5 dc38 8ered280. See also: https://www.youtube .com/watch?v=2edE4kdoO Iw. For more on Ishihara, see Nagaoka 20I0: I3, $2 \mathrm{I}-23$.

63. In Japan, as elsewhere, so-called "cognitive disorders" are thought to lead to sexual crimes (Kagami 20IO: I3; McLelland 20I2: 479). This position is 
increasingly common sense, and those who argue against it are perverts and the enemy of children.

64. Feminist thinker and educator Fujimoto Yukari draws attention to how problematic healthy youth ordinances and strategies for passing them can be for free speech, thinking and the democratic process (Fujimoto 20II: 30-3 I). Journalist Nagaoka Yoshiyuki also highlights the problems of policing thought and paternalist creation of "youth" as a category to be protected and nurtured (Nagaoka 20I0: 26I; also McLelland 20I I: 359-36I). At a conference I attended called "Regulation and Freedom of Expression: The Arrest of Rokudenashiko and the Politics of Bodily Expression" (Hyōgen no kisei to jiyü: Rokudenashiko taihō jiken, soshite, shintai hyōgen no poritikusu) on September I 5, 20I4, there was a general sense from the lawyers, educators, artists and critics in attendance that Japan is in the grip of ongoing and heightened concern about sexual expression, which is leading to state intervention.

65. While a distinction used to be made between "actual" and "virtual" child pornography based on whether or not the image was of a real person and thus a record of a crime where a child was harmed (McLelland 2005: 63-64), the tendency now is to collapse together actual and virtual forms in child pornography laws. Indeed, in 2019, the United Nations recommended that countries treat drawings and other art as equivalent to real images of child abuse (Prostasia 2020). Even when acknowledging lack of scientific proof of the imagined connection between drawings of abuse and actual abuse, a judge in Canada concluded that, "for a perverse or depraved mind, any child pornography material, written or visual, will pose an undue risk for minors since it will serve to fuel a certain behavioral deviance. Human nature teaches us that everything, the best and the worst, is possible, even probable" (Prostasia 2020). This is a direct statement of the logic of sexual risk management and policing potential crimes and criminals.

66. This also occurs in extra-legal activities such as "pedohunting," where online activists "locate and target people who could potentially do something illegal" (Stroud 2016:27I). As with the discussion of protecting children more generally, these online activists tend to see in "polarized terms" of "innocent victim" and "evil perpetrators," which justifies their intervention. (Recall the "gothic narrative" [Kincaid I998: IO-I2].) As social media scholar Scott R. Stroud argues, however, such activism raises serious ethical issues (Stroud 20I6: 278).

67. Leheny argues that this law was pushed through with international pressure, and used to police problematic youth populations rather than protect children (Leheny 2006: 5I).

68. Gaiman was commenting on the fact that cartoon characters from the television series The Simpsons were deemed abuse victims in an Australian 
court: "I think it's nonsensical in every way that it could possibly be nonsensical. The Simpsons characters aren't real people. They definitely aren't real children. (Given that they first appeared in the late eighties, they're also all over eighteen now...)" (Gaiman 2008). While intentionally provocative, one does come away wondering how to legally discern the age of a cartoon character. Consider, for example, the cartoon character Lupin III as discussed by producer Suzuki Toshio: " $[\mathrm{H}]$ ow old do you think Lupin is? The interesting thing is that the answer depends entirely on the viewer. For small children he is about the age of an uncle; for preteens he is 20 ; for $2 \mathrm{I}$-year-olds he is in his thirties. Each generation sees him as being a little older than they are. Don't you think this is amazing, that Lupin's age should change according to the viewer?" (Suzuki 201 8: 93-94). Precisely because Lupin is a drawing, lines on paper or celluloid, he has no physical age to settle the matter. This is why Gaiman later stated even more strongly, "Child porn is a crime and an evil. Manga are lines on paper” (Gaiman 20I2).

69. Historically, a de facto legal ban in Japan on depictions of pubic hair might have encouraged the use of young models, in combination with cultural understandings of artistic value and child models as asexual, which thereby allowed pornographers to avoid scrutiny under obscenity laws.

70. The quote about Eromanga Sensei comes from Stirling Griff, a senator in Australia. His name appeared in the news again in October 2020 , when it was reported that Australian authorities were cracking down on the importation of sexually explicit comics from Japan (Butler 2020). The "hentai ban," as many called it, was a symbolic shutting out of the imagined threat and contagion from Japan (see Hinton 20I4). Importantly, Griff was not alone in condemning content and demanding stricter regulations, which will not stop at the importation of physical media. In addition to legislative and legal actions against such content, private companies and distributors have also taken matters into their own hands. For example, in July 2020, it was reported that the manga version of Eromanga Sensei was among many works delisted from Amazon Kindle (Pineda 2020). This occurred only on the English-language site, with the original releases still available for purchase in Japanese on the Japanese-language site, and the reasons for many of the delistings remain unclear. This is not the first time that works have disappeared from Amazon without warning, and it has happened in Japan, as well. In July 20I3, for example, 46 adult comics - eromanga - suddenly disappeared from Amazon Japan's e-book marketplace for causes unknown (Nagayama 20I4: 339-340). Certain publishers, series and keywords appear to have been targeted for violation of some sort of standard, be it Japanese or global, but the vague process of deliberation and denial of an opportunity to appeal troubles many activists.

$7 \mathrm{I}$. This is something that Urobuchi himself recognizes. In a flurry of social media and internet activity around the time of the announcement of his win 
as the scenario writer for Puella Magi Madoka Magica, Urobuchi specifically underscored his connections to the bishōjo game industry, history of producing content that many find wildly offensive (if not obscene) and the fact that then-recent moves by the Tokyo Metropolitan Government had curtailed the creative freedom of others to produce work as he did (Kuro-Mac 20I2). While there are numerous reasons to doubt that the Japanese government would knowingly praise or promote the output of the bishōjo game industry, the case of Urobuchi demonstrates how core talent can get caught up in campaigns surrounding "Cool Japan” (for more, see Galbraith 20I9: 227-260). Interestingly, in 2020, when a global pandemic shut down face-to-face events and cut off revenue streams, Wakakusa Masaya, who independently produces and distributes sexually explicit computer games for players over the age of $\mathrm{I} 8$, applied and was approved for financial support from the Agency for Cultural Affairs (Furusato 202I). Perhaps the government had by then recognized the value of such bottom-up production for the creative industries as a whole. Nevertheless, very few politicians and bureaucrats are willing to publicly announce such a position, and many, many more go along with pushes for increased regulation spurred by international outrage.

72. It is not surprising that this trial brought together concern for the perceived abnormality of "otaku," the healthy development of youth and the future of Japan. As Cather summarizes, "the fact that manga (and otaku) were symbols of national importance only fueled that state's desire to police them" (Cather 20I 2: 246).

73. For a brief introduction, see: http://www.kkı up.jp/archives/n40776.html. 74. Personal interview (January 26, 20I 5). For more on the event, see: http:// www.akihabara-sixteen.com/.

75. For example, Messe Sanoh on Chūō Street began to stock bishōjo games from around 1987.

76. Personal interview (July 2, 2013).

77. When I requested an interview with Nitroplus, they responded by email but declined to speak about their past in bishōjo games (mail received on August 6, 20I3).

78. For more on this struggle, see Galbraith 20I9. For comparative cases of how revaluation of land and minority identities can lead to policing and punishing sexual and social outsiders in urban settings in the name of "safe spaces," see Hanhardt 2013. Particularly helpful is the idea of a "simultaneously flexible and fixed language of threat, in which violence is imagined as the central risk" (Hanhardt 2013: 9). This is tied to issues of visibility, borders and inclusion and exclusion. While obviously very different from Hanhardt's cases, from 2007 into the 2010 , the discourse that Akihabara's streets had become "unsafe," imaginatively associated with queer performers and a mass 
murderer, allowed politicians and police to introduce and enforce strict rules and regulations to manage the "threat." It is telling that the protectionism of this neighborhood coincided with public and private investment in redevelopment that inflated property value, as well as its revaluation as a symbol of "Cool Japan."

79. In a personal interview (January 9, 2015 ), one activist from the organization Light House explained, "It [Akihabara] is such a great example of the problems that we just take people there and let them see for themselves." Indeed, this activist admitted to being somewhat upset to see the stores dealing with the most objectionable content disappearing from the street amid growing criticism, because this made the task of pointing them out more difficult.

8०. See: http://www.excaddy.jp/charara/top.html.

$8 \mathrm{I}$. The mail was received on October I7, $20 \mathrm{I}_{4}$.

82. The CNN survey, which was titled "Should Japan ban sexually explicit video games?" was posted on the news outlet's webpage in April 2010. At one point, it was at the top of the page.

83. Writing on the boundary-policing practices of a website for distributing male-male erotica, legal scholar Scott Beattie explains, "Censorship is a divisive issue for all communities but it is also constitutive, a practice through which they define themselves, establish their barriers and the relationship with broader publics" (Beattie 2018: I72). He goes on to highlight "the constitutive and world-building role of regulatory communities and the importance of self-regulation in shaping counterpublics" (Beattie 20I8: I72). If, as Beattie suggests, "Online art communities constitute themselves through aesthetic practice and internal regulatory activity" (Beattie 20I8: I78), then this also happens offline in areas such as Akihabara and events such as Charara!!

84. Personal interview (May 23, 20I4).

85. See: http://www.denkigai.net/dg/.

86. See: www.minori.ph.

87. See for example MangaGamer (https://www.mangagamer.com/), Sekai Project (https://sekaiproject.com/) and JAST USA (https://www.jastusa.com/). Importantly, the global distribution of bishōjo games was not planned from the start, but rather was an after-the-fact attempt to make already existing content available in new markets through collaboration with fans. Behind the spread of adult computer games from Japan beyond its borders is what has been called "progress against the law" (Leonard 2005: 28I), whereby fans desiring content draw it into new circulations despite a lack of official releases or even official channels for release. This is very much how the market for 
anime was established in North America, for example, with early adopters spreading the material through clubs and mailing lists, starting localization companies and generally translating for others. As in the case of anime, this new content being drawn across borders can challenge dominant norms and values and lead to debates and emergent alternatives (Eng 2012: 100-I03; see also McLelland 2005). Rejection of bishōjo games as perverse or criminal confront divergent understandings in groups, communities and (sub)cultures connecting and communicating online. And there are signs of changing minds, from bishōjo games (minus explicit content, but with links to easily add it after purchase) making the list of best-selling titles on mainstream digital distribution site Steam (Grayson 2019) to indie games such as Doki Doki Literature Club! (Team Salvato, 20I7) not only garnering critical acclaim but also demonstrating a mastery of the genre by North American developers. Indeed, from its title to its character aesthetics, Doki Doki Literature Club! is a bishōjo game produced in the style of Japan but outside that country and in dialogue with producers and fans within and beyond its borders.

88. See: http://www49.atwiki.jp/aniwotawiki/sp/pages/2538.html.

89. Unless otherwise indicated, all direct quotes from Ataru below come from a personal interview (January I2, 20I5).

90. The shared appreciation for Leaf generally and To Heart specifically should not be underestimated. In a personal interview (September I6, 20I4), Nakamura Jin recalled that his enthusiasm for Leaf's games inspired him to organize perhaps the first fan event for bishōjo games in 1996. The event was attended by Leaf staff, 96 creative groups and I, 500 visitors.

9I. I am certainly not the first to highlight the enunciator's exception in the context of virtual regulation. Writing on the historic concern about women reading novels, religious studies scholar Joseph P. Laycock points out that, "It is significant that these opponents of fiction were not afraid that they might confuse fantasy and reality. This was always framed as a danger for some other class of people" (Laycock 201 5: 227).

92. For parallels with Mazzarella, see Williams I989: I 2; Kipnis I996: viii. Part of the regulatory response to pornography comes from the discourse of obscenity, which begins for Williams not with the axiomatic statement, "I know it when I see it," but rather with the realization that, "It moves me" (Williams r989: 5).

93. Thinkers in Japan are taking this even further. For example, at a symposium held at Tokyo University of the Arts on October 5, 20I4, one speaker, Ogura Toshimaru, argued that the government was regulating sexual expression with the baseline assumption that what stimulates or overly stimulates is "obscene." At the same event, Yamada Kumiko, who organizes a feminist 
reading group that I regularly attended, questioned whether or not it made sense to regulate this way, because we do not know what stimulates people or how to qualify the intensity of response.

94. In a personal interview (February I6, 20I 5), feminist critic Fujimoto Yukari gestured in a similar direction. From her perspective as an editor, critic and educator with experience in the industry in various roles, Fujimoto argued that many people in Japan perceive manga fans as a class of people who are simple minded, undereducated, easily aroused and so on. As with the "pissing man" in India (Mazzarella 20I3: I4-I 5), the dangerous class of manga readers in Japan tend to be imagined as an underemployed, unmarried underclass. These readers, especially men, are the ones treated as potential criminals. While Fujimoto focused her comments on manga, they are certainly suggestive of how bishōjo gamers might be perceived as a dangerous class.

95. All quotes come from a personal interview (October II, 20I4).

96. This chapter follows literary critic and social theorist Michael Warner's approach to publics, which come into being in relation to texts and their circulation, are self-organizing and include unknown others (Warner 2002: 50), but is not concerned with larger theoretical debates about publics. It is in Warner's earlier work with literary critic and social theorist Lauren Berlant (Berlant and Warner 1998), and in his book The Trouble with Normal (Warner 2000), where the political importance of publics, counterpublics and sex in public is clearest.

97. Warner states this outright: "Publics [...] are virtual entities, not voluntary associations" (Warner 2002: 6I).

98. While some may bristle at the application of concepts from queer theory to the case of bishojjo gamers, who appear to be heterosexual men oriented toward women, I follow philosopher Judith Butler in seeing queerness as not an identity, but rather an alliance, which is "uneasy and unpredictable" (Butler 201 5: 70).

99. As Warner writes, "people of very unremarkable gender identity, object choice, and sexual practice might still passionately identify with and associate with queer people. Subjectively, they feel nothing of the normalcy that might be attributed to them" (Warner 2000: 37).

Ioo. "Failure is not an extinction of the possible, not a dead end. Instead, failure frames the possible in negative terms without actually erasing all possibilities. [...] In this way, the commonsensical antipathy toward public sex, sexual hypocrisy, or virtual sex works to foreclose the possibilities for queer and other, alternative intimacies to take form" (McGlotten 20I3: 37-38). As an example of this, McGlotten draws attention to criticism of gamers, or "otaku," for their supposed social and sexual failures, which are 
deemed pathological (McGlotten 20I3: 54). McGlotten argues that screen interaction "summons us to imagine a more expansive array of potential modes of relating. These virtual intimacies, the constellation of latent capacities and routes that might be actualized, or not, serve as reminders that the generativity of queer socialities has not been exhausted, and that we cannot know in advance or for certain what forms our intimacies with ourselves or others might take" (McGlotten 2013: I36). Where McGlotten discusses sex between players as characters in games, and meetups between players offline (McGlotten 20I3: 56-60), I would draw attention to virtual intimacies with game characters.

Iо . Unless otherwise indicated, all direct quotes from Honda comes from a personal interview (September 26, 2009).

I02. Warner explicitly states that he is trying to imagine the conditions under which an alternative ethical culture exists (Warner 2000: vii-viii), which is to say that he is involved in the struggle for imagination. Indeed, drawing on Rubin's work, Warner points to the politics of sex and "victimless crimes," "imaginary threats" and "the imaginary rules of sex" (Warner 2000: 25-27). Further, critiques of public sex cultures such as pornography tend to come in a language of disgust that "make a rival point of view seem unimaginable" (Warner 2000: I8I).

I03. Personal conversation (July I2, 20I4).

I04. Recall Yamada Tarō's address at the Comic Market in August 20 I 5 (Chapter I). The comment on the Olympics was made by Yamaguchi Takashi at the conference "Manga Futures: Institutional and Fan Approaches in Japan and Beyond" (November I, 20I4).

I05. While I am not in complete agreement with her approach to pornography, particularly that images can assault, I stand with Cornell in her fight to expand spaces of imagination rather than close them down, which is part of "liberating the imagination" (Cornell I995: I 58 ; also 98-99, I38, I 44-I 52). We differ in our approach to "the protection of the imaginary domain" (Cornell I995: 4), which for Cornell means protection of women from being forced to see images that make them into sex objects and limit their potential to transform themselves into individuated beings (Cornell I995: IO, IO3-IO4, I2I). I more broadly see protection of the imaginary domain as a project against juridification of the imagination. So while we are in agreement that, "as feminists, we have nothing to gain, and a lot to lose, by any attempts to sexually purify public space" (Cornell I995: I0; also 27), Cornell would still like to see sexual images kept out of sight (Cornell I995: I04, I 47-I 48, I 50-I 5I), which might suggest that Akihabara needs to be better zoned. (Then again, "communities which allow the proliferation of sexual imaginaries are ones in which the environment itself, by encouraging 
tolerance, also helps to discourage violence" [Cornell I995: I 53].) This follows from her position that images can assault and harm women in the imaginary domain, which I find problematic, especially when the images in question are cartoons and are made distinct from "real girls and women." The bottom line, for Cornell and myself, is that one "cannot control the sexuality of others" (Cornell I995: I I; also I63, 233).

I06. It should be noted that the production company, Milk Factory, was entirely aware that it was pushing boundaries and expected backlash. The goal might well have been shock marketing. See: https://twitter .com/milkfactory_/status/I I 90 I 89530449473536 ? ref_src=twsrc\% ${ }_{5} \mathrm{Etfw} \% 7$ Ctwcamp\% ${ }_{5}$ Etweetembed\% 7Ctwterm\% ${ }_{5}$ Ei I 90 I 89530449473536 \&ref_url=https \%3A \% 2F\% 2Fotapol.com\%2F2O I 9\%2F I I \% 2Fpost-8 573 I .html.

I07. As Rubin puts it, "The processes by which erotic minorities form communities and the forces that seek to inhibit them lead to struggles over the nature and boundaries of sexual zones" (Rubin 20II: I66). What we see in Akihabara is the struggle over norms of reading, or sorting members of the public on their affective sense of moe. "Strangers," Warner explains, "are less strange if you can trust them to read as you read" (Warner 2002: 83).

I08. Indeed, bishōjo game producers increasingly speak of circulation and its "ethical considerations" (Kagami 20I0: 220).

I09. This reference to safe sex comes from the experience of homosexual men and HIV/AIDS in North America, but proves useful in thinking public sex and ethics more generally. As psychologist Miodrag Popovic suggests, watching pornography is "the ultimate safe sex method," which also "facilitates learning" (Popovic 2007: 264). He highlights the existence of "fantasists," or people who are satisfied with fantasy. In this group would certainly be "otaku," or those who historically rejected even "real" pornography and oriented themselves toward fiction.

I Io. Personal interview (November I 2, 2009).

I I I. All direct quotes in this paragraph are from a personal interview (December 3, 2014). The direct quotes in the remainder of the paragraphs in this section come from personal conversation with Miyamoto as we walked around the area together.

I I2. Miyamoto, like many others, associates bishōjo games with the "abnormal," for example desire for nonhuman characters both in the stories (robots, animals, aliens) and games (fictional characters, drawings). He is personally attracted to the genre because "the object of affection is relatively free." $\mathrm{He}$ gave the example of loving a robot shaped like a "drum can." This he takes as a life lesson that teaches us that love comes in many shapes and expands the horizons of who, and what, can be an object of desire and affection. 
I I3. Miyamoto also worries about the possibility of filtering and blocking information online making certain content invisible, or at least increasingly marginal. He claims that many bishōjo games no longer appear in Amazon. co.jp searches.

I 4. Miyamoto estimates that the industry as a whole is selling perhaps half as much as it was at its height. He attributes this to the outdated sales techniques of selling games in material packages at physical stores and charging a high price for long and involved stories, which is out of synch with the general trend toward cheap downloadable games that are played casually.

I I 5 . In both the United States and Japan, concerns have been raised about limiting access to public places, materials and information to learn about sex (Nagaoka 2010: 253; boyd 2014: IO2-IO5).

I I6. Conversely, if violence, sex and sexual violence are taboo even in the context of fantasy and play, then players will be unable to make sense of them and develop a "code of ethics" (Laycock 20I 5: I7 I, I90-I95, 2I8-2I9; also Brey 2008).

I 7. All quotes from Matsumura Kazutoshi come from a personal interview (July 23, 20I3).

I I 8. Circus' offices are located in Saitama Prefecture. How the place we met in Akihabara is related I do not know, and the person who set the meeting up told me not to ask Matsumura questions about his business or finances.

I I9. Izumi, who trained to be a voice actress, got her first job in the industry at Circus, where she was paid to dress in character costumes and interact with fans. After about five years of this, she was hired as full-time staff in the company (personal interview, July 2, 20I3).

I 20. This speaks to queer theorist Bonnie Ruberg's take on infamously offensive games such as Custer's Revenge. For Ruberg, "knowing that the game is offensive does not suffice to make sense of the uncomfortable feelings it inspires. It is equally, if not more, important to experience the alarm that comes with playing - that worrying sense that we are complicit when we maneuver the cowboy toward his goal [i.e., rape]" (Ruberg 20I 5: I 20). This seems in line with this chapter's approach to bishojo games, but Ruberg warns that players can "overcome the initial ethical hurdle of Custer's Revenge" and “quickly lose sight of the game's problematic content” (Ruberg 20I 5: I 20). For Ruberg, there is real danger that games can "convince us to accept ourselves as unquestioning agents of violence" (Ruberg 20 I 5: I 20), but bishōjo games suggest the possibility of players lingering with feelings of complicity in sexual abuse.

I 2 I. Personal interview (February I6, 20I 5 ).

I 22. Personal interview (February 26, 2010). 
I 23. Itō Gō, personal interview (March I9, 20I0). In his discussion of Walt Disney's early animation, Nagayama Kaoru refers to the eroticism of "overly smooth movement" and "an excessive sense of vitality" (Nagayama 20I4: 30). Tracing how this informed Tezuka Osamu's "anime-like manga," or moving images in still form, Nagayama refers to "the eroticism of lines in and of themselves" (sen sono mono no motsu erotishizumu) (Nagayama 2OI4: 38 ).

\section{I24. Personal interview (September I, 20I4).}

I 25. Personal interview (October I6, 2009).

I26. Azuma draws attention to the example of Konami's Tokimeki Memorial

3 (200I), which made use of three-dimensional, computer-generated graphics and, despite being a beloved franchise and technical advance, failed commercially. As Azuma sees it, this was a result of players rejecting the character images, which did not conform to the preferred two-dimensional style. See: https://en.wikipedia.org/wiki/Tokimeki_Memorial_3:_Yakusoku_no_Ano _Basho_deMo. There have, however, been various attempts to design a three-dimensional body that would be responded to as "moe." For an explicit example of this in robotics, see Katō et al 2014.

I27. Indeed, Lamarre touched on affective attunement in a personal interview (April I9, 2010).

I28. Personal interview (September I2, 20I4).

I29. Personal interview (July 24, 20I 5 ).

I30. Personal interview (February 9, 2015).

I 3 I. In other words, role language is "fictionalized orality" (Teshigawara and Kinsui 20II: 38 ).

I32. Personal interview (September I9, 20I4).

I33. Personal interview (December I 8, 2009).

I34. As a form of melodramatic imagination, bishōjo games are in many ways similar to soap operas, where the goal is to "elicit as many and as complex emotions from viewers as possible" (Blumenthal I997: 53). This is done by focusing on still images - the body in arrest, reacting to other bodies - dense with potential meaning. In soap operas, "the close-ups on faces, of important objects, the deliberate movement of characters across a room, the lingering of the camera on a face at the end of the scene, the exchange of meaningful glances - work to make every gesture and action seem highly coded and significant" (Geraghty I99I: 30). This overcoding adds far more signifying possibilities than are necessary to move the narrative forward. As pioneering researcher Tania Modleski points out, characters "get together and have prolonged, involved, intensely emotional discussions with each other" 
(Modleski I983: 68). What is happening is less important than what might be happening, or might happen. In this way, "the narrative, by placing ever more complex obstacles between desire and fulfillment, makes anticipation of an end an end in itself" (Modleski I982: 88). This is an apt description of bishōjo games, where fulfillment of desire is made complex and anticipation becomes key. As researchers of soap operas and the melodramatic imagination underscore, there is something masochistic about this pleasure.

I35. All quotes come from a personal interview (December I8, 2009).

I36. In a personal interview (February 26, 20I0), Saitō Tamaki singled out the characters of Air as examples of "extremely strange figures, or strange compositions."

I37. Similarly, if "entertainment is purging the affects" (Horkheimer and Adorno 2002: I I 5), this is not what we are seeing in bishōjo games.

I38. It is worth noting that McCloud's longer definition of comics includes that they are "intended to [...] produce an aesthetic response in the viewer" (McCloud I994: 9). That "aesthetic response" might refer to comics as images intended to move.

I39. See: http://www.moetionworks.com/pink/.

I40. The interaction occurred on August I3, 2015.

I4I. One is reminded here of theorist Tim Ingold, who describes ancient religious practices of "walking through" paintings into other worlds (Ingold 2OII: I99).

I42. Their slogan, in English, is as follows: "Moemotion Works Pink: It's Soulful, and We're the Specialists who Creates MOE and EMOTION."

I43. Indeed, so common is this technique of having viewers fill in the blanks in Japanese comics and cartoons that there is even a term for it: "mind completion" (nōnai hokan). I have also heard a version of this referring to comics and cartoon fans who develop "the faculty of converting in the mind" (nonai de henkan suru kinō).

I 44. "Most of the time, the player-character is only peripherally visible on screen and has no voice of its own; even though non-player characters have voices, the player-character only communicates through written dialogue options in which there are very many options" (Waern 201 5: 54). With the exception of the last part about the wealth of choices, Waern may well be describing the protagonists of bishōjo games.

I45. It is typically only in rare instances that one reflects on action, for example in Call of Duty: Modern Warfare 2 (Activision, 2009), where the player is forced to walk slowly and deliberately through an airport and take part in a terrorist attack against unarmed civilians. 


\section{I46. Personal interview (August 3I, 20I4).}

I47. Indeed, film scholar Laura Mulvey, who popularized critique of the male gaze with her original essay in 1975 , seems to anticipate this when she writes of films where "the powerful look of the male protagonist (characteristic of traditional narrative film) is broken in favour of the image in direct erotic rapport with the spectator" (Mulvey 2009: 22).

I48. As media scholar Forrest Greenwood puts it, "In directing the shōjo's gaze out toward the viewer [...] many modern bishōjo games disrupt this hierarchy, forcing the viewer to regard the shōjo as being something more than a mute, passive object" (Greenwood 20I4: 250).

I49. Sasakibara's interaction with fictional characters as "human" is all the more plausible when we consider social science demonstrating that humans tend to treat as human and seek social interaction with what is "cute," including fictional characters (Sherman and Haidt 20II: 5), and human minds mimic the states of those they interact with, "even if those other minds are imagined” (Zimbardo and Coulombe 2015: I32).

I 50. Sasakibara is not alone in this experience. At an event (February I I, 20I 5), one female bishōjo gamer said that the most effective marketing for bishōjo games is when the image of the cute girl meets her gaze: "When there is a cute girl on the floor of the station and our eyes meet, I don't want to step on her."

I 5 I. In her discussion of photography and the politics of the gaze, theorist Ariella Azoulay argues that recognition of the demands of the one being gazed at and gazing back leads to relational and ethical engagement (Azoulay 2008: I 8-23, I 47-I 50).

I 52. The dynamic of the character facing the player and looking out at him recalls philosopher Emmanuel Levinas' approach to the face of the other, which says, "You shall not commit murder" (Levinas I969: 199). The face, in its nudity and defenselessness, offers "ethical resistance that paralyzes my powers" (Levinas I969: I99). Put slightly differently, the face compels me not to act: "Do not kill me." The face offers "passive resistance to the desire that is my freedom" (Bergo 20II). It is startling how resonant Levinas is with Sasakibara, who advances that the character, in her nudity and defenselessness, says, "Do not hurt me," which limits the player's freedom to act (Sasakibara 2003: I26; also Kulick and Rydström 201 5: 274-276). For Sasakibara, as for Levinas, ethics point us toward nonviolence. For both, it begins with an "interruption," or affective moment.

I 53. To be clear, this is not the only and inevitable experience or response to play. Queer theorist Andrea Wood, for example, highlights how some players "make choices that will take them on the quickest path to unlocking the 
myriad sexual vignettes" (Wood 20I I: 356), which seems to deemphasize story and reflection on one's involvement in a scene and responsibility for actions.

I 54. Personal interview (August 3 I, 20I4).

I 55 . On November 2, 20I9, visiting Gatebox' offices in Akihabara for follow-up fieldwork and to participate in a promotional "premium experience," I was reminded of the importance of designing relationships. In a personal conversation, Marketing Team Manager Nishizaki Shüji zeroed in on the uniqueness of the Gatebox device, namely that it houses a character named Azuma Hikari who is "cute" (kawaii) and "responds" (han'nō suru). Without any prompting, Nishizaki recommended I look into an art experiment titled "Rhythm o" (I974), in which Marina Abramović stood still and allowed visitors at an exhibition to view and act on her (Yuen 20I7). The actions became increasingly violent, which Nishizaki believes reveals a valuable lesson for designers. When one does not respond, or is reduced to a state of "non-resistance" (muteikō), they are easy to victimize. In short, in becoming an object, Abramović was abused as less than human. For his part, Nishizaki reasons that designed responses are key to users treating Azuma Hikari better than an object, or as something more than a "thing." I could not help but think about Sasakibara's theory of the cute girl character looking at the player and demanding to be treated with care, which impinges on his ability to act on this "someone" who is "human." While it is not a bishōjo game, I nevertheless find it fascinating that people in the Gatebox company, with offices in the shared space of Akihabara, have come to similar conclusions about the need to design more human interactions and relationships with cute girl characters. Like Sasakibara, Nishizaki also sees these interactions and relationships, supported by media and technology, as "fulfilling user needs." In an age of atomization, alienation and anomie, Nishizaki imagines users wanting Azuma Hikari or another character in the future to be their wife, daughter, sister, "slut" (bicchi) and so on. The majority of current users of Gatebox are men, but Nishizaki tells me that women are on the rise, and I did in fact observe several women participating in the premium experience in just the hour or so I spoke with staff. According to Nishizaki, the company is in the process of designing a male character to specifically target new users.

I 56. For a discussion of The Song of Saya fostering "negative emotions" and challenging how playing games "should feel," see Sousa 2020. Reading games such as this as queering norms is both provocative and productive. For a complementary analysis of queer antisociality in manga and anime, see Jones 20I3.

I 57. The internalization of the female other as character brings to mind queer theorist Jack Halberstam's critique of the position of white men: "like 
the mechanics of dominant culture itself, they absorb whatever they see and make it part of themselves" (Halberstam 20I I: 67). There is, however, real tension between Sasakibara and Halberstam, who goes on to advocate certain forms of forgetting, specifically forgetting the subject position to allow for unknowing and open encounters and relations. Given the many parallels with examples of moe media, there may be room for an approach that adopts and follows through on Halberstam's provocative reading of Dude, Where's My Car? (2000). The redemptive reading is of men who stupidly forget who they are and can thus "immerse themselves in perversion and fantasy without either disgust or judgment. Their tolerance is revealed to be part and parcel to their stupidity, and their stupidity is represented as a likeable absence of critical judgement which relieves them of being either politically sensitive (aware of their own biases) or politically biased (homophobic)" (Halberstam 20I I: 63). In this mode, the dude "lacks self-knowledge and fails to internalize social biases appropriate to his subject position" (Halberstam 20I I: 66). For Halberstam, "forgetfulness becomes a rupture with the eternally self-generating present, a break with a self-authorizing past, and an opportunity for a non-hetero-reproductive future" (Halberstam 20II: 70). This constant movement of perversion resonates with readings of moe media, as well as critiques of the reinscription of sexual and gendered lines (Lamarre 2006: 370-385). Writing on moe and "otaku movement," media theorist Thomas Lamarre underscores possible transference from "corporate culture," or "the homosocial workplace, normative heterosexuality, and the sex industry" (Lamarre 2006: 376; see also Allison I994). For Lamarre, the danger here is that sexual stereotypes and their connections to corporate culture and received sociosexual formations go unacknowledged, which thus allows them to go unchallenged, if they are not also bolstered by unquestioned repetition. One might also consider feminist scholar Sara Ahmed's approach to happy objects and the stickiness of affect, which "sustains or preserves the connection between ideas, values, and objects" (Ahmed 2010: 29).

I 58 . For comparison, see Kulick and Rydström 20I 5: 274-276.

I 59. Personal interview (August 3 I, 20I4).

I60. One is reminded here of a vignette from philosopher Slavoj Žižek, who recalls meeting BDSM practitioners and thinking that they were the nicest people in the world (Žižek 20I5). As Žižek sees it, these practitioners have faced and worked through their own obscenity and shared it with others. This "obscene contact" allows them to be "the nicest people." Given the case of Sasakibara, and what I experienced in the field, bishōjo gamers seem similar.

I6I. There is a danger, however, that games might not be disturbing or unsettling enough to impact and shift ways of seeing and being in the world, or the danger of what theorist Christopher Howard describes as "an ethics of the other [that] is also still containable within a postmodern tolerance that 
simply perpetuates [...] exploitation" (Howard 20I4:385). The importance of Sasakibara's critical insight is precisely in working through and resisting "insatiable destructive appetite" (Howard 20I4: 385 ).

I62. All quotes from Matsumura come from a personal interview (July 23, 20I3).

I63. See for example: http://www.getchu.com/soft.phtml?id=5 I.

I64. As an example of such intimacy, literary critics and social theorists Lauren Berlant and Michael Warner present "erotic feeding," where a man force feeds his restrained partner keeping him at the edge of gagging, which involves "trust and violation" (Berlant and Warner I998: 565). Another example comes from anthropologist of sex Don Kulick, who introduces a subculture where obese women are desired by men who cannot physically have vaginally penetrative sex with them, but take pleasure in watching them eat (Kulick 2005). Some women as performers desire to be "taken to immobility" by men as "feeders," which is to say to be fed to the point where they can no longer walk (Kulick 2005: 82). This makes the women completely dependent on the men, which both partners desire. The women are made vulnerable and dependent, but this ideally leads to intimacy and care. As with bishōjo games, the power dynamics of such relationships raise questions about ethics and politics. For more, see Nagayama 2014.

I65. All quotes come from interactions on January 22, 2015.

I66. In the I980s, Matsuda Seiko was the top idol in Japan, and her image was so conscientiously produced and performed that people began to call her a "burikko," which means "fake girl/child." Fans, however, supported Matsuda, because they in fact did not want anything more "real" from her and appreciated her idol image (Kijima 20I 2b: I 5 I-I 53). Even as women performed as idols and images, fictional women became idols in the I980s. One can see this in manga artists producing "photo albums" of drawn "glamour shots" of their cute girl characters, and in magazines such as Manga Burikko, which presented drawings of cute girl characters as gravure photography. As can be gleaned from its title, Manga Burikko intimates that the cute girl characters in its pages are idols like Matsuda Seiko, but even more imagined and created.

I67. While I do not share Kōta's position on $\mathrm{AKB}_{4} 8$ being a simple story of exploitation and abuse (Galbraith 20I7b), I do appreciate his struggle to draw a line between the virtual and actual, fiction and reality, which I try to unpack in this chapter. When writing it, Ataru, another bishōjo game player I came to know in Akihabara (see Chapter 2), posted an article about a female member of the Diet condemning the United Nations' request that Japan do more to ban virtual child pornography (Nascimento-Lajoie 20I6). Ataru drew attention to another article, this one by an NGO claiming that young women were being abused in the Japanese pornography industry (Japan 
Times 20I6). Tellingly, Ataru agreed with both articles, arguing that more should be done to protect actual girls and women and less focus should be on virtual girls and women in comics, cartoons and games. The complexity of such a position is what I try to unpack.

168. Although there is not space to fully pursue the connections, an important text here is philosopher Simone de Beauvoir's The Ethics of Ambiguity (originally published in I947). I am especially thinking about the move to identify ethics in a world without transcendental law or moral absolutes, which encourages embracing freedom and choosing how to act in relations with others. Precisely because we are free in our nothingness, both a subject of action and an object to be acted on, we can take note of ourselves and choose what to do (De Beauvoir 201 5: 69-73).

I69. This is not, to be clear, about embracing positivity and jettisoning identitarian baggage along with politics, which is a standing critique of "the affective turn" (Hemmings 2005: 549-55 I). Surely Sedgwick (2003: I 24, I3 $8-$ I39) acknowledges all the important work that critical reading has done to draw attention to class, gender and race relations, but drawing attention to these relations does not necessarily change them. As an example of the issue, theorist Dick Hebdige (I979: $\mathrm{I}_{3}-\mathrm{I} 4$ ) writes that "there is an ideological dimension to every signification" and "every social formation." The imperative, then, is to read for what we already know is there, and Sedgwick questions whether that is the only thing to do. Scholars see the problem everywhere and read into everything, which can amount to nothing. Worse, scholars can be satisfied with their ability to read, and read well; in reading and knowing, scholars hope for change. Meanwhile, to those not engaged in these critical reading practices, scholars appear "paranoid" - indeed, crazy. Scholars are not open to the possibility of things being different, unknown, and so hunker down; nothing changes, the divide between those who know and do not widens and things devolve into finger pointing and name calling. As highlighted by the election of Donald J. Trump in November 2016 and the entrenched and knowing positions associated with it, and as Sedgwick (2003: I44) anticipated, critical habits - thinking that revealing hidden meaning and violence will change things, and that anyone exposed to such knowledge will be changed by it - may have made scholars unable to "respond to environmental (e.g., political) change." In this spirit, I acknowledge that media, fictional or otherwise, has an impact on "reality," but resist familiar critiques, which tend to lead to predictable conclusions. I am concerned with a situation where "anything but a paranoid critical stance has come to seem naïve, pious, or complaisant" (Sedgwick 2003: I26), because scholars already know that things are "problematic" and must reveal "problems" to be "political." Like theorist Robyn Wiegman, who is also inspired by Sedgwick, I am not convinced that the right critical discourse or tools applied to the right object will lead to the political results critics so desire (Wiegman 
20I 2: 3). Rather than try to make the object produce these results, and be disappointed when it cannot, I pursue a politics of engagement and relation with the object and openness to its affects.

I70. See also the related discussion of how "paradigmatic reading," in order to maintain its authority, must ignore contingency and "the mistake" (Wiegman 20I2, chapter five).

I7I. One of the organizers of the event presented himself to me as a failed man who only now, in his thirties, has finally begun to climb "the stairway to adulthood" (otona no kaidan). While I doubted from his appearance and success that this man was single or a virgin, the phrase "stairway to adulthood" is often used to refer to social and sexual immaturity. In other words, this man was presenting himself as a late bloomer. This playful assertion and undermining of masculinity was common at the Denkigai Matsuri. The official hashtag for Twitter, for example, was “denkiguy," another example of unqualified and pathetic machismo.

I 72. The word translated here as "trained" is typically used for animals (i.e., training or breaking animals). It is also used in adult manga, anime and games and "training" characters, or "breaking" them in, sexually. Use of the word here increases the potential insult, because men in the audience are implied to be trained animals, but this also increases the sexual undertone. The men were sexually trained and trained to behave, sexually.

I73. See for example: http://detail.chiebukuro.yahoo.co.jp/qa/question _detail/qI2 I057045 I2.

I74. See: https://www.discogs.com/\% $/ \mathrm{E}_{3} \% 8 \mathrm{I} \% \mathrm{~A} 8 \% \mathrm{E}_{3} \% 82 \% 8 \mathrm{D} \% \mathrm{E}_{7} \%$

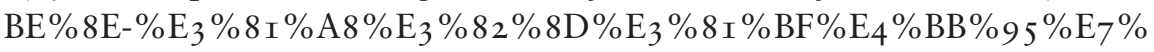
$\mathrm{AB} \% 8 \mathrm{~B} \% \mathrm{E}_{3} \% 8 \mathrm{I} \% \mathrm{~A} 6 /$ release/2994753.

I75. The event was Erogē Song Only DJ Event EEE Vol. 4, which was held in Osaka on September i9, 2010.

176. In a similar way, Momoi Halko, a voice actress who got her start singing music for bishōjo games (see Chapter 2), performs a number where she and other women simply repeat the English words "Sex...and violence!" over and over again in different cute girl character voices. In the background, one hears stock lines from adult manga, anime and games, as well as women performing exaggerated male voices responding to them. The song sounds like a celebration of sex and violence, but is also a subtle critique. It ultimately does not encourage sex and violence in reality, but rather reflection on imaginings of, and responses to, it in virtual worlds.

I77. The adult manga adaptation of Moonstone's Little Sister Paradise 2:

More Older Brother and Little Sister Everyday Fuck Fest (Imōto paradaisu 2: O-nii-chan to go nin no imōto no motto ecchi shimakuri na mainichi, 20I3) 
was the first publication to be deemed harmful under the revised language of the Tokyo Metropolitan Ordinance Regarding the Healthy Development of Youths.

I78. Not only does the player interacting with the image enter into the imaginary space of action, but so too does the voice actress. For an example of the importance of imagination in bishojo game sex, see the depiction of voice actresses in Voice Work (Koe de oshigoto, 20IO-20II).

I79. Hayase is not alone in this sharing with fans. Kagami Hiroyuki, a scenario writer for bishōjo games, vividly recalls letters from players detailing for him what works and what they want more of (Kagami 2010: 26-29). In a personal interview (February 9, 20I 5), Kagami described this as the most fun and rewarding part of his job. "I want people to come up to me and tell me these things," Kagami said. "That is how I can get to know the players and do my job better." Similarly, at an event (February I I, 20I 5 ), character designer Fukumimi said, "Please tweet your reactions to the game! We want to hear from you. It keeps us motivated." He also relayed the story of a fan who approached him at the Comic Market and said simply "I came," or ejaculated while playing one of his games. "That is the sort of straight and honest response we want."

I 80. The spoken Japanese was "Rori... Rori... Rori desu!" The pauses seemed to have been inserted for dramatic effect, but also because she could not think of a better way to portray the character and was thinking before settling definitively on "loli."

I 8 I. Before leaving, the voice actress performed a character song about a girl in love with her "big sister." The song, which touches on the types of lesbian and little sister, was still brought back around to "Lolita." When the older woman asked the voice actress again what she thinks about her character, the voice actress responded, "Lolis are so cute."

I 82. The Japanese, as relayed by Ayumi as she read the comments for the audience in the room, was, "Shō! Shō! Shō! Shō! Shō!"

I 83. Returning to Tokyo after fieldwork, I was reminded of Fukumimi's popularity. In May 20I6, walking down Chūō Street, which is the main thoroughfare of Akihabara, I noticed that hundreds of men were using a particular fan to cool themselves. Given away as a promotion by Sofmap, a major seller of bishōjo games located on Chūo Street, the fan featured a character designed by Fukumimi. The cute girl character appeared to be between Io and I 2 years old and was wearing a cheerleader outfit that exposed her bellybutton, which I overheard men discuss as both cute and erotic. So a sexualized girl-child character on fans used openly throughout Akihabara, where these images did not look at all out of place. Certainly Fukumimi is 
not an outsider in Akihabara or the bishōjo gaming world, and his popularity suggests that whatever problems he has should be considered shared ones. For an image of the fan, see: http://blog.goo.ne.jp/omaketeki/e/cf 2666 aafi 3 cfao 5 faodd 937 e 4 c 85 f 55 .

I 84. Harata translates "rinri" as "morality," but there is already a word for that in Japanese, "dōtoku." Ethics seems to more accurately capture the philosophical dimensions of what Harata and others are discussing in contemporary Japan.

I 85 . Unless otherwise indicated, all quotes come from a personal interview and subsequent interactions (both on April 26, 20I 5 ).

I 86. For his part, Harata draws on the writings of psychiatrist Saitō Tamaki, who has worked with "otaku" and defines them as people sexually attracted to fictional characters (Saitō 2007; Saitō 20I I). Based on his personal and professional experience, Saitō argues that "otaku" are aware of the distinction between fiction and reality, are attracted to fiction as such and, despite their perverse sex lives in fictional worlds, are sexually "normal" in the real world. Harata takes from this the idea of "virtual sexuality" (vācharu sekushuariti), for example something distinct from pedophilia in "lolicon," or an attraction to cute girl characters in manga, anime and games.

I 87. The Japanese is "genjitsu no ningenzō towa mattaku betsujigen no kyarakutā.” Recall the discussion of dimensions and the two-dimensional in Chapter I.

I 88. In fact, Harata criticizes approaches to manga, anime and games as always and obviously "two-dimensional" as "simplistic" (Harata 2006: I I4). For Harata, such approaches are political stances against treating "otaku” as a "reserve army of criminals." The challenge is to go beyond a simplistic position against another simplistic position to the nuanced reality of lived experience.

I 89. For example, Harata points out that the more seriously and objectively one attempts to apply the law to the discussion of virtuality, for example whether or not a fictional character is old enough to legally consent, the more that the law itself confuses and conflates reality and fiction (Harata 20I I: I33). This is a fundamental problem with virtual regulation.

I90. Harata suggests that scholars observe "otaku" and see if ethics encourage them to severe fiction from reality in action and practice (Harata 20 I 2: 9). As I see it, we must not only observe "otaku," but also live and struggle with them to understand and negotiate lines.

I9I. Harata also refers to this as "realization crisis" (genjitsu-ka kiki) and "latent risk" (senzai-teki kiken-sei) (Harata 20I 2: 6). By way of comparison, I find somewhat problematic anthropologist Shaka McGlotten's discussion of 
the men featured on To Catch a Predator, who intend to meet children they have encountered online (McGlotten 20I3: 37-38). These are not merely "creepy online fantasists" (McGlotten 2013:38), but men who wanted to interact with real children, thought that they were doing so and sought to meet them in real life. If bishōjo game players are on the side of fiction, then these men are on the side of reality. The distinction is an important one that we must not lose sight of. Although inspired by his approach to virtual intimacies as that which "might be actualized, or not" (McGlotten 2013: I36), missing here are ethics that discourage actualization that can really harm others.

I92. While the law deals with rights, and right and wrong, it has trouble with an expanded sense of justice as defined by anthropologists Don Kulick and Jens Rydström (2015). For them, "a just society will be one that both protects its citizens from abuse and provides possibilities and opportunities for individuals to develop their sexuality together with others" (Kulick and Rydström 20I 5: 287). Beyond rights in a narrow sense - "Is sex a right?" - this approach considers how protection and provision work to acknowledge and facilitate, rather than just deny and prevent, the capacity for intimacy and sexual satisfaction. Part of this would be, I argue, understanding and supporting emergent forms of media literacy and ethics that decrease the possibility of harm and increase the possibility of developing sexuality with others. To make illegal the imaginary sex in and around bishōjo games would be, for Kulick and Rydström, unjust. Indeed, I encountered a bishōjo game player who was also a lawyer and argued for constitutional protection of imaginary sex as part of "the pursuit of happiness" (kôfuku tsuiky $\bar{u})$.

193. Lambek argues that ethics are not an object to be located, but rather "intrinsic to action and practice" (Lambek 20I 5 b: $\mathrm{I}_{2} 8$ ). The question is less what ethics are than the when and how of ethical action. For Lambek, "ethics emerges at multiple scales of performance" (Lambek 20I5 b: I3 I). Resonating with the ethics of moe as a response and "performative ambivalence," Lambek writes, "It is precisely because practice is not mechanical, automatic, or fully determined that we have ethics. We must continuously exercise our judgement with respect to what we do or say. The criteria by which we do so are made relevant, brought into play, by means of performative acts" (Lambek 20I5 b: I 29). Performative acts are marked by contingency and precariousness, because "the outcome is always at stake" (Lambek 2OI 5 b: I3O).

I94. For more on the development of media literacy and ethics, see Chapter 2. Harata builds on Saitō's insight that there is nothing natural about being attracted to fictional characters, which means that one "must be trained" (Harata 2006: I I 5). I heard similar statements from Saitō and Honda Tōru in personal interviews (February 26, 2010 and September 26, 2009, respectively). 
I95. For the full language of MacKinnon's proposed anti-porn ordinance, see Dworkin and MacKinnon I988: 99-105.

I96. As feminist legal philosopher Drucilla Cornell glosses it, MacKinnon makes "an argument of 'addiction,' premised on her understanding of the viewing of pornography as two-dimensional sex. The man who has two-dimensional sex will want more. He will want to enact the scene on a real woman. A fantasy object will no longer be enough for him. [...] For MacKinnon, then, there is an inevitable causal connection between the consumption of pornography and the way in which men will be incited to act in the real world" (Cornell I995: I23-I 24). Pornography thus is a clear and present danger to girls and women and must be regulated. Whether or not "otaku" will "turn two-dimensional sex into three-dimensional sex" (Cornell I995: I 24) is the question.

I97. Personally, I find MacKinnon to be wildly imaginative and creative, which takes her reader in unexpected directions. For example, MacKinnon writes that, "Pornography is masturbation material. It is used as sex. It therefore is sex" (MacKinnon I993: I7). In three short, staccato sentences, MacKinnon makes pornography itself into sex, which posits that sex with images is real sex. This is as perverse as it is provocative, and MacKinnon comes to sound like a manga/anime fan (Lamarre 2006: 375-380). "Twodimensional sex" is a turn of phrase that MacKinnon and "otaku" share, and both agree that it is real. In this way, MacKinnon unintentionally opens up "different dimensions" of what is commonly thought of as "sex" (Shigematsu I999: I 28). Much as literary theorist Leo Bersani returned to MacKinnon to develop a theory of sex as subject-shattering (Bersani I987: 2I3-2I8), one finds in her writing glimmers of a radical theory of sex with images and its reality.

I98. Sociologist David Oswell states that, "The ethical intensity of the virtual image lies precisely in its capacity to refer to a scene beyond itself" (Oswell 2006: 258), which has been interpreted as a reference to a scene of real crimes against children. See: http://www.ecpat.net/sites/default/files /Thematic_Paper_ICTPsy_ENG.pdf. When considering "manga/anime-like realism" (Ōtsuka 2003: 24), however, one wonders about the supposedly necessary connection to "objective reality" (Oswell 2006: 258).

I99. This drives home a point made by cultural critic Laura Kipnis, who once asked, "What kind of a society sends its citizens to prison for their fantasies?” (Kipnis I996: 3). The question was rhetorical, as she went on to discuss the case of Daniel DePew, a man sentenced to 35 years in prison for sexual fantasies about "a crime that never happened" (Kipnis I996: 4). To be more specific, the victim was "a fictional, nonexistent child" (Kipnis I996: I2), which DePew imagined abusing. So what kind of a society? One like the United States. Or the United Kingdom, Australia or Canada. 
200. As an introductory American textbook on criminology puts it, Handley's "behavior was criminal and not merely deviant" (Siegel 20II: I 5). 20I. See for example: https://twitter.com/i/web/status/874283 I I 406276608 O. 202. While a striking example, this is just one of many times that Comic LO drew this kind of line. On the front cover of the March 2005 issue, which is as usual dominated by drawings of cute girl characters, enormous white text reads, "These are not children." The back cover is an advertisement announcing that, "we will never forgive criminals." After drawing this hard line comes a reminder: "Yes! Lolita. No! Touch."

203. Harata refers to this as "diverse "law" (Harata 20I 2: 8).

204. For his part, Condry goes as far as writing, "To say this is somehow separate from the ' $3 \mathrm{D}$ world' makes no sense" (Condry 20I3: 20I).

205. This has been noted among manga/anime fans in other parts of the world, as well. Even as fans orient themselves to fiction and so "deliberately [...] break from reality" (Zanghellini 2009: I73), they at times "militate against any realistic interpretations" (McLelland 2005: 69), which reflects an explicit and deliberate separation.

206. The date in question was May 5, 2014.

207. See: http://tsukiyume.com/.

208. See: http://hajikon.binarypot.info/.

209. This comment was made by an event organizer on the morning of May 6, 20I4.

2I0. The logic here is not unlike that of the Comic Market and the manga industry's unspoken agreement with fanzine publishers (Pink 2007).

2 I I. In separate work, Wood describes her method as a way to address "the experiential and phenomenological act of watching television" (Wood 2009: I06). For Wood, texts are too often treated as "two-dimensional," and social interaction with texts adds "a third dimension" (Wood 2009: 106). One of my aims for this chapter is to address the missing third dimension of bishōjo games, which are rhetorically and emphatically described as "two-dimensional" (nijigen).

2I 2. Alternatively, Skeggs and Wood refer to "affective noises" such as tuts, gasps and sighs, which speak to "a powerful nonverbal response" (Skeggs and Wood 201 2: I27).

2I3. The initial experience is not unlike a noise event (Novak 20I3, chapter one).

2 I4. See: https://www.youtube.com/watch?v=CnaZlw IczMs. 
2 I 5. I am thinking here of Azuma Hiroki, a philosopher who has done much to introduce bishojo games into critical discussions in Japan. In early writing, Azuma describes moe as follows: "On exposure to certain characters, designs or character voices, the same picture, or voice, will start to circle around in their skull as if the connectors in their brain had been snapped, as if they were possessed. Not a few otaku talk about the experience in those terms" (quoted in Kinsella 2006: 75). This can be observed at Club Moonlight Dream Terrace in moe responses to the images and voices of characters as they flash on screen and pour into the space.

216. For more on the dynamic of vulnerability and trust in the phenomenon of public sleeping, see anthropologist Lorraine Plourde's account of cat cafés (Plourde 20I4: I24-I25).

2 I7. See: http://twipla.jp/events/I 2329I.

2I 8 . The religious undertones of this should not be underestimated. Recall that men kneel in front of the screen when overwhelmed by moving images. Even as they call certain games "god games" (kamigē), here they kneel before the power of the cute girl character as "god."

2 I9. See: https://www.youtube.com/watch?v=6Q-Z4eizaxY.

220. The date in question was May 5, 20I4.

22 I. Personal interview (December I 8, 2009).

222. These men, sometimes called "bimote" or "the unpopular," are sexist in different ways than bishöjo game producers and players. In activist literature and social media, self-identified himote sometimes blame their failure on unreasonable and demanding women, which shades into open misogyny. The underlying assumption that women should be available to men speaks to a profound sense of entitlement, which, when lost, can lead to violence. To put this into the terms that I have been using in this book, himote seem to be confusing their fiction of what women are and should be for reality, and in the process pressuring real women to conform to their fiction. Forcing a human being to be an image is, as Žižek puts it, mortifying (Fiennes 2006). While bishojo game producers and players may be sexist, they make a distinction between fiction and reality and struggle to not confuse or conflate them. The producers and players I came to know did not think that women or society owed them anything, and they had no desire for a return of "normal" relations between men and women. In the politically fraught arena of contemporary Japan, the distinction between himote and bishōjo game producers and players matters.

223. Saitō posits that not only work relations, but also personal relations such as family can be toxic, which he refers to as "the bad side of bonds" (Saitō and Jō 20I 4: I 55 ). 
224. In Anti-Oedipus, philosopher Gilles Deleuze and psychoanalyst Félix Guattari critique psychoanalysis for focusing on representation instead of production, substituting a theater for the factory of the unconscious, limiting interpretation to the family and the Oedipal triangle and thereby pinning down and pathologizing the subject (Deleuze and Guattari I983). The family-myth displaces the true couple: desiring-production and social-field. Deleuze and Guattari theorize that all desire is social investment. For them, Oedipus is a means of "integration into the group" (Deleuze and Guattari I983: I03), which reproduces the family in service of capitalism. (There is also a national dimension.) This only works to the extent that desire is blocked at prearranged impasses. Oedipus reduces desire to familial determinations that no longer have "anything to do with the social field actually invested by the libido" (Deleuze and Guattari I983: 62). This is why Oedipus must be destroyed: "Destroying beliefs and representations, theatrical scenes" (Deleuze and Guattari 1983: 3 I4). After the destruction, engineers work on machines to support their productive working and undo the blockages. The work is of "ensuring this functioning in the forms of attraction and production of intensities; thereafter integrating the failures in the attractive functioning, as well as enveloping the zero degree in the intensities produced; and thereby causing the desiring-machines to start up again" (Deleuze and Guattari I983: 339). While I am interested in "strange flows" (Deleuze and Guattari 1983: I I6), I am less convinced than Deleuze and Guattari about the revolutionary potential of desire.

225. In full: “The question posed by desire is not 'What does it mean?' but rather 'How does it work?' How do these machines, these desiring-machines, work - yours and mine? With what sort of breakdowns as a part of their functioning? How do they pass from one body to another?" (Deleuze and Guattari I983: I08). While I have no interest in returning to or rehabilitating Freud, his Three Essays on the Theory of Sexuality (originally published in I905) is brimming over with wild ideas that make a good deal of sense out of the context of psychoanalysis and as everyday observations and insights. For example, boys are attracted to trains because of "mechanical excitation" and "the pleasurable character of the sensation of motion" (Freud I962: 80-82). Such language certainly resonates with Deleuze and Guattari.

226. See: https://www.youtube.com/watch?v=SmXb3gFJK8o.

227. Others have referred to this as "a life in descent" (Mukaiyachi 2006: $3-4$ ), which is intended to allow even those with no experience of success to live at ease.

228. I am thinking here of McGlotten's discussion of pornography as part of "a creative and enlivening practice of life in the twenty-first century" (McGlotten 20I3: I4). 
229. As anthropologist Naisargi N. Dave writes, distance from "moral norms" and "institutional power" are "the condition of possibility for the creative practice of new, and multiple, affective relational forms" (Dave 20I0: 373). An event such as Hajikon allows for "the imaginative labor of inventing formerly unimaginable possibilities" (Dave 20Iо: 373).

230. In the introduction to her book Violation: Rape in Gaming, feminist thinker Clarisse Thorn recounts an example of fiction and reality getting confused in a rape scene. For this live-action-role-playing game, the players were locked into a building overnight. One player, male, raped another player, female, but it was unclear whether or not this was the character, person or both. The female player was traumatized and pressed charges, but it was difficult to prove that it had not been "play," because the lines of fiction and reality were so blurred (Thorn 2OI2: 2I-22). The result of this dangerous game was real harm.

23I. While talking about living with a cute doll and playing dress up with it seems to be maintaining a line, it is potentially crossed when Ōtsuka elaborates on forming post-family units with highschool girls who are drawn to his home by his domestic partner's shōjo manga (Ōtsuka and Nakamori I989a: 7I-72; Ötsuka and Nakamori I989b: 239-240).

232. See: http://erogetrailers.com/video/9705.

233. At times they can hear the voice as it cracks, which reveals the limits of the human vocalist. They can hear the voice's "grain," which indexes the body (Fiske 20II: 230-23I). It is telling that Roland Barthes, the theorist who discusses the voice in this way (and is cited in Fiske 20I I: 230-23 I), uses sexual metaphors (i.e., orgasm) to explain its affect.

234. Although there is insufficient space here to fully expand, I find Lamerichs' approach to anime conventions useful in multiple ways. Not only does she treat these conventions as affective space, but also "imaginative space," where fans "reiterate a story again at a site" and are "reliving it again" (Lamerichs 20I4a: 268). They are also "social space," where fans "enjoy things together" (Lamerichs 20I4a: 269). This is clearly applicable to Hajikon and bishōjo game events like it.

235. This title is homage to Neon Genesis Evangelion (Shin seiki Evangerion, I995-I996), specifically episode 25 of the original animated television series, which is titled "A World that's Ending" (Owaru sekai) in Japanese and "Do You Love Me?" in English. Section one of this conclusion, "Take Care of Yourself," is the English title of episode 26, and the final section, "The Beast that Shouted 'I/Love' at the Heart of the World" (Sekai no chüshin de "ai" o sakenda kemono), is the Japanese title of episode 26. I have translated "ai" as "I/Love" because it is written in katakana in the Japanese, which suggests a 
phonetic pronunciation of "I," but ai also can mean "love." This is plausible given that the title is itself homage to Harlan Ellison's story "The Beast that Shouted Love at the Heart of the World" (I968). The middle section of this conclusion is titled in reference to the films Neon Genesis Evangelion: Death \& Rebirth (Shin seiki Evangerion gekijō-ban: Shi to shinsei, 1997) and The End of Evangelion (Shin seiki Evangerion gekijō-ban: Ea / Magokoro o, kimi ni, I997).

236. Quoted in Roe 2018.

237. The date in question was August I7, 20I4. Day three of the Comic Market was concentrated on fanzines targeting male fans.

238. See: http://upfg.lullsound.com/akiba-u.ac.jp/.

239. See: https://en.wikipedia.org/wiki/Touhou_Project.

240. The dates were September 27 and 28, 20I4.

24I. Sōmen are fine, white noodles, which we went to eat on several occasions during the tour.

242. When my partner, who was born and raised in Tokyo, heard this story in November 20I6, she repeated the words several times, as if in disbelief and thinking them to be mistaken or somehow foreign. "Go-anzen ni? Go-anzen ni? Go-anzen ni?" When I assured her that it was really what these men said in dozens of audio recordings, she retorted, "Hen na hitotachi!" What a bunch of weirdoes! The greeting is not, it turns out, limited to Akihabara University, but it nevertheless struck my partner as something strange and imagined.

243. Philosopher Judith Butler writes, "Precisely because a living being may die, it is necessary to care for that being so that it may live" (Butler 2009: I4). This condition is shared, and one's life is thus always in the hands of others. In this way, Butler advances an ethics and politics of life, because "our shared exposure to precarity is $[\ldots]$ one ground of our potential equality and our reciprocal obligations to produce together conditions of livable lives" (Butler 20I 5: 2I8).

244. Depending on the character used in writing, mono can mean "person" or "thing."

245. This photo was taken as part of information gathering for an article titled "Love in 2-D," which was published in the New York Times Magazine (Katayama 2009). While it speaks of the "phenomenon" of Japanese men in love with characters and body pillows, this man, "Nisan," is the main example and comes off as pathetic in many ways. It turns out, however, that "Nisan" is a man who performs his affection for this fictional character in public as a gambit for recognition, and he plays journalists to get images like this out there. This is a social game to make his love and relationship more visible and "real." 
246. This photo was taken in Odaiba after the Comic Market in August 20I4. The photographer is Ramon McGlown, who kindly shared the image with me.

247. This photo is one of a series I took in August 2014.

248. As anthropologists Don Kulick and Jens Rydström put it, "The exploration and fulfillment of erotic desire involve reaching out beyond the self to engage with others - be this in real life or in fantasy. In this sense, sexuality even when it is solitary - is always social" (Kulick and Rydström 20I 5: I 20). This is perhaps even truer when the sex in question is imaginary, which can lead to intimate sharing of imaginary sex.

249. Make no mistake that such support is needed. I am reminded of Tomizawa Masahiko, who devoted his life to the prospect of a new collective fantasy with new values and always stood on the side of those whose interests were undervalued or rejected (Seno I989: I39-I46). Resonating with many so-called "otaku," for example saying he desired to be a woman and was more oriented toward the manga/anime "two-dimensional," Tomizawa edited the anthology series Bishōjo Syndrome (Bishōjo shōkōgun, I985-). It took up lolicon material that would make other critics ashamed, but Tomizawa, himself more invested in creature features but standing with others on his principle of people liking what they like and deciding their own values, defended it with powerful rhetoric. When Tomizawa passed away in 1986, he was only 30 years old. Alone in his apartment, he died from overwork and health complications; his body was discovered two weeks later. Although deeply respected by peers and revered by followers, the quiet man apparently did not feel close enough to anyone after moving to Tokyo to think that he could reach out for assistance or take a break (Seno I989: I48-I49). In a moving "requiem," or rather eulogy, writer Seno Mitsurō lovingly details Tomizawa's life, but nonetheless warns of a present when someone like him and indeed us can face "such a death" (Seno I989: I39). While Seno seems to emphasize the need to value the everyday effort required to sustain life, I wonder what might have been done to support a man like Tomizawa in his struggles. As he affirmed others in liking what they liked, even the lowliest of lolicon, perhaps someone might have reached out to him and said, "I love what you do," or even just, "I love you." Maybe it was waiting for him to say something and break the silence that condemned him to abandonment and desperate toil, which literally killed him. I find it revealing that this tribute to Tomizawa and cautionary tale about his life and death is the first essay in the section "The Otaku Way of Life" in The Book of Otaku (Otaku no hon, 1989). Clearly, the editors of the volume were exploring something like the ethics and values of life among those Ōtsuka Eiji and Nakamori Akio contemporaneously dubbed "the abandoned" (Ōtsuka and Nakamori I989b: 214-216). 
250. "Freedom of imagination/creation" (sōzo no jiy $\bar{u})$ comes from a personal interview (March I6, 2015) with Sugino Nao.

$25 \mathrm{I}$. Here I am thinking about political thinkers J.K. Gibson-Graham, who advocate a politics around "new forms of community energized by pleasure, fun, eroticism, and connection across all sorts of divides and differences" (Gibson-Graham 2006: I 8). While I like energy, eroticism and connection, I am hesitant to use the term "community."

252. I am thinking of Butler, who writes that, "Survival depends less on the established boundary to the self than on the constitutive sociality of the body" (Butler 2009: 54). Reading the poems of prisoners in Guantanamo Bay, Butler explains, "the body is also what lives on, breathes, tries to carve its breath into stone; its breathing is precarious - it can be stopped by the force of another's torture. But if this precarious status can become the condition of suffering, it also serves the condition of responsiveness, of a formulation of affect" (Butler 2009: 6I).

253. In the final pages of his book Perv, writer Jesse Bering concludes: "To guide us forward, we must emblazon every star in the sky with the reminder that a lustful thought is not an immoral act. And our handrails would have to be painstakingly carved from the logic that in the absence of demonstrable harm the inherent subjectivity of sex makes it a matter of private governance. Finally, and most imposing of all, we'd each have to promise to walk this brave new path completely naked from here to eternity, removing this weighty plumage of sexual normalcy and strutting, proudly, our more deviant sexual selves. You go first" (Bering 20I3: 232-233). In my fieldwork, I observed that the imaginary sex, violence and crime of bishōjo game producers and players did not lead to "immoral acts," but rather ethical activity. There was no demonstrable harm, but sex was a matter of social governance rather than "private." This is what it means to walk together as people who have shed sexual normalcy and strut their abnormal sexual selves.

254. These phrases are slang coming from online bulletin boards, where Japanese language is intentionally butchered. So, owatta and hajimatta, or the past tense of the verbs "to end" and "to begin," are shortened to owata and hajimata and written in katakana.

255. Writing of the movement of "otaku," or manga/anime fans, media theorist Thomas Lamarre argues that desire moves in a perversion that does not settle into fixed forms (Lamarre 2006: 383 ). The corollary to perversion is proliferation, as in perverse movement leads to the proliferation of the character across media and material forms. So it is that movement, or shared affective response to characters, "generates a world, a reality" (Lamarre 2006: 386-387). This is where I find Butler useful, because she theorizes that precariousness "relies on a conception of the body as fundamentally dependent on, and conditioned by, a sustained and sustainable world; responsiveness 
- and thus, ultimately, responsibility - is located in the affective responses to a sustainable and impinging world" (Butler 2009: 34). My position is that "otaku" movement in shared affective response to characters creates a world, and movement in that world is perverse, but we are responsible for reflecting on actions in a sustainable and impinging world.

256. Although in this book I have focused primarily on male players of bishōjo games, I do not want to give the impression that "otaku" culture is in any way solely a male domain. While often omitted from histories of manga and anime in Japan, girls and women have been important players in fan culture since at least the I970s. For example, the first anime fan club of which there is historical record was dedicated to Triton of the Sea (Umi no Toriton, I972) (Sasakibara 2004: 2I). Based on the manga by Tezuka Osamu, directed by Tomino Yoshiyuki and featuring a twist ending that calls into question the distinction between good and evil, Triton of the Sea attracted older fans to anime, which had been primarily for children. Attracted to the charismatic male protagonist, girls and women dominated the rosters of Triton fan clubs. While Space Battleship Yamato (Uchū senkan Yamato, I974-I975) is often remembered as kicking off the anime fan movement in Japan, few realize that girls and women journeyed to the production studio to pay homage (Clements 20I3: I48). During the I970s, attendance at the Comic Market, founded in I 975 and now the world's largest gathering of manga and anime fans, was dominated by girls and women (Shimotsuki 2008: I 8). They have remained the statistical majority. Nevertheless, because of the overwhelming influence of male critics writing histories biased toward male genres (Clements 20I3: I48) as well as the stereotype of hardcore fans as male (Kam 20I3 b: I63-I65), girls and women have dropped out of the history of manga and anime. This has changed in recent years, as manga, anime and games targeting women have done phenomenally well. So, while male fans have Akihabara in Tokyo, female fans have Ikebukuro in Tokyo. While male fans have bishōjo games, female fans have otome games, which are a growing industry. While male fans have an ethics of affect, so, too, do female fans separate fiction from reality in distinct ways (Galbraith 2015). The relation between men and cute girl characters is where the potential for harm is most immediate, calls for virtual regulation are most persistent and the ethics of affect are most clearly defined, but there is much work left to be done beyond that and this book.

257. Malinowski I989: I65.

258 . Even setting aside the numerous times that he calls informants "savages" and "niggers," which perhaps at the time meant something different than the slurs they read as today, Malinowski undeniably goes on tangential tears that lead him to disturbing thoughts such as: "On the whole my feelings toward the natives are decidedly tending to "Exterminate the brutes;", "I am still subject to petty irritations in my relations with the boys, whom I should treat as dogs;" "The natives still irritate me, particularly Ginger, whom I 
could willingly beat to death. I understand all the German and Belgium colonial atrocities" (Malinowski I989: 69, 268, 279). He outright admits to "strongly hating the niggers," "hatred for the niggers" and being driven to "a state of white rage and hatred for bronze-colored skin" (Malinowski I989: 238, 26I, 264).

259. As theorist Clifford Geertz formulates it, "the Diary presents the image of a womanizing café intellectual cast among savages" (Malinowski I989: 85 ). The characterization brilliantly captures Malinowski hating his informants ("savages") and hating himself ("womanizing café intellectual”).

260. At one juncture, there is even an entry that obliquely hints at unsettling desire for underage girls: "I sat with Molilakwa and two girls (his daughter and Kavala, 7 years). Purely fatherly feelings, then spoiled, and I directed my thoughts at E.R.M. [his fiancé to be] to shake off lewdness" (Malinowski I989: I92). Another similar dart from underage girls occurs later: "I look at the slender, agile bodies of little girls in the village and I long - not for them, but for her [from context, probably E.R.M.]” (Malinowski I989: 253).

26r. With typical eloquence, Geertz outlines the dynamic as follows: "The Western Imagination, to the degree one can talk intelligibly about such a vast and elusive entity at all, has tended to construct rather different representations for itself of the otherness of others as it has come into practical contact with one or another sort of them. [...] But Japan, about the last such elsewhere located, or anyway penetrated, has been for us more absolutely otherwise. It has been the Impossible Object. An enormous something, trim, intricate, and madly busy, that, like an Escher drawing, fails to compute" (Geertz I989: II6-II7).

262. As it turns out, this is exactly what happened. See: http://www.bbc .co.uk/news/magazine-30698640. Also: http://www.bbc.co.uk/programmes /bo4wwkhl.

263. I am thinking here of Allison's reading of work that explores the construction of and relation to objects of desire in "Japan" (Allison 20I2, especially the discussion of Treat I999). If talking about others always risks unselfconsciously playing out desires "through the disguise of projecting them onto someone else" (Allison 20I 2: 3 I 8), then perverse methodology turns this inside out. It encourages an unsettling of self and other, subject and object, and the dynamics of power involved in desiring and knowing the other or object of interest. Considering the "erotics of epistemology (or epistemological erotics)" (Allison 20I2: 3 I9) raises questions about how we imagine and create others and objects and relate to them. 


\section{References}

Adelstein, Jake, and Angela Erika Kubo. 20I4. “Japan's Kiddie Porn Empire: Bye-Bye?" The Daily Beast, June 3. http://www.thedailybeast.com/articles /20I4/06/o3/japan-s-kiddie-porn-empire-bye-bye.html (last accessed on May I 5, 202I)

Adler, Amy. 200I. "The Perverse Law of Child Pornography," Columbia Law Review (IOI:2), 209-273. DOI: https://doi.org/I0.2307/I I 23799

Aiba, Keiko. 20 г r. "Japanese Women Professional Wrestlers and Body Image," in Kumiko Fujimura-Fanselow (ed), Transforming Japan: How Feminism and Diversity are Making a Difference, 268-283. New York: The Feminist Press at the City University of New York.

Akagi, Akira. I993. "Bishōjo shōkōgun: Rorikon to iu yokubō," New Feminism Review (3), 230-234.

Akagi, Tomohiro. 2007. "War is the Only Solution: A Freeter Explains the Plight and Future of Japan's Marginal Workers," Kyoko Selden (trans), Japan Focus. http://japanfocus.org/-akagi-tomohiro/2452/article.html (last accessed on May I 5, 202I)

Alexy, Allison. 2019. "Introduction: The Stakes of Intimacy in Contemporary Japan," in Allison Alexy and Emma E. Cook (ed), Intimate Japan: Ethnographies of Closeness and Conflict, I-34. Honolulu, HI: University of Hawai'i Press.

Ali, Rami. 201 5. "A New Solution to the Gamer's Dilemma," Ethics and Information Technology (I 7), 267-274. DOI: https://link.springer.com /article/IO.I007/sio676-0I 5-938I-X

Allison, Anne. 1994. Nightwork: Sexuality, Pleasure, and Corporate Masculinity in a Tokyo Hostess Club. Chicago, IL: University of Chicago Press.

-2000. Permitted and Prohibited Desires: Mothers, Comics, and Censorship in Japan. Berkeley, CA: University of California Press.

Imagination. Berkeley, CA: University of California Press. 
. 20I 2. "American Geishas and Oriental/ist Fantasies," in Purnima Mankekar and Louisa Schein (ed), Media, Erotics, and Transnational Asia, 297-32 I. Durham, NC: Duke University Press.

- 2013. Precarious Japan. Durham, NC: Duke University Press.

Amar, Paul. 20I I. "Middle East Masculinity Studies: Discourses of 'Men in Crisis,' Industries of Gender Revolution," Journal of Middle East Women's Studies (7:3), 36-70. DOI: https://doi.org/I0.2979 /jmiddeastwomstud.7.3.36

Anderson, Ben. 20I 2. "Affect and Biopower: Towards a Politics of Life," Transactions of the Institute of British Geographers (37:I), 28-43. DOI: https://www.jstor.org/stable/4 I 427926

Andlauer, Letitia. 20I 8. "Pursuing One’s Own Prince: Love's Fantasy in Otome Game Contents and Fan Practice," Mechademia: Second Arc (I I:I), I66-I 83. DOI: https://doi.org/IO.5749/mech.I I.I.oI66

Anime Comic Tone. 2009. "Hirasawa Katsuei o keiyū shite keisatsu ni todoita ittsū no tegami.” https://web.archive.org/web/20I903 I 505 I 5 I 4/, http:// www.geocities.co.jp/AnimeComic-Tone/90 I 8/letter.html (last accessed on May I 5, 202I)

Anime News Network. 2010. "Christopher Handley Sentenced to 6 Months for 'Obscene' Manga (Updated)," February I I. https://www.animenews network.com/news/2010-02-I I/christopher-handley-sentenced-to-6 -months-for-obscene-manga (last accessed on May I 5, 202 I)

Aoki, Mizuho. 2016. "In Sexless Japan, Almost Half of Single Young Men and Women are Virgins: Survey," The Japan Times, September I6. http:// www.japantimes.co.jp/news/20 I6/o9/I 6/national/social-issues/sexless-ja pan-almost-half-young-men-women-virgins-survey/\#.WC27B9xdUbI (last accessed on May I 5, 202I)

Aoyama, Yuko, and Hiro Izushi. 2004. "Creative Resources of the Japanese Video Game Industry,” in Dominic Power and Allen J. Scott (ed), Cultural Industries and the Production of Culture, I IO-I 29. London: Routledge.

Ashcraft, Brian. 2009. "Erotic Game Developer Explains Foreign Access Web Blocking," Kotaku, June 25. http://kotaku.com/5302747/erotic-game-deve loper-explains-foreign-access-web-blocking (last accessed on May I 5, 202 I)

Attwood, Feona, and Clarissa Smith. 20 Iо. "Extreme Concern: Regulating 'Dangerous Pictures' in the United Kingdom," Journal of Law and Society (37:I), I7 I-I 88. DOI: https://doi.org/IO.I I I I/j.I467-6478.20I0.00500.X

Azoulay, Ariella. 2008. The Civil Contract of Photography. New York: Zone Books. 
Azuma, Hiroki. 2009. Otaku: Japan's Database Animals, Jonathan E. Abel and Shion Kono (trans). Minneapolis, MN: University of Minnesota Press.

Bartel, Christopher. 20I 2. "Resolving the Gamer's Dilemma," Ethics and Information Technology (I4), I I-I6. DOI: https://link.springer.com /article/IO.I007/sI0676-0I I-9280-8

Bastow, Clem. 201 5. "Dungeons \& Dragons and the Ethics of Imaginary Violence," Hopes \& Fears. http://www.hopesandfears.com/hopes/culture /video-games/2 I 6625-dungeons-dragons-violence-ethics (last accessed on May I 5, 202I)

Baudinette, Thomas. 201 8. "Finding the Law' Through Creating and Consuming Gay Manga in Japan," in Ashley Pearson, Thomas Giddens and Kieran Tranter (ed), Law and Justice in Japanese Popular Culture: From Crime Fighting Robots to Duelling Pocket Monsters, I 5 5-I 67. London: Routledge.

Beattie, Scott. 2018. "Regulating Counterpublics in Yaoi Online Fan Communities," in Ashley Pearson, Thomas Giddens and Kieran Tranter (ed), Law and Justice in Japanese Popular Culture: From Crime Fighting Robots to Duelling Pocket Monsters, I68-182. London: Routledge.

Benedict, Ruth. 2006. The Chrysanthemum and the Sword: Patterns of Japanese Culture. Boston, MA: Mariner Books.

Bengo News. 20I9. "Akihabara ni adaruto gēmu no kyodai kōkoku Tōkyōto ga genchi chōsa, Chiyoda-ku wa shidō e," Bengo Dotto Komu Nyūsu, November I I. https://www.beng04.com/c_23/n_I0366/ (last accessed on May I 5, 202I)

Bergo, Bettina. 20 I I. "Emmanuel Levinas," Stanford Encyclopedia of Philosophy, August 3. plato.stanford.edu/entries/levinas/ (last accessed on May I 5, 202 I)

Bering, Jesse. 2013. Perv: The Sexual Deviant in All of Us. New York: Scientific American.

Berlant, Lauren. 2007. "Nearly Utopian, Nearly Normal: Post-Fordist Affect in La Promesse and Rosetta," Public Culture (19:2), 273-30I. DOI: https://doi.org/IO.I2 I 5/08992363-2006-036

Berlant, Lauren, and Michael Warner. I998. "Sex in Public," Critical Inquiry (24:2), 547-566. DOI: https://www.journals.uchicago.edu/doi/ıo.Io86 1448884

Berman, Marshall. 2009. On the Town: One Hundred Years of Spectacle in Times Square. New York: Verso. 
Bersani, Leo. I987. "Is the Rectum the Grave?” October (43), I97-222. DOI: https://doi.org/I0.2307/3397574

Biehl, João, and Peter Locke. 20ıо. "Deleuze and the Anthropology of Becoming," Current Anthropology (5 I:3), 3 I7-35 I. DOI: https://doi .org/IO.I086/65 I466

Biehl, João, and Torben Eskerod. 2007. Will to Live: AIDS Therapies and the Politics of Survival. Princeton, NJ: Princeton University Press.

Blumenthal, Dannielle. I997. Women and Soap Opera: A Cultural Feminist Perspective. New York: Praeger.

Bogost, Ian. 20I I. How to Do Things with Videogames. Minneapolis, MN: University of Minnesota Press.

Bourgois, Philippe, and Jeffrey Schonberg. 2009. Righteous Dopefiend. Berkeley, CA: University of California Press.

Bourne, Craig, and Emily Caddick Bourne. 2019. "Players, Characters, and the Gamer's Dilemma," Journal of Aesthetics and Art Criticism (77:2), I33-I43. DOI: https://doi.org/IO. I I I I/jaac. I 2634

boyd, danah. 20I4. It's Complicated: The Social Lives of Networked Teens. New Haven, CT: Yale University Press.

Brey, Philip. I999. "The Ethics of Representation and Action in Virtual Reality," Ethics and Information Technology (I), 5-I4. DOI: https://doi .org/IO.I023/A:I01006990746I

- 2008. "Virtual Reality and Computer Simulation," in Kenneth Einar Himma and Herman T. Tavani (ed), Handbook of Information and Computer Ethics, 36I-384. Hoboken, NJ: John Wiley and Sons.

Butler, Gavin. 2020. "Japanese Hentai is Now Banned in Australia," Vice, October 27. https://www.vice.com/en/article/xgz8md/japanese-hentai-is -now-banned-in-australia (last accessed on May I 5, 202 I)

Butler, Judith. 2009. Frames of War: When is Life Grievable? New York: Verso.

- 20I 5. Notes Toward a Performative Theory of Assembly. Cambridge, MA: Harvard University Press.

Cather, Kirsten. 201 2. The Art of Censorship in Postwar Japan. Honolulu, HI: University of Hawai'i Press.

Chödrön, Pema. 2008. Comfortable with Uncertainty: Io 8 Teachings on Cultivating Fearlessness and Compassion. Boston, MA: Shambhala.

Clements, Jonathan. 20I3. Anime: A History. New York: Palgrave. 
Clifford, James. I986. "Introduction: Partial Truths," in James Clifford and George E. Marcus (ed), Writing Culture: The Poetics and Politics of Ethnography, I-26. Berkeley, CA: University of California Press.

Clingenpeel, Zac. 202 r. "Ban Sale of Grand Theft Auto, Other Violent Video Games, State Rep Says," Chicago Sun-Times, February 22. https://chicago .suntimes.com/news/202 I/2/22/2229547 I/grand-theft-auto-illinois-ban -violent-video-games-carjackings-evans-operation-safe-pump (last accessed on May I 5, 202I)

Coleman, Gabriella. 2004 "The Political Agnosticism of Free and Open Source Software and the Inadvertent Politics of Contrast," Anthropological Quarterly (77:3), 507-5 19. DOI: https://www.jstor.org /stable/33I 8232

Comic Market Committee. 20I4. "What is Comic Market?" The Official Comic Market Site, January. http://www.comiket.co.jp/info-a/WhatIsEng 20I4OI.pdf (last accessed on May I 5, 202I)

Connell, Raewyn W. 2000. The Boys and the Men. Cambridge, United Kingdom: Polity Press.

Consalvo, Mia. 20I 2. "Confronting Toxic Gamer Culture: A Challenge for Feminist Game Studies Scholars," Ada: A Journal of Gender, New Media \& Technology (I:I). https://adanewmedia.org/20I 2/I I/issue I-consalvo/ (last accessed on May I 5, 202I)

Condry, Ian. 2013. The Soul of Anime: Collaborative Creativity and Japan's Media Success Story. Durham, NC: Duke University Press.

Coombe, Rosemary J. I998. "Contingent Articulations: A Critical Cultural Studies of Law," in Austin Sarat and Thomas R. Kearns (ed), Law in the Domains of Culture, 2I-64. Ann Arbor, MI: University of Michigan Press.

Cornell, Drucilla. 1995. The Imaginary Domain: Abortion, Pornography and Sexual Harassment. London: Routledge.

Coughlan, Matt. 2020. "Senator Calls for Child Abuse Anime Review," The Canberra Times, February 26. https://www.canberratimes.com.au/story $16650325 /$ senator-calls-for-child-abuse-anime-review/?fbclid=IwARoGvtf Lloj IcxtD6FGL2aJ2LnYifD 4cQNjwdNZw9A-oy5Y-8jl_jSjZAeA (last accessed on May I 5, 202I)

Das, Veena. 20I0. "Engaging the Life of the Other: Love and Everyday Life," in Michael Lambek (ed), Ordinary Ethics: Anthropology, Language, and Action, 376-399. New York: Fordham University Press.

Dave, Naisargi N. 20I0. "Between Queer Ethics and Sexual Morality," in Michael Lambek (ed), Ordinary Ethics: Anthropology, Language, and Action, 368-375. New York: Fordham University Press. 
Day, Sophie. 2010. "Ethics Between Public and Private: Sex Workers' Relationships in London," in Michael Lambek (ed), Ordinary Ethics: Anthropology, Language, and Action, 292-309. New York: Fordham University Press.

De Beauvoir, Simone. 20I 5. The Ethics of Ambiguity, Bernard Frechtman (trans). New York: Open Road Integrated Media.

Deigh, John. 20Iо. Cambridge Introductions to Philosophy: An Introduction to Ethics. Cambridge, United Kingdom: University of Cambridge Press.

Deleuze, Gilles, and Félix Guattari. I983. Anti-Oedipus: Capitalism and Schizophrenia, Robert Hurley, Mark Seem and Helen R. Lane (trans). Minneapolis, MN: University of Minnesota Press.

Dewey, Caitlin. 20I4. “The Only Guide to Gamergate You Will Ever Need to Read," The Washington Post, October I 4. https://www.washingtonpost .com/news/the-intersect/wp/20 I 4/Io/I 4/the-only-guide-to-gamergate-you -will-ever-need-to-read/?utm_term=.coecor $97392 \mathrm{c}$ (last accessed on May I 5,202 I)

Douglas, Mary. 1966. Purity and Danger: An Analysis of the Concepts of Pollution and Taboo. London: Routledge.

Dworkin, Andrea, and Catharine A. MacKinnon. I988. Pornography and Civil Rights: A New Day for Women's Equality. Minneapolis, MN: Organizing Against Pornography.

Dyer-Witheford, Nick, and Greig de Peuter. 2009. Games of Empire: Global Capitalism and Videogames. Minneapolis, MN: University of Minnesota Press.

Editors. I989. "Introduction: Otaku o shirazu shite 90 nendai wa katarenai," in Bessatsu Takarajima Henshūbu (ed), Bessatsu takarajima Io4 gō: Otaku no hon, 2-3. Tokyo: JICC shuppankyoku.

Ellison, Harlan. 20I3. "Harlan Ellison's Watching 28," October 8. https://www .youtube.com/watch?v=ujk_AFcZork (last accessed on May I 5, 202 I)

Ema, Arisa, Hiromitsu Hattori, Hirotaka Osawa and Naonori Akiya. 20I 5. "Ethics and Social Responsibility: Case Study of a Journal Cover Design Under Fire," Crossings, 93 5-940. DOI: https://dl.acm.org/doi/pdf/Io. I I 45 /2702613.2732809

Eng, Lawrence. 20I 2. "Strategies of Engagement: Discovering, Defining, and Describing Otaku Culture in the United States," in Mizuko Ito, Daisuke Okabe and Izumi Tsuji (ed), Fandom Unbound: Otaku Culture in a Connected World, 85-Io4. New Haven, CT: Yale University Press. 
Fassin, Didier. 2013. "Why Ethnography Matters: On Anthropology and Its Publics," Cultural Anthropology (28:4), 62 I-646. DOI: https://doi .org/IO.I I I I/cuan. I 2030

Felski, Rita. 2008. Uses of Literature. Oxford, United Kingdom: Blackwell Publishing. Press.

Fiennes, Sophie. 2006. The Pervert's Guide to Cinema. London: P Guide.

Fiske, John. 20I r. Television Culture. London: Routledge.

Flowers, Amy. 1998. The Fantasy Factory: An Insider's Guide of the Phone Sex Industry. Philadelphia, PA: University of Pennsylvania Press.

Foucault, Michel. 1988. Politics, Philosophy, Culture: Interviews and Other Writings, I977-1984. London: Routledge.

Freeman, Elizabeth. 2002. The Wedding Complex: Forms of Belonging in Modern American Culture. Durham, NC: Duke University Press.

Freud, Sigmund. 1962. Three Essays on the Theory of Sexuality. New York: Basic Books.

Fujimoto, Yukari. 1998. Watashi no ibasho wa doko ni aru no? Shōjo manga ga utsusu kokoro no katachi. Tokyo: Gakuyō shobō.

—_. 20I I. "Yūgai jōhō kisei o meguru mondai ni tsuite: Tojōrei kaiseian 'hijitsuzai seishōnen' kisei o chūshin ni," Hō to kompyūta (29), 27-43.

- 20I 5. "The Evolution of BL as 'Playing with Gender:' Viewing the Genesis and Development of BL from a Contemporary Perspective," in Mark McLelland, Kazumi Nagaike, Katsuhiko Suganuma and James Welker (ed), Boys Love Manga and Beyond: History, Culture, and Community in Japan, 76-92. Jackson, MI: University Press of Mississippi.

Furedi, Frank. 201 5. "The Moral Crusade Against Paedophilia," in Viviene E. Cree, Gary Clapton and Mark Smith (ed), Revisiting Moral Panics, 7-I 8. Bristol, United Kingdom: Policy Press.

Furusato, Takumi. 202I. "Derivative Content and Property Rights: How Does Fanfiction Work in the Anime and Manga Industry?" Anime News Network, March I 2. https://www.animenewsnetwork.com/feature/202 I -03-I 2/derivative-content-and-property-rights-how-does-fanfiction-work-in -the-anime-and-manga-industry/.I70398 (last accessed on May I 5, 202 I)

Gaiman, Neil. 2008. “The Word 'Person' Included Fictional or Imaginary Characters...” Neil Gaiman’s Journal, December 8. http://journal. 
neilgaiman.com/2008/I 2/word-person-included-fictional-or.html (last accessed on May I 5, 202I)

. 20I 2. "Child Porn Is A Crime," Twitter, June I 5. https://twitter.com /neilhimself/status/2I370780465 I962370 (last accessed on May I 5, 202 I)

Galbraith, Patrick W. 201 5. "Moe Talk: Affective Communication Among Female Fans of Yaoi in Japan," in Mark McLelland, Kazumi Nagaike, Katsuhiko Suganuma and James Welker (ed), Boys Love Manga and Beyond: History, Culture and Community in Japan, I 53-168. Jackson, MI: University Press of Mississippi.

- 20I7a. "RapeLay and the Return of the Sex Wars in Japan," Porn Studies (4:I), I05-I26. DOI: https://doi.org/IO.IO80/23268743.20I6.I 25 2I 59

- 20I7b. "AKB Business: Idols and Affective Economics in Contemporary Japan,” in Alisa Freedman and Toby Slade (ed), Introducing Japanese Popular Culture, I 5 8-167. London: Routledge.

- 2019. Otaku and the Struggle for Imagination in Japan. Durham, NC: Duke University Press.

Galbraith, Patrick W., and Jessica Bauwens-Sugimoto. 2020. “Translators' Introduction: Eromanga in the Global Now," in Nagayama Kaoru, Erotic Comics in Japan: An Introduction to Eromanga, I3-38. Amsterdam, Netherlands: University of Amsterdam Press.

Game Faqs. 2017. "Why are Japanese Games so Focused on Fetishism?" https://gamefaqs.gamespot.com/boards/691087-playstation-4/748054I4? page $=\mathrm{I} 2$ (last accessed on May I 5, 202 I )

Ganzon, Sarah Christina. 2019. "Growing the Otome Game Market: Fan Labor and Otome Game Communities Online," Human Technology (I 5:3), 347-366. DOI: https://doi.org/IO.I70I I/ht/urn.20 I9I I 265024

Garcia, Angela. 20I0. The Pastoral Clinic: Addiction and Dispossession along the Rio Grande. Berkeley, CA: University of California Press.

Gardner, Richard A. 2008. "Aum Shinrikyō and the Panic About Manga and Anime," in Mark W. MacWilliams (ed), Japanese Visual Culture: Explorations in the World of Manga and Anime, 200-2 I 8. Armonk, NY: M.E. Sharpe.

Geertz, Clifford. 1973. The Interpretation of Cultures. New York: Basic Books.

- 1989. Works and Lives: The Anthropologist as Author. Stanford, CA: Stanford University Press.

Gentile, Douglas A., Craig A. Anderson, Shintaro Yukawa, Nobuko Ihori, Muniba Saleem, Lim Kam Ming, Akiko Shibuya, Albert K. Liau, 
Angeline Khoo, Brad J. Bushman, L. Rowell Huesmann and Akira Sakamoto. 2009. "The Effects of Prosocial Video Games on Prosocial Behaviors: International Evidence from Correlational, Longitudinal, and Experimental Studies," Personality and Social Psychology Bulletin (35:6), 752-763. DOI: https://doi.org/IO.I I 77\% 2Fo I 46I 67209333045

Geraghty, Christine. I991. Women and Soap Opera: A Study of Prime Time Soaps. Cambridge, United Kingdom: Polity.

Gibson-Graham, J.K. 2006. A Postcapitalist Politics. Minneapolis, MN: University of Minnesota Press.

Gigguk. 20I7. “Eromanga Sensei: A Modern Masterpiece,” June 4. https:// www.youtube.com/watch?v=ohseORduMkM (last accessed on May I 5, 2O2I)

Gilbert, Ben. 2017. “The \$2,500 Answer to Amazon’s Echo Could Make Japan's Sex Crisis Even Worse,” Business Insider, December 3 I. http:// www.businessinsider.com/gatebox-ai-the-japanese-amazon-echo-photos -2016-I 2 (last accessed on May I 5, 202 I)

Graeber, David. 2004. Fragments of an Anarchist Anthropology. Chicago, IL: Prickly Paradigm Press.

Gravett, Paul. 2004. Manga: Sixty Years of Japanese Comics. London: Laurence King Publishing.

Grayson, Nathan. 20I9. “Two of Steam's Top Games Last Month Were Anime Sex Games,” Kotaku, August 20. https://kotaku.com/two-of-steams -top-games-last-month-were-anime-sex-games-I83738743 I (last accessed on May I 5, 202I)

Greenwood, Forrest. 2013. "A Spectral Pop Star Takes the Stage: Hatsune Miku and the Materialization of the Ephemeral in Contemporary Otaku Culture," Spectator: The University of Southern California Journal of Film and Television (33:I), IO-I7. DOI: https://cinema.usc.edu/spectator /33.I/2_Greenwood.pdf

- 20I4. "The Girl at the Center of the World: Gender, Genre, and Remediation in Bishōjo Media Works," in Frenchy Lunning (ed), Mechademia 9: Origins, 237-253. Minneapolis, MN: University of Minnesota Press.

Hack, Brett. 201 5. "Ominous Images of Youth: Worlds, Identities, and Violence in Japanese News Media and When They Cry," in Frenchy Lunning (ed), Mechademia IO: World Renewal, 236-250. Minneapolis, MN: University of Minnesota Press.

Hajdu, David. 2008. The Io-Cent Plague: The Great Comic-Book Scare and How It Changed America. New York: Picador. 
Halberstam, Judith. 20I I. The Queer Art of Failure. Durham, NC: Duke University Press.

Hall, Stuart. I987. “Gramsci and Us,” Marxism Today, June. http://www .banmarchive.org.uk/collections/mt/pdf/87_06_i6.pdf (last accessed on May I 5, 202I)

Hall, Stuart, Chas Critcher, Tony Jefferson, John Clarke and Brian Roberts. I978. Policing the Crisis: Mugging, the State, and Law and Order. London: Macmillan Press.

Hanhardt, Christina B. 20I3. Safe Space: Gay Neighborhood History and the Politics of Violence. Durham, NC: Duke University Press.

Harata, Shin'ichirō. 2006. “Vācharu ‘jidō poruno' kisei no ronri to 'moe' no rinri," Journal of Socio-Information Studies (I I:I), I09-I 20.

- 2008. "Jidō poruno hō wa 'moe' o sabakeru ka," Kokubungaku $(53: 16), 76-85$.

—. 20I I. "Vāchariti kisei no hōga: 'Jun jidō poruno' oyobi ‘hijitsuzai seishōnen' kisei ni tsuite," Information Network Law Review (Io), I 25-I34.

—. 20I 2. "Hyōgen kisei to vāchariti: 'Kakareta jidō gyakutai’ o meguru hō to rinri," Shizuoka daigaku jōhōgaku kenkyū (I7), I-I 2.

Haraway, Donna J. I988. "Situated Knowledges: The Science Question in Feminism and the Privilege of Partial Perspective," Feminist Studies ( I 4:3), 575-599. DOI: https://doi.org/I0.2307/3 I 78066

- I99I. Simians, Cyborgs, and Women: The Reinvention of Nature. London: Routledge.

Hardt, Michael. I999. “Affective Labor," boundary 2 (26:2), 89-Io0.

Harrington, C. Lee, and Denise D. Bielby. I995. Soap Fans: Pursing Pleasure and Making Meaning in Everyday Life. Philadelphia, PA: Temple University Press.

Hasegawa, Kazumi. 20I3. "Falling in Love with History: Japanese Girls' Otome Sexuality and Queering Historical Imagination," in Matthew Wilhelm Kapell and Andrew B.R. Elliott (ed), Playing the Past: Digital Games and the Simulation of History, I3 5-I 50. London: Bloomsbury.

Hayakawa, Kiyoshi, Yamazaki Ryū, Kimata Naohiro, Shimizu Ginrei and Satō Kaede. 2008. Meido kissa de aimashō. Tokyo: Āruzu shuppan.

Hebdige, Dick. I979. Subculture: The Meaning of Style. London: Methuen Publishing. 
Hellmann, Melissa. 20 4 4 “Japan Finally Bans Child Pornography,” Time, June I 8. http://time.com/2892728/japan-finally-bans-child-pornography/ (last accessed on May I 5, 202 I)

Hemmings, Clare. 2005. "Invoking Affect: Cultural Theory and the Ontological Turn," Cultural Studies (I9:5), 548-567. DOI: https://doi.org /IO.1080/09502380500365473

Hinton, Perry R. 20I4. "The Cultural Context and the Interpretation of Japanese 'Lolita Complex' Style Anime," Intercultural Communication Studies (23:2), 54-68. DOI: https://www-s3-live.kent.edu/s 3 fs-root/s 3 fs -public/file/Perry-R-Hinton.pdf

Hiruma, Takashi. 20I9. "Akihabara no kōkoku mondai no kachū demo senden wa zokkō 'Motto! Haramase! Honoo no oppai chō ero apuri gakuen' no tanryoku no tsuyosa," Otapol, November 20. https://otapol.com/2019 /I I/post-8 573 I.html (last accessed on May I 5, 202 I)

Hochschild, Arlie Russell. 2016. Strangers in Their Own Land: Anger and Mourning on the American Right. New York: The New Press.

Hofmann, Jennifer-Naomi. 2017. "Translation as Activism: An Interview with Philip Boehm," Literary Hub, March 6. https://lithub.com/translation -as-activism-an-interview-with-philip-boehm/ (last accessed on May I 5, 202I)

Honda, Tōru. 2005. Moeru otoko. Tokyo: Chikuma shobō.

Honda, Tōru, and Yanashita Ki'ichirō. 2008. "Tokubetsu taidan: 'Jiken o okoshita koto igai, hotondo boku to issho nan desu," in Yōsensha Mook Henshūbu (ed), Akiba jiken o dō yomu ka!? 68-73. Tokyo: Yōsensha.

Horkheimer, Max, and Theodor Adorno. 2002. "The Culture Industry: Enlightenment as Mass Deception," in Edmund Jephcott (trans), Gunzelin Schmid Noerr (ed), Dialectic of Enlightenment: Philosophical Fragments, 94-I36. Stanford, CA: Stanford University Press.

Howard, Christopher. 20I4. "The Ethics of Sekai-kei: Reading Hiroki Azuma with Slavoj Žižek," Science Fiction Film and Television (7:3), 365-386.

DOI: https://doi.org/I0.3828/sfftv.20I4.2I

Hutchinson, Rachael. 20I9. Japanese Culture Through Videogames. London: Routledge.

Ingold, Tim. 20I I. Being Alive: Essays on Movement, Knowledge and Description. London: Routledge.

Inforest. 2005. Meido-san taizen. Tokyo: Inforest Co., Ltd. 
Ishida, Minori. 2019. "Sounds and Sighs: 'Voice Porn' for Women,” in Jaqueline Berndt, Kazumi Nagaike and Fusami Ogi (ed), Shōjo Across Media: Exploring 'Girl' Practices in Contemporary Japan, 283-299. New York: Palgrave.

IT Media. 20I 8. “'Ai shiteiru node:' 2-jigen kyara to 'honki no kyoshiki,' 30-dai dansei no kattō," August I6. http://www.itmedia.co.jp/news/articles /I 808/I 6/newso22.html (last accessed on May I 5, 202 I)

Ito, Mizuko. 2008. "Mobilizing the Imagination in Everyday Play: The Case of Japanese Media Mixes," in Kirsten Drotner and Sonia Livingstone (ed), The International Handbook of Children, Media and Culture, 397-4 I 2. London: Sage Publications.

- 20I 2. "Introduction," in Mizuko Ito, Daisuke Okabe and Izumi Tsuji (ed), Fandom Unbound: Otaku Culture in a Connected World, xi-xxxi. New Haven, CT: Yale University Press.

Iwabuchi, Koichi. 2010. "Undoing Inter-national Fandom in the Age of Brand Nationalism," in Frenchy Lunning (ed), Mechademia 5: Fanthropologies, 87-96. Minneapolis, MN: University of Minnesota Press.

Jacobs, Katrien. 2012. People's Pornography: Sex and Surveillance on the Chinese Internet. Chicago, IL: University of Chicago Press.

Japan Times. 2016. “Japan's Porn Industry Preys on Young Women: Activists," March 4. https://web.archive.org/web/20160306103205if_/, http://www.japantimes.co.jp/news/201 6/03/o4/national/social-issues /rights-group-japan-needs-law-moves-force-young-women-appear-porn -videos/\#.VtwHLuvLfBU (last accessed on May I 5, 202 I)

- 2019. "Deputy PM Taro Aso Apologizes After Blaming Childless for Rising Social Security Costs and Graying Population,” February 5. https:// web.archive.org/web/20I90205 I 82954if_/, https:/www.japantimes.co.jp /news/2019/02/05/national/taro-aso-blames-women-not-having-babies/\# .XFnWNevLfBU (last accessed on May I 5, 202 I)

Jenkins, Henry, Ravi Purushotma, Margaret Weigel, Katie Clinton and Alice J. Robison. 2009. Confronting the Challenges of Participatory Culture: Media Education for the 2 st Century. Cambridge, MA: MIT Press.

Jones, Anna Maria. 20I3. "The Victorian Childhood of Manga: Toward a Queer Theory of the Child in Toboso Yana's Kuroshitsuji," Criticism (5 5:I), I-4I. DOI: https://doi.org/IO.I3 I Io/criticism.5 5.I.OOOI

Kagami, Hiroyuki. 2oı Hijitsuzai seishōnen ron: Otaku to shihonshugi. Tokyo: Ai'ikusha. 
Kain, Erik. 20 I 5. "The Top Ten Best-Selling Video Games of 2014," Forbes, January I9. https://www.forbes.com/sites/erikkain/20I 5/OI/I 9/the-top-ten -best-selling-video-games-of-20 I 4/\# 5 b8 cb 5 f68 2cf (last accessed on May I 5, 202 I)

Kam, Thiam Huat. 20Iza. “The Anxieties that Make the 'Otaku': Capital and the Common Sense of Consumption in Contemporary Japan,” Japanese Studies (33:I), 39-6I. DOI: https://doi.org/Io.Io80/I037I397 .2013 .768336

. 2013b. "The Common Sense that Makes the 'Otaku:' Rules for Consuming Popular Culture in Contemporary Japan," Japan Forum (25:2), I 5 I-I73. DOI: https://doi.org/IO.IO8O/O95 55803.20 I 2.74348 I

- 20I 5. “'Otaku' as Label: Concerns over Productive Capacities in Contemporary Capitalist Japan,” in Patrick W. Galbraith, Thiam Huat Kam and Bjoern-Ole Kamm (ed), Debating Otaku in Contemporary Japan: Historical Perspectives and New Horizons, I79-I95. London: Bloomsbury.

Katayama, Lisa. 2009. "Love in 2-D," The New York Times Magazine, July 2I. http://www.nytimes.com/2009/07/26/magazine/26FOB-2DLove-t .html?_r=o (last accessed on May I 5, 202I)

Katō, Kenta, Kanō Masayoshi, Yamada Kōji and Nakamura Tsuyoshi. 20 I 4. "Robotto apiaransu ni okeru 'moe' no dezain kentō," 3 oth Fuzzy System Symposium, Kōchi Prefecture, Japan, September I-3. https://www.jstage .jst.go.jp/article/fss/30/o/30_I/_pdf (last accessed on May I 5, 202I)

Kelly, William W. 2004. "Introduction: Locating the Fans," in William W. Kelly (ed), Fanning the Flames: Fans and Consumer Culture in Contemporary Japan, I-I6. Albany, NY: State University of New York Press.

Kelty, Chris. 2005. "Geeks, Social Imaginaries, and Recursive Publics," Cultural Anthropology (20:2), I85-2I4. DOI: https://doi.org/IO.I 525 /can.2005.20.2.I 85

Kijima, Yoshimasa. 20I 2a. “The Fighting Gamer Otaku Community: What Are They 'Fighting' About?" in Mizuko Ito, Daisuke Okabe and Izumi Tsuji (ed), Fandom Unbound: Otaku Culture in a Connected World, 249-274. New Haven, CT: Yale University Press.

. 20I2b. "Why Make E-moe-tional Attachments to Fictional Characters? The Cultural Sociology of the Post-Modern,” Leonie R. Stickland (trans), in Katsuya Minamida and Izumi Tsuji (ed), Pop Culture and the Everyday in Japan: Sociological Perspectives, I49-I70. Melbourne, Australia: Trans Pacific Press. 
Kikuchi, Satoru. 2008. "'Otaku' sutereotaipu no hensen to Akihabara burando," Chi'iki burando kenkyū (4), 47-78.

Kim, Hyeshin. 2009. "Women's Games in Japan: Gendered Identity and Narrative Construction,” Theory, Culture \& Society (26: 2-3), I65-188. DOI: https://doi.org/IO.II77\% 2Fo263276409103132

Kincaid, James. I998. Erotic Innocence: The Culture of Child Molesting. Durham, NC: Duke University Press.

Kinsella, Sharon. I995. "Cuties in Japan," in Lise Skov and Brian Moeran (ed), Women, Media, and Consumption in Japan, 220-254. Honolulu, HI: University of Hawai'i Press.

- 2000. Adult Manga: Culture and Power in Contemporary Japanese Society. Honolulu, HI: University of Hawai'i Press.

- 2006. “Minstrelized Girls: Male Performers of Japan’s Lolita Complex,” Japan Forum ( I 8:I), 65-87. DOI: https://doi.org/Io.1080 lo95558005004983I9

Kipnis, Laura. I996. Bound and Gagged: Pornography and the Politics of Fantasy in America. New York: Grove Press.

Kjeldgaard-Christiansen, Jens. 2020. "Splintering the Gamer's Dilemma: Moral Intuitions, Motivational Assumptions, and Action Prototypes," Ethics and Information Technology (22), 93-IO2. DOI: https://link.springer .com/article/IO. I007/sI0676-0I9-095 I 8-X

Kohn, Eduardo. 20I3. How Forests Think: Toward an Anthropology Beyond the Human. Berkeley, CA: University of California Press.

Koide, Chitoko, and Obana Takashi. 20 I 8. “'Otome gēmu’ no rekishi-teki kenkyū: Kyarakutā bunseki o chūshin ni,” Ōsaka shōin joshi daigaku kenkyū kiyō (8), 69-74.

Kopits, Steven. 20I7. “Japan’s Demographic Crisis Will Only Get Worse,” National Interest, July I9. https://nationalinterest.org/feature/japans -demographic-crisis-will-only-get-worse-heres-why-2 I 594 (last accessed on May I 5, 202I)

Kulick, Don. 2005 "Porn," in Don Kulick and Anne Meneley (ed), Fat: The Anthropology of an Obsession, 77-92. New York: Penguin Books.

Kulick, Don, and Jens Rydström. 20I 5. Loneliness and Its Opposite: Sex, Disability, and the Ethics of Engagement. Durham, NC: Duke University Press.

Kumi, Kaoru. 2016. "Who Are We Kidding: Subliminal Child-Porn Images in Japanese Manga and Anime," Animation World Network, January 25. http:/www.awn.com/print/animationworld/who-are-we-kidding 
-subliminal-child-porn-images-japanese-manga-and-anime (last accessed on May I 5, 202I)

Kuro-Mac. 20I 2. "'Mado magi’ kyakuhonshō Urobuchi Gen-san komento," Kuro makku no boyaki, February 2I. https://gold.ap.teacup.com/multitudo /I006.html (last accessed on May I 5, 202I)

Lah, Kyung. 20Iо. “'RapeLay’ Video Game Goes Viral Amid Outrage,” CNN, March 30. http://www.cnn.com/20Io/WORLD/asiapcf/o3/30/japan .video.game.rape/ (last accessed on May I 5, 202I)

Lamarre, Thomas. 2006. "Otaku Movement," in Tomiko Yoda and Harry Harootunian (ed), Japan After Japan: Social and Cultural Life from the Recessionary I990s to the Present, 358-394. Durham, NC: Duke University Press.

- 2009. The Anime Machine: A Media Theory of Animation. Minneapolis, MN: University of Minnesota Press.

- 201 5. "Regional TV: Affective Media Geographies," Asiascape: Digital Asia (2), 93-I26. DOI: https://doi.org/IO.I I63/22I423 I 2 -I 234002 I

Lambek, Michael. 20ı0a. "Introduction," in Michael Lambek (ed), Ordinary Ethics: Anthropology, Language, and Action, I-38. New York: Fordham University Press.

. 20Iob. "Toward an Ethics of the Act," in Michael Lambek (ed), Ordinary Ethics: Anthropology, Language, and Action, 39-63. New York: Fordham University Press.

- 20I 5 a. The Ethical Condition: Essays on Action, Person, and Value. Chicago, IL: University of Chicago Press.

. 20I 5 b. "On the Immanence of the Ethical: A Response to Michael Lempert, 'No Ordinary Ethics,'” Anthropological Theory (I 5:2), I 28-I32. DOI: https://doi.org/IO.I I77\% \%2FI46349961 5576628

Lamerichs, Nicolle. 20I 4a. "Embodied Fantasy: The Affective Space of Anime Conventions," in Linda Duits, Koos Zwaan and Stijn Reijnders (ed), The Ashgate Research Companion to Fan Cultures, 263-274. Surrey, United Kingdom: Ashgate Publishing.

- 20I4b. "Romancing Pigeons: The Deconstruction of the Dating-Sim in Hatoful Boyfriend," Well Played (3:2), 43-6I. DOI: https:// doi.org/IO.II $84 / \mathrm{RI}_{\text {I }} 66870$ I 7

Laycock, Joseph P. 201 5. Dangerous Games: What the Moral Panic over Role-Playing Games Says about Play, Religion, and Imagined Worlds. Oakland, CA: University of California Press. 
Leheny, David. 2006. Think Global, Fear Local: Sex, Violence, and Anxiety in Contemporary Japan. Ithaca, NY: Cornell University Press.

Lenoir, Tim. 2000. “'All but War is Simulation:' The Military-Entertainment Complex," Configurations (8), 289-335. DOI: https://web.stanford.edu /dept/HPST/TimLenoir/Publications/Lenoir_AllButWarIsSimulation.pdf

Leonard, Sean. 2005. "Progress Against the Law: Anime and Fandom, With the Key to the Globalization of Culture," International Journal of Cultural Studies (8:3), 28 I-305. DOI: https://doi.org/IO.I I 77\% 2FI367877905055679

Lessig, Lawrence. 2004. Free Culture: The Nature and Future of Creativity. New York: Penguin Books.

Levinas, Emmanuel. I969. Totality and Infinity: An Essay on Exteriority, Alphonso Lingis (trans). Pittsburgh, PA: Duquesne University Press.

Levy, Neil. 2002. "Virtual Child Pornography: The Eroticization of Inequality," Ethics and Information Technology (4), 319-323. DOI: https://link.springer.com/article/IO.I023/A:I02I37260I 566

Luck, Morgan. 2009. “The Gamer's Dilemma: An Analysis of the Arguments for the Moral Distinction Between Virtual Murder and Virtual Paedophilia," Ethics and Information Technology ( I I), 3 I-36. DOI: https://link.springer.com/article/ıo.I007/sı0676-008-9I68-4

- 2018. "Has Ali Dissolved the Gamer's Dilemma?" Ethics and Information Technology (20), I 57-I62. DOI: https://doi.org/I0.I007 /sio676-oi 8-9455-7

Luck, Morgan, and Nathan Ellerby. 20I3. "Has Bartel Resolved the Gamer's Dilemma?" Ethics and Information Technology (I 5), 229-233. DOI: https://doi.org/IO.I007/sI0676-OI3-9322-5

MacKinnon, Catharine A. I982. "Feminism, Marxism, Method, and the State: An Agenda for Theory," Signs: Journal of Women in Culture and Society (7:3), 5 I 5-544. DOI: https://www.journals.uchicago.edu/doi labs/ıo. I086/493898

—. I993. Only Words. Cambridge, MA: Harvard University Press.

-. I997. "Sexuality," in Linda Nicholson (ed), The Second Wave: A Reader in Feminist Theory, I 58-180. London: Routledge.

Maggs, Sam. 20I 5. "I Give Up: Soulcalibur: Lost Swords Hires Hentai Artist to Design Female 'Armor,'” The Mary Sue, February 26. http://www.the marysue.com/lost-sword-hentai-armor/ (last accessed on May I 5, 202 I) 
Maher, Bill. 2020. "Robosexuals," Real Time with Bill Maher, HBO, February I4. https://www.youtube.com/watch?v=fHZMj5 PXyBE\&feature=youtu.be\&fbclid=IwAR2_gQAE_Lg8TKgLSkRcdIiyko ZzjTfybpcnQ_PnTlr-eDxO9oxOwmYc37s (last accessed on May I 5, 202 I)

Malinowski, Bronisław. 1989. A Diary in the Strict Sense of the Term, Norbert Guterman (trans). Stanford, CA: Stanford University Press.

-20I4. Argonauts of the Western Pacific: An Account of Native Enterprise and Adventure in the Archipelagoes of Melanesian New Guinea. London: Routledge.

Markey, Patrick M., and Christopher J. Ferguson. 2017. Moral Combat: Why the War on Violent Video Games is Wrong. Dallas, TX: BenBella Books.

Mäyrä, Frans. 2008. An Introduction to Game Studies: Games in Culture. London: Sage.

Mazzarella, William. 20I3. Censorium: Cinema and the Open Edge of Mass Publicity. Durham, NC: Duke University Press.

McCloud, Scott. I994. Understanding Comics: The Invisible Art. New York: Harper Perennial.

- 2000. Reinventing Comics: How Imagination and Technology Are Revolutionizing an Art Form. New York: Harper Perennial.

McCormick, Matt. 200I. "Is It Wrong to Play Violent Video Games?” Ethics and Information Technology (3), 277-287. DOI: https://doi.org/I0.1023 /A:IOI3802II943 I

McGee, Oona. 2019. "This Japanese Man Dated a Cockroach, Dreamed of Having Sex with It,” Sora News, January 27. https://soranews24.com /20I9/OI/27/this-japanese-man-dated-a-cockroach-and-dreamed-of-having -sex-with-it-\% $\%$ \% $80 \%$ 9ovideo $\% \mathrm{E}_{3} \% 80 \%$ I / (last accessed on May I 5 , 202I)

McGlotten, Shaka. 2013. Virtual Intimacies: Media, Affect, and Queer Sociality. Albany, NY: State University of New York Press.

McLelland, Mark. 2005. "The World of Yaoi: The Internet, Censorship and the Global 'Boys' Love' Fandom,” Australian Feminist Law Journal (32), 6I-77. DOI: https://doi.org/IO.IO80/I3200968.2005.I0854344

- 20I I. "Thought Policing or the Protection of Youth? Debate in Japan Over the 'Non-existent Youth Bill,', International Journal of Comic Art (I3:I), 348-367. DOI: https://ro.uow.edu.au/artspapers/260/

_. 201 2. "Australia's 'Child-Abuse Material' Legislation, Internet Regulation and the Juridification of the Imagination," International 
Journal of Cultural Studies (I 5:5), 467-483. DOI: https://doi.org /IO.II77\% 2FI3678779II42I082

- 2017. "Introduction: Negotiating 'Cool Japan' in Research and Teaching," in Mark McLelland (ed), The End of Cool Japan: Ethical, Legal, and Cultural Challenges to Japanese Popular Culture, I-30. London: Routledge.

Meyers, Chris. 2009. "Japanese Man Takes Video Game Character as Wife," Reuters, December 2I. https://www.reuters.com/article/us-japan-videogame -idUSTRE 5 BJiXX2009I 220 (last accessed on May I 5, 202I)

Minotti, Mike. 2016. "How Keiji Inafune's ReCore Prizes Color and Cute Robots Over Realism and Blood," Venture Beat, June 28. http://venture beat.com/20I 6/06/28/keiji-inafune-on-how-recore-gives-the-xbox-one-a -dose-of-japanese-flavor/ (last accessed on May I 5, 202I)

Mitchell, W.J.T. 2005. What Do Pictures Want? The Lives and Loves of Images. Chicago, IL: University of Chicago Press.

Mizuho. 20I4. "Kontentsu sangyō no tenbō: Kontentsu sangyō no sara naru hatten no tame ni," Mizuho sangyō chōsa.

Moberg, Mark. 2013. Engaging Anthropological Theory: A Social and Political History. London: Routledge.

Modleski, Tania. 1982. Loving with a Vengeance: Mass Produced Fantasies for Women. Hamden, CT: Archon Books.

- I983. "The Rhythms of Reception: Daytime Television and Women's Work," in E. Ann Kaplan (ed), Regarding Television: Critical Approaches, 67-75. Los Angeles: American Film Institute.

Mori, Akio. 2002. Gèmu nō no kyōfu. Tokyo: NHK shuppan.

Mori, Kurumi, Emi Nobuhiro and Kae Inoue. 20I 8. "Moms Continue to Face Hurdles Returning to Work as Abe Wavers on Day Care and Women's Empowerment Goals," The Japan Times, October 4. https:// www.japantimes.co.jp/news/201 8/10/04/business/moms-continue-face -hurdles-returning-work-abe-wavers-day-care-womens-empowerment -goals/\#.XF5irNFS_fY (last accessed on May I 5, 202I)

Morikawa, Ka'ichirō. 2003. Shuto no tanjō: Moeru toshi Akihabara. Tokyo: Gentōsha.

- 2008. Zōho shuto no tanjō: Moeru toshi Akihabara. Tokyo: Gentōsha.

Mukaiyachi, Ikuyoshi. 2006. Anshin shite zetsubō dekiru jinsei. NHK shuppan. 
Mulvey, Laura. 2009. "Visual Pleasure and Narrative Cinema," in Visual and Other Pleasures, I4-26. New York: Palgrave.

Nader, Karim. 2020. "Virtual Competitions and the Gamer's Dilemma," Ethics and Information Technology (22), 239-245. DOI: https://link .springer.com/article/IO.I007/sI0676-020-09532-4

Nagaoka, Yoshiyuki. 20Iо. Manga wa naze kisei sareru no ka: "Yūgai" o meguru hanseiki no kōbō. Tokyo: Heibonsha.

Nagayama, Kaoru. 20I4. Zōho eromanga sutadiizu: "Kairaku sōchi” toshite no manga nyümon. Tokyo: Chikuma bunko.

Nakamura, Karen. 2013. A Disability of the Soul: An Ethnography of Schizophrenia and Mental Illness in Contemporary Japan. Ithaca, NY: Cornell University Press.

Nakasatomi, Hiroshi. 2013. "RapeLay' and the Problem of Legal Reform in Japan," Caroline Norma (trans), Electronic Journal of Contemporary Japanese Studies ( I 2:3). http://www.japanesestudies.org.uk/ejcjs/vol I 2 /iss 3/nakasatomi.html (last accessed on May I 5, 202I)

Nascimento-Lajoie, Alexis. 20I6. "Female Japanese Representative Refutes UN Suggestion to Ban Media Depicting Sexual Violence,” Niche Gamer, March I. http://nichegamer.com/2016/o3/japanese-representative-refutes -un-suggestion-to-ban-media-depicting-sexual-violence/ (last accessed on May I 5, 202 I)

Navaro-Yashin, Yael. 20 2. The Make-Believe Space: Affective Geography in a Postwar Polity. Durham, NC: Duke University Press.

Ngai, Sianne. 2005. "The Cuteness of the Avant-Garde," Critical Inquiry (3 I:4), 8 I I-847. DOI: https://www.journals.uchicago.edu/doi/Io.Io86/4445 I6

- 201 2. Our Aesthetic Categories: Zany, Cute, Interesting. Cambridge, MA: Harvard University Press.

Nihon Keizai Shimbun. 20I I. "Moe-kei da kedo kakoku: Anime 'Madoka Magika' no kata yaburi seisakusha ga kataru hitto no himitsu," August I I. http://www.nikkei.com/article/DGXNASFKo3о M _UIA800CI000000/?df=2 (last accessed on May I 5, 202I)

Novak, David. 2013. Japanoise: Music at the Edge of Circulation. Durham, NC: Duke University Press.

Okabe, Tsugumi, and Jérémie Pelletier-Gagnon. 2019. "Playing with Pain: The Politics of Asobigokoro in Enzai Falsely Accused," Journal of the Japanese Association for Digital Humanities (4:I), 37-53. DOI: https:// doi.org/IO.I7928/jjadh.4.I_37 
Okada, Toshio, Morikawa Ka'ichirō and Murakami Takashi. 2005. "Otaku Talk," in Murakami Takashi (ed), Little Boy: The Arts of Japan's Exploding Subculture, I65-1 85 . New Haven, CT: Yale University Press.

O’Mara, Sean, and Matt Schley. 20I 5. “'Tentacle Master' Toshio Maeda: The Hentai Manga Pioneer Explains Why He Thinks Moe is for Perverts," Otaku USA, September 28. http://otakuusamagazine.com/Manga/News I /Interview-Tentacle-Master-Toshio-Maeda-6904.aspx (last accessed on May I 5, 202I)

Ortega-Brena, Mariana. 2009. "Peek-a-boo, I See You: Watching Japanese Hard-Core Animation," Sexuality \& Culture (I3), I7-3 I.

Ost, Suzanne. 2009. Child Pornography and Sexual Grooming: Legal and Societal Responses. Cambridge, United Kingdom: Cambridge University Press.

Ostrovsky, Simon. 20I 5. "Schoolgirls for Sale in Japan,” Vice News, July 20. https://news.vice.com/video/schoolgirls-for-sale-in-japan (last accessed on May I 5, 202I)

Oswell, David. 2006. "When Images Matter: Internet Child Pornography, Forms of Observation and an Ethics of the Virtual," Information, Communication and Society (9:2), 244-265. DOI: https://doi.org /I0.1080/I3691 I 80600630807

Ōtsuka, Eiji. 2003. Kyarakutā shōsetsu no tsukurikata. Tokyo: Kōdansha.

- 2004. "Otaku” no seishin shi: I980 nendai ron. Tokyo: Kōdansha gendai shinsho.

- 20I 5. "Otaku Culture as 'Conversion Literature,” Patrick W. Galbraith (trans), in Patrick W. Galbraith, Thiam Huat Kam and BjoernOle Kamm (ed), Debating Otaku in Contemporary Japan: Historical Perspectives and New Horizons, xii-xxix. London: Bloomsbury.

Ōtsuka, Eiji, and Nakamori Akio. I989a. "Bokura wa media no kodomo da," in Ōta Shuppan Henshūbu (ed), M no sedai: Bokura to Miyazaki-kun, I3-98. Tokyo: Ōta shuppan.

I989b. "Kimi to boku niwa, mirai ga aru," in Ōta Shuppan Henshūbu (ed), M no sedai: Bokura to Miyazaki-kun, I76-257. Tokyo: Ōta shuppan.

Paasonen, Susanna. 20I I. Carnal Resonance: Affect and Online Pornography. Cambridge, MA: MIT Press.

- 2018. "The Affective and Affectless Bodies of Monster Toon Porn," in Paul G. Nixon and Isabel K. Düsterhöft (ed), Sex in the Digital Age, Io-24. London: Routledge. 
Patridge, Stephanie L. 20 I I. "The Incorrigible Social Meaning of Video Game Imagery," Ethics and Information Technology (13), 303-3 I2. DOI: https://link.springer.com/article/Io.1007/sı0676-0I0-9250-6

- 2013. "Pornography, Ethics, and Video Games," Ethics and Information Technology (I 5), 25-34. DOI: https://link.springer.com/article /IO.I007/sI0676-OI2-93 IO-I

Pearson, Ashley, Thomas Giddens and Kieran Tranter. 2018. Law and Justice in Japanese Popular Culture: From Crime Fighting Robots to Duelling Pocket Monsters. London: Routledge.

Pelletier-Gagnon, Jérémie, and Martin Picard. 20 I 5. "Beyond RapeLay: Self-Regulation in the Japanese Erotic Video Game Industry," in Matthew Wysocki and Evan W. Lauteria (ed), Rated M for Mature: Sex and Sexuality in Video Games, 28-4I. London: Bloomsbury.

Pigg, Stacy Leigh. 20 2. "Sexuality," in Didier Fassin (ed), A Companion to Moral Anthropology, 320-338. Hoboken, NJ: John Wiley and Sons.

Pineda, Rafael Antonio. 2020. "J-Novel Club: Amazon Delists Some Light Novels, Manga on Kindle," Anime News Network, July I4. https://www .animenewsnetwork.com/news/2020-07-I 4/j-novel-club-amazon-delists -some-light-novels-manga-on-kindle/.I6I 802 (last accessed on May I 5 , 202I)

Pink, Daniel H. 2007. “Japan, Ink: Inside the Manga Industrial Complex," Wired, October 22. http://www.wired.com/techbiz/media/magazine/I 5-I I /ff_manga (last accessed on May I 5, 202I)

Pittman, Matthew, and Tom Bivin. 20I6. "Just War Craft: Virtue Ethics and DotA," in Amber Davisson and Paul Booth (ed), Controversies in Digital Ethics, 9 I-I06. London: Bloomsbury.

Plourde, Lorraine. 2014. "Cat Cafés, Affective Labor, and the Healing Boom in Japan," Japanese Studies (34:2), I I 5-I33. DOI: https://doi.org/IO.IO80 /I037I397.20I4.928I 83

Popovic, Miodrag. 2007. "Establishing New Breeds of (Sex) Offenders:

Science or Political Control?" Sexual and Relationship Therapy (22:2), 255-27I. DOI: https://doi.org/IO.I080/I468 I99060I I I0850

Prostasia. 2020. “A Welcome Victory in Canada,” Prostasia Newsletter \#27, October I. https://prostasia.org/newsletter/?email_id=74 (last accessed on May I 5, 202I)

Prough, Jennifer. 20I I. Straight from the Heart: Gender, Intimacy, and the Cultural Production of Shōjo Manga. Honolulu, HI: University of Hawai'i Press. 
Richards, Tina. 201 5. "Tokimeki Memorial Girl's Side: Enacting Femininity to Avoid Dying Alone," ToDigra (2:I), IOI-I27. DOI: http://todigra.org /index.php/todigra/article/view/43/88

Riles, Annelise. 20I 2. "Response: Power and Truth in Japanese Ethnography," HAU: Journal of Ethnographic Theory (2:2). https:/www .journals.uchicago.edu/doi/full/IO.I43 I8/hau2.2.02 I (last accessed on May I 5, 202I)

Ripley, Will, Hilary Whiteman and Edmund Henry. 20I4. "Sexually Explicit Japan Manga Evades New Laws on Child Pornography," CNN, June I 8. http://edition.cnn.com/20I4/06/I 8/world/asia/japan-manga-anime-porno graphy/ (last accessed on May I 5, 202I)

Roe, Mike. 201 8. "Fans Mourn Sci-Fi Legend Harlan Ellison,” LAist, June 28. http://www.laist.com/20I8/06/28/fans_mourn_sci-fi_legend_harlan _ellison.php (last accessed on May I 5, 202 I)

Ruberg, Bonnie. 20I 5. "No Fun: The Queer Potential of Video Games that Annoy, Anger, Disappoint, Sadden, and Hurt," QED: A Journal of GLBTQ Worldmaking (2:2), I08-I24. DOI: https:/doi.org/IO.I432 I /qed.2.2.0108

Rubin, Gayle S. 20I I. Deviations: A Gayle Rubin Reader. Durham, NC: Duke University Press.

Russell, Diana. I993. "Pornography and Rape: A Causal Model," in Diana Russell (ed), Making Violence Sexy: Feminist Views on Pornography, I 20-I 50. New York: Teachers College Press.

Rutherford, Danilyn. 20г 2. "Kinky Empiricism," Cultural Anthropology (27:3), 465-479. DOI: https://doi.org/IO.I I I I/j. I 548-I360.20 I 2.OI I 54.X

Ryall, Julian. 20I 5. "Valentine’s Day: Single Japanese Men Protest 'Chocolate-Giving Arms Race,'” The Telegraph, February I4. http://www .telegraph.co.uk/news/worldnews/asia/japan/I I 4 I 30 I 8/Valentines -Day-single-Japanese-men-protest-chocolate-giving-arms-race.html (last accessed on May I 5, 202 I)

Saitō, Tamaki. 2007. “Otaku Sexuality,” Christopher Bolton (trans), in Christopher Bolton, Stan Csiscery-Ronay Jr. and Takayuki Tatsumi (ed), Robot Ghosts and Wired Dreams: Japanese Science Fiction from Origins to Anime, 222-249. Minneapolis, MN: University of Minnesota Press.

- 20I I. Beautiful Fighting Girl, J. Keith Vincent and Dawn Lawson (trans). Minneapolis, MN: University of Minnesota Press.

Saitō, Tamaki, and Jō Shigeyuki. 20I4. "Nihon no kigyō bunka to 'kokoro no yamai," Ushio (6), I 50-I 57. 
Sakai, Naoki. I997. Translation and Subjectivity: On "Japan" and Cultural Nationalism. Minneapolis, MN: University of Minnesota Press.

Sakakibara, Hiroki. 20I6. "Eroge gyōkai eroge no uriage ga nobinayamu igai na riyū towa??” Raku Job, January 23. http://raku-job.jp/news/companyrep /8705/ (last accessed on May I 5, 202 I)

Saler, Michael. 20I2. As If: Modern Enchantment and the Literary Prehistory of Virtual Reality. Oxford, United Kingdom: Oxford University Press.

Salter, Anastasia, and Bridget Blodgett. 2017. Toxic Geek Masculinity in Media: Sexism, Trolling, and Identity Policing. New York: Palgrave.

Sarkeesian, Anita. 20I4. "Women as Background Decoration: Part I," Feminist Frequency, June I6. https://www.youtube.com/watch?v=4 ZPSrwedvsg (last accessed on May I 5, 202I)

Sasakibara, Gō. 2003. "Kizu tsukeru sei, dankai no sedai kara otaku sedai e: Gyarugē-teki sekushariti no kigen,” in Ōtsuka Eiji (ed), Shingenjitsu Vol 2, IOI-I 28. Tokyo: Kadokawa shoten.

- 2004. "Bishōjo" no gendai shi: Moe to kyarakutā. Tokyo: Kōdansha gendai shinsho.

. 2005. "Otaku no romantishizumu to tenkō: 'Shisen-ka suru watashi' no bōryoku no yukue," in Sasakibara Gō (ed), "Senjika” no Otaku, I6-44. Tokyo: Kadokawa shoten.

Schodt, Frederik L. I983. Manga! Manga! The World of Japanese Comics. Tokyo: Kodansha International.

- I996. Dreamland Japan: Writings on Modern Manga. Berkeley, CA: Stone Bridge Press.

Sedgwick, Eve Kosofsky. I993. Tendencies. Durham, NC: Duke University Press.

- 2003. Touching Feeling: Affect, Pedagogy, Performativity. Durham, NC: Duke University Press.

Seddon, Robert Francis John. 20I3. "Getting 'Virtual' Wrongs Right," Ethics and Information Technology ( I 5), I-I I. DOI: https://doi.org/IO.IO07 /sI0676-OI2-9304-z

Seno, Mitsurō. I989. "Otaku ni shisu: Junkyōsha Tomizawa Masahiko e no rekuiemu," in Bessatsu Takarajima Henshūbu (ed), Bessatsu takarajima I04 gō: Otaku no hon, I38-I49. Tokyo: JICC shuppankyoku.

Seto, Michael C., James M. Cantor and Ray Blanchard. 2006. "Child Pornography Offenses are a Valid Diagnostic Indicator of Pedophilia,” 
Journal of Abnormal Psychology (I I 5:3), 6IO-6 I 5. DOI: https://psycnet .apa.org/doi/ıo.1037/002 I-843X.I I 5.3.6IO

Sherman, Gary D., and Jonathan Haidt. 20 г r. "Cuteness and Disgust: The Humanizing and Dehumanizing Effects of Emotion," Emotion Review (3:3), I-7. DOI: https://doi.org/IO.I I 77\% 2FI 7540739 I I 402396

Shigematsu, Setsu. 1999. "Dimensions of Desire: Sex, Fantasy, and Fetish in Japanese Comics," in John A. Lent (ed), Themes in Asian Cartooning: Cute, Cheap, Mad, and Sexy, I27-163. Bowling Green, OH: Bowling Green State University Popular Press.

Shimotsuki, Takanaka. 2008. Komikku māketto no sōseiki. Tokyo: Asahi shimbun shuppan.

Shiokawa, Kanako. I999. "Cute but Deadly: Women and Violence in Japanese Comics," in John A. Lent (ed), Themes in Asian Cartooning: Cute, Cheap, Mad, and Sexy, 93-I25. Bowling Green, OH: Bowling Green State University Popular Press.

Shūkan Gendai. 2020. "Kabukichō yori kowai... Ima, Akihabara ga bottakuri no seichi ni natteiru! Yakuza, hangure no 'arata na shinogi no ba," October 30. https://gendai.ismedia.jp/articles/-/76853 ?page $=2$ (last accessed on May I 5, 202I)

Siegel, Larry J. 20 I r. Criminology: The Core. Stamford, CT: Cengage Learning.

Silvio, Teri. 2019. Puppets, Gods, and Brands: Theorizing the Age of Animation from Taiwan. Honolulu, HI: University of Hawai'i Press.

Skeggs, Beverley, and Helen Wood. 20 I 2. Reacting to Reality Television: Performance, Audience and Value. London: Routledge.

Slater, David H., and Patrick W. Galbraith. 20I r. "Re-Narrating Social Class and Masculinity in Neoliberal Japan: An Examination of the Media Coverage of the 'Akihabara Incident' of 2008," Electronic Journal of Contemporary Japanese Studies. http://www.japanesestudies.org.uk/articles /20I I/SlaterGalbraith.html (last accessed on May I 5, 202 I)

Sousa, Ana Matilde. 2020. “She's Not Your Waifu; She's an Eldritch Abomination: Saya no uta and Queer Antisociality in Japanese Visual Novels," Mechademia: Second Arc (I3:I), 72-IO0. DOI: https://doi.org /I0.5749/mech.I3.I.0072

Spinoza, Benedict de. 2005. Ethics, Edwin Curley (trans). New York: Penguin Books.

Standing, Guy. 20I r. The Precariat: The New Dangerous Class. London: Bloomsbury. 
Steinberg, Marc. 2012. Anime's Media Mix: Franchising Toys and Characters in Japan. Minneapolis, MN: University of Minnesota Press.

Steinberg, Neil. 2016. "The New Science of Cute," The Guardian, July I9. https://www.theguardian.com/world/20I6/jul/I9/kumamon-the-new -science-of-cute (last accessed on May I 5, 202 I)

Stevenson, Lisa. 20I4. Life Beside Itself: Imagining Care in the Canadian Arctic. Oakland, CA: University of California Press.

Stewart, Kathleen. 2007. Ordinary Affects. Durham, NC: Duke University Press.

Stroud, Scott R. 2016. “'Be a Bully to Beat a Bully:' Twitter Ethics, Online Identity, and the Culture of Quick Revenge," in Amber Davisson and Paul Booth (ed), Controversies in Digital Ethics, 264-278. London: Bloomsbury.

Sugano, Yoshihisa "Koshian.” 20ı 9. "Akiba chūō dōri no I 8-kin gēmu kanban wa naze mondai na no ka o majime ni kangaeru," Blogos, November 8. https://blogos.com/article/4 I 6056/ (last accessed on May I 5, 202 I)

Suzuki, Toshio. 2018. Mixing Work with Pleasure: My Life at Studio Ghibli, Roger Speares (trans). Tokyo: Japan Publishing Industry Foundation for Culture.

Takahashi, Mizuki. 2008. "Opening the Closed World of Shōjo Manga," in Mark W. MacWilliams (ed), Japanese Visual Culture: Explorations in the World of Manga and Anime, I I4-I 36. Armonk, NY: M.E. Sharpe.

Tamagawa, Hiroaki. 20 I 2. "Comic Market as Space for Self-Expression in Otaku Culture," in Mizuko Ito, Daisuke Okabe and Izumi Tsuji (ed), Fandom Unbound: Otaku Culture in a Connected World, I07-132. New Haven, CT: Yale University Press.

Taussig, Michael. 2009. What Color is the Sacred? Chicago, IL: University of Chicago Press.

Tavinor, Grant. 2009. The Art of Videogames. West Sussex, United Kingdom. Wiley-Blackwell.

Taylor, Emily. 2007. "Dating-Simulation Games: Leisure and Gaming of Japanese Youth Culture," Southeast Review of Asian Studies (29), I92-208. DOI: http://www.asia-studies.com/asia/SERAS/2007/I2_Taylor $-2007 . \mathrm{pdf}$

Teshigawara, Mihoko, and Kinsui Satoshi. 20 I I. "Modern Japanese 'Role Language' (Yakuwarigo): Fictionalised Orality in Japanese Literature and Popular Culture," Sociolinguistic Studies (5:I), 37-58. DOI: https://dx.doi .org/ıO. I 558 /sols.v5iı.37 
Thomsen, Michael. 2010. "The Year in Sex 20ıо: Nipple Wasps, Sex Crimes, Thumb Puppets and Grinding to Kinect," IGN, December Ir. https:// www.ign.com/articles/20I0/I 2/I I/the-year-in-sex-20IO (last accessed on May I 5, 202I)

Thorn, Clarisse. 2012. "Introduction: Reflections on Game Rape, Feminism, Sadomasochism, and Selfhood," in Clarisse Thorn and Julian Dibbell (ed), Violation: Rape in Gaming, I-24. Lexington, KY: Amazon Digital Services.

Tomita, Hidenori. I989. "Shōhi shakai to narushishizumu," Kansai daigaku daigakuin ningen kagaku: Shakaigaku, shinrigaku kenkyū (32), 2-20.

Treat, John Whittier. I993. "Yoshimoto Banana Writes Home: Shōjo Culture and the Nostalgic Subject," The Journal of Japanese Studies (19:2), 353-387. DOI: https://doi.org/I0.2307/I32644

- 1999. Great Mirrors Shattered: Homosexuality, Orientalism, and Japan. Oxford, United Kingdom: Oxford University Press.

Tsing, Anna Lowenhaupt. 201 5. The Mushroom at the End of the World: On the Possibility of Life in Capitalist Ruins. Princeton, NJ: Princeton University Press.

Tsuchimoto, Ariko. I989. "Rorikon, nijikon, ningyō-ai: Kakū no bishōjo ni taku sareta kyōdō gensō," in Bessatsu Takarajima Henshūbu (ed), Bessatsu takarajima I04 gō: Otaku no hon, IO2-I I 5 . Tokyo: JICC shuppankyoku.

Turkle, Sherry. 20I I. Alone Together: Why We Expect More from Technology and Less from Each Other. New York: Basic Books.

TV Takkuru. 20I4. "Rorikon bōryoku anime kisei wa hitsuyō?," Biito Takeshi no TV Takkuru, September I. https://www.dailymotion.com/video /x25oyio_\% $\mathrm{E}_{3} \% 83 \% 93 \% \mathrm{E}_{3} \% 83 \% \mathrm{BC} \% \mathrm{E}_{3} \% 83 \% 88 \% \mathrm{E}_{3} \% 8 \mathrm{r} \% 9 \mathrm{~F} \% \mathrm{E}_{3}$ \%8г \% 9 г $\%$ Е $\% 8$ г $\% 97 \%$ Е $\% 8$ г \%AE\%ЕF\%BD\%94\%EF\%BD ${ }_{9} 6 \% \mathrm{E}_{3} \% 82 \% \mathrm{BF} \% \mathrm{E}_{3} \% 83 \% 83 \% \mathrm{E}_{3} \% 82 \% \mathrm{AF} \% \mathrm{E}_{3} \% 83 \% \mathrm{AB}-\mathrm{I} 4090$ I _news (last accessed on May I 5, 202I)

Valenti, Jessica. 201 5. "Anita Sarkeesian Interview: ‘The Word “Troll” Feels Too Childish. This Is Abuse," The Guardian, August 29. https://www .theguardian.com/technology/20 I 5/aug/29/anita-sarkeesian-gamergate -interview-jessica-valenti (last accessed on May I 5, 202I)

Vincent, J. Keith. 20 I I. "Making It Real: Fiction, Desire, and the Queerness of the Beautiful Fighting Girl," in Saitō Tamaki, Beautiful Fighting Girl, ix-xxv. Minneapolis, MN: University of Minnesota Press.

Waern, Annika. 20I 5. “'I'm in love with someone that doesn't exist!' Bleed in the Context of a Computer Game," in Jessica Enevold and Esther 
MacCallum-Stewart (ed), Game Love: Essays on Play and Affection, 38-65. Jefferson, NC: McFarland \& Company.

Warner, Michael. 2000. The Trouble with Normal: Sex, Politics, and the Ethics of Queer Life. Cambridge, MA: Harvard University Press. . 2002. "Publics and Counterpublics," Public Culture (4:I), 49-90. DOI: https://doi.org/IO.I2I 5/08992363-I4-I-49

Weiss, Margot. 20I I. Techniques of Pleasure: BDSM and the Circuits of Sexuality. Durham, NC: Duke University Press.

Wertham, Fredric. 2004. Seduction of the Innocent. Laurel, NY: Main Road Books.

Wiegman, Robyn. 20I2. Object Lessons. Durham, NC: Duke University Press. Williams, Alex. 20I9. "Do You Take This Robot..." The New York Times, January I9. https://www.nytimes.com/20I9/oI/I 9/style/sex-robots.html (last accessed on May I 5, 202 I)

Williams, Linda. 1989. Hard Core: Power, Pleasure, and the "Frenzy of the Visible." Berkeley, CA: University of California Press.

Wirman, Hanna. 20 I 5. "Princess Peach Loves Your Enemies, Too," in Jessica Enevold and Esther MacCallum-Stewart (ed), Game Love: Essays on Play and Affection, 169-193. Jefferson, NC: McFarland \& Company.

Wood, Andrea. 20I r. "Choose Your Own Queer Erotic Adventure: Young Adults, Boys' Love Computer Games and the Sexual Politics of Visual Play," in Michelle Ann Abate and Kenneth Kidd (ed), Over the Rainbow: Queer Children's and Young Adult Literature, 354-377. Ann Arbor. MI: University of Michigan Press.

Wood, Helen. 2009. Talking with Television: Women, Talk Shows, and Modern Self-Reflexivity. Urbana, IL: University of Illinois Press.

Yamada, Masahiro. 20I4. "Kazoku” nanmin: Shōgai mikon ritsu 25\% shakai no shōgeki. Tokyo: Asahi shimbun shuppan.

Yamanaka, Tomomi. 20I0. “'Otaku' shi o kaitaku suru: I980 nendai no 'kūhaku no rokunenkan' o megutte," Kokugo kenkyū (28), ıо-26.

Yan, Sophia. 20I6. "Japan's Female Lawmakers Are Way Behind Saudi Arabia's," CNN Money, September 29. http://money.cnn.com/20I 6/o9/29 /news/economy/japan-women-government/ (last accessed on May I 5, 202I)

Yano, Christine R. 2013. Pink Globalization: Hello Kitty's Trek Across the Pacific. Durham, NC: Duke University Press.

Yano Research Institute. 20I 2. “'Otaku’ shijō ni kan suru chōsa kekka 20I 2," Yano keizai kenkyūjo. 


\section{kenkyūjo.}

Yaraon. 20I3. "'Otome gēmu' ni hamaru josei-tachi: Bishōjo gēmu shijō o oinuku ikioi de kakudai," September 22. http://yaraon-blog.com/archives /506I4 (last accessed on May I 5, 202I)

- 2015. "Komikku LO henshū ' 8 -sai wa osanasugiru. Dokusha ga motometeiru no wa 9-sai,"” December 2. http://yaraon-blog.com/archives /74357 (last accessed on May I 5, 202 I)

Yoshimoto, Taimatsu. 2009. Otaku no kigen. Tokyo: NTT shuppan.

Young, Garry. 20I3. "Enacting Taboos as Means to an End; But What End? On the Morality of Motivations for Child Murder and Paedophilia within Gamespace," Ethics and Information Technology (I 5), I3-23. DOI: https://link.springer.com/article/ıo.1007/sı0676-oI 2-9306-x

Young, Jock. 20I I. The Criminological Imagination. Cambridge, United Kingdom: Polity.

Yuen, Karin. 20I7. "Kankyaku ni yotte fuku o hagitorareta josei ātisuto mo: Nikutai no genkai ni chōsen suru geijutsuka-tachi," Logmi, January 29. https://logmi.jp/business/articles/I 83004 (last accessed on May I 5, 202I)

Zanghellini, Aleardo. 2009. "Underage Sex and Romance in Japanese Homoerotic Manga and Anime," Social and Legal Studies (г 8:2), I 59-I77. DOI: https://doi.org/IO.I I77\% 2Fo964663909103623

Zimbardo, Phillip, and Nikita D. Coulombe. 2015. Man (Dis)connected: How Technology has Sabotaged What it Means to be Male. London: Rider Books.

Žižek, Slavoj. 20I 5. "Slavoj Žižek on Synthetic Sex and 'Being Yourself,” Big Think, June 7. https://www.youtube.com/watch?v=7xYO-VMZUGo (last accessed on May I 5, 202I) 
Based on fieldwork in Tokyo, this book explores how and to what effect lines are drawn by producers, players and critics of adult computer games. Focusing on interactions with mengalanime-style characters, these games often feature explicit sex acts. Noting that the characters can appear quite young, legal actions have been taken in a number of countries to cotegorize and prohibit such content as child abuse meteriel. While Japanese politicians continue to debate a similer course, adult computer game producers, players and critics are drawing their oun lines between fiction and reelity and orienting themselves toward the drawn lines of mangalanime-style characters. The book argues for understanding this everyday practice as an ethics of affective response to fictional characters. Dccurring individually and socielly in both private and public spaces, this response not only discourages harming humen beings, but also supports life in morethen-humen worlds.

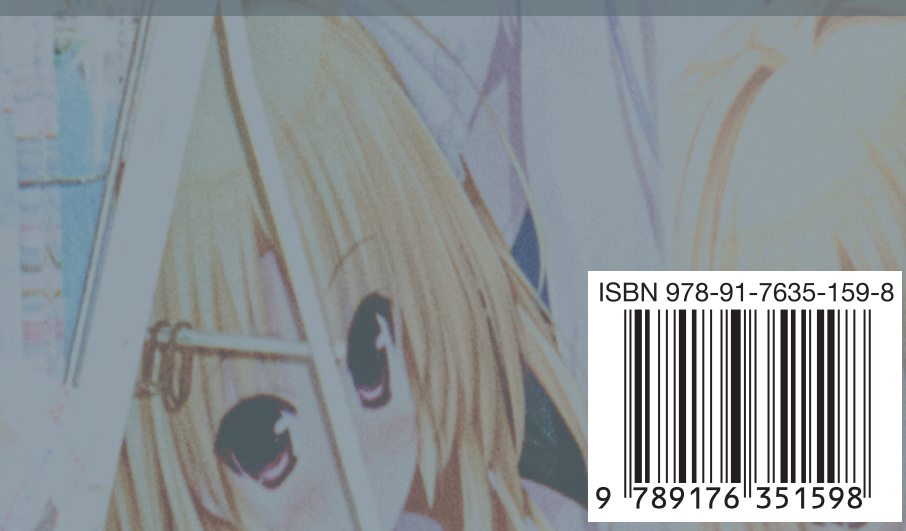

